\title{
EFICIÊNCIA DE DIFERENTES TIPOS DE COAGULANTES NA COAGULAÇÃO, FLOCULAÇÃO E SEDIMENTAÇÃO DE ÁGUA COM COR OU TURBIDEZ ELEVADA
}

\section{Gerson Pavanelli}

Dissertação apresentada à Escola de Engenharia de São Carlos da Universidade de São Paulo, como parte dos requisitos para obtenção do título de Mestre em Hidráulica e Saneamento

ORIENTADOR: Prof. Dr. Luiz Di Bernardo

São Carlos 


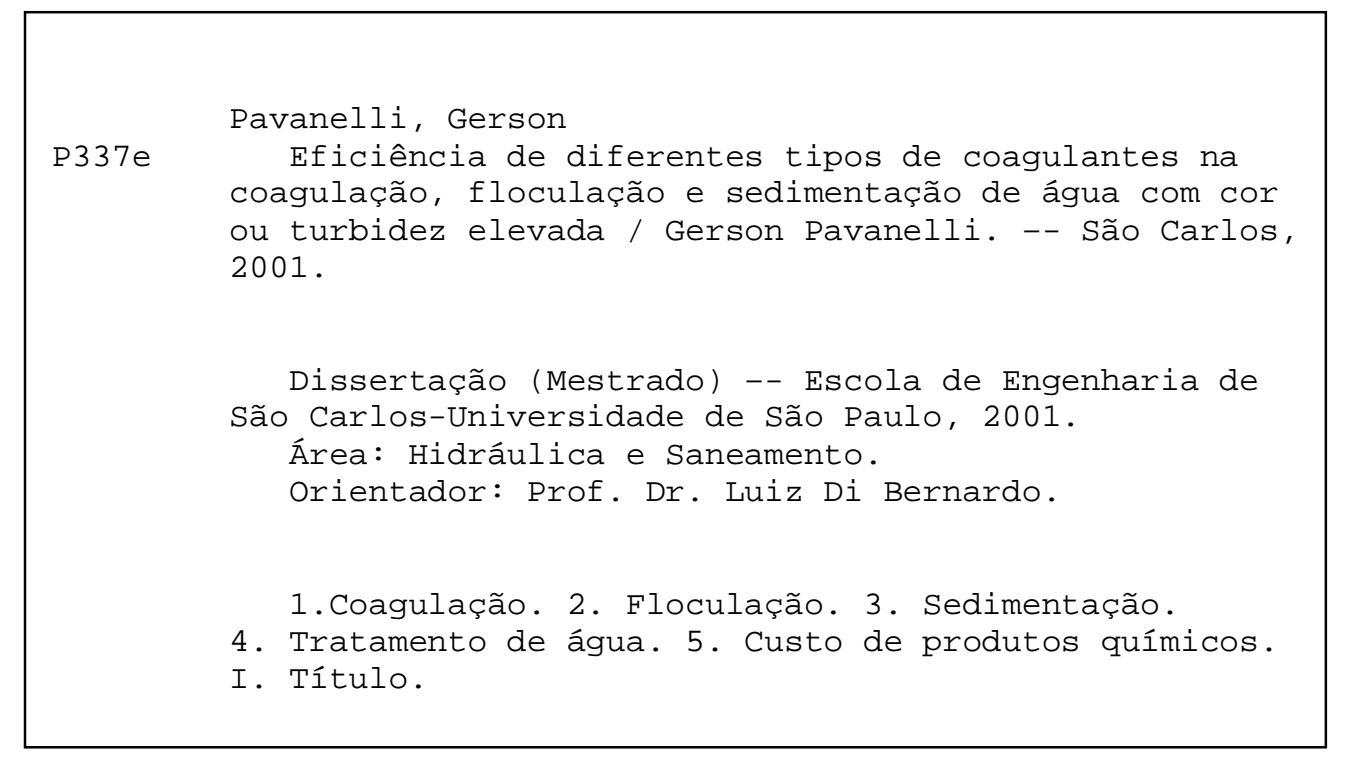


À minha família,

minha querida esposa Liliane, meus

filhos Alisson, Everton e Bianca, pelo

apoio e companheirismo ao longo do curso. 


\section{AGRADECIMENTOS}

A Deus, em primeiro lugar, pela vida, saúde, pelo Seu encaminhamento em todas as coisas, desde o início e durante este mestrado, e certamente até sua conclusão.

Aos amigos da SANEPAR, Wagner Schuchardt, Sergio Wippel, Décio Jurgensen, Afonso Marangoni, Edgar Faust Filho, Nelson Müller Junior, Lauro Klas Junior que, graças ao empenho em conseguir patrocínio, tornaram esse mestrado uma realidade.

Ao Professor Dr. Luiz Di Bernardo, por sua instrução e orientação para que este trabalho fosse encaminhado da melhor forma possível, bem como por contribuir na parte experimental com fornecimento de equipamentos e material de consumo, sem os quais a pesquisa não teria sucesso.

Aos professores do Departamento de Hidráulica e Saneamento da EESC/USP, pela amizade e conhecimento demonstrados. Aos funcionários da secretaria que sempre atendem aos alunos com ânimo e disposição na prestação de serviços.

Aos técnicos do Laboratório de Saneamento, grande Júlio, Paulo, Chico e Cidinha, pela pronta ajuda prestada no desenvolvimento das atividades da parte experimental.

A Liliane, pelo carinho, amizade, companhia e apoio nos tantos momentos difíceis surgidos, a qual não mediu esforços para dar sua contribuição como esposa.

Aos verdadeiros amigos do curso de Hidráulica e Saneamento da USP, os quais ofereceram uma das coisas mais preciosas nesta vida: a amizade.

Certamente esqueci de citar nomes de muitos que ajudaram neste "trabalho de equipe", mas agradeço sinceramente a todos aqueles que direta ou mesmo indiretamente contribuíram para seu êxito. 


\section{SUMÁRIO}

LISTA DE FIGURAS....................................................................................................i

LISTA DE TABELAS...............................................................................................................

LISTA DE ABREVIATURAS E SIGLAS.................................................................viii

LISTA DE SÍMBOLOS.......................................................................................ix

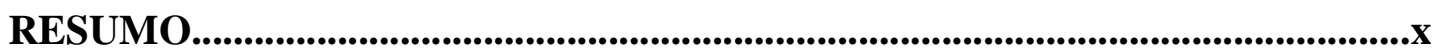

ABSTRACT ....................................................................................................................

1 INTRODUÇÃO........................................................................................................................1

2 OBJETIVOS........................................................................................................................

3 REVISÃO DA LITERATURA......................................................................................

4 MATERIAIS E MÉTODOS................................................................................40

5 RESULTADOS E DISCUSSÃO...........................................................................50

6 CONCLUSÕES E RECOMENDAÇÕES.................................................................88

ANEXO A - Ensaios SA - Água I..............................................................................92

ANEXO B - Ensaios CF - Água I.................................................................................105

ANEXO C - Ensaios HCA - Água I........................................................................123

ANEXO D - Ensaios SF - Água I.............................................................................135

ANEXO E - Ensaios SA - Água II...................................................................................149

ANEXO F - Ensaios CF - Água II.....................................................................164 
ANEXO G - Ensaios HCA - Água II.............................................................180

ANEXO H - Ensaios SF - Água II.......................................................................194

7 REFERÊNCIAS BIBLIOGRÁFICAS.................................................213 


\section{LISTA DE FIGURAS}

FIGURA 3.1 - Distribuição dos tamanhos das partículas presentes na água 5

FIGURA 3.2 - Cargas superficiais da partícula de caulinita 7

FIGURA 3.3 - Constituintes do sistema ácido carbônico em função do pH com pressão de $1 \mathrm{~atm}$ e temperatura de $25^{\circ} \mathrm{C}$

FIGURA 3.4 - Configuração esquemática da dupla camada elétrica .11

FIGURA 3.5 - Energia potencial de interação entre as partículas coloidais. 12

FIGURA 3.6 - Diagrama de coagulação (típico). .16

FIGURA 3.7 - Classificação das Tecnologias de Tratamento 18

FIGURA 3.8 - Regiões de remoção de turbidez (200uT), cor verdadeira (5uC), com sulfato de alumínio.

FIGURA 3.9 - Regiões de remoção de Cor Verdadeira (100uC), Turbidez (0uT) com Sulfato de Alumínio.....

FIGURA 3.10 - Regiões de remoção de Cor Verdadeira (100uC), Turbidez (2730uT) com Sulfato de Alumínio. 
FIGURA 3.11 - Regiões de remoção de Cor Verdadeira (100uC), Turbidez (5uT) com Sulfato de Alumínio.

FIGURA 3.12 - Regiões com Porcentagem da Cor Aparente Remanescente com Coagulante Sulfato de Alumínio e Velocidade de Sedimentação $2 \mathrm{~cm} / \mathrm{min}$, sendo as características da água bruta: Cor Verdadeira (100uC), Cor Aparente (150uC), Turbidez (5uT). .25

FIGURA 3.13 - Regiões com Turbidez Remanescente com Turbidez (25uT), Cor Aparente $(150 \mathrm{uC})$, Cor Verdadeira $(70 \mathrm{uC})$, Coagulante Sulfato de Alumínio e Velocidade de Sedimentação $2,5 \mathrm{~cm} / \mathrm{min}$.

FIGURA 3.14 - Fração Remanescente da Turbidez em Função do Tempo de Floculação e Respectivos Gradientes de Velocidade Ótimos - Coagulante Sulfato de Alumínio $\left(20 \mathrm{mg} / \mathrm{l} ; \mathrm{pH}=6,32 ; \mathrm{Gmr}=400 \mathrm{~s}^{-1} ; \mathrm{Tmr}=5 \mathrm{~s}\right.$ e Velocidade de Sedimentação $2,5 \mathrm{~cm} / \mathrm{min})$.

FIGURA 3.15 - Fração Remanescente da Turbidez em Função do Tempo de Floculação e Respectivos Gradientes de Velocidade Ótimos - Coagulante Sulfato de Alumínio $\left(25 \mathrm{mg} / 1 ; \mathrm{pH}=6,3 ; \mathrm{Gmr}=400 \mathrm{~s}^{-1} ; \mathrm{Tmr}=15 \mathrm{~s}\right.$ e Velocidade de Sedimentação $2,5 \mathrm{~cm} / \mathrm{min})$ .29

FIGURA 3.16 - Diagrama de Equilíbrio Heterogêneos do $\mathrm{Al}(\mathrm{OH})_{3}$ .33

FIGURA 3.17 - Diagrama de Equilíbrio Heterogêneos do $\mathrm{Fe}(\mathrm{OH})_{3}$ .36

FIGURA 4.1 - Fotografia do Reator Estático. 41

FIGURA 4.2 - Fotografia do Agitador para Caulinita. .41

FIGURA 4.3 - Fotografia do Reator Estático, pHmetro e Turbidímetro..... .42 
FIGURA 5.1 - Gráfico com Valores de pH versus Dosagem do Coagulante Sulfato de Alumínio - Água I - Turbidez de $100 \mathrm{uT}$ - Vs=4cm/min

FIGURA 5.2 - Gráfico com Valores de pH versus Dosagem do Coagulante Sulfato de Alumínio - Água I - Turbidez de 100uT - Vs=2cm/min. 54

FIGURA 5.3 - Gráfico com Valores de pH versus Dosagem do Coagulante Cloreto Férrico - Água I - Turbidez de $100 \mathrm{uT}-\mathrm{Vs}=4 \mathrm{~cm} / \mathrm{min}$ .57

FIGURA 5.4 - Gráfico com Valores de pH versus Dosagem do Coagulante Cloreto Férrico - Água I - Turbidez de 100uT - Vs=2cm/min. .58

FIGURA 5.5 - Gráfico com Valores de pH versus Dosagem do Coagulante Hidroxicloreto de Alumínio - Água I - Turbidez de 100uT $\mathrm{Vs}=4 \mathrm{~cm} / \mathrm{min}$ .61

FIGURA 5.6 - Gráfico com Valores de pH versus Dosagem do Coagulante Hidroxicloreto de Alumínio - Água I - Turbidez de 100uT $\mathrm{Vs}=2 \mathrm{~cm} / \mathrm{min}$ 62

FIGURA 5.7 - Gráfico com Valores de pH versus Dosagem do Coagulante Sulfato Férrico - Água I - Turbidez de $100 \mathrm{uT}-\mathrm{Vs}=4 \mathrm{~cm} / \mathrm{min}$ .65

FIGURA 5.8 - Gráfico com Valores de pH versus Dosagem do Coagulante Sulfato Férrico - Água I - Turbidez de $100 \mathrm{uT}$ - Vs=2cm $/ \mathrm{min}$. .66

FIGURA 5.9 - Gráfico com Valores de pH versus Dosagem do Coagulante Sulfato de Alumínio - Água II - Cor Verdadeira de 100uC $\mathrm{Vs}=2 \mathrm{~cm} / \mathrm{min}$ 70 
FIGURA 5.10 - Gráfico com Valores de pH versus Dosagem do Coagulante Sulfato de Alumínio - Água II - Cor Verdadeira de 100uT $\mathrm{Vs}=1 \mathrm{~cm} / \mathrm{min}$ .71

FIGURA 5.11 - Gráfico com Valores de pH versus Dosagem do Coagulante Cloreto Férrico - Água II - Cor Verdadeira de $100 \mathrm{uC}$ $\mathrm{Vs}=2 \mathrm{~cm} / \mathrm{min}$ 74

FIGURA 5.12 - Gráfico com Valores de pH versus Dosagem do Coagulante Cloreto Férrico - Água II - Cor Verdadeira de 100uT $\mathrm{Vs}=1 \mathrm{~cm} / \mathrm{min}$. 75

FIGURA 5.13 - Gráfico com Valores de pH versus Dosagem do Coagulante Hidroxicloreto de Alumínio - Água II - Cor Verdadeira de 100uC $\mathrm{Vs}=2 \mathrm{~cm} / \mathrm{min}$ 78

FIGURA 5.14 - Gráfico com Valores de pH versus Dosagem do Coagulante Hidroxicloreto de Alumínio - Água II - Cor Verdadeira de 100uT $\mathrm{Vs}=1 \mathrm{~cm} / \mathrm{min}$

FIGURA 5.15 - Gráfico com Valores de pH versus Dosagem do Coagulante Sulfato Férrico - Água II - Cor Verdadeira de 100uC $\mathrm{Vs}=2 \mathrm{~cm} / \mathrm{min}$

FIGURA 5.16 - Gráfico com Valores de pH versus Dosagem do Coagulante Sulfato Férrico - Água II - Cor Verdadeira de 100uT $\mathrm{Vs}=1 \mathrm{~cm} / \mathrm{min}$ .83 


\section{LISTA DE TABELAS}

TABELA 3.1 - Classificação das substâncias húmicas. .7

TABELA 3.2 - Parâmetros adotado em outros estudos .26

TABELA 3.3 - Composição físico-química do sulfato de alumínio líquido. 30

TABELA 3.4 - Propriedades e especificações do cloreto férrico .34

TABELA 3.5 - Características e especificações do hidróxido de alumínio. 37

TABELA 3.6 - Composição de metais pesados do hidróxido de alumínio. .38

TABELA 3.7 - Composição química e física do sulfato férrico. 39

TABELA 4.1 - Características das águas de estudo Tipo I e II. . .45

TABELA 4.2 - Parâmetros Físicos da pesquisa para as águas de estudo. .48 
TABELA 4.3 - Parâmetros Monitorados .49

TABELA 5.1 - Regiões dos Diagramas de Coagulação com Sulfato de Alumínio e Valores de Turbidez Remanescente Água Tipo I. .52

TABELA 5.2 - Regiões dos Diagramas de Coagulação com Cloreto Férrico e Valores de Turbidez Remanescente Água Tipo I. .56

TABELA 5.3 - Regiões dos Diagramas de Coagulação com Hidroxicloreto de Alumínio e Valores de Turbidez Remanescente Água Tipo I..... .60

TABELA 5.4 - Regiões dos Diagramas de Coagulação com Sulfato Férrico e Valores de Turbidez Remanescente Água Tipo I. .64

TABELA 5.5 - Regiões dos Diagramas de Coagulação com Sulfato de Alumínio e Valores de Turbidez Remanescente Água Tipo II .69

TABELA 5.6 - Regiões dos Diagramas de Coagulação com Cloreto Férrico e Valores de Turbidez Remanescente Água Tipo II. .73

TABELA 5.7 - Regiões dos Diagramas de Coagulação com Hidroxicloreto de Alumínio e Valores de Turbidez Remanescente Água Tipo II. . .77 
TABELA 5.8 - Regiões dos Diagramas de Coagulação com Sulfato Férrico e Valores de Turbidez Remanescente Água Tipo II .81

TABELA 5.9 - Preços dos Coagulantes e Alcalinizante .84

TABELA 5.10 - Composição de Custos para água Tipo I com Vs=4cm/min. 85

TABELA 5.11 - Composição de Custos para água Tipo I com Vs=2cm/min. . .85

TABELA 5.12 - Composição de Custos para água Tipo II com Vs=2cm/min. .86

TABELA 5.13 - Composição de Custos para água Tipo II com Vs=1cm/min. .86

TABELA 6.1 - Intervalos de pH ótimos para água tipo I .89

TABELA 6.2 - Intervalos de pH ótimos para água tipo II .89 


\section{LISTA DE ABREVIATURAS E SIGLAS}

\begin{tabular}{|c|c|}
\hline AWWA & - American Water Works Association \\
\hline DBO & - Demanda Bioquímica de Oxigênio \\
\hline EESC & - Escola de Engenharia de São Carlos \\
\hline ETA & - Estação de Tratamento de Água \\
\hline $\mathrm{PE}$ & - Poli Estireno \\
\hline PM & - Peso Molecular \\
\hline PP & - Poli Propileno \\
\hline PTFE & - Poli Tetra Fluoroetileno (Teflon) \\
\hline PVC & - Cloreto de Polivinila \\
\hline ST & - Standard Methods \\
\hline THM & - Trialometanos \\
\hline USP & - Universidade de São Paulo \\
\hline CEPIS & $\begin{array}{l}\text { - Centro Panamericano de Ingeniaría Sanitária y Ciências Del } \\
\text { Ambiente }\end{array}$ \\
\hline SANEPAR & - Companhia de Saneamento do Paraná \\
\hline AS & - Sulfato de Alumínio \\
\hline $\mathrm{CF}$ & - Cloreto Férrico \\
\hline HCL & - Hidroxicloreto de Alumínio \\
\hline SF & - Sulfato Férrico \\
\hline
\end{tabular}




\section{LISTA DE SÍMBOLOS}

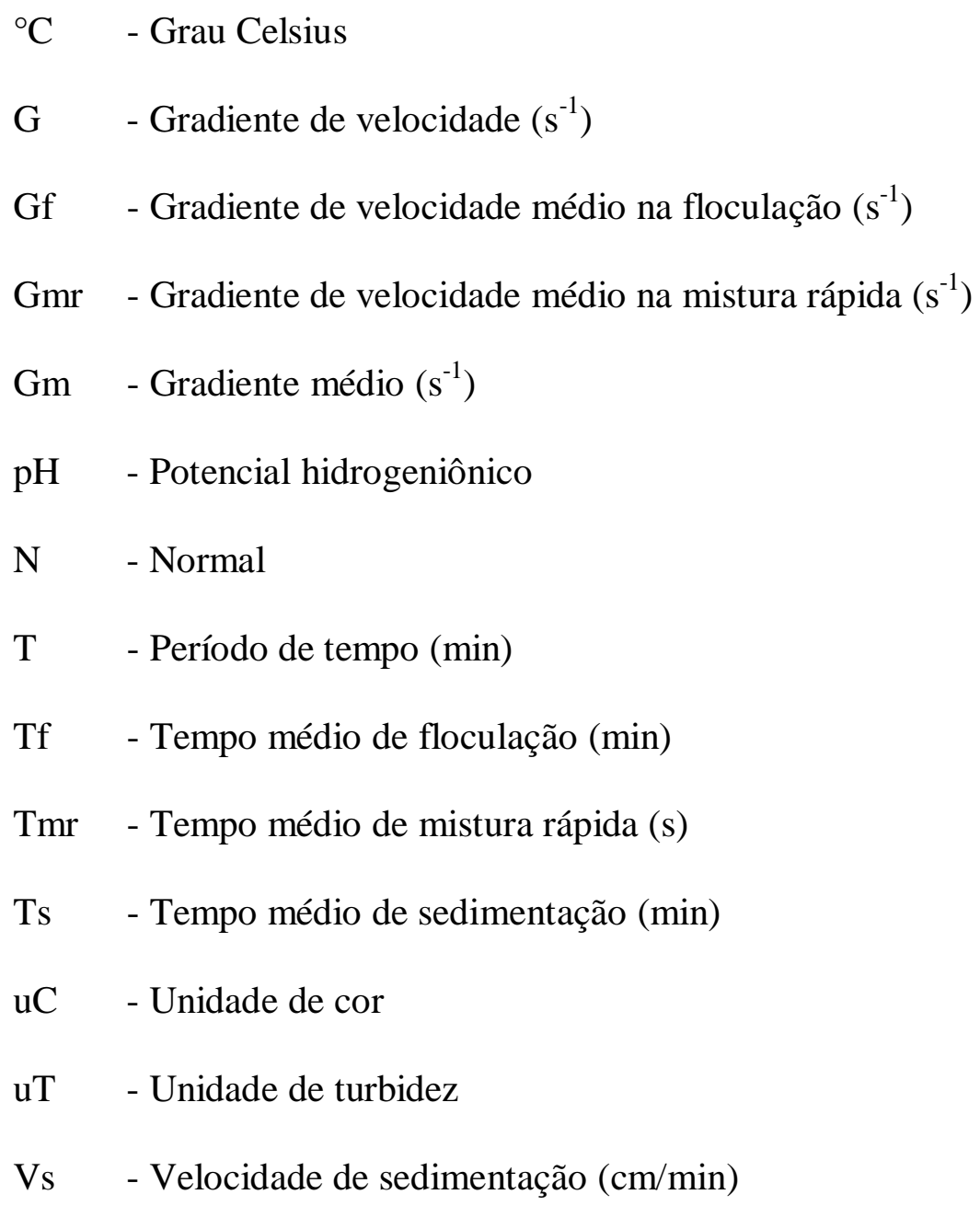




\section{RESUMO}

PAVANELLI, G. (2001). Eficiência de diferentes tipos de coagulantes na coagulação, floculação e sedimentação de água com cor ou turbidez elevada. São Carlos, 2001. 216p. Dissertação (Mestrado) - Escola de Engenharia de São Carlos, Universidade de São Paulo.

A proposta deste trabalho foi utilizar quatro diferentes coagulantes - sulfato de alumínio, cloreto férrico, hidroxicloreto de alumínio e sulfato férrico; construir os diagramas de coagulação; e assinalar as regiões de maior ou menor eficiência de remoção de turbidez ou de cor.

Para permitir uma avaliação de custos na utilização dos coagulantes, observou-se nos diagramas a região onde os valores de turbidez remanescente são aproximadamente iguais para diferentes coagulantes. Com essa consideração, foi estabelecida a relação entre consumo e custo dos produtos químicos utilizados.

Os coagulantes que apresentaram particularidades para as águas estudadas foram: o cloreto férrico que mostrou melhor desempenho para valores de $\mathrm{pH}$ baixos; o sulfato férrico que mostrou-se mais econômico; e o hidroxicloreto de alumínio que atua numa grande faixa de $\mathrm{pH}$.

Na conclusão dos estudos, verifica-se que cada água a ser tratada deve ser analisada através de diagramas de coagulação, visando a otimização dos parâmetros de $\mathrm{pH}$ versus dosagens e buscando o melhor coagulante pelo menor custo.

Palavras-chave: coagulação, floculação, sedimentação, tratamento de água, custo de produtos químicos. 


\section{ABSTRACT}

PAVANELLI, G. (2001). Efficiency of different types of coagulants in the coagulation, flocculation and sedimentation of water with high turbidity or color. São Carlos, 2001. 216p. Dissertação (Mestrado) - Escola de Engenharia de São Carlos, Universidade de São Paulo.

The purpose of this study was to use four different coagulants - aluminum sulphate, iron chloride, polyaluminum hidroxichloride and ferric sulphate; to build the coagulation diagrams; and to mark the regions of higher or lower efficiency in the removal of turbidity or color.

To allow a cost appraisal in the use of the coagulants, the region where the values of remaining turbidity, which are approximately the same for different coagulants, was examined in the diagrams. This being taken into consideration, the relation between consumption and cost of the chemical products was established.

The coagulants that presented certain peculiarities for the studied waters were: iron chloride, that showed better performance for low $\mathrm{pH}$ values; the ferric sulphate, that showed itself as more economical; and the polyaluminum hidroxichloride, that functions in a large interval of $\mathrm{pH}$.

In the conclusion of the study, it was observed that each type of water to be treated must be analyzed through coagulation diagrams, aiming at the optimization of $\mathrm{pH}$ parameters versus dosages and looking for the best coagulant with lower cost.

Key words: coagulation, flocculation, sedimentation, water treatment, costs of chemical products. 


\section{INTRODUÇÃO}

Em nosso planeta existe uma limitação da disponibilidade de água doce, tanto que defensores do meio ambiente (ambientalistas), verificando o balanço global da terra, teoricamente comprovaram que, ainda neste século (XXI $-\approx$ ano 2070), ocorrerá a escassez de água doce para consumo humano.

Atualmente, verifica-se a degradação da natureza de forma indiscriminada, pelo controle precário dos lançamentos de resíduos nos rios. Além disso, a mata ciliar está sendo substituída por plantações agrícolas, visando a ampliação da área de cultivo e conseqüentemente o aumento do lucro. Este procedimento, dentre outros grandes prejuízos ambientais, gera um aumento significativo da turbidez dos cursos d'água. Além de mais turva, a qualidade da água dos rios torna-se cada vez pior, com maior variedade de componentes químicos, físicos e biológicos, dificultando e encarecendo seu tratamento. É fundamental que cientistas da área de saneamento se envolvam com esta gama de variáveis que influenciam diretamente a qualidade da água, propiciando seu efetivo tratamento para o consumo direto e indireto dos seres humanos. É em tal contexto que esse projeto de pesquisa se insere.

Um dos primeiros passos no processo de tratamento da água do manancial, na entrada de água bruta de uma ETA (Estação de Tratamento de Água), é a coagulação química. Dada a importância da coagulação na ETA, tornam-se imprescindíveis estudos mais aprofundados sobre os diversos tipos de coagulantes. Caso esta etapa de coagulação não tenha êxito, todas as demais estarão prejudicadas, a ponto de, em certas situações, obrigar o descarte de toda a água efluente da ETA por estar fora dos padrões de potabilidade. A coagulação consiste em adicionar o composto químico (coagulante) ao afluente de água bruta na ETA e, no mesmo instante, promover, por meio de mistura rápida hidráulica ou mecânica, a homogeneização da mistura. 
Este trabalho visa investigar a eficiência de alguns tipos de coagulantes aplicados ao tratamento convencional de água, reiterando que é de suma importância a atuação eficaz do coagulante químico que exerce influência direta em todas as etapas posteriores do tratamento da água. Foram utilizados os seguintes tipos de coagulantes: Sulfato de Alumínio, Cloreto Férrico, Hidróxicloreto de Alumínio e Sulfato Férrico, sendo estes os principais coagulantes disponíveis no mercado para tratamento de água.

Nestes experimentos foram determinados alguns parâmetros da coagulação química, pois estes definem a melhor ou pior qualidade da água tratada, e foi realizada uma comparação dos custos dos compostos químicos utilizados. Para cada coagulante químico foi obedecida a metodologia descrita posteriormente, e obtidos parâmetros de dosagem otimizados através do diagrama de coagulação para dois tipos de água. No estudo foram utilizadas águas do poço da EESC-USP às quais foram acrescentados caulinita e ácido húmico para obtenção de turbidez e cor elevadas, respectivamente. 


\section{OBJETIVOS}

Os objetivos de pesquisa foram os seguintes:

- Obter dosagens adequadas dos seguintes tipos de coagulantes: Sulfato de Alumínio, Cloreto Férrico, Hidróxicloreto de Alumínio e Sulfato Férrico, visando obtenção das condições otimizadas de coagulação no mecanismo da varredura para águas com turbidez elevada ou com cor elevada.

- Efetuar comparação de custos dos diferentes coagulantes. 


\section{REVISÃO DA LITERATURA}

\subsection{INTRODUÇÃO}

A necessidade de consumo de água potável para os seres humanos é vital para sua sobrevivência. Segundo AZEVEDO NETTO (1990), devido à pequena quantidade que pode ser diretamente aproveitada - somente $0,3 \%$, "sendo a maior parte subterrânea" - ainda assim ela não é apropriada para o consumo humano, tornando-se necessário retirar suas impurezas, adequando-a aos "padrões de potabilidade".

Tais impurezas em geral são retiradas no processo de coagulação seguido pelas operações de floculação, sedimentação (ou flotação) e filtração.

\subsection{IMPUREZAS DA ÁGUA}

As impurezas encontradas nas águas superficiais são as seguintes: sólidos dissolvidos em forma ionizada, gases dissolvidos, compostos orgânicos dissolvidos e matéria em suspensão, tais como, microrganismos (bactérias, algas e fungos) e colóides. A maioria destas impurezas apresenta cargas negativas em suas superfícies, repelindo-se umas às outras, mantendo-se em suspensão estável por longos períodos de tempo. Tais partículas apresentam-se em tamanhos de diversas ordens de grandeza, conforme FIGURA 3.1.

A água é um meio de transporte para diversas doenças. Segundo Di Bernardo (1999), conforme notas de aula, podem existir microrganismos na água em forma de espórios ${ }^{1}$ que resistem à desinfecção por longo tempo de contato, dificultando assim sua eliminação.

\footnotetext{
${ }^{1}$ Segundo o Novo Dicionário Aurélio, a grafia preconizada pelo Vocabulário Ortográfico de 1943 é espório., embora também possamos encontrar esporo.
} 


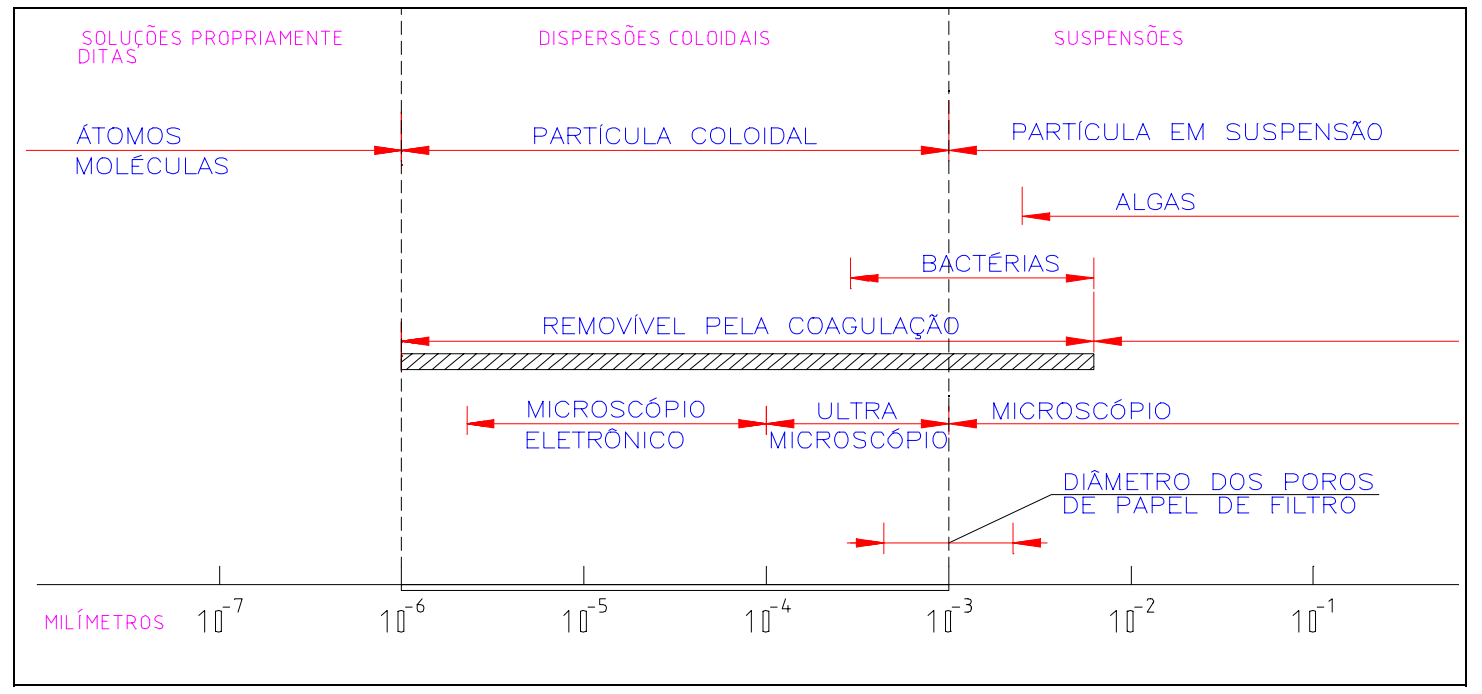

FIGURA 3.1 - Distribuição do tamanho das partículas presentes na água CEPIS (1973).

As partículas de Suspensões têm tamanhos que variam de $10^{-3} \mathrm{~mm}$ a $10^{-1} \mathrm{~mm}$, de forma que, por meio de sedimentação ou flotação, consegue-se a separação das fases líquida/sólida em tempo razoável (na prática, em torno de uma hora).

A faixa em forma de retângulo hachurada na FIGURA 3.1 corresponde às dispersões coloidais nas quais pode atuar a coagulação química. Nesta faixa, as partículas têm tamanho de “. $.10^{-6} \mathrm{~mm}$ a $10^{-3} \mathrm{~mm}$ e alguns zooplânctons, já pertencentes às suspensões, têm diâmetro de aproximadamente $10^{-2} \mathrm{~mm}$." (AMERICAN WATER WORKS ASSOCIATION-AWWA, 1990, Cap. 6, p. 270). Essas partículas, devido ao tamanho reduzido, levariam um tempo muito longo para sedimentar, impossibilitando sua remoção somente por sedimentação. Por meio de produtos químicos (sais de ferro e alumínio), pode-se promover a união destas partículas, adicionando-se o produto químico (denominado coagulante) na água bruta, e rapidamente procurando-se homogeneizar a mistura mecânica ou hidraulicamente; este processo é denominado "coagulação". Após a coagulação, a água percorre uma série de reatores, cada um deles dotado de um gradiente médio de velocidade, fazendo com que as partículas presentes na água bruta unam-se formando os "flocos"; esta operação é denominada "floculação". 


\subsection{CARACTERÍSTICAS FÍSICAS DA ÁGUA}

As principais medidas físicas que podem ser feitas na água são cor e turbidez. É interessante comentar que a cor pode ser aparente ou verdadeira da água, sendo que essa última pode ser medida após centrifugação da amostra em laboratório de acordo com método descrito na $20^{\mathrm{a}}$ edição do Standard Methods (1998). Além destas medidas, ainda podem ser consideradas: a temperatura, o potencial zeta, entre outras.

\section{TURBIDEZ}

A turbidez pode ser definida como sendo o grau de redução que a luz sofre ao atravessar uma certa quantidade de água, devido à presença das partículas e substâncias que esta contém. Em sua maior parte, a turbidez é provocada pela ação das chuvas, que, por meio de seus caminhos de escoamento na superfície do solo, carreiam partículas de areia e argila. As areias são partículas sedimentáveis sem coagulação, não constituindo portanto objeto deste estudo. As argilas são formadas basicamente por argilominerais compostos de silicatos hidratados de alumínio e ferro, com certo teor de elementos alcalinos e alcalinos terrosos, matéria orgânica, partículas de quartzo, pirita, calcita e outros minerais residuais. Dentre as principais argilas tem-se a caulinita, montmorilonita, ilita e moscovita.

Morfologicamente, as argilas se apresentam sob o formato de plaquetas superpostas. No caso da caulinita, predomina, em suas superfícies, uma camada recoberta por átomos de oxigênio, outra camada composta por grupos funcionais hidroxilas. Segundo VAN OLPHEN (1977) apud MENDES - "Devido a esse aspecto e a substituições isomórficas no retículo cristalino, essas faces assumem carga residual negativa (para $\mathrm{pH}>2$ ). No entanto, nas faces menores, esse reticulado cristalino é interrompido, deixando uma deficiência de cargas negativas pela presença de íons positivos fortemente polarizantes." - Esta descrição pode ser visualizada pela FIGURA 3.2 .

COR

A cor da água, na maioria dos casos, é provocada por compostos orgânicos de origem vegetal que, pela atividade de microrganismos e pelos resíduos das atividades humanas, se decompõem. 
Com a decomposição da matéria orgânica natural, ocorre a formação das substâncias húmicas, classificadas de acordo com a solubilidade em diferentes condições. Esta classificação, proposta em 1919 (citada por MENDES-1989, p.11, segundo ODEN) e utilizada por diversos pesquisadores, é mostrada no TABELA 3.1.

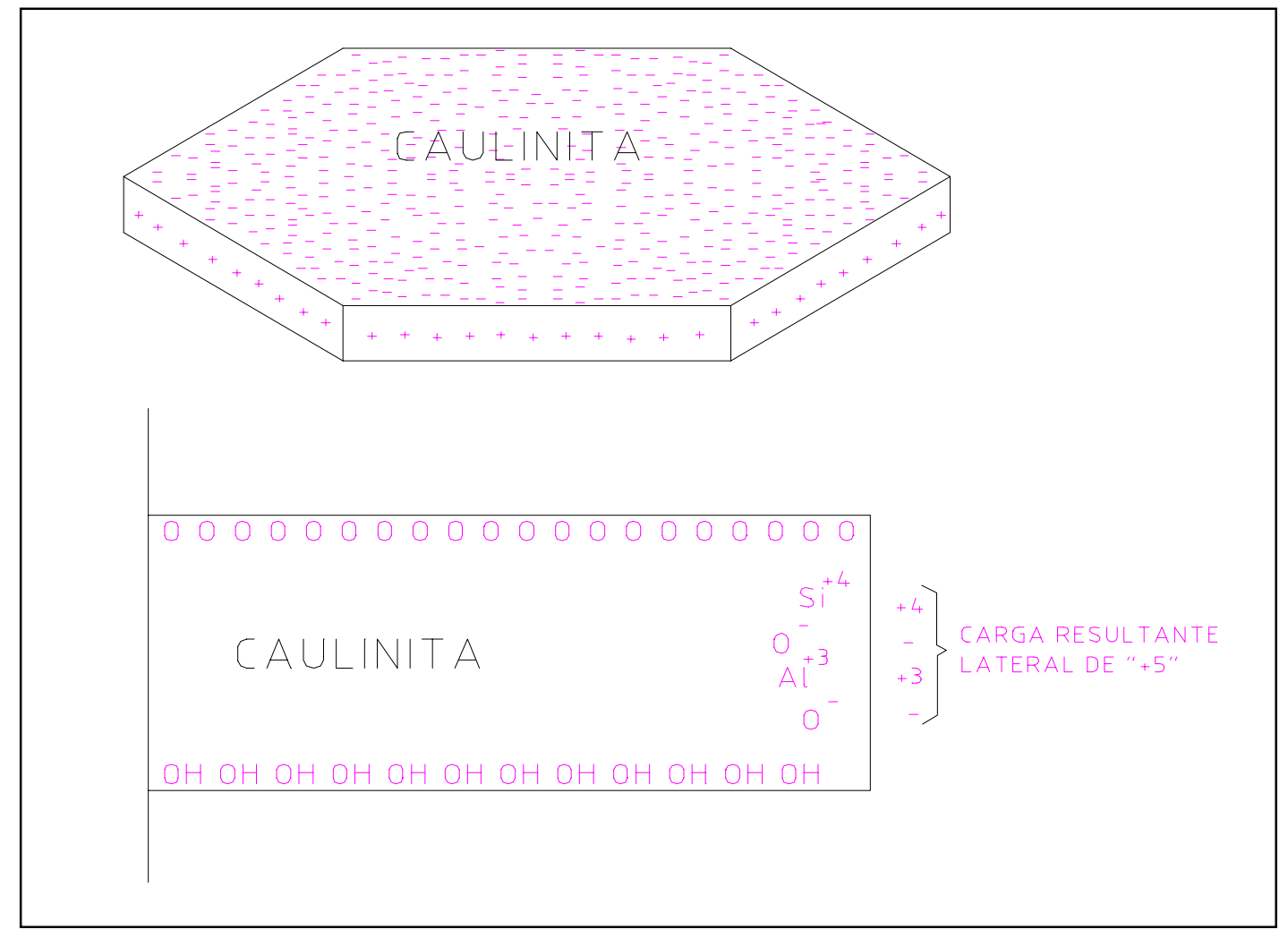

FIGURA 3.2 - Cargas superficiais da partícula de caulinita (apud MENDES segundo VAN OLPHEN).

TABELA 3.1 - Classificação das substâncias húmicas (apud MENDES-1989, p.11, segundo, ODEN).

\begin{tabular}{|l|l|}
\hline NOME DA FRAÇÃO & CARACTERÍSTICA \\
\hline Ácido húmico & Fração solúvel em NaOH e insolúvel em ácidos minerais e álcool. \\
\hline Ácido fúlvico & Fração solúvel em ácidos minerais e NaOH. \\
\hline Ácido himatomelânico & Fração solúvel em $\mathrm{NaOH}$ e álcool; insolúvel em ácidos minerais. \\
\hline Humina & Resíduo da separação dos comp. ant. (insolúvel em água e $\mathrm{NaOH}$ ). \\
\hline
\end{tabular}


BLACK \& CHRISTMAN (1963), através de evaporação à baixa pressão e posterior solubilização em diferentes valores de $\mathrm{pH}$, separaram as frações dos compostos orgânicos, causadores de cor de diversas fontes de águas naturais, verificando que as concentrações desses compostos variavam de 15 a $50 \mathrm{mg} / 1$, sendo o ácido fúlvico, o principal constituinte, com $87 \%$, o ácido himatomelânico com $11 \%$ e o ácido húmico com $2 \%$. Segundo MIDWOOD \& FELBECK (1968), em solos turfosos há predominância da fração de ácido fúlvico $(\approx 80 \%)$.

\section{TEMPERATURA}

É importante conhecer as possíveis variações de temperatura ao longo dos processos e operações no tratamento da água, pois, a temperatura tem influência no desempenho das unidades de mistura rápida, floculação, desinfecção e nas reações de hidrólise do coagulante e solubilidade de gases.

\section{POTENCIAL ZETA}

O potencial zeta, ou potencial eletrocinético, é um parâmetro utilizado para determinação da carga eletrostática superficial das partículas coloidais presentes na água. Sua medida pode ser considerada como um bom índice para medir a magnitude das interações repulsivas entre tais partículas.

Na FIGURA 3.5, a uma certa distância da superfície da partícula, geralmente onde se inicia a camada difusa, está o plano de cisalhamento cujo seu potencial é o potencial zeta.

Segundo YOKOSAWA (2001), os óxidos sofrem protonação quando em solução aquosa ácida, e desprotonação quando em solução aquosa alcalina, portanto o potencial zeta é dependente do $\mathrm{pH}$ do meio, da espessura da dupla camada elétrica, que por sua vez depende da concentração de íons adsorvidos e da força iônica da suspensão. Ainda se as partículas possuem carga alta, elas se repelem umas às outras e o colóide é estável. Caso as partículas tenham carga resultante próxima de zero, o movimento browniano das partículas é transmitido ao colóide, tendo como efeito final a aglomeração das partículas, podendo este fato levar à floculação. 


\title{
3.4.CARACTERÍSTICAS QUÍMICAS DA ÁGUA
}

\author{
ALCALINIDADE, ACIDEZ e pH
}

A alcalinidade da água é importante na coagulação química, pois os coagulantes comumente têm atuação como ácidos em solução, reduzindo a alcalinidade e baixando o valor do $\mathrm{pH}$, sendo necessária freqüentemente a adição de alcalinizante para o equilíbrio do $\mathrm{pH}$.

A alcalinidade da água pode ser entendida como a capacidade na neutralização de ácidos, e a acidez, de neutralização de bases. Nas soluções aquosas, as características de alcalinidade e acidez baseiam-se normalmente no sistema do ácido carbônico $\left(\mathrm{H}_{2} \mathrm{CO}_{3}\right)$, que é um ácido diprótico fraco que possui três pontos de equivalência, com as principais reações como seguem, e considerando a temperatura de $25^{\circ} \mathrm{C}$ :
$\mathrm{CO}_{2}(\mathrm{aq})+\mathrm{H}_{2} \mathrm{O}$
$\mathrm{H}_{2} \mathrm{CO}_{3}$
$\left(K_{1}=10^{-2,8}\right)$
$\mathrm{H}_{2} \mathrm{CO}_{3}$
$\mathrm{H}^{+}+\mathrm{H}_{2} \mathrm{CO}_{3}^{-}$
$\left(\mathrm{K}_{2}=10^{-3,5}\right)$
$\mathrm{HCO}_{3}^{-}$
$\mathrm{H}_{2}+\mathrm{CO}_{3}^{2-}$
$\left(K_{3}=10^{-10,3}\right)$

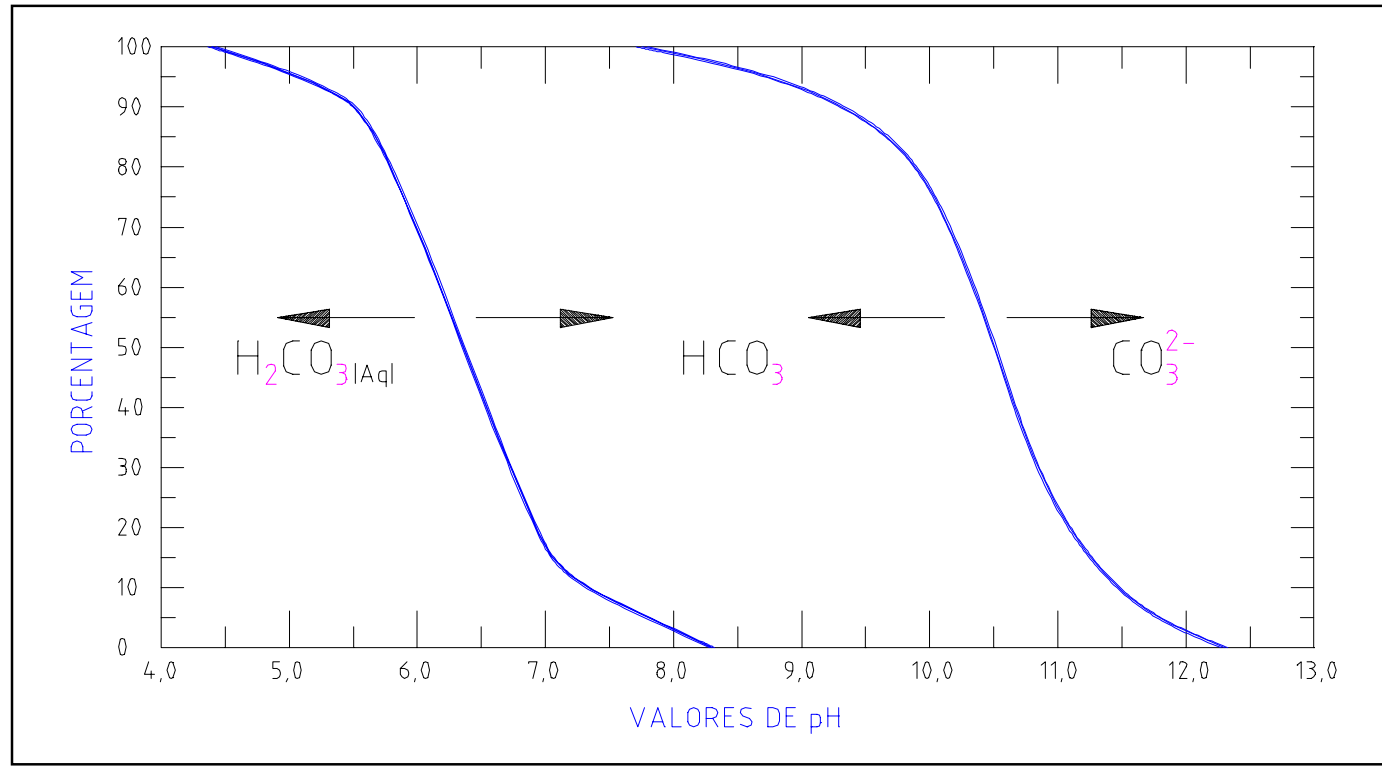

FIGURA 3.3 - Constituintes do sistema do ácido carbônico em função do pH com pressão de $1 \mathrm{~atm}$ e temperatura de $25^{\circ} \mathrm{C}$ (DI BERNARDO, 1993). 
A FIGURA 3.3 ilustra os constituintes do sistema do ácido carbônico em função do $\mathrm{pH}$. Considerando essa figura, a alcalinidade em função do $\mathrm{pH}$ para temperatura de $25^{\circ} \mathrm{C}$ e pressão de $1 \mathrm{~atm}$, pode ser dividida nas seguintes faixas:

$\mathrm{pH}=12,3-9,4:$ alcalinidade de hidróxidos e carbonatos

$\mathrm{pH}=9,4-8,3:$ alcalinidade de carbonatos e bicarbonatos

$\mathrm{pH}=8,3-4,4:$ alcalinidade de bicarbonatos somente

\subsection{INTERAÇÃO ENTRE PARTÍCULAS COLOIDAIS}

Em um sistema bifásico (sólido-líquido) onde existe uma grande concentração de partículas coloidais, umas se aproximam das outras e/ou chocam-se entre si devido ao movimento contínuo e desordenado dessas mesmas partículas (movimento browniano), permitindo-se uma interação entre as camadas difusas (ver FIGURA 3.4), fazendo com que ocorra atração devido à força de van der Walls e repulsão devido à força eletrostática ou da dupla camada elétrica.

\section{FORÇA DE VAN DER WALLS}

A força de van der Walls tem origem na interação de dipolos elétricos atômicos e moleculares, estando associada às flutuações na densidade eletrônica dos átomos. Conforme cita DI BERNARDO et al (1993), para dois átomos a força atrativa de van der Walls é inversamente proporcional à sétima potência da distância entre eles, porém, para duas partículas constituídas de grande número de átomos, as forças atuantes sobre cada par de átomos são aditivas, resultando em uma energia de atração inversamente proporcional ao quadrado da distância entre as superfícies das partículas.

\section{DUPLA CAMADA ELÉTRICA (DCE)}

A força da dupla camada elétrica tem sua origem na superfície das partículas sólidas, onde ocorre adsorção ou dessorção de íons entre a partícula sólida e a solução circundante.

As partículas coloidais possuem predominantemente cargas negativas, as quais atraem uma grande quantidade de íons de carga oposta (positiva) presentes na solução, porém devido as 
dimensões das superfícies das partículas, apenas um número limitado de íons positivos consegue ser adsorvidos. Esta adsorção faz com que os íons adsorvidos permaneçam de maneira rígida sobre a superfície da partícula, dando origem à denominada camada compacta ou camada de Stern.

Quando íons negativos aproximam-se da camada compacta, atraem consigo alguns íons positivos, resultando na formação da camada difusa, que engloba a camada compacta, na realidade, a camada difusa resulta da atração de íons positivos, repulsão eletrostática de íons negativos e difusão térmica.

O conjunto das camadas, compacta e difusa, resulta na denominada dupla camada elétrica (DCE).

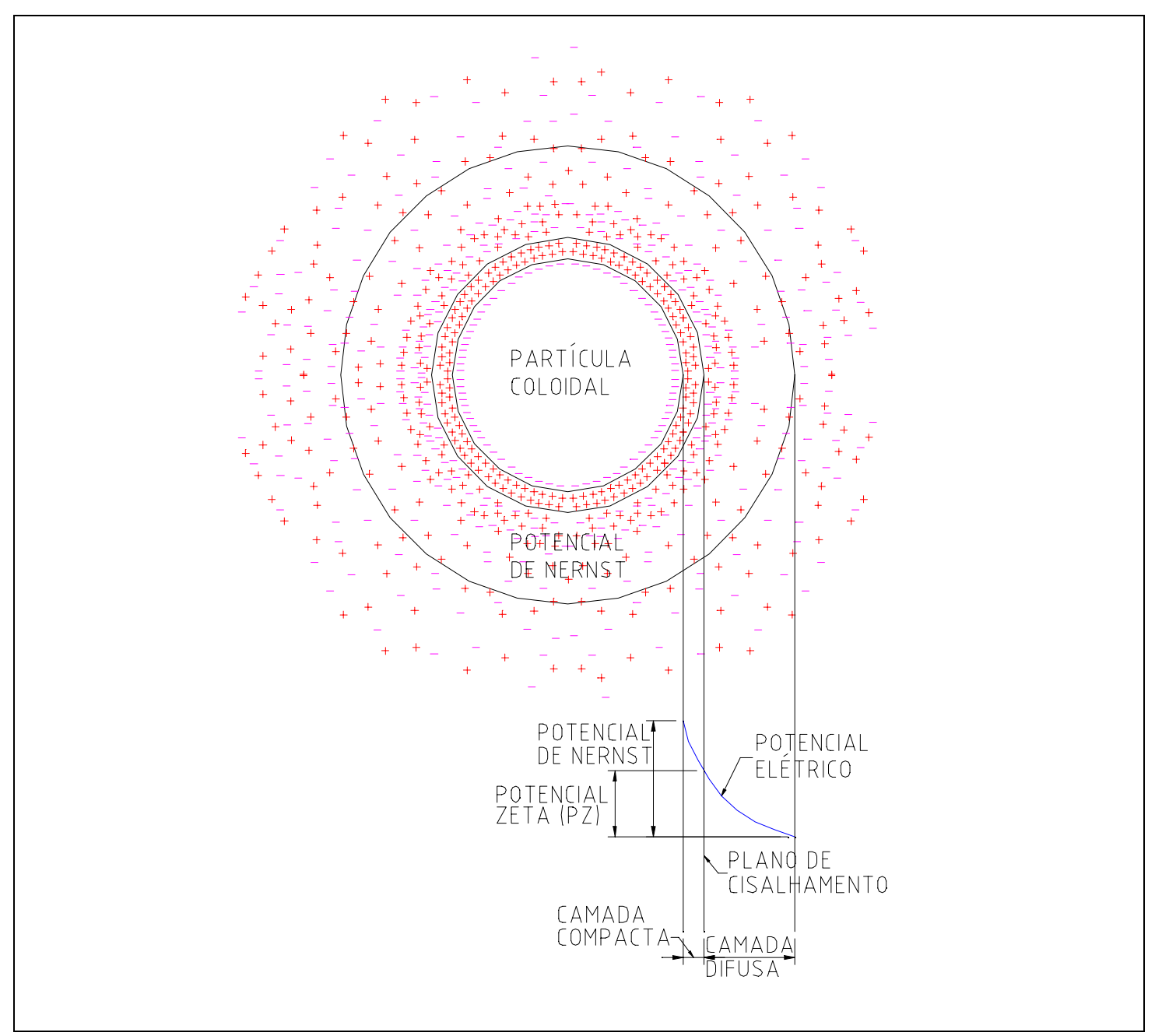

FIGURA 3.4 - Configuração esquemática da dupla camada elétrica (apud DI BERNARDO p. 164, segundo AWWA). 


\section{TEORIA DLVO}

$\mathrm{Na}$ ciência dos colóides é fundamental citar a teoria DLVO originada das pesquisas dos cientistas russos Derjaguin e Landau e dos cientistas holandeses Verwey e Overbeek. Esta teoria sugere que a estabilidade de uma suspensão coloidal pode ser descrita pela interação total resultante das contribuições das interações atrativas (força de van der Walls) e repulsivas (forças da DCE). Assim, pela teoria DLVO, para se ter uma suspensão estável é necessário que as forças de interações repulsivas superem as forças de atração de van der Walls. Desta forma, para curtas ou longas distâncias (ver FIGURA 3.5) sempre o efeito entre as partículas é atrativo; no entanto, a partir de uma distância "d" da superfície da partícula, a repulsão predomina em um certo intervalo de distância.

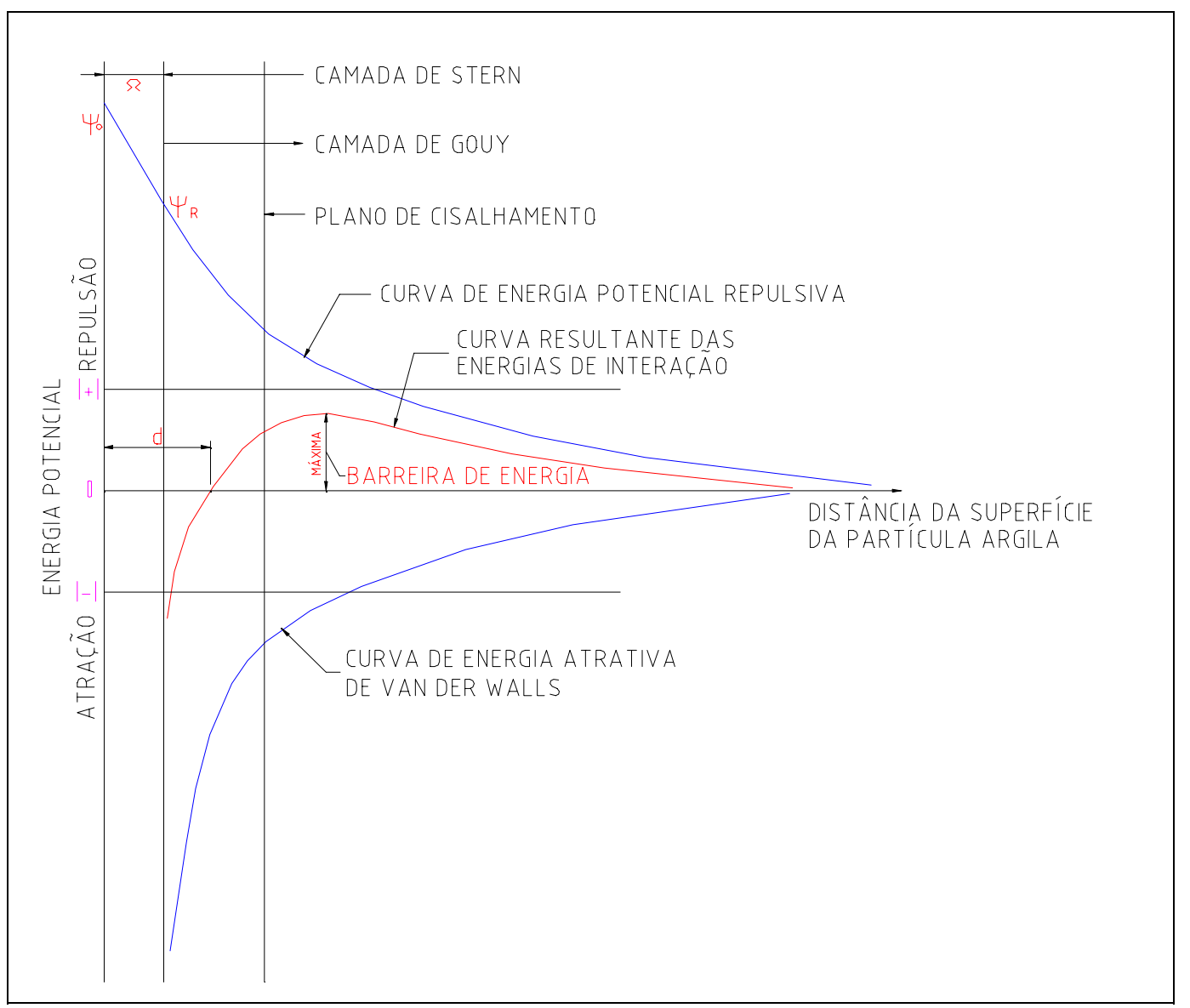

FIGURA 3.5 - Energia potencial de interação entre as partículas coloidais (CEPIS, 1984). 


\subsection{MECANISMOS DE COAGULAÇÃO}

Segundo o catálogo da PAN-AMERICANA S.A.-Indústrias Químicas, a história da separação das impurezas em dispersões coloidais da água (coagulação) é antiga. No Egito, farinhas de favas e de amendoim já eram utilizadas para remoção das partículas coloidais. $\mathrm{Na}$ Índia eram usadas nozes moídas e, na China, o alume, um sulfato duplo de alumínio e potássio. Esse último é o verdadeiro precursor dos modernos coagulantes minerais. Em 1853, na Inglaterra, J. Simpson fez as primeiras tentativas de coagulação em grande escala com sulfato de alumínio. A primeira patente, no entanto, foi em 1885 por Isaiah Hyatt nas instalações dos Departamentos de Água Potável das cidades de Somerville e Ravidan, em Nova Jersey.

A coagulação corresponde à desestabilização da dispersão coloidal, obtida por redução das forças de repulsão entre as partículas com cargas negativas, por meio da adição de produto químico apropriado, habitualmente com sais de ferro ou de alumínio ou de polímeros sintéticos, seguidos por agitação rápida, com o intuito de homogeneizar a mistura.

Os principais mecanismos que atuam na coagulação são: compressão de camada difusa; adsorção e neutralização; varredura; e adsorção e formação de pontes.

\section{COMPRESSÃO DA CAMADA DIFUSA}

Esse mecanismo de coagulação ocasiona a desestabilização das partículas coloidais através da adição de íons de carga contrária. Segundo DI BERNARDO (1993), já em 1900, SCHULZE e HARDY, por meio das teorias de Derjaguin, Landau, Verwey e OverbeekDLVO, mostraram que quanto maior a carga do íon positivo, menor a quantidade requerida para a coagulação. Ao desestabilizar colóides negativos, as concentrações molares dos metais $\mathrm{Na}^{+}, \mathrm{Ca}^{++}, \mathrm{Al}^{+++}$variam de 1000: 10: 1. Este fenômeno é explicado pela grande concentração de cargas positivas que causam excesso de íons na camada difusa, fazendo com que reduza o volume de sua esfera para manter-se eletricamente neutra (ver FIGURAS $3.4 \mathrm{e}$ 3.5), reduzindo o potencial elétrico (Potencial Zeta) e predominando a força de van der Waals. 
Neste mecanismo pode-se citar como exemplo o encontro de água doce de rios com pequena força iônica que ao desaguar o seu efluente e misturar-se com a água no mar, promove a formação de depostos neste encontro.

De acordo com DI BERNARDO (1993), vale o destaque de dois aspectos:

- A quantidade de eletrólitos para conseguir a coagulação é praticamente independente da concentração de colóides na água.

- Não é possível causar a reversão de carga dos colóides (reestabilização) para quaisquer quantidades de eletrólitos adicionados.

\section{ADSORÇÃO E NEUTRALIZAÇÃO DE CARGA}

Na dispersão coloidal, ao adicionar-se o coagulante, ocorre interações entre coagulantecolóide, coagulante-solvente e colóide-solvente.

Segundo MENDES (1989), algumas espécies químicas são capazes de serem adsorvidas na superfície das partículas coloidais. Como tais espécies são de carga contrária à da superfície dos colóides, ocorrerá a desestabilização. Esta desestabilização é causada pelo coagulante em dosagens bem inferiores às do mecanismo da dupla camada.

Conforme DI BERNARDO A. S. (2001), existem três diferenças principais relacionados com os mecanismos de compressão da camada difusa e o de adsorção e neutralização de carga:

- Como já citado, a desestabilização dos colóides ocorre com dosagens bem inferiores.

- Existe uma relação estequiométrica entre a concentração dos colóides e a quantidade necessária de espécies desestabilizantes por adsorção.

- É possível a reversão de carga superficial das partículas coloidais através de superdosagem de espécies adsorvíveis.

Para DI BERNARDO (1993), este mecanismo deve ser utilizado em Estações de tratamento de água cujo processo, após coagulação, seja a filtração direta, pois as partículas desestabilizadas ficarão retidas no interior do meio filtrante da unidade de filtração. 


\section{VARREDURA}

Neste mecanismo, segundo DI BERNARDO (1993), conforme a quantidade de coagulante (sal), do pH da mistura e da concentração de alguns tipos de íons presentes na água, poderá ocorrer a formação de precipitados como $\mathrm{AI}(\mathrm{OH})_{3 \mathrm{p}}, \mathrm{Fe}(\mathrm{OH})_{3 \mathrm{p}}$, ou outros, dependendo do coagulante empregado.

O mecanismo da varredura vem sendo bastante empregado em estações de tratamento de água do tipo completa, sendo esta com floculação/sedimentação antecedendo à filtração. Os flocos formados são maiores do que aqueles formados pela adsorção e neutralização de cargas; conseqüentemente, suas velocidades de sedimentação são maiores.

\section{ADSORÇÃO E FORMAÇÃO DE PONTES}

Segundo MENDES (1989), este mecanismo é desenvolvido por intermédio da utilização de compostos orgânicos (polímeros) sintéticos ou naturais, utilizados como coagulantes; podem apresentar sítios ionizáveis ao longo de suas cadeias, podendo ser classificados como catiônicos, aniônicos, anfóteros.

Para MENDES (1989), pode ser explicado o comportamento dos polímeros como coagulantes, baseando-se na sua adsorção à superfície das partículas coloidais, seguida pela redução da carga ou pelo entrelaçamento das partículas nas cadeias do polímero.

Como citado por DI BERNARDO A.S. (1993), pesquisa com esses compostos têm mostrado que é possível a desestabilização de colóides (com cargas negativas) tanto com polímeros catiônicos como aniônicos. Desta maneira, tanto o mecanismo da compressão da camada difusa como o de adsorção e neutralização de cargas, não podem caracterizar o mecanismo de adsorção e formação de pontes.

\section{DIAGRAMA DE COAGULAÇÃO}

AMIRTHARAJAH \& MILLS (1982) desenvolveram o diagrama de coagulação para o sulfato de alumínio (FIGURA 3.6), considerando dosagens de $\mathrm{Al}_{2}\left(\mathrm{SO}_{4}\right)_{3}$. 14,3 $\mathrm{H}_{2} \mathrm{O}$ versus 
pH da mistura. Pode-se notar regiões distintas para diferentes mecanismos de coagulação, seja na adsorção e neutralização de cargas, na varredura, ou na combinação de ambas.

$\mathrm{Na}$ região de coagulação por varredura ocorre excessiva formação de precipitados de hidróxido de alumínio, cujas partículas coloidais estão aprisionadas. Esta região é recomendada para ETA com tratamento completo, pois os flocos são densos e ficam retidos no decantador.

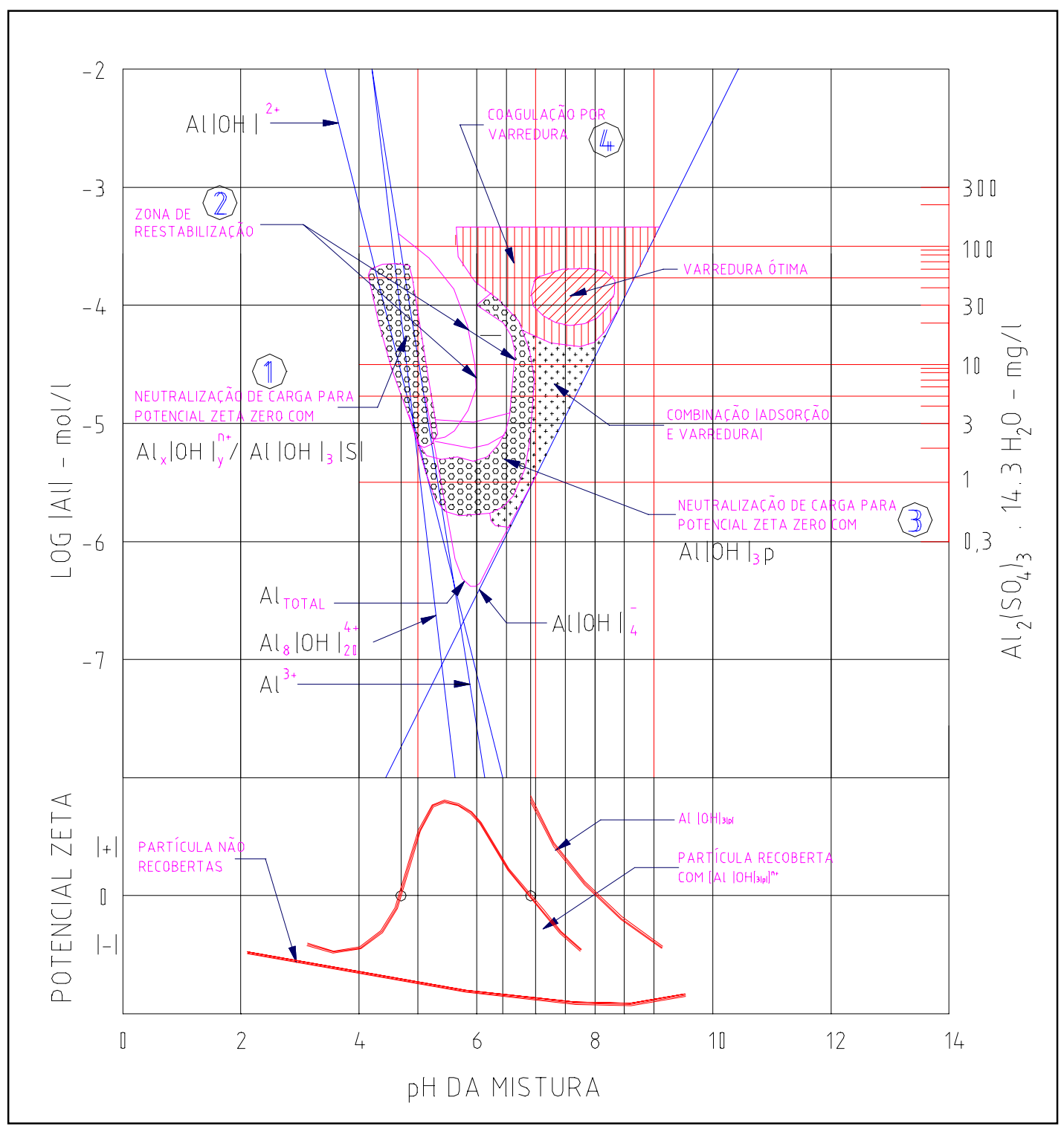

FIGURA 3.6 - Diagrama de coagulação (típico) com o sulfato de alumínio para remoção de turbidez AMIRTHARAJH (1989). 


\section{REGIÃO 1}

Nesta região pode ocorrer a neutralização de carga das partículas coloidais pelas espécies hidrolisadas de alumínio, que são adsorvidas na superfície dos colóides. Com o pH no valor aproximado de 4,7, o potencial zeta se aproxima de zero, e a dosagem de sulfato de alumínio poderá variar entre 5 a $70 \mathrm{mg} / 1$.

\section{REGIÃO 2}

Esta região com o valor do $\mathrm{pH}$ maior do que 4,7, tem o valor do potencial zeta positivo, e também os colóides se tornam positivos, sendo esta zona caracterizada pela reestabilização. A delimitação superior da região de reestabilização inicia-se a região de desestabilização, que conforme cita DI BERNARDO (1993), tem sido atribuído à presença de íons $\mathrm{SO}_{4}{ }^{2-} \mathrm{e}$ ao aprisionamento dos colóides reestabilizados em complexos de sulfato do tipo $\mathrm{Al}\left(\mathrm{H}_{2} \mathrm{O}\right) \mathrm{SO}_{4}^{+}$.

\section{REGIÃO 3}

Segundo ARMITHARAJAH \& MILLS (1982), esta região tem denominação de "corona", com dosagens compreendidas entre 3 e $30 \mathrm{mg} / 1$, sendo a região ideal para coagulação quando se tem filtração direta. Nesta região é que o valor do potencial zeta atinge seu máximo. Quando o valor de $\mathrm{pH}$ está em torno de 6,9 e dosagem de coagulante $10 \mathrm{mg} / \mathrm{l}$, e o valor do potencial zeta aproxima-se de zero.

\section{REGIÃO 4}

Nesta região, onde predomina a coagulação pelo mecanismo da varredura, com $\mathrm{pH}$ variando no intervalo de 5,5 a 9 e dosagens acima de $30 \mathrm{mg} / \mathrm{l}$, ocorre a formação de precipitados de hidróxidos de alumínio, juntamente com as partículas coloidais aprisionadas aos mesmos. A tecnologia de tratamento para esta região é do tipo com estações completas, ou seja, com decantadores antecedendo aos filtros, pois os flocos obtidos são de tamanho maior quando comparado aos flocos das outras regiões, sendo facilmente removidos pelos decantadores. 


\subsection{TECNOLOGIAS DE TRATAMENTO}

Na FIGURA 3.7 são apresentadas as tecnologias destinadas ao tratamento de água para consumo humano. Estas tecnologias podem ser divididas naquelas que precedem de coagulação e outras que não necessitam da coagulação. No tratamento através da filtração lenta, não há necessidade de coagulação química; as outras tecnologias necessitam da coagulação.

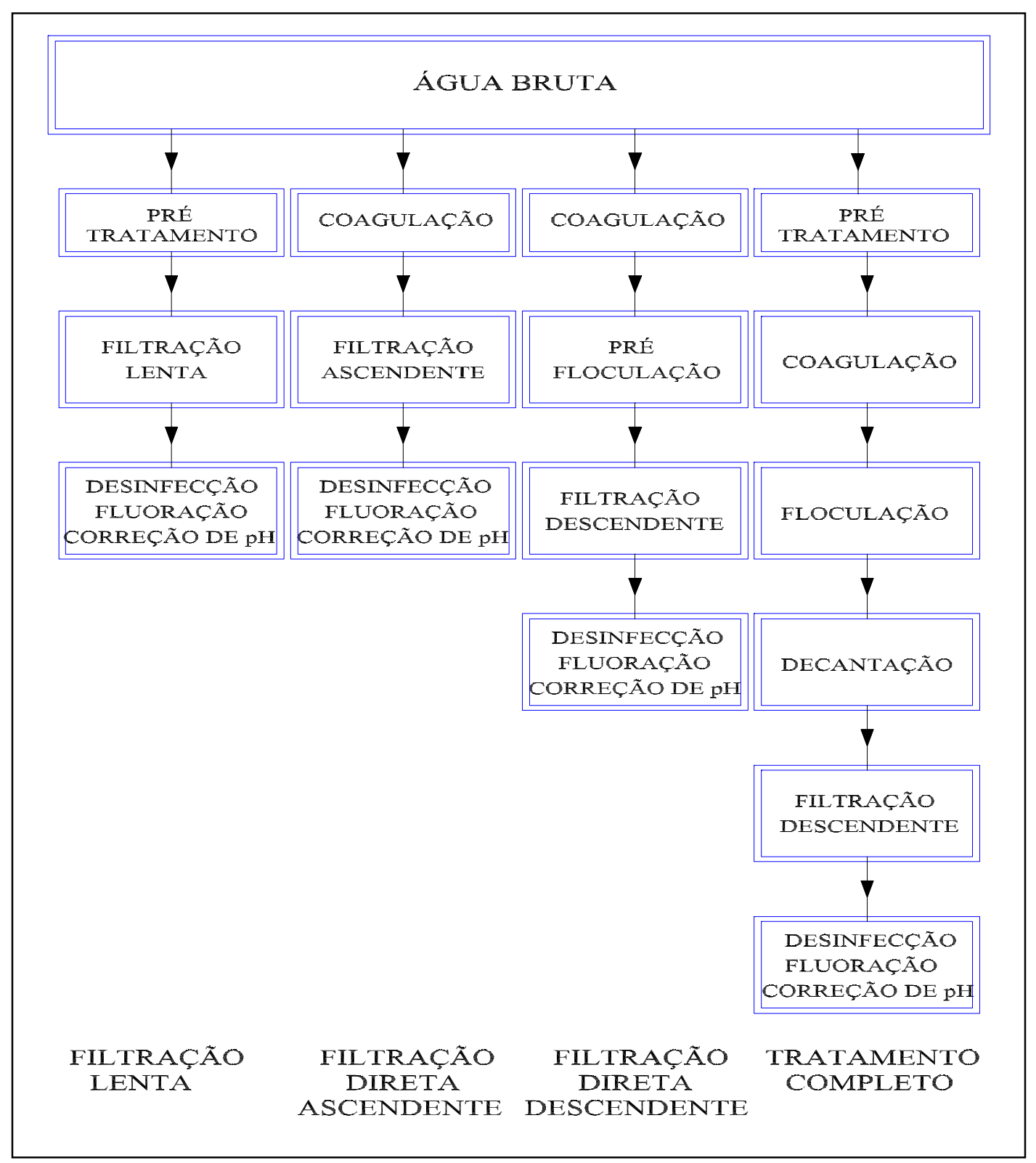

FIGURA 3.7 - Classificação das tecnologias de tratamento de água para consumo humano. FONTE: DI BERNARDO (1995). 
O tratamento da água para consumo humano, basicamente, consiste em produzir água atendendo aos padrões de potabilidade. Pode requerer apenas a filtração lenta, porém, no Brasil é comum a utilização de outras tecnologias de tratamento.

Normalmente em captações de alguns cursos d'água e em lagos, onde não se tenham picos nos valores de turbidez, principalmente em épocas chuvosas, a estação de tratamento poderá ser por filtração direta precedida de coagulação por adsorção e neutralização de cargas.

Em locais onde a qualidade da água bruta não permitir, a estação deverá ser do tipo completa; neste caso, a coagulação será do no mecanismo da varredura.

\subsection{COAGULAÇÃO PARA REMOÇÃO DE TURBIDEZ OU COR}

A FIGURA 3.8 mostra um diagrama de coagulação feito por DI BERNARDO et al (1993). A água utilizada para o estudo foi preparada com caulinita e substâncias húmicas, com as seguintes características: turbidez de $220 \mathrm{uT}$; cor verdadeira $5 \mathrm{uC}$; alcalinidade igual a $30 \mathrm{mg} / 1$ de $\mathrm{CaCO}_{3}$; temperatura $20^{\circ} \mathrm{C}$; condutância específica $72 \mu \mathrm{Mho} / \mathrm{cm}$ e o valor do $\mathrm{pH}$ de 7,5 .

As variações de $\mathrm{pH}$ foram feitas com acidificante ou alcalinizante. Para elevar o $\mathrm{pH}$ foi utilizado hidróxido de sódio e para baixar o pH foi utilizado ácido clorídrico.

Os parâmetros utilizados para os ensaios foram: para mistura rápida $\mathrm{Gmr}=900 \mathrm{~s}^{-1}$ e $\mathrm{Tmr}=2 \mathrm{~s}$; para floculação $\mathrm{Gf}=30 \mathrm{~s}-1$ e Tf=20min; com velocidade de sedimentação $\mathrm{Vs}=2 \mathrm{~cm} / \mathrm{min}$.

A região A com $80 \%$ de remoção, caracteriza o mecanismo predominantemente de adsorção das espécies hidrolisadas do alumínio, causando a neutralização de carga; a região B com 95\% de remoção, pitado de alumínio, caracterizando o mecanismo da varredura. Para a região A foram obtidos valores de $\mathrm{pH}$ entre 4,6 e 5,2 versus dosagens de sulfato de alumínio $\mathrm{Al}_{2}\left(\mathrm{SO}_{4}\right)_{3} .18 \mathrm{H}_{2} \mathrm{O}$ entre 8 a $12 \mathrm{mg} / \mathrm{l}$. Para região $\mathrm{B}$ foram conseguidos valores de $\mathrm{pH}$ entre 6,4 e 7,8 versus dosagens de sulfato de alumínio $\mathrm{Al}_{2}\left(\mathrm{SO}_{4}\right)_{3} .18 \mathrm{H}_{2} \mathrm{O}$ entre 40 a $80 \mathrm{mg} / \mathrm{l}$. 
DOSAGEN DE Al $2\left(\mathrm{SO}_{4}\right)_{3} .18 \mathrm{H}_{2} \mathrm{O}(\mathrm{mg} /$ litro $)$

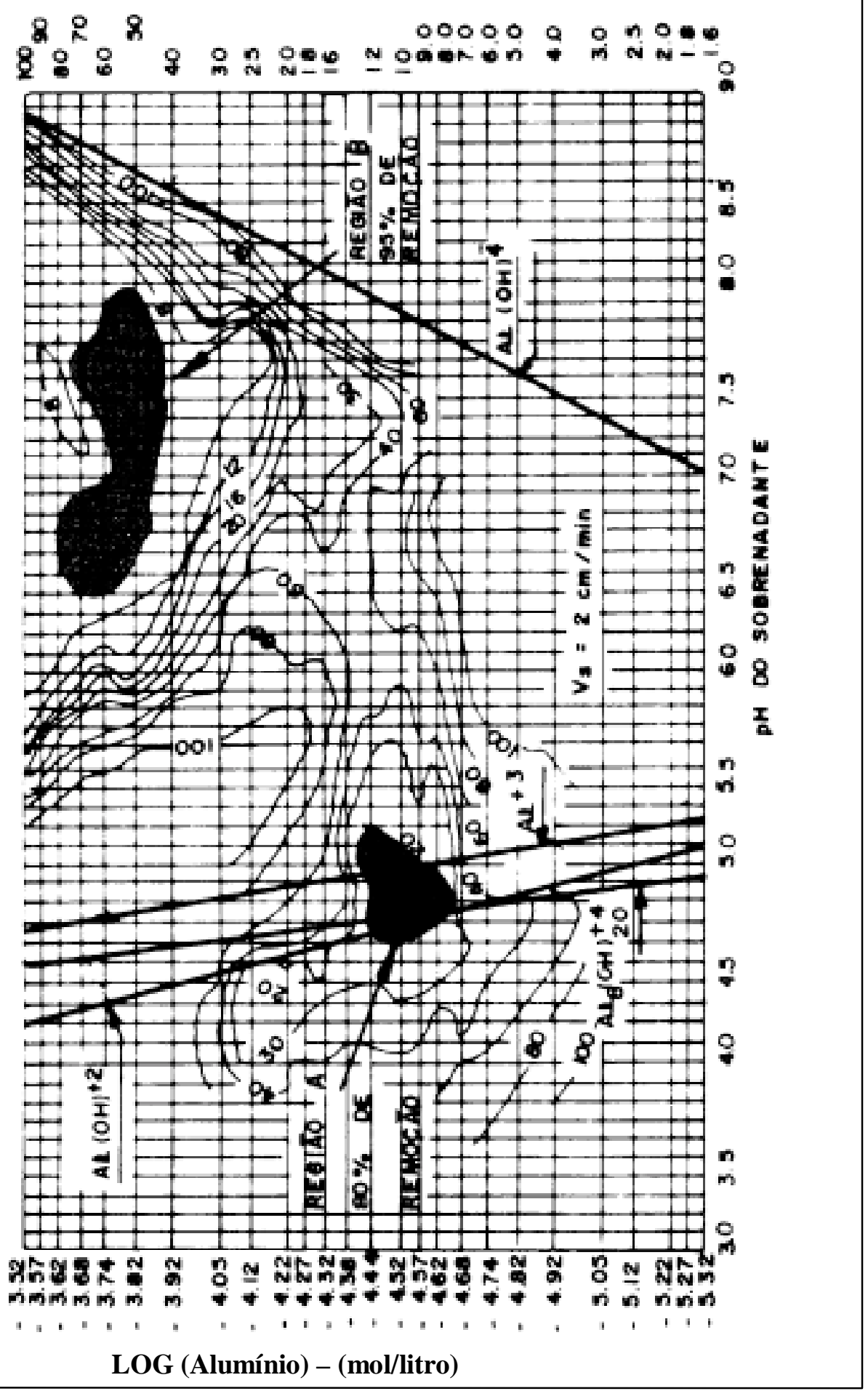

FIGURA 3.8 - Regiões de remoção de Turbidez (200uT), Cor Verdadeira (5uC), com Sulfato de Alumínio - PA (para análise).

FONTE: DI BERNARDO et al (1993). 
De acordo com estudos feitos por AMIRTHARAJAH (1989), através do diagrama de coagulação, foram representadas as regiões otimizadas para remoção de cor e turbidez com sulfato de alumínio. A FIGURA 3.9 mostra regiões nas quais a dispersão preparada estava com cor verdadeira de $100 \mathrm{uC}$ e sem turbidez; já na FIGURA 3.10 a dispersão preparada estava com cor verdadeira de $100 \mathrm{uC}$ e turbidez de 27 a 30uT. Nas FIGURAS 3.9 e 3.10 verificam-se resultados dos experimentos de coagulação, de acordo com os quais se obteve remoção de cor verdadeira igual ou acima de 90\%. Em seu experimento, foram utilizadas dispersões com diferentes concentrações de ácido húmico e caulinita. Duas regiões distintas destacam-se na FIGURA 3.9: uma região com pH na faixa de 6 a 8,3 com dosagens de coagulante de $12 \mathrm{mg} / \mathrm{l}$ a $55 \mathrm{mg} / \mathrm{l}$ aproximadamente, outra com $\mathrm{pH}$ na faixa de 4 a $4,8 \mathrm{com}$ dosagens de coagulante acima de 10mg/l. Na FIGURA 3.10 destacam-se: uma região com $\mathrm{pH}$ na faixa de 5,8 a 8,3 com dosagens de coagulante de $8 \mathrm{mg} / \mathrm{l} \mathrm{a} 100 \mathrm{mg} / \mathrm{l}$ aproximadamente, outra com pH na faixa de 4 a 5,5, com dosagens de coagulante acima de 4mg/l.

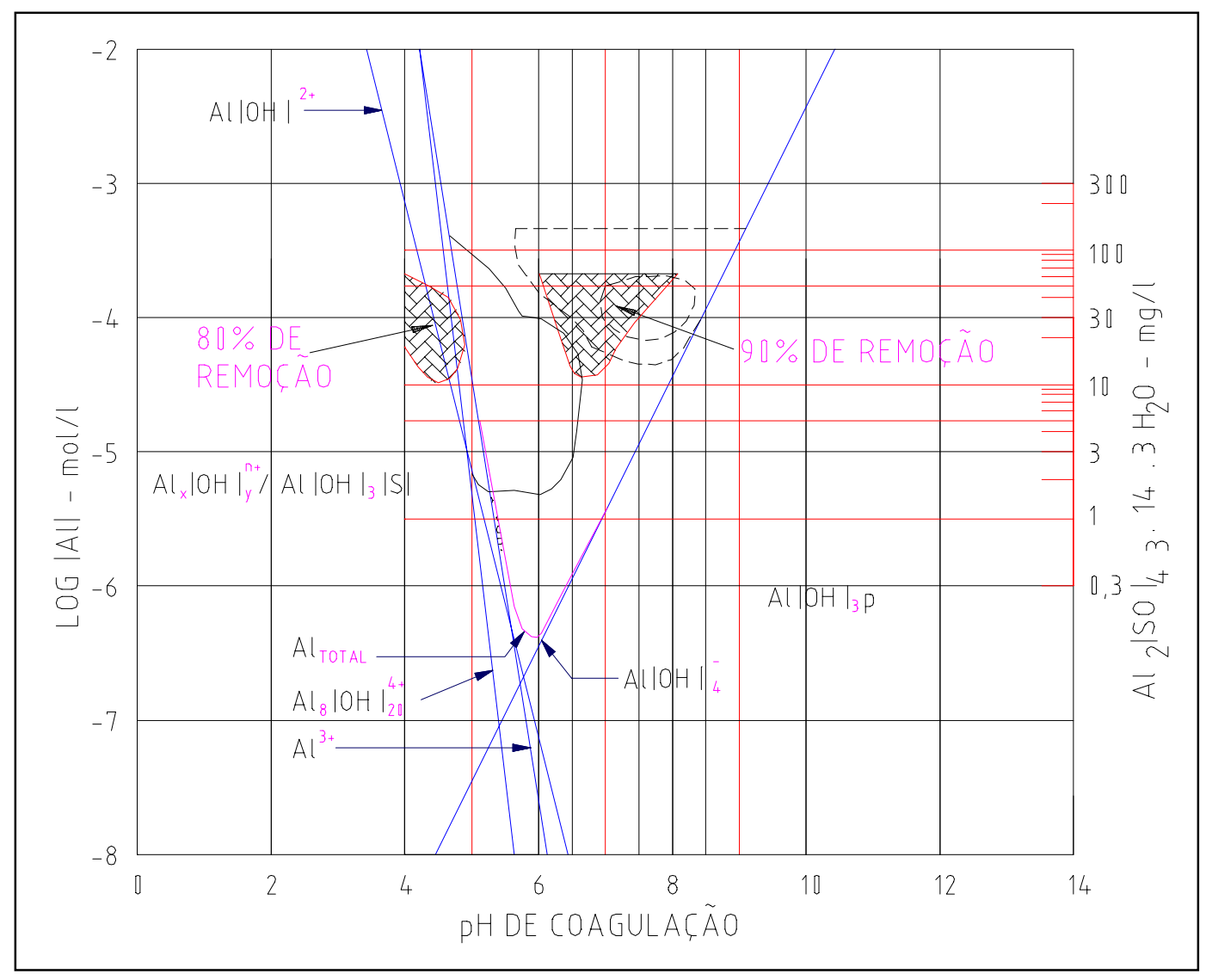

FIGURA 3.9 - Regiões de remoção de Cor Verdadeira (100uC), Turbidez (0uT) com Sulfato de Alumínio.

FONTE: AMIRTHARAJAH (1989). 
É interessante destacar que, para dispersões com cor e turbidez, as regiões otimizadas foram ampliadas com relação às dispersões somente com cor; provavelmente isso se deve ao aumento do número de partículas, conseqüentemente ampliando o número de colisões e melhorando assim a cinética de floculação.

A FIGURA 3.11 mostra um outro diagrama de coagulação do sulfato de alumínio, feito por DI BERNARDO et al (1993). Nesse diagrama, a água utilizada foi preparada com substâncias húmicas e caulinita e apresentou as seguintes características: cor verdadeira de 100uC; cor aparente de 130uC; turbidez de 5uT; alcalinidade de $40 \mathrm{mg} / \mathrm{l} \mathrm{de} \mathrm{CaCO}_{3} ; \mathrm{pH}=$ 7,5 ; temperatura de $20^{\circ} \mathrm{C}$. Foi utilizado dosagens de 10 a $200 \mathrm{mg} / \mathrm{l}$ de sulfato de alumínio $\mathrm{Al}_{2}\left(\mathrm{SO}_{4}\right)_{3} .18 \mathrm{H}_{2} \mathrm{O}$, e pH variando de 3,3 a 8,7 e com $\mathrm{Vs}=1,0 \mathrm{~cm} / \mathrm{min}$.

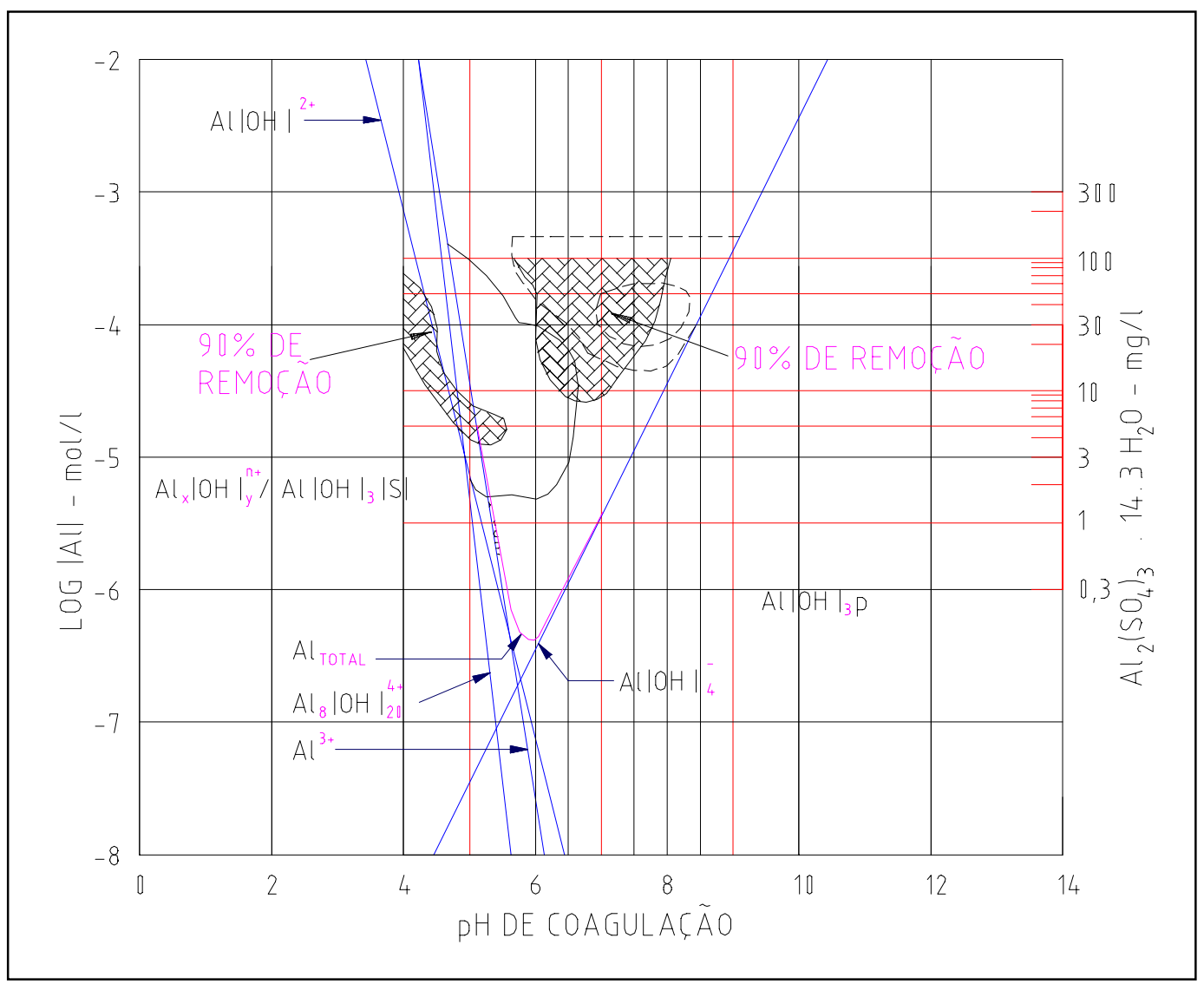

FIGURA 3.10 - Regiões de remoção de Cor Verdadeira (100uC), Turbidez (27-30uT) com Sulfato de Alumínio.

FONTE: AMIRTHARAJAH (1989). 
Destaca-se na FIGURA 3.11 uma região com remoção de cor aparente superior a 60\%, com dosagens de coagulante sulfato de alumínio de 14 a $80 \mathrm{mg} / \mathrm{l}$ contra $\mathrm{pH}$ de 3,8 a 4,9 caracterizando o mecanismo de adsorção e neutralização de cargas. Numa outra região cujo mecanismo é o da varredura, a remoção de cor aparente chega a 97,6\%. As condições ótimas de coagulação para o mecanismo de adsorção-neutralização foram: dosagem de sulfato de alumínio de $20 \mathrm{mg} / \mathrm{l}$ e pH de coagulação de 4,4. As condições ótimas de coagulação para o mecanismo de varredura foram: dosagem de sulfato de alumínio de $140 \mathrm{mg} / \mathrm{l} \mathrm{e} \mathrm{pH}$ de coagulação de 6,15 .

Segundo DI BERNARDO, as diferenças nos resultados com relação à FIGURA 3.10 deve-se ao menor valor da turbidez, e à utilização de substâncias húmicas ao invés de um produto comercial.

Em outro estudo realizado por COSTA (1992), a água apresentou as seguintes características: cor verdadeira $(100 \mathrm{uC})$; cor aparente $150 \mathrm{uC}$; turbidez $(5 \mathrm{uT})$; alcalinidade 30 $\mathrm{mg} / \mathrm{l}$ de $\mathrm{CaCO}_{3}$. Ele trabalhou com dosagens de 10 a $200 \mathrm{mg} / \mathrm{l}$ de sulfato de alumínio $\mathrm{Al}_{2}\left(\mathrm{SO}_{4}\right)_{3} .18 \mathrm{H}_{2} \mathrm{O}$, e $\mathrm{pH}$ variando de 4,3 a 8 (ver FIGURA 3.12).

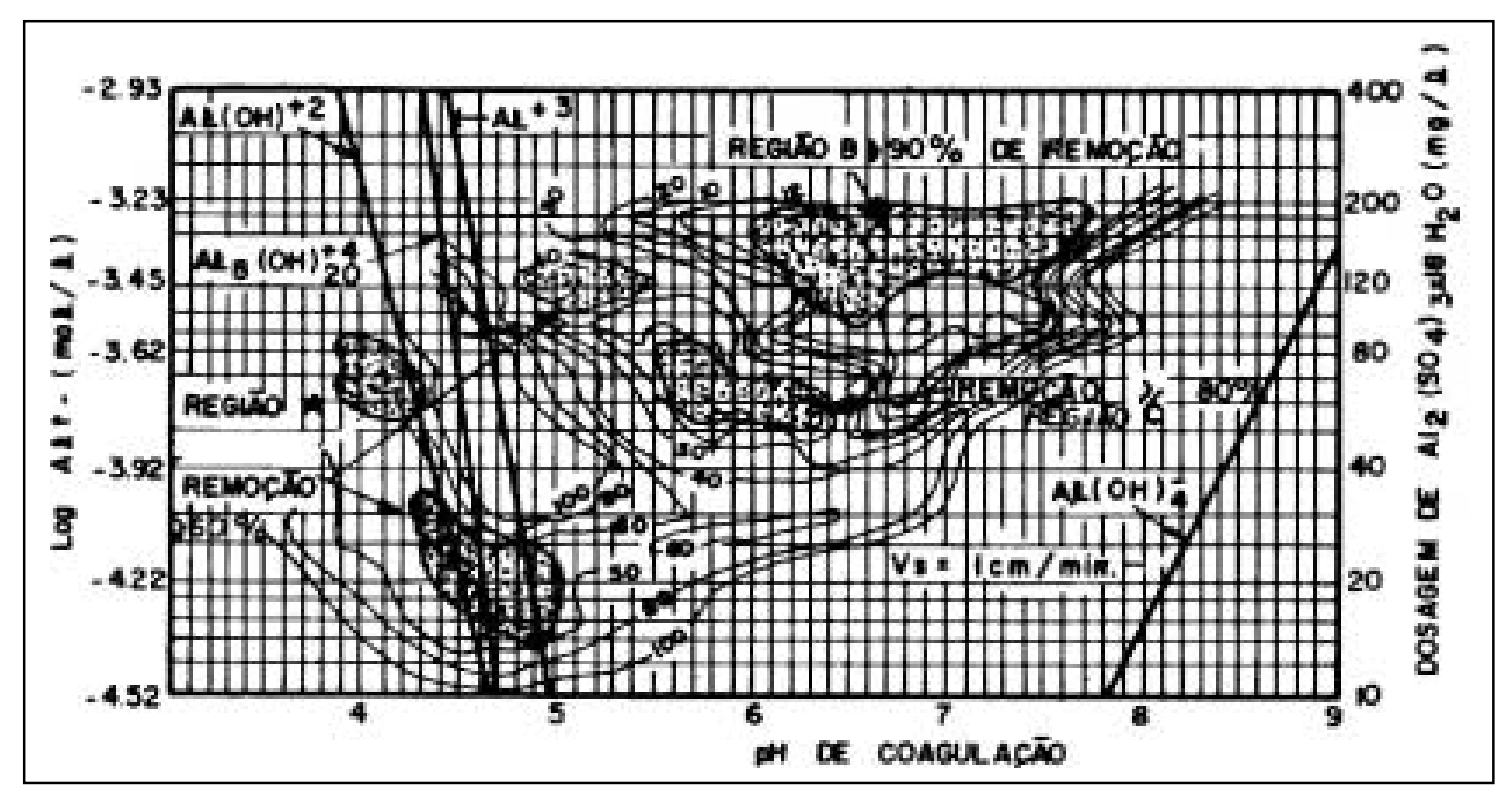

FIGURA 3.11 - Regiões de remoção de Cor Verdadeira (100uC), Turbidez (5uT) com Sulfato de Alumínio.

FONTE: DI BERNARDO et al (1993). 
Destaca-se na FIGURA 3.12 uma região com remoção de cor aparente superior a 60\%, com dosagens de coagulante sulfato de alumínio de 10 a $80 \mathrm{mg} / \mathrm{l}$ contra $\mathrm{pH}$ de 4,3 a 5,6 caracterizando o mecanismo de adsorção e neutralização de cargas. Numa outra região cujo mecanismo é o da varredura, a remoção de cor aparente chega a 97,6\%. As condições ótimas de coagulação para o mecanismo de adsorção-neutralização foram: dosagem de sulfato de alumínio de $25 \mathrm{mg} / \mathrm{l}$ e pH de coagulação de 5,1. As condições ótimas de coagulação para o mecanismo de varredura foram: dosagem de sulfato de alumínio de $155 \mathrm{mg} / \mathrm{l}$ e $\mathrm{pH}$ de coagulação de 6,4 .

Conforme o estudo de BRITO (1998), com o diagrama de coagulação ilustrado na FIGURA 3.13, sua água tinha as seguintes características: cor aparente $150 \mathrm{uC}$; cor verdadeira $70 \mathrm{uC}$ turbidez 25uT; $\mathrm{pH}=7,5$; alcalinidade $33 \mathrm{mg} / \mathrm{l}$ de $\mathrm{CaCO}_{3}$. Ela trabalhou com dosagens de 10 a $80 \mathrm{mg} / \mathrm{l}$ de sulfato de alumínio $\mathrm{PA} \mathrm{Al}_{2}\left(\mathrm{SO}_{4}\right)_{3}$. 14 a $18 \mathrm{H}_{2} \mathrm{O}$, e pH variando de 5,1 a 8,8 e velocidade de sedimentação de 2,5cm/min. Destaca-se na FIGURA 3.13 uma região com turbidez remanescente de 20 a $30 \%$ da turbidez inicial, com dosagens de coagulante sulfato de alumínio de 10 a $40 \mathrm{mg} / \mathrm{l}$ contra $\mathrm{pH}$ de 6 a 7. 
DOSAGEN DE Al $\mathrm{Al}_{2}\left(\mathrm{SO}_{4}\right)_{3}$. 14 a $18 \mathrm{H}_{2} \mathrm{O}(\mathrm{mg} /$ litro)

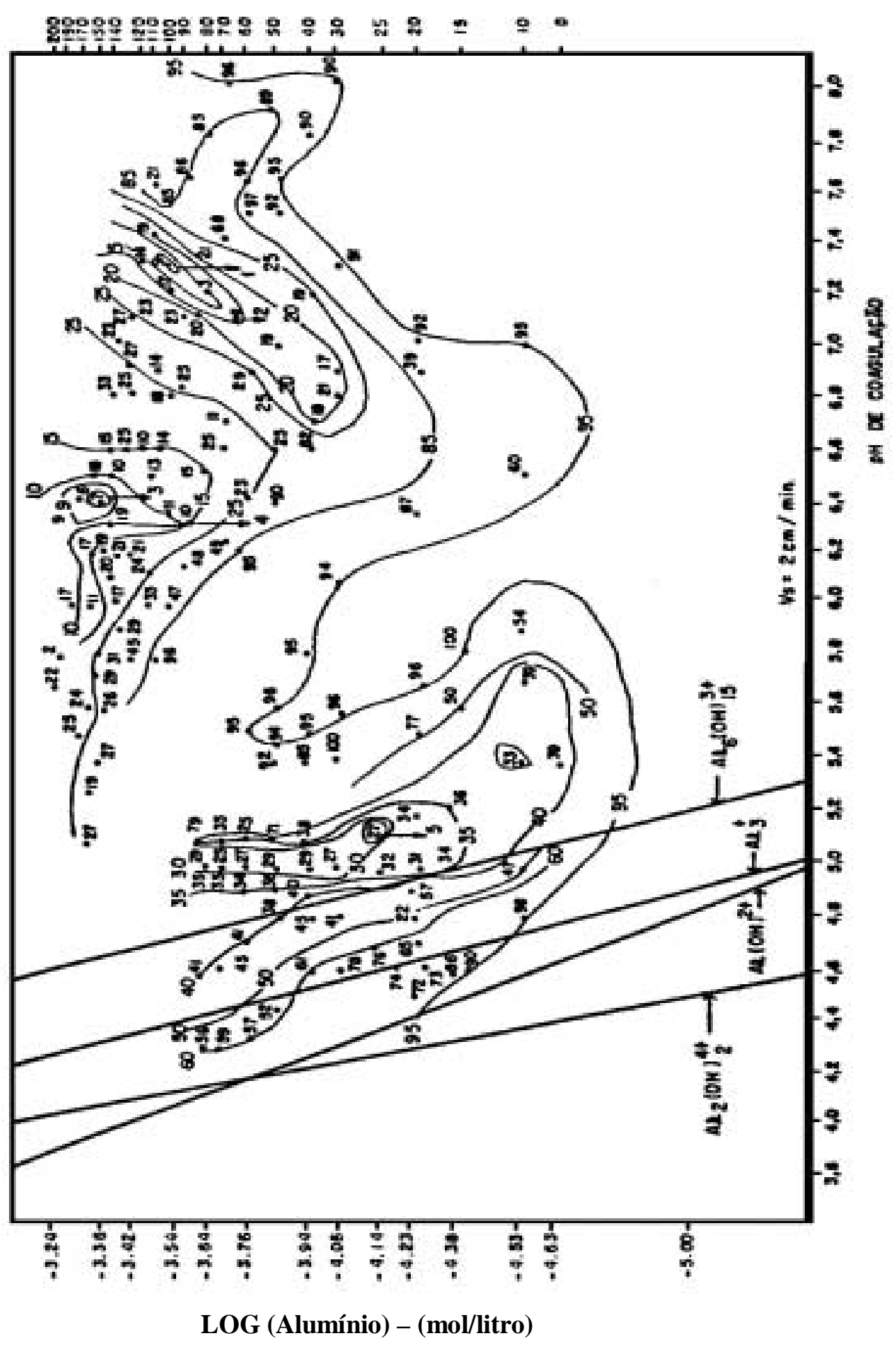

FIGURA 3.12 - Regiões com Porcentagem da Cor Aparente Remanescente com Coagulante Sulfato de Alumínio e Velocidade de Sedimentação $2 \mathrm{~cm} / \mathrm{min}$, sendo as características da água bruta: Cor Verdadeira (100uC), Cor Aparente $150 \mathrm{uC}$ Turbidez (5uT)..

FONTE: COSTA (1992). 


\section{MISTURA RÁPIDA/FLOCULAÇÃO}

Para os estudos citados de MENDES, COSTA e BRITO, foram determinados alguns parâmetros de mistura rápida e floculação que podem ser vistos na TABELA 3.2.

TABELA 3.2 - Parâmetros adotados em outros estudos

\begin{tabular}{|c|c|c|c|c|c|}
\hline PESQUISA & ÁGUA DE ESTUDO & Tmr (s) & $\operatorname{Gmr}\left(\mathrm{s}^{-1}\right)$ & $\mathrm{Tf}(\min )$ & Gf $\left(\mathrm{s}^{-1}\right)$ \\
\hline \begin{tabular}{|l|} 
MENDES \\
Coagulante \\
Sulfato de \\
Alumínio
\end{tabular} & $\begin{array}{l}\text { Vs }=1 \mathrm{~cm} / \mathrm{min} \\
\text { Cor Verdadeira } 100 \mathrm{uC} \\
\text { Cor Aparente } 131,9 \mathrm{uC} \\
\text { Turbidez }(5 \mathrm{uT}) \\
\text { Alcal. } 40 \mathrm{mg} / \mathrm{l} \mathrm{de} \mathrm{CaCO}_{3}\end{array}$ & $\begin{array}{c}2 \\
\text { otimizado }\end{array}$ & $\begin{array}{c}500 \\
\text { otimizado }\end{array}$ & $\begin{array}{c}30 \\
\text { otimizado }\end{array}$ & $\begin{array}{c}5,4 \\
\text { otimizado }\end{array}$ \\
\hline \begin{tabular}{|ll} 
COSTA & \\
Coagulante \\
Sulfato de \\
Alumínio
\end{tabular} & $\begin{array}{l}\text { Vs }=2 \mathrm{~cm} / \mathrm{min} \\
\text { Cor Verdadeira } 100 \mathrm{uC} \\
\text { Cor Aparente } 150 \mathrm{uC} \\
\text { Turbidez 5uT } \\
\text { Alcal. } 30 \mathrm{mg} / \mathrm{l} \text { de } \mathrm{CaCO}_{3}\end{array}$ & $\begin{array}{c}5 \\
\text { arbitrado }\end{array}$ & $\begin{array}{c}700 \\
\text { arbitrado }\end{array}$ & $\begin{array}{c}40 \\
\text { arbitrado }\end{array}$ & $\begin{array}{c}10 \\
\text { arbitrado }\end{array}$ \\
\hline \begin{tabular}{|l|} 
BRITO \\
Coagulante \\
Sulfato de \\
Alumínio
\end{tabular} & $\begin{array}{l}\text { Vs }=2,5 \mathrm{~cm} / \mathrm{min} \\
\text { Cor Aparente } 150 \mathrm{uC} \\
\text { Cor Verdadeira } 12,5 \mathrm{uC} \\
\text { Turbidez } 25 \mathrm{uT} \\
\text { Alcal. } 33 \mathrm{mg} / \mathrm{l} \text { de } \mathrm{CaCO}_{3}\end{array}$ & $\begin{array}{c}5 \\
\text { otimizado }\end{array}$ & $\begin{array}{c}400 \\
\text { otimizado }\end{array}$ & $\begin{array}{c}20 \\
\text { otimizado }\end{array}$ & $\begin{array}{c}20 \\
\text { otimizado }\end{array}$ \\
\hline $\begin{array}{l}\text { BRITO } \\
\text { Coagulante } \\
\text { Cloreto } \\
\text { Férrico }\end{array}$ & $\begin{array}{l}\text { Vs }=2,5 \mathrm{~cm} / \mathrm{min} \\
\text { Cor Aparente } 210 \mathrm{uC} \\
\text { Cor Verdadeira } 20 \mathrm{uC} \\
\text { Turbidez } 27 \mathrm{uT} \\
\text { Alcal. } 23 \mathrm{mg} / \mathrm{l} \mathrm{de} \mathrm{CaCO}_{3}\end{array}$ & $\begin{array}{c}15 \\
\text { otimizado }\end{array}$ & $\begin{array}{c}400 \\
\text { otimizado }\end{array}$ & $\begin{array}{c}20 \\
\text { otimizado }\end{array}$ & $\begin{array}{c}35 \\
\text { otimizado }\end{array}$ \\
\hline $\begin{array}{l}\text { CONCEIÇÂO } \\
\text { Coagulante } \\
\text { Sulfato de } \\
\text { Alumínio }\end{array}$ & $\begin{array}{l}\text { Vs }=2,5 \mathrm{~cm} / \mathrm{min} \\
\text { Cor Aparente } 150 \mathrm{uC} \\
\text { Cor Verdadeira } 70 \mathrm{uC} \\
\text { Turbidez } 16 \mathrm{uT} \\
\text { Alcal. } 50 \mathrm{mg} / \mathrm{l} \text { de } \mathrm{CaCO}_{3}\end{array}$ & $\begin{array}{c}20 \\
\text { arbitrado }\end{array}$ & $\begin{array}{c}600 \\
\text { arbitrado }\end{array}$ & $\begin{array}{c}30 \\
\text { arbitrado }\end{array}$ & $\begin{array}{c}20 \\
\text { arbitrado }\end{array}$ \\
\hline \begin{tabular}{|l|} 
DI \\
BERNARDO \\
A. S. (2000) \\
Coagulante \\
Sulfato de \\
Alumínio \\
\end{tabular} & $\begin{array}{l}\text { Vs }=2,0 \mathrm{~cm} / \mathrm{min} \\
\text { Cor Aparente } 195 \mathrm{uC} \\
\text { Cor Verdadeira } 32,5 \mathrm{uC} \\
\text { Turbidez 26uT } \\
\text { Alcal. } 25 \mathrm{mg} / \mathrm{l} \text { de } \mathrm{CaCO}_{3}\end{array}$ & $\begin{array}{c}10 \\
\text { otimizado }\end{array}$ & $\begin{array}{c}1000 \\
\text { otimizado }\end{array}$ & $\begin{array}{c}24 \\
\text { otimizado }\end{array}$ & $\begin{array}{c}25 \\
\text { otimizado }\end{array}$ \\
\hline $\begin{array}{l}\text { MARINELLI } \\
\text { Coagulante } \\
\text { Sulfato de } \\
\text { Alumínio }\end{array}$ & $\begin{array}{l}\text { Vs }=2 \mathrm{~cm} / \mathrm{min} \\
\text { Cor Verdadeira } 29 \mathrm{uC} \\
\text { Cor Aparente } 209 \mathrm{uC} \\
\text { Turbidez 25uT } \\
\text { Alcal. } 25 \mathrm{mg} / \mathrm{l} \mathrm{de} \mathrm{CaCO}_{3}\end{array}$ & $\begin{array}{c}20 \\
\text { arbitrado }\end{array}$ & $\begin{array}{c}1000 \\
\text { arbitrado }\end{array}$ & $\begin{array}{c}20 \\
\text { arbitrado }\end{array}$ & $\begin{array}{c}20 \\
\text { arbitrado }\end{array}$ \\
\hline
\end{tabular}




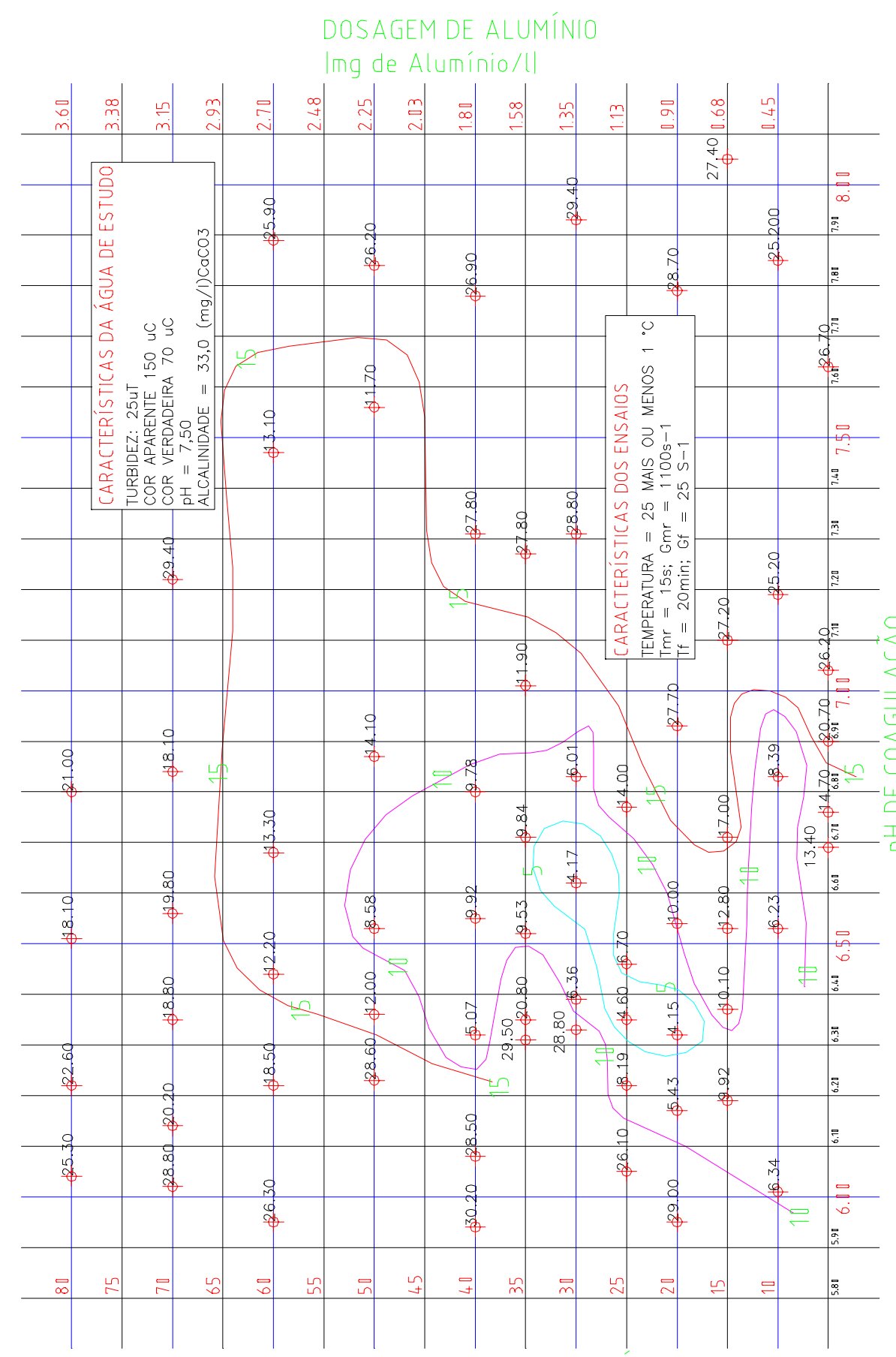


BRITO (1998) chegou a uma conclusão importante com estudos profundos feitos para a determinação dos coeficientes de agregação $\left(K_{A}\right)$ e de ruptura $\left(K_{B}\right)$, observando-se que à medida que foi maior o tempo de sedimentação (menores Vs) os valores de $\mathrm{K}_{\mathrm{A}}$ aumentaram e os valores de $\mathrm{K}_{\mathrm{B}}$ diminuíram, ocorrendo uma estabilização de ambos coeficientes para $\mathrm{Vs}=$ 0,$25 ; 0,010$ e $0,05 \mathrm{~cm} / \mathrm{min}$, sugerindo que realmente a velocidade de sedimentação influi na determinação desses coeficientes e “...conclui-se que tanto para mistura rápida, quanto para a floculação, a seleção dos valores do gradiente de velocidade e do tempo de agitação que otimizam tais operações é substancialmente influenciada pela velocidade de sedimentação dos flocos." Desta forma, deve-se ter cuidado na escolha dos parâmetros nos dimensionamentos de ETA, considerando que quaisquer variações tais como aumento de vazão, ampliações, poderão influenciar a otimização prevista inicialmente, devendo principalmente os projetos fazerem tal previsão.

BRITO (1998), estudando otimização dos parâmetros de mistura rápida e floculação, inicialmente através de pares de valores de $\mathrm{pH}$ de coagulação versus dosagem de coagulante escolhidos no diagrama de coagulação, fixou os parâmetros da floculação ( $\mathrm{Tf}=20 \mathrm{~min}$ e $\mathrm{Gf}=25 \mathrm{~s}^{-1}$ ) e posteriormente, com variação dos parâmetros de mistura rápida e velocidade de sedimentação, chegou aos valores de otimização de mistura rápida.

Com a dosagem dos coagulantes e valores de pH de coagulação, e os parâmetros de mistura rápida conseguidos anteriormente, procedeu aos ensaios da otimização de floculação. Fazendo variações nos parâmetros Tf e Gf, chegou aos gráficos apresentados nas FIGURA 3.14 para velocidade de sedimentação de $2,5 \mathrm{~cm} / \mathrm{min}$ e coagulante sulfato de alumínio e, na FIGURA 3.15, para velocidade de sedimentação de $2,5 \mathrm{~cm} / \mathrm{min}$ e coagulante cloreto férrico.

Das FIGURAS 3.14 e 3.15 pode-se concluir que o valor de turbidez remanescente não sofre alterações significativas à partir de um certo tempo de floculação.

Para o caso de uma unidade de floculação composta por câmaras em série, PÁDUA et al (1998) propuseram uma metodologia para determinação dos gradientes de velocidades em cada câmara. Esta metodologia é de extrema importância, porém, por não ser utilizada neste estudo, está apenas sendo citada para conhecimento. 


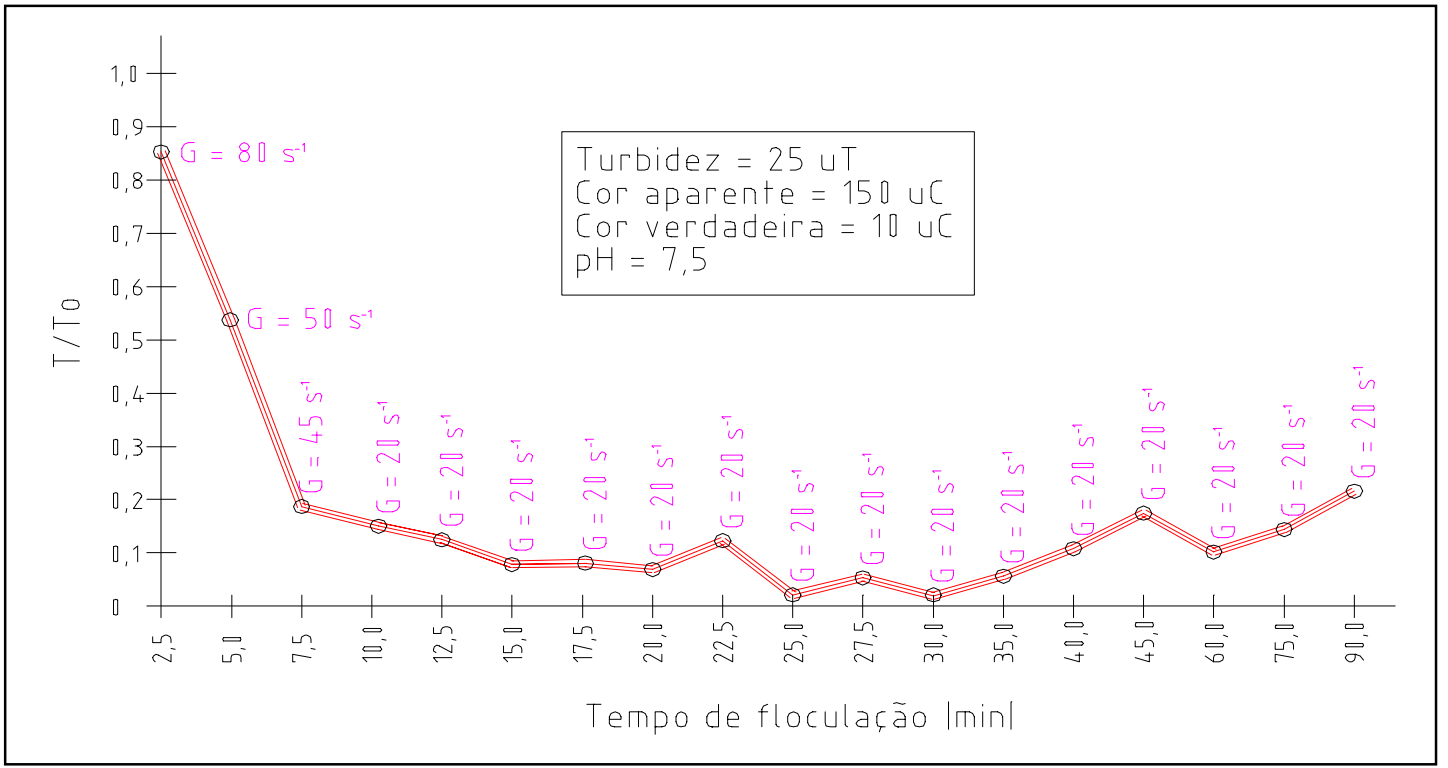

FIGURA 3.14 -Fração Remanescente da Turbidez em Função do Tempo de Floculação e Respectivos Gradientes de Velocidade Ótimos - Coagulante Sulfato de Alumínio (20mg/l; $\mathrm{pH}=6,32 ; \mathrm{Gmr}=400 \mathrm{~s}^{-1} ; \mathrm{Tmr}=5 \mathrm{~s}$ e Velocidade de Sedimentação $\left.2,5 \mathrm{~cm} / \mathrm{min}\right)$.

FONTE: BRITO (1998).

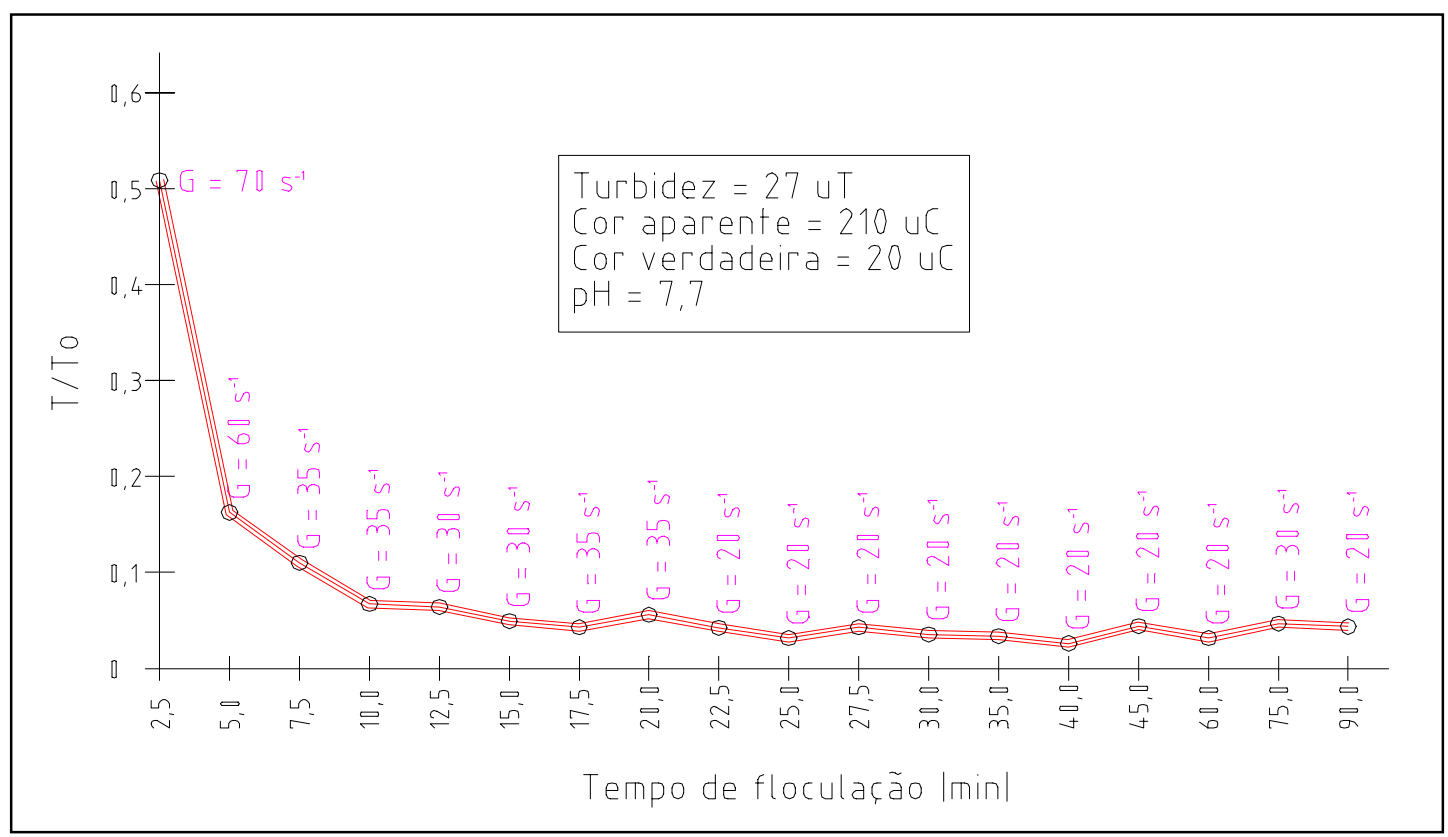

FIGURA 3.15 -Fração Remanescente da Turbidez em Função do Tempo de Floculação e Respectivos Gradientes de Velocidade Ótimos - Coagulante Cloreto Férrico (25mg/l; $\mathrm{pH}=6,3 ; \mathrm{Gmr}=400 \mathrm{~s}^{-1} ; \mathrm{Tmr}=15 \mathrm{~s}$ e Velocidade de Sedimentação $2,5 \mathrm{~cm} / \mathrm{min}$ ).

FONTE: BRITO (1998). 


\subsection{CARACTERÍSTICAS DE SAIS DE ALUMÍNIO E DE FERRO}

\subsubsection{SULFATO DE ALUMÍNIO}

A espécie química do Sulfato de Alumínio tem por fórmula química $\mathrm{AI}_{2}\left(\mathrm{SO}_{4}\right)_{3} \cdot \mathrm{nH}_{2} \mathrm{O}$, em que " $n$ " representa aproximadamente 14 a 18 moléculas de água de cristalização. Quando anidro tem peso molecular aproximadamente igual a $\mathrm{PM}=342,16$, e decompõe-se a temperatura de $600^{\circ} \mathrm{C}$ com desprendimento de anidrido sulfúrico. O produto com 14 moléculas de água de cristalização é aproximadamente 12\% mais duro que com 18 moléculas.

O Sulfato de Alumínio Líquido é fabricado a partir de hidrato de alumínio, mantendo-se um teor de água suficiente para impedir sua cristalização. Quanto à composição química, é comercializado com 7 a $8 \%$ de alumina $\left(\mathrm{Al}_{2} \mathrm{O}_{3}\right)$; com teores acima de $8,26 \%$, o produto pode cristalizar. Na realidade este produto atinge $48,4 \%$ de concentração quando em forma sólida, devido a água de constituição presente nas moléculas do produto, vide TABELA 3.3. Quando é um produto de boa qualidade, não apresenta resíduos insolúveis e é incolor.

TABELA 3.3 - Composição físico-química do sulfato de alumínio líquido (produto da Indústria NHEEL QUÏMICA LTDA).

\begin{tabular}{|l|c|}
\hline \multicolumn{2}{|c|}{ TABELA DE COMPOSIÇ̃̃O FÍSICO - QUÍMICA } \\
\hline Composição & Sulfato Alumínio - Isento Ferro (líquido) \\
\hline$\% \mathrm{AI}_{2} \mathrm{O}_{3}$ & 8,5 \\
\hline$\% \mathrm{Fe}_{2} \mathrm{O}_{3}$ & 0,047 \\
\hline$\%$ Acidez ou $\mathrm{AI}_{2} \mathrm{O}_{3}$ Livre & $0,3-0,5$ \\
\hline$\%$ Insolúveis & - \\
\hline Massa Específica $\left(\mathrm{g} / \mathrm{cm}^{3}\right)$ a $15^{\circ} \mathrm{C}$ & 26 \\
\hline Viscosidade $(\mathrm{Cp})$ a $15^{\circ} \mathrm{C}$ & 3,5 \\
\hline pH de solução a $1 \%$ & -17 \\
\hline Ponto Congelamento $\left({ }^{\circ} \mathrm{C}\right)$ & Incolor \\
\hline Cor & $50 \%$ \\
\hline Concentração do produto (massa/massa) & 26 \\
\hline
\end{tabular}




\section{DIAGRAMA SE SOLUBILIDADE DO ALUMÍNIO}

Quando da adição do coagulante químico nas estações de tratamento de água (ETAs), algumas espécies hidrolisadas poderão estar presentes para um determinado valor de $\mathrm{pH}$. Em seguida mostram-se algumas reações de hidrólise em temperatura de $25^{\circ} \mathrm{C}$.

Equações de hidrólise das espécies $\log K$
$\mathrm{Al}^{3+}+\mathrm{H}_{2} \mathrm{O} \longrightarrow \mathrm{Al}(\mathrm{OH})^{2+}+\mathrm{H}^{+} \quad-5,02$
$2 \mathrm{Al}^{3+}+2 \mathrm{H}_{2} \mathrm{O} \longrightarrow \mathrm{Al}_{2}(\mathrm{OH})_{2}{ }^{4+}+2 \mathrm{H}^{+} \quad-6,27$
$6 \mathrm{Al}^{3+}+15 \mathrm{H}_{2} \mathrm{O} \longleftrightarrow \mathrm{Al}_{6}(\mathrm{OH})_{15}{ }^{3+}+15 \mathrm{H}^{+}-47,00$
$8 \mathrm{Al}^{3+}+20 \mathrm{H}_{2} \mathrm{O} \longrightarrow \mathrm{Al}_{8}(\mathrm{OH})_{20}{ }^{5+}+20 \mathrm{H}^{+}-68,70$
$\mathrm{Al}(\mathrm{OH})_{3(\mathrm{p})}+\quad \longrightarrow \mathrm{Al}^{3+}+3 \mathrm{OH}^{-}-32,34$
$\mathrm{Al}^{+3}+4 \mathrm{H}_{2} \mathrm{O} \longrightarrow \mathrm{Al}(\mathrm{OH})_{4}{ }^{-}+\mathrm{H}^{+} \quad-23,57$

CONSTRUÇÃO DO DIAGRAMA DE SOLUBILIDADE

a) Espécie $\mathrm{Al}(\mathrm{OH})^{2+}$
$\mathrm{Al}^{+3}+\mathrm{H}_{2} \mathrm{O} \longrightarrow \mathrm{Al}(\mathrm{OH})^{2+}+\mathrm{H}^{+} \quad-5,02$
$\mathrm{Al}(\mathrm{OH})_{3(\mathrm{p})}$

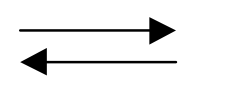
$\mathrm{Al}^{3+}(\mathrm{aq})+3 \mathrm{OH}^{-}(\mathrm{aq})$
$-32,34$
$\mathrm{H}^{+} \quad+$
$\mathrm{OH}^{-}$

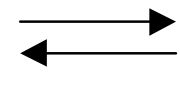
$\mathrm{H}_{2} \mathrm{O}$
$-14,00$

$\mathrm{Al}(\mathrm{OH})_{3(\mathrm{p})}$

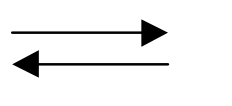

$\mathrm{Al}(\mathrm{OH})^{2+}+2 \mathrm{OH}^{-}$

$(\log \mathrm{K}=?)$ 
$K=\frac{\left[A l(O H)^{2+}\right] \cdot\left[O H^{-}\right]^{2}}{\left[A l(O H)_{3(p)}\right]}$

Do sistema das três equações de hidrólise, resulta:

$$
\begin{aligned}
10^{-5,02} & =\frac{\left[\mathrm{Al}(\mathrm{OH})^{2+}\right] \cdot\left[\mathrm{H}^{+}\right]}{\left[A L^{3+}\right]} \\
10^{-32,34} & =\frac{\left[A l^{3+}\right] \cdot\left[\mathrm{OH}^{-}\right]^{3}}{\left[\mathrm{Al}(\mathrm{OH})_{3(p)}\right]} \\
10^{-14,00} & =\frac{\left[\mathrm{H}^{+}\right] \cdot\left[\mathrm{OH}{ }^{-}\right]}{\left[\mathrm{H}_{2} \mathrm{O}\right]}
\end{aligned}
$$

Assumindo que a atividade do precipitado $\mathrm{Al}(\mathrm{OH})_{3(\mathrm{p})}$ seja igual a unidade para que a constante de equilíbrio seja expressa em termos da espécie solúvel de $\mathrm{Al}^{3+} \mathrm{e} \mathrm{H}^{+}$e, tomandose o logaritmo de ambos os lados da equação (10), obtém-se:

$\log \mathrm{K}=\log \left[\mathrm{Al}(\mathrm{OH})^{2+}\right]+2 \log \left[\mathrm{OH}^{-}\right]$

O mesmo procedimento, aplicando-se às equações 7,8 e 9 , fornece:

$$
\begin{aligned}
& -5,02=\log \left[\mathrm{Al}(\mathrm{OH})^{2+}\right]+\log \left[\mathrm{H}^{+}\right]-\log \left[\mathrm{Al}^{3+}\right] \\
& -32,34=\log \left[\mathrm{Al}^{3+}\right]+3 \log \left[\mathrm{OH}^{-}\right] \\
& +14,00=-\log \left[\mathrm{H}^{+}\right]-\log \left[\mathrm{OH}^{-}\right]
\end{aligned}
$$$$
-23,36=\log \left[\mathrm{Al}(\mathrm{OH})^{2+}\right]+2 \log \left[\mathrm{OH}^{-}\right]
$$

e

$\log \left[\mathrm{H}^{+}\right]+\log \left[\mathrm{OH}^{-}\right]=-14 \Rightarrow \log \left[\mathrm{H}^{+}\right]=-14-\log \left[\mathrm{OH}^{-}\right]$

$\mathrm{e} \mathrm{pH}=-\log \left[\mathrm{OH}^{-}\right]$

$\left.\begin{array}{l}-23,36=\log \left[\mathrm{Al}(\mathrm{OH})^{2+}\right]+2 \cdot\left(-14-\log \left[\mathrm{H}^{+}\right]\right) \\ -23,36=\log \left[\mathrm{Al}(\mathrm{OH})^{2+}\right]-28-2 \cdot \log \left[\mathrm{H}^{+}\right]\end{array}\right\} \Rightarrow \quad \log \left[\mathrm{Al}(\mathbf{O H})^{2+}\right]=\mathbf{4 , 6 4}-\mathbf{2} \mathbf{p H}$

b) Espécie $\mathrm{Al}^{3+}$

$$
\log \left[\mathrm{Al}^{3+}\right]=9,66-3 \mathrm{pH}
$$

c) Espécie $\mathrm{Al}_{6}(\mathrm{OH})_{15}{ }^{3+}$

$$
\log \left[\mathrm{Al}_{6}(\mathrm{OH})_{15}{ }^{3+}\right]=10,96-3 \mathrm{pH}
$$


d) Espécie $\mathrm{Al}_{8}(\mathrm{OH})_{20}{ }^{4+} \quad \log \left[\mathrm{Al}_{13}(\mathrm{OH})_{34}{ }^{5+}\right]=8,58-4 \mathrm{pH}$

e) Espécie $\mathrm{Al}_{2}(\mathrm{OH})_{2}{ }^{4+}$

$$
\log \left[\mathrm{Al}_{2}(\mathrm{OH})_{2}{ }^{4+}\right]=13,05-4 \mathrm{pH}
$$

f) Espécie $\mathrm{Al}(\mathrm{OH})_{4}$

$$
\log \left[\mathrm{Al}(\mathrm{OH})_{4}{ }^{-}\right]=\mathbf{p H}-13,91
$$

Utilizando-se as equações de número 12 a 17, o diagrama das espécies hidrolisadas de alumínio é construído em função do pH, conforme mostra a FIGURA 3.16.

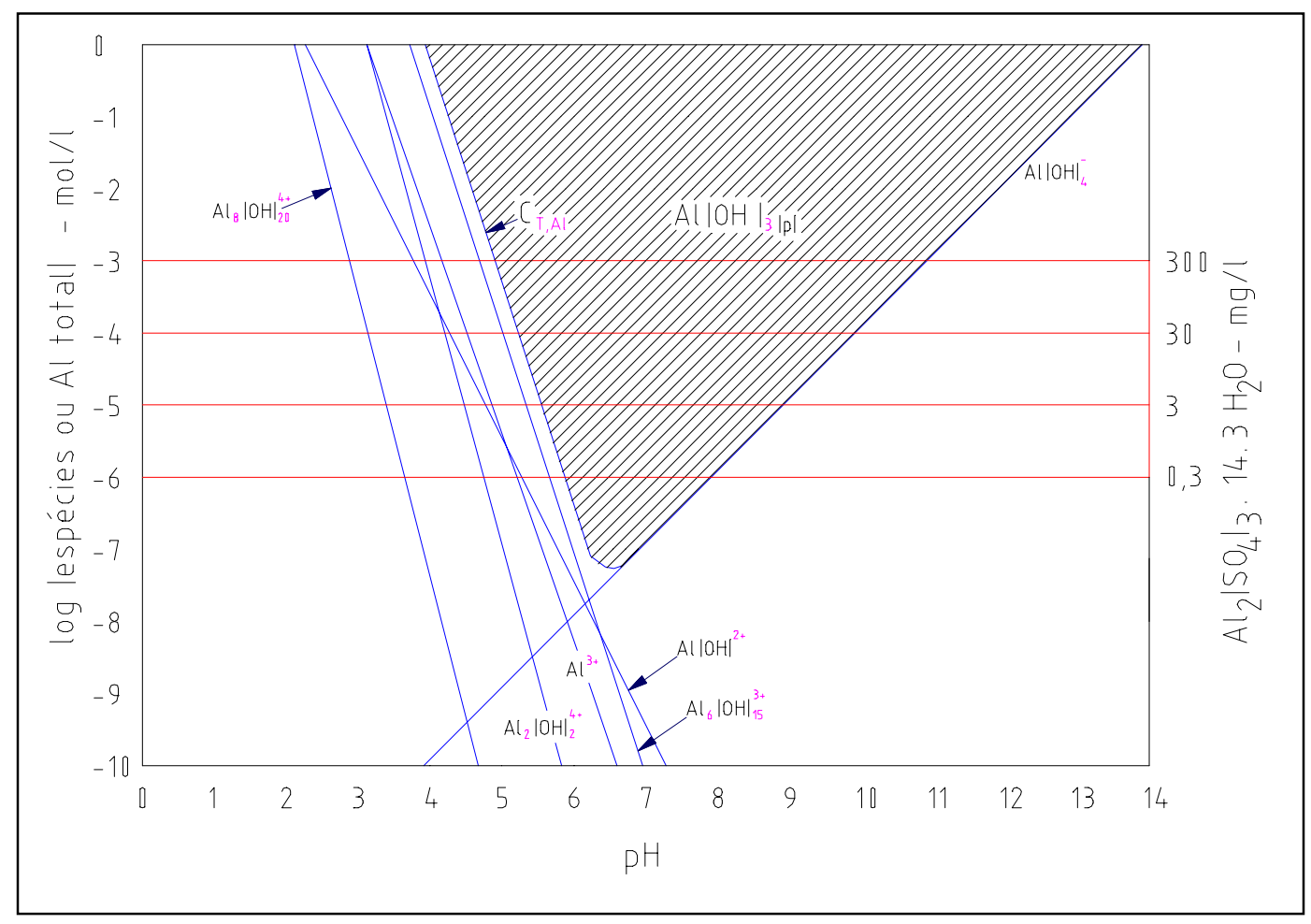

FIGURA 3.16 - Diagrama de Equilíbrio Heterogêneos do $\mathrm{Al}(\mathrm{OH})_{3}$.

FONTE: DI BERNARDO (1993)

A concentração de alumínio total é dada pela seguinte expressão:

$\mathrm{C}_{\mathrm{T}, \mathrm{Al}}=\left[\mathrm{Al}(\mathrm{OH})^{2+}\right]+\left[\mathrm{Al}^{3+}\right]+6 \cdot\left[\mathrm{Al}_{6}(\mathrm{OH})_{15}{ }^{3+}\right]+8 \cdot\left[\mathrm{Al}_{8}(\mathrm{OH})_{20}{ }^{4+}\right]+2 \cdot\left[\mathrm{Al}_{2}(\mathrm{OH})_{2}{ }^{4+}\right]+\left[\mathrm{Al}(\mathrm{OH})_{4}{ }^{-}\right]$

Para cada valor de $\mathrm{pH}$, substituir seu valor nas equações e obter o valor da concentração de cada espécie (aplicando o anti-log). Substituir estes valores na equação acima $\left(\mathrm{C}_{\mathrm{T}, \mathrm{Al}}\right)$ e efetuar a soma. Em seguida, aplicar o logaritmo (base 10) no valor obtido. Assim, para um 
valor de $\mathrm{pH}$, é obtido o valor da concentração total de alumínio. Refazendo-se os cálculos para os demais valores de $\mathrm{pH}$, são obtidos os respectivos valores da concentração total de alumínio e, finalmente, pode ser traçada a região que delimita a formação do precipitado, ligando-se os pontos.

\subsubsection{CLORETO FÉRRICO}

A reação a quente do ácido clorídrico, concentrado com o minério de ferro (hematita- $\mathrm{Fe}_{2} \mathrm{O}_{3}$ ), seguido de resfriamento e filtração, proporciona a produção de cloreto férrico com elevado índice de pureza. A concentração final do produto resulta da combinação entre variáveis do processo produtivo e a temperatura ambiente mínima das regiões de aplicação. Determinouse uma concentração de ordem de $40 \%$ em peso de $\mathrm{FeCI}_{3}$, garantindo-se assim que o produto manterá suas características físicas em qualquer região do País.

Atualmente, para atender à crescente demanda de água potável, torna-se necessário tratar águas superficiais contaminadas. A utilização do cloreto férrico diminui drasticamente a turbidez e a DBO, e elimina fosfatos; uma boa parte de metais pesados (mercúrio, chumbo) ou venenosos (arsênio, selênio, bário) também é eliminada, quando a coagulação é realizada em valores elevados de $\mathrm{pH}$.

Conforme NHEEL QUÍMICA LTDA, se a água bruta contiver ferro e/ou manganês, ou, se durante o ano ela tiver valores de $\mathrm{pH}$ muito variáveis, o uso do $\mathrm{FeCI}_{3}$ garantirá elevado padrão de água tratada, sem causar problemas na rede de distribuição. Na TABELA 3.4 são apresentadas algumas características do cloreto férrico.

TABELA 3.4 - Propriedades e especificações do cloreto férrico (produto da Indústria NHEEL QUÍMICA LTDA).

\begin{tabular}{|l|c|}
\hline \multicolumn{2}{|c|}{ PROPRIEDADES } \\
\hline FÓRMULA QUÍMICA & $\mathrm{FeCI}_{3}$ \\
\hline MASSA MOLECULAR (g) & 270,35 \\
\hline MASSA ESPECÍFICA $\left(20^{\circ} \mathrm{C}\right) \mathrm{kg} / \mathrm{l}$ & 1,428 \\
\hline CONCENTRAÇÃO (PESO) & $39,30 \%$ \\
\hline
\end{tabular}


Continuação da TABELA 3.4 - Propriedades e especificações do cloreto férrico (produto da Indústria NHEEL QUÏMICA LTDA).

\begin{tabular}{|l|c|}
\hline \multicolumn{2}{|c|}{ ESPECIFICAÇÕES } \\
\hline APARÊNCIA & LÍQUIDA \\
\hline COLORAÇÃO & MARROM \\
\hline FeCI $_{2}(\mathrm{PESO} \%)$ & $<0,5$ \\
\hline HCL $($ PESO \%) & $<1,0$ \\
\hline
\end{tabular}

\section{DIAGRAMA SE SOLUBILIDADE DO FERRO}

Quando da adição do coagulante químico nas estações de tratamento de água (ETAs), algumas espécies hidrolisadas poderão estar presentes para um determinado valor de $\mathrm{pH}$. Em seguida mostram-se algumas reações de hidrólise em temperatura de $25^{\circ} \mathrm{C}$.

Equações de hidrólise das espécies $\log K$

\begin{tabular}{|c|c|c|c|c|c|c|c|}
\hline \multicolumn{3}{|c|}{$\mathrm{Fe}(\mathrm{OH})_{3(\mathrm{p})}$} & $\stackrel{4}{\longrightarrow}$ & $\mathrm{Fe}^{3+}(\mathrm{aq})$ & \multicolumn{2}{|c|}{$3 \mathrm{OH}^{-}(\mathrm{aq})$} & $-37,50$ \\
\hline $\mathrm{Fe}^{3+}$ & + & $\mathrm{H}_{2} \mathrm{O}$ & $\longleftrightarrow$ & $\mathrm{Fe}(\mathrm{OH})^{2+}$ & + & $\mathrm{H}^{+}$ & $-3,00$ \\
\hline $\mathrm{Fe}^{3+}$ & + & $2 \mathrm{H}_{2} \mathrm{O}$ & $\longrightarrow$ & $\mathrm{Fe}(\mathrm{OH})_{2}^{+}$ & + & $2 \mathrm{H}^{+}$ & $-6,40$ \\
\hline $2 \mathrm{Fe}^{3+}$ & + & $2 \mathrm{H}_{2} \mathrm{O}$ & $\longrightarrow$ & $\mathrm{Fe}_{2}(\mathrm{OH})_{2}{ }^{4+}$ & + & $2 \mathrm{H}^{+}$ & $-3,10$ \\
\hline $\mathrm{Fe}^{3+}$ & + & $4 \mathrm{H}_{2} \mathrm{O}$ & $\longrightarrow$ & $\mathrm{Fe}(\mathrm{OH})_{2}^{-}$ & + & $4 \mathrm{H}^{+}$ & $-23,50$ \\
\hline $\mathrm{Fe}^{3+}$ & + & $3 \mathrm{H}_{2} \mathrm{O}$ & $\longrightarrow$ & $\mathrm{Fe}(\mathrm{OH})_{3}{ }^{0}$ & + & $3 \mathrm{H}^{+}$ & $-13,50$ \\
\hline
\end{tabular}

CONSTRUÇÃO DO DIAGRAMA DE SOLUBILIDADE
a) Espécie $\mathrm{Fe}(\mathrm{OH})^{2+}$
$\log \left[\mathrm{Fe}(\mathrm{OH})^{2+}\right]=1,5-2 \mathrm{pH}$ 
b) Espécie $\mathrm{Fe}(\mathrm{OH})_{2}{ }^{+}$

c) Espécie $\mathrm{Fe}_{2}(\mathrm{OH})_{2}{ }^{4+}$

d) Espécie $\mathrm{Fe}(\mathrm{OH})_{4}{ }^{-}$

e) Espécie $\mathrm{Fe}^{3+}$

f) Espécie $\mathrm{Fe}(\mathrm{OH})_{3}{ }^{0}$ $\log \left[\mathrm{Fe}(\mathrm{OH})_{2}^{+}\right]=1,9-\mathrm{pH}$

$$
\log \left[\mathrm{Fe}^{3+}\right]=4,5-3 \mathrm{pH}
$$

Utilizando-se as equações de número 7 a 12, o diagrama das espécies hidrolisadas de ferro é construído em função do pH, conforme mostra a FIGURA 3.17.

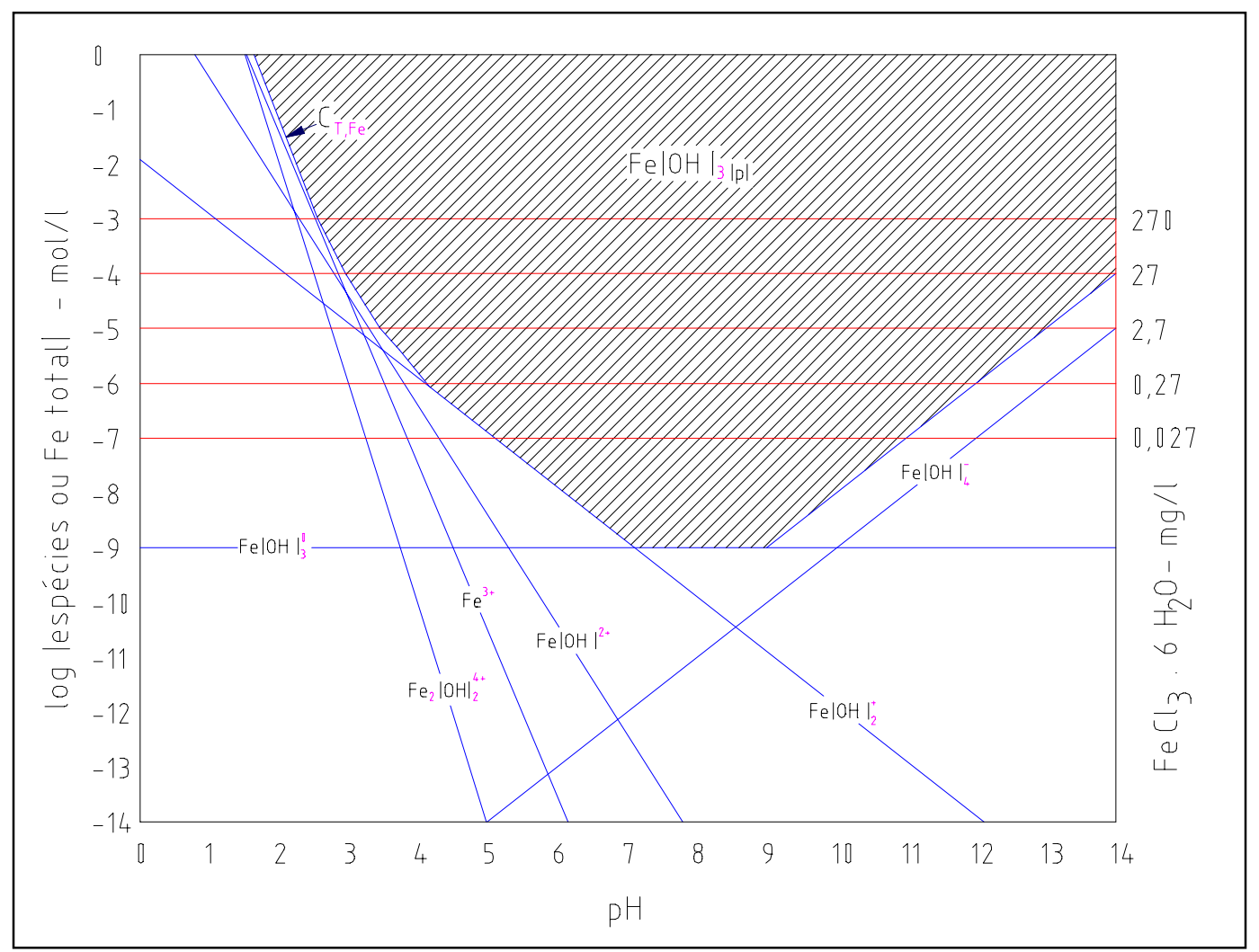

FIGURA 3.17 - Diagrama de Equilíbrio Heterogêneos do $\mathrm{Fe}(\mathrm{OH})_{3}$.

FONTE: DI BERNARDO (1993)

A concentração de ferro total é dada pela seguinte expressão:

$\mathrm{C}_{\mathrm{T}, \mathrm{Fe}}=\left[\mathrm{Fe}(\mathrm{OH})_{4}{ }^{-}\right]+\left[\mathrm{Fe}^{3+}\right]+2 \cdot\left[\mathrm{Fe}_{2}(\mathrm{OH})_{2}{ }^{4+}\right]+\left[\mathrm{Fe}(\mathrm{OH})_{2}{ }^{+}\right]+\left[\mathrm{Fe}(\mathrm{OH})^{2+}\right]$ 


\subsubsection{HIDRÓXICLORETO DE ALUMÍNIO}

O hidróxicloreto de Alumínio, na maioria dos casos, revela-se como coagulante superior ao Sulfato de Alumínio. Para a eliminação das substâncias coloidais, sua eficácia, em média, é 1,5 e 2,5 vezes superior em igualdade de dosagem em íon $\mathrm{AI}^{3+}$ à dos outros sais de alumínio habitualmente utilizados.

É importante esclarecer as diferenças existentes entre o Cloreto de Alumínio e o Hidróxicloreto de Alumínio. O Cloreto de Alumínio tem a fórmula bruta $\mathrm{AICI}_{3}$, sendo que, no Hidróxicloreto de Alumínio, os átomos de cloro são parcialmente substituídos por grupos básicos $\mathrm{OH}$. O Hidróxicloreto de Alumínio é um sal de Alumínio prepolimerizado, de fórmula bruta $\mathrm{AI}_{\mathrm{n}}(\mathrm{OH})_{\mathrm{m}} \mathrm{Cl}_{3 \mathrm{n}-\mathrm{m}}$, na qual a relação $\mathrm{m} / 3 \mathrm{n} \times 100$ representa a basicidade do produto. Em função dessa basicidade, o Hidróxicloreto de Alumínio, durante a hidrólise, libera, em igualdade de dosagem de íons metálicos, uma quantidade de ácido consideravelmente menor do cloreto de alumínio e dos coagulantes tradicionais como sulfato de alumínio e cloreto férrico. Isso provoca uma menor variação do $\mathrm{pH}$ do meio tratado ou um menor consumo de neutralizante para reconduzir o $\mathrm{pH}$ ao seu valor original.

Devido ao seu estado prepolimerizado e à característica de sua estrutura molecular condensada com pontes de oxigênio entre os átomos de alumínio, o Hidróxicloreto de Alumínio apresenta vantagens na floculação em relação aos demais coagulantes inorgânicos não prepolimerizados, principalmente pela maior concentração de elemento ativo $\left(\mathrm{Al}_{2} \mathrm{O}_{3}\right)$. $\mathrm{O}$ Hidróxicloreto de Alumínio, polímero mineral de peso molecular elevado (ver TABELA 3.5 e 3.6), é produzido em alguns países e é conhecido como PAC (Poly Aluminium Chloride). Na Europa, EUA e Japão, existem indústrias que fabricam o Hidróxicloreto de Alumínio em quantidades superiores a 500.000 t/ano.

TABELA 3.5 - Características e especificações do hidróxicloreto de alumínio (produto da Indústria PAN-AMERICANA S.A.).

\begin{tabular}{|l|c|}
\hline \multicolumn{2}{|c|}{ CARACTERÍSTICAS E ESPECIFICAÇÕES } \\
\hline Fórmula Química & $\mathrm{AI}_{\mathrm{n}}(\mathrm{OH})_{\mathrm{m}} \mathrm{Cl}_{3 \mathrm{n}-\mathrm{m}}$ \\
\hline Aspecto & Líquido pouco viscoso \\
\hline Cor & Amarelo-Âmbar claro \\
\hline
\end{tabular}


Continuação da TABELA 3.5 - Características e especificações do hidróxicloreto de alumínio (produto da Indústria PAN-AMERICANA S.A.).

\begin{tabular}{|l|c|}
\hline $\mathrm{AI}_{2} \mathrm{O}_{3}(\mathrm{~m} / \mathrm{m}-\%)$ & 16,80 \\
\hline Ferro $(\mathrm{mg} / \mathrm{kg})$ & 50 máx. \\
\hline Basicidade $(\%)$ & $42-46$ \\
\hline Peso Específico $\left(\mathrm{t} / \mathrm{m}^{3}\right)$ & $1,2-1,4$ \\
\hline $\mathrm{pH}\left(\mathrm{sol} 1 \% \mathrm{H}_{2} \mathrm{O}\right)$ & $3,5-4,2$ \\
\hline
\end{tabular}

TABELA 3.6 - Composição de metais pesados do hidróxicloreto de alumínio.

\begin{tabular}{|l|c|c|}
\hline \multicolumn{1}{|c|}{ METAIS PESADOS } & Valor Típico $(\mathrm{mg} / \mathrm{kg})$ & Valor Máximo $(\mathrm{mg} / \mathrm{kg})$ \\
\hline $\mathrm{Hg}$ (mercúrio) & $<0,3$ & 0,4 \\
\hline $\mathrm{Cd}$ (cádmio) & $<1,0$ & 2,2 \\
\hline $\mathrm{Ag}$ (prata) & $<1,0$ & 22 \\
\hline $\mathrm{Pb}$ (chumbo) & $<7,0$ & 22 \\
\hline $\mathrm{Cr}$ (cromo) & $<3,0$ & 22 \\
\hline As (arsênio) & $<0,3$ & 4 \\
\hline Se (selênio) & $<4,0$ & 22 \\
\hline
\end{tabular}

O Hidróxicloreto de Alumínio, do ponto de vista da regulamentação de transporte, é classificado como produto corrosivo com UN n. 1760. Portanto, as soluções que são corrosivas devem normalmente ser transportadas e estocadas em aço revestido de ebonite, em PVC, polietileno, poliéster e fibra de vidro. Para as tubulações, deve-se dar preferência ao material plástico (PVC, epóxi, PE, PP). O bombeamento deve ser feito com equipamentos resistentes ao ácido clorídrico (bombas com juntas de PTFE, etc.).

\subsubsection{SULFATO FÉRRICO}

Os sais de ferro são muito utilizados como coagulantes para tratamento de água. Suas reações são as de neutralização de cargas, e formação de hidróxidos insolúveis de ferro. 
Devido à baixa solubilidade dos hidróxidos férricos, eles podem agir sobre uma ampla faixa de $\mathrm{pH}$.

Na coagulação, a formação de flocos é mais rápida, devido ao alto peso molecular comparado ao alumínio; por conseguinte, os flocos são mais densos, e o tempo de sedimentação é reduzido significativamente. O lodo formado também é mais compacto, principalmente quando se tem baixa temperatura. Comparado com sulfatos, os cloretos férricos têm baixo consumo de alcalinidade, e, conseqüentemente, menor redução de $\mathrm{pH}$. $\mathrm{O}$ sulfato férrico é disponibilizado no mercado de forma granular ou líquida (ver TABELA $3.7)$.

TABELA 3.7 - Composição química e física do sulfato férrico granulado (produto da Indústria KEMWATER DO BRASIL LTDA).

\begin{tabular}{|l|c|}
\hline \multicolumn{2}{|c|}{ PROPRIEDADES QUÍMICAS E FÍSICAS } \\
\hline $\mathrm{Fe}_{\text {total }}[\mathrm{Fe} \mathrm{III}]$ & $21 \pm 1 \%$ \\
\hline Ferro Ferroso ( FeII ) & Máximo $1 \%$ \\
\hline Aparência & Grânulos amarelos acinzentado \\
\hline Acidez livre $\left(\mathrm{H}_{2} \mathrm{SO}_{4}\right)$ & $\leqslant 1,5 \%$ \\
\hline Tamanho das partículas & $\mathrm{D}_{50} 2$ a $3 \mathrm{~mm}, 100 \%$ sendo menor que $7 \mathrm{~mm}$ \\
\hline Ângulo de repouso & $37^{\circ}$ \\
\hline Fórmula do Sulfato Férrico sólido & $\mathrm{Fe}_{2}\left(\mathrm{SO}_{4}\right)_{3} \cdot \mathrm{nH}_{2} \mathrm{O}$ com $7 \leqslant \mathrm{n} \geqslant 9$ \\
\hline
\end{tabular}

O sulfato férrico é um líquido ácido, corrosivo, e isto tem de ser levado em conta ao manusear o produto. O sulfato férrico líquido está disponível como uma solução a 11,5\% em ferro. É armazenado sob forma não-diluída, em tanques de material apropriado, tais como, plástico, à base de cobertura de borracha, ou aço resistente a ácidos.

O sulfato férrico é dosado usualmente sob forma não-diluída com equipamento apropriado. De modo a obter uma dosagem mais precisa, o produto comercial pode ser diluído num volume tal que o $\mathrm{pH}$ da solução seja menor que 2,0. Sob altas razões de diluição, pode ocorrer a precipitação de hidróxidos férricos que levam à diminuição da eficiência na coagulação do produto. 


\section{MATERIAIS E MÉTODOS}

Neste capítulo são apresentados os equipamentos, materiais utilizados e a metodologia.

Todo o processo foi desenvolvido nos laboratórios de saneamento da EESC/USP.

\subsection{EQUIPAMENTOS}

Foram utilizados os seguintes equipamentos: potenciômetro modelo 420A da marca ORION, com acessórios: eletrodo (ver FIGURA 4.3), adaptador elétrico, porta eletrodo e manual; Turbidímetro modelo 2100P da marca HACH com: três Cubetas de calibração, adaptador elétrico, seis cubetas para medição (ver FIGURA 4.3); Espectofotômetro de leitura digital, modelo DR 4000 da marca HACH, com duas cubetas; Zetâmetro da marca MALVERN Instruments acoplado ao microcomputador; Centrífuga de bancada, modelo 215 da marca FANEM; Condutivímetro modelo DS-15 da marca HORIBA; Agitador marca FISATON $220 \mathrm{v}$, com rotação variável e pedestal suporte para bureta de vidro; Equipamento estático (JAR TEST) da marca NOVA ÉTICA com: 6 jarros, 18 cubetas dosadoras, 24 cubetas de coleta, seis cubetas de descarte e motor com variação de rotações de 20 a 600 rpm (ver FIGURA 4.1); Cronômetro digital com precisão de 0,01s; Termômetro de bulbo; Balança eletrônica marca METTLER; Agitador mecânico tipo furadeira acoplado a eixo vertical com paletas e recipiente em acrílico com capacidade para 25 litros (ver FIGURA 4.2). 


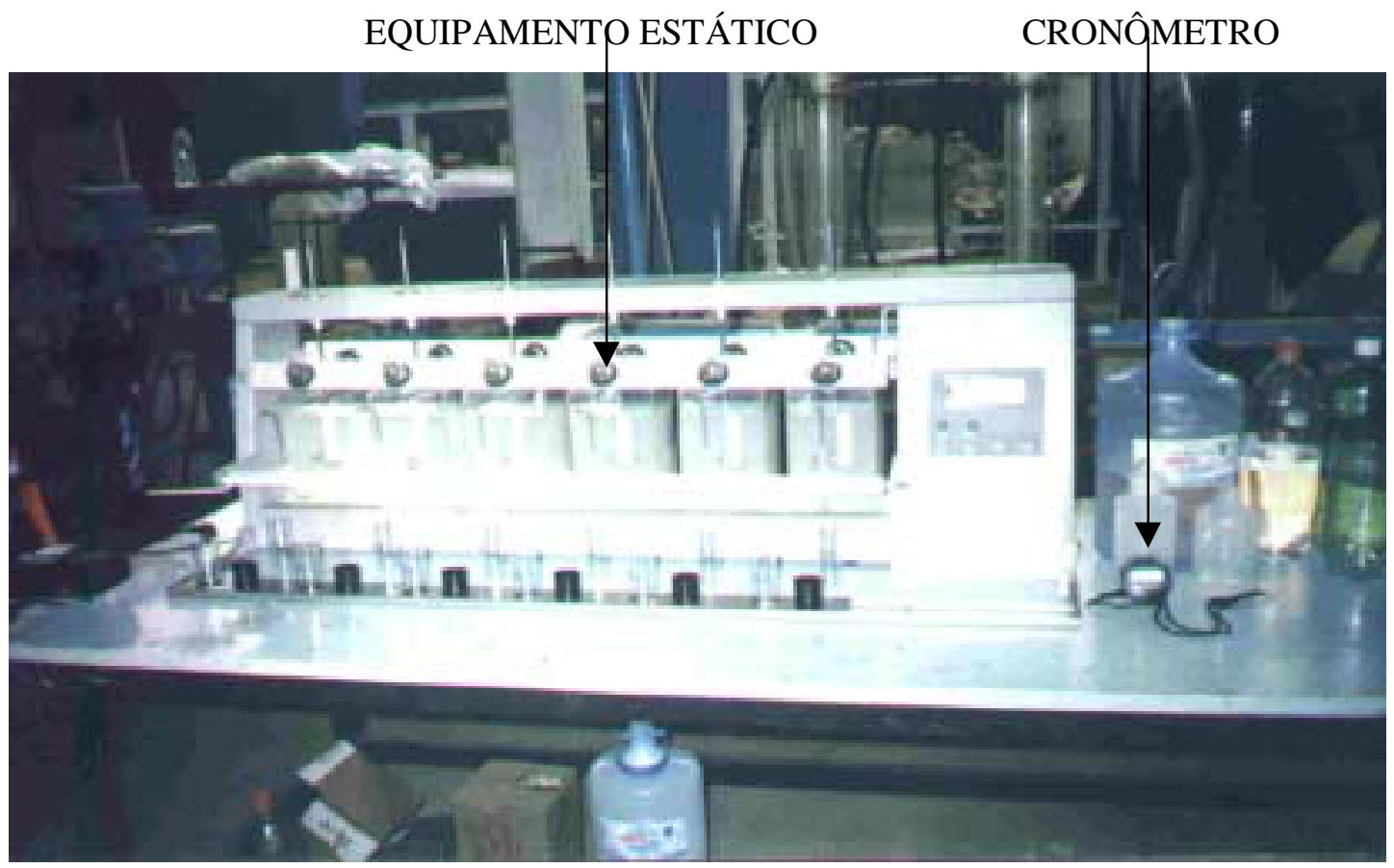

FIGURA 4.1 - Fotografia do Equipamento Estático (Jar Test).

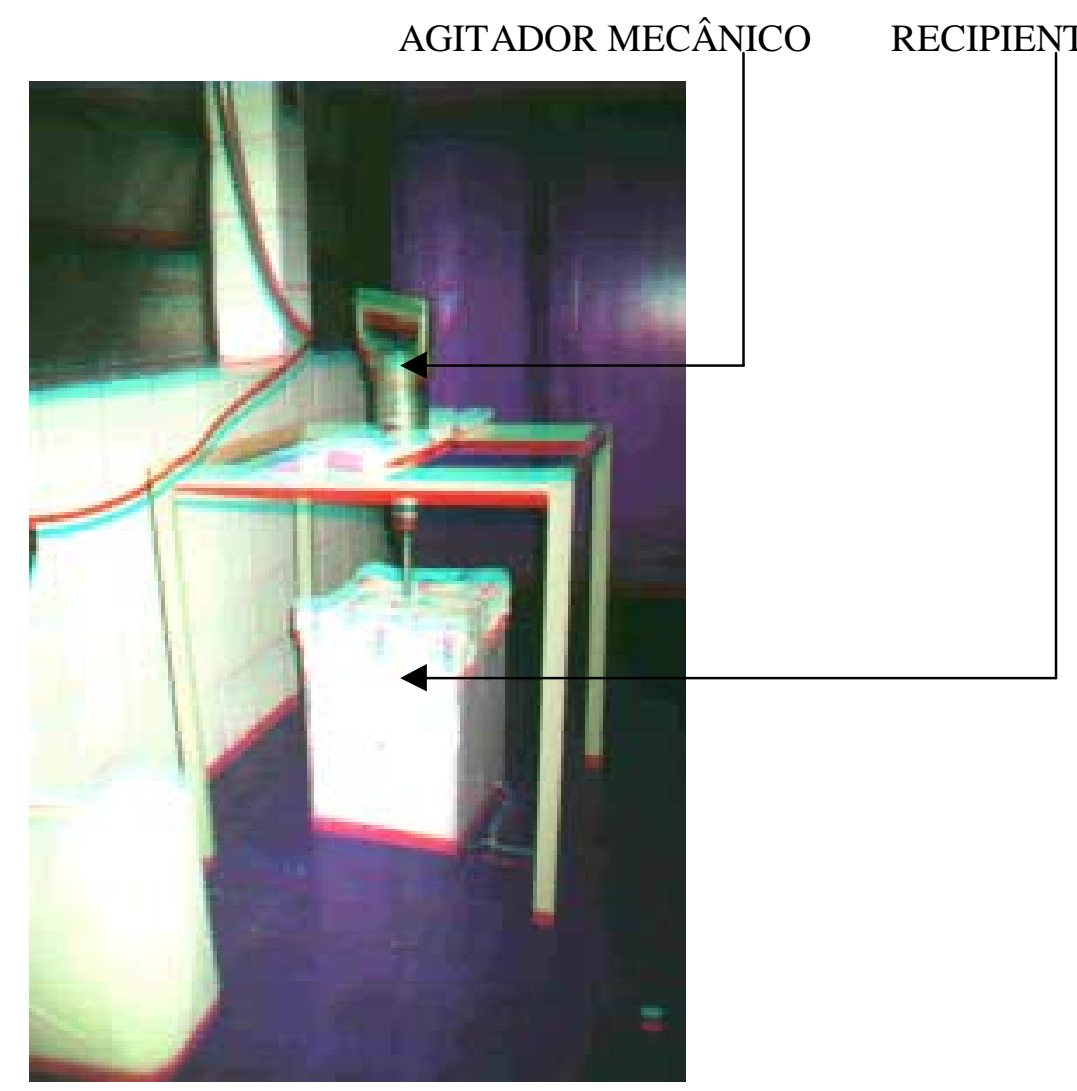

FIGURA 4.2 - Fotografia do Agitador para dispersão mãe - Caulinita. 


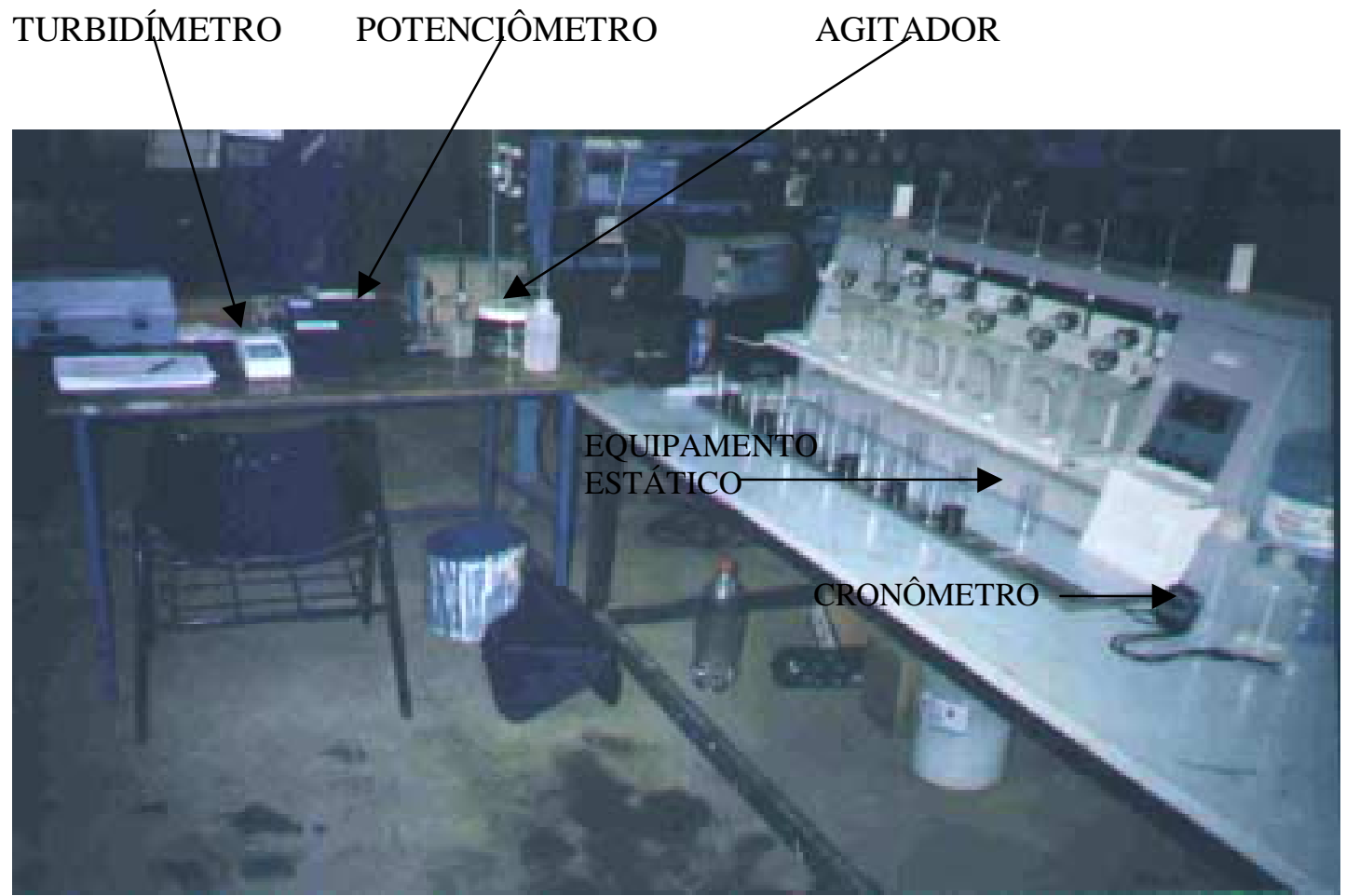

FIGURA 4.3 - Fotografia do Equipamento Estático à direita, potenciômetro e Turbidímetro à esquerda.

\subsection{MATERIAIS}

\subsubsection{PRODUTOS QUÍMICOS}

Os coagulantes estudados foram os seguintes:

- Sulfato de alumínio $\mathrm{Al}_{2}\left(\mathrm{SO}_{4}\right)_{3} \times 14,3 \mathrm{H}_{2} \mathrm{O}$

- Cloreto férrico $\mathrm{FeCl}_{3}$ × $6 \mathrm{H}_{2} \mathrm{O}$

- Hidróxicloreto de alumínio $\mathrm{Al}_{\mathrm{n}}(\mathrm{OH})_{\mathrm{m}} \mathrm{Cl}_{3 \mathrm{n}-\mathrm{m}}$

- Sulfato férrico $\mathrm{Fe}_{2}\left(\mathrm{SO}_{4}\right)_{3}$ × $8 \mathrm{H}_{2} \mathrm{O}$

Além dos coagulantes, os seguintes produtos foram usados:

Ácido sulfúrico $\mathrm{H}_{2} \mathrm{SO}_{4}$ a $0,03 \mathrm{~N}$; Ácido clorídrico $\mathrm{HCl}$ a $0,1 \mathrm{~N}$; Hidróxido de sódio $\mathrm{NaOH}$ a 0,1N; Caulinita (da FISHER Scientific Company - New Jersey ou similar) utilizada para acrescentar Turbidez à água; Ácido Húmico (da ALDRICH Chemical Company Inc - USA 
ou similar) utilizado para proporcionar cor à água; Soluções padrão para pH de 4,0 e 7,0, utilizadas para aferição do potenciômetro; Silicone viscoso e Água destilada.

\subsubsection{MATERIAIS DIVERSOS}

Foram utilizados os seguintes materiais:

Baldes e panos para limpeza; Baldes para transferência de água da caixa d'água para o Jar Test; Pissetas para limpeza de vidrarias; Copos Becker para fazer medição de alcalinidade, pH; Suporte para transportar cubetas de amostra do Jar Test; Balões volumétricos de 100, 1000 e 2000ml; Provetas de 3, 10, 20 e 50ml; Frascos Erlenmayer; Bancada suporte para Jar Test; Garrafas plásticas de refrigerante Pet de dois litros para fazer gelo e armazenar coagulantes após a diluição; Caixa d'água em PVC da marca MAXICAIXA com capacidade para 1500 litros; Ebulidor 220v para aquecimento da água.

\subsection{PROCEDIMENTOS}

O trabalho foi feito com dois tipos de água, e foram estudados quatro tipos de coagulantes.

Os seguintes passos foram adotados: preparo das águas de estudo; execução dos ensaios de coagulação, floculação e decantação; medição dos parâmetros; construção dos diagramas.

\subsubsection{PREPARO DAS ÁGUAS}

A partir de água do poço da EESC/USP foram preparados dois tipos de água - Tipo I e Tipo II.

A água Tipo I possui elevada turbidez e baixa cor verdadeira; a água do Tipo II tem alta cor verdadeira e baixa turbidez. Na preparação das águas, foram usados ácido húmico e caulinita.

\subsubsection{1. ÁGUA TIPO I}

Para a Turbidez foi empregada a caulinita ( Kaulin K-5 da FISHER Scientific Company New Jersey. 
Segundo CAMPOS (1980), com a finalidade de reduzir os erros na preparação das amostras e também de remover as partículas de argila (Kaolin K-5) de maior tamanho, é necessária a preparação de uma suspensão-mãe de argila em água deionizada. Essa suspensão-mãe foi preparada mediante adição de argila em água deionizada, utilizando-se um recipiente de acrílico com capacidade útil de 18 litros, e para este volume foram adicionados $386 \mathrm{~g}$ de Kaolin K-5, sendo o restante completado com água deionizada.

Após 2 (duas) horas de agitação violenta, seguidas por 15 (quinze) horas de repouso (ver FIGURA 4.2), coletou-se o sobrenadante dessa suspensão, colocando-a em recipientes adequados (previamente lavados), e mantidos cheios com água deionizada por um período de 15 dias. A água em estudo foi coletada do poço e armazenada em reservatório de PVC com capacidade de 1500 litros. A dispersão-mãe já pronta foi então adicionada aos poucos na caixa de PVC, e com uma vassoura de nylon a dispersão foi homogeneizada.

A turbidez foi controlada para não ultrapassar o limite de 100 uT. Foi necessária a preparação de mais uma suspensão-mãe para conseguir a turbidez desejada. Foram aguardados 20 dias para estabilização da dispersão, isto é, até ao medir-se os parâmetros necessários da água de estudo neste período, não se observam alterações, e chegando-se às seguintes características para água tipo I (ver TABELA 4.1).

\subsubsection{2. ÁGUA TIPO II}

Inicialmente, foi adicionada parte da dispersão-mãe preparada para água I, para obtenção de turbidez de 5 uT para água II. Posteriormente, para conseguir a cor foi adicionado Ácido Húmico (da ALDRICH Chemical Company Inc - USA).

O ácido húmico foi cuidadosa e gradativamente adicionado. Concomitantemente foi sendo medida a cor. Esta fase foi difícil, pois, para medir a turbidez, a leitura é imediata, mas para medir a cor verdadeira, de acordo com o STANDARS METHODS (1998), é necessário efetuar a centrifugação da amostra. Esta rotina demora mais ou menos uma hora para chegar ao resultado. Após esta fase, aguardou-se a estabilização das características da água II (ver TABELA 4.1). 
TABELA 4.1 - Características das águas de estudo tipo I e tipo II.

\begin{tabular}{|c|c|c|}
\hline PARÂMETRO & ÁGUA TIPO I & ÁGUA TIPO II \\
\hline Cor Aparente $(\mathrm{uC})$ & - & 160 \\
\hline Cor Verdadeira (uC) & - & 102 \\
\hline Turbidez (uT) & 102 & 6,2 \\
\hline pH com agitação & 7,60 & 7,55 \\
\hline pH sem agitação & 7,75 & 7,95 \\
\hline Alcalinidade $\left(\mathrm{mg} / \mathrm{l}\right.$ de $\left.\mathrm{CaCO}_{3}\right)$ & 30 & 30 \\
\hline Condutividade $(\mu \mathrm{S} / \mathrm{cm})-25^{\circ} \mathrm{C}$ & 50 & 50 \\
\hline Dureza $\left(\mathrm{mg} / \mathrm{l} \mathrm{de} \mathrm{CaCO}_{3}\right)$ & 15,2 & 15,2 \\
\hline
\end{tabular}

\subsubsection{ENSAIOS NO EQUIPAMENTO ESTÁTICO}

Os ensaios no equipamento estático foram feitos na seqüência e de acordo com os procedimentos:

- Colocar o coagulante nas cubetas de acordo com dosagem preestabelecida, com pipetas ou seringas.

- Colocar com pipetas, o acidificante $(\mathrm{HCl}$ a $0,1 \mathrm{~N})$ e/ou alcalinizante $(\mathrm{NaOH}$ a $0,1 \mathrm{~N})$ dentro dos jarros, conforme $\mathrm{pH}$ desejado.

- Homogeneizar a água da caixa d'água mexendo com vassoura de nylon.

- Coletar em um balde de 20 a 25 litros, e em seguida adequar a temperatura da água para $25^{\circ} \mathrm{C}$, se necessário, utilizando o ebulidor ou garrafas de água congeladas.

- Colocar a água do balde nos jarros, de forma que os dois litros de cada jarro foram completados em três ou quatro vez. Este procedimento tem como finalidade se obter maior homogeneidade no conteúdo dos jarros.

- Ligar o aparelho e descer as paletas de forma a agitar um pouco os jarros, para misturar o acidificante e/ou alcalinizante, antes de adicionar o coagulante.

- Ajustar a rotação da mistura rápida (Gmr - segundo o gráfico do aparelho), e o cronômetro, no mesmo instante em que é adicionado o coagulante.

- Baixar a rotação após o Tmr para Gf e aguardar o cronômetro após Tf.

- Desligar após decorrer Tf, embora no cronômetro o tempo seja Tmr + Tf. 
- Fazer uma tabela de tempos de coleta antecipadamente, para nesta fase proceder as coletas de acordo com as velocidades de sedimentação definidas anteriormente. $\mathrm{O}$ tubo de coleta no jarro está localizado a $7,00 \mathrm{~cm}$ abaixo da superfície da água. Determinando-se por esta distância as Vs.

- Iniciar com o tempo calculado para $\mathrm{Vs}_{1}$ a coleta considerando $12 \mathrm{~s}$ antes e $10 \mathrm{~s}$ depois, ou seja, 2 s servem para descartar o conteúdo do tubo de coleta, e depois por 20 s servem para coletar a amostra.

- Substituir, para cada $\mathrm{Vs}_{1}$, as cubetas de coleta para a nova $\mathrm{Vs}_{2}$ e, assim consecutivamente, se necessário.

- Medir os parâmetros desejados - pH, turbidez ou cor aparente da amostra nas cubetas de coleta.

\subsubsection{MEDIÇÃO DOS PARÂMETROS}

\subsubsection{MEDIÇÃO DO pH.}

Os valores de $\mathrm{pH}$ são importantes para o traçado do diagrama. Anteriormente ao início da bateria de medidas no potenciômetro (após as coletas do Jar Test), deve-se calibrá-lo com as soluções tampões com pH 4 e 7. Em seguida, deve-se iniciar as medidas partindo do pH mais baixo para o mais alto. Às vezes, não se sabe ao certo se uma amostra tem valor de $\mathrm{pH}$ maior ou menor que outra, porém, sempre que possível deve-se proceder da maneira recomendada.

\subsubsection{MEDIÇÃO DE TURBIDEZ}

Após a calibração do turbidímetro, no início dos trabalhos, e mantendo o aparelho ligado, não há necessidade de novas calibrações, no decorrer do trabalho, para efetuar novas medidas.

Um cuidado especial deve-se ter com a cubeta, pois se estiver suja, ocorrerá interferência nos resultados. O uso esporádico de silicone viscoso na cubeta facilitará sua limpeza.

A homogeneização da amostra é muito importante, já que os resultados serão totalmente alterados caso ela seja esquecida. Deve-se fazer a leitura imediatamente após a colocação da amostra na cubeta do turbidímetro, pois o valor da leitura modifica-se com o tempo devido a variação de temperatura. 


\subsubsection{MEDIÇÃO DE COR}

\section{a) COR VERDADEIRA}

O primeiro passo para obter a cor verdadeira é a centrifugação da amostra. É importante que no interior da centrífuga as amostras sejam distribuídas de forma balanceada, pois, caso contrário, a força centrífuga poderá danificar o equipamento.

Após a centrifugação, cuidadosamente, deve-se fazer a retirada das cubetas da centrífuga, colocando em um frasco Erlenmayer somente um pouco de líquido de cada uma das cubetas. Evitando-se assim que as partículas centrifugadas possam interferir no resultado.

Faz-se então a leitura da amostra.

\section{b) COR APARENTE}

Feita a leitura da cor aparente no espectofotômetro DR-4000 da HACH, deve-se tomar cuidado com a seleção da curva de calibração, a qual definirá o valor da cor.

Além disso, a cubeta deve estar limpa com água destilada, para não interferir nos resultados das leituras das amostras. Aqui também, como no turbidímetro, deve-se passar silicone viscoso na cubeta para facilitar sua limpeza.

\subsubsection{TRAÇADO DOS DIAGRAMAS}

No local dos ensaios, deve-se ter um papel milimetrado para se registrar os parâmetros $-\mathrm{pH}$, Dosagem e Turbidez ou Cor remanescentes de cada amostra.

Este procedimento servirá como direcionamento e orientação para os próximos valores de $\mathrm{pH}$ e Dosagem nos ensaios subseqüentes.

Com os diversos pontos conseguidos, torna-se possível definir o traçado de curvas com a mesma turbidez ou cor remanescentes. Desta maneira, obtém-se regiões cujos valores poderão ser estudados, visando o melhor desempenho na aplicação do coagulante para determinada água (ver FIGURA 3.4 - exemplo genérico). 


\subsection{CONDIÇÕES DO EXPERIMENTO}

No projeto de pesquisa foram estipuladas, inicialmente, as condições dos parâmetros físicos para a pesquisa, no entanto, ao longo da revisão da literatura, baseando-se nos parâmetros de outros estudos, foram adotados os valores constantes na TABELA 4.2.

No caso da água tipo I foram mantidos os parâmetros previstos inicialmente no projeto. Já para a água tipo II, levou-se em conta o resultado da pesquisa de COSTA (1992) que trabalhou com uma água semelhante, mas que apresentava as características turbidez 5uT, Cor verdadeira $100 \mathrm{uC}$ e alcalinidade de $30 \mathrm{mg} / 1$ de $\mathrm{CaCO}_{3}$ e tendo adotado os parâmetros para mistura rápida, $\mathrm{Gmr}=700 \mathrm{~s}^{-1} \mathrm{e} \mathrm{Tmr}=5 \mathrm{~s}$, e para floculação Gf $=10 \mathrm{~s}^{-1} \mathrm{e} \mathrm{Tf}=40 \mathrm{~min}$.

Também MENDES (1989) usou em sua pesquisa uma água preparada em laboratório com Turbidez 5uT, Cor verdadeira $100 \mathrm{uC}$ e alcalinidade de $40 \mathrm{mg} / 1$ de $\mathrm{CaCO}_{3}$, e otimizou os parâmetros para mistura rápida em $\mathrm{Gmr}=500 \mathrm{~s}-1 \mathrm{e} \mathrm{Tmr}=5 \mathrm{~s}$, e para floculação com Gf = $12 \mathrm{~s}^{-1}$ e $\mathrm{Tf}=30 \mathrm{~min}$.

Considerando os dados de COSTA e MENDES foram adotados os valores da TABELA 4.2.

TABELA 4.2 - Parâmetros físicos da pesquisa para as águas de estudo tipo I e II.

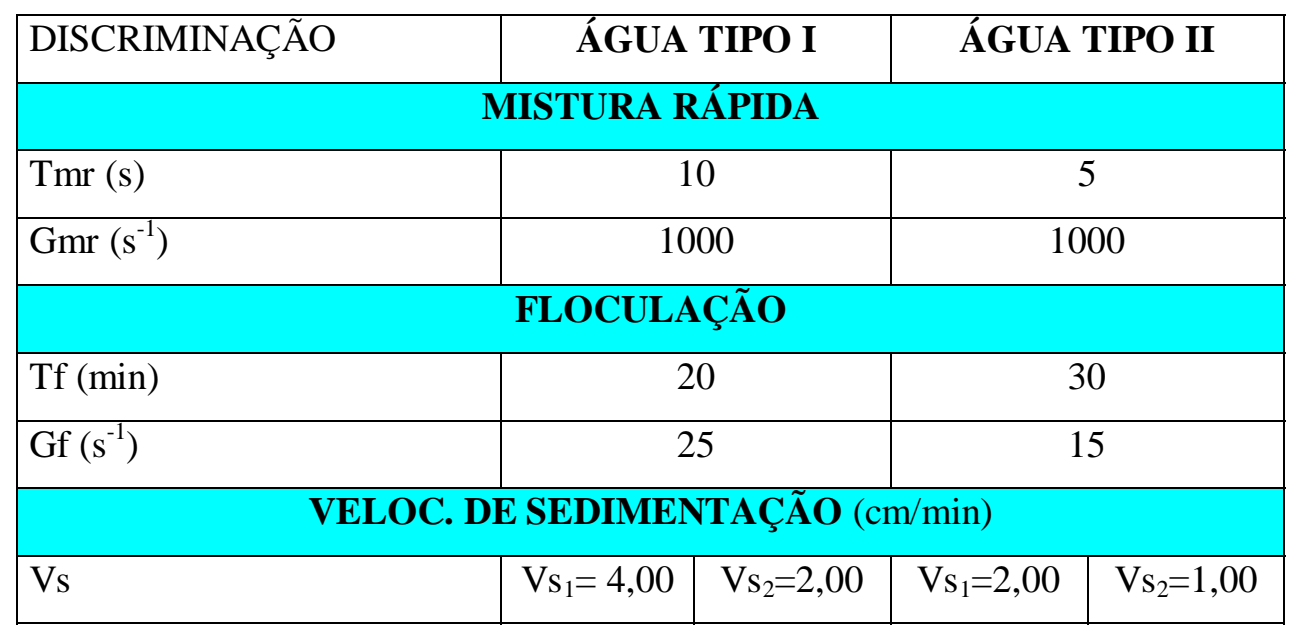




\subsection{PARÂMETROS MONITORADOS}

Na TABELA 4.3 são apresentados os parâmetros e a freqüência de medição.

TABELA 4.3 - Parâmetros monitorados durante os experimentos.

\begin{tabular}{|l|c|c|l|}
\hline \multicolumn{3}{|c|}{ PARÂMETROS MONITORADOS } \\
\hline \multicolumn{1}{|c|}{ Parâmetro } & Água Tipo I & Água Tipo II & \multicolumn{1}{c|}{ Freqüência } \\
\hline $\mathrm{pH}$ & $\mathrm{X}$ & $\begin{array}{l}\text { Diariamente da água bruta e dos } \\
\text { sobrenadante nos ensaios }\end{array}$ \\
\hline Turbidez & $\mathrm{X}$ & $\begin{array}{l}\text { Diariamente da água bruta e dos } \\
\text { sobrenadante nos ensaios }\end{array}$ \\
\hline Temperatura & $\mathrm{X}$ & $\mathrm{X}$ & Diariamente e nos ensaios \\
\hline Alcalinidade & $\mathrm{X}$ & $\mathrm{X}$ & Diariamente \\
\hline Cor Aparente & $\mathrm{X}$ & $\mathrm{X}$ & Diariamente da água bruta e dos \\
& & & sobrenadante nos ensaios \\
\hline Cor Verdadeira & Somente no início & $\mathrm{X}$ & Diariamente \\
\hline Condutividade & $\mathrm{X}$ & $\mathrm{X}$ & Semanalmente \\
\hline
\end{tabular}

A temperatura da água foi fixada na faixa de $25 \pm 1{ }^{\circ} \mathrm{C}$ utilizando-se ebulidor elétrico para aumentá-la, ou, gelo para diminuí-la. O gelo utilizado era formado por meio de uma garrafa Pet com 2 litros de água, evidentemente que a garrafa mantinha-se fechada durante seu contato com a água de estudo. 


\section{RESULTADOS E DISCUSSÕES}

Neste item são apresentados os resultados obtidos e a sua discussão.

\section{1 ÁGUA TIPO I}

A água de estudo tipo I tem como característica principal - elevada turbidez com valor aproximado de $100 \mathrm{uT}$.

Os dados resultantes dos ensaios da água tipo I estão nos ANEXOS de A a D, como segue:

- Sulfato de alumínio

- Cloreto férrico

- Hidroxicloreto de alumínio

- Sulfato férrico
ANEXO A

ANEXO B

ANEXO C

ANEXO D

Para permitir uma comparação entre os resultados dos quatro tipos de coagulantes, todos os ensaios da água tipo I foram realizados com os parâmetros citados na TABELA 4.2 do capítulo anterior; estes parâmetros são: para mistura rápida, Tmr $=10 \mathrm{~s}$ e $\mathrm{Gmr}=1000 \mathrm{~s}^{-1}$; para floculação, $T f=20 \mathrm{~min}$ e $\mathrm{Gf}=25 \mathrm{~s}^{-1}$; e com velocidades de sedimentação de $4 \mathrm{~cm} / \mathrm{min}$ e $2 \mathrm{~cm} / \mathrm{min}$.

\subsubsection{DIAGRAMA DE COAGULAÇÃO DO SULFATO DE ALUMÍNIO}

Nas FIGURAS 5.1 e 5.2, pode-se verificar que a curva com o menor valor de turbidez remanescente é a curva de 5 uT. A TABELA 5.1 fornece os resultados das faixas otimizadas de $\mathrm{pH}$ e dosagens de coagulantes. As dosagens de coagulantes nos gráficos estão nas formas: à esquerda - produto comercial em miligramas por litro - e à direita - alumínio em 
miligramas por litro. As velocidades de sedimentação consideradas foram de $4 \mathrm{~cm} / \mathrm{min}$ e $2 \mathrm{~cm} / \mathrm{min}$.

Para o gráfico da FIGURA 5.1, com $\mathrm{Vs}_{\mathrm{s}}=4 \mathrm{~cm} / \mathrm{min}$, a região otimizada para a curva de turbidez remanescente com valor de $5 \mathrm{uT}$ tem os valores de $\mathrm{pH}$ entre 6,64 a 7,17 versus dosagens de sulfato de alumínio $\mathrm{Al}_{2}\left(\mathrm{SO}_{4}\right)_{3}$ x $14,3 \mathrm{H}_{2} \mathrm{O}$ entre $52 \mathrm{mg} / \mathrm{l}$ a $68 \mathrm{mg} / \mathrm{l}$.

Serão analisados os gráficos das FIGURA 5.2 e FIGURA 3.8 do capítulo anterior, considerando que ambos foram estudados com velocidade de sedimentação de $2 \mathrm{~cm} / \mathrm{min}$ e com turbidez elevada. Nesta comparação é importante a observação de que o coagulante sulfato de alumínio utilizado neste estudo tem a fórmula $\mathrm{Al}_{2}\left(\mathrm{SO}_{4}\right)_{3}$ x $14,3 \mathrm{H}_{2} \mathrm{O}(\mathrm{PM}=600)$, e o do outro estudo, tem a fórmula $\mathrm{Al}_{2}\left(\mathrm{SO}_{4}\right)_{3}$ x $18 \mathrm{H}_{2} \mathrm{O}$ (PM=666). O coagulante $\mathrm{Al}_{2}\left(\mathrm{SO}_{4}\right)_{3} \times$ $18 \mathrm{H}_{2} \mathrm{O}$ tem mais água nas suas moléculas de constituição, conseqüentemente, ele tem uma concentração de alumínio $10 \%$ menor em relação ao coagulante $\mathrm{Al}_{2}\left(\mathrm{SO}_{4}\right)_{3}$ x 14,3 $\mathrm{H}_{2} \mathrm{O}$.

Considerando o gráfico da FIGURA 5.2, nota-se que a região otimizada para a curva com valor de turbidez remanescente de $5 \mathrm{uT}$, tem valores de $\mathrm{pH}$ entre 6,45 e 7,47 versus dosagens de sulfato de alumínio $\mathrm{Al}_{2}\left(\mathrm{SO}_{4}\right)_{3}$ x 14,3 $\mathrm{H}_{2} \mathrm{O}$ entre $32 \mathrm{mg} / \mathrm{l}$ e valores maiores que $80 \mathrm{mg} / \mathrm{l}$. Na FIGURA 3.8, a região com melhores resultados encontra-se para os valores de $\mathrm{pH}$ entre 6,4 e 8,0, e com dosagens de sulfato de alumínio $\mathrm{Al}_{2}\left(\mathrm{SO}_{4}\right)_{3}$ x $18 \mathrm{H}_{2} \mathrm{O}$ entre $42 \mathrm{mg} / \mathrm{l}$ e $80 \mathrm{mg} / \mathrm{l}$. Considerando-se as diferenças nas concentrações de alumínio no coagulante, este mesmo intervalo de dosagens corresponde de $37,8 \mathrm{mg} / \mathrm{l} \mathrm{a} 72,0 \mathrm{mg} / \mathrm{l}$.

Desta forma, pode-se concluir que tanto a água deste estudo com turbidez de 100uT, quanto à do estudo de DI BERNARDO et al (1993), determinaram no gráfico de pH de coagulação versus dosagens de coagulante, regiões próximas, apesar de que a água preparada neste estudo foi com substâncias húmicas (comercial), e a água do outro estudo, foi com substâncias húmicas naturais. 
TABELA 5.1 - Regiões dos Diagramas de Coagulação com Sulfato de Alumínio e Valores de Turbidez Remanescente - Água Tipo I

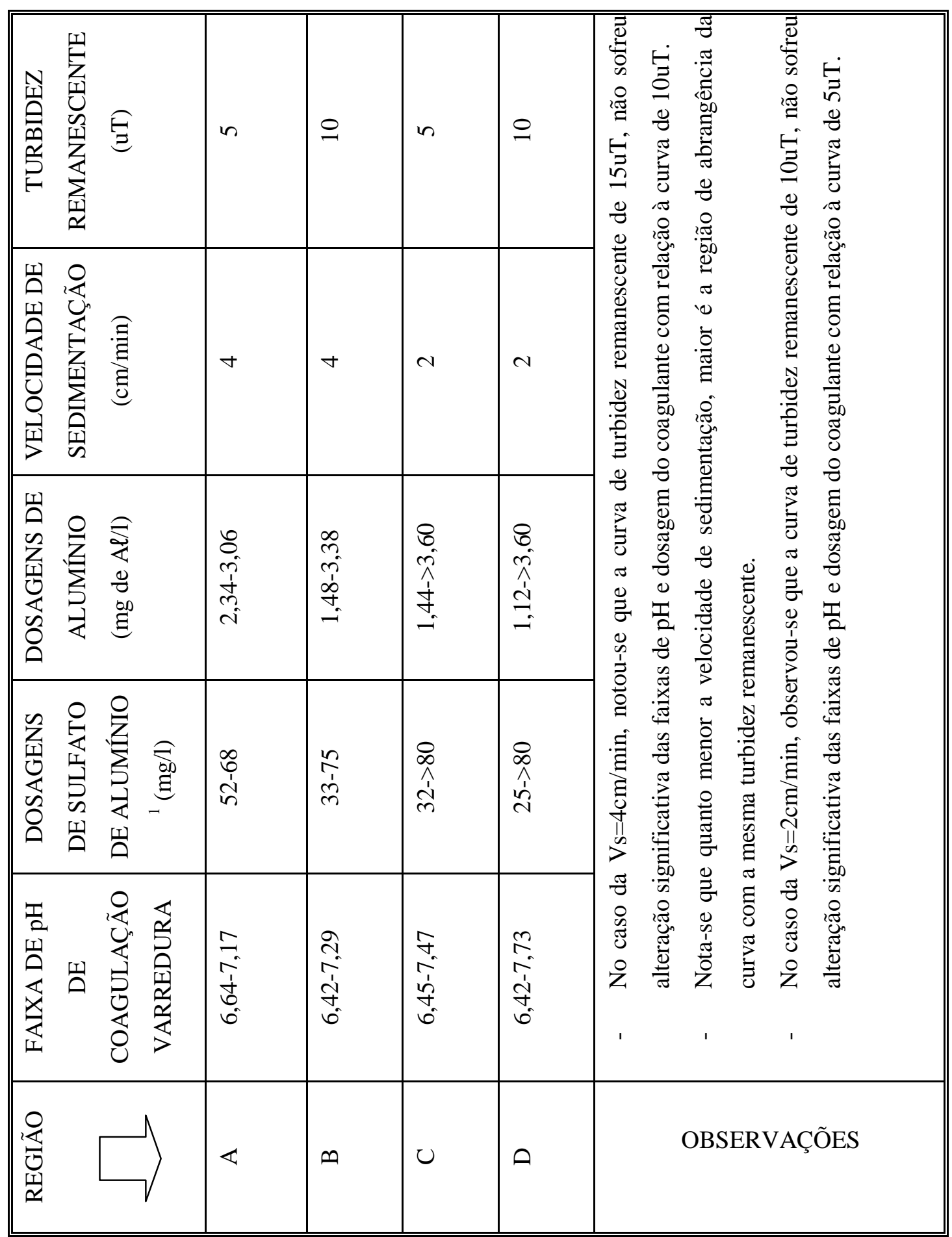

\footnotetext{
${ }^{1}$ produto comercial com $8,5 \%$ de $\mathrm{Al}_{2} \mathrm{O}_{3}$.
} 
|1/OIUIயก। $\forall$ әр Бய

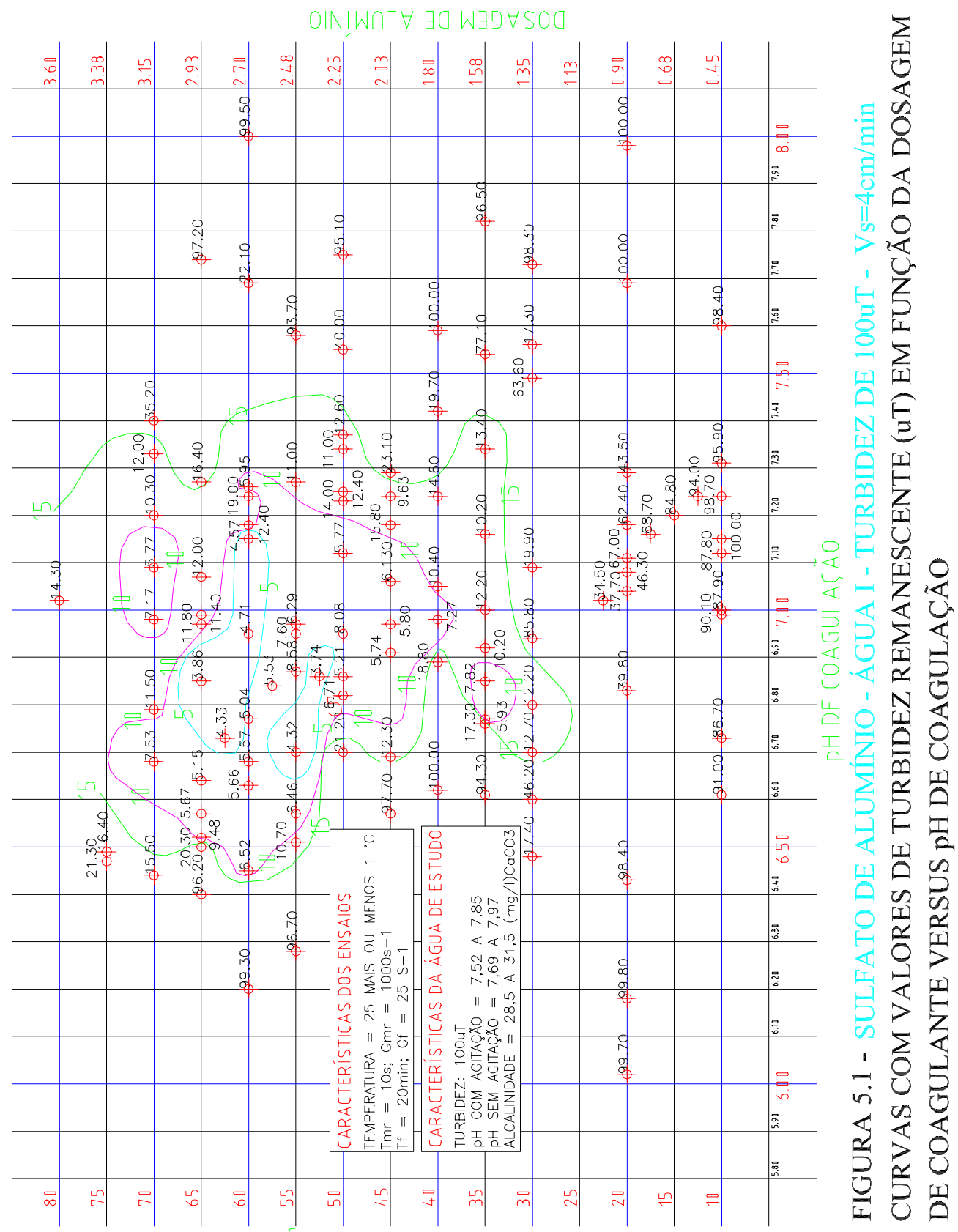

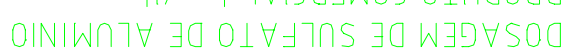


|1/0!บ!யח

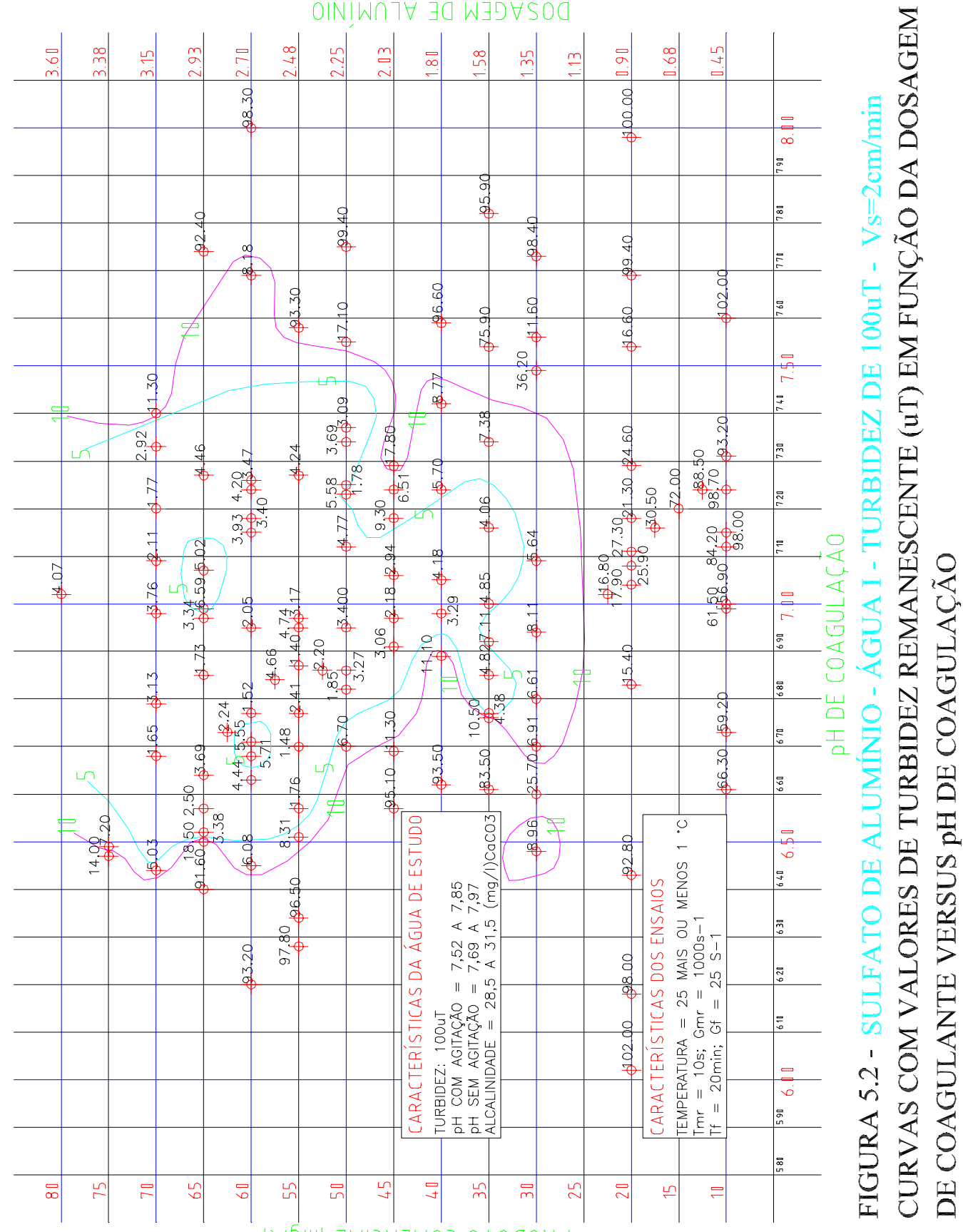

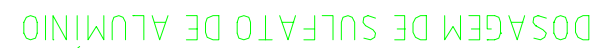




\subsubsection{DIAGRAMA DE COAGULAÇÃO CLORETO FÉRRICO}

Pode ser verificado nas FIGURAS 5.3 e 5.4, que a curva com menor valor de turbidez remanescente é de 5 uT.

A TABELA 5.2 fornece os resultados das faixas otimizadas de $\mathrm{pH}$ e turbidez remanescente para velocidades de sedimentação de $4 \mathrm{~cm} / \mathrm{min}$ e $2 \mathrm{~cm} / \mathrm{min}$.

As regiões de melhores resultados observados no gráfico da FIGURA 5.3, encontram-se para valores de $\mathrm{pH}$ entre 5,90 e 6,71, e para dosagens do coagulante cloreto férrico de $23 \mathrm{mg} / \mathrm{l} \mathrm{a}$ $78 \mathrm{mg} / \mathrm{l}$.

A FIGURA 5.4, mostra uma região com os melhores resultados definidos para valores de $\mathrm{pH}$ entre 5,84 e 7,41, versus dosagens de coagulante de $13 \mathrm{mg} / \mathrm{l}$ a valores maiores que $80 \mathrm{mg} / \mathrm{l}$. 
TABELA 5.2 - Regiões dos Diagramas de Coagulação com Cloreto Férrico e Valores de Turbidez Remanescente - Água Tipo I

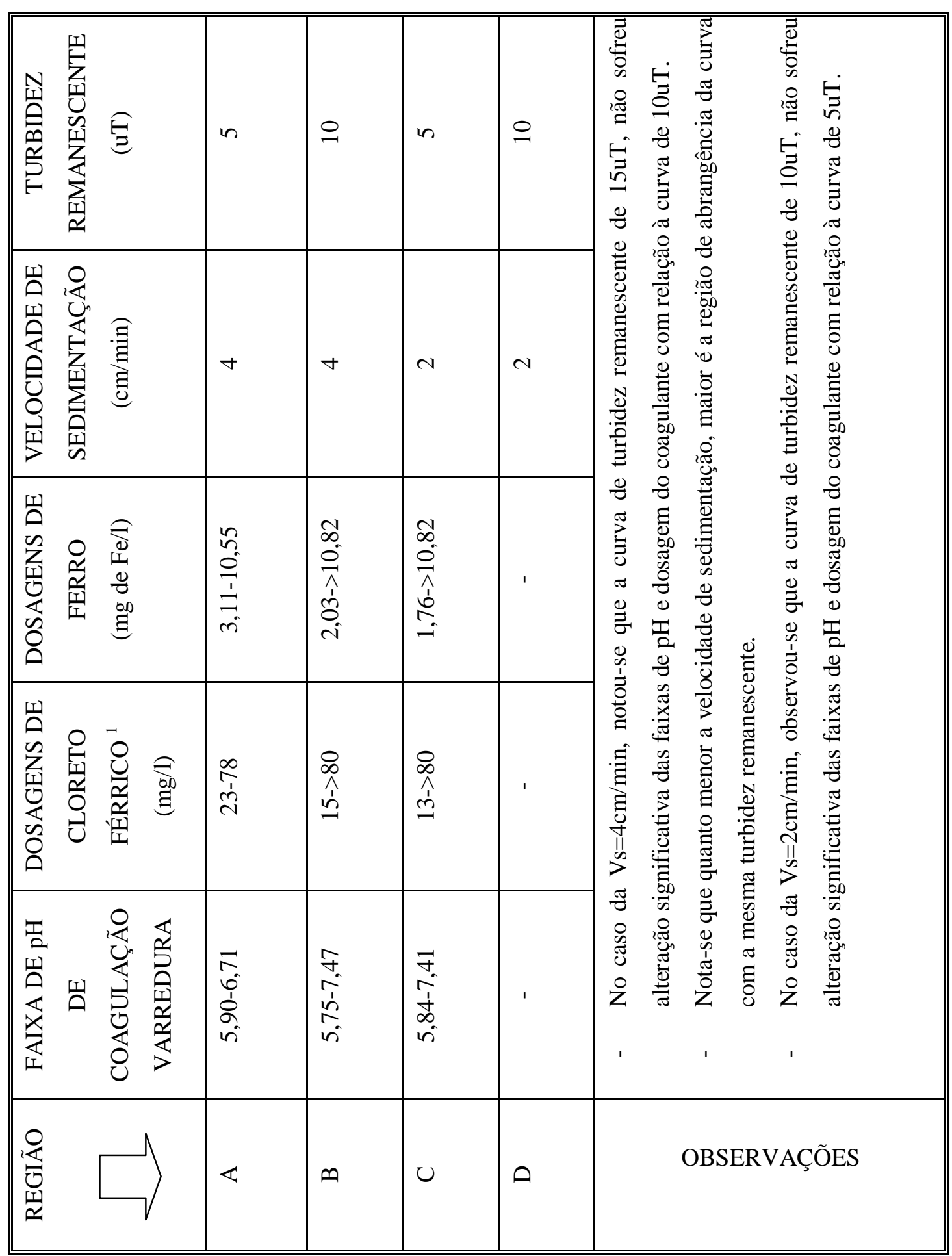

\footnotetext{
${ }^{1}$ produto comercial com $39,30 \%$ de $\mathrm{FeCl}_{3}$.
} 
$\mid 1 / 0\lrcorner\lrcorner \partial \dashv$ әр $6 \uplus \mid$

OYY $\exists \exists \exists O W \exists D \forall S O 0$

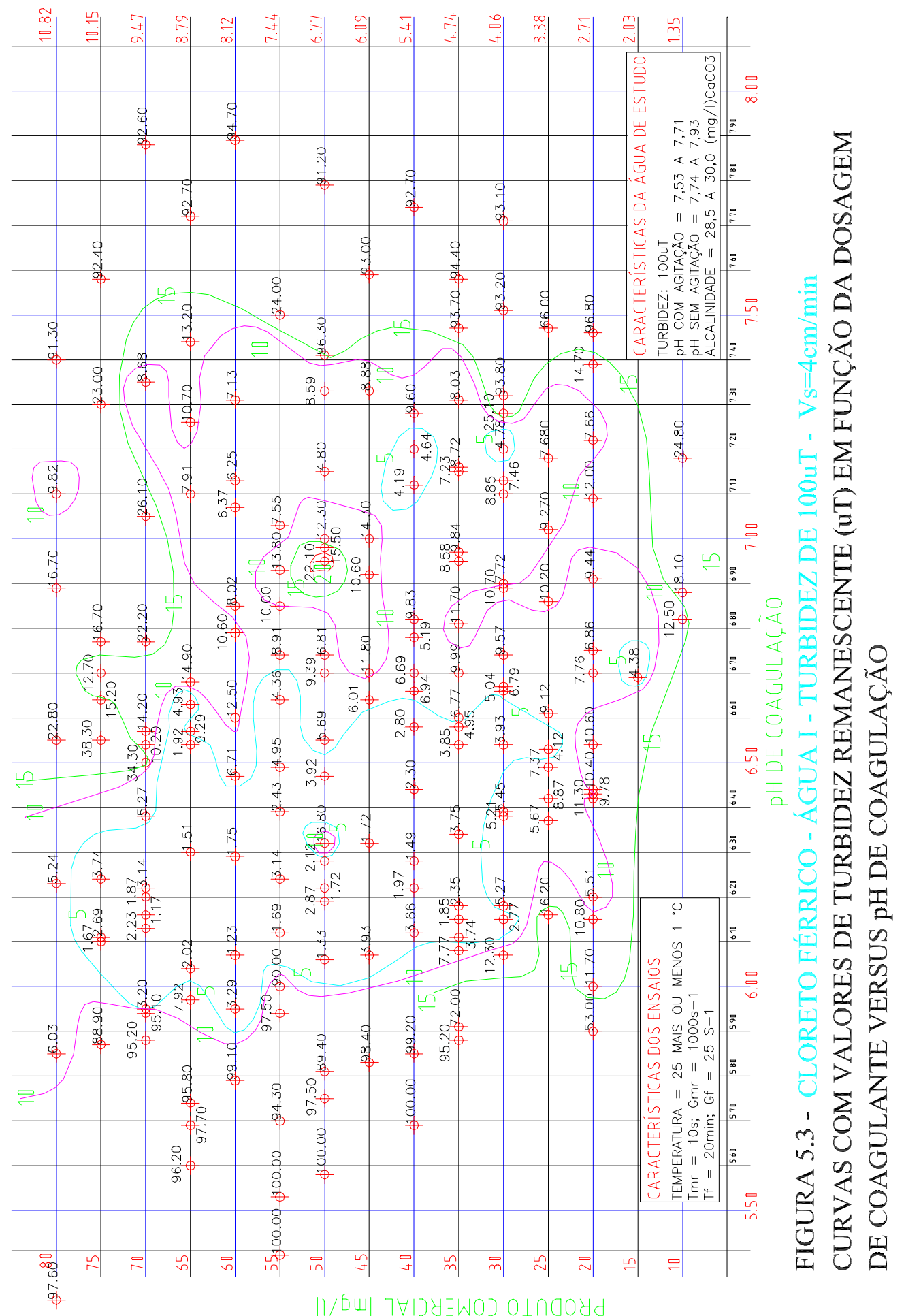

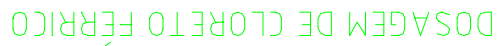


|1/0」」ә」 әр 6ய|

OУY $\exists \exists \exists 0$ W $\exists \forall \forall S O 0$

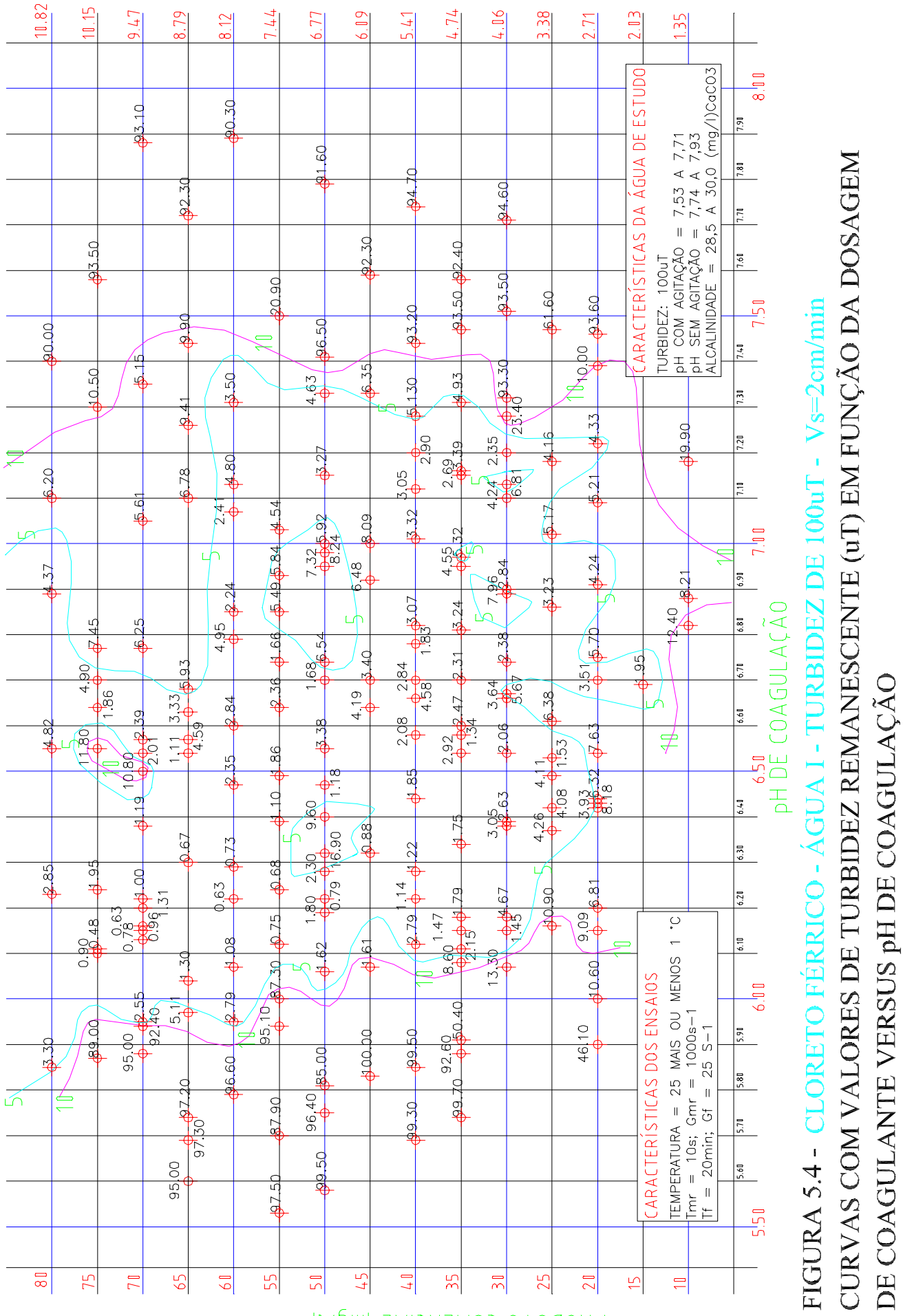

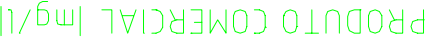

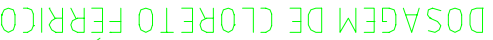




\subsubsection{DIAGRAMA DE COAGULAÇÃO DO HIDROXICLORETO DE ALUMÍNIO}

Este coagulante não é muito utilizado nas estações de tratamento de água do Brasil, no entanto, possui algumas características interessantes, como, por exemplo, sua atuação em uma extensa faixa de $\mathrm{pH}$.

Pode ser verificado nas FIGURAS 5.5 e 5.6, que a curva com menor valor de turbidez remanescente é de $5 \mathrm{uT}$.

A TABELA 5.3 fornece os resultados das faixas otimizadas de $\mathrm{pH}$ e turbidez remanescente para velocidades de sedimentação de $4 \mathrm{~cm} / \mathrm{min}$ e $2 \mathrm{~cm} / \mathrm{min}$.

No desenvolvimento do experimento notou-se que, logo após o início da floculação, na maioria dos ensaios ocorreu rapidamente a formação dos flocos, o que não foi constatado com os outros coagulantes. Um outro fato interessante é que a floculação somente aconteceu para valores de $\mathrm{pH}$ acima de aproximadamente 6,90; logo abaixo deste valor de $\mathrm{pH}$, neste estudo, não houve formação de flocos. Acima do valor de $\mathrm{pH}=6,90$, a turbidez remanescente fica com valores baixos por uma longa faixa de $\mathrm{pH}$ (acima de 10).

Observa-se na FIGURA 5.5 que a região com melhor desempenho (5uT) encontra-se no intervalo de valores de $\mathrm{pH}$ entre 6,85 a 7,39, versus valores de dosagens do coagulante hidroxicloreto de alumínio com valores de $16 \mathrm{mg} / \mathrm{l} \mathrm{a}$ valores maiores que $65 \mathrm{mg} / \mathrm{l}$.

Para o gráfico da FIGURA 5.6, observa-se que a região otimizada situa-se no intervalo de valores de $\mathrm{pH}$ entre 6,73 e 8,63, correspondendo à valores de dosagens do hidroxicloreto de alumínio de $13 \mathrm{mg} / \mathrm{l}$ a valores maiores que $65 \mathrm{mg} / \mathrm{l}$. 
TABELA 5.3 - Regiões dos Diagramas de Coagulação com Hidroxicloreto de Alumínio e Valores de Turbidez Remanescente - Água Tipo I

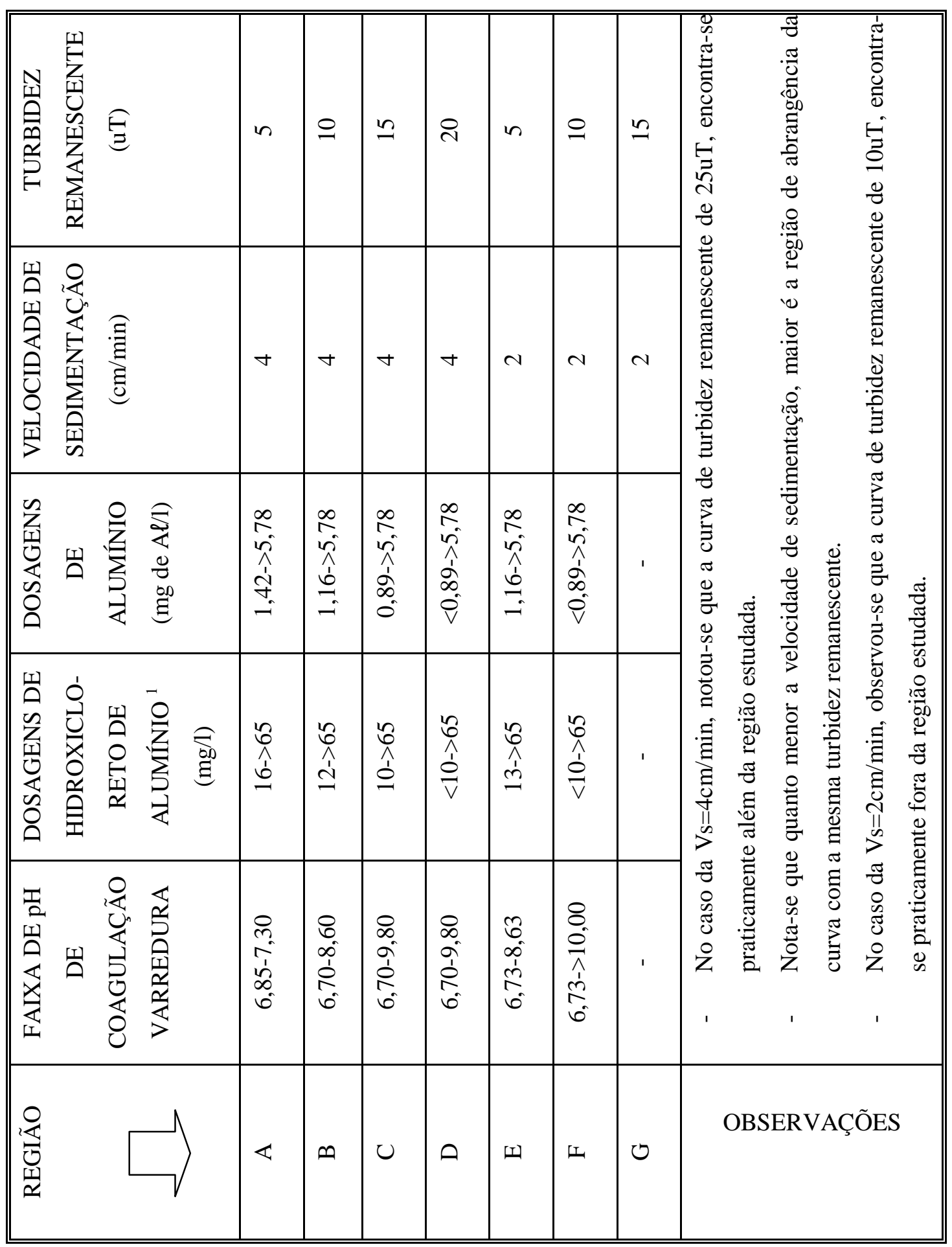

\footnotetext{
${ }^{1}$ produto comercial com $16,80 \%$ de $\mathrm{Al}_{2} \mathrm{O}_{3}$.
} 


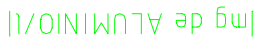

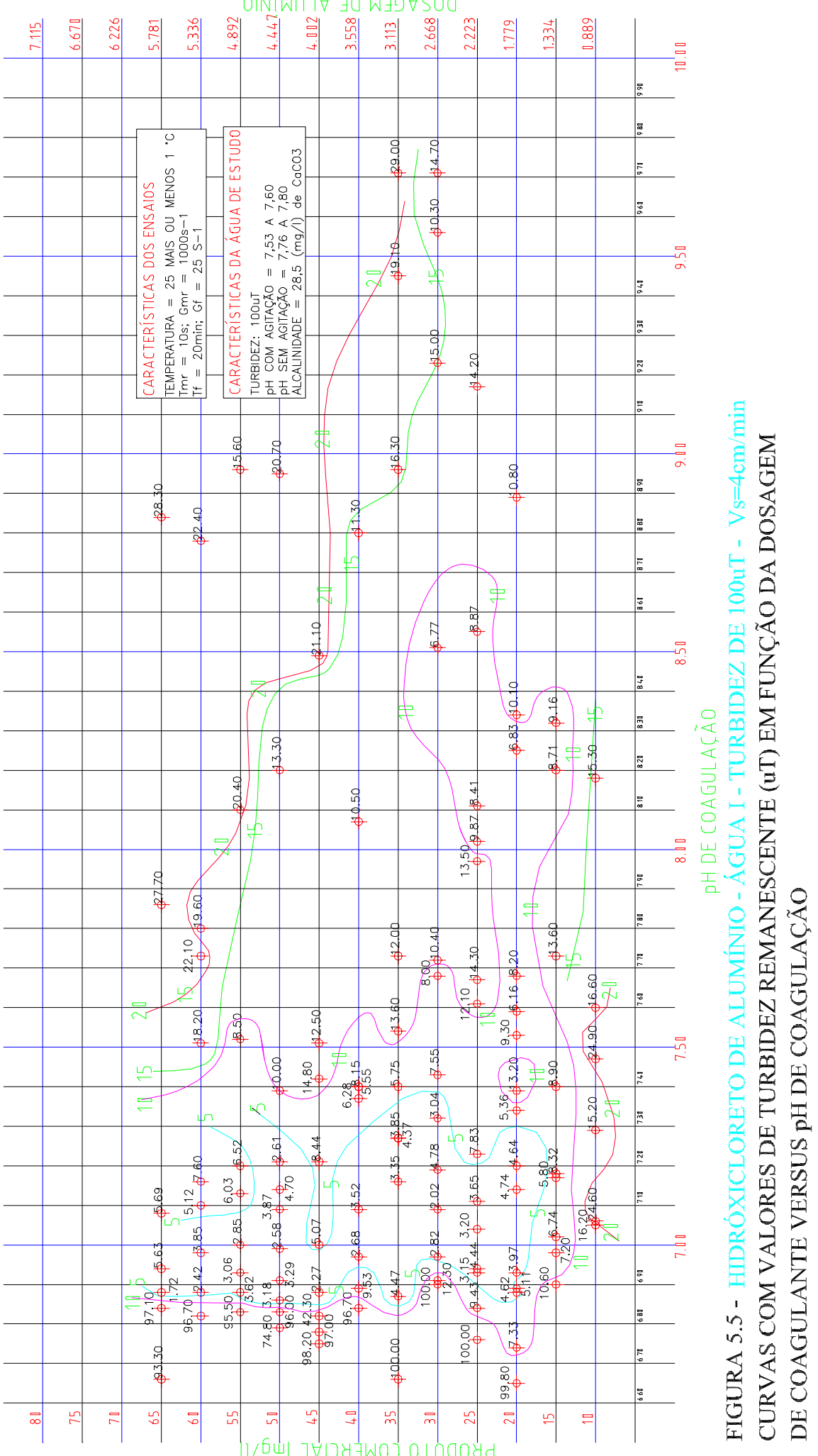

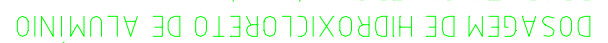


|I/OINIWก7 7 әр $6 \Psi \mid$

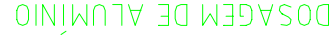

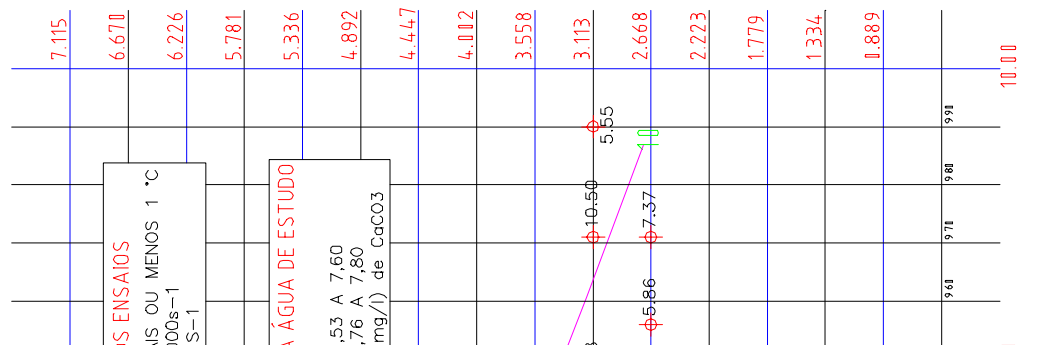

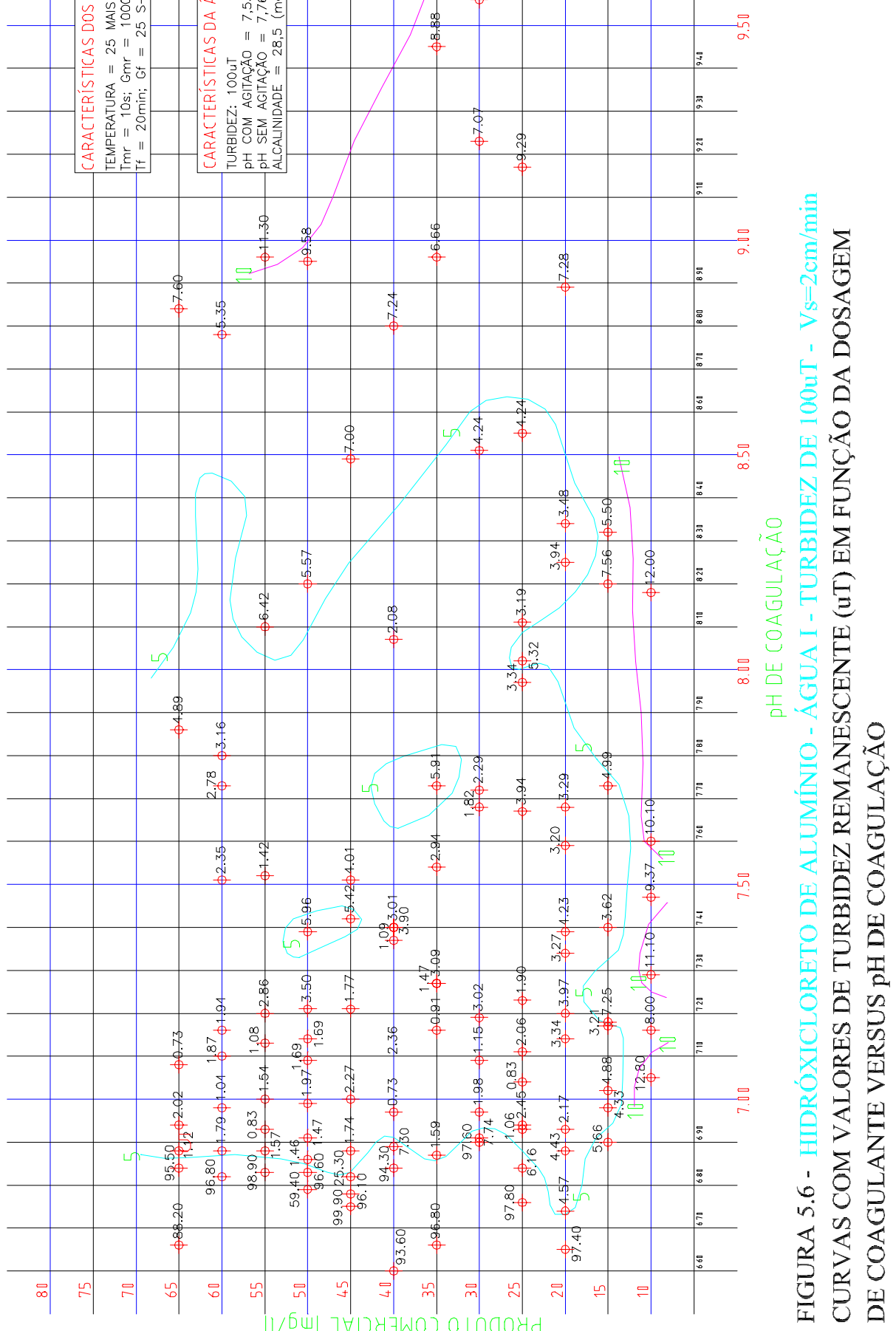




\subsubsection{DIAGRAMA DE COAGULAÇÃO DO SULFATO FÉRRICO}

Este coagulante atua em extensos intervalos de $\mathrm{pH}$, porém com valores mais baixos de $\mathrm{pH}$ do que os outros coagulantes.

A TABELA 5.4 fornece os resultados das faixas otimizadas de $\mathrm{pH}$ e turbidez remanescente para velocidades de sedimentação de $4 \mathrm{~cm} / \mathrm{min}$ e $2 \mathrm{~cm} / \mathrm{min}$.

A otimização deste coagulante para a água estudada ocorreu abaixo dos valores de $\mathrm{pH}=6,7$ para $\mathrm{Vs}=4 \mathrm{~cm} / \mathrm{min}$ e $\mathrm{pH}=7,00$ para $\mathrm{Vs}=2 \mathrm{~cm} / \mathrm{min}$, ao contrário deste, o hidróxicloreto de alumínio, que tem sua otimização, acima dos valores de $\mathrm{pH}$ citados.

A região otimizada para o sulfato férrico, geralmente tem valores de dosagens menores do que as dos outros coagulantes estudados, quando considera-se a região inferior do gráfico.

A região de menores valores de turbidez remanescente está delimitada pela curva com valor de 5uT; na FIGURA 5.7, esta região otimizada é definida para os valores de dosagens do coagulante sulfato férrico entre $17 \mathrm{mg} / \mathrm{l} \mathrm{e} 53 \mathrm{mg} / \mathrm{l}$.

A FIGURA 5.8, mostra as regiões com menores valores de turbidez remanescente (5uT), para os valores de $\mathrm{pH}$ entre 4,15 e 7,09 versus valores de dosagens de menor que $10 \mathrm{mg} / \mathrm{l} \mathrm{a}$ valores maiores que $60 \mathrm{mg} / \mathrm{l}$. 
TABELA 5.4 - Regiões dos Diagramas de Coagulação com Sulfato Férrico e Valores de Turbidez Remanescente - Água Tipo I

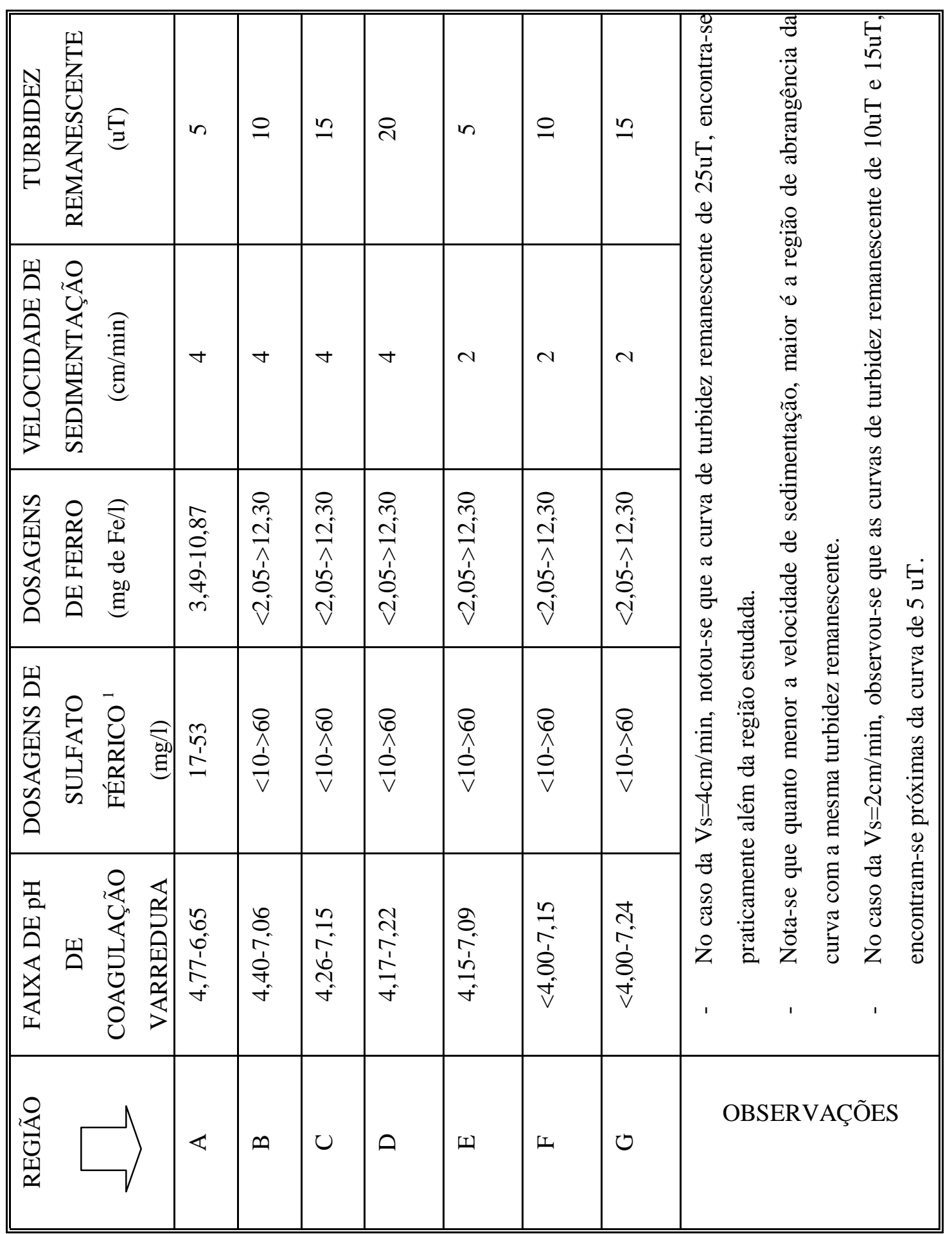

${ }^{1}$ produto comercial com $20,53 \%$ de FeIII . 
|1/0yy

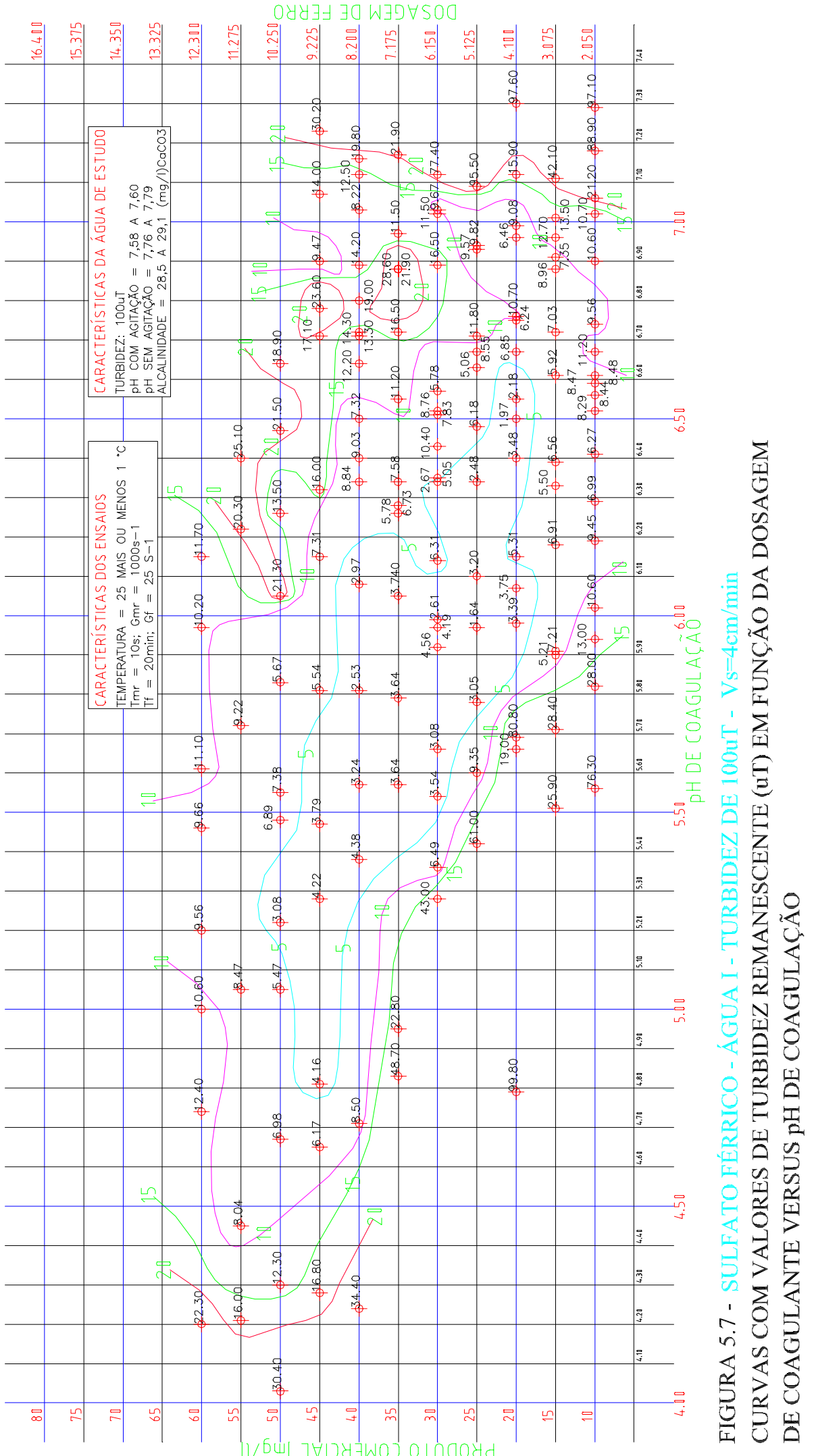

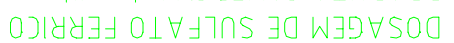


|1/0уу
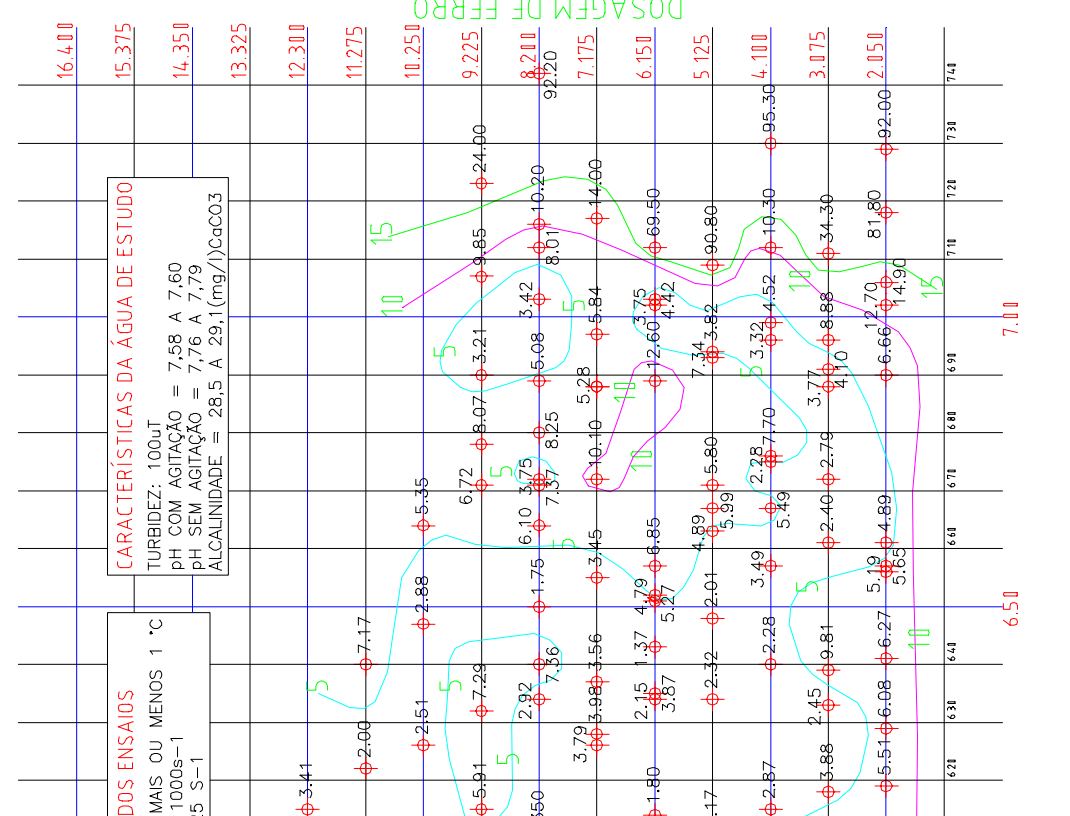

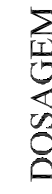
年

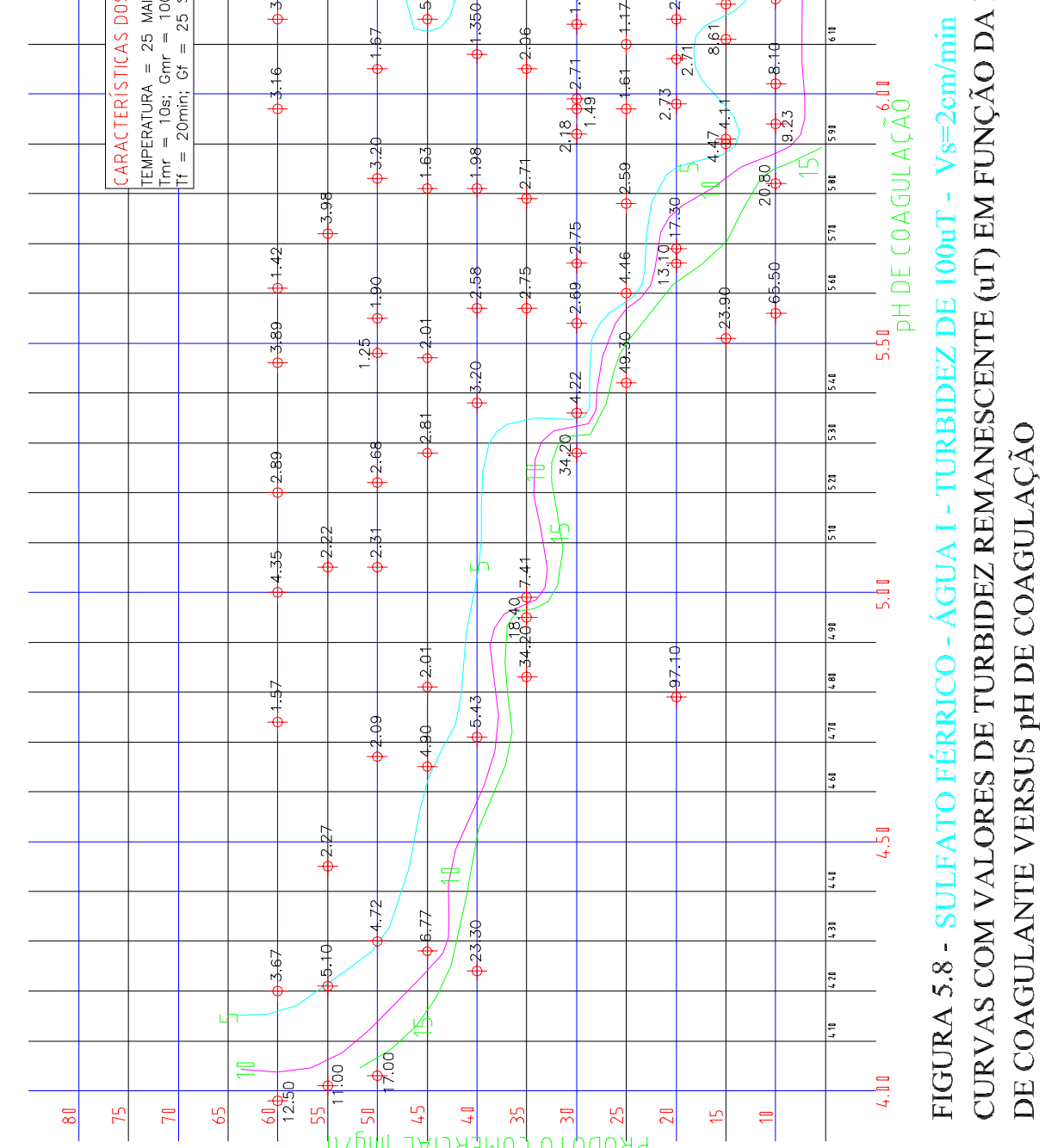




\section{2 ÁGUA TIPO II}

A água de estudo tipo II tem como característica principal a cor verdadeira elevada, com valor aproximado de $100 \mathrm{uC}$.

Os dados resultantes dos ensaios da água tipo II estão nos ANEXOS de E a H, como segue:

- Sulfato de alumínio

- Cloreto férrico

- Hidroxicloreto de alumínio

- Sulfato férrico

\author{
ANEXO E \\ ANEXO F \\ ANEXO G \\ ANEXO H
}

Para permitir uma comparação entre os resultados dos quatro tipos de coagulantes, todos os ensaios da água tipo II foram realizados com os parâmetros citados na TABELA 4.2 do capítulo anterior; estes parâmetros são: para mistura rápida, $\mathrm{Tmr}=5 \mathrm{~s}$ e $\mathrm{Gmr}=1000 \mathrm{~s}^{-1}$; para floculação, $\mathrm{Tf}=30 \mathrm{~min}$ e $\mathrm{Gf}=25 \mathrm{~s}^{-1}$; e com velocidades de sedimentação de $2 \mathrm{~cm} / \mathrm{min}$ e $1 \mathrm{~cm} / \mathrm{min}$.

\subsubsection{DIAGRAMA DE COAGULAÇÃO DO SULFATO DE ALUMÍNIO}

Analisando o diagrama mostrado na FIGURA 5.9, nota-se que o valor da curva de cor aparente remanescente com melhor resultado é a de valor $20 \mathrm{uC}$, porém, esta curva apresenta uma região com forma quase pontual, o que torna mais coerente a utilização da curva imediatamente posterior, que é a de valor $30 \mathrm{uC}$.

Para a FIGURA 5.10, a velocidade de sedimentação é menor, portanto, foram obtidos valores menores para curvas de cor aparente remanescente.

A TABELA 5.5 fornece os resultados das faixas otimizadas de $\mathrm{pH}$ e cor aparente remanescente para velocidades de sedimentação de $2 \mathrm{~cm} / \mathrm{min}$ e $1 \mathrm{~cm} / \mathrm{min}$.

Neste estudo para água tipo II, foi utilizado produto comercial (ácido húmico) para dar cor (100uT); também como coagulante o sulfato de alumínio $\mathrm{Al}_{2}\left(\mathrm{SO}_{4}\right)_{3}$ x $14,3 \mathrm{H}_{2} \mathrm{O}$ comercial. Dos estudos verificados no estado da arte, o que mais se aproxima deste, foi o de 
AMIRTHARAJAH (1989), no entanto, os resultados apresentados nos gráficos das FIGURAS 3.9 e 3.10, do capítulo três, está com as dosagens máximas limitadas, respectivamente, às dosagens de $55 \mathrm{mg} / \mathrm{l}$ e $100 \mathrm{mg} / \mathrm{l}$.

Em contrapartida, DI BERNARDO et al (1993) e COSTA (1992), estudaram águas com cor conseguida por substâncias húmicas naturais, e o coagulante utilizado foi o sulfato de alumínio $\mathrm{Al}_{2}\left(\mathrm{SO}_{4}\right)_{3}$ x $18 \mathrm{H}_{2} \mathrm{O}$ (PA - para análise). Os gráficos destes estudos estão representados nas FIGURAS 3.11 e 3.12, do capítulo três. Para o gráfico da FIGURA 3.11, para o mecanismo da varredura, com mais de $90 \%$ de remoção, $\mathrm{Vs}=1 \mathrm{~cm} / \mathrm{min}$, observam-se os valores de $\mathrm{pH}$ entre 5,95 e 7,75 e com dosagens de $100 \mathrm{mg} / \mathrm{l}$ a valores maiores que 200mg/l. O gráfico de COSTA (1992), mostrado na FIGURA 3.12 para o mecanismo da varredura, com mais de $80 \%$ de remoção, $\mathrm{Vs}=2 \mathrm{~cm} / \mathrm{min}$, possui duas regiões: uma região tem os valores de $\mathrm{pH}$ entre 5,8 a 6,6 e as dosagens do coagulante sulfato de alumínio de 80 a 200 $\mathrm{mg} / \mathrm{l}$; a outra região tem os valores de $\mathrm{pH}$ entre 6,7 a 7,6 e dosagens de coagulante de 30 a $150 \mathrm{mg} / \mathrm{l}$.

Os resultados encontrados neste estudo para $V_{s}=2 \mathrm{~cm} / \mathrm{min}$, são mostrados na FIGURA 5.9, com as regiões de melhores desempenhos sendo delimitadas pelas curvas com valores de cor aparente remanescente de $30 \mathrm{uC}$. Para tais regiões, os valores de $\mathrm{pH}$ e dosagens são: a primeira região com os valores de $\mathrm{pH}$ entre 6,4 a 6,8 e os valores de dosagens de $250 \mathrm{mg} / \mathrm{l} \mathrm{a}$ $270 \mathrm{mg} / \mathrm{l}$; a segunda região, pontual, com pH entre 6,7 a 6,8 e dosagens de $170 \mathrm{mg} / \mathrm{l}$ a 190 mg/l. Estes resultados estão mais próximos dos resultados obtidos por COSTA (1992).

Para Vs=1cm/min, os resultados deste estudo são apresentados pelo gráfico da FIGURA 5.10, o qual mostra as regiões com melhores desempenhos, sendo elas delimitadas pelas curvas dos valores de cor aparente remanescente de $15 \mathrm{uC}$ e $20 \mathrm{uC}$ (esta última está mais definida). Para as regiões da curva com valor de $20 \mathrm{uC}$, os valores de $\mathrm{pH}$ e dosagens são: $\mathrm{pH}$ entre 6,2 a 7,25 e dosagens de $250 \mathrm{mg} / \mathrm{l}$ a valores maiores que $360 \mathrm{mg} / \mathrm{l}$. Estes resultados estão mais próximos dos resultados obtidos por DI BERNARDO et al (1993). 
TABELA 5.5 - Regiões dos Diagramas de Coagulação com Sulfato de Alumínio e Valores de Cor Aparente Remanescente - Água Tipo II

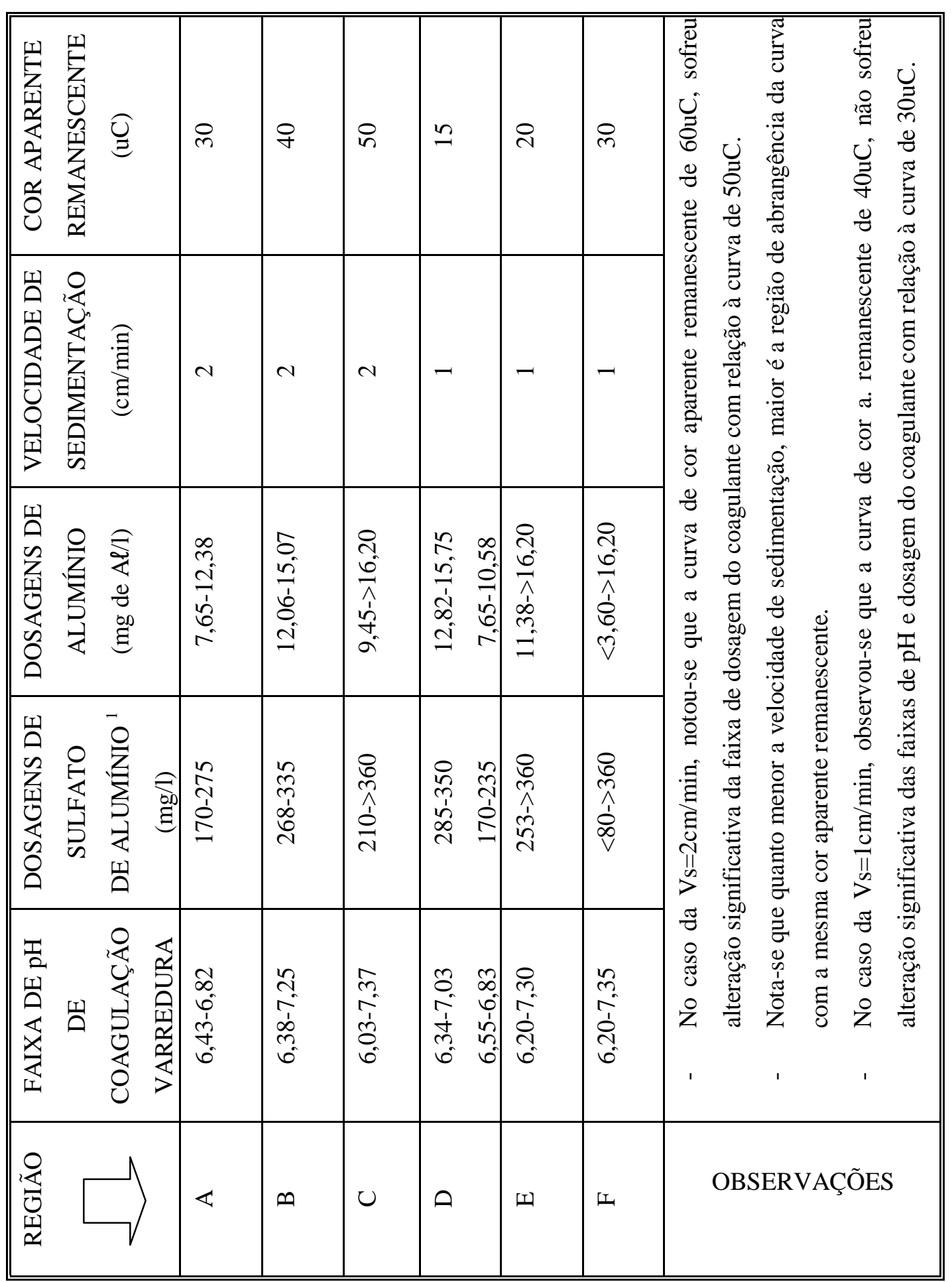

\footnotetext{
${ }^{1}$ produto comercial com $8,5 \%$ de $\mathrm{Al}_{2} \mathrm{O}_{3}$.
} 


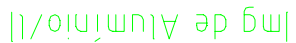

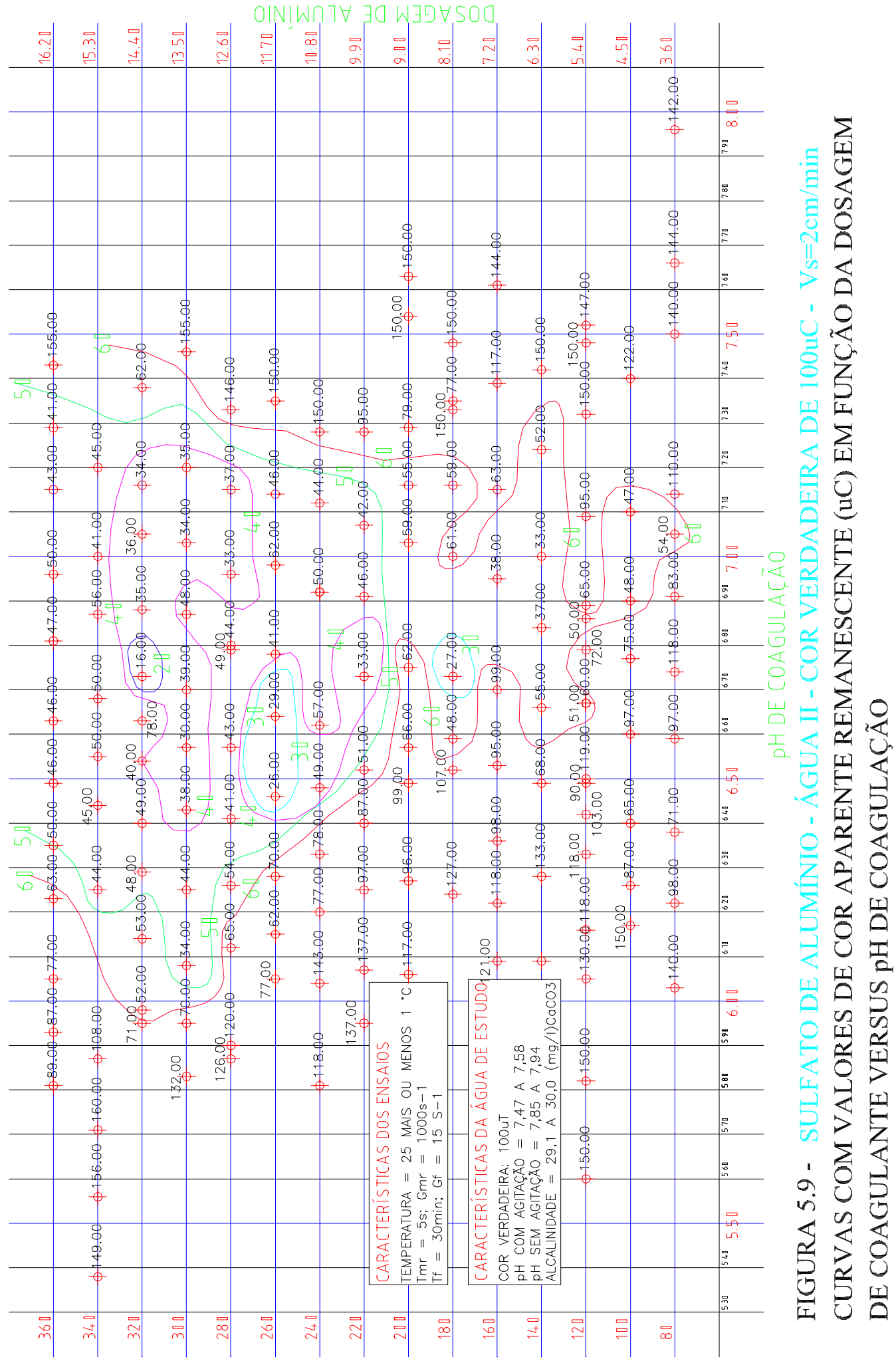


|)/OIUแกI

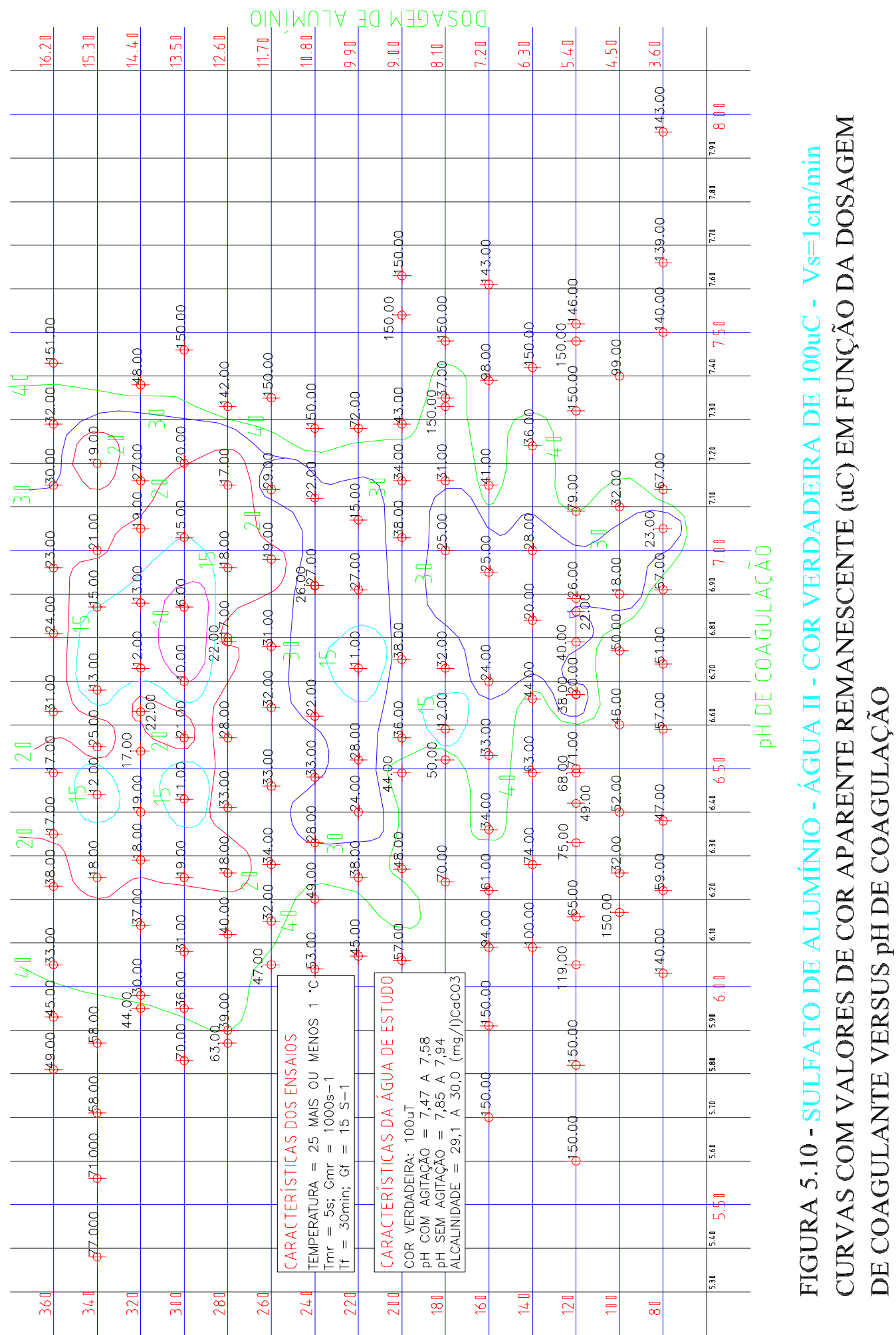




\subsubsection{DIAGRAMA DE COAGULAÇÃO CLORETO FÉRRICO}

Pode ser verificado nas FIGURAS 5.10 e 5.11 que a curva com menor cor aparente remanescente é de $10 \mathrm{uT}$.

A TABELA 5.6 fornece os resultados das faixas otimizadas de $\mathrm{pH}$ e cor aparente remanescente para velocidades de sedimentação de $2 \mathrm{~cm} / \mathrm{min}$ e $1 \mathrm{~cm} / \mathrm{min}$.

Na FIGURA 5.11, a região com menores valores de cor aparente remanescente está delimitada pela curva com valor de $10 \mathrm{uT}$; esta região otimizada é definida para valores de $\mathrm{pH}$ entre 5,87 e 6,26, e valores de dosagens do coagulante cloreto férrico entre $130 \mathrm{mg} / \mathrm{l} \mathrm{e}$ $220 \mathrm{mg} / \mathrm{l}$.

Para a FIGURA 5.12, a região com menores valores de cor aparente remanescente está delimitada pela curva com valor de $10 \mathrm{uT}$; esta região otimizada é definida para valores de $\mathrm{pH}$ entre 5,80 e 7,23, e valores de dosagens do coagulante cloreto férrico entre $110 \mathrm{mg} / \mathrm{l} \mathrm{e}$ $282 \mathrm{mg} / \mathrm{l}$. 
TABELA 5.6 - Regiões dos Diagramas de Coagulação com Cloreto Férrico e Valores de Cor Aparente Remanescente - Água Tipo II

\begin{tabular}{|c|c|c|c|c|c|c|c|c|c|c|}
\hline 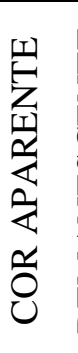 & 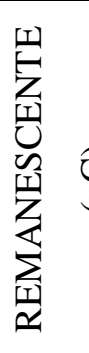 & $\stackrel{0}{\Xi}$ & 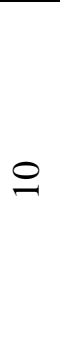 & $\stackrel{n}{n}$ & กิ & $\stackrel{0}{=}$ & $\underline{n}$ & \multirow{5}{*}{\multicolumn{3}{|c|}{ 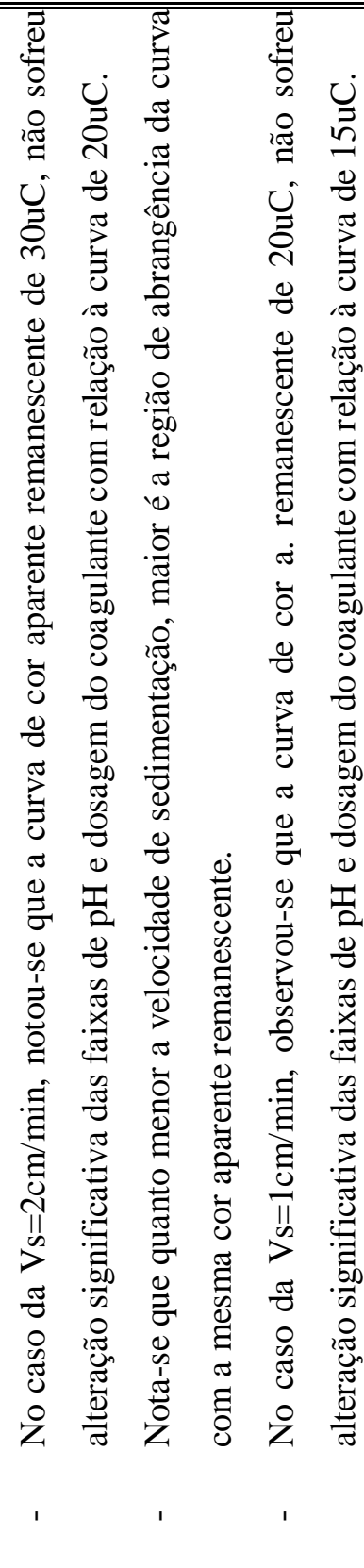 }} \\
\hline 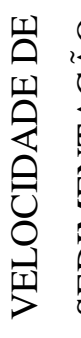 & 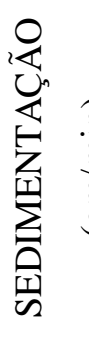 & 氞 & $\sim$ & $N$ & $N$ & - & - & & & \\
\hline 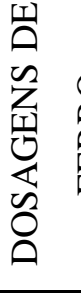 & $\begin{array}{l}0 \\
0 \\
\frac{a}{a} \\
\frac{\pi}{I} \\
-1\end{array}$ & $\begin{array}{l}\overparen{\delta} \\
\text { II } \\
0 \\
0 \\
00 \\
\Xi\end{array}$ & 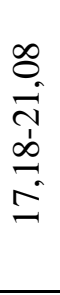 & 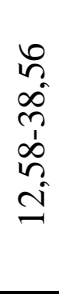 & 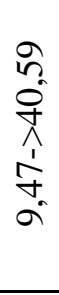 & $\begin{array}{l}\text { ते } \\
\infty \\
i \\
i \\
\vdots \\
\dot{I}\end{array}$ & $\begin{array}{l}\hat{n} \\
\hat{o} \\
\hat{1} \\
\hat{1} \\
\infty \\
\infty \\
\infty\end{array}$ & & & \\
\hline 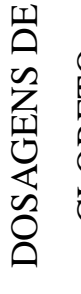 & 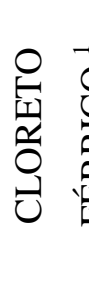 & 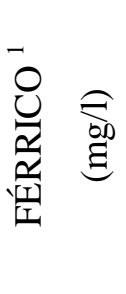 & $\frac{\infty}{\frac{\infty}{1}}$ & 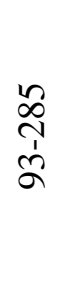 & $\begin{array}{l}8 \\
\stackrel{0}{\hat{~}} \\
\hat{2}\end{array}$ & $\begin{array}{l}\text { D. } \\
\text { 1 } \\
\infty \\
0 \\
0\end{array}$ & $\begin{array}{l}\stackrel{8}{\infty} \\
\hat{\hat{1}} \\
\hat{b}\end{array}$ & & & \\
\hline 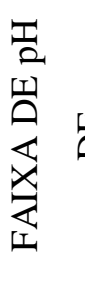 & 峲 & 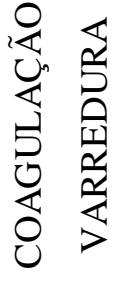 & 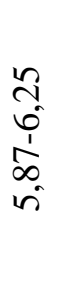 & $\begin{array}{l}n \\
n \\
0 \\
1 \\
\infty \\
\infty \\
n\end{array}$ & $\begin{array}{l}\frac{n}{i} \\
\frac{i}{+} \\
\dot{r}\end{array}$ & \begin{tabular}{l}
$n$ \\
\multirow{1}{n}{} \\
$\frac{1}{\infty}$ \\
$n$
\end{tabular} & $\begin{array}{l}\frac{1}{2} \\
\frac{1}{\infty} \\
i \\
i\end{array}$ & & & \\
\hline 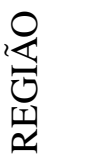 & & & $\ll$ & $\varphi$ & $U$ & $\theta$ & 피 & OBSE & ERVAÇ & ÕES \\
\hline
\end{tabular}

\footnotetext{
${ }^{1}$ produto comercial com $39,30 \%$ de $\mathrm{FeCl}_{3}$.
} 


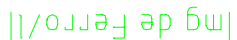

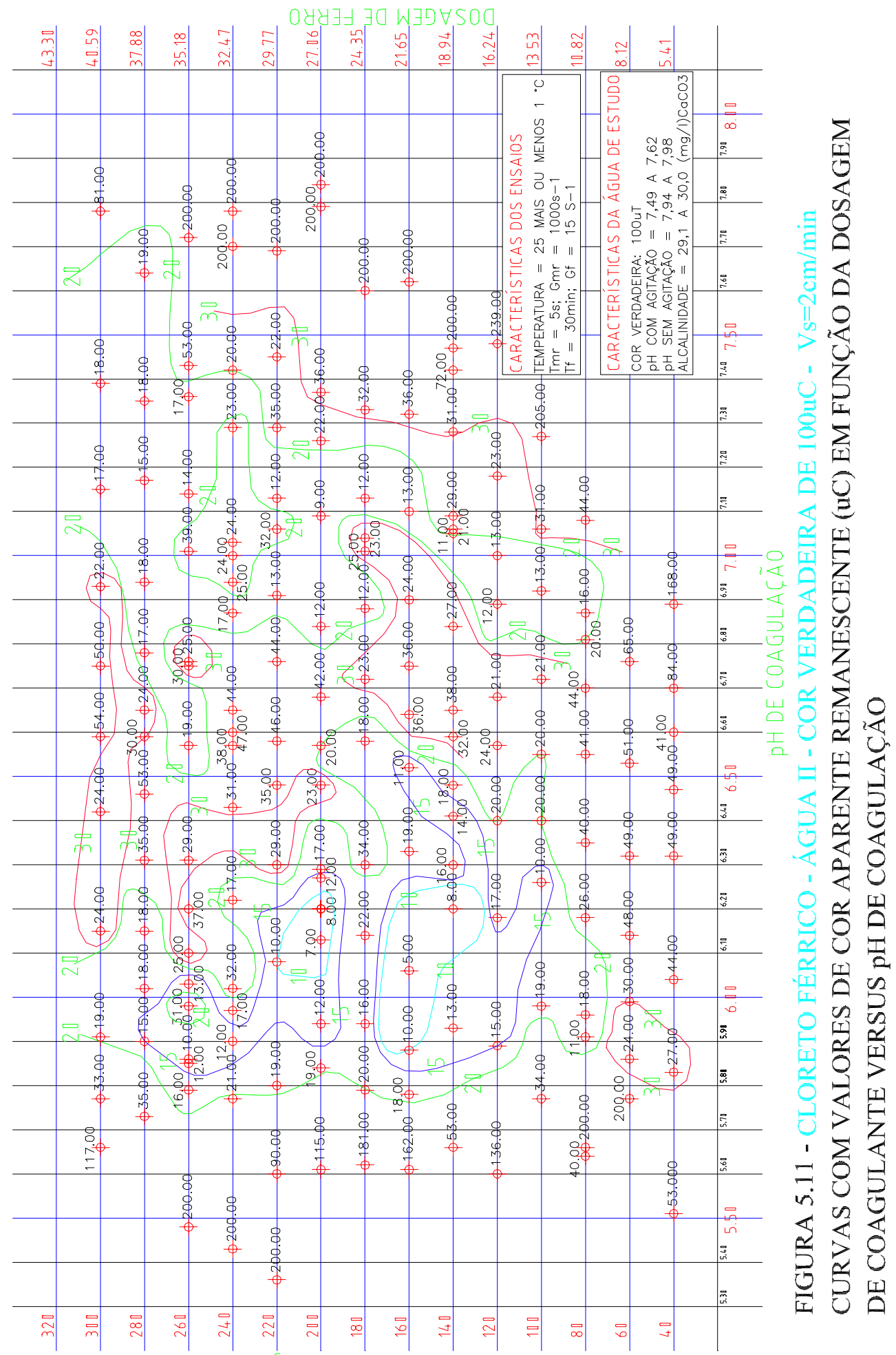

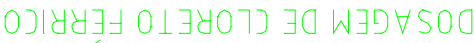


$\mid 7 / 0\lrcorner\lrcorner \partial \sqsupset \partial p 6 \uplus \mid$

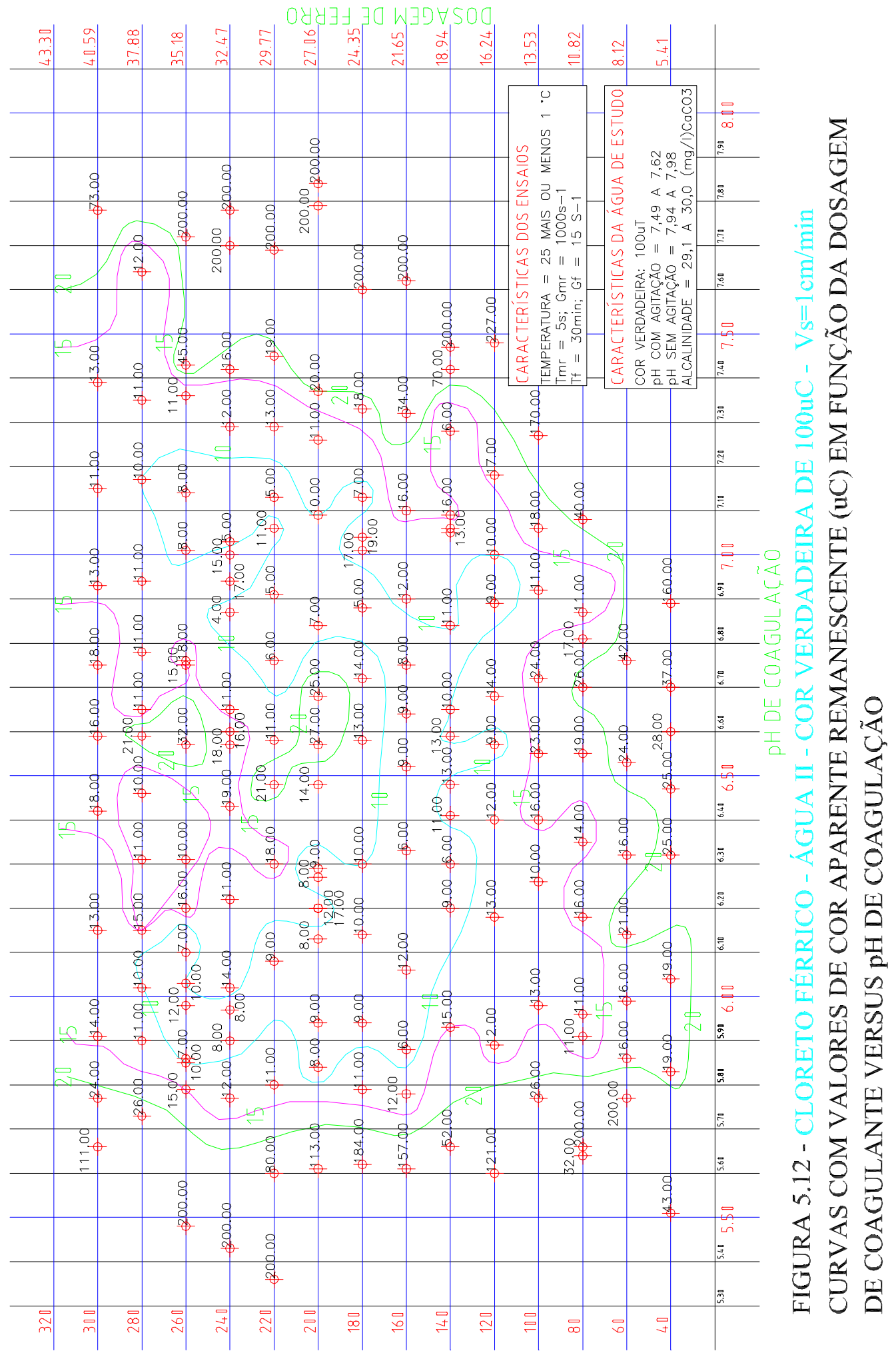




\subsubsection{DIAGRAMA DE COAGULAÇÃO DO HIDROXICLORETO DE ALUMÍNIO}

Na remoção de cor, as curvas de cor aparente remanescente apresentam valores maiores que as curvas de cor aparente remanescente.

Pode-se verificar na FIGURA 5.13 que a curva com menor cor aparente remanescente é de 10 uT, e na FIGURA 5.14, a curva com menor cor aparente remanescente é de 5 uT.

A TABELA 5.7 fornece os resultados das faixas otimizadas de $\mathrm{pH}$ e cor aparente remanescente para velocidades de sedimentação de $2 \mathrm{~cm} / \mathrm{min}$ e $1 \mathrm{~cm} / \mathrm{min}$.

O hidroxicloreto de alumínio apresentou as regiões com maior remoção de cor aparente do que os outros coagulantes.

Na FIGURA 5.13, a região com menores valores de cor aparente remanescente está delimitada pela curva com valor de $10 \mathrm{uT}$; esta região otimizada é definida para valores de $\mathrm{pH}$ entre 6,48 e 7,17, e valores de dosagens do coagulante hidroxicloreto de alumínio entre $240 \mathrm{mg} / \mathrm{l}$ e valores maiores que $220 \mathrm{mg} / \mathrm{l}$.

Para a FIGURA 5.14, a região com menores valores de cor aparente remanescente está delimitada pela curva com valor de 5uT; esta região otimizada é definida para valores de $\mathrm{pH}$ entre 6,50 e 7,12, e valores de dosagens do coagulante hidroxicloreto de alumínio entre 250 $\mathrm{mg} / \mathrm{l}$ e valores maiores que $320 \mathrm{mg} / \mathrm{l}$. 
TABELA 5.7 - Regiões dos Diagramas de Coagulação com Hidroxicloreto de Alumínio e Valores de Cor Aparente Remanescente - Água Tipo II

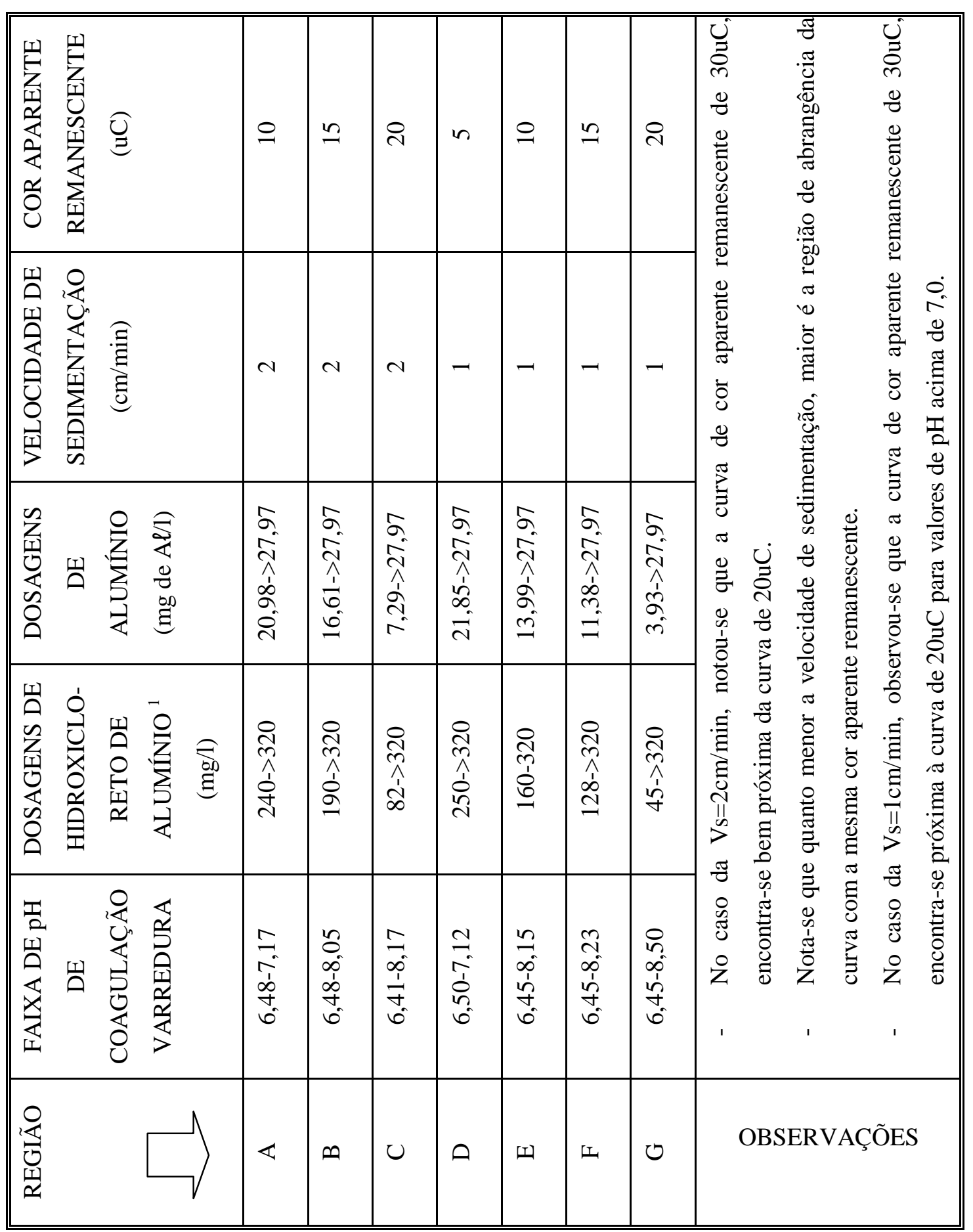

\footnotetext{
${ }^{1}$ produto comercial com $16,80 \%$ de $\mathrm{Al}_{2} \mathrm{O}_{3}$.
} 


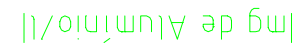

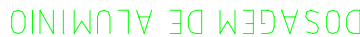

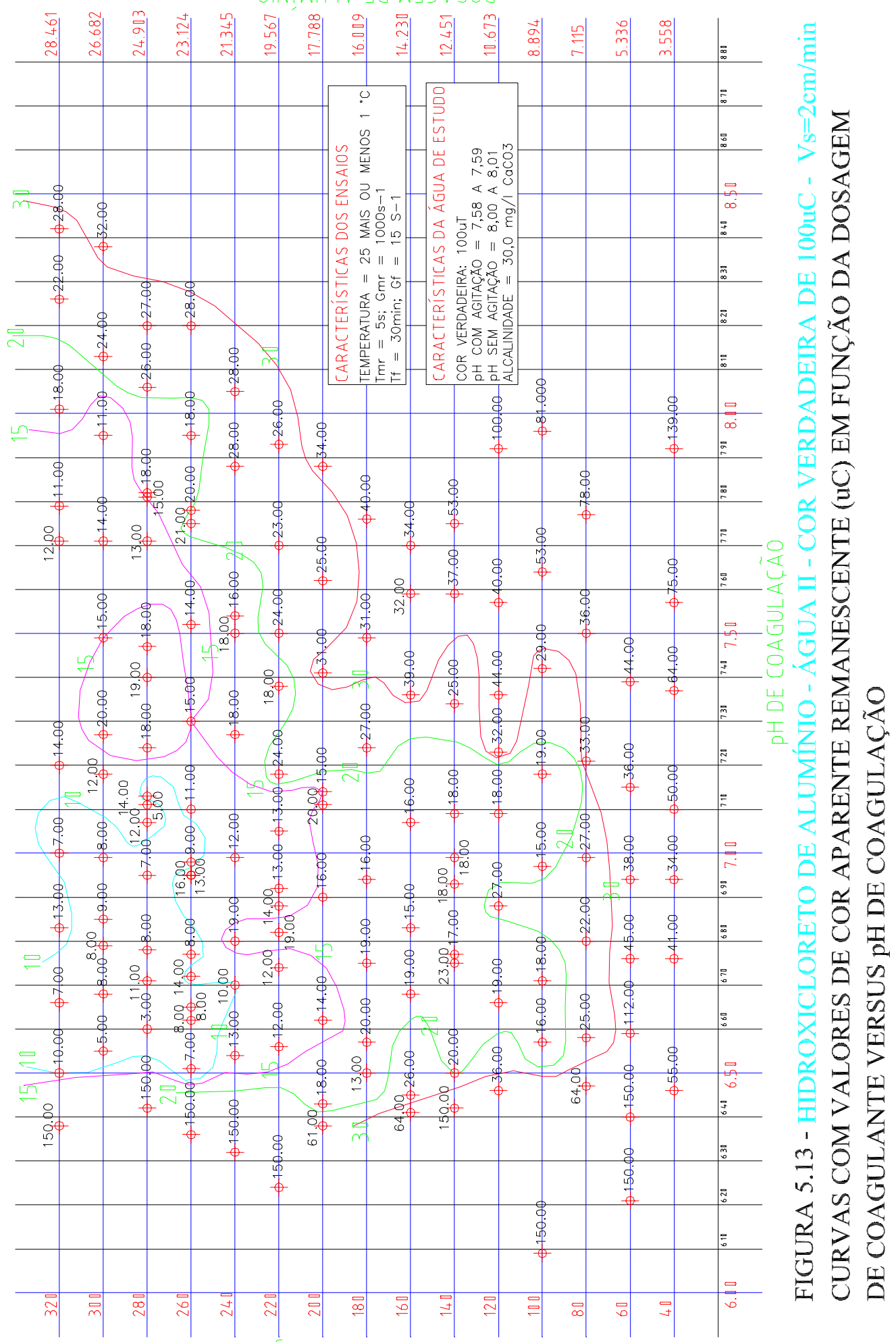

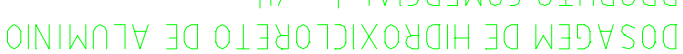


I/OIUIயก। $\forall$ әр $6 \uplus$

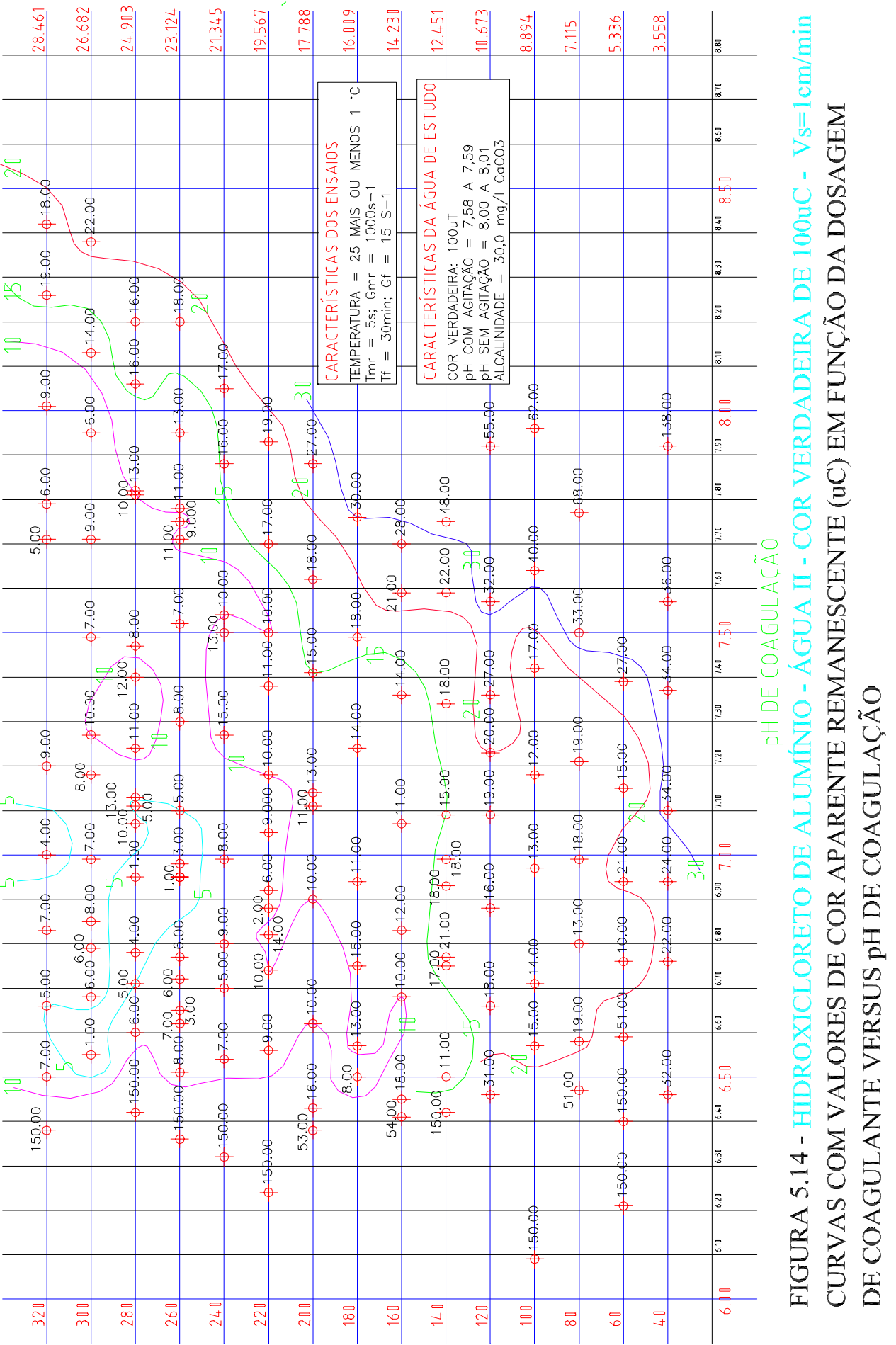

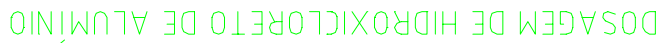




\subsubsection{DIAGRAMA DE COAGULAÇÃO DO SULFATO FÉRRICO}

Este coagulante trabalha com intervalos de $\mathrm{pH}$ extensos, porém com valores de $\mathrm{pH}$ mais baixos que os dos outros coagulantes.

Pode-se verificar na FIGURA 5.15 que a curva com menor cor aparente remanescente é de 35 uC, e na FIGURA 5.16, que a curva com menor cor aparente remanescente é de 20 uT.

A TABELA 5.8 fornece os resultados das faixas otimizadas de $\mathrm{pH}$ e cor aparente remanescente para velocidades de sedimentação de $2 \mathrm{~cm} / \mathrm{min}$ e $1 \mathrm{~cm} / \mathrm{min}$.

Com relação aos outros diagramas, verifica-se que as curvas na FIGURA 5.16 apresentam-se esparsas, sendo por isso melhor visualizadas na figura que na TABELA 5.8.

O sulfato férrico apresentou as regiões com menor remoção de cor aparente do que os outros coagulantes.

Na FIGURA 5.15, as regiões com menores valores de cor aparente remanescente são delimitadas pelas curvas com valor de $35 \mathrm{uT}$; estas regiões otimizadas são definidas para valores de $\mathrm{pH}$ entre 6,20 e 7,48, e valores de dosagens do coagulante sulfato férrico entre 30 $\mathrm{mg} / \mathrm{l}$ e $258 \mathrm{mg} / \mathrm{l}$.

Para a FIGURA 5.16, as regiões com menores valores de cor aparente remanescente são delimitadas pelas curvas com valor de 20uT; estas regiões otimizadas são definidas para valores de $\mathrm{pH}$ entre 4,75 e 7,18, e dosagens do coagulante sulfato férrico, desde valores abaixo de $20 \mathrm{mg} / \mathrm{l}$ até o valor $217 \mathrm{mg} / \mathrm{l}$. 
TABELA 5.8 - Regiões dos Diagramas de Coagulação com Sulfato Férrico e Valores de Cor Aparente Remanescente - Água Tipo II

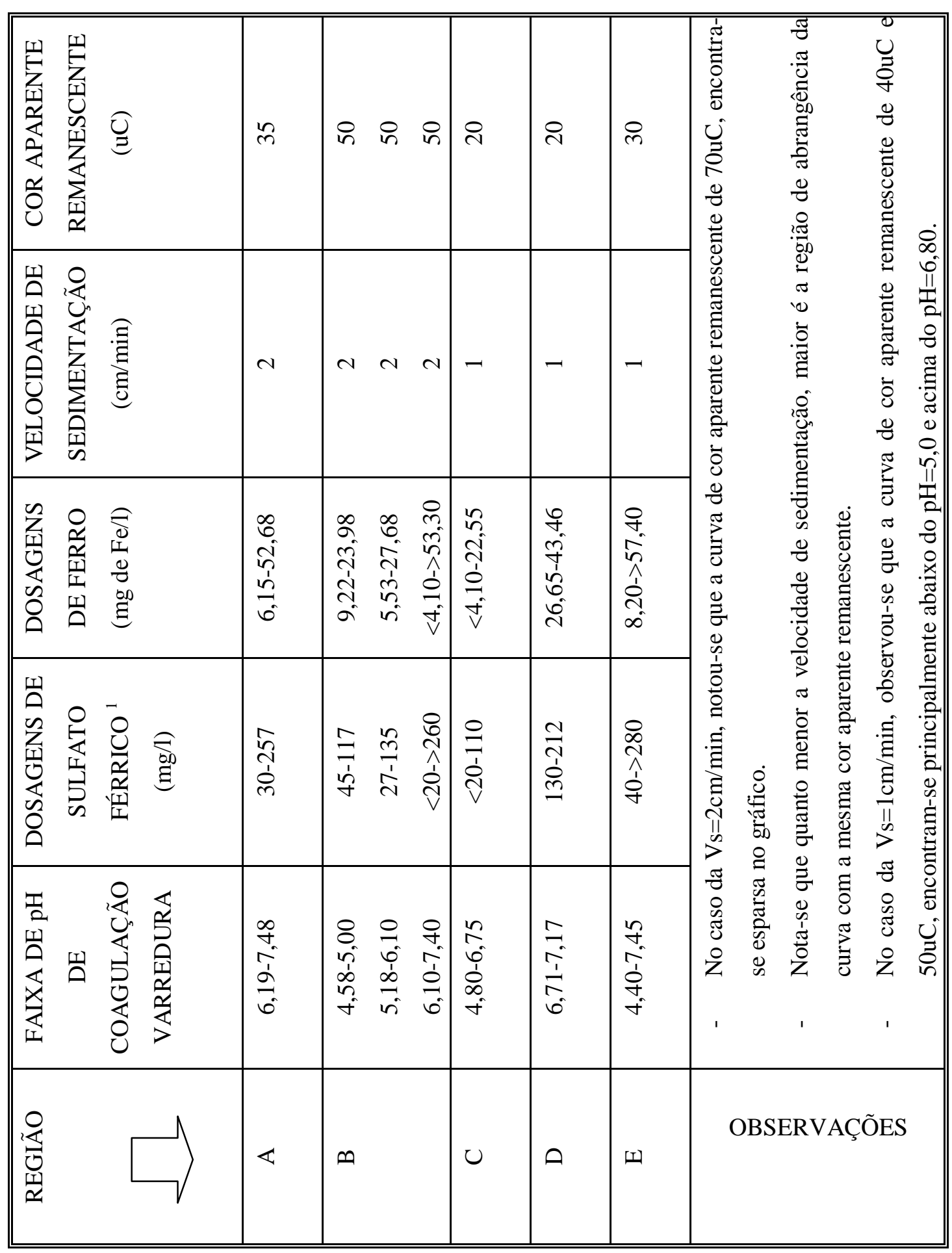

${ }^{1}$ produto comercial com $20,53 \%$ de FeIII . 


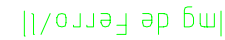

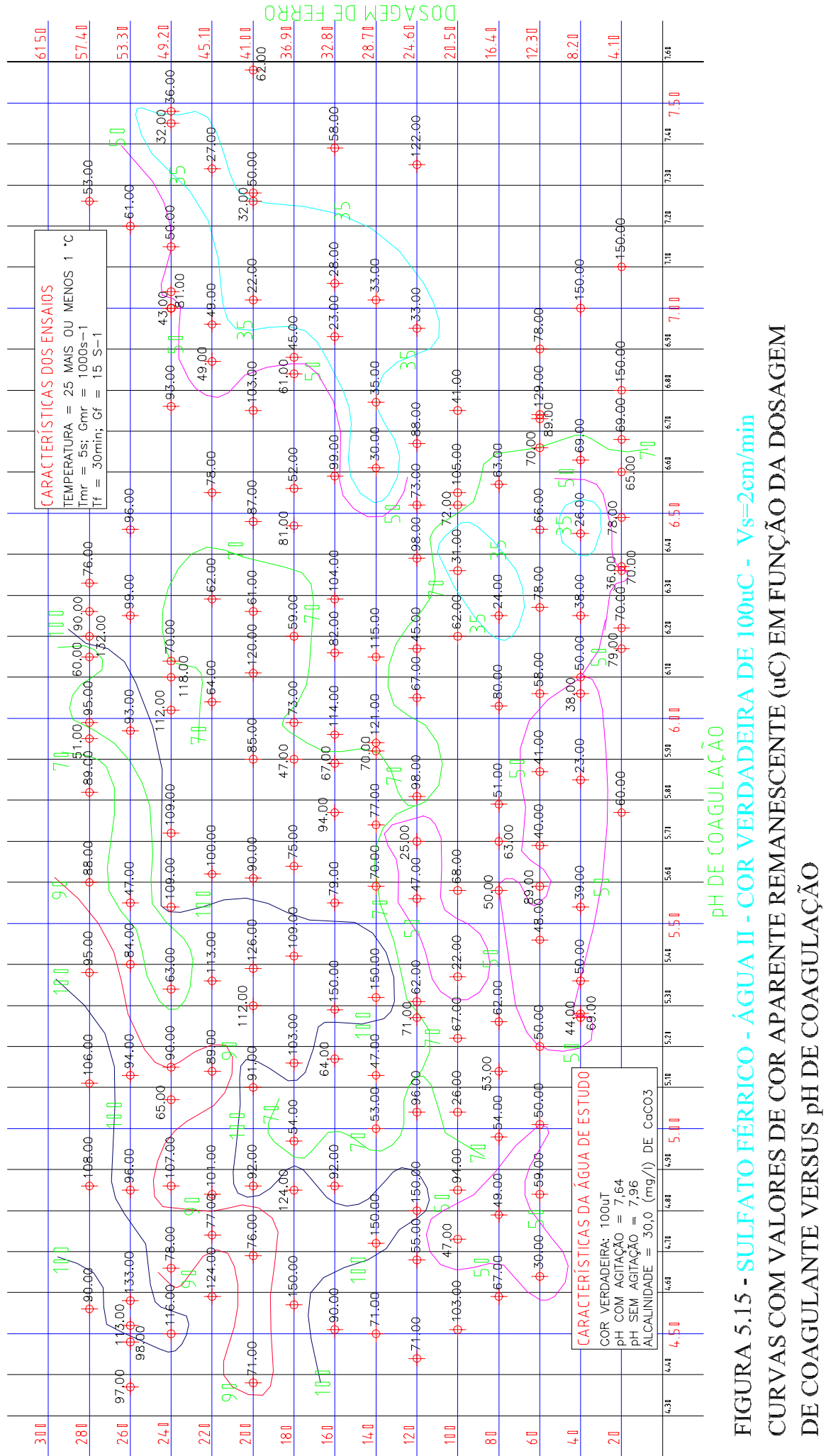

ojydy $0 \perp \forall \exists 7 n s \exists 0$ W 
Џ 0$\lrcorner\lrcorner \partial \dashv \partial р$ Бய

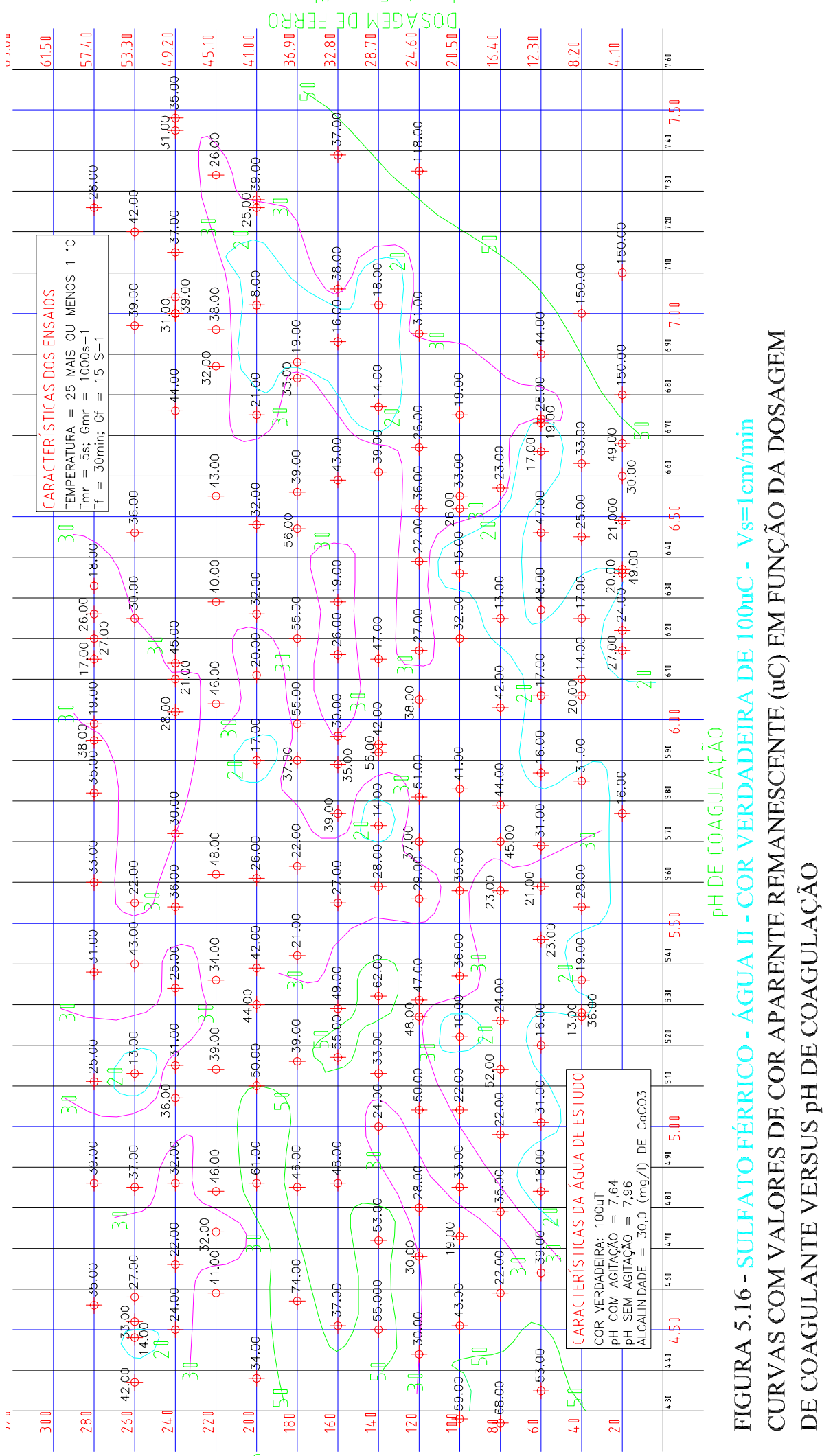

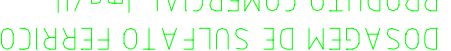




\subsection{CUSTOS}

Os custos dos coagulantes e alcalinizante da TABELA 5.9 foram fornecidos pelo setor de Aquisição de Materiais (USMA) da Companhia de Saneamento do Paraná - SANEPAR, com exceção do Hidroxicloreto de Alumínio, cujo preço foi fornecido pelo representante da Indústria PAN AMERICANA S.A.

TABELA 5.9 - Preços dos coagulantes e do alcalinizante

\begin{tabular}{|l|c|c|}
\hline \multicolumn{1}{|c|}{$\begin{array}{c}\text { Descrição do coagulante } \\
\text { Posto em Curitiba/PR }\end{array}$} & \multicolumn{2}{c|}{$\begin{array}{c}\text { Preço por tonelada } \\
\text { Mês ref. Fev/2001 }\end{array}$} \\
\cline { 2 - 3 } & REAIS - R\$ & DÓLAR - U\$ (*) \\
\hline Sulfato de Alumínio Líquido & 137,00 & 68,84 \\
\hline Cloreto Férrico líquido & 290,00 & 145,73 \\
\hline Hidróxicloreto de Alumínio & 600,00 & 301,51 \\
\hline Sulfato Férrico & 200,00 & 100,50 \\
\hline Hidróxido de sódio & 670,00 & 336,68 \\
\hline
\end{tabular}

(*) - valor considerado para o dólar fev/2001 - R \$1,99.

A tabela acima fornece os custos dos produtos químicos sem as especificações técnicas dos mesmos; no entanto, tal especificação é importante na determinação de limitações de elemento ativo na coagulação, quantidades limites de metais pesados, quantidade de impurezas, acidez livre, entre outras.

Além dos custos constantes da TABELA 5.9, numa ETA devemos também considerar outros custos, tais como: a especificação técnica do produto, o transporte, o preparo da solução/diluição, o armazenamento, a forma de dosagem, a metodologia de dosagens, otimizações dos parâmetros básicos da ETA, entre outras.

Nos diagramas de coagulação, procurou-se tomar coordenadas próximas ao intervalo de $\mathrm{pH}$ de 6,50 a 8,50 para atender aos padrões de potabilidade. Além das coordenadas consideradas nas TABELAS 5.10, 5.11, 5.12 e 5.13 para composição dos custos, outras coordenadas que tinham probabilidade de terem custo menor, também foram verificadas para confirmação de que o menor custo levantado, correspondesse o mais próximo possível da realidade, porém, 
este estudo não esgotou em absoluto às discussões sobre o assunto devido a sua complexidade de suas variáveis envolvidas.

\subsubsection{AVALIAÇÃO DE CUSTOS PARA ÁGUA TIPO I}

TABELA 5.10 - Composição de Custos para Água Tipo I com Vs=4cm/min e Turbidez Remanescente $\leqslant 5 \mathrm{uT}$.

\begin{tabular}{|c|c|c|c|c|c|}
\hline \multirow[t]{2}{*}{$\begin{array}{l}\text { COAGU- } \\
\text { LANTE }\end{array}$} & \multirow[t]{2}{*}{$\begin{array}{c}\text { pH de } \\
\text { coagulação }\end{array}$} & \multirow{2}{*}{$\begin{array}{c}\text { Dosagem de } \\
\text { Coagulante } \\
(\mathrm{mg} / \mathrm{l})\end{array}$} & \multirow{2}{*}{$\begin{array}{l}\text { Consumo de } \\
\text { Alcalinizante } \\
\qquad(\mathrm{mg} / \mathrm{l})\end{array}$} & \multicolumn{2}{|c|}{$\begin{array}{c}\text { Custo total (R\$) } \\
\text { Para } 1000 \mathrm{~m}^{3}\end{array}$} \\
\hline & & & & REAIS - R\$ & DÓLAR - U\$ \\
\hline SA líquido & 6,90 & 60 & 2,0 & 9,56 & 4,80 \\
\hline CF líquido & 6,50 & 35 & 0,0 & 10,15 & 5,10 \\
\hline $\mathrm{HCA}$ & 7,10 & 20 & 1,5 & 13,00 & 6,53 \\
\hline SF líquido & 6,60 & 20 & 1,0 & 4,67 & 2,35 \\
\hline
\end{tabular}

TABELA 5.11 - Composição de Custos para Água Tipo I com Vs=2cm/min e Turbidez Remanescente $\leqslant 5 \mathrm{uT}$.

\begin{tabular}{|c|c|c|c|c|c|}
\hline \multirow[t]{2}{*}{$\begin{array}{l}\text { COAGU- } \\
\text { LANTE }\end{array}$} & \multirow[t]{2}{*}{$\begin{array}{c}\text { pH de } \\
\text { coagulação }\end{array}$} & \multirow{2}{*}{$\begin{array}{c}\text { Dosagem de } \\
\text { Coagulante } \\
(\mathrm{mg} / \mathrm{l})\end{array}$} & \multirow{2}{*}{$\begin{array}{c}\text { Consumo de } \\
\text { Alcalinizante } \\
(\mathrm{mg} / \mathrm{l})\end{array}$} & \multicolumn{2}{|c|}{$\begin{array}{c}\text { Custo total }(\mathrm{R} \$) \\
\text { Para } 1000 \mathrm{~m}^{3}\end{array}$} \\
\hline & & & & REAIS - R \$ & DÓLAR - U\$ \\
\hline SA líquido & 7,05 & 40 & 2,5 & 7,16 & 3,60 \\
\hline CF líquido & 6,90 & 25 & 0,0 & 7,25 & 3,64 \\
\hline HCA & 7,10 & 15 & 0,0 & 9,00 & 4,52 \\
\hline SF líquido & 6,80 & 15 & 0,5 & 3,34 & 1,68 \\
\hline
\end{tabular}

\subsubsection{AVALIAÇÃO DOS CUSTOS PARA ÁGUA TIPO II.}

Analogamente ao procedimento adotado para Água Tipo I, constroem-se as TABELA $5.12 \mathrm{e}$ TABELA 5.13. 
TABELA 5.12 - Composição de Custos para Água Tipo II com Vs=2cm/min e Cor aparente aparente Remanescente $\leqslant 35 \mathrm{uT}$.

\begin{tabular}{|c|c|c|c|c|c|}
\hline \multirow[t]{2}{*}{$\begin{array}{l}\text { COAGU- } \\
\text { LANTE }\end{array}$} & \multirow[t]{2}{*}{$\begin{array}{c}\text { pH de } \\
\text { coagulação }\end{array}$} & \multirow{2}{*}{$\begin{array}{c}\text { Dosagem de } \\
\text { Coagulante } \\
(\mathrm{mg} / \mathrm{l})\end{array}$} & \multirow{2}{*}{$\begin{array}{c}\text { Consumo de } \\
\text { Alcalinizante } \\
\text { (mg/l) }\end{array}$} & \multicolumn{2}{|c|}{$\begin{array}{c}\text { Custo total }(\mathrm{R} \$) \\
\text { Para } 1000 \mathrm{~m}^{3}\end{array}$} \\
\hline & & & & REAIS - R \$ & DÓLAR - U\$ \\
\hline SA líquido & 6,60 & 260 & 37 & 60,41 & 30,36 \\
\hline CF líquido & 6,90 & 90 & 20 & 39,50 & 19,85 \\
\hline $\mathrm{HCA}$ & 6,70 & 80 & 11 & 55,37 & 27,82 \\
\hline SF líquido & 7,00 & 130 & 47 & 57,49 & 28,89 \\
\hline
\end{tabular}

TABELA 5.13 - Composição de Custos para Água Tipo II com Vs=1cm/min e Cor aparente Remanescente $\leqslant 20 \mathrm{uT}$.

\begin{tabular}{|c|c|c|c|c|c|}
\hline \multirow[t]{2}{*}{$\begin{array}{l}\text { COAGU- } \\
\text { LANTE }\end{array}$} & \multirow[t]{2}{*}{$\begin{array}{c}\mathrm{pH} \text { de } \\
\text { coagulação }\end{array}$} & \multirow{2}{*}{$\begin{array}{c}\text { Dosagem de } \\
\text { Coagulante } \\
(\mathrm{mg} / \mathrm{l})\end{array}$} & \multirow{2}{*}{$\begin{array}{c}\text { Consumo de } \\
\text { Alcalinizante } \\
\text { (mg/l })\end{array}$} & \multicolumn{2}{|c|}{$\begin{array}{c}\text { Custo total }(\mathrm{R} \$) \\
\text { Para } 1000 \mathrm{~m}^{3}\end{array}$} \\
\hline & & & & REAIS - R\$ & DÓLAR - U\$ \\
\hline SA líquido & 6,95 & 270 & 44 & 66,67 & 33,50 \\
\hline CF líquido & 6,40 & 60 & 6,5 & 21,76 & 10,93 \\
\hline $\mathrm{HCA}$ & 6,80 & 60 & 6,5 & 40,36 & 20,28 \\
\hline SF líquido & 6,40 & 80 & 22 & 30,74 & 15,45 \\
\hline
\end{tabular}

\subsubsection{ANÁLISE DOS CUSTOS}

Para remoção de turbidez, o Sulfato Férrico Líquido apresentou menor custo que os outros coagulantes, como pode ser observado nos resultados constantes nas TABELAS 5.10, 5.11.

$\mathrm{O}$ valor limite de turbidez remanescente $\leqslant 5 \mathrm{uT}$ para as curvas dos diagramas de coagulação da água tipo I, pode ser atendida por todos os coagulantes na composição dos custos, mas, para água tipo II, foi necessário limitar o valor da curva de menor cor aparente remanescente, a qual todos os diagramas de coagulação pudessem atender, assim, para cada velocidade de 
sedimentação foi necessário um valor, no caso, para $\mathrm{Vs}=2 \mathrm{~cm} / \mathrm{min}$ o valor da curva de Cor aparente Remanescente foi $\leqslant 35 \mathrm{uT}$, e para Vs=1 $\mathrm{cm} / \mathrm{min}$ o valor da curva de Cor aparente Remanescente foi $\leqslant 20 \mathrm{uT}$.

Para remoção de cor aparente, os menores custos foram apresentados pelo Cloreto Férrico Líquido, como demonstrados nas TABELA 5.12 e 5.13. 


\section{CONCLUSÕES E RECOMENDAÇÕES}

\subsection{CONCLUSÕES:}

Neste trabalho de pesquisa, chegou-se às seguintes conclusões:

a) Em equipamento estático pode-se determinar, para uma água qualquer, valores de pH e dosagens para um coagulante, visando à otimização destes parâmetros.

b) A utilização do diagrama de coagulação como uma ferramenta tem se mostrado de grande utilidade para definir nele regiões otimizadas de turbidez ou cor remanescentes.

c) Pode-se conseguir uma grande economia no consumo de produtos químicos para o tratamento de água, quando se estuda, com os coagulantes disponíveis, os intervalos de $\mathrm{pH}$ e dosagens otimizados através dos diagramas de coagulação.

d) Comparando os diagramas de coagulação para os diversos coagulantes estudados, verificou-se que:

- Nem sempre grandes dosagens proporcionarão uma grande remoção de turbidez ou cor remanescente.

- Observando-se os intervalos de pH ótimos para a água tipo I (remoção de turbidez), nota-se que o cloreto e o sulfato férrico tiveram melhores desempenhos para intervalos de valores de $\mathrm{pH}$ baixos (ver TABELA 6.1). 
TABELA 6.1 - Intervalos de pH ótimos para água tipo I.

\begin{tabular}{|c|c|}
\hline COAGULANTE & INTERVALOS DE PH ÓTIMOS \\
\hline SA & 6,64 a 7,17 \\
\hline CF & 5,90 a 6,71 \\
\hline HCA & 6,85 a 7,30 \\
\hline SF & 4,77 a 6,65 \\
\hline
\end{tabular}

- Já para água tipo II (remoção de cor) nos Intervalos de pH ótimos observados, foram obtidos melhores resultados com o cloreto férrico em valores baixos de $\mathrm{pH}$ (ver TABELA 6.2). Os grupos funcionais ou a massa molar das moléculas do ácido húmico usado podem ter concorrido para esse fato, embora esse aspecto não tivesse sido estudado.

TABELA 6.2 - Intervalos de pH ótimos para água tipo II.

\begin{tabular}{|c|c|}
\hline COAGULANTE & INTERVALOS DE PH ÓTIMOS \\
\hline SA & 6,43 a 6,82 \\
\hline CF & 5,87 a 6,25 \\
\hline HCA & 6,50 a 7,12 \\
\hline SF & $6,19-7,17$ \\
\hline
\end{tabular}

- Para água tipo I (turbidez elevada) com o coagulante HCA, pode-se trabalhar com uma grande faixa de $\mathrm{pH}$, sem que com isso houvesse perda significativa de eficiência na remoção de turbidez.

- Na água tipo II (cor elevada), observando-se o gráfico de dosagem versus $\mathrm{pH}$ do SF, é notado uma grande variação de posições das regiões delimitadas pelas curvas de mesma cor aparente remanescente. 
e) Através dos diagramas, pode-se observar que as regiões com melhor remoção de turbidez ou cor definem claramente intervalos de $\mathrm{pH}$ e dosagens para o coagulante estudado; também, quanto menor a velocidade de sedimentação, maior será a região delimitada no diagrama de coagulação pela curva de mesmo valor de turbidez ou cor remanescente.

f) O hidróxicloreto de alumínio apresenta uma grande faixa de $\mathrm{pH}$ com grande remoção de turbidez e/ou de cor, principalmente de turbidez, porém CINTRA et al (1995), conclui que acima do valor de $\mathrm{pH}=7,3$ resulta em alumínio solúvel na água tratada.

\subsection{RECOMENDAÇÕES:}

No decorrer da pesquisa ocorreram dificuldades, para apoio de futuros estudos que tenham alguma afinidade com este trabalho, seguem algumas recomendações a fim de evitar tais dificuldades:

a) Na preparação das águas, deve-se atentar para o volume preparado, trabalhando com uma margem de segurança, para que posteriormente não haja falta da água de estudo, impossibilitando assim a execução dos ensaios finais.

b) Para dar cor artificialmente com o ácido húmico, deve-se fazer a adição de ácido na água "lentamente", controlando os valores da cor aparente e verdadeira até o resultado desejado.

c) Para comprovação dos dados otimizados, deve-se fazer uma reprodução dos mesmos, utilizando as mesmas dosagens, a fim de comprovar os resultados.

E para finalizar este trabalho, seguem alguns comentários:

d) Cada ETA e cada água bruta possuem características ímpares, portanto, o melhor coagulante será aquele que atender as necessidades econômicas. 
e) O coagulante adquirido em forma de líquido fornece melhores condições de operação, simplificam o armazenamento, a diluição, e elimina alguns problemas de insalubridade para aquelas pessoas que manuseiam o produto, devendo, no entanto, ser considerada a distância do transporte que tem sua influência no custo do produto. 
ANEXO - A

ENSAIOS DO REATOR ESTÁTICO - ÁGUA I PARA O COAGULANTE

SULFATO DE ALUMÍNIO 
ESTUDO DE COAGULAÇÃO-FLOCULAÇÃO-SEDIMENTAÇÃO

\begin{tabular}{|c|c|c|c|c|c|c|c|c|}
\hline \multirow{2}{*}{\multicolumn{2}{|c|}{$\begin{array}{l}\text { ENSAIO N }{ }^{\circ}: 01 \\
\text { Data : } 01 / 02 / 00\end{array}$}} & \multirow{2}{*}{\multicolumn{2}{|c|}{$\begin{array}{l}\text { COAGULANTE } \\
\text { Sulfato Alumínio }\end{array}$}} & \multicolumn{3}{|c|}{ MISTURA RÁPIDA } & \multicolumn{2}{|c|}{ FLOCULAÇÃO } \\
\hline & & & & $\mathrm{Tmr}=10 \mathrm{~s}$ & \multicolumn{2}{|c|}{ Gmr $=1000 \mathrm{~s}^{-1}$} & $\mathbf{T f}=\mathbf{2 0} \mathrm{min}$ & $\mathbf{G f}=25 \mathrm{~s}^{-1}$ \\
\hline \multicolumn{9}{|c|}{ CARACTERÍSTICAS DA ÁGUA DE ESTUDO } \\
\hline \multirow{2}{*}{\multicolumn{2}{|c|}{ Turbidez (uT) }} & \multirow{2}{*}{\multicolumn{2}{|c|}{$\begin{array}{c}\text { Alcalinidade Total } \\
\left(\mathrm{mg} / \ell \mathrm{CaCO}_{3}\right)\end{array}$}} & \multirow{2}{*}{\multicolumn{2}{|c|}{ pH }} & \multirow{2}{*}{\multicolumn{2}{|c|}{$\begin{array}{c}\text { Temperatura } \\
{ }^{\circ} \mathrm{C}\end{array}$}} & \multirow{2}{*}{$\begin{array}{l}\text { Potencial } \\
\text { Zeta }(\mathrm{mV})\end{array}$} \\
\hline & & & & & & & & \\
\hline \multicolumn{2}{|c|}{102} & \multicolumn{2}{|c|}{29} & 8.02 & 7.81 & \multicolumn{2}{|r|}{25} & - \\
\hline \multirow{2}{*}{ FRASCO } & \multicolumn{4}{|c|}{ DOSAGEM DE PRODUTO QUÍMICO } & \multirow{2}{*}{$\begin{array}{c}\text { pH } \\
\text { de } \\
\text { Coagulação }\end{array}$} & \multirow{2}{*}{\multicolumn{2}{|c|}{$\begin{array}{c}\mathrm{T}_{\mathrm{s1}}=1,75 \mathrm{~min} \\
\mathrm{~V}_{\mathrm{s1}}=4.0 \mathrm{~cm} / \mathrm{min} \\
\begin{array}{c}\text { Turbidez } \\
\text { (uT) }\end{array}\end{array}$}} & \multirow{2}{*}{$\begin{array}{c}T_{\mathrm{s} 2}=3.50 \mathrm{~min} \\
\mathrm{~V}_{\mathrm{s} 2}=2.0 \mathrm{~cm} / \mathrm{min} \\
\begin{array}{c}\text { Turbidez } \\
\text { (uT) }\end{array}\end{array}$} \\
\hline & \multicolumn{2}{|c|}{$\begin{array}{c}\text { Sulfato de } \\
\text { Alumínio } \\
(\mathrm{mg} / \mathfrak{l})\end{array}$} & $\begin{array}{c}\text { Ácido } \\
\text { Clorídrico } \\
0.1 \mathrm{~N}(\mathrm{m \ell} / \mathrm{l})\end{array}$ & $\begin{array}{l}\text { Hidróxido de } \\
\text { Sódio } 0.1 \mathrm{~N} \\
(\mathrm{~m} \ell / \ell)\end{array}$ & & & & \\
\hline 1 & \multicolumn{2}{|c|}{10.0} & - & - & 7.31 & & 95.9 & 93.2 \\
\hline 2 & \multicolumn{2}{|c|}{12.5} & - & - & 7.24 & & 94.0 & 88.5 \\
\hline 3 & \multicolumn{2}{|c|}{15.0} & - & - & 7.20 & & 84.8 & 72.0 \\
\hline 4 & \multicolumn{2}{|c|}{17.5} & - & - & 7.16 & & 68.7 & 30.5 \\
\hline 5 & \multicolumn{2}{|c|}{20.0} & - & - & 7.08 & & 46.3 & 25.9 \\
\hline 6 & & 2.5 & - & - & 7.02 & & 34.5 & 16.8 \\
\hline
\end{tabular}

\section{ESTUDO DE COAGULAÇÃO-FLOCULAÇÃO-SEDIMENTAÇÃO}

\begin{tabular}{|c|c|c|c|c|c|c|}
\hline \multirow{2}{*}{$\begin{array}{l}\text { ENSAIO No: } 02 \\
\text { Data : } 02 / 02 / 00\end{array}$} & \multirow{2}{*}{$\begin{array}{l}\text { COAGULANTE } \\
\text { Sulfato de Alumíni }\end{array}$} & \multicolumn{3}{|c|}{ MISTURA RÁPIDA } & \multicolumn{2}{|c|}{ FLOCULAÇÃO } \\
\hline & & $\mathrm{Tmr}=10 \mathrm{~s}$ & $\mathbf{G m}$ & & $T f=20 \mathrm{~min}$ & Gf $=25 \mathrm{~s}^{-1}$ \\
\hline \multicolumn{7}{|c|}{ CARACTERÍSTICAS DA ÁGUA DE ESTUDO } \\
\hline \multirow{2}{*}{ Turbidez (uT) } & \multirow{2}{*}{$\begin{array}{l}\text { Alcalinidade Total } \\
\left(\mathrm{mg} / \ell \mathrm{CaCO}_{3}\right)\end{array}$} & \multicolumn{2}{|c|}{ pH } & \multirow{2}{*}{\multicolumn{2}{|c|}{$\begin{array}{c}\text { Temperatura } \\
{ }^{\circ} \mathrm{C} \\
\end{array}$}} & \multirow{2}{*}{$\begin{array}{r}\text { Potencial } \\
\text { Zeta }(\mathrm{mV})\end{array}$} \\
\hline & & S/ agit. & $\mathrm{C} /$ agit. & & & \\
\hline 102 & 29 & 8.02 & 7.81 & & 25 & - \\
\hline
\end{tabular}

\begin{tabular}{|c|c|c|c|c|c|c|}
\hline \multirow{2}{*}{ FRASCO } & \multicolumn{3}{|c|}{ DOSAGEM DE PRODUTO QUÍMICO } & \multirow{2}{*}{$\begin{array}{c}\text { pH } \\
\text { de } \\
\text { Coagulação }\end{array}$} & \multirow{2}{*}{$\begin{array}{c}\begin{array}{c}T_{\mathrm{sl}}=1,75 \mathrm{~min} \\
\mathrm{~V}_{\mathrm{s1}}=4.0 \mathrm{~cm} / \mathrm{min}\end{array} \\
\begin{array}{c}\text { Turbidez } \\
(\mathrm{uT})\end{array}\end{array}$} & \multirow{2}{*}{$\begin{array}{c}T_{\mathrm{s} 2}=3.50 \mathrm{~min} \\
\mathrm{~V}_{\mathrm{s} 2}=2.0 \mathrm{~cm} / \mathrm{min}\end{array}$} \\
\hline & $\begin{array}{c}\text { Sulfato de } \\
\text { Alumínio } \\
(\mathrm{mg} / \mathrm{\ell})\end{array}$ & $\begin{array}{c}\text { Ácido } \\
\text { Clorídrico } \\
0.1 \mathrm{~N}(\mathrm{~m} \ell / \ell)\end{array}$ & $\begin{array}{l}\text { Hidróxido de } \\
\text { Sódio 0.1N } \\
(\mathrm{m} \ell / \ell)\end{array}$ & & & \\
\hline 1 & 10.0 & - & - & 7.15 & 105 & 98.0 \\
\hline 2 & 20.0 & - & - & 7.18 & 62.4 & 21.3 \\
\hline 3 & 30.0 & - & - & 7.09 & 19.9 & 5.64 \\
\hline 4 & 40.0 & - & - & - & 9.18 & - \\
\hline 5 & 50.0 & - & - & - & 8.12 & - \\
\hline 6 & 60.0 & - & - & 6.68 & 5.57 & 5.71 \\
\hline
\end{tabular}




\section{ESTUDO DE COAGULAÇÃO-FLOCULAÇÃO-SEDIMENTAÇÃO}

\begin{tabular}{|c|c|c|c|c|c|c|}
\hline \multirow{2}{*}{$\begin{array}{l}\text { ENSAIO N }^{\circ}: 03 \\
\text { Data : } 02 / 02 / 00\end{array}$} & \multirow{2}{*}{$\begin{array}{l}\text { COAGULANTE } \\
\text { Sulfato de Alumínio }\end{array}$} & \multicolumn{3}{|c|}{ MISTURA RÁPIDA } & \multicolumn{2}{|c|}{ FLOCULAÇÃO } \\
\hline & & $\mathrm{Tmr}=10 \mathrm{~s}$ & Gm & & $\mathbf{T f}=\mathbf{2 0} \mathrm{min}$ & $G f=25 \mathrm{~s}^{-1}$ \\
\hline \multicolumn{7}{|c|}{ CARACTERÍSTICAS DA ÁGUA DE ESTUDO } \\
\hline \multirow{2}{*}{ Turbidez (uT) } & \multirow{2}{*}{$\begin{array}{c}\text { Alcalinidade Total } \\
\left(\mathrm{mg} / \ell \mathrm{CaCO}_{3}\right)\end{array}$} & \multicolumn{2}{|c|}{ pH } & \multirow{2}{*}{\multicolumn{2}{|c|}{$\begin{array}{c}\text { Temperatura } \\
{ }^{\circ} \mathrm{C} \\
\end{array}$}} & \multirow{2}{*}{$\begin{array}{r}\text { Potencial } \\
\text { Zeta }(\mathrm{mV}) \\
\end{array}$} \\
\hline & & S/ agit. & $\mathrm{C} /$ agit. & & & \\
\hline 102 & 29 & 8.02 & 7.81 & & 25 & - \\
\hline
\end{tabular}

\begin{tabular}{|c|c|c|c|c|c|c|}
\hline \multirow{2}{*}{ FRASCO } & \multicolumn{3}{|c|}{ DOSAGEM DE PRODUTO QUÍMICO } & \multirow{2}{*}{$\begin{array}{c}\text { pH } \\
\text { de } \\
\text { Coagulação }\end{array}$} & \multirow{2}{*}{$\begin{array}{c}\begin{array}{c}T_{\mathrm{s} 1}=1,75 \mathrm{~min} \\
\mathrm{~V}_{\mathrm{s} 1}=4.0 \mathrm{~cm} / \mathrm{min}\end{array} \\
\begin{array}{c}\text { Turbidez } \\
(\mathrm{uT})\end{array}\end{array}$} & \multirow{2}{*}{ 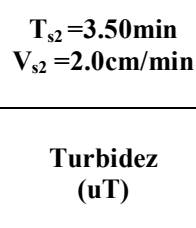 } \\
\hline & $\begin{array}{c}\text { Sulfato de } \\
\text { Alumínio } \\
(\mathrm{mg} / \mathfrak{l})\end{array}$ & $\begin{array}{c}\text { Ácido } \\
\text { Clorídrico } \\
0.1 \mathrm{~N}(\mathrm{~m} \ell / \ell)\end{array}$ & $\begin{array}{l}\text { Hidróxido de } \\
\text { Sódio 0.1N } \\
(\mathrm{m} \ell / \ell)\end{array}$ & & & \\
\hline 1 & 10.0 & - & - & 7.6 & 98.4 & 102.0 \\
\hline 2 & 20.0 & - & - & 7.11 & 67.0 & 27.3 \\
\hline 3 & 30.0 & - & - & 6.94 & 85.8 & 8.11 \\
\hline 4 & 40.0 & - & - & - & 11.1 & - \\
\hline 5 & 50.0 & - & - & 6.70 & 21.2 & 6.70 \\
\hline 6 & 60.0 & - & - & 6.71 & - & 5.55 \\
\hline
\end{tabular}

\section{ESTUDO DE COAGULAÇÃO-FLOCULAÇÃO-SEDIMENTAÇÃO}

\begin{tabular}{|c|c|c|c|c|c|c|}
\hline \multirow{2}{*}{$\begin{array}{l}\text { ENSAIO No: } 04 \\
\text { Data : } 03 / 02 / 00\end{array}$} & \multirow{2}{*}{$\begin{array}{l}\text { COAGULANTE } \\
\text { Sulfato de Alumíni }\end{array}$} & \multicolumn{3}{|c|}{ MISTURA RÁPIDA } & \multicolumn{2}{|c|}{ FLOCULAÇÃO } \\
\hline & & $\mathrm{Tmr}=10 \mathrm{~s}$ & & & $T f=20 \mathrm{~min}$ & Gf $=25 \mathrm{~s}^{-1}$ \\
\hline \multicolumn{7}{|c|}{ CARACTERÍSTICAS DA ÁGUA DE ESTUDO } \\
\hline \multirow{2}{*}{ Turbidez (uT) } & \multirow{2}{*}{$\begin{array}{c}\text { Alcalinidade Total } \\
\left(\mathrm{mg} / \mathrm{l} \mathrm{CaCO}_{3}\right)\end{array}$} & \multicolumn{2}{|c|}{ pH } & \multirow{2}{*}{\multicolumn{2}{|c|}{$\begin{array}{l}\text { Temperatura } \\
{ }^{\circ} \mathrm{C}\end{array}$}} & \multirow{2}{*}{$\begin{array}{l}\text { Potencial } \\
\text { Zeta }(m V)\end{array}$} \\
\hline & & S/ agit. & $\mathrm{C} /$ agit. & & & \\
\hline 102 & 30 & 7.72 & 7.62 & & 25 & - \\
\hline
\end{tabular}

\begin{tabular}{|c|c|c|c|c|c|c|}
\hline \multirow{2}{*}{ FRASCO } & \multicolumn{3}{|c|}{ DOSAGEM DE PRODUTO QUÍMICO } & \multirow{2}{*}{$\begin{array}{c}\text { pH } \\
\text { de } \\
\text { Coagulação }\end{array}$} & \multirow{2}{*}{$\begin{array}{c}\begin{array}{c}T_{\mathrm{sl}}=1,75 \mathrm{~min} \\
\mathrm{~V}_{\mathrm{s} 1}=4.0 \mathrm{~cm} / \mathrm{min}\end{array} \\
\begin{array}{c}\text { Turbidez } \\
\text { (uT) }\end{array}\end{array}$} & \multirow{2}{*}{$\begin{array}{c}T_{\mathrm{s} 2}=3.50 \mathrm{~min} \\
\mathrm{~V}_{\mathrm{s} 2}=2.0 \mathrm{~cm} / \mathrm{min} \\
\begin{array}{c}\text { Turbidez } \\
\text { (uT) }\end{array}\end{array}$} \\
\hline & $\begin{array}{c}\text { Sulfato de } \\
\text { Alumínio } \\
(\mathrm{mg} / \mathfrak{l})\end{array}$ & $\begin{array}{c}\text { Ácido } \\
\text { Clorídrico } \\
0.1 \mathrm{~N}(\mathrm{~m} \ell / \ell)\end{array}$ & $\begin{array}{l}\text { Hidróxido de } \\
\text { Sódio 0.1N } \\
(\mathrm{ml} / \mathfrak{\ell})\end{array}$ & & & \\
\hline 1 & 40.0 & - & 4.0 & 7.24 & 14.6 & 5.7 \\
\hline 2 & 40.0 & - & 6.0 & 7.42 & 19.7 & 8.77 \\
\hline 3 & 40.0 & - & 8.0 & 7.59 & 102.0 & 96.6 \\
\hline 4 & 40.0 & 3.65 & - & 6.89 & 18.8 & 11.1 \\
\hline 5 & 40.0 & 5.47 & - & 6.62 & 101.0 & 93.5 \\
\hline 6 & 40.0 & 7.29 & - & 6.35 & 105.0 & 99.0 \\
\hline
\end{tabular}




\section{ESTUDO DE COAGULAÇÃO-FLOCULAÇÃO-SEDIMENTAÇÃO}

\begin{tabular}{|c|c|c|c|c|c|c|}
\hline \multirow{2}{*}{$\begin{array}{l}\text { ENSAIO N }{ }^{\circ}: 05 \\
\text { Data : } 04 / 02 / 00\end{array}$} & \multirow{2}{*}{$\begin{array}{l}\text { COAGULANTE } \\
\text { Sulfato de Alumíni } \\
\end{array}$} & \multicolumn{3}{|c|}{ MISTURA RÁPIDA } & \multicolumn{2}{|c|}{ FLOCULAÇÃO } \\
\hline & & $T m r=10 \mathrm{~s}$ & $\mathbf{G m}$ & & $T f=20 \mathrm{~min}$ & Gf $=25 \mathrm{~s}^{-1}$ \\
\hline \multicolumn{7}{|c|}{ CARACTERÍSTICAS DA ÁGUA DE ESTUDO } \\
\hline \multirow{2}{*}{ Turbidez (uT) } & \multirow{2}{*}{$\begin{array}{l}\text { Alcalinidade Total } \\
\left(\mathrm{mg} / \ell \mathrm{CaCO}_{3}\right)\end{array}$} & \multicolumn{2}{|c|}{ pH } & \multirow{2}{*}{\multicolumn{2}{|c|}{$\begin{array}{c}\text { Temperatura } \\
{ }^{\circ} \mathrm{C} \\
\end{array}$}} & \multirow{2}{*}{$\begin{array}{l}\text { Potencial } \\
\text { Zeta }(\mathrm{mV})\end{array}$} \\
\hline & & S/ agit. & $\mathrm{C} /$ agit. & & & \\
\hline 105 & 31.5 & 7.72 & 7.63 & & 25 & - \\
\hline
\end{tabular}

\begin{tabular}{|c|c|c|c|c|c|c|}
\hline \multirow{2}{*}{ FRASCO } & \multicolumn{3}{|c|}{ DOSAGEM DE PRODUTO QUÍMICO } & \multirow{2}{*}{$\begin{array}{c}\text { pH } \\
\text { de } \\
\text { Coagulação }\end{array}$} & \multirow{2}{*}{$\begin{array}{c}\begin{array}{c}T_{\mathrm{s} 1}=1,75 \mathrm{~min} \\
\mathrm{~V}_{\mathrm{s} 1}=4.0 \mathrm{~cm} / \mathrm{min}\end{array} \\
\begin{array}{c}\text { Turbidez } \\
\text { (uT) }\end{array}\end{array}$} & \multirow{2}{*}{$\begin{array}{c}T_{\mathrm{s} 2}=3.50 \mathrm{~min} \\
\mathrm{~V}_{\mathrm{s} 2}=2.0 \mathrm{~cm} / \mathrm{min} \\
\begin{array}{c}\text { Turbidez } \\
\text { (uT) }\end{array}\end{array}$} \\
\hline & $\begin{array}{c}\text { Sulfato de } \\
\text { Alumínio } \\
(\mathrm{mg} / \mathfrak{l})\end{array}$ & $\begin{array}{c}\text { Ácido } \\
\text { Clorídrico } \\
0.1 \mathrm{~N}(\mathrm{~m} \ell / \ell)\end{array}$ & $\begin{array}{l}\text { Hidróxido de } \\
\text { Sódio 0.1N } \\
(\mathrm{ml} / \mathfrak{l})\end{array}$ & & & \\
\hline 1 & 60.0 & - & 4.0 & 6.95 & 4.71 & 2.05 \\
\hline 2 & 60.0 & - & 6.0 & 7.15 & 4.57 & 3.93 \\
\hline 3 & 60.0 & - & 8.0 & 7.26 & 5.95 & 3.47 \\
\hline 4 & 60.0 & 3.65 & - & - & 95.4 & - \\
\hline 5 & 60.0 & 5.47 & - & 6.20 & 99.3 & 93.2 \\
\hline 6 & 60.0 & 7.29 & - & 5.80 & 96.1 & 101.0 \\
\hline
\end{tabular}

\section{ESTUDO DE COAGULAÇÃO-FLOCULAÇÃO-SEDIMENTAÇÃO}

\begin{tabular}{|c|c|c|c|c|c|c|}
\hline \multirow{2}{*}{$\begin{array}{l}\text { ENSAIO N }{ }^{\circ}: 06 \\
\text { Data : } 07 / 02 / 00\end{array}$} & \multirow{2}{*}{$\begin{array}{c}\text { COAGULANTE } \\
\text { Sulfato de Alumínio }\end{array}$} & \multicolumn{3}{|c|}{ MISTURA RÁPIDA } & \multicolumn{2}{|c|}{ FLOCULAÇÃO } \\
\hline & & $\mathrm{Tmr}=10 \mathrm{~s}$ & $\mathbf{G m}$ & & $T f=20 \min$ & $G f=25 \mathrm{~s}^{-1}$ \\
\hline \multicolumn{7}{|c|}{ CARACTERÍSTICAS DA ÁGUA DE ESTUDO } \\
\hline \multirow{2}{*}{ Turbidez (uT) } & \multirow{2}{*}{$\begin{array}{c}\text { Alcalinidade Total } \\
\left(\mathrm{mg} / \ell \mathrm{CaCO}_{3}\right)\end{array}$} & \multicolumn{2}{|c|}{ pH } & \multirow{2}{*}{\multicolumn{2}{|c|}{$\begin{array}{c}\text { Temperatura } \\
{ }^{\circ} \mathrm{C} \\
\end{array}$}} & \multirow{2}{*}{$\begin{array}{l}\text { Potencial } \\
\text { Zeta }(\mathrm{mV})\end{array}$} \\
\hline & & S/ agit. & $\mathrm{C} /$ agit. & & & \\
\hline 101 & 31.5 & 7.94 & 7.85 & & 25 & - \\
\hline
\end{tabular}

\begin{tabular}{|c|c|c|c|c|c|c|}
\hline \multirow{2}{*}{ FRASCO } & \multicolumn{3}{|c|}{ DOSAGEM DE PRODUTO QUÍMICO } & \multirow{2}{*}{$\begin{array}{c}\text { pH } \\
\text { de } \\
\text { Coagulação }\end{array}$} & \multirow{2}{*}{$\begin{array}{c}\begin{array}{c}\mathrm{T}_{\mathrm{s} 1}=1,75 \mathrm{~min} \\
\mathrm{~V}_{\mathrm{s} 1}=4.0 \mathrm{~cm} / \mathrm{min}\end{array} \\
\begin{array}{c}\text { Turbidez } \\
(\mathrm{uT})\end{array}\end{array}$} & \multirow{2}{*}{$\begin{array}{c}T_{\mathrm{s} 2}=3.50 \mathrm{~min} \\
\mathrm{~V}_{\mathrm{s} 2}=2.0 \mathrm{~cm} / \mathrm{min} \\
\begin{array}{c}\text { Turbidez } \\
(\mathbf{u T})\end{array}\end{array}$} \\
\hline & $\begin{array}{c}\text { Sulfato de } \\
\text { Alumínio } \\
(\mathrm{mg} / \mathrm{l})\end{array}$ & $\begin{array}{c}\text { Ácido } \\
\text { Clorídrico } \\
0.1 \mathrm{~N}(\mathrm{~m} \ell / \ell)\end{array}$ & $\begin{array}{l}\text { Hidróxido de } \\
\text { Sódio 0.1N } \\
(\mathrm{m} \ell / \ell)\end{array}$ & & & \\
\hline 1 & 20.0 & - & 4.0 & 7.98 & 104.0 & 102.0 \\
\hline 2 & 20.0 & - & 6.0 & 8.15 & 99.8 & 98.1 \\
\hline 3 & 20.0 & - & 8.0 & 8.34 & 102.0 & 103.0 \\
\hline 4 & 20.0 & 3.65 & - & 7.54 & - & 16.6 \\
\hline 5 & 20.0 & 5.47 & - & - & 83.6 & - \\
\hline 6 & 20.0 & 7.29 & - & 7.29 & 43.5 & 24.6 \\
\hline
\end{tabular}




\section{ESTUDO DE COAGULAÇÃO-FLOCULAÇÃO-SEDIMENTAÇÃO}

\begin{tabular}{|c|c|c|c|c|c|c|}
\hline \multirow{2}{*}{$\begin{array}{l}\text { ENSAIO N }^{\circ}: 07 \\
\text { Data : } 07 / 02 / 00\end{array}$} & \multirow{2}{*}{$\begin{array}{l}\text { COAGULANTE } \\
\text { Sulfato de Alumínio }\end{array}$} & \multicolumn{3}{|c|}{ MISTURA RÁPIDA } & \multicolumn{2}{|c|}{ FLOCULAÇÃO } \\
\hline & & $T m r=10 \mathrm{~s}$ & Gm & & $T f=20 \mathrm{~min}$ & Gf $=25 \mathrm{~s}^{-1}$ \\
\hline \multicolumn{7}{|c|}{ CARACTERÍSTICAS DA ÁGUA DE ESTUDO } \\
\hline \multirow{2}{*}{ Turbidez (uT) } & \multirow{2}{*}{$\begin{array}{c}\text { Alcalinidade Total } \\
\left(\mathrm{mg} / \ell \mathrm{CaCO}_{3}\right)\end{array}$} & \multicolumn{2}{|c|}{ pH } & \multirow{2}{*}{\multicolumn{2}{|c|}{$\begin{array}{c}\text { Temperatura } \\
{ }^{\circ} \mathrm{C} \\
\end{array}$}} & \multirow{2}{*}{$\begin{array}{l}\text { Potencial } \\
\text { Zeta }(\mathrm{mV})\end{array}$} \\
\hline & & S/ agit. & $\mathrm{C} /$ agit. & & & \\
\hline $98.3 / 99.3$ & 29.1 & 7.74 & 7.58 & & 25 & - \\
\hline
\end{tabular}

\begin{tabular}{|c|c|c|c|c|c|c|}
\hline \multirow{2}{*}{ FRASCO } & \multicolumn{3}{|c|}{ DOSAGEM DE PRODUTO QUÍMICO } & \multirow{2}{*}{$\begin{array}{c}\text { pH } \\
\text { de } \\
\text { Coagulação }\end{array}$} & \multirow{2}{*}{$\begin{array}{c}\begin{array}{c}T_{\mathrm{s} 1}=1,75 \mathrm{~min} \\
\mathrm{~V}_{\mathrm{s} 1}=4.0 \mathrm{~cm} / \mathrm{min}\end{array} \\
\begin{array}{c}\text { Turbidez } \\
(\mathrm{uT})\end{array}\end{array}$} & \multirow{2}{*}{ 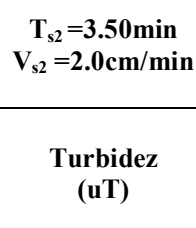 } \\
\hline & $\begin{array}{c}\text { Sulfato de } \\
\text { Alumínio } \\
(\mathrm{mg} / \mathfrak{l})\end{array}$ & $\begin{array}{c}\text { Ácido } \\
\text { Clorídrico } \\
0.1 \mathrm{~N}(\mathrm{~m} \ell / \ell)\end{array}$ & $\begin{array}{l}\text { Hidróxido de } \\
\text { Sódio 0.1N } \\
(\mathrm{m} \ell / \ell)\end{array}$ & & & \\
\hline 1 & 60.0 & - & - & 6.45 & 6.52 & 6.08 \\
\hline 2 & 70.0 & - & 5.0 & 6.79 & 11.5 & 3.13 \\
\hline 3 & 80.0 & - & 10.0 & 7.02 & 14.3 & 4.07 \\
\hline 4 & 90.0 & - & 15.0 & 7.37 & 24.5 & 9.52 \\
\hline 5 & 100.0 & - & 20.0 & 7.59 & 98.8 & 95.2 \\
\hline 6 & 65.0 & - & - & 6.57 & 5.67 & 2.50 \\
\hline
\end{tabular}

\section{ESTUDO DE COAGULAÇÃO-FLOCULAÇÃO-SEDIMENTAÇÃO}

\begin{tabular}{|c|c|c|c|c|c|c|}
\hline \multirow{2}{*}{$\begin{array}{l}\text { ENSAIO } N^{\circ}: 08 \\
\text { Data : } 07 / 02 / 00\end{array}$} & \multirow{2}{*}{$\begin{array}{l}\text { COAGULANTE } \\
\text { Sulfato de Alumínic }\end{array}$} & \multicolumn{3}{|c|}{ MISTURA RÁPIDA } & \multicolumn{2}{|c|}{ FLOCULAÇÃO } \\
\hline & & $\mathrm{Tmr}=10 \mathrm{~s}$ & & $\mathrm{~s}^{-1}$ & $T f=20 \mathrm{~min}$ & $G f=25 \mathrm{~s}^{-1}$ \\
\hline \multicolumn{7}{|c|}{ CARACTERÍSTICAS DA ÁGUA DE ESTUDO } \\
\hline \multirow{2}{*}{ Turbidez (uT) } & \multirow{2}{*}{$\begin{array}{c}\text { Alcalinidade Total } \\
\left(\mathrm{mg} / \ell \mathrm{CaCO}_{3}\right)\end{array}$} & \multicolumn{2}{|c|}{ pH } & \multirow{2}{*}{\multicolumn{2}{|c|}{$\begin{array}{c}\text { Temperatura } \\
{ }^{\circ} \mathrm{C}\end{array}$}} & \multirow{2}{*}{$\begin{array}{l}\text { Potencial } \\
\text { Zeta }(m V)\end{array}$} \\
\hline & & S/ agit. & $\mathrm{C} /$ agit. & & & \\
\hline $98.3 / 99.3$ & 29.1 & 7.74 & 7.58 & & 25 & - \\
\hline
\end{tabular}

\begin{tabular}{|c|c|c|c|c|c|c|}
\hline \multirow{2}{*}{ FRASCO } & \multicolumn{3}{|c|}{ DOSAGEM DE PRODUTO QUÍMICO } & \multirow{2}{*}{$\begin{array}{c}\text { pH } \\
\text { de } \\
\text { Coagulação }\end{array}$} & \multirow{2}{*}{$\begin{array}{c}\begin{array}{c}T_{\mathrm{s} 1}=1,75 \mathrm{~min} \\
\mathrm{~V}_{\mathrm{s} 1}=4.0 \mathrm{~cm} / \mathrm{min}\end{array} \\
\begin{array}{c}\text { Turbidez } \\
\text { (uT) }\end{array}\end{array}$} & \multirow{2}{*}{$\begin{array}{c}T_{\mathrm{s} 2}=3.50 \mathrm{~min} \\
\mathrm{~V}_{\mathrm{s} 2}=2.0 \mathrm{~cm} / \mathrm{min} \\
\begin{array}{c}\text { Turbidez } \\
\text { (uT) }\end{array}\end{array}$} \\
\hline & $\begin{array}{l}\text { Sulfato de } \\
\text { Alumínio } \\
(\mathrm{mg} / \mathfrak{l})\end{array}$ & $\begin{array}{c}\text { Ácido } \\
\text { Clorídrico } \\
0.1 \mathrm{~N}(\mathrm{~m} \ell / \ell)\end{array}$ & $\begin{array}{l}\text { Hidróxido de } \\
\text { Sódio 0.1N } \\
(\mathrm{m} \ell / \ell)\end{array}$ & & & \\
\hline 1 & 60.0 & - & - & 6.63 & 5.66 & 4.44 \\
\hline 2 & 65.0 & - & - & 6.52 & 9.48 & 3.38 \\
\hline 3 & 70.0 & - & - & 6.44 & 15.5 & 5.03 \\
\hline 4 & 75.0 & - & - & 6.47 & 21.3 & 14.0 \\
\hline 5 & - & - & - & - & - & - \\
\hline 6 & - & - & - & - & - & - \\
\hline
\end{tabular}




\section{ESTUDO DE COAGULAÇÃO-FLOCULAÇÃO-SEDIMENTAÇÃO}

\begin{tabular}{|c|c|c|c|c|c|c|}
\hline \multirow{2}{*}{$\begin{array}{l}\text { ENSAIO N }^{\circ}: 09 \\
\text { Data : } 08 / 02 / 00\end{array}$} & \multirow{2}{*}{$\begin{array}{l}\text { COAGULANTE } \\
\text { Sulfato de Alumíni }\end{array}$} & \multicolumn{3}{|c|}{ MISTURA RÁPIDA } & \multicolumn{2}{|c|}{ FLOCULAÇÃO } \\
\hline & & $T m r=10 \mathrm{~s}$ & Gm & & $T f=20 \mathrm{~min}$ & Gf $=25 \mathrm{~s}^{-1}$ \\
\hline \multicolumn{7}{|c|}{ CARACTERÍSTICAS DA ÁGUA DE ESTUDO } \\
\hline \multirow{2}{*}{ Turbidez (uT) } & \multirow{2}{*}{$\begin{array}{c}\text { Alcalinidade Total } \\
\left(\mathrm{mg} / \ell \mathrm{CaCO}_{3}\right)\end{array}$} & \multicolumn{2}{|c|}{ pH } & \multirow{2}{*}{\multicolumn{2}{|c|}{$\begin{array}{c}\text { Temperatura } \\
{ }^{\circ} \mathrm{C} \\
\end{array}$}} & \multirow{2}{*}{$\begin{array}{l}\text { Potencial } \\
\text { Zeta }(\mathrm{mV})\end{array}$} \\
\hline & & S/ agit. & $\mathrm{C} /$ agit. & & & \\
\hline $104 / 103$ & 30.9 & 7.97 & 7.84 & & 25 & - \\
\hline
\end{tabular}

\begin{tabular}{|c|c|c|c|c|c|c|}
\hline \multirow{2}{*}{ FRASCO } & \multicolumn{3}{|c|}{ DOSAGEM DE PRODUTO QUÍMICO } & \multirow{2}{*}{$\begin{array}{c}\text { pH } \\
\text { de } \\
\text { Coagulação }\end{array}$} & \multirow{2}{*}{$\begin{array}{c}\begin{array}{c}T_{\mathrm{s} 1}=1,75 \mathrm{~min} \\
\mathrm{~V}_{\mathrm{s} 1}=4.0 \mathrm{~cm} / \mathrm{min}\end{array} \\
\begin{array}{c}\text { Turbidez } \\
(\mathrm{uT})\end{array}\end{array}$} & \multirow{2}{*}{ 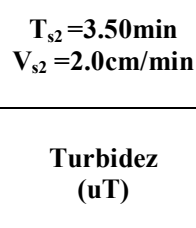 } \\
\hline & $\begin{array}{c}\text { Sulfato de } \\
\text { Alumínio } \\
(\mathrm{mg} / \mathfrak{l})\end{array}$ & $\begin{array}{c}\text { Ácido } \\
\text { Clorídrico } \\
0.1 \mathrm{~N}(\mathrm{~m} \ell / \ell)\end{array}$ & $\begin{array}{l}\text { Hidróxido de } \\
\text { Sódio 0.1N } \\
(\mathrm{m} \ell / \ell)\end{array}$ & & & \\
\hline 1 & 50.0 & - & - & 6.86 & 5.21 & 3.27 \\
\hline 2 & 52.5 & - & - & 6.86 & 3.74 & 2.20 \\
\hline 3 & 55.0 & - & - & 6.77 & - & 2.41 \\
\hline 4 & 57.5 & - & - & 6.84 & 5.53 & 4.66 \\
\hline 5 & 60.0 & - & - & 6.77 & 5.04 & 1.52 \\
\hline 6 & 62.5 & - & - & 6.73 & 4.33 & 2.24 \\
\hline
\end{tabular}

\section{ESTUDO DE COAGULAÇÃO-FLOCULAÇÃO-SEDIMENTAÇÃO}

\begin{tabular}{|c|c|c|c|c|c|c|}
\hline \multirow{2}{*}{$\begin{array}{l}\text { ENSAIO N }^{\circ}: 10 \\
\text { Data : } 08 / 02 / 00\end{array}$} & \multirow{2}{*}{$\begin{array}{l}\text { COAGULANTE } \\
\text { Sulfato de Alumíni } \\
\end{array}$} & \multicolumn{3}{|c|}{ MISTURA RÁPIDA } & \multicolumn{2}{|c|}{ FLOCULAÇÃO } \\
\hline & & $\mathrm{Tmr}=10 \mathrm{~s}$ & & & $T f=20 \mathrm{~min}$ & Gf $=25 \mathrm{~s}^{-1}$ \\
\hline \multicolumn{7}{|c|}{ CARACTERÍSTICAS DA ÁGUA DE ESTUDO } \\
\hline \multirow{2}{*}{ Turbidez (uT) } & \multirow{2}{*}{$\begin{array}{c}\text { Alcalinidade Total } \\
\left(\mathrm{mg} / \mathfrak{l} \mathrm{CaCO}_{3}\right)\end{array}$} & \multicolumn{2}{|c|}{ pH } & \multirow{2}{*}{\multicolumn{2}{|c|}{$\begin{array}{c}\text { Temperatura } \\
{ }^{\circ} \mathrm{C} \\
\end{array}$}} & \multirow{2}{*}{$\begin{array}{r}\text { Potencial } \\
\text { Zeta }(\mathrm{mV}) \\
\end{array}$} \\
\hline & & S/ agit. & $\mathrm{C} /$ agit. & & & \\
\hline $104 / 103$ & 30.9 & 7.97 & 7.84 & & 25 & - \\
\hline
\end{tabular}

\begin{tabular}{|c|c|c|c|c|c|c|}
\hline \multirow{2}{*}{ FRASCO } & \multicolumn{3}{|c|}{ DOSAGEM DE PRODUTO QUÍMICO } & \multirow{2}{*}{$\begin{array}{c}\text { pH } \\
\text { de } \\
\text { Coagulação }\end{array}$} & \multirow{2}{*}{$\begin{array}{c}\begin{array}{c}T_{\mathrm{s} 1}=1,75 \mathrm{~min} \\
\mathrm{~V}_{\mathrm{s} 1}=4.0 \mathrm{~cm} / \mathrm{min}\end{array} \\
\begin{array}{c}\text { Turbidez } \\
\text { (uT) }\end{array}\end{array}$} & \multirow{2}{*}{$\begin{array}{c}\begin{array}{c}\mathrm{T}_{\mathrm{s} 2}=3.50 \mathrm{~min} \\
\mathrm{~V}_{\mathrm{s} 2}=2.0 \mathrm{~cm} / \mathrm{min}\end{array} \\
\begin{array}{c}\text { Turbidez } \\
(\mathrm{uT})\end{array}\end{array}$} \\
\hline & $\begin{array}{l}\text { Sulfato de } \\
\text { Alumínio } \\
(\mathrm{mg} / \mathfrak{l})\end{array}$ & $\begin{array}{c}\text { Ácido } \\
\text { Clorídrico } \\
0.1 \mathrm{~N}(\mathrm{~m} \ell / \ell)\end{array}$ & $\begin{array}{l}\text { Hidróxido de } \\
\text { Sódio 0.1N } \\
(\mathrm{m} \ell / \ell)\end{array}$ & & & \\
\hline 1 & 30.0 & - & 4.0 & 7.49 & 63.6 & 36.2 \\
\hline 2 & 30.0 & - & 6.0 & 7.73 & 98.3 & 98.4 \\
\hline 3 & 30.0 & - & 8.0 & - & 97.4 & - \\
\hline 4 & 30.0 & 3.65 & - & 6.80 & 12.2 & 6.61 \\
\hline 5 & 30.0 & 5.47 & - & 6.70 & 12.7 & 6.91 \\
\hline 6 & 30.0 & 7.29 & - & 6.60 & 46.2 & 25.7 \\
\hline
\end{tabular}




\section{ESTUDO DE COAGULAÇÃO-FLOCULAÇÃO-SEDIMENTAÇÃO}

\begin{tabular}{|c|c|c|c|c|c|c|}
\hline \multirow{2}{*}{$\begin{array}{l}\text { ENSAIO N }{ }^{\circ}: 11 \\
\text { Data : } 08 / 02 / 00\end{array}$} & \multirow{2}{*}{$\begin{array}{l}\text { COAGULANTE } \\
\text { Sulfato de Alumíni } \\
\end{array}$} & \multicolumn{3}{|c|}{ MISTURA RÁPIDA } & \multicolumn{2}{|c|}{ FLOCULAÇÃO } \\
\hline & & $T m r=10 \mathrm{~s}$ & $\mathbf{G m}$ & & $T f=20 \mathrm{~min}$ & Gf $=25 \mathrm{~s}^{-1}$ \\
\hline \multicolumn{7}{|c|}{ CARACTERÍSTICAS DA ÁGUA DE ESTUDO } \\
\hline \multirow{2}{*}{ Turbidez (uT) } & \multirow{2}{*}{$\begin{array}{l}\text { Alcalinidade Total } \\
\left(\mathrm{mg} / \ell \mathrm{CaCO}_{3}\right)\end{array}$} & \multicolumn{2}{|c|}{ pH } & \multirow{2}{*}{\multicolumn{2}{|c|}{$\begin{array}{c}\text { Temperatura } \\
{ }^{\circ} \mathrm{C} \\
\end{array}$}} & \multirow{2}{*}{$\begin{array}{l}\text { Potencial } \\
\text { Zeta }(\mathrm{mV})\end{array}$} \\
\hline & & S/ agit. & $\mathrm{C} /$ agit. & & & \\
\hline 102 & 31.5 & 7.93 & 7.77 & & 25 & - \\
\hline
\end{tabular}

\begin{tabular}{|c|c|c|c|c|c|c|}
\hline \multirow{2}{*}{ FRASCO } & \multicolumn{3}{|c|}{ DOSAGEM DE PRODUTO QUÍMICO } & \multirow{2}{*}{$\begin{array}{c}\text { pH } \\
\text { de } \\
\text { Coagulação }\end{array}$} & \multirow{2}{*}{$\begin{array}{c}\begin{array}{c}T_{\mathrm{s} 1}=1,75 \mathrm{~min} \\
\mathrm{~V}_{\mathrm{s} 1}=4.0 \mathrm{~cm} / \mathrm{min}\end{array} \\
\begin{array}{c}\text { Turbidez } \\
(\mathrm{uT})\end{array}\end{array}$} & \multirow{2}{*}{$\begin{array}{c}\begin{array}{c}T_{\mathrm{s} 2}=3.50 \mathrm{~min} \\
\mathrm{~V}_{\mathrm{s} 2}=2.0 \mathrm{~cm} / \mathrm{min}\end{array} \\
\begin{array}{c}\text { Turbidez } \\
(\mathrm{uT})\end{array}\end{array}$} \\
\hline & $\begin{array}{c}\text { Sulfato de } \\
\text { Alumínio } \\
(\mathrm{mg} / \mathfrak{l})\end{array}$ & $\begin{array}{c}\text { Ácido } \\
\text { Clorídrico } \\
0.1 \mathrm{~N}(\mathrm{~m} \ell / \ell)\end{array}$ & $\begin{array}{l}\text { Hidróxido de } \\
\text { Sódio 0.1N } \\
(\mathrm{m} \ell / \ell)\end{array}$ & & & \\
\hline 1 & 50.0 & 3.65 & - & - & 98.6 & - \\
\hline 2 & 50.0 & - & 2.0 & 7.12 & 5.77 & 4.77 \\
\hline 3 & 50.0 & - & 4.0 & 7.25 & 12.4 & 1.78 \\
\hline 4 & 50.0 & - & 6.0 & 7.37 & 12.6 & 3.09 \\
\hline 5 & 50.0 & - & 8.0 & 7.55 & 40.0 & 17.1 \\
\hline 6 & 50.0 & - & 10.0 & 7.75 & 95.1 & 99.4 \\
\hline
\end{tabular}

\section{ESTUDO DE COAGULAÇÃO-FLOCULAÇÃO-SEDIMENTAÇÃO}

\begin{tabular}{|c|c|c|c|c|c|c|}
\hline \multirow{2}{*}{$\begin{array}{l}\text { ENSAIO } N^{\circ}: 12 \\
\text { Data : } 08 / 02 / 00\end{array}$} & \multirow{2}{*}{$\begin{array}{c}\text { COAGULANTE } \\
\text { Sulfato de Alumíni }\end{array}$} & \multicolumn{3}{|c|}{ MISTURA RÁPIDA } & \multicolumn{2}{|c|}{ FLOCULAÇÃO } \\
\hline & & $T m r=10 \mathrm{~s}$ & & & Tf $=20 \mathrm{~min}$ & Gf $=25 \mathrm{~s}^{-1}$ \\
\hline \multicolumn{7}{|c|}{ CARACTERÍSTICAS DA ÁGUA DE ESTUDO } \\
\hline \multirow{2}{*}{ Turbidez (uT) } & \multirow{2}{*}{$\begin{array}{l}\text { Alcalinidade Total } \\
\left(\mathrm{mg} / \ell \mathrm{CaCO}_{3}\right)\end{array}$} & \multicolumn{2}{|c|}{ pH } & \multirow{2}{*}{\multicolumn{2}{|c|}{$\begin{array}{c}\text { Temperatura } \\
{ }^{\circ} \mathrm{C}\end{array}$}} & \multirow{2}{*}{$\begin{array}{l}\text { Potencial } \\
\text { Zeta }(\mathrm{mV})\end{array}$} \\
\hline & & $\mathrm{S} /$ agit. & $\mathrm{C} /$ agit. & & & \\
\hline 102 & 31.5 & 7.93 & 7.77 & & 25 & - \\
\hline
\end{tabular}

\begin{tabular}{|c|c|c|c|c|c|c|}
\hline \multirow{2}{*}{ FRASCO } & \multicolumn{3}{|c|}{ DOSAGEM DE PRODUTO QUÍMICO } & \multirow{2}{*}{$\begin{array}{c}\text { pH } \\
\text { de } \\
\text { Coagulação }\end{array}$} & \multirow{2}{*}{$\begin{array}{c}\begin{array}{c}T_{\mathrm{s} 1}=1,75 \mathrm{~min} \\
\mathrm{~V}_{\mathrm{s} 1}=4.0 \mathrm{~cm} / \mathrm{min}\end{array} \\
\begin{array}{c}\text { Turbidez } \\
\text { (uT) }\end{array}\end{array}$} & \multirow{2}{*}{$\begin{array}{c}\begin{array}{c}\mathrm{T}_{\mathrm{s} 2}=3.50 \mathrm{~min} \\
\mathrm{~V}_{\mathrm{s} 2}=2.0 \mathrm{~cm} / \mathrm{min}\end{array} \\
\begin{array}{c}\text { Turbidez } \\
(\mathrm{uT})\end{array}\end{array}$} \\
\hline & $\begin{array}{l}\text { Sulfato de } \\
\text { Alumínio } \\
(\mathrm{mg} / \mathfrak{l})\end{array}$ & $\begin{array}{c}\text { Ácido } \\
\text { Clorídrico } \\
0.1 \mathrm{~N}(\mathrm{~m} \ell / \ell)\end{array}$ & $\begin{array}{l}\text { Hidróxido de } \\
\text { Sódio 0.1N } \\
(\mathrm{m} \ell / \ell)\end{array}$ & & & \\
\hline 1 & 70.0 & 1.83 & - & - & 104.0 & - \\
\hline 2 & 70.0 & - & 4.0 & 6.98 & 7.17 & 3.76 \\
\hline 3 & 70.0 & - & 6.0 & 7.09 & 5.77 & 2.11 \\
\hline 4 & 70.0 & - & 8.0 & 7.20 & 10.3 & 1.77 \\
\hline 5 & 70.0 & - & 10.0 & 7.33 & 12.0 & 2.92 \\
\hline 6 & 70.0 & - & 12.0 & 7.40 & 35.2 & 11.3 \\
\hline
\end{tabular}




\section{ESTUDO DE COAGULAÇÃO-FLOCULAÇÃO-SEDIMENTAÇÃO}

\begin{tabular}{|c|c|c|c|c|c|c|}
\hline \multirow{2}{*}{$\begin{array}{l}\text { ENSAIO N }^{\circ}: 13 \\
\text { Data : } 09 / 02 / 00\end{array}$} & \multirow{2}{*}{$\begin{array}{l}\text { COAGULANTE } \\
\text { Sulfato de Alumínio }\end{array}$} & \multicolumn{3}{|c|}{ MISTURA RÁPIDA } & \multicolumn{2}{|c|}{ FLOCULAÇÃO } \\
\hline & & $\mathrm{Tmr}=10 \mathrm{~s}$ & Gm & & $\mathbf{T f}=\mathbf{2 0} \mathrm{min}$ & $G f=25 \mathrm{~s}^{-1}$ \\
\hline \multicolumn{7}{|c|}{ CARACTERÍSTICAS DA ÁGUA DE ESTUDO } \\
\hline \multirow{2}{*}{ Turbidez (uT) } & \multirow{2}{*}{$\begin{array}{c}\text { Alcalinidade Total } \\
\left(\mathrm{mg} / \ell \mathrm{CaCO}_{3}\right)\end{array}$} & \multicolumn{2}{|c|}{ pH } & \multirow{2}{*}{\multicolumn{2}{|c|}{$\begin{array}{c}\text { Temperatura } \\
{ }^{\circ} \mathrm{C} \\
\end{array}$}} & \multirow{2}{*}{$\begin{array}{r}\text { Potencial } \\
\text { Zeta }(\mathrm{mV}) \\
\end{array}$} \\
\hline & & S/ agit. & $\mathrm{C} /$ agit. & & & \\
\hline 105 & 29.1 & 7.85 & 7.65 & & 25 & - \\
\hline
\end{tabular}

\begin{tabular}{|c|c|c|c|c|c|c|}
\hline \multirow{2}{*}{ FRASCO } & \multicolumn{3}{|c|}{ DOSAGEM DE PRODUTO QUÍMICO } & \multirow{2}{*}{$\begin{array}{c}\text { pH } \\
\text { de } \\
\text { Coagulação }\end{array}$} & \multirow{2}{*}{$\begin{array}{c}\begin{array}{c}T_{\mathrm{s} 1}=1,75 \mathrm{~min} \\
\mathrm{~V}_{\mathrm{s} 1}=4.0 \mathrm{~cm} / \mathrm{min}\end{array} \\
\begin{array}{c}\text { Turbidez } \\
(\mathrm{uT})\end{array}\end{array}$} & \multirow{2}{*}{ 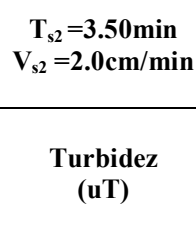 } \\
\hline & $\begin{array}{c}\text { Sulfato de } \\
\text { Alumínio } \\
(\mathrm{mg} / \mathfrak{l})\end{array}$ & $\begin{array}{c}\text { Ácido } \\
\text { Clorídrico } \\
0.1 \mathrm{~N}(\mathrm{~m} \ell / \ell)\end{array}$ & $\begin{array}{l}\text { Hidróxido de } \\
\text { Sódio 0.1N } \\
(\mathrm{m} \ell / \ell)\end{array}$ & & & \\
\hline 1 & 10.0 & 1.82 & - & 7.24 & 98.7 & 98.7 \\
\hline 2 & 10.0 & 3.65 & - & 7.12 & 87.8 & 84.2 \\
\hline 3 & 10.0 & 5.47 & - & 6.99 & 90.1 & 61.5 \\
\hline 4 & 20.0 & 3.65 & - & 7.04 & 37.7 & 17.9 \\
\hline 5 & 20.0 & 7.29 & - & 6.83 & 39.8 & 15.4 \\
\hline 6 & 20.0 & 10.94 & - & 6.43 & 98.4 & 92.8 \\
\hline
\end{tabular}

\section{ESTUDO DE COAGULAÇÃO-FLOCULAÇÃO-SEDIMENTAÇÃO}

\begin{tabular}{|c|c|c|c|c|c|c|}
\hline \multirow{2}{*}{$\begin{array}{l}\text { ENSAIO } N^{\circ}: 14 \\
\text { Data : } 09 / 02 / 00\end{array}$} & \multirow{2}{*}{$\begin{array}{c}\text { COAGULANTE } \\
\text { Sulfato de Alumíni }\end{array}$} & \multicolumn{3}{|c|}{ MISTURA RÁPIDA } & \multicolumn{2}{|c|}{ FLOCULAÇÃO } \\
\hline & & $T m r=10 \mathrm{~s}$ & & & Tf $=20 \mathrm{~min}$ & Gf $=25 \mathrm{~s}^{-1}$ \\
\hline \multicolumn{7}{|c|}{ CARACTERÍSTICAS DA ÁGUA DE ESTUDO } \\
\hline \multirow{2}{*}{ Turbidez (uT) } & \multirow{2}{*}{$\begin{array}{l}\text { Alcalinidade Total } \\
\left(\mathrm{mg} / \ell \mathrm{CaCO}_{3}\right)\end{array}$} & \multicolumn{2}{|c|}{ pH } & \multirow{2}{*}{\multicolumn{2}{|c|}{$\begin{array}{c}\text { Temperatura } \\
{ }^{\circ} \mathrm{C}\end{array}$}} & \multirow{2}{*}{$\begin{array}{l}\text { Potencial } \\
\text { Zeta }(\mathrm{mV})\end{array}$} \\
\hline & & $\mathrm{S} /$ agit. & $\mathrm{C} /$ agit. & & & \\
\hline 102 & 29.1 & 7.69 & 7.52 & & 25 & - \\
\hline
\end{tabular}

\begin{tabular}{|c|c|c|c|c|c|c|}
\hline \multirow{2}{*}{ FRASCO } & \multicolumn{3}{|c|}{ DOSAGEM DE PRODUTO QUÍMICO } & \multirow{2}{*}{$\begin{array}{c}\text { pH } \\
\text { de } \\
\text { Coagulação }\end{array}$} & \multirow{2}{*}{$\begin{array}{c}\begin{array}{c}T_{\mathrm{sl}}=1,75 \mathrm{~min} \\
\mathrm{~V}_{\mathrm{s} 1}=4.0 \mathrm{~cm} / \mathrm{min}\end{array} \\
\begin{array}{c}\text { Turbidez } \\
\text { (uT) }\end{array}\end{array}$} & \multirow{2}{*}{$\begin{array}{c}T_{\mathrm{s} 2}=3.50 \mathrm{~min} \\
\mathrm{~V}_{\mathrm{s} 2}=2.0 \mathrm{~cm} / \mathrm{min} \\
\begin{array}{c}\text { Turbidez } \\
\text { (uT) }\end{array}\end{array}$} \\
\hline & $\begin{array}{c}\text { Sulfato de } \\
\text { Alumínio } \\
(\mathrm{mg} / \mathfrak{l})\end{array}$ & $\begin{array}{c}\text { Ácido } \\
\text { Clorídrico } \\
0.1 \mathrm{~N}(\mathrm{~m} \ell / \ell)\end{array}$ & $\begin{array}{l}\text { Hidróxido de } \\
\text { Sódio 0.1N } \\
(\mathrm{ml} / \mathfrak{\ell})\end{array}$ & & & \\
\hline 1 & 10.0 & 7.29 & - & 7.00 & 87.9 & 56.9 \\
\hline 2 & 10.0 & 9.11 & - & 6.73 & 86.7 & 59.2 \\
\hline 3 & 10.0 & 10.94 & - & 6.61 & 91.0 & 66.3 \\
\hline 4 & 20.0 & 12.74 & - & 6.02 & 99.7 & 102.0 \\
\hline 5 & 20.0 & - & 2.0 & - & - & - \\
\hline 6 & 20.0 & - & 3.0 & - & 95.3 & - \\
\hline
\end{tabular}




\section{ESTUDO DE COAGULAÇÃO-FLOCULAÇÃO-SEDIMENTAÇÃO}

\begin{tabular}{|c|c|c|c|c|c|c|}
\hline \multirow{2}{*}{$\begin{array}{l}\text { ENSAIO N }{ }^{\circ}: 15 \\
\text { Data : } 09 / 02 / 00\end{array}$} & \multirow{2}{*}{$\begin{array}{l}\text { COAGULANTE } \\
\text { Sulfato de Alumíni } \\
\end{array}$} & \multicolumn{3}{|c|}{ MISTURA RÁPIDA } & \multicolumn{2}{|c|}{ FLOCULAÇÃO } \\
\hline & & $T m r=10 \mathrm{~s}$ & $\mathbf{G m}$ & & $T f=20 \mathrm{~min}$ & Gf $=25 \mathrm{~s}^{-1}$ \\
\hline \multicolumn{7}{|c|}{ CARACTERÍSTICAS DA ÁGUA DE ESTUDO } \\
\hline \multirow{2}{*}{ Turbidez (uT) } & \multirow{2}{*}{$\begin{array}{l}\text { Alcalinidade Total } \\
\left(\mathrm{mg} / \ell \mathrm{CaCO}_{3}\right)\end{array}$} & \multicolumn{2}{|c|}{ pH } & \multirow{2}{*}{\multicolumn{2}{|c|}{$\begin{array}{c}\text { Temperatura } \\
{ }^{\circ} \mathrm{C} \\
\end{array}$}} & \multirow{2}{*}{$\begin{array}{l}\text { Potencial } \\
\text { Zeta }(\mathrm{mV})\end{array}$} \\
\hline & & S/ agit. & $\mathrm{C} /$ agit. & & & \\
\hline 102 & 28.5 & 7.89 & 7.70 & & 25 & - \\
\hline
\end{tabular}

\begin{tabular}{|c|c|c|c|c|c|c|}
\hline \multirow{2}{*}{ FRASCO } & \multicolumn{3}{|c|}{ DOSAGEM DE PRODUTO QUÍMICO } & \multirow{2}{*}{$\begin{array}{c}\text { pH } \\
\text { de } \\
\text { Coagulação }\end{array}$} & \multirow{2}{*}{$\begin{array}{c}T_{\mathrm{s} 1}=1,75 \mathrm{~min} \\
\mathrm{~V}_{\mathrm{s1}}=4.0 \mathrm{~cm} / \mathrm{min}\end{array}$} & \multirow{2}{*}{$\begin{array}{c}T_{\mathrm{s} 2}=3.50 \mathrm{~min} \\
\mathrm{~V}_{\mathrm{s} 2}=\mathbf{2 . 0 \mathrm { cm } / \mathrm { min }} \\
\begin{array}{c}\text { Turbidez } \\
\text { (uT) }\end{array}\end{array}$} \\
\hline & $\begin{array}{l}\text { Sulfato de } \\
\text { Alumínio } \\
(\mathrm{mg} / \mathfrak{l})\end{array}$ & $\begin{array}{c}\text { Ácido } \\
\text { Clorídrico } \\
0.1 \mathrm{~N}(\mathrm{m \ell} / \ell)\end{array}$ & $\begin{array}{l}\text { Hidróxido de } \\
\text { Sódio 0.1N } \\
(\mathrm{ml} / \mathfrak{l})\end{array}$ & & & \\
\hline 1 & 10.0 & 14.58 & - & 5.57 & 97.8 & 88.2 \\
\hline 2 & 10.0 & 13.65 & - & 5.74 & 89.5 & 94.3 \\
\hline 3 & 20.0 & 9.11 & - & 6.18 & 99.8 & 98.0 \\
\hline 4 & 20.0 & - & 5.0 & 7.69 & 100.0 & 99.4 \\
\hline 5 & 20.0 & - & 7.0 & - & 101.0 & - \\
\hline 6 & 30.0 & - & 2.0 & 7.56 & 17.3 & 11.6 \\
\hline
\end{tabular}

\section{ESTUDO DE COAGULAÇÃO-FLOCULAÇÃO-SEDIMENTAÇÃO}

\begin{tabular}{|c|c|c|c|c|c|c|}
\hline \multirow{2}{*}{$\begin{array}{l}\text { ENSAIO } N^{\circ}: 16 \\
\text { Data : } 09 / 02 / 00\end{array}$} & \multirow{2}{*}{$\begin{array}{c}\text { COAGULANTE } \\
\text { Sulfato de Alumíni }\end{array}$} & \multicolumn{3}{|c|}{ MISTURA RÁPIDA } & \multicolumn{2}{|c|}{ FLOCULAÇÃO } \\
\hline & & $T m r=10 \mathrm{~s}$ & & & Tf $=20 \mathrm{~min}$ & Gf $=25 \mathrm{~s}^{-1}$ \\
\hline \multicolumn{7}{|c|}{ CARACTERÍSTICAS DA ÁGUA DE ESTUDO } \\
\hline \multirow{2}{*}{ Turbidez (uT) } & \multirow{2}{*}{$\begin{array}{l}\text { Alcalinidade Total } \\
\left(\mathrm{mg} / \ell \mathrm{CaCO}_{3}\right)\end{array}$} & \multicolumn{2}{|c|}{ pH } & \multirow{2}{*}{\multicolumn{2}{|c|}{$\begin{array}{c}\text { Temperatura } \\
{ }^{\circ} \mathrm{C}\end{array}$}} & \multirow{2}{*}{$\begin{array}{l}\text { Potencial } \\
\text { Zeta }(\mathrm{mV})\end{array}$} \\
\hline & & S/ agit. & $\mathrm{C} /$ agit. & & & \\
\hline 102 & 28.5 & 7.89 & 7.70 & & 25 & - \\
\hline
\end{tabular}

\begin{tabular}{|c|c|c|c|c|c|c|}
\hline \multirow{2}{*}{ FRASCO } & \multicolumn{3}{|c|}{ DOSAGEM DE PRODUTO QUÍMICO } & \multirow{2}{*}{$\begin{array}{c}\text { pH } \\
\text { de } \\
\text { Coagulação }\end{array}$} & \multirow{2}{*}{$\begin{array}{c}\begin{array}{c}T_{\mathrm{s} 1}=1,75 \mathrm{~min} \\
\mathrm{~V}_{\mathrm{s} 1}=4.0 \mathrm{~cm} / \mathrm{min}\end{array} \\
\begin{array}{c}\text { Turbidez } \\
\text { (uT) }\end{array}\end{array}$} & \multirow{2}{*}{$\begin{array}{c}\begin{array}{c}\mathrm{T}_{\mathrm{s} 2}=3.50 \mathrm{~min} \\
\mathrm{~V}_{\mathrm{s} 2}=2.0 \mathrm{~cm} / \mathrm{min}\end{array} \\
\begin{array}{c}\text { Turbidez } \\
(\mathrm{uT})\end{array}\end{array}$} \\
\hline & $\begin{array}{l}\text { Sulfato de } \\
\text { Alumínio } \\
(\mathrm{mg} / \mathfrak{l})\end{array}$ & $\begin{array}{c}\text { Ácido } \\
\text { Clorídrico } \\
0.1 \mathrm{~N}(\mathrm{~m} \ell / \ell)\end{array}$ & $\begin{array}{l}\text { Hidróxido de } \\
\text { Sódio 0.1N } \\
(\mathrm{m} \ell / \ell)\end{array}$ & & & \\
\hline 1 & 60.0 & - & 10.0 & 7.69 & 22.1 & 8.18 \\
\hline 2 & 60.0 & - & 14.0 & 8.00 & 99.5 & 98.3 \\
\hline 3 & 60.0 & - & 18.0 & - & 97.8 & - \\
\hline 4 & 70.0 & - & 16.0 & - & 97.0 & - \\
\hline 5 & 70.0 & - & 20.0 & - & 97.1 & - \\
\hline 6 & 70.0 & - & 24.0 & - & 97.4 & - \\
\hline
\end{tabular}




\section{ESTUDO DE COAGULAÇÃO-FLOCULAÇÃO-SEDIMENTAÇÃO}

\begin{tabular}{|c|c|c|c|c|c|c|}
\hline \multirow{2}{*}{$\begin{array}{l}\text { ENSAIO N }^{\circ}: 17 \\
\text { Data : } 22 / 02 / 00\end{array}$} & \multirow{2}{*}{$\begin{array}{l}\text { COAGULANTE } \\
\text { Sulfato de Alumínio }\end{array}$} & \multicolumn{3}{|c|}{ MISTURA RÁPIDA } & \multicolumn{2}{|c|}{ FLOCULAÇÃO } \\
\hline & & $T m r=10 \mathrm{~s}$ & Gm & & $T f=20 \mathrm{~min}$ & Gf $=25 \mathrm{~s}^{-1}$ \\
\hline \multicolumn{7}{|c|}{ CARACTERÍSTICAS DA ÁGUA DE ESTUDO } \\
\hline \multirow{2}{*}{ Turbidez (uT) } & \multirow{2}{*}{$\begin{array}{c}\text { Alcalinidade Total } \\
\left(\mathrm{mg} / \ell \mathrm{CaCO}_{3}\right)\end{array}$} & \multicolumn{2}{|c|}{ pH } & \multirow{2}{*}{\multicolumn{2}{|c|}{$\begin{array}{c}\text { Temperatura } \\
{ }^{\circ} \mathrm{C} \\
\end{array}$}} & \multirow{2}{*}{$\begin{array}{l}\text { Potencial } \\
\text { Zeta }(\mathrm{mV})\end{array}$} \\
\hline & & S/ agit. & $\mathrm{C} /$ agit. & & & \\
\hline $99 / 98.8$ & 30 & 7.87 & 7.71 & & 25 & - \\
\hline
\end{tabular}

\begin{tabular}{|c|c|c|c|c|c|c|}
\hline \multirow{2}{*}{ FRASCO } & \multicolumn{3}{|c|}{ DOSAGEM DE PRODUTO QUÍMICO } & \multirow{2}{*}{$\begin{array}{c}\text { pH } \\
\text { de } \\
\text { Coagulação }\end{array}$} & \multirow{2}{*}{$\begin{array}{c}\begin{array}{c}T_{\mathrm{s} 1}=1,75 \mathrm{~min} \\
\mathrm{~V}_{\mathrm{s} 1}=4.0 \mathrm{~cm} / \mathrm{min}\end{array} \\
\begin{array}{c}\text { Turbidez } \\
\text { (uT) }\end{array}\end{array}$} & \multirow{2}{*}{$\begin{array}{c}\begin{array}{c}T_{\mathrm{s} 2}=3.50 \mathrm{~min} \\
\mathrm{~V}_{\mathrm{s} 2}=2.0 \mathrm{~cm} / \mathrm{min}\end{array} \\
\begin{array}{c}\text { Turbidez } \\
(\mathbf{u T})\end{array}\end{array}$} \\
\hline & $\begin{array}{c}\text { Sulfato de } \\
\text { Alumínio } \\
(\mathrm{mg} / \mathfrak{l})\end{array}$ & $\begin{array}{c}\text { Ácido } \\
\text { Clorídrico } \\
0.1 \mathrm{~N}(\mathrm{~m} \ell / \ell)\end{array}$ & $\begin{array}{l}\text { Hidróxido de } \\
\text { Sódio 0.1N } \\
(\mathrm{m \ell} / \mathfrak{\ell})\end{array}$ & & & \\
\hline 1 & 35.0 & 7.29 & - & 6.61 & 94.3 & 83.5 \\
\hline 2 & 35.0 & 5.47 & - & 6.76 & 17.3 & 10.5 \\
\hline 3 & 35.0 & 3.65 & - & 6.92 & 10.2 & 7.11 \\
\hline 4 & 35.0 & - & 4.0 & 7.34 & 13.4 & 7.38 \\
\hline 5 & 35.0 & - & 6.0 & 7.54 & 77.1 & 75.9 \\
\hline 6 & 35.0 & - & 8.0 & 7.82 & 96.5 & 95.9 \\
\hline
\end{tabular}

\section{ESTUDO DE COAGULAÇÃO-FLOCULAÇÃO-SEDIMENTAÇÃO}

\begin{tabular}{|c|c|c|c|c|c|c|}
\hline \multirow{2}{*}{$\begin{array}{l}\text { ENSAIO N } \mathbf{N}^{\circ}: 18 \\
\text { Data : } 22 / 02 / 00\end{array}$} & \multirow{2}{*}{$\begin{array}{c}\text { COAGULANTE } \\
\text { Sulfato de Alumínio } \\
\end{array}$} & \multicolumn{3}{|c|}{ MISTURA RÁPIDA } & \multicolumn{2}{|c|}{ FLOCULAÇÃO } \\
\hline & & $T m r=10 \mathrm{~s}$ & Gm & & $T f=20 \mathrm{~min}$ & $G f=25 \mathrm{~s}^{-1}$ \\
\hline \multicolumn{7}{|c|}{ CARACTERÍSTICAS DA ÁGUA DE ESTUDO } \\
\hline \multirow{2}{*}{ Turbidez (uT) } & \multirow{2}{*}{$\begin{array}{l}\text { Alcalinidade Total } \\
\left(\mathrm{mg} / \ell \mathrm{CaCO}_{3}\right)\end{array}$} & \multicolumn{2}{|c|}{ pH } & \multirow{2}{*}{\multicolumn{2}{|c|}{$\begin{array}{c}\text { Temperatura } \\
{ }^{\circ} \mathrm{C}\end{array}$}} & \multirow{2}{*}{$\begin{array}{l}\text { Potencial } \\
\text { Zeta }(\mathrm{mV})\end{array}$} \\
\hline & & S/ agit. & $\mathrm{C} /$ agit. & & & \\
\hline $99 / 98.8$ & 30 & 7.87 & 7.71 & & 25 & - \\
\hline
\end{tabular}

\begin{tabular}{|c|c|c|c|c|c|c|}
\hline \multirow{2}{*}{ FRASCO } & \multicolumn{3}{|c|}{ DOSAGEM DE PRODUTO QUÍMICO } & \multirow{2}{*}{$\begin{array}{c}\text { pH } \\
\text { de } \\
\text { Coagulação }\end{array}$} & \multirow{2}{*}{$\begin{array}{c}\begin{array}{c}T_{\mathrm{s} 1}=1,75 \mathrm{~min} \\
\mathrm{~V}_{\mathrm{s} 1}=4.0 \mathrm{~cm} / \mathrm{min}\end{array} \\
\begin{array}{c}\text { Turbidez } \\
\text { (uT) }\end{array}\end{array}$} & \multirow{2}{*}{$\begin{array}{c}\begin{array}{c}\mathrm{T}_{\mathrm{s} 2}=3.50 \mathrm{~min} \\
\mathrm{~V}_{\mathrm{s} 2}=2.0 \mathrm{~cm} / \mathrm{min}\end{array} \\
\begin{array}{c}\text { Turbidez } \\
(\mathrm{uT})\end{array}\end{array}$} \\
\hline & $\begin{array}{l}\text { Sulfato de } \\
\text { Alumínio } \\
(\mathrm{mg} / \mathfrak{l})\end{array}$ & $\begin{array}{c}\text { Ácido } \\
\text { Clorídrico } \\
0.1 \mathrm{~N}(\mathrm{~m} \ell / \ell)\end{array}$ & $\begin{array}{l}\text { Hidróxido de } \\
\text { Sódio 0.1N } \\
(\mathrm{m} \ell / \ell)\end{array}$ & & & \\
\hline 1 & 45.0 & 5.47 & - & 6.57 & 97.7 & 95.1 \\
\hline 2 & 45.0 & 3.65 & - & 6.69 & 12.3 & 11.3 \\
\hline 3 & 45.0 & 1.82 & - & 6.91 & 5.74 & 3.06 \\
\hline 4 & 45.0 & - & 2.0 & 7.06 & 6.13 & 2.94 \\
\hline 5 & 45.0 & - & 4.0 & 6.97 & 5.80 & 2.18 \\
\hline 6 & 45.0 & - & 6.0 & 7.24 & 9.63 & 6.51 \\
\hline
\end{tabular}


ESTUDO DE COAGULAÇÃO-FLOCULAÇÃO-SEDIMENTAÇÃO

\begin{tabular}{|c|c|c|c|c|c|c|}
\hline \multirow{2}{*}{$\begin{array}{l}\text { ENSAIO N }{ }^{\circ}: 19 \\
\text { Data : } 22 / 02 / 00\end{array}$} & \multirow{2}{*}{$\begin{array}{c}\text { COAGULANTE } \\
\text { Sulfato de Alumíni } \\
\end{array}$} & \multicolumn{3}{|c|}{ MISTURA RÁPIDA } & \multicolumn{2}{|c|}{ FLOCULAÇ̃̃O } \\
\hline & & $T m r=10 \mathrm{~s}$ & & & $T f=20 \mathrm{~min}$ & Gf $=25 \mathrm{~s}^{-1}$ \\
\hline \multicolumn{7}{|c|}{ CARACTERÍSTICAS DA ÁGUA DE ESTUDO } \\
\hline \multirow{2}{*}{ Turbidez (uT) } & \multirow{2}{*}{$\begin{array}{l}\text { Alcalinidade Total } \\
\left(\mathrm{mg} / \ell \mathrm{CaCO}_{3}\right)\end{array}$} & \multicolumn{2}{|c|}{ pH } & \multirow{2}{*}{\multicolumn{2}{|c|}{$\begin{array}{c}\text { Temperatura } \\
{ }^{\circ} \mathrm{C} \\
\end{array}$}} & \multirow{2}{*}{$\begin{array}{l}\text { Potencial } \\
\text { Zeta }(\mathrm{mV})\end{array}$} \\
\hline & & S/ agit. & $\mathrm{C} /$ agit. & & & \\
\hline $99 / 98.8$ & 30 & 7.87 & 7.71 & & 25 & - \\
\hline
\end{tabular}

\begin{tabular}{|c|c|c|c|c|c|c|}
\hline \multirow{2}{*}{ FRASCO } & \multicolumn{3}{|c|}{ DOSAGEM DE PRODUTO QUÍMICO } & \multirow{2}{*}{$\begin{array}{c}\text { pH } \\
\text { de } \\
\text { Coagulação }\end{array}$} & \multirow{2}{*}{$\begin{array}{c}\begin{array}{c}T_{\mathrm{s} 1}=1,75 \mathrm{~min} \\
\mathrm{~V}_{\mathrm{s} 1}=4.0 \mathrm{~cm} / \mathrm{min}\end{array} \\
\begin{array}{c}\text { Turbidez } \\
\text { (uT) }\end{array}\end{array}$} & \multirow{2}{*}{$\begin{array}{c}\mathrm{T}_{\mathrm{s} 2}=3.50 \mathrm{~min} \\
\mathrm{~V}_{\mathrm{s} 2}=2.0 \mathrm{~cm} / \mathrm{min} \\
\begin{array}{c}\text { Turbidez } \\
\text { (uT) }\end{array}\end{array}$} \\
\hline & $\begin{array}{c}\text { Sulfato de } \\
\text { Alumínio } \\
(\mathrm{mg} / \mathrm{\ell})\end{array}$ & $\begin{array}{c}\text { Ácido } \\
\text { Clorídrico } \\
0.1 \mathrm{~N}(\mathrm{~m} \ell / \ell)\end{array}$ & $\begin{array}{l}\text { Hidróxido de } \\
\text { Sódio 0.1N } \\
(\mathrm{m} \ell / \ell)\end{array}$ & & & \\
\hline 1 & 55.0 & 5.47 & - & 6.28 & 96.7 & 97.8 \\
\hline 2 & 55.0 & 3.65 & - & 6.34 & - & 96.5 \\
\hline 3 & 55.0 & 182 & - & 6.51 & 10.7 & 8.31 \\
\hline 4 & 55.0 & - & 4.0 & 6.97 & 6.29 & 3.17 \\
\hline 5 & 55.0 & - & 8.0 & 7.27 & 11.0 & 4.24 \\
\hline 6 & 55.0 & - & 12.0 & 7.58 & 93.7 & 93.3 \\
\hline
\end{tabular}

\section{ESTUDO DE COAGULAÇÃO-FLOCULAÇÃO-SEDIMENTAÇÃO}

\begin{tabular}{|c|c|c|c|c|c|c|}
\hline \multirow{2}{*}{$\begin{array}{l}\text { ENSAIO } N^{\circ}: 20 \\
\text { Data }: 23 / 02 / 00\end{array}$} & \multirow{2}{*}{$\begin{array}{l}\text { COAGULANTE } \\
\text { Sulfato de Alumíni }\end{array}$} & \multicolumn{3}{|c|}{ MISTURA RÁPIDA } & \multicolumn{2}{|c|}{ FLOCULAÇÃO } \\
\hline & & $\mathrm{Tmr}=10 \mathrm{~s}$ & & & $T f=20 \mathrm{~min}$ & Gf $=25 \mathrm{~s}^{-1}$ \\
\hline \multicolumn{7}{|c|}{ CARACTERÍSTICAS DA ÁGUA DE ESTUDO } \\
\hline \multirow{2}{*}{ Turbidez (uT) } & \multirow{2}{*}{$\begin{array}{c}\text { Alcalinidade Total } \\
\left(\mathrm{mg} / \mathrm{l} \mathrm{CaCO}_{3}\right)\end{array}$} & \multicolumn{2}{|c|}{ pH } & \multirow{2}{*}{\multicolumn{2}{|c|}{$\begin{array}{l}\text { Temperatura } \\
{ }^{\circ} \mathrm{C}\end{array}$}} & \multirow{2}{*}{$\begin{array}{r}\text { Potencial } \\
\text { Zeta }(\mathrm{mV}) \\
\end{array}$} \\
\hline & & S/ agit. & $\mathrm{C} /$ agit. & & & \\
\hline 101 & 29.1 & 7.86 & 7.68 & & 25 & - \\
\hline
\end{tabular}

\begin{tabular}{|c|c|c|c|c|c|c|}
\hline \multirow{2}{*}{ FRASCO } & \multicolumn{3}{|c|}{ DOSAGEM DE PRODUTO QUÍMICO } & \multirow{2}{*}{$\begin{array}{c}\text { pH } \\
\text { de } \\
\text { Coagulação }\end{array}$} & \multirow{2}{*}{$\begin{array}{c}\begin{array}{c}\mathrm{T}_{\mathrm{s} 1}=1,75 \mathrm{~min} \\
\mathrm{~V}_{\mathrm{s} 1}=4.0 \mathrm{~cm} / \mathrm{min}\end{array} \\
\begin{array}{c}\text { Turbidez } \\
(\mathrm{uT})\end{array}\end{array}$} & \multirow{2}{*}{$\begin{array}{c}T_{\mathrm{s} 2}=3.50 \mathrm{~min} \\
\mathrm{~V}_{\mathrm{s} 2}=2.0 \mathrm{~cm} / \mathrm{min} \\
\begin{array}{c}\text { Turbidez } \\
(\mathbf{u T})\end{array}\end{array}$} \\
\hline & $\begin{array}{c}\text { Sulfato de } \\
\text { Alumínio } \\
(\mathrm{mg} / \mathfrak{l})\end{array}$ & $\begin{array}{c}\text { Ácido } \\
\text { Clorídrico } \\
0.1 \mathrm{~N}(\mathrm{~m} \ell / \ell)\end{array}$ & $\begin{array}{l}\text { Hidróxido de } \\
\text { Sódio 0.1N } \\
(\mathrm{m} \ell / \ell)\end{array}$ & & & \\
\hline 1 & 65.0 & 1.82 & - & 6.40 & 96.2 & 91.6 \\
\hline 2 & 65.0 & 0.91 & - & 6.50 & 20.3 & 18.5 \\
\hline 3 & 65.0 & - & 2.0 & 6.64 & 5.15 & 3.69 \\
\hline 4 & 65.0 & - & 6.0 & 6.99 & 11.4 & 6.59 \\
\hline 5 & 65.0 & - & 10.0 & 7.27 & 16.4 & 4.46 \\
\hline 6 & 65.0 & - & 14.0 & 7.74 & 97.2 & 92.4 \\
\hline
\end{tabular}


ESTUDO DE COAGULAÇÃO-FLOCULAÇÃO-SEDIMENTAÇÃO

\begin{tabular}{|c|c|c|c|c|c|c|}
\hline \multirow{2}{*}{$\begin{array}{l}\text { ENSAIO N }{ }^{\circ}: 21 \\
\text { Data : } 01 / 03 / 00\end{array}$} & \multirow{2}{*}{$\begin{array}{l}\text { COAGULANTE } \\
\text { Sulfato de Alumíni } \\
\end{array}$} & \multicolumn{3}{|c|}{ MISTURA RÁPIDA } & \multicolumn{2}{|c|}{ FLOCULAÇÃO } \\
\hline & & $T m r=10 \mathrm{~s}$ & $\mathbf{G m}$ & & $T f=20 \mathrm{~min}$ & Gf $=25 \mathrm{~s}^{-1}$ \\
\hline \multicolumn{7}{|c|}{ CARACTERÍSTICAS DA ÁGUA DE ESTUDO } \\
\hline \multirow{2}{*}{ Turbidez (uT) } & \multirow{2}{*}{$\begin{array}{l}\text { Alcalinidade Total } \\
\left(\mathrm{mg} / \ell \mathrm{CaCO}_{3}\right)\end{array}$} & \multicolumn{2}{|c|}{ pH } & \multirow{2}{*}{\multicolumn{2}{|c|}{$\begin{array}{c}\text { Temperatura } \\
{ }^{\circ} \mathrm{C} \\
\end{array}$}} & \multirow{2}{*}{$\begin{array}{l}\text { Potencial } \\
\text { Zeta }(\mathrm{mV})\end{array}$} \\
\hline & & S/ agit. & $\mathrm{C} /$ agit. & & & \\
\hline 102 & 28.5 & 7.79 & 7.62 & & 25 & - \\
\hline
\end{tabular}

\begin{tabular}{|c|c|c|c|c|c|c|}
\hline \multirow{2}{*}{ FRASCO } & \multicolumn{3}{|c|}{ DOSAGEM DE PRODUTO QUÍMICO } & \multirow{2}{*}{$\begin{array}{c}\text { pH } \\
\text { de } \\
\text { Coagulação }\end{array}$} & \multirow{2}{*}{$\begin{array}{c}\begin{array}{c}T_{\mathrm{s} 1}=1,75 \mathrm{~min} \\
\mathrm{~V}_{\mathrm{s} 1}=4.0 \mathrm{~cm} / \mathrm{min}\end{array} \\
\begin{array}{c}\text { Turbidez } \\
(\mathrm{uT})\end{array}\end{array}$} & \multirow{2}{*}{$\begin{array}{c}\mathrm{T}_{\mathrm{s} 2}=3.50 \mathrm{~min} \\
\mathrm{~V}_{\mathrm{s} 2}=2.0 \mathrm{~cm} / \mathrm{min} \\
\begin{array}{c}\text { Turbidez } \\
\text { (uT) }\end{array}\end{array}$} \\
\hline & $\begin{array}{c}\text { Sulfato de } \\
\text { Alumínio } \\
(\mathrm{mg} / \mathrm{\ell})\end{array}$ & $\begin{array}{c}\text { Ácido } \\
\text { Clorídrico } \\
0.1 \mathrm{~N}(\mathrm{~m} \ell / \ell)\end{array}$ & $\begin{array}{l}\text { Hidróxido de } \\
\text { Sódio 0.1N } \\
(\mathrm{m} \ell / \ell)\end{array}$ & & & \\
\hline 1 & 50.0 & - & 3.0 & 6.82 & 6.71 & 1.85 \\
\hline 2 & 55.0 & 0.91 & - & 6.57 & 6.46 & 1.76 \\
\hline 3 & 55.0 & - & 2.0 & 6.70 & 4.32 & 1.48 \\
\hline 4 & 60.0 & - & 9.0 & 7.24 & 19.0 & 4.20 \\
\hline 5 & 65.0 & - & 4.0 & 6.85 & 3.86 & 1.73 \\
\hline 6 & 65.0 & - & 8.0 & 7.07 & 12.0 & 5.02 \\
\hline
\end{tabular}

\section{ESTUDO DE COAGULAÇÃO-FLOCULAÇÃO-SEDIMENTAÇÃO}

\begin{tabular}{|c|c|c|c|c|c|c|}
\hline \multirow{2}{*}{$\begin{array}{l}\text { ENSAIO } N^{\circ}: 22 \\
\text { Data : } 02 / 03 / 00\end{array}$} & \multirow{2}{*}{$\begin{array}{c}\text { COAGULANTE } \\
\text { Sulfato de Alumíni }\end{array}$} & \multicolumn{3}{|c|}{ MISTURA RÁPIDA } & \multicolumn{2}{|c|}{ FLOCULAÇÃO } \\
\hline & & $T m r=10 \mathrm{~s}$ & & & Tf $=20 \mathrm{~min}$ & Gf $=25 \mathrm{~s}^{-1}$ \\
\hline \multicolumn{7}{|c|}{ CARACTERÍSTICAS DA ÁGUA DE ESTUDO } \\
\hline \multirow{2}{*}{ Turbidez (uT) } & \multirow{2}{*}{$\begin{array}{l}\text { Alcalinidade Total } \\
\left(\mathrm{mg} / \ell \mathrm{CaCO}_{3}\right)\end{array}$} & \multicolumn{2}{|c|}{ pH } & \multirow{2}{*}{\multicolumn{2}{|c|}{$\begin{array}{c}\text { Temperatura } \\
{ }^{\circ} \mathrm{C}\end{array}$}} & \multirow{2}{*}{$\begin{array}{l}\text { Potencial } \\
\text { Zeta }(\mathrm{mV})\end{array}$} \\
\hline & & $\mathrm{S} /$ agit. & $\mathrm{C} /$ agit. & & & \\
\hline 99.2 & 29.1 & 7.75 & 7.52 & & 25 & - \\
\hline
\end{tabular}

\begin{tabular}{|c|c|c|c|c|c|c|}
\hline \multirow{2}{*}{ FRASCO } & \multicolumn{3}{|c|}{ DOSAGEM DE PRODUTO QUÍMICO } & \multirow{2}{*}{$\begin{array}{c}\text { pH } \\
\text { de } \\
\text { Coagulação }\end{array}$} & \multirow{2}{*}{$\begin{array}{c}\begin{array}{c}\mathrm{T}_{\mathrm{s} 1}=1,75 \mathrm{~min} \\
\mathrm{~V}_{\mathrm{s} 1}=4.0 \mathrm{~cm} / \mathrm{min}\end{array} \\
\begin{array}{c}\text { Turbidez } \\
(\mathrm{uT})\end{array}\end{array}$} & \multirow{2}{*}{$\begin{array}{c}T_{\mathrm{s} 2}=3.50 \mathrm{~min} \\
\mathrm{~V}_{\mathrm{s} 2}=2.0 \mathrm{~cm} / \mathrm{min} \\
\begin{array}{c}\text { Turbidez } \\
(\mathbf{u T})\end{array}\end{array}$} \\
\hline & $\begin{array}{c}\text { Sulfato de } \\
\text { Alumínio } \\
(\mathrm{mg} / \mathfrak{l})\end{array}$ & $\begin{array}{c}\text { Ácido } \\
\text { Clorídrico } \\
0.1 \mathrm{~N}(\mathrm{~m} \ell / \ell)\end{array}$ & $\begin{array}{l}\text { Hidróxido de } \\
\text { Sódio 0.1N } \\
(\mathrm{m} \ell / \ell)\end{array}$ & & & \\
\hline 1 & 35.0 & 1.82 & - & 6.77 & 5.93 & 4.38 \\
\hline 2 & 35.0 & - & - & 6.85 & 7.82 & 4.82 \\
\hline 3 & 35.0 & - & 2.0 & 7.00 & 12.2 & 4.85 \\
\hline 4 & 40.0 & - & 2.0 & 6.98 & 7.27 & 3.29 \\
\hline 5 & 45.0 & - & 6.0 & 7.18 & 15.8 & 9.30 \\
\hline 6 & 45.0 & - & 7.0 & 7.29 & 23.1 & 17.8 \\
\hline
\end{tabular}


ESTUDO DE COAGULAÇÃO-FLOCULAÇÃO-SEDIMENTAÇÃO

\begin{tabular}{|c|c|c|c|c|c|c|}
\hline \multirow{2}{*}{$\begin{array}{l}\text { ENSAIO N: } 23 \\
\text { Data : } 02 / 03 / 00\end{array}$} & \multirow{2}{*}{$\begin{array}{l}\text { COAGULANTE } \\
\text { Sulfato de Alumínio }\end{array}$} & \multicolumn{3}{|c|}{ MISTURA RÁPIDA } & \multicolumn{2}{|c|}{ FLOCULAÇÃO } \\
\hline & & $\mathrm{Tmr}=10 \mathrm{~s}$ & \multicolumn{2}{|c|}{$\mathrm{Gmr}=1000 \mathrm{~s}^{-1}$} & $T f=20 \mathrm{~min}$ & $G f=25 s^{-1}$ \\
\hline \multicolumn{7}{|c|}{ CARACTERÍSTICAS DA ÁGUA DE ESTUDO } \\
\hline \multirow{2}{*}{ Turbidez (uT) } & \multirow{2}{*}{$\begin{array}{c}\text { Alcalinidade Total } \\
\left(\mathrm{mg} / \mathrm{l} \mathrm{CaCO}_{3}\right)\end{array}$} & \multicolumn{2}{|c|}{ pH } & \multirow{2}{*}{\multicolumn{2}{|c|}{$\begin{array}{c}\text { Temperatura } \\
{ }^{\circ} \mathrm{C} \\
\end{array}$}} & \multirow{2}{*}{$\begin{array}{l}\text { Potencial } \\
\text { Zeta }(\mathrm{mV}) \\
\end{array}$} \\
\hline & & S/ agit. & $\mathrm{C} /$ agit. & & & \\
\hline 99.2 & 29.1 & 7.75 & 7.52 & & 25 & - \\
\hline
\end{tabular}

\begin{tabular}{|c|c|c|c|c|c|c|}
\hline \multirow{2}{*}{ FRASCO } & \multicolumn{3}{|c|}{ DOSAGEM DE PRODUTO QUÍMICO } & \multirow{2}{*}{$\begin{array}{c}\text { pH } \\
\text { de } \\
\text { Coagulação }\end{array}$} & \multirow{2}{*}{$\begin{array}{c}\mathrm{T}_{\mathrm{s} 1}=1,75 \mathrm{~min} \\
\mathrm{~V}_{\mathrm{s} 1}=4.0 \mathrm{~cm} / \mathrm{min} \\
\\
\text { Turbidez } \\
(\mathrm{uT})\end{array}$} & \multirow{2}{*}{$\begin{array}{c}T_{\mathrm{s} 2}=3.50 \mathrm{~min} \\
\mathbf{V}_{\mathrm{s} 2}=\mathbf{2 . 0 \mathrm { cm } / \mathrm { min }} \\
\\
\begin{array}{c}\text { Turbidez } \\
(\mathrm{uT})\end{array}\end{array}$} \\
\hline & $\begin{array}{c}\text { Sulfato de } \\
\text { Alumínio } \\
(\mathrm{mg} / \ell)\end{array}$ & $\begin{array}{c}\text { Ácido } \\
\text { Clorídrico } \\
\mathbf{0 . 1 N}(\mathrm{m} \ell / \ell)\end{array}$ & $\begin{array}{c}\text { Hidróxido de } \\
\text { Sódio } 0.1 \mathrm{~N} \\
(\mathrm{~m} \ell / \ell)\end{array}$ & & & \\
\hline 1 & 50.0 & - & 5.0 & 6.95 & 8.08 & 3.40 \\
\hline 2 & 55.0 & - & 4.0 & 6.87 & 8.58 & 1.40 \\
\hline 3 & 55.0 & - & 6.0 & 6.95 & 7.60 & 4.74 \\
\hline 4 & 65.0 & - & 7.0 & 6.97 & 11.8 & 3.34 \\
\hline 5 & 70.0 & - & 3.0 & 6.68 & 7.53 & 1.65 \\
\hline 6 & 75.0 & - & 2.0 & 6.49 & 16.4 & 7.20 \\
\hline
\end{tabular}

\section{ESTUDO DE COAGULAÇÃO-FLOCULAÇÃO-SEDIMENTAÇÃO}

\begin{tabular}{|c|c|c|c|c|c|c|}
\hline \multirow{2}{*}{$\begin{array}{l}\text { ENSAIO N }{ }^{\circ}: 24 \\
\text { Data : } 02 / 03 / 00\end{array}$} & \multirow{2}{*}{$\begin{array}{c}\text { COAGULANTE } \\
\text { Sulfato de Alumíni }\end{array}$} & \multicolumn{3}{|c|}{ MISTURA RÁPIDA } & \multicolumn{2}{|c|}{ FLOCULAÇÃO } \\
\hline & & $T m r=10 \mathrm{~s}$ & Gm & & $T f=20 \mathrm{~min}$ & $G f=25 \mathrm{~s}^{-1}$ \\
\hline \multicolumn{7}{|c|}{ CARACTERÍSTICAS DA ÁGUA DE ESTUDO } \\
\hline \multirow{2}{*}{ Turbidez (uT) } & \multirow{2}{*}{$\begin{array}{l}\text { Alcalinidade Total } \\
\left(\mathrm{mg} / \ell \mathrm{CaCO}_{3}\right)\end{array}$} & \multicolumn{2}{|c|}{ pH } & \multirow{2}{*}{\multicolumn{2}{|c|}{$\begin{array}{c}\text { Temperatura } \\
{ }^{\circ} \mathrm{C}\end{array}$}} & \multirow{2}{*}{$\begin{array}{l}\text { Potencial } \\
\text { Zeta }(\mathrm{mV})\end{array}$} \\
\hline & & S/ agit. & $\mathrm{C} /$ agit. & & & \\
\hline 99.2 & 29.1 & 7.75 & 7.52 & & 25 & - \\
\hline
\end{tabular}

\begin{tabular}{|c|c|c|c|c|c|c|}
\hline \multirow{2}{*}{ FRASCO } & \multicolumn{3}{|c|}{ DOSAGEM DE PRODUTO QUÍMICO } & \multirow{2}{*}{$\begin{array}{c}\text { pH } \\
\text { de } \\
\text { Coagulação }\end{array}$} & \multirow{2}{*}{$\begin{array}{c}\begin{array}{c}T_{\mathrm{s} 1}=1,75 \mathrm{~min} \\
\mathrm{~V}_{\mathrm{s} 1}=4.0 \mathrm{~cm} / \mathrm{min}\end{array} \\
\begin{array}{c}\text { Turbidez } \\
(\mathrm{uT})\end{array}\end{array}$} & \multirow{2}{*}{$\begin{array}{c}\mathrm{T}_{\mathrm{s} 2}=3.50 \mathrm{~min} \\
\mathrm{~V}_{\mathrm{s} 2}=2.0 \mathrm{~cm} / \mathrm{min}\end{array}$} \\
\hline & $\begin{array}{c}\text { Sulfato de } \\
\text { Alumínio } \\
(\mathrm{mg} / \mathfrak{l})\end{array}$ & $\begin{array}{c}\text { Ácido } \\
\text { Clorídrico } \\
0.1 \mathrm{~N}(\mathrm{~m} \ell / \ell)\end{array}$ & $\begin{array}{l}\text { Hidróxido de } \\
\text { Sódio 0.1N } \\
(\mathrm{m} \ell / \ell)\end{array}$ & & & \\
\hline 1 & 30.0 & 6.38 & - & 6.48 & 17.4 & 8.96 \\
\hline 2 & 35.0 & - & 3.0 & 7.16 & 10.2 & 4.06 \\
\hline 3 & 40.0 & - & 3.0 & 7.05 & 10.4 & 4.18 \\
\hline 4 & 50.0 & - & 6.0 & 7.23 & 14.0 & 5.58 \\
\hline 5 & 50.0 & - & 7.0 & 7.34 & 11.0 & 3.69 \\
\hline 6 & 60.0 & - & 7.5 & 7.18 & 12.4 & 3.40 \\
\hline
\end{tabular}


ANEXO - B

ENSAIOS DO REATOR ESTÁTICO - ÁGUA I PARA O COAGULANTE

CLORETO FÉRRICO 
ESTUDO DE COAGULAÇÃO-FLOCULAÇÃO-SEDIMENTAÇÃO

\begin{tabular}{|c|c|c|c|c|c|c|}
\hline \multirow{2}{*}{$\begin{array}{l}\text { ENSAIO N }^{\circ}: 01 \\
\text { Data : } 23 / 02 / 00\end{array}$} & \multirow{2}{*}{$\begin{array}{c}\text { COAGULANTE } \\
\text { Cloreto Férrico }\end{array}$} & \multicolumn{3}{|c|}{ MISTURA RÁPIDA } & \multicolumn{2}{|c|}{ FLOCULAÇÃO } \\
\hline & & $\mathrm{Tmr}=10 \mathrm{~s}$ & & & $\mathbf{T f}=\mathbf{2 0} \mathrm{min}$ & $G \mathbf{f}=25 \mathrm{~s}^{-1}$ \\
\hline \multicolumn{7}{|c|}{ CARACTERÍSTICAS DA ÁGUA DE ESTUDO } \\
\hline \multirow{2}{*}{ Turbidez (uT) } & \multirow{2}{*}{$\begin{array}{c}\text { Alcalinidade Total } \\
\left(\mathrm{mg} / \ell \mathrm{CaCO}_{3}\right)\end{array}$} & \multicolumn{2}{|c|}{ pH } & \multirow{2}{*}{\multicolumn{2}{|c|}{$\begin{array}{c}\text { Temperatura } \\
{ }^{\circ} \mathrm{C} \\
\end{array}$}} & \multirow{2}{*}{$\begin{array}{r}\text { Potencial } \\
\text { Zeta }(\mathrm{mV}) \\
\end{array}$} \\
\hline & & S/ agit. & $\mathrm{C} /$ agit. & & & \\
\hline 101 & 29.1 & 7.86 & 7.68 & & 25 & - \\
\hline
\end{tabular}

\begin{tabular}{|c|c|c|c|c|c|c|}
\hline \multirow{2}{*}{ FRASCO } & \multicolumn{3}{|c|}{ DOSAGEM DE PRODUTO QUÍMICO } & \multirow{2}{*}{$\begin{array}{c}\text { pH } \\
\text { de } \\
\text { Coagulação }\end{array}$} & \multirow{2}{*}{$\begin{array}{c}T_{\mathrm{s} 1}=1,75 \mathrm{~min} \\
\mathrm{~V}_{\mathrm{s} 1}=4.0 \mathrm{~cm} / \mathrm{min}\end{array}$} & \multirow{2}{*}{$\begin{array}{c}\begin{array}{c}T_{\mathrm{s} 2}=3.50 \mathrm{~min} \\
\mathrm{~V}_{\mathrm{s} 2}=2.0 \mathrm{~cm} / \mathrm{min}\end{array} \\
\begin{array}{c}\text { Turbidez } \\
(\mathbf{u T})\end{array}\end{array}$} \\
\hline & $\begin{array}{l}\text { Cloreto Férrico } \\
(\mathrm{mg} / \mathfrak{l})\end{array}$ & $\begin{array}{c}\text { Ácido } \\
\text { Clorídrico } \\
0.1 \mathrm{~N}(\mathrm{~m} \ell / \ell)\end{array}$ & $\begin{array}{l}\text { Hidróxido de } \\
\text { Sódio 0.1 } \\
(\mathrm{ml} / \mathfrak{l})\end{array}$ & & & \\
\hline 1 & 20.0 & 5.47 & - & 6.70 & 7.76 & 3.51 \\
\hline 2 & 20.0 & 3.65 & - & 6.75 & 6.86 & 5.70 \\
\hline 3 & 20.0 & 1.82 & - & 6.91 & 9.44 & 4.24 \\
\hline 4 & 20.0 & - & - & 7.09 & 12.0 & 5.21 \\
\hline 5 & 20.0 & - & 2.0 & 7.22 & 7.66 & 4.33 \\
\hline 6 & 20.0 & - & 4.0 & 7.39 & 14.7 & 10.0 \\
\hline
\end{tabular}

\section{ESTUDO DE COAGULAÇÃO-FLOCULAÇÃO-SEDIMENTAÇÃO}

\begin{tabular}{|c|c|c|c|c|c|c|}
\hline \multirow{2}{*}{$\begin{array}{l}\text { ENSAIO N }{ }^{\circ}: 02 \\
\text { Data : } 23 / 02 / 00\end{array}$} & \multirow{2}{*}{$\begin{array}{c}\text { COAGULANTE } \\
\text { Cloreto Férrico }\end{array}$} & \multicolumn{3}{|c|}{ MISTURA RÁPIDA } & \multicolumn{2}{|c|}{ FLOCULAÇÃO } \\
\hline & & $\mathrm{Tmr}=10 \mathrm{~s}$ & & & $T f=20 \min$ & $G f=25 \mathrm{~s}^{-1}$ \\
\hline \multicolumn{7}{|c|}{ CARACTERÍSTICAS DA ÁGUA DE ESTUDO } \\
\hline \multirow{2}{*}{ Turbidez (uT) } & \multirow{2}{*}{$\begin{array}{c}\text { Alcalinidade Total } \\
\left(\mathrm{mg} / \ell \mathrm{CaCO}_{3}\right)\end{array}$} & \multicolumn{2}{|c|}{ pH } & \multirow{2}{*}{\multicolumn{2}{|c|}{$\begin{array}{c}\text { Temperatura } \\
{ }^{\circ} \mathrm{C} \\
\end{array}$}} & \multirow{2}{*}{$\begin{array}{l}\text { Potencial } \\
\text { Zeta }(\mathrm{mV})\end{array}$} \\
\hline & & S/ agit. & $\mathrm{C} /$ agit. & & & \\
\hline 101 & 29.1 & 7.86 & 7.68 & & 25 & - \\
\hline
\end{tabular}

\begin{tabular}{|c|c|c|c|c|c|c|}
\hline \multirow{2}{*}{ FRASCO } & \multicolumn{3}{|c|}{ DOSAGEM DE PRODUTO QUÍMICO } & \multirow{2}{*}{$\begin{array}{c}\text { pH } \\
\text { de } \\
\text { Coagulação }\end{array}$} & \multirow{2}{*}{$\begin{array}{c}\begin{array}{c}T_{\mathrm{s} 1}=1,75 \mathrm{~min} \\
\mathrm{~V}_{\mathrm{s} 1}=4.0 \mathrm{~cm} / \mathrm{min}\end{array} \\
\begin{array}{c}\text { Turbidez } \\
\text { (uT) }\end{array}\end{array}$} & \multirow{2}{*}{$\begin{array}{c}\mathrm{T}_{\mathrm{s} 2}=3.50 \mathrm{~min} \\
\mathrm{~V}_{\mathrm{s} 2}=2.0 \mathrm{~cm} / \mathrm{min} \\
\begin{array}{c}\text { Turbidez } \\
\text { (uT) }\end{array}\end{array}$} \\
\hline & $\begin{array}{l}\text { Cloreto Férrico } \\
(\mathrm{mg} / \mathfrak{l})\end{array}$ & $\begin{array}{c}\text { Ácido } \\
\text { Clorídrico } \\
0.1 \mathrm{~N}(\mathrm{~m} \ell / \mathfrak{l})\end{array}$ & $\begin{array}{l}\text { Hidróxido de } \\
\text { Sódio 0.1N } \\
(\mathrm{m} \ell / \ell)\end{array}$ & & & \\
\hline 1 & 10.0 & 7.29 & - & 6.82 & 12.5 & 12.4 \\
\hline 2 & 10.0 & 5.47 & - & 6.88 & 18.1 & 8.21 \\
\hline 3 & 10.0 & 1.82 & - & 7.18 & 24.8 & 19.9 \\
\hline 4 & 10.0 & - & - & 7.43 & 94.0 & 93.0 \\
\hline 5 & 10.0 & - & 2.0 & 7.59 & 92.4 & 92.5 \\
\hline 6 & 10.0 & - & 4.0 & 7.98 & 93.4 & 89.8 \\
\hline
\end{tabular}


ESTUDO DE COAGULAÇÃO-FLOCULAÇÃO-SEDIMENTAÇÃO

\begin{tabular}{|c|c|c|c|c|c|c|}
\hline \multirow{2}{*}{$\begin{array}{l}\text { ENSAIO N }^{\circ}: 03 \\
\text { Data : } 23 / 02 / 00\end{array}$} & \multirow{2}{*}{$\begin{array}{l}\text { COAGULANTE } \\
\text { Cloreto Férico }\end{array}$} & \multicolumn{3}{|c|}{ MISTURA RÁPIDA } & \multicolumn{2}{|c|}{ FLOCULAÇÃO } \\
\hline & & $\mathrm{Tmr}=10 \mathrm{~s}$ & Gm & & $T f=20 \mathrm{~min}$ & $G f=25 \mathrm{~s}^{-1}$ \\
\hline \multicolumn{7}{|c|}{ CARACTERÍSTICAS DA ÁGUA DE ESTUDO } \\
\hline \multirow{2}{*}{ Turbidez (uT) } & \multirow{2}{*}{$\begin{array}{c}\text { Alcalinidade Total } \\
\left(\mathrm{mg} / \ell \mathrm{CaCO}_{3}\right)\end{array}$} & \multicolumn{2}{|c|}{ pH } & \multirow{2}{*}{\multicolumn{2}{|c|}{$\begin{array}{c}\text { Temperatura } \\
{ }^{\circ} \mathrm{C} \\
\end{array}$}} & \multirow{2}{*}{$\begin{array}{l}\text { Potencial } \\
\text { Zeta }(\mathrm{mV})\end{array}$} \\
\hline & & S/ agit. & $\mathrm{C} /$ agit. & & & \\
\hline 101 & 29.1 & 7.86 & 7.68 & & 25 & - \\
\hline
\end{tabular}

\begin{tabular}{|c|c|c|c|c|c|c|}
\hline \multirow{2}{*}{ FRASCO } & \multicolumn{3}{|c|}{ DOSAGEM DE PRODUTO QUÍMICO } & \multirow{2}{*}{$\begin{array}{c}\text { pH } \\
\text { de } \\
\text { Coagulação }\end{array}$} & \multirow{2}{*}{$\begin{array}{c}\begin{array}{c}T_{\mathrm{s} 1}=1,75 \mathrm{~min} \\
\mathrm{~V}_{\mathrm{s} 1}=4.0 \mathrm{~cm} / \mathrm{min}\end{array} \\
\begin{array}{c}\text { Turbidez } \\
\text { (uT) }\end{array}\end{array}$} & \multirow{2}{*}{$\begin{array}{c}\mathrm{T}_{\mathrm{s} 2}=3.50 \mathrm{~min} \\
\mathrm{~V}_{\mathrm{s} 2}=2.0 \mathrm{~cm} / \mathrm{min} \\
\begin{array}{c}\text { Turbidez } \\
\text { (uT) }\end{array}\end{array}$} \\
\hline & $\begin{array}{c}\text { Cloreto Férrico } \\
(\mathrm{mg} / \mathfrak{l})\end{array}$ & $\begin{array}{c}\text { Ácido } \\
\text { Clorídrico } \\
0.1 \mathrm{~N}(\mathrm{~m} \ell / \ell)\end{array}$ & $\begin{array}{l}\text { Hidróxido de } \\
\text { Sódio 0.1N } \\
(\mathrm{m} \ell / \ell)\end{array}$ & & & \\
\hline 1 & 25.0 & 7.29 & - & 6.16 & 16.2 & 10.9 \\
\hline 2 & 25.0 & 3.65 & - & 6.53 & 4.12 & 1.53 \\
\hline 3 & 25.0 & - & - & 6.86 & 10.2 & 3.23 \\
\hline 4 & 25.0 & - & 1.0 & 7.02 & 9.27 & 5.17 \\
\hline 5 & 25.0 & - & 3.0 & 7.18 & 7.68 & 4.16 \\
\hline 6 & 25.0 & - & 6.0 & 7.47 & 66.0 & 61.6 \\
\hline
\end{tabular}

\section{ESTUDO DE COAGULAÇÃO-FLOCULAÇÃO-SEDIMENTAÇÃO}

\begin{tabular}{|c|c|c|c|c|c|c|}
\hline \multirow{2}{*}{$\begin{array}{l}\text { ENSAIO No: } 04 \\
\text { Data : } 23 / 02 / 00\end{array}$} & \multirow{2}{*}{$\begin{array}{l}\text { COAGULANTE } \\
\text { Cloreto Férrico }\end{array}$} & \multicolumn{3}{|c|}{ MISTURA RÁPIDA } & \multicolumn{2}{|c|}{ FLOCULAÇÃO } \\
\hline & & $\mathrm{Tmr}=10 \mathrm{~s}$ & & & $T f=20 \mathrm{~min}$ & Gf $=25 \mathrm{~s}^{-1}$ \\
\hline \multicolumn{7}{|c|}{ CARACTERÍSTICAS DA ÁGUA DE ESTUDO } \\
\hline \multirow{2}{*}{ Turbidez (uT) } & \multirow{2}{*}{$\begin{array}{c}\text { Alcalinidade Total } \\
\left(\mathrm{mg} / \mathrm{l} \mathrm{CaCO}_{3}\right)\end{array}$} & \multicolumn{2}{|c|}{ pH } & \multirow{2}{*}{\multicolumn{2}{|c|}{$\begin{array}{l}\text { Temperatura } \\
{ }^{\circ} \mathrm{C}\end{array}$}} & \multirow{2}{*}{$\begin{array}{r}\text { Potencial } \\
\text { Zeta }(\mathrm{mV}) \\
\end{array}$} \\
\hline & & S/ agit. & $\mathrm{C} /$ agit. & & & \\
\hline $98 / 99$ & - & - & - & & 25 & - \\
\hline
\end{tabular}

\begin{tabular}{|c|c|c|c|c|c|c|}
\hline \multirow{2}{*}{ FRASCO } & \multicolumn{3}{|c|}{ DOSAGEM DE PRODUTO QUÍMICO } & \multirow{2}{*}{$\begin{array}{c}\text { pH } \\
\text { de } \\
\text { Coagulação }\end{array}$} & \multirow{2}{*}{$\begin{array}{c}\begin{array}{c}\mathrm{T}_{\mathrm{s} 1}=1,75 \mathrm{~min} \\
\mathrm{~V}_{\mathrm{s} 1}=4.0 \mathrm{~cm} / \mathrm{min}\end{array} \\
\begin{array}{c}\text { Turbidez } \\
(\mathrm{uT})\end{array}\end{array}$} & \multirow{2}{*}{$\begin{array}{c}\mathrm{T}_{\mathrm{s} 2}=3.50 \mathrm{~min} \\
\mathrm{~V}_{\mathrm{s} 2}=2.0 \mathrm{~cm} / \mathrm{min} \\
\begin{array}{c}\text { Turbidez } \\
(\mathrm{uT})\end{array}\end{array}$} \\
\hline & $\begin{array}{c}\text { Cloreto Férrico } \\
(\mathrm{mg} / \mathbf{\ell})\end{array}$ & $\begin{array}{c}\text { Ácido } \\
\text { Clorídrico } \\
0.1 \mathrm{~N}(\mathrm{~m} \ell / \ell)\end{array}$ & $\begin{array}{l}\text { Hidróxido de } \\
\text { Sódio 0.1N } \\
(\mathrm{m} \ell / \ell)\end{array}$ & & & \\
\hline 1 & 30.0 & 9.11 & - & 5.18 & 98.0 & 97.4 \\
\hline 2 & 30.0 & 5.47 & - & 6.15 & 2.77 & 1.45 \\
\hline 3 & 30.0 & 1.82 & - & 6.54 & 3.93 & 2.06 \\
\hline 4 & 30.0 & - & - & 6.74 & 9.57 & 2.38 \\
\hline 5 & 30.0 & - & 2.0 & 6.90 & 7.72 & 2.84 \\
\hline 6 & 30.0 & - & 6.0 & 7.20 & 4.78 & 2.35 \\
\hline
\end{tabular}


ESTUDO DE COAGULAÇÃO-FLOCULAÇÃO-SEDIMENTAÇÃO

\begin{tabular}{|c|c|c|c|c|c|c|}
\hline \multirow{2}{*}{$\begin{array}{l}\text { ENSAIO N }{ }^{\circ}: 05 \\
\text { Data : } 24 / 02 / 00\end{array}$} & \multirow{2}{*}{$\begin{array}{c}\text { COAGULANTE } \\
\text { Cloreto Férrico }\end{array}$} & \multicolumn{3}{|c|}{ MISTURA RÁPIDA } & \multicolumn{2}{|c|}{ FLOCULAÇÃO } \\
\hline & & $\mathrm{Tmr}=10 \mathrm{~s}$ & Gm & & $T f=20 \mathrm{~min}$ & Gf $=25 \mathrm{~s}^{-1}$ \\
\hline \multicolumn{7}{|c|}{ CARACTERÍSTICAS DA ÁGUA DE ESTUDO } \\
\hline \multirow{2}{*}{ Turbidez (uT) } & \multirow{2}{*}{$\begin{array}{l}\text { Alcalinidade Total } \\
\left(\mathrm{mg} / \ell \mathrm{CaCO}_{3}\right)\end{array}$} & \multicolumn{2}{|c|}{ pH } & \multirow{2}{*}{\multicolumn{2}{|c|}{$\begin{array}{c}\text { Temperatura } \\
{ }^{\circ} \mathrm{C} \\
\end{array}$}} & \multirow{2}{*}{$\begin{array}{l}\text { Potencial } \\
\text { Zeta }(\mathrm{mV})\end{array}$} \\
\hline & & S/ agit. & $\mathrm{C} /$ agit. & & & \\
\hline $98 / 101$ & 30 & 7.93 & 7.71 & & 25 & - \\
\hline
\end{tabular}

\begin{tabular}{|c|c|c|c|c|c|c|}
\hline \multirow{2}{*}{ FRASCO } & \multicolumn{3}{|c|}{ DOSAGEM DE PRODUTO QUÍMICO } & \multirow{2}{*}{$\begin{array}{c}\text { pH } \\
\text { de } \\
\text { Coagulação }\end{array}$} & \multirow{2}{*}{$\begin{array}{c}\begin{array}{c}T_{\mathrm{s1}}=1,75 \mathrm{~min} \\
\mathrm{~V}_{\mathrm{s1}}=4.0 \mathrm{~cm} / \mathrm{min}\end{array} \\
\begin{array}{c}\text { Turbidez } \\
(\mathrm{uT})\end{array}\end{array}$} & \multirow{2}{*}{$\begin{array}{c}\mathrm{T}_{\mathrm{s} 2}=3.50 \mathrm{~min} \\
\mathrm{~V}_{\mathrm{s} 2}=2.0 \mathrm{~cm} / \mathrm{min} \\
\begin{array}{c}\text { Turbidez } \\
\text { (uT) }\end{array}\end{array}$} \\
\hline & $\begin{array}{l}\text { Cloreto Férrico } \\
(\mathrm{mg} / \mathrm{l})\end{array}$ & $\begin{array}{c}\text { Ácido } \\
\text { Clorídrico } \\
0.1 \mathrm{~N}(\mathrm{~m} \ell / \ell)\end{array}$ & $\begin{array}{l}\text { Hidróxido de } \\
\text { Sódio 0.1N } \\
(\mathrm{m} \ell / \ell)\end{array}$ & & & \\
\hline 1 & 35.0 & 7.29 & - & 5.74 & - & 99.7 \\
\hline 2 & 35.0 & 3.65 & - & 6.18 & 2.35 & 1.79 \\
\hline 3 & 35.0 & - & - & 6.58 & 4.95 & 1.34 \\
\hline 4 & 35.0 & - & 4.0 & 6.97 & 9.84 & 5.32 \\
\hline 5 & 35.0 & - & 6.0 & 7.16 & 8.72 & 3.99 \\
\hline 6 & 35.0 & - & 8.0 & 7.31 & 8.03 & 4.93 \\
\hline
\end{tabular}

\section{ESTUDO DE COAGULAÇÃO-FLOCULAÇÃO-SEDIMENTAÇÃO}

\begin{tabular}{|c|c|c|c|c|c|c|}
\hline \multirow{2}{*}{$\begin{array}{l}\text { ENSAIO } N^{\circ}: 06 \\
\text { Data : } 24 / 02 / 00\end{array}$} & \multirow{2}{*}{$\begin{array}{c}\text { COAGULANTE } \\
\text { Cloreto Férrico }\end{array}$} & \multicolumn{3}{|c|}{ MISTURA RÁPIDA } & \multicolumn{2}{|c|}{ FLOCULAÇÃO } \\
\hline & & $T m r=10 \mathrm{~s}$ & & & Tf $=20 \mathrm{~min}$ & Gf $=25 \mathrm{~s}^{-1}$ \\
\hline \multicolumn{7}{|c|}{ CARACTERÍSTICAS DA ÁGUA DE ESTUDO } \\
\hline \multirow{2}{*}{ Turbidez (uT) } & \multirow{2}{*}{$\begin{array}{l}\text { Alcalinidade Total } \\
\left(\mathrm{mg} / \ell \mathrm{CaCO}_{3}\right)\end{array}$} & \multicolumn{2}{|c|}{ pH } & \multirow{2}{*}{\multicolumn{2}{|c|}{$\begin{array}{c}\text { Temperatura } \\
{ }^{\circ} \mathrm{C}\end{array}$}} & \multirow{2}{*}{$\begin{array}{l}\text { Potencial } \\
\text { Zeta }(m V)\end{array}$} \\
\hline & & S/ agit. & $\mathrm{C} /$ agit. & & & \\
\hline $98 / 101$ & 30 & 7.93 & 7.71 & & 25 & - \\
\hline
\end{tabular}

\begin{tabular}{|c|c|c|c|c|c|c|}
\hline \multirow{2}{*}{ FRASCO } & \multicolumn{3}{|c|}{ DOSAGEM DE PRODUTO QUÍMICO } & \multirow{2}{*}{$\begin{array}{c}\text { pH } \\
\text { de } \\
\text { Coagulação }\end{array}$} & \multirow{2}{*}{$\begin{array}{c}\begin{array}{c}T_{\mathrm{s} 1}=1,75 \mathrm{~min} \\
\mathrm{~V}_{\mathrm{s} 1}=4.0 \mathrm{~cm} / \mathrm{min}\end{array} \\
\begin{array}{c}\text { Turbidez } \\
(\mathrm{uT})\end{array}\end{array}$} & \multirow{2}{*}{$\begin{array}{c}\begin{array}{c}T_{\mathrm{s} 2}=3.50 \mathrm{~min} \\
\mathrm{~V}_{\mathrm{s} 2}=2.0 \mathrm{~cm} / \mathrm{min}\end{array} \\
\begin{array}{c}\text { Turbidez } \\
(\mathrm{uT})\end{array}\end{array}$} \\
\hline & $\begin{array}{c}\text { Cloreto Férrico } \\
(\mathrm{mg} / \mathfrak{\ell})\end{array}$ & $\begin{array}{c}\text { Ácido } \\
\text { Clorídrico } \\
0.1 \mathrm{~N}(\mathrm{~m} \ell / \ell)\end{array}$ & $\begin{array}{l}\text { Hidróxido de } \\
\text { Sódio 0.1N } \\
(\mathrm{ml} / \mathfrak{\ell})\end{array}$ & & & \\
\hline 1 & 40.0 & 5.47 & - & 5.69 & 102.0 & 99.3 \\
\hline 2 & 40.0 & 1.82 & - & 6.22 & 1.97 & 1.14 \\
\hline 3 & 40.0 & - & - & 6.44 & 2.30 & 1.85 \\
\hline 4 & 40.0 & - & 4.0 & - & - & - \\
\hline 5 & 40.0 & - & 10.0 & 7.28 & 9.60 & 5.13 \\
\hline 6 & 40.0 & - & 16.0 & 8.24 & 94.5 & 93.0 \\
\hline
\end{tabular}


ESTUDO DE COAGULAÇÃO-FLOCULAÇÃO-SEDIMENTAÇÃO

\begin{tabular}{|c|c|c|c|c|c|c|}
\hline \multirow{2}{*}{$\begin{array}{l}\text { ENSAIO N }{ }^{\circ}: 07 \\
\text { Data : } 24 / 02 / 00\end{array}$} & \multirow{2}{*}{$\begin{array}{c}\text { COAGULANTE } \\
\text { Cloreto Férrico }\end{array}$} & \multicolumn{3}{|c|}{ MISTURA RÁPIDA } & \multicolumn{2}{|c|}{ FLOCULAÇ̃̃O } \\
\hline & & $\mathrm{Tmr}=10 \mathrm{~s}$ & & & $T f=20 \mathrm{~min}$ & Gf $=25 \mathrm{~s}^{-1}$ \\
\hline \multicolumn{7}{|c|}{ CARACTERÍSTICAS DA ÁGUA DE ESTUDO } \\
\hline \multirow{2}{*}{ Turbidez (uT) } & \multirow{2}{*}{$\begin{array}{l}\text { Alcalinidade Total } \\
\left(\mathrm{mg} / \ell \mathrm{CaCO}_{3}\right)\end{array}$} & \multicolumn{2}{|c|}{ pH } & \multirow{2}{*}{\multicolumn{2}{|c|}{$\begin{array}{c}\text { Temperatura } \\
{ }^{\circ} \mathrm{C} \\
\end{array}$}} & \multirow{2}{*}{$\begin{array}{l}\text { Potencial } \\
\text { Zeta }(\mathrm{mV})\end{array}$} \\
\hline & & S/ agit. & $\mathrm{C} /$ agit. & & & \\
\hline $98 / 101$ & 30 & 7.93 & 7.71 & & 25 & - \\
\hline
\end{tabular}

\begin{tabular}{|c|c|c|c|c|c|c|}
\hline \multirow{2}{*}{ FRASCO } & \multicolumn{3}{|c|}{ DOSAGEM DE PRODUTO QUÍMICO } & \multirow{2}{*}{$\begin{array}{c}\text { pH } \\
\text { de } \\
\text { Coagulação }\end{array}$} & \multirow{2}{*}{$\begin{array}{c}\begin{array}{c}T_{\mathrm{s} 1}=1,75 \mathrm{~min} \\
\mathrm{~V}_{\mathrm{s} 1}=4.0 \mathrm{~cm} / \mathrm{min}\end{array} \\
\begin{array}{c}\text { Turbidez } \\
\text { (uT) }\end{array}\end{array}$} & \multirow{2}{*}{$\begin{array}{c}\mathrm{T}_{\mathrm{s} 2}=3.50 \mathrm{~min} \\
\mathrm{~V}_{\mathrm{s} 2}=2.0 \mathrm{~cm} / \mathrm{min} \\
\begin{array}{c}\text { Turbidez } \\
\text { (uT) }\end{array}\end{array}$} \\
\hline & $\begin{array}{c}\text { Cloreto Férrico } \\
(\mathrm{mg} / \mathfrak{l})\end{array}$ & $\begin{array}{c}\text { Ácido } \\
\text { Clorídrico } \\
0.1 \mathrm{~N}(\mathrm{~m} \ell / \ell)\end{array}$ & $\begin{array}{l}\text { Hidróxido de } \\
\text { Sódio 0.1N } \\
(\mathrm{m} \ell / \ell)\end{array}$ & & & \\
\hline 1 & 45.0 & 3.65 & - & 5.83 & 98.6 & 101.0 \\
\hline 2 & 45.0 & 1.82 & - & 6.07 & 3.93 & 1.61 \\
\hline 3 & 45.0 & - & - & 6.32 & 1.72 & 0.88 \\
\hline 4 & 45.0 & - & 4.0 & 6.70 & 11.8 & 3.40 \\
\hline 5 & 45.0 & - & 8.0 & - & 13.6 & - \\
\hline 6 & 45.0 & - & 12.0 & 7.33 & 8.88 & 6.35 \\
\hline
\end{tabular}

\section{ESTUDO DE COAGULAÇÃO-FLOCULAÇÃO-SEDIMENTAÇÃO}

\begin{tabular}{|c|c|c|c|c|c|c|}
\hline \multirow{2}{*}{$\begin{array}{l}\text { ENSAIO } N^{\circ}: 08 \\
\text { Data : } 24 / 02 / 00\end{array}$} & \multirow{2}{*}{$\begin{array}{c}\text { COAGULANTE } \\
\text { Cloreto Férrico }\end{array}$} & \multicolumn{3}{|c|}{ MISTURA RÁPIDA } & \multicolumn{2}{|c|}{ FLOCULAÇÃO } \\
\hline & & $T m r=10 \mathrm{~s}$ & & & Tf $=20 \mathrm{~min}$ & Gf $=25 \mathrm{~s}^{-1}$ \\
\hline \multicolumn{7}{|c|}{ CARACTERÍSTICAS DA ÁGUA DE ESTUDO } \\
\hline \multirow{2}{*}{ Turbidez (uT) } & \multirow{2}{*}{$\begin{array}{l}\text { Alcalinidade Total } \\
\left(\mathrm{mg} / \ell \mathrm{CaCO}_{3}\right)\end{array}$} & \multicolumn{2}{|c|}{ pH } & \multirow{2}{*}{\multicolumn{2}{|c|}{$\begin{array}{c}\text { Temperatura } \\
{ }^{\circ} \mathrm{C}\end{array}$}} & \multirow{2}{*}{$\begin{array}{l}\text { Potencial } \\
\text { Zeta }(m V)\end{array}$} \\
\hline & & S/ agit. & $\mathrm{C} /$ agit. & & & \\
\hline $98 / 101$ & 30 & 7.93 & 7.71 & & 25 & - \\
\hline
\end{tabular}

\begin{tabular}{|c|c|c|c|c|c|c|}
\hline \multirow{2}{*}{ FRASCO } & \multicolumn{3}{|c|}{ DOSAGEM DE PRODUTO QUÍMICO } & \multirow{2}{*}{$\begin{array}{c}\text { pH } \\
\text { de } \\
\text { Coagulação }\end{array}$} & \multirow{2}{*}{$\begin{array}{c}\begin{array}{c}T_{\mathrm{s1}}=1,75 \mathrm{~min} \\
\mathrm{~V}_{\mathrm{s1} 1}=4.0 \mathrm{~cm} / \mathrm{min}\end{array} \\
\begin{array}{c}\text { Turbidez } \\
\text { (uT) }\end{array}\end{array}$} & \multirow{2}{*}{$\begin{array}{c}\mathrm{T}_{\mathrm{s} 2}=3.50 \mathrm{~min} \\
\mathrm{~V}_{\mathrm{s} 2}=2.0 \mathrm{~cm} / \mathrm{min} \\
\begin{array}{c}\text { Turbidez } \\
(\mathrm{uT})\end{array}\end{array}$} \\
\hline & $\begin{array}{c}\text { Cloreto Férrico } \\
(\mathrm{mg} / \mathfrak{\ell})\end{array}$ & $\begin{array}{c}\text { Ácido } \\
\text { Clorídrico } \\
0.1 \mathrm{~N}(\mathrm{~m} \ell / \ell)\end{array}$ & $\begin{array}{l}\text { Hidróxido de } \\
\text { Sódio 0.1N } \\
(\mathrm{m} \ell / \ell)\end{array}$ & & & \\
\hline 1 & 50.0 & 1.82 & - & - & - & - \\
\hline 2 & 50.0 & - & - & 6.22 & 1.72 & 0.79 \\
\hline 3 & 50.0 & - & 4.0 & 6.47 & 3.92 & 1.18 \\
\hline 4 & 50.0 & - & 10.0 & 7.00 & 12.3 & 5.92 \\
\hline 5 & 50.0 & - & 16.0 & 7.33 & 8.59 & 4.63 \\
\hline 6 & 50.0 & - & 20.0 & 7.79 & 91.2 & 91.6 \\
\hline
\end{tabular}


ESTUDO DE COAGULAÇÃO-FLOCULAÇÃO-SEDIMENTAÇÃO

\begin{tabular}{|c|c|c|c|c|c|c|}
\hline \multirow{2}{*}{$\begin{array}{l}\text { ENSAIO N }{ }^{\circ}: 09 \\
\text { Data : } 24 / 02 / 00\end{array}$} & \multirow{2}{*}{$\begin{array}{c}\text { COAGULANTE } \\
\text { Cloreto Férrico }\end{array}$} & \multicolumn{3}{|c|}{ MISTURA RÁPIDA } & \multicolumn{2}{|c|}{ FLOCULAÇÃO } \\
\hline & & $\mathrm{Tmr}=10 \mathrm{~s}$ & Gm & & $T f=20 \mathrm{~min}$ & Gf $=25 \mathrm{~s}^{-1}$ \\
\hline \multicolumn{7}{|c|}{ CARACTERÍSTICAS DA ÁGUA DE ESTUDO } \\
\hline \multirow{2}{*}{ Turbidez (uT) } & \multirow{2}{*}{$\begin{array}{l}\text { Alcalinidade Total } \\
\left(\mathrm{mg} / \ell \mathrm{CaCO}_{3}\right)\end{array}$} & \multicolumn{2}{|c|}{ pH } & \multirow{2}{*}{\multicolumn{2}{|c|}{$\begin{array}{c}\text { Temperatura } \\
{ }^{\circ} \mathrm{C} \\
\end{array}$}} & \multirow{2}{*}{$\begin{array}{l}\text { Potencial } \\
\text { Zeta }(\mathrm{mV})\end{array}$} \\
\hline & & S/ agit. & $\mathrm{C} /$ agit. & & & \\
\hline $98 / 101$ & 30 & 7.93 & 7.71 & & 25 & - \\
\hline
\end{tabular}

\begin{tabular}{|c|c|c|c|c|c|c|}
\hline \multirow{2}{*}{ FRASCO } & \multicolumn{3}{|c|}{ DOSAGEM DE PRODUTO QUÍMICO } & \multirow{2}{*}{$\begin{array}{c}\text { pH } \\
\text { de } \\
\text { Coagulação }\end{array}$} & \multirow{2}{*}{$\begin{array}{c}T_{\mathrm{s} 1}=1,75 \mathrm{~min} \\
\mathrm{~V}_{\mathrm{s} 1}=4.0 \mathrm{~cm} / \mathrm{min}\end{array}$} & \multirow{2}{*}{$\begin{array}{c}\begin{array}{c}T_{\mathrm{s} 2}=3.50 \mathrm{~min} \\
\mathbf{V}_{\mathrm{s} 2}=2.0 \mathrm{~cm} / \mathrm{min}\end{array} \\
\qquad \begin{array}{c}\text { Turbidez } \\
\text { (uT) }\end{array}\end{array}$} \\
\hline & $\begin{array}{c}\text { Cloreto Férrico } \\
(\mathrm{mg} / \mathfrak{l})\end{array}$ & $\begin{array}{c}\text { Ácido } \\
\text { Clorídrico } \\
0.1 \mathrm{~N}(\mathrm{~m} \ell / \ell)\end{array}$ & $\begin{array}{l}\text { Hidróxido de } \\
\text { Sódio 0.1N } \\
(\mathrm{ml} / \mathfrak{l})\end{array}$ & & & \\
\hline 1 & 55.0 & 0.91 & - & 5.94 & 97.5 & 95.1 \\
\hline 2 & 55.0 & - & - & 6.00 & 90.0 & 87.3 \\
\hline 3 & 55.0 & - & 4.0 & 6.39 & 2.43 & 1.10 \\
\hline 4 & 55.0 & - & 10.0 & 6.93 & 13.8 & 5.84 \\
\hline 5 & 55.0 & - & 16.0 & 7.50 & 24.0 & 20.9 \\
\hline 6 & 55.0 & - & 22.0 & 8.57 & 92.3 & 91.4 \\
\hline
\end{tabular}

\section{ESTUDO DE COAGULAÇÃO-FLOCULAÇÃO-SEDIMENTAÇÃO}

\begin{tabular}{|c|c|c|c|c|c|c|}
\hline \multirow{2}{*}{$\begin{array}{l}\text { ENSAIO N } N^{\circ}: 10 \\
\text { Data }: 24 / 02 / 00\end{array}$} & \multirow{2}{*}{$\begin{array}{c}\text { COAGULANTE } \\
\text { Cloreto Férrico }\end{array}$} & \multicolumn{3}{|c|}{ MISTURA RÁPIDA } & \multicolumn{2}{|c|}{ FLOCULAÇÃO } \\
\hline & & $\mathrm{Tmr}=10 \mathrm{~s}$ & & $\mathrm{~s}^{-1}$ & $T f=20 \mathrm{~min}$ & $G f=25 \mathrm{~s}^{-1}$ \\
\hline \multicolumn{7}{|c|}{ CARACTERÍSTICAS DA ÁGUA DE ESTUDO } \\
\hline \multirow{2}{*}{ Turbidez (uT) } & \multirow{2}{*}{$\begin{array}{c}\text { Alcalinidade Total } \\
\left(\mathrm{mg} / \ell \mathrm{CaCO}_{3}\right)\end{array}$} & \multicolumn{2}{|c|}{ pH } & \multirow{2}{*}{\multicolumn{2}{|c|}{$\begin{array}{c}\text { Temperatura } \\
{ }^{\circ} \mathrm{C}\end{array}$}} & \multirow{2}{*}{$\begin{array}{l}\text { Potencial } \\
\text { Zeta }(m V)\end{array}$} \\
\hline & & S/ agit. & $\mathrm{C} /$ agit. & & & \\
\hline $98 / 101$ & 30 & 7.93 & 7.71 & & 25 & - \\
\hline
\end{tabular}

\begin{tabular}{|c|c|c|c|c|c|c|}
\hline \multirow{2}{*}{ FRASCO } & \multicolumn{3}{|c|}{ DOSAGEM DE PRODUTO QUÍMICO } & \multirow{2}{*}{$\begin{array}{c}\text { pH } \\
\text { de } \\
\text { Coagulação }\end{array}$} & \multirow{2}{*}{$\begin{array}{c}\begin{array}{c}T_{\mathrm{s} 1}=1,75 \mathrm{~min} \\
\mathrm{~V}_{\mathrm{s} 1}=4.0 \mathrm{~cm} / \mathrm{min}\end{array} \\
\begin{array}{c}\text { Turbidez } \\
\text { (uT) }\end{array}\end{array}$} & \multirow{2}{*}{$\begin{array}{c}\begin{array}{c}\mathrm{T}_{\mathrm{s} 2}=3.50 \mathrm{~min} \\
\mathrm{~V}_{\mathrm{s} 2}=2.0 \mathrm{~cm} / \mathrm{min}\end{array} \\
\begin{array}{c}\text { Turbidez } \\
(\mathrm{uT})\end{array}\end{array}$} \\
\hline & $\begin{array}{c}\text { Cloreto Férrico } \\
(\mathrm{mg} / \mathfrak{l})\end{array}$ & $\begin{array}{c}\text { Ácido } \\
\text { Clorídrico } \\
0.1 \mathrm{~N}(\mathrm{~m} \ell / \ell)\end{array}$ & $\begin{array}{l}\text { Hidróxido de } \\
\text { Sódio 0.1N } \\
(\mathrm{ml} / \mathfrak{l})\end{array}$ & & & \\
\hline 1 & 60.0 & - & - & 5.79 & 99.1 & 96.6 \\
\hline 2 & 60.0 & - & 4.0 & 6.22 & - & 0.63 \\
\hline 3 & 60.0 & - & 10.0 & 6.79 & 10.6 & 4.95 \\
\hline 4 & 60.0 & - & 16.0 & 7.31 & 7.13 & 3.50 \\
\hline 5 & 60.0 & - & 20.0 & 7.89 & 94.7 & 90.3 \\
\hline 6 & 60.0 & - & 24.0 & 8.57 & 93.4 & 91.7 \\
\hline
\end{tabular}


ESTUDO DE COAGULAÇÃO-FLOCULAÇÃO-SEDIMENTAÇÃO

\begin{tabular}{|c|c|c|c|c|c|c|}
\hline \multirow{2}{*}{$\begin{array}{l}\text { ENSAIO No: } 11 \\
\text { Data : } 24 / 02 / 00\end{array}$} & \multirow{2}{*}{$\begin{array}{l}\text { COAGULANTE } \\
\text { Cloreto Férrico }\end{array}$} & \multicolumn{3}{|c|}{ MISTURA RÁPIDA } & \multicolumn{2}{|c|}{ FLOCULAÇÃO } \\
\hline & & $\mathrm{Tmr}=10 \mathrm{~s}$ & \multicolumn{2}{|c|}{$\mathrm{Gmr}=1000 \mathrm{~s}^{-1}$} & $T f=20 \mathrm{~min}$ & $G f=25 s^{-1}$ \\
\hline \multicolumn{7}{|c|}{ CARACTERÍSTICAS DA ÁGUA DE ESTUDO } \\
\hline \multirow{2}{*}{ Turbidez (uT) } & \multirow{2}{*}{$\begin{array}{c}\text { Alcalinidade Total } \\
\left(\mathrm{mg} / \ell \mathrm{CaCO}_{3}\right)\end{array}$} & \multicolumn{2}{|c|}{ pH } & \multirow{2}{*}{\multicolumn{2}{|c|}{$\begin{array}{c}\text { Temperatura } \\
{ }^{\circ} \mathrm{C} \\
\end{array}$}} & \multirow{2}{*}{$\begin{array}{l}\text { Potencial } \\
\text { Zeta }(\mathrm{mV}) \\
\end{array}$} \\
\hline & & S/ agit. & $\mathrm{C} /$ agit. & & & \\
\hline $98 / 101$ & 30 & 7.93 & 7.71 & & 25 & - \\
\hline
\end{tabular}

\begin{tabular}{|c|c|c|c|c|c|c|}
\hline \multirow{2}{*}{ FRASCO } & \multicolumn{3}{|c|}{ DOSAGEM DE PRODUTO QUÍMICO } & \multirow{2}{*}{$\begin{array}{c}\text { pH } \\
\text { de } \\
\text { Coagulação }\end{array}$} & \multirow{2}{*}{$\begin{array}{c}T_{\mathrm{s} 1}=1,75 \mathrm{~min} \\
\mathrm{~V}_{\mathrm{s} 1}=4.0 \mathrm{~cm} / \mathrm{min} \\
\begin{array}{c}\text { Turbidez } \\
\text { (uT) }\end{array}\end{array}$} & \multirow{2}{*}{$\begin{array}{c}T_{\mathrm{s} 2}=3.50 \mathrm{~min} \\
\mathrm{~V}_{\mathrm{s} 2}=\mathbf{2 . 0 \mathrm { cm } / \mathrm { min }} \\
\\
\begin{array}{c}\text { Turbidez } \\
(\mathrm{uT})\end{array}\end{array}$} \\
\hline & $\begin{array}{l}\text { Cloreto Férrico } \\
\qquad(\mathrm{mg} / \ell)\end{array}$ & $\begin{array}{c}\text { Ácido } \\
\text { Clorídrico } \\
0.1 \mathrm{~N}(\mathrm{~m} \ell / \ell)\end{array}$ & $\begin{array}{c}\text { Hidróxido de } \\
\text { Sódio 0.1N } \\
(\mathrm{m} \ell / \ell)\end{array}$ & & & \\
\hline 1 & 65.0 & - & 1.0 & 5.60 & 96.2 & 95.0 \\
\hline 2 & 65.0 & - & 4.0 & 5.97 & 7.92 & 5.11 \\
\hline 3 & 65.0 & - & 10.0 & 6.57 & 9.29 & 4.59 \\
\hline 4 & 65.0 & - & 16.0 & 7.10 & 7.91 & 6.78 \\
\hline 5 & 65.0 & - & 20.0 & 7.44 & 13.2 & 9.90 \\
\hline 6 & 65.0 & - & 22.0 & 7.72 & 92.7 & 92.3 \\
\hline
\end{tabular}

\section{ESTUDO DE COAGULAÇÃO-FLOCULAÇÃO-SEDIMENTAÇÃO}

\begin{tabular}{|c|c|c|c|c|c|c|}
\hline \multirow{2}{*}{$\begin{array}{l}\text { ENSAIO } N^{\circ}: 12 \\
\text { Data : } 24 / 02 / 00\end{array}$} & \multirow{2}{*}{$\begin{array}{c}\text { COAGULANTE } \\
\text { Cloreto Férrico }\end{array}$} & \multicolumn{3}{|c|}{ MISTURA RÁPIDA } & \multicolumn{2}{|c|}{ FLOCULAÇÃO } \\
\hline & & $T m r=10 \mathrm{~s}$ & & & Tf $=20 \mathrm{~min}$ & Gf $=25 \mathrm{~s}^{-1}$ \\
\hline \multicolumn{7}{|c|}{ CARACTERÍSTICAS DA ÁGUA DE ESTUDO } \\
\hline \multirow{2}{*}{ Turbidez (uT) } & \multirow{2}{*}{$\begin{array}{l}\text { Alcalinidade Total } \\
\left(\mathrm{mg} / \ell \mathrm{CaCO}_{3}\right)\end{array}$} & \multicolumn{2}{|c|}{ pH } & \multirow{2}{*}{\multicolumn{2}{|c|}{$\begin{array}{c}\text { Temperatura } \\
{ }^{\circ} \mathrm{C}\end{array}$}} & \multirow{2}{*}{$\begin{array}{l}\text { Potencial } \\
\text { Zeta }(m V)\end{array}$} \\
\hline & & S/ agit. & $\mathrm{C} /$ agit. & & & \\
\hline $98 / 101$ & 30 & 7.93 & 7.71 & & 25 & - \\
\hline
\end{tabular}

\begin{tabular}{|c|c|c|c|c|c|c|}
\hline \multirow{2}{*}{ FRASCO } & \multicolumn{3}{|c|}{ DOSAGEM DE PRODUTO QUÍMICO } & \multirow{2}{*}{$\begin{array}{c}\text { pH } \\
\text { de } \\
\text { Coagulação }\end{array}$} & \multirow{2}{*}{$\begin{array}{c}\begin{array}{c}T_{\mathrm{sl}}=1,75 \mathrm{~min} \\
\mathrm{~V}_{\mathrm{s} 1}=4.0 \mathrm{~cm} / \mathrm{min}\end{array} \\
\begin{array}{c}\text { Turbidez } \\
\text { (uT) }\end{array}\end{array}$} & \multirow{2}{*}{$\begin{array}{c}\begin{array}{c}T_{\mathrm{s} 2}=3.50 \mathrm{~min} \\
\mathrm{~V}_{\mathrm{s} 2}=2.0 \mathrm{~cm} / \mathrm{min}\end{array} \\
\begin{array}{c}\text { Turbidez } \\
(\mathrm{uT})\end{array}\end{array}$} \\
\hline & $\begin{array}{c}\text { Cloreto Férrico } \\
(\mathrm{mg} / \mathfrak{\ell})\end{array}$ & $\begin{array}{c}\text { Ácido } \\
\text { Clorídrico } \\
0.1 \mathrm{~N}(\mathrm{~m} \ell / \ell)\end{array}$ & $\begin{array}{l}\text { Hidróxido de } \\
\text { Sódio 0.1N } \\
(\mathrm{ml} / \mathfrak{\ell})\end{array}$ & & & \\
\hline 1 & 70.0 & - & 3.0 & 5.88 & 95.2 & 95.0 \\
\hline 2 & 70.0 & - & 6.0 & 6.15 & - & 0.96 \\
\hline 3 & 70.0 & - & 10.0 & 6.54 & 10.2 & 2.01 \\
\hline 4 & 70.0 & - & 16.0 & 7.05 & 26.1 & 5.61 \\
\hline 5 & 70.0 & - & 20.0 & 7.35 & 8.68 & 5.15 \\
\hline 6 & 70.0 & - & 24.0 & 7.88 & 92.6 & 93.1 \\
\hline
\end{tabular}


ESTUDO DE COAGULAÇÃO-FLOCULAÇÃO-SEDIMENTAÇÃO

\begin{tabular}{|c|c|c|c|c|c|c|}
\hline \multirow{2}{*}{$\begin{array}{l}\text { ENSAIO No: } 13 \\
\text { Data : } 25 / 02 / 00\end{array}$} & \multirow{2}{*}{$\begin{array}{l}\text { COAGULANTE } \\
\text { Cloreto Férrico }\end{array}$} & \multicolumn{3}{|c|}{ MISTURA RÁPIDA } & \multicolumn{2}{|c|}{ FLOCULAÇÃO } \\
\hline & & $\mathrm{Tmr}=10 \mathrm{~s}$ & \multicolumn{2}{|c|}{$\mathrm{Gmr}=1000 \mathrm{~s}^{-1}$} & $T f=20 \mathrm{~min}$ & $G f=25 s^{-1}$ \\
\hline \multicolumn{7}{|c|}{ CARACTERÍSTICAS DA ÁGUA DE ESTUDO } \\
\hline \multirow{2}{*}{ Turbidez (uT) } & \multirow{2}{*}{$\begin{array}{c}\text { Alcalinidade Total } \\
\left(\mathrm{mg} / \ell \mathrm{CaCO}_{3}\right)\end{array}$} & \multicolumn{2}{|c|}{ pH } & \multirow{2}{*}{\multicolumn{2}{|c|}{$\begin{array}{c}\text { Temperatura } \\
{ }^{\circ} \mathrm{C} \\
\end{array}$}} & \multirow{2}{*}{$\begin{array}{l}\text { Potencial } \\
\text { Zeta }(\mathrm{mV}) \\
\end{array}$} \\
\hline & & S/ agit. & $\mathrm{C} /$ agit. & & & \\
\hline $101 / 98$ & 28.5 & 7.76 & 7.53 & & 25 & - \\
\hline
\end{tabular}

\begin{tabular}{|c|c|c|c|c|c|c|}
\hline \multirow{2}{*}{ FRASCO } & \multicolumn{3}{|c|}{ DOSAGEM DE PRODUTO QUÍMICO } & \multirow{2}{*}{$\begin{array}{c}\text { pH } \\
\text { de } \\
\text { Coagulação }\end{array}$} & \multirow{2}{*}{$\begin{array}{c}T_{\mathrm{s} 1}=1,75 \mathrm{~min} \\
\mathrm{~V}_{\mathrm{s} 1}=4.0 \mathrm{~cm} / \mathrm{min} \\
\begin{array}{c}\text { Turbidez } \\
\text { (uT) }\end{array}\end{array}$} & \multirow{2}{*}{$\begin{array}{c}T_{\mathrm{s} 2}=3.50 \mathrm{~min} \\
\mathrm{~V}_{\mathrm{s} 2}=\mathbf{2 . 0 \mathrm { cm } / \mathrm { min }} \\
\\
\begin{array}{c}\text { Turbidez } \\
(\mathrm{uT})\end{array}\end{array}$} \\
\hline & $\begin{array}{l}\text { Cloreto Férrico } \\
\qquad(\mathrm{mg} / \ell)\end{array}$ & $\begin{array}{c}\text { Ácido } \\
\text { Clorídrico } \\
0.1 \mathrm{~N}(\mathrm{~m} \ell / \ell)\end{array}$ & $\begin{array}{c}\text { Hidróxido de } \\
\text { Sódio 0.1N } \\
(\mathrm{m} \ell / \ell)\end{array}$ & & & \\
\hline 1 & 75.0 & - & 2.0 & 4.63 & 99.6 & 99.4 \\
\hline 2 & 75.0 & - & 4.0 & 5.16 & 98.9 & 96.7 \\
\hline 3 & 75.0 & - & 10.0 & 6.10 & 1.67 & 0.90 \\
\hline 4 & 75.0 & - & 16.0 & 6.77 & 16.7 & 7.45 \\
\hline 5 & 75.0 & - & 22.0 & 7.30 & 23.0 & 10.5 \\
\hline 6 & 75.0 & - & 24.0 & 7.58 & 92.4 & 93.5 \\
\hline
\end{tabular}

\section{ESTUDO DE COAGULAÇÃO-FLOCULAÇÃO-SEDIMENTAÇÃO}

\begin{tabular}{|c|c|c|c|c|c|c|}
\hline \multirow{2}{*}{$\begin{array}{l}\text { ENSAIO N }{ }^{\circ}: 14 \\
\text { Data : } 25 / 02 / 00\end{array}$} & \multirow{2}{*}{$\begin{array}{c}\text { COAGULANTE } \\
\text { Cloreto Férrico }\end{array}$} & \multicolumn{3}{|c|}{ MISTURA RÁPIDA } & \multicolumn{2}{|c|}{ FLOCULAÇÃO } \\
\hline & & $T m r=10 \mathrm{~s}$ & Gm & & $T f=20 \mathrm{~min}$ & $G f=25 \mathrm{~s}^{-1}$ \\
\hline \multicolumn{7}{|c|}{ CARACTERÍSTICAS DA ÁGUA DE ESTUDO } \\
\hline \multirow{2}{*}{ Turbidez (uT) } & \multirow{2}{*}{$\begin{array}{l}\text { Alcalinidade Total } \\
\left(\mathrm{mg} / \ell \mathrm{CaCO}_{3}\right)\end{array}$} & \multicolumn{2}{|c|}{ pH } & \multirow{2}{*}{\multicolumn{2}{|c|}{$\begin{array}{c}\text { Temperatura } \\
{ }^{\circ} \mathrm{C}\end{array}$}} & \multirow{2}{*}{$\begin{array}{l}\text { Potencial } \\
\text { Zeta }(\mathrm{mV})\end{array}$} \\
\hline & & S/ agit. & $\mathrm{C} /$ agit. & & & \\
\hline $101 / 98$ & 28.5 & 7.76 & 7.53 & & 25 & - \\
\hline
\end{tabular}

\begin{tabular}{|c|c|c|c|c|c|c|}
\hline \multirow{2}{*}{ FRASCO } & \multicolumn{3}{|c|}{ DOSAGEM DE PRODUTO QUÍMICO } & \multirow{2}{*}{$\begin{array}{c}\text { pH } \\
\text { de } \\
\text { Coagulação }\end{array}$} & \multirow{2}{*}{$\begin{array}{c}\begin{array}{c}\mathrm{T}_{\mathrm{s} 1}=1,75 \mathrm{~min} \\
\mathrm{~V}_{\mathrm{s} 1}=4.0 \mathrm{~cm} / \mathrm{min}\end{array} \\
\begin{array}{c}\text { Turbidez } \\
(\mathrm{uT})\end{array}\end{array}$} & \multirow{2}{*}{$\begin{array}{c}\mathrm{T}_{\mathrm{s} 2}=3.50 \mathrm{~min} \\
\mathrm{~V}_{\mathrm{s} 2}=2.0 \mathrm{~cm} / \mathrm{min} \\
\begin{array}{c}\text { Turbidez } \\
(\mathrm{uT})\end{array}\end{array}$} \\
\hline & $\begin{array}{c}\text { Cloreto Férrico } \\
(\mathrm{mg} / \mathfrak{\ell})\end{array}$ & $\begin{array}{c}\text { Ácido } \\
\text { Clorídrico } \\
0.1 \mathrm{~N}(\mathrm{~m} \ell / \ell)\end{array}$ & $\begin{array}{l}\text { Hidróxido de } \\
\text { Sódio 0.1N } \\
(\mathrm{m} \ell / \ell)\end{array}$ & & & \\
\hline 1 & 80.0 & - & 8.0 & 5.85 & 6.03 & 3.30 \\
\hline 2 & 80.0 & - & 12.0 & 6.23 & 5.24 & 2.85 \\
\hline 3 & 80.0 & - & 16.0 & 6.55 & 22.8 & 4.82 \\
\hline 4 & 80.0 & - & 20.0 & 6.89 & 16.7 & 4.37 \\
\hline 5 & 80.0 & - & 24.0 & 7.10 & 9.82 & 6.20 \\
\hline 6 & 80.0 & - & 26.0 & 7.40 & 91.3 & 90.0 \\
\hline
\end{tabular}


ESTUDO DE COAGULAÇÃO-FLOCULAÇÃO-SEDIMENTAÇÃO

\begin{tabular}{|c|c|c|c|c|c|c|}
\hline \multirow{2}{*}{$\begin{array}{l}\text { ENSAIO N }{ }^{\circ}: 15 \\
\text { Data }: 25 / 02 / 00\end{array}$} & \multirow{2}{*}{$\begin{array}{c}\text { COAGULANTE } \\
\text { Cloreto Férrico }\end{array}$} & \multicolumn{3}{|c|}{ MISTURA RÁPIDA } & \multicolumn{2}{|c|}{ FLOCULAÇÃO } \\
\hline & & $\mathrm{Tmr}=10 \mathrm{~s}$ & Gm & & $\mathbf{T f}=\mathbf{2 0} \mathrm{min}$ & $\mathbf{G f}=25 \mathrm{~s}^{-1}$ \\
\hline \multicolumn{7}{|c|}{ CARACTERÍSTICAS DA ÁGUA DE ESTUDO } \\
\hline \multirow{2}{*}{ Turbidez (uT) } & \multirow{2}{*}{$\begin{array}{l}\text { Alcalinidade Total } \\
\left(\mathrm{mg} / \ell \mathrm{CaCO}_{3}\right)\end{array}$} & \multicolumn{2}{|c|}{ pH } & \multirow{2}{*}{\multicolumn{2}{|c|}{$\begin{array}{c}\text { Temperatura } \\
{ }^{\circ} \mathrm{C} \\
\end{array}$}} & \multirow{2}{*}{$\begin{array}{r}\text { Potencial } \\
\text { Zeta }(\mathrm{mV})\end{array}$} \\
\hline & & S/ agit. & $\mathrm{C} /$ agit. & & & \\
\hline $101 / 98$ & 28.5 & 7.76 & 7.53 & & 25 & - \\
\hline
\end{tabular}

\begin{tabular}{|c|c|c|c|c|c|c|}
\hline \multirow{2}{*}{ FRASCO } & \multicolumn{3}{|c|}{ DOSAGEM DE PRODUTO QUÍMICO } & \multirow{2}{*}{$\begin{array}{c}\text { pH } \\
\text { de } \\
\text { Coagulação }\end{array}$} & \multirow{2}{*}{$\begin{array}{c}\begin{array}{c}T_{\mathrm{s} 1}=1,75 \mathrm{~min} \\
\mathrm{~V}_{\mathrm{s} 1}=4.0 \mathrm{~cm} / \mathrm{min}\end{array} \\
\begin{array}{c}\text { Turbidez } \\
(\mathrm{uT})\end{array}\end{array}$} & \multirow{2}{*}{$\begin{array}{c}\mathrm{T}_{\mathrm{s} 2}=3.50 \mathrm{~min} \\
\mathrm{~V}_{\mathrm{s} 2}=2.0 \mathrm{~cm} / \mathrm{min} \\
\begin{array}{c}\text { Turbidez } \\
\text { (uT) }\end{array}\end{array}$} \\
\hline & $\begin{array}{c}\text { Cloreto Férrico } \\
(\mathrm{mg} / \mathfrak{\ell})\end{array}$ & $\begin{array}{c}\text { Ácido } \\
\text { Clorídrico } \\
0.1 \mathrm{~N}(\mathrm{~m} \ell / \ell)\end{array}$ & $\begin{array}{l}\text { Hidróxido de } \\
\text { Sódio 0.1N } \\
(\mathrm{m} \ell / \ell)\end{array}$ & & & \\
\hline 1 & 20.0 & 7.29 & - & 6.20 & 5.51 & 6.81 \\
\hline 2 & 20.0 & - & 5.0 & 7.46 & 96.8 & 93.6 \\
\hline 3 & 30.0 & - & 8.0 & 7.32 & 93.8 & 93.3 \\
\hline 4 & 35.0 & - & 10.0 & 7.58 & 94.4 & 92.4 \\
\hline 5 & 45.0 & - & 14.0 & 7.59 & 93.0 & 92.3 \\
\hline 6 & 80.0 & - & 6.0 & 5.30 & 97.6 & 94.8 \\
\hline
\end{tabular}

\section{ESTUDO DE COAGULAÇÃO-FLOCULAÇÃO-SEDIMENTAÇÃO}

\begin{tabular}{|c|c|c|c|c|c|c|}
\hline \multirow{2}{*}{$\begin{array}{l}\text { ENSAIO } N^{\circ}: 16 \\
\text { Data : } 29 / 02 / 00\end{array}$} & \multirow{2}{*}{$\begin{array}{c}\text { COAGULANTE } \\
\text { Cloreto Férrico }\end{array}$} & \multicolumn{3}{|c|}{ MISTURA RÁPIDA } & \multicolumn{2}{|c|}{ FLOCULAÇÃO } \\
\hline & & $T m r=10 \mathrm{~s}$ & & & Tf $=20 \mathrm{~min}$ & Gf $=25 \mathrm{~s}^{-1}$ \\
\hline \multicolumn{7}{|c|}{ CARACTERÍSTICAS DA ÁGUA DE ESTUDO } \\
\hline \multirow{2}{*}{ Turbidez (uT) } & \multirow{2}{*}{$\begin{array}{l}\text { Alcalinidade Total } \\
\left(\mathrm{mg} / \ell \mathrm{CaCO}_{3}\right)\end{array}$} & \multicolumn{2}{|c|}{ pH } & \multirow{2}{*}{\multicolumn{2}{|c|}{$\begin{array}{c}\text { Temperatura } \\
{ }^{\circ} \mathrm{C}\end{array}$}} & \multirow{2}{*}{$\begin{array}{l}\text { Potencial } \\
\text { Zeta }(\mathrm{mV})\end{array}$} \\
\hline & & S/ agit. & $\mathrm{C} /$ agit. & & & \\
\hline 102 & 30 & 7.74 & 7.58 & & 25 & - \\
\hline
\end{tabular}

\begin{tabular}{|c|c|c|c|c|c|c|}
\hline \multirow{2}{*}{ FRASCO } & \multicolumn{3}{|c|}{ DOSAGEM DE PRODUTO QUÍMICO } & \multirow{2}{*}{$\begin{array}{c}\text { pH } \\
\text { de } \\
\text { Coagulação }\end{array}$} & \multirow{2}{*}{$\begin{array}{c}\begin{array}{c}\mathrm{T}_{\mathrm{s} 1}=1,75 \mathrm{~min} \\
\mathrm{~V}_{\mathrm{s} 1}=4.0 \mathrm{~cm} / \mathrm{min}\end{array} \\
\begin{array}{c}\text { Turbidez } \\
\text { (uT) }\end{array}\end{array}$} & \multirow{2}{*}{$\begin{array}{c}T_{\mathrm{s} 2}=3.50 \mathrm{~min} \\
\mathrm{~V}_{\mathrm{s} 2}=2.0 \mathrm{~cm} / \mathrm{min}\end{array}$} \\
\hline & $\begin{array}{c}\text { Cloreto Férrico } \\
(\mathrm{mg} / \mathfrak{l})\end{array}$ & $\begin{array}{c}\text { Ácido } \\
\text { Clorídrico } \\
0.1 \mathrm{~N}(\mathrm{~m} \ell / \ell)\end{array}$ & $\begin{array}{l}\text { Hidróxido de } \\
\text { Sódio 0.1N } \\
(\mathrm{ml} / \mathfrak{l})\end{array}$ & & & \\
\hline 1 & 20.0 & 6.0 & - & 6.44 & 10.4 & 6.32 \\
\hline 2 & 20.0 & 6.5 & - & 6.42 & 11.3 & 3.93 \\
\hline 3 & 25.0 & 4.5 & - & 6.42 & 8.87 & 4.08 \\
\hline 4 & 25.0 & 6.0 & - & 6.37 & 5.67 & 4.26 \\
\hline 5 & 30.0 & 3.65 & - & 6.39 & 5.45 & 2.63 \\
\hline 6 & 30.0 & 6.5 & - & 6.18 & 5.27 & 4.67 \\
\hline
\end{tabular}


ESTUDO DE COAGULAÇÃO-FLOCULAÇÃO-SEDIMENTAÇÃO

\begin{tabular}{|c|c|c|c|c|c|c|}
\hline \multirow{2}{*}{$\begin{array}{l}\text { ENSAIO N: } 17 \\
\text { Data : } 29 / 02 / 00\end{array}$} & \multirow{2}{*}{$\begin{array}{l}\text { COAGULANTE } \\
\text { Cloreto Férrico }\end{array}$} & \multicolumn{3}{|c|}{ MISTURA RÁPIDA } & \multicolumn{2}{|c|}{ FLOCULAÇÃO } \\
\hline & & $\mathrm{Tmr}=10 \mathrm{~s}$ & \multicolumn{2}{|c|}{$\mathrm{Gmr}=1000 \mathrm{~s}^{-1}$} & $T f=20 \mathrm{~min}$ & $G f=25 s^{-1}$ \\
\hline \multicolumn{7}{|c|}{ CARACTERÍSTICAS DA ÁGUA DE ESTUDO } \\
\hline \multirow{2}{*}{ Turbidez (uT) } & \multirow{2}{*}{$\begin{array}{c}\text { Alcalinidade Total } \\
\left(\mathrm{mg} / \ell \mathrm{CaCO}_{3}\right)\end{array}$} & \multicolumn{2}{|c|}{ pH } & \multirow{2}{*}{\multicolumn{2}{|c|}{$\begin{array}{c}\text { Temperatura } \\
{ }^{\circ} \mathrm{C} \\
\end{array}$}} & \multirow{2}{*}{$\begin{array}{l}\text { Potencial } \\
\text { Zeta }(\mathrm{mV}) \\
\end{array}$} \\
\hline & & S/ agit. & $\mathrm{C} /$ agit. & & & \\
\hline 102 & 30 & 7.74 & 7.58 & & 25 & - \\
\hline
\end{tabular}

\begin{tabular}{|c|c|c|c|c|c|c|}
\hline \multirow{2}{*}{ FRASCO } & \multicolumn{3}{|c|}{ DOSAGEM DE PRODUTO QUÍMICO } & \multirow{2}{*}{$\begin{array}{c}\text { pH } \\
\text { de } \\
\text { Coagulação }\end{array}$} & \multirow{2}{*}{$\begin{array}{c}\mathrm{T}_{\mathrm{s} 1}=1,75 \mathrm{~min} \\
\mathrm{~V}_{\mathrm{s} 1}=4.0 \mathrm{~cm} / \mathrm{min} \\
\\
\text { Turbidez } \\
(\mathrm{uT})\end{array}$} & \multirow{2}{*}{$\begin{array}{c}T_{\mathrm{s} 2}=3.50 \mathrm{~min} \\
\mathbf{V}_{\mathrm{s} 2}=\mathbf{2 . 0 \mathrm { cm } / \mathrm { min }} \\
\\
\begin{array}{c}\text { Turbidez } \\
(\mathrm{uT})\end{array}\end{array}$} \\
\hline & $\begin{array}{l}\text { Cloreto Férrico } \\
(\mathrm{mg} / \ell)\end{array}$ & $\begin{array}{c}\text { Ácido } \\
\text { Clorídrico } \\
0.1 \mathrm{~N}(\mathrm{~m} \ell / \ell)\end{array}$ & $\begin{array}{c}\text { Hidróxido de } \\
\text { Sódio 0.1N } \\
(\mathrm{m} \ell / \ell)\end{array}$ & & & \\
\hline 1 & 20.0 & 9.11 & - & 6.15 & 10.8 & 9.09 \\
\hline 2 & 20.0 & 5.47 & - & 6.43 & 9.78 & 8.18 \\
\hline 3 & 25.0 & 3.65 & - & 6.49 & 7.37 & 4.11 \\
\hline 4 & 30.0 & 7.29 & - & 6.07 & 12.3 & 13.3 \\
\hline 5 & 30.0 & 2.73 & - & 6.38 & 5.21 & 3.05 \\
\hline 6 & 35.0 & 5.47 & - & 6.08 & 7.77 & 8.6 \\
\hline
\end{tabular}

\section{ESTUDO DE COAGULAÇÃO-FLOCULAÇÃO-SEDIMENTAÇÃO}

\begin{tabular}{|c|c|c|c|c|c|c|}
\hline \multirow{2}{*}{$\begin{array}{l}\text { ENSAIO } N^{\circ}: 18 \\
\text { Data : } 29 / 02 / 00\end{array}$} & \multirow{2}{*}{$\begin{array}{c}\text { COAGULANTE } \\
\text { Cloreto Férrico }\end{array}$} & \multicolumn{3}{|c|}{ MISTURA RÁPIDA } & \multicolumn{2}{|c|}{ FLOCULAÇÃO } \\
\hline & & $T m r=10 \mathrm{~s}$ & & & Tf $=20 \mathrm{~min}$ & Gf $=25 \mathrm{~s}^{-1}$ \\
\hline \multicolumn{7}{|c|}{ CARACTERÍSTICAS DA ÁGUA DE ESTUDO } \\
\hline \multirow{2}{*}{ Turbidez (uT) } & \multirow{2}{*}{$\begin{array}{l}\text { Alcalinidade Total } \\
\left(\mathrm{mg} / \ell \mathrm{CaCO}_{3}\right)\end{array}$} & \multicolumn{2}{|c|}{ pH } & \multirow{2}{*}{\multicolumn{2}{|c|}{$\begin{array}{c}\text { Temperatura } \\
{ }^{\circ} \mathrm{C}\end{array}$}} & \multirow{2}{*}{$\begin{array}{l}\text { Potencial } \\
\text { Zeta }(\mathrm{mV})\end{array}$} \\
\hline & & S/ agit. & $\mathrm{C} /$ agit. & & & \\
\hline 102 & 30 & 7.74 & 7.58 & & 25 & - \\
\hline
\end{tabular}

\begin{tabular}{|c|c|c|c|c|c|c|}
\hline \multirow{2}{*}{ FRASCO } & \multicolumn{3}{|c|}{ DOSAGEM DE PRODUTO QUÍMICO } & \multirow{2}{*}{$\begin{array}{c}\mathrm{pH} \\
\text { de } \\
\text { Coagulação }\end{array}$} & \multirow{2}{*}{$\begin{array}{c}\begin{array}{c}T_{\mathrm{s}}=1,75 \mathrm{~min} \\
\mathrm{~V}_{\mathrm{s} 1}=4.0 \mathrm{~cm} / \mathrm{min}\end{array} \\
\begin{array}{c}\text { Turbidez } \\
(\mathrm{uT})\end{array}\end{array}$} & \multirow{2}{*}{$\begin{array}{c}T_{\mathrm{s} 2}=3.50 \mathrm{~min} \\
\mathrm{~V}_{\mathrm{s} 2}=2.0 \mathrm{~cm} / \mathrm{min} \\
\begin{array}{c}\text { Turbidez } \\
\text { (uT) }\end{array}\end{array}$} \\
\hline & $\begin{array}{c}\text { Cloreto Férrico } \\
(\mathrm{mg} / \mathfrak{l})\end{array}$ & $\begin{array}{c}\text { Ácido } \\
\text { Clorídrico } \\
0.1 \mathrm{~N}(\mathrm{~m} \ell / \ell)\end{array}$ & $\begin{array}{l}\text { Hidróxido de } \\
\text { Sódio 0.1N } \\
\quad(\mathrm{ml} / \mathfrak{\ell})\end{array}$ & & & \\
\hline 1 & 20.0 & 10.93 & - & 5.90 & 53.0 & 46.1 \\
\hline 2 & 20.0 & 3.65 & - & 6.54 & 10.6 & 7.63 \\
\hline 3 & 25.0 & 1.82 & - & 6.61 & 9.12 & 6.38 \\
\hline 4 & 30.0 & - & - & 6.67 & 6.79 & 5.67 \\
\hline 5 & 35.0 & 7.29 & - & 5.88 & 95.2 & 92.6 \\
\hline 6 & 35.0 & 1.82 & - & - & 5.34 & - \\
\hline
\end{tabular}


ESTUDO DE COAGULAÇÃO-FLOCULAÇÃO-SEDIMENTAÇÃO

\begin{tabular}{|c|c|c|c|c|c|c|}
\hline \multirow{2}{*}{$\begin{array}{l}\text { ENSAIO N }{ }^{\circ}: 19 \\
\text { Data : } 29 / 02 / 00\end{array}$} & \multirow{2}{*}{$\begin{array}{c}\text { COAGULANTE } \\
\text { Cloreto Férrico }\end{array}$} & \multicolumn{3}{|c|}{ MISTURA RÁPIDA } & \multicolumn{2}{|c|}{ FLOCULAÇÃO } \\
\hline & & $\mathrm{Tmr}=10 \mathrm{~s}$ & Gm & & $T f=20 \mathrm{~min}$ & Gf $=25 \mathrm{~s}^{-1}$ \\
\hline \multicolumn{7}{|c|}{ CARACTERÍSTICAS DA ÁGUA DE ESTUDO } \\
\hline \multirow{2}{*}{ Turbidez (uT) } & \multirow{2}{*}{$\begin{array}{l}\text { Alcalinidade Total } \\
\left(\mathrm{mg} / \ell \mathrm{CaCO}_{3}\right)\end{array}$} & \multicolumn{2}{|c|}{ pH } & \multirow{2}{*}{\multicolumn{2}{|c|}{$\begin{array}{c}\text { Temperatura } \\
{ }^{\circ} \mathrm{C} \\
\end{array}$}} & \multirow{2}{*}{$\begin{array}{l}\text { Potencial } \\
\text { Zeta }(\mathrm{mV})\end{array}$} \\
\hline & & S/ agit. & $\mathrm{C} /$ agit. & & & \\
\hline 102 & 30 & 7.74 & 7.58 & & 25 & - \\
\hline
\end{tabular}

\begin{tabular}{|c|c|c|c|c|c|c|}
\hline \multirow{2}{*}{ FRASCO } & \multicolumn{3}{|c|}{ DOSAGEM DE PRODUTO QUÍMICO } & \multirow{2}{*}{$\begin{array}{c}\text { pH } \\
\text { de } \\
\text { Coagulação }\end{array}$} & \multirow{2}{*}{$\begin{array}{c}\begin{array}{c}T_{\mathrm{s} 1}=1,75 \mathrm{~min} \\
\mathrm{~V}_{\mathrm{s} 1}=4.0 \mathrm{~cm} / \mathrm{min}\end{array} \\
\begin{array}{c}\text { Turbidez } \\
(\mathrm{uT})\end{array}\end{array}$} & \multirow{2}{*}{ 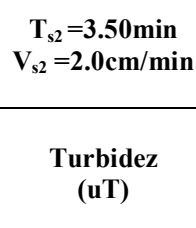 } \\
\hline & $\begin{array}{c}\text { Cloreto Férrico } \\
(\mathrm{mg} / \mathfrak{l})\end{array}$ & $\begin{array}{c}\text { Ácido } \\
\text { Clorídrico } \\
0.1 \mathrm{~N}(\mathrm{~m} \ell / \ell)\end{array}$ & $\begin{array}{l}\text { Hidróxido de } \\
\text { Sódio 0.1N } \\
(\mathrm{m} \ell / \ell)\end{array}$ & & & \\
\hline 1 & 30.0 & - & 7.5 & 7.51 & 93.2 & 93.5 \\
\hline 2 & 30.0 & - & 9.5 & 7.71 & 93.1 & 94.6 \\
\hline 3 & 35.0 & - & 9.0 & 7.47 & 93.7 & 93.5 \\
\hline 4 & 40.0 & 3.65 & - & 6.12 & 3.66 & 2.79 \\
\hline 5 & 40.0 & - & 2.0 & 6.70 & 6.69 & 2.84 \\
\hline 6 & 40.0 & - & 12.0 & 7.74 & 92.7 & 94.7 \\
\hline
\end{tabular}

\section{ESTUDO DE COAGULAÇÃO-FLOCULAÇÃO-SEDIMENTAÇÃO}

\begin{tabular}{|c|c|c|c|c|c|c|}
\hline \multirow{2}{*}{$\begin{array}{l}\text { ENSAIO } N^{\circ}: 20 \\
\text { Data : } 29 / 02 / 00\end{array}$} & \multirow{2}{*}{$\begin{array}{c}\text { COAGULANTE } \\
\text { Cloreto Férrico }\end{array}$} & \multicolumn{3}{|c|}{ MISTURA RÁPIDA } & \multicolumn{2}{|c|}{ FLOCULAÇÃO } \\
\hline & & $T m r=10 \mathrm{~s}$ & & & Tf $=20 \mathrm{~min}$ & Gf $=25 \mathrm{~s}^{-1}$ \\
\hline \multicolumn{7}{|c|}{ CARACTERÍSTICAS DA ÁGUA DE ESTUDO } \\
\hline \multirow{2}{*}{ Turbidez (uT) } & \multirow{2}{*}{$\begin{array}{l}\text { Alcalinidade Total } \\
\left(\mathrm{mg} / \ell \mathrm{CaCO}_{3}\right)\end{array}$} & \multicolumn{2}{|c|}{ pH } & \multirow{2}{*}{\multicolumn{2}{|c|}{$\begin{array}{c}\text { Temperatura } \\
{ }^{\circ} \mathrm{C}\end{array}$}} & \multirow{2}{*}{$\begin{array}{l}\text { Potencial } \\
\text { Zeta }(m V)\end{array}$} \\
\hline & & S/ agit. & $\mathrm{C} /$ agit. & & & \\
\hline 102 & 30 & 7.74 & 7.58 & & 25 & - \\
\hline
\end{tabular}

\begin{tabular}{|c|c|c|c|c|c|c|}
\hline \multirow{2}{*}{ FRASCO } & \multicolumn{3}{|c|}{ DOSAGEM DE PRODUTO QUÍMICO } & \multirow{2}{*}{$\begin{array}{c}\text { pH } \\
\text { de } \\
\text { Coagulação }\end{array}$} & \multirow{2}{*}{$\begin{array}{c}\begin{array}{c}T_{\mathrm{s} 1}=1,75 \mathrm{~min} \\
\mathrm{~V}_{\mathrm{s} 1}=4.0 \mathrm{~cm} / \mathrm{min}\end{array} \\
\begin{array}{c}\text { Turbidez } \\
\text { (uT) }\end{array}\end{array}$} & \multirow{2}{*}{$\begin{array}{c}T_{\mathrm{s} 2}=3.50 \mathrm{~min} \\
\mathrm{~V}_{\mathrm{s} 2}=2.0 \mathrm{~cm} / \mathrm{min} \\
\begin{array}{c}\text { Turbidez } \\
\text { (uT) }\end{array}\end{array}$} \\
\hline & $\begin{array}{c}\text { Cloreto Férrico } \\
(\mathrm{mg} / \mathfrak{l})\end{array}$ & $\begin{array}{c}\text { Ácido } \\
\text { Clorídrico } \\
0.1 \mathrm{~N}(\mathrm{~m} \ell / \ell)\end{array}$ & $\begin{array}{l}\text { Hidróxido de } \\
\text { Sódio 0.1N } \\
(\mathrm{ml} / \mathfrak{l})\end{array}$ & & & \\
\hline 1 & 35.0 & - & - & 6.54 & 3.85 & 2.92 \\
\hline 2 & 35.0 & - & 1.0 & 6.60 & 6.77 & 2.47 \\
\hline 3 & 35.0 & - & 2.0 & 6.70 & 9.99 & 2.31 \\
\hline 4 & 45.0 & 2.73 & - & - & 19.9 & - \\
\hline 5 & 45.0 & - & 1.0 & - & 4.63 & - \\
\hline 6 & 45.0 & - & 5.0 & 6.64 & 6.01 & 4.19 \\
\hline
\end{tabular}


ESTUDO DE COAGULAÇÃO-FLOCULAÇÃO-SEDIMENTAÇÃO

\begin{tabular}{|c|c|c|c|c|c|c|}
\hline \multirow{2}{*}{$\begin{array}{l}\text { ENSAIO N }{ }^{\circ}: 21 \\
\text { Data : } 29 / 02 / 00\end{array}$} & \multirow{2}{*}{$\begin{array}{c}\text { COAGULANTE } \\
\text { Cloreto Férrico }\end{array}$} & \multicolumn{3}{|c|}{ MISTURA RÁPIDA } & \multicolumn{2}{|c|}{ FLOCULAÇÃO } \\
\hline & & $\mathrm{Tmr}=10 \mathrm{~s}$ & $\mathbf{G m}$ & & $T f=20 \mathrm{~min}$ & Gf $=25 \mathrm{~s}^{-1}$ \\
\hline \multicolumn{7}{|c|}{ CARACTERÍSTICAS DA ÁGUA DE ESTUDO } \\
\hline \multirow{2}{*}{ Turbidez (uT) } & \multirow{2}{*}{$\begin{array}{l}\text { Alcalinidade Total } \\
\left(\mathrm{mg} / \ell \mathrm{CaCO}_{3}\right)\end{array}$} & \multicolumn{2}{|c|}{ pH } & \multirow{2}{*}{\multicolumn{2}{|c|}{$\begin{array}{c}\text { Temperatura } \\
{ }^{\circ} \mathrm{C} \\
\end{array}$}} & \multirow{2}{*}{$\begin{array}{l}\text { Potencial } \\
\text { Zeta }(\mathrm{mV})\end{array}$} \\
\hline & & S/ agit. & $\mathrm{C} /$ agit. & & & \\
\hline 102 & 30 & 7.74 & 7.58 & & 25 & - \\
\hline
\end{tabular}

\begin{tabular}{|c|c|c|c|c|c|c|}
\hline \multirow{2}{*}{ FRASCO } & \multicolumn{3}{|c|}{ DOSAGEM DE PRODUTO QUÍMICO } & \multirow{2}{*}{$\begin{array}{c}\text { pH } \\
\text { de } \\
\text { Coagulação }\end{array}$} & \multirow{2}{*}{$\begin{array}{c}T_{\mathrm{s} 1}=1,75 \mathrm{~min} \\
\mathrm{~V}_{\mathrm{s} 1}=4.0 \mathrm{~cm} / \mathrm{min}\end{array}$} & \multirow{2}{*}{$\begin{array}{c}\begin{array}{c}T_{\mathrm{s} 2}=3.50 \mathrm{~min} \\
\mathrm{~V}_{\mathrm{s} 2}=2.0 \mathrm{~cm} / \mathrm{min}\end{array} \\
\begin{array}{c}\text { Turbidez } \\
(\mathrm{uT})\end{array}\end{array}$} \\
\hline & $\begin{array}{c}\text { Cloreto Férrico } \\
(\mathrm{mg} / \mathfrak{l})\end{array}$ & $\begin{array}{c}\text { Ácido } \\
\text { Clorídrico } \\
0.1 \mathrm{~N}(\mathrm{~m} \ell / \ell)\end{array}$ & $\begin{array}{l}\text { Hidróxido de } \\
\text { Sódio 0.1N } \\
(\mathrm{ml} / \mathfrak{l})\end{array}$ & & & \\
\hline 1 & 40.0 & - & 3.0 & 6.66 & 6.94 & 4.58 \\
\hline 2 & 40.0 & - & 6.0 & 6.82 & 9.83 & 3.07 \\
\hline 3 & 40.0 & - & 8.0 & 7.01 & - & 3.32 \\
\hline 4 & 50.0 & 0.91 & - & 6.19 & 2.87 & 1.80 \\
\hline 5 & 50.0 & - & 2.0 & 6.28 & 2.12 & 2.30 \\
\hline 6 & 50.0 & - & 6.0 & 6.55 & 5.69 & 3.38 \\
\hline
\end{tabular}

\section{ESTUDO DE COAGULAÇÃO-FLOCULAÇÃO-SEDIMENTAÇÃO}

\begin{tabular}{|c|c|c|c|c|c|c|}
\hline \multirow{2}{*}{$\begin{array}{l}\text { ENSAIO } N^{\circ}: 22 \\
\text { Data : } 29 / 02 / 00\end{array}$} & \multirow{2}{*}{$\begin{array}{c}\text { COAGULANTE } \\
\text { Cloreto Férrico }\end{array}$} & \multicolumn{3}{|c|}{ MISTURA RÁPIDA } & \multicolumn{2}{|c|}{ FLOCULAÇÃO } \\
\hline & & $T m r=10 \mathrm{~s}$ & & & Tf $=20 \mathrm{~min}$ & Gf $=25 \mathrm{~s}^{-1}$ \\
\hline \multicolumn{7}{|c|}{ CARACTERÍSTICAS DA ÁGUA DE ESTUDO } \\
\hline \multirow{2}{*}{ Turbidez (uT) } & \multirow{2}{*}{$\begin{array}{l}\text { Alcalinidade Total } \\
\left(\mathrm{mg} / \ell \mathrm{CaCO}_{3}\right)\end{array}$} & \multicolumn{2}{|c|}{ pH } & \multirow{2}{*}{\multicolumn{2}{|c|}{$\begin{array}{c}\text { Temperatura } \\
{ }^{\circ} \mathrm{C}\end{array}$}} & \multirow{2}{*}{$\begin{array}{l}\text { Potencial } \\
\text { Zeta }(\mathrm{mV})\end{array}$} \\
\hline & & S/ agit. & $\mathrm{C} /$ agit. & & & \\
\hline 102 & 30 & 7.74 & 7.58 & & 25 & - \\
\hline
\end{tabular}

\begin{tabular}{|c|c|c|c|c|c|c|}
\hline \multirow{2}{*}{ FRASCO } & \multicolumn{3}{|c|}{ DOSAGEM DE PRODUTO QUÍMICO } & \multirow{2}{*}{$\begin{array}{c}\text { pH } \\
\text { de } \\
\text { Coagulação }\end{array}$} & \multirow{2}{*}{$\begin{array}{c}\begin{array}{c}T_{\mathrm{s1}}=1,75 \mathrm{~min} \\
\mathrm{~V}_{\mathrm{s} 1}=4.0 \mathrm{~cm} / \mathrm{min}\end{array} \\
\begin{array}{c}\text { Turbidez } \\
(\mathrm{uT})\end{array}\end{array}$} & \multirow{2}{*}{$\begin{array}{c}T_{\mathrm{s} 2}=3.50 \mathrm{~min} \\
\mathrm{~V}_{\mathrm{s} 2}=2.0 \mathrm{~cm} / \mathrm{min} \\
\begin{array}{c}\text { Turbidez } \\
\text { (uT) }\end{array}\end{array}$} \\
\hline & $\begin{array}{c}\text { Cloreto Férrico } \\
(\mathrm{mg} / \mathfrak{l})\end{array}$ & $\begin{array}{c}\text { Ácido } \\
\text { Clorídrico } \\
0.1 \mathrm{~N}(\mathrm{~m} \ell / \ell)\end{array}$ & $\begin{array}{l}\text { Hidróxido de } \\
\text { Sódio 0.1N } \\
(\mathrm{ml} / \mathfrak{l})\end{array}$ & & & \\
\hline 1 & 20.0 & 10.02 & - & 6.00 & 11.7 & 10.6 \\
\hline 2 & 35.0 & 6.38 & - & 5.91 & 72.0 & 50.4 \\
\hline 3 & 35.0 & 3.65 & - & 6.11 & 3.74 & 2.15 \\
\hline 4 & 35.0 & 0.92 & - & 6.34 & 3.75 & 1.75 \\
\hline 5 & 30.0 & - & 1.0 & 6.66 & 5.04 & 3.64 \\
\hline 6 & 35.0 & - & 4.0 & 6.81 & 11.7 & 3.24 \\
\hline
\end{tabular}


ESTUDO DE COAGULAÇÃO-FLOCULAÇÃO-SEDIMENTAÇÃO

\begin{tabular}{|c|c|c|c|c|c|c|}
\hline \multirow{2}{*}{$\begin{array}{l}\text { ENSAIO N }{ }^{\circ}: 23 \\
\text { Data : } 29 / 02 / 00\end{array}$} & \multirow{2}{*}{$\begin{array}{c}\text { COAGULANTE } \\
\text { Cloreto Férrico }\end{array}$} & \multicolumn{3}{|c|}{ MISTURA RÁPIDA } & \multicolumn{2}{|c|}{ FLOCULAÇÃO } \\
\hline & & $\mathrm{Tmr}=10 \mathrm{~s}$ & Gm & & $T f=20 \mathrm{~min}$ & Gf $=25 \mathrm{~s}^{-1}$ \\
\hline \multicolumn{7}{|c|}{ CARACTERÍSTICAS DA ÁGUA DE ESTUDO } \\
\hline \multirow{2}{*}{ Turbidez (uT) } & \multirow{2}{*}{$\begin{array}{l}\text { Alcalinidade Total } \\
\left(\mathrm{mg} / \ell \mathrm{CaCO}_{3}\right)\end{array}$} & \multicolumn{2}{|c|}{ pH } & \multirow{2}{*}{\multicolumn{2}{|c|}{$\begin{array}{c}\text { Temperatura } \\
{ }^{\circ} \mathrm{C} \\
\end{array}$}} & \multirow{2}{*}{$\begin{array}{l}\text { Potencial } \\
\text { Zeta }(\mathrm{mV})\end{array}$} \\
\hline & & S/ agit. & $\mathrm{C} /$ agit. & & & \\
\hline 102 & 30 & 7.74 & 7.58 & & 25 & - \\
\hline
\end{tabular}

\begin{tabular}{|c|c|c|c|c|c|c|}
\hline \multirow{2}{*}{ FRASCO } & \multicolumn{3}{|c|}{ DOSAGEM DE PRODUTO QUÍMICO } & \multirow{2}{*}{$\begin{array}{c}\text { pH } \\
\text { de } \\
\text { Coagulação }\end{array}$} & \multirow{2}{*}{$\begin{array}{c}\begin{array}{c}T_{\mathrm{s} 1}=1,75 \mathrm{~min} \\
\mathrm{~V}_{\mathrm{s} 1}=4.0 \mathrm{~cm} / \mathrm{min}\end{array} \\
\begin{array}{c}\text { Turbidez } \\
(\mathrm{uT})\end{array}\end{array}$} & \multirow{2}{*}{ 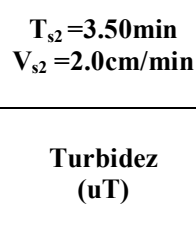 } \\
\hline & $\begin{array}{c}\text { Cloreto Férrico } \\
(\mathrm{mg} / \mathfrak{l})\end{array}$ & $\begin{array}{c}\text { Ácido } \\
\text { Clorídrico } \\
0.1 \mathrm{~N}(\mathrm{~m} \ell / \ell)\end{array}$ & $\begin{array}{l}\text { Hidróxido de } \\
\text { Sódio 0.1N } \\
(\mathrm{m} \ell / \ell)\end{array}$ & & & \\
\hline 1 & 40.0 & 5.47 & - & 5.85 & 99.2 & 99.5 \\
\hline 2 & 40.0 & - & 5.0 & - & 15.3 & - \\
\hline 3 & 40.0 & & 9.0 & 7.20 & 4.64 & 2.90 \\
\hline 4 & 40.0 & -- & 11.0 & 7.44 & - & 93.2 \\
\hline 5 & 30.0 & - & 5.0 & 7.10 & 8.85 & 4.24 \\
\hline 6 & 30.0 & - & 3.0 & 6.89 & 10.7 & 7.96 \\
\hline
\end{tabular}

\section{ESTUDO DE COAGULAÇÃO-FLOCULAÇÃO-SEDIMENTAÇÃO}

\begin{tabular}{|c|c|c|c|c|c|c|}
\hline \multirow{2}{*}{$\begin{array}{l}\text { ENSAIO } N^{\circ}: 24 \\
\text { Data : } 29 / 02 / 00\end{array}$} & \multirow{2}{*}{$\begin{array}{c}\text { COAGULANTE } \\
\text { Cloreto Férrico }\end{array}$} & \multicolumn{3}{|c|}{ MISTURA RÁPIDA } & \multicolumn{2}{|c|}{ FLOCULAÇÃO } \\
\hline & & $T m r=10 \mathrm{~s}$ & & & Tf $=20 \mathrm{~min}$ & Gf $=25 \mathrm{~s}^{-1}$ \\
\hline \multicolumn{7}{|c|}{ CARACTERÍSTICAS DA ÁGUA DE ESTUDO } \\
\hline \multirow{2}{*}{ Turbidez (uT) } & \multirow{2}{*}{$\begin{array}{l}\text { Alcalinidade Total } \\
\left(\mathrm{mg} / \ell \mathrm{CaCO}_{3}\right)\end{array}$} & \multicolumn{2}{|c|}{ pH } & \multirow{2}{*}{\multicolumn{2}{|c|}{$\begin{array}{c}\text { Temperatura } \\
{ }^{\circ} \mathrm{C}\end{array}$}} & \multirow{2}{*}{$\begin{array}{r}\text { Potencial } \\
\text { Zeta }(\mathrm{mV}) \\
\end{array}$} \\
\hline & & S/ agit. & $\mathrm{C} /$ agit. & & & \\
\hline 102 & 30 & 7.74 & 7.58 & & 25 & - \\
\hline
\end{tabular}

\begin{tabular}{|c|c|c|c|c|c|c|}
\hline \multirow{2}{*}{ FRASCO } & \multicolumn{3}{|c|}{ DOSAGEM DE PRODUTO QUÍMICO } & \multirow{2}{*}{$\begin{array}{c}\text { pH } \\
\text { de } \\
\text { Coagulação }\end{array}$} & \multirow{2}{*}{$\begin{array}{c}\begin{array}{c}T_{\mathrm{s} 1}=1,75 \mathrm{~min} \\
\mathrm{~V}_{\mathrm{s} 1}=4.0 \mathrm{~cm} / \mathrm{min}\end{array} \\
\begin{array}{c}\text { Turbidez } \\
\text { (uT) }\end{array}\end{array}$} & \multirow{2}{*}{$\begin{array}{c}\begin{array}{c}\mathrm{T}_{\mathrm{s} 2}=3.50 \mathrm{~min} \\
\mathrm{~V}_{\mathrm{s} 2}=2.0 \mathrm{~cm} / \mathrm{min}\end{array} \\
\begin{array}{c}\text { Turbidez } \\
(\mathrm{uT})\end{array}\end{array}$} \\
\hline & $\begin{array}{c}\text { Cloreto Férrico } \\
(\mathrm{mg} / \mathfrak{l})\end{array}$ & $\begin{array}{c}\text { Ácido } \\
\text { Clorídrico } \\
0.1 \mathrm{~N}(\mathrm{~m} \ell / \ell)\end{array}$ & $\begin{array}{l}\text { Hidróxido de } \\
\text { Sódio 0.1N } \\
(\mathrm{m} \ell / \ell)\end{array}$ & & & \\
\hline 1 & 50.0 & 1.82 & - & 5.75 & 97.5 & 96.4 \\
\hline 2 & 50.0 & 3.65 & - & 5.58 & 101.0 & 99.5 \\
\hline 3 & 50.0 & - & 8.0 & 6.70 & 9.39 & 1.68 \\
\hline 4 & 50.0 & - & 12.0 & 7.15 & 4.80 & 3.27 \\
\hline 5 & 50.0 & - & 14.0 & 7.41 & 96.3 & 96.5 \\
\hline 6 & 35.0 & - & 6.0 & 7.15 & 7.23 & 2.69 \\
\hline
\end{tabular}


ESTUDO DE COAGULAÇÃO-FLOCULAÇÃO-SEDIMENTAÇÃO

\begin{tabular}{|c|c|c|c|c|c|c|}
\hline \multirow{2}{*}{$\begin{array}{l}\text { ENSAIO N: } 25 \\
\text { Data : } 29 / 02 / 00\end{array}$} & \multirow{2}{*}{$\begin{array}{l}\text { COAGULANTE } \\
\text { Cloreto Férrico }\end{array}$} & \multicolumn{3}{|c|}{ MISTURA RÁPIDA } & \multicolumn{2}{|c|}{ FLOCULAÇÃO } \\
\hline & & $\mathrm{Tmr}=10 \mathrm{~s}$ & \multicolumn{2}{|c|}{$\mathrm{Gmr}=1000 \mathrm{~s}^{-1}$} & $T f=20 \mathrm{~min}$ & $G f=25 s^{-1}$ \\
\hline \multicolumn{7}{|c|}{ CARACTERÍSTICAS DA ÁGUA DE ESTUDO } \\
\hline \multirow{2}{*}{ Turbidez (uT) } & \multirow{2}{*}{$\begin{array}{c}\text { Alcalinidade Total } \\
\left(\mathrm{mg} / \ell \mathrm{CaCO}_{3}\right)\end{array}$} & \multicolumn{2}{|c|}{$\mathrm{pH}$} & \multirow{2}{*}{\multicolumn{2}{|c|}{$\begin{array}{c}\text { Temperatura } \\
{ }^{\circ} \mathrm{C} \\
\end{array}$}} & \multirow{2}{*}{$\begin{array}{l}\text { Potencial } \\
\text { Zeta }(\mathrm{mV}) \\
\end{array}$} \\
\hline & & S/ agit. & $\mathrm{C} /$ agit. & & & \\
\hline 102 & 30 & 7.74 & 7.58 & & 25 & - \\
\hline
\end{tabular}

\begin{tabular}{|c|c|c|c|c|c|c|}
\hline \multirow{2}{*}{ FRASCO } & \multicolumn{3}{|c|}{ DOSAGEM DE PRODUTO QUÍMICO } & \multirow{2}{*}{$\begin{array}{c}\text { pH } \\
\text { de } \\
\text { Coagulação }\end{array}$} & \multirow{2}{*}{$\begin{array}{c}\mathrm{T}_{\mathrm{s} 1}=1,75 \mathrm{~min} \\
\mathrm{~V}_{\mathrm{s} 1}=4.0 \mathrm{~cm} / \mathrm{min} \\
\\
\text { Turbidez } \\
(\mathrm{uT})\end{array}$} & \multirow{2}{*}{$\begin{array}{c}T_{\mathrm{s} 2}=3.50 \mathrm{~min} \\
\mathbf{V}_{\mathrm{s} 2}=\mathbf{2 . 0 \mathrm { cm } / \mathrm { min }} \\
\\
\begin{array}{c}\text { Turbidez } \\
(\mathrm{uT})\end{array}\end{array}$} \\
\hline & $\begin{array}{l}\text { Cloreto Férrico } \\
(\mathrm{mg} / \ell)\end{array}$ & $\begin{array}{c}\text { Ácido } \\
\text { Clorídrico } \\
0.1 \mathrm{~N}(\mathrm{~m} \ell / \ell)\end{array}$ & $\begin{array}{c}\text { Hidróxido de } \\
\text { Sódio 0.1N } \\
(\mathrm{m} \ell / \ell)\end{array}$ & & & \\
\hline 1 & 60.0 & - & 6.0 & 6.29 & 1.75 & 0.73 \\
\hline 2 & 60.0 & - & 8.0 & 6.47 & 6.71 & 2.35 \\
\hline 3 & 60.0 & - & 12.0 & 6.85 & 8.02 & 2.24 \\
\hline 4 & 60.0 & - & 14.0 & 7.07 & 6.37 & 2.41 \\
\hline 5 & 70.0 & - & 4.5 & 5.94 & 95.1 & 92.4 \\
\hline 6 & 70.0 & - & 8.0 & 6.20 & 1.87 & 1.31 \\
\hline
\end{tabular}

\section{ESTUDO DE COAGULAÇÃO-FLOCULAÇÃO-SEDIMENTAÇÃO}

\begin{tabular}{|c|c|c|c|c|c|c|}
\hline \multirow{2}{*}{$\begin{array}{l}\text { ENSAIO } N^{\circ}: 26 \\
\text { Data : } 01 / 03 / 00\end{array}$} & \multirow{2}{*}{$\begin{array}{c}\text { COAGULANTE } \\
\text { Cloreto Férrico }\end{array}$} & \multicolumn{3}{|c|}{ MISTURA RÁPIDA } & \multicolumn{2}{|c|}{ FLOCULAÇÃO } \\
\hline & & $T m r=10 \mathrm{~s}$ & & & Tf $=20 \mathrm{~min}$ & Gf $=25 \mathrm{~s}^{-1}$ \\
\hline \multicolumn{7}{|c|}{ CARACTERÍSTICAS DA ÁGUA DE ESTUDO } \\
\hline \multirow{2}{*}{ Turbidez (uT) } & \multirow{2}{*}{$\begin{array}{l}\text { Alcalinidade Total } \\
\left(\mathrm{mg} / \ell \mathrm{CaCO}_{3}\right)\end{array}$} & \multicolumn{2}{|c|}{ pH } & \multirow{2}{*}{\multicolumn{2}{|c|}{$\begin{array}{c}\text { Temperatura } \\
{ }^{\circ} \mathrm{C}\end{array}$}} & \multirow{2}{*}{$\begin{array}{l}\text { Potencial } \\
\text { Zeta }(\mathrm{mV})\end{array}$} \\
\hline & & S/ agit. & $\mathrm{C} /$ agit. & & & \\
\hline 102 & 28.5 & 7.79 & 7.62 & & 25 & - \\
\hline
\end{tabular}

\begin{tabular}{|c|c|c|c|c|c|c|}
\hline \multirow{2}{*}{ FRASCO } & \multicolumn{3}{|c|}{ DOSAGEM DE PRODUTO QUÍMICO } & \multirow{2}{*}{$\begin{array}{c}\mathrm{pH} \\
\text { de } \\
\text { Coagulação }\end{array}$} & \multirow{2}{*}{$\begin{array}{c}\begin{array}{c}T_{\mathrm{s}}=1,75 \mathrm{~min} \\
\mathrm{~V}_{\mathrm{s} 1}=4.0 \mathrm{~cm} / \mathrm{min}\end{array} \\
\begin{array}{c}\text { Turbidez } \\
(\mathrm{uT})\end{array}\end{array}$} & \multirow{2}{*}{$\begin{array}{c}T_{\mathrm{s} 2}=3.50 \mathrm{~min} \\
\mathrm{~V}_{\mathrm{s} 2}=2.0 \mathrm{~cm} / \mathrm{min} \\
\begin{array}{c}\text { Turbidez } \\
(\mathrm{uT})\end{array}\end{array}$} \\
\hline & $\begin{array}{c}\text { Cloreto Férrico } \\
(\mathrm{mg} / \mathfrak{l})\end{array}$ & $\begin{array}{c}\text { Ácido } \\
\text { Clorídrico } \\
0.1 \mathrm{~N}(\mathrm{~m} \ell / \ell)\end{array}$ & $\begin{array}{l}\text { Hidróxido de } \\
\text { Sódio 0.1N } \\
\quad(\mathrm{ml} / \mathfrak{\ell})\end{array}$ & & & \\
\hline 1 & 35.0 & - & 5.0 & 6.95 & 8.58 & 4.55 \\
\hline 2 & 40.0 & - & 4.0 & 6.78 & 5.19 & 1.83 \\
\hline 3 & 50.0 & - & 7.0 & 6.74 & 6.81 & 6.54 \\
\hline 4 & 50.0 & - & 9.0 & 6.95 & 22.1 & 7.32 \\
\hline 5 & 50.0 & - & 10.0 & 6.98 & 15.5 & 8.24 \\
\hline 6 & 50.0 & - & 13.0 & 6.32 & 16.8 & 16.9 \\
\hline
\end{tabular}


ESTUDO DE COAGULAÇÃO-FLOCULAÇÃO-SEDIMENTAÇÃO

\begin{tabular}{|c|c|c|c|c|c|c|}
\hline \multirow{2}{*}{$\begin{array}{l}\text { ENSAIO N }{ }^{\circ}: 27 \\
\text { Data : } 01 / 03 / 00\end{array}$} & \multirow{2}{*}{$\begin{array}{c}\text { COAGULANTE } \\
\text { Cloreto Férrico }\end{array}$} & \multicolumn{3}{|c|}{ MISTURA RÁPIDA } & \multicolumn{2}{|c|}{ FLOCULAÇÃO } \\
\hline & & $\mathrm{Tmr}=10 \mathrm{~s}$ & Gm & & $T f=20 \mathrm{~min}$ & Gf $=25 \mathrm{~s}^{-1}$ \\
\hline \multicolumn{7}{|c|}{ CARACTERÍSTICAS DA ÁGUA DE ESTUDO } \\
\hline \multirow{2}{*}{ Turbidez (uT) } & \multirow{2}{*}{$\begin{array}{l}\text { Alcalinidade Total } \\
\left(\mathrm{mg} / \ell \mathrm{CaCO}_{3}\right)\end{array}$} & \multicolumn{2}{|c|}{ pH } & \multirow{2}{*}{\multicolumn{2}{|c|}{$\begin{array}{c}\text { Temperatura } \\
{ }^{\circ} \mathrm{C} \\
\end{array}$}} & \multirow{2}{*}{$\begin{array}{l}\text { Potencial } \\
\text { Zeta }(\mathrm{mV})\end{array}$} \\
\hline & & S/ agit. & $\mathrm{C} /$ agit. & & & \\
\hline 102 & 28.5 & 7.79 & 7.62 & & 25 & - \\
\hline
\end{tabular}

\begin{tabular}{|c|c|c|c|c|c|c|}
\hline \multirow{2}{*}{ FRASCO } & \multicolumn{3}{|c|}{ DOSAGEM DE PRODUTO QUÍMICO } & \multirow{2}{*}{$\begin{array}{c}\text { pH } \\
\text { de } \\
\text { Coagulação }\end{array}$} & \multirow{2}{*}{$\begin{array}{c}T_{\mathrm{s} 1}=1,75 \mathrm{~min} \\
\mathrm{~V}_{\mathrm{s} 1}=4.0 \mathrm{~cm} / \mathrm{min}\end{array}$} & \multirow{2}{*}{$\begin{array}{c}\begin{array}{c}T_{\mathrm{s} 2}=3.50 \mathrm{~min} \\
\mathbf{V}_{\mathrm{s} 2}=2.0 \mathrm{~cm} / \mathrm{min}\end{array} \\
\qquad \begin{array}{c}\text { Turbidez } \\
\text { (uT) }\end{array}\end{array}$} \\
\hline & $\begin{array}{c}\text { Cloreto Férrico } \\
(\mathrm{mg} / \mathfrak{l})\end{array}$ & $\begin{array}{c}\text { Ácido } \\
\text { Clorídrico } \\
0.1 \mathrm{~N}(\mathrm{~m} \ell / \ell)\end{array}$ & $\begin{array}{l}\text { Hidróxido de } \\
\text { Sódio 0.1N } \\
(\mathrm{ml} / \mathfrak{l})\end{array}$ & & & \\
\hline 1 & 70.0 & - & 5.0 & 5.95 & 3.20 & 2.55 \\
\hline 2 & 70.0 & - & 7.0 & 6.13 & 2.23 & 0.78 \\
\hline 3 & 70.0 & - & 8.0 & 6.22 & 3.14 & 1.00 \\
\hline 4 & 70.0 & - & 9.0 & 6.38 & 5.27 & 1.19 \\
\hline 5 & 70.0 & - & 12.0 & 6.57 & 14.2 & 2.39 \\
\hline 6 & 70.0 & - & 14.0 & 6.77 & 22.2 & 6.25 \\
\hline
\end{tabular}

\section{ESTUDO DE COAGULAÇÃO-FLOCULAÇÃO-SEDIMENTAÇÃO}

\begin{tabular}{|c|c|c|c|c|c|c|}
\hline \multirow{2}{*}{$\begin{array}{l}\text { ENSAIO N } N^{\circ}: 28 \\
\text { Data }: 01 / 03 / 00\end{array}$} & \multirow{2}{*}{$\begin{array}{c}\text { COAGULANTE } \\
\text { Cloreto Férrico }\end{array}$} & \multicolumn{3}{|c|}{ MISTURA RÁPIDA } & \multicolumn{2}{|c|}{ FLOCULAÇÃO } \\
\hline & & $\mathrm{Tmr}=10 \mathrm{~s}$ & & $\mathrm{~s}^{-1}$ & $T f=20 \mathrm{~min}$ & $G f=25 \mathrm{~s}^{-1}$ \\
\hline \multicolumn{7}{|c|}{ CARACTERÍSTICAS DA ÁGUA DE ESTUDO } \\
\hline \multirow{2}{*}{ Turbidez (uT) } & \multirow{2}{*}{$\begin{array}{l}\text { Alcalinidade Total } \\
\left(\mathrm{mg} / \ell \mathrm{CaCO}_{3}\right)\end{array}$} & \multicolumn{2}{|c|}{ pH } & \multirow{2}{*}{\multicolumn{2}{|c|}{$\begin{array}{c}\text { Temperatura } \\
{ }^{\circ} \mathrm{C}\end{array}$}} & \multirow{2}{*}{$\begin{array}{l}\text { Potencial } \\
\text { Zeta }(\mathrm{mV})\end{array}$} \\
\hline & & S/ agit. & $\mathrm{C} /$ agit. & & & \\
\hline 102 & 28.5 & 7.79 & 7.62 & & 25 & - \\
\hline
\end{tabular}

\begin{tabular}{|c|c|c|c|c|c|c|}
\hline \multirow{2}{*}{ FRASCO } & \multicolumn{3}{|c|}{ DOSAGEM DE PRODUTO QUÍMICO } & \multirow{2}{*}{$\begin{array}{c}\text { pH } \\
\text { de } \\
\text { Coagulação }\end{array}$} & \multirow{2}{*}{$\begin{array}{c}\begin{array}{c}T_{\mathrm{s} 1}=1,75 \mathrm{~min} \\
\mathrm{~V}_{\mathrm{s} 1}=4.0 \mathrm{~cm} / \mathrm{min}\end{array} \\
\begin{array}{c}\text { Turbidez } \\
\text { (uT) }\end{array}\end{array}$} & \multirow{2}{*}{$\begin{array}{c}\begin{array}{c}\mathrm{T}_{\mathrm{s} 2}=3.50 \mathrm{~min} \\
\mathrm{~V}_{\mathrm{s} 2}=2.0 \mathrm{~cm} / \mathrm{min}\end{array} \\
\begin{array}{c}\text { Turbidez } \\
(\mathrm{uT})\end{array}\end{array}$} \\
\hline & $\begin{array}{c}\text { Cloreto Férrico } \\
(\mathrm{mg} / \mathfrak{l})\end{array}$ & $\begin{array}{c}\text { Ácido } \\
\text { Clorídrico } \\
0.1 \mathrm{~N}(\mathrm{~m} \ell / \ell)\end{array}$ & $\begin{array}{l}\text { Hidróxido de } \\
\text { Sódio 0.1N } \\
(\mathrm{ml} / \mathfrak{l})\end{array}$ & & & \\
\hline 1 & 65.0 & - & 2.0 & 5.69 & 97.7 & 97.3 \\
\hline 2 & 65.0 & - & 3.0 & 5.74 & 95.8 & 97.2 \\
\hline 3 & 65.0 & - & 5.0 & 6.04 & 2.02 & 1.30 \\
\hline 4 & 55.0 & - & 1.0 & 5.40 & 101.0 & 96.3 \\
\hline 5 & 55.0 & - & 2.0 & 5.53 & 102.0 & 97.5 \\
\hline 6 & 55.0 & - & 3.0 & 5.70 & 94.3 & 87.9 \\
\hline
\end{tabular}


ESTUDO DE COAGULAÇÃO-FLOCULAÇÃO-SEDIMENTAÇÃO

\begin{tabular}{|c|c|c|c|c|c|c|}
\hline \multirow{2}{*}{$\begin{array}{l}\text { ENSAIO N }{ }^{\circ}: 29 \\
\text { Data : } 01 / 03 / 00\end{array}$} & \multirow{2}{*}{$\begin{array}{c}\text { COAGULANTE } \\
\text { Cloreto Férrico }\end{array}$} & \multicolumn{3}{|c|}{ MISTURA RÁPIDA } & \multicolumn{2}{|c|}{ FLOCULAÇÃO } \\
\hline & & $\mathrm{Tmr}=10 \mathrm{~s}$ & Gm & & $T f=20 \mathrm{~min}$ & Gf $=25 \mathrm{~s}^{-1}$ \\
\hline \multicolumn{7}{|c|}{ CARACTERÍSTICAS DA ÁGUA DE ESTUDO } \\
\hline \multirow{2}{*}{ Turbidez (uT) } & \multirow{2}{*}{$\begin{array}{l}\text { Alcalinidade Total } \\
\left(\mathrm{mg} / \ell \mathrm{CaCO}_{3}\right)\end{array}$} & \multicolumn{2}{|c|}{ pH } & \multirow{2}{*}{\multicolumn{2}{|c|}{$\begin{array}{c}\text { Temperatura } \\
{ }^{\circ} \mathrm{C} \\
\end{array}$}} & \multirow{2}{*}{$\begin{array}{l}\text { Potencial } \\
\text { Zeta }(\mathrm{mV})\end{array}$} \\
\hline & & S/ agit. & $\mathrm{C} /$ agit. & & & \\
\hline 102 & 28.5 & 7.79 & 7.62 & & 25 & - \\
\hline
\end{tabular}

\begin{tabular}{|c|c|c|c|c|c|c|}
\hline \multirow{2}{*}{ FRASCO } & \multicolumn{3}{|c|}{ DOSAGEM DE PRODUTO QUÍMICO } & \multirow{2}{*}{$\begin{array}{c}\text { pH } \\
\text { de } \\
\text { Coagulação }\end{array}$} & \multirow{2}{*}{$\begin{array}{c}T_{\mathrm{s} 1}=1,75 \mathrm{~min} \\
\mathrm{~V}_{\mathrm{s} 1}=4.0 \mathrm{~cm} / \mathrm{min}\end{array}$} & \multirow{2}{*}{$\begin{array}{c}\begin{array}{c}T_{\mathrm{s} 2}=3.50 \mathrm{~min} \\
\mathrm{~V}_{\mathrm{s} 2}=2.0 \mathrm{~cm} / \mathrm{min}\end{array} \\
\begin{array}{c}\text { Turbidez } \\
(\mathrm{uT})\end{array}\end{array}$} \\
\hline & $\begin{array}{c}\text { Cloreto Férrico } \\
(\mathrm{mg} / \mathfrak{l})\end{array}$ & $\begin{array}{c}\text { Ácido } \\
\text { Clorídrico } \\
0.1 \mathrm{~N}(\mathrm{~m} \ell / \ell)\end{array}$ & $\begin{array}{l}\text { Hidróxido de } \\
\text { Sódio 0.1N } \\
(\mathrm{ml} / \mathfrak{l})\end{array}$ & & & \\
\hline 1 & 35.0 & 4.56 & - & 6.15 & 1.85 & 1.47 \\
\hline 2 & 40.0 & 0.91 & - & 6.28 & 1.49 & 1.22 \\
\hline 3 & 30.0 & - & 6.0 & 7.13 & 7.46 & 6.81 \\
\hline 4 & 40.0 & - & 1.0 & 6.58 & 2.80 & 2.08 \\
\hline 5 & 40.0 & - & 8.5 & 7.12 & 4.19 & 3.05 \\
\hline 6 & 45.0 & - & 7.0 & 6.92 & 10.6 & 6.48 \\
\hline
\end{tabular}

\section{ESTUDO DE COAGULAÇÃO-FLOCULAÇÃO-SEDIMENTAÇÃO}

\begin{tabular}{|c|c|c|c|c|c|c|}
\hline \multirow{2}{*}{$\begin{array}{l}\text { ENSAIO N } N^{\circ}: 30 \\
\text { Data }: 01 / 03 / 00\end{array}$} & \multirow{2}{*}{$\begin{array}{c}\text { COAGULANTE } \\
\text { Cloreto Férrico }\end{array}$} & \multicolumn{3}{|c|}{ MISTURA RÁPIDA } & \multicolumn{2}{|c|}{ FLOCULAÇÃO } \\
\hline & & $\mathrm{Tmr}=10 \mathrm{~s}$ & & $\mathrm{~s}^{-1}$ & $T f=20 \mathrm{~min}$ & $G f=25 \mathrm{~s}^{-1}$ \\
\hline \multicolumn{7}{|c|}{ CARACTERÍSTICAS DA ÁGUA DE ESTUDO } \\
\hline \multirow{2}{*}{ Turbidez (uT) } & \multirow{2}{*}{$\begin{array}{l}\text { Alcalinidade Total } \\
\left(\mathrm{mg} / \ell \mathrm{CaCO}_{3}\right)\end{array}$} & \multicolumn{2}{|c|}{ pH } & \multirow{2}{*}{\multicolumn{2}{|c|}{$\begin{array}{c}\text { Temperatura } \\
{ }^{\circ} \mathrm{C}\end{array}$}} & \multirow{2}{*}{$\begin{array}{r}\text { Potencial } \\
\text { Zeta }(\mathrm{mV}) \\
\end{array}$} \\
\hline & & S/ agit. & $\mathrm{C} /$ agit. & & & \\
\hline 102 & 28.5 & 7.79 & 7.62 & & 25 & - \\
\hline
\end{tabular}

\begin{tabular}{|c|c|c|c|c|c|c|}
\hline \multirow{2}{*}{ FRASCO } & \multicolumn{3}{|c|}{ DOSAGEM DE PRODUTO QUÍMICO } & \multirow{2}{*}{$\begin{array}{c}\text { pH } \\
\text { de } \\
\text { Coagulação }\end{array}$} & \multirow{2}{*}{$\begin{array}{c}\begin{array}{c}T_{\mathrm{s} 1}=1,75 \mathrm{~min} \\
\mathrm{~V}_{\mathrm{s} 1}=4.0 \mathrm{~cm} / \mathrm{min}\end{array} \\
\begin{array}{c}\text { Turbidez } \\
\text { (uT) }\end{array}\end{array}$} & \multirow{2}{*}{$\begin{array}{c}\begin{array}{c}\mathrm{T}_{\mathrm{s} 2}=3.50 \mathrm{~min} \\
\mathrm{~V}_{\mathrm{s} 2}=2.0 \mathrm{~cm} / \mathrm{min}\end{array} \\
\begin{array}{c}\text { Turbidez } \\
(\mathrm{uT})\end{array}\end{array}$} \\
\hline & $\begin{array}{c}\text { Cloreto Férrico } \\
(\mathrm{mg} / \mathfrak{l})\end{array}$ & $\begin{array}{c}\text { Ácido } \\
\text { Clorídrico } \\
0.1 \mathrm{~N}(\mathrm{~m} \ell / \ell)\end{array}$ & $\begin{array}{l}\text { Hidróxido de } \\
\text { Sódio 0.1N } \\
(\mathrm{ml} / \mathfrak{l})\end{array}$ & & & \\
\hline 1 & 65.0 & - & 6.0 & 6.30 & 1.51 & 0.67 \\
\hline 2 & 65.0 & - & 12.0 & 6.68 & 14.9 & 5.93 \\
\hline 3 & 65.0 & - & 18.0 & 7.26 & 10.7 & 9.41 \\
\hline 4 & 55.0 & - & 6.0 & 6.64 & 4.36 & 2.36 \\
\hline 5 & 55.0 & - & 8.0 & 6.74 & 8.91 & 1.66 \\
\hline 6 & 55.0 & - & 12.0 & 7.03 & 7.55 & 4.54 \\
\hline
\end{tabular}


ESTUDO DE COAGULAÇÃO-FLOCULAÇÃO-SEDIMENTAÇÃO

\begin{tabular}{|c|c|c|c|c|c|c|}
\hline \multirow{2}{*}{$\begin{array}{l}\text { ENSAIO N: } 31 \\
\text { Data : } 01 / 03 / 00\end{array}$} & \multirow{2}{*}{$\begin{array}{l}\text { COAGULANTE } \\
\text { Cloreto Férrico }\end{array}$} & \multicolumn{3}{|c|}{ MISTURA RÁPIDA } & \multicolumn{2}{|c|}{ FLOCULAÇÃO } \\
\hline & & $\mathrm{Tmr}=10 \mathrm{~s}$ & \multicolumn{2}{|c|}{$\mathrm{Gmr}=1000 \mathrm{~s}^{-1}$} & $T f=20 \mathrm{~min}$ & $G f=25 s^{-1}$ \\
\hline \multicolumn{7}{|c|}{ CARACTERÍSTICAS DA ÁGUA DE ESTUDO } \\
\hline \multirow{2}{*}{ Turbidez (uT) } & \multirow{2}{*}{$\begin{array}{c}\text { Alcalinidade Total } \\
\left(\mathrm{mg} / \ell \mathrm{CaCO}_{3}\right)\end{array}$} & \multicolumn{2}{|c|}{$\mathrm{pH}$} & \multirow{2}{*}{\multicolumn{2}{|c|}{$\begin{array}{c}\text { Temperatura } \\
{ }^{\circ} \mathrm{C} \\
\end{array}$}} & \multirow{2}{*}{$\begin{array}{l}\text { Potencial } \\
\text { Zeta }(\mathrm{mV}) \\
\end{array}$} \\
\hline & & S/ agit. & $\mathrm{C} /$ agit. & & & \\
\hline 102 & 28.5 & 7.79 & 7.62 & & 25 & - \\
\hline
\end{tabular}

\begin{tabular}{|c|c|c|c|c|c|c|}
\hline \multirow{2}{*}{ FRASCO } & \multicolumn{3}{|c|}{ DOSAGEM DE PRODUTO QUÍMICO } & \multirow{2}{*}{$\begin{array}{c}\text { pH } \\
\text { de } \\
\text { Coagulação }\end{array}$} & \multirow{2}{*}{$\begin{array}{c}T_{\mathrm{s} 1}=1,75 \mathrm{~min} \\
\mathrm{~V}_{\mathrm{s} 1}=4.0 \mathrm{~cm} / \mathrm{min} \\
\begin{array}{c}\text { Turbidez } \\
(\mathrm{uT})\end{array}\end{array}$} & \multirow{2}{*}{$\begin{array}{c}T_{\mathrm{s} 2}=3.50 \mathrm{~min} \\
\mathrm{~V}_{\mathrm{s} 2}=\mathbf{2 . 0 \mathrm { cm } / \mathrm { min }} \\
\\
\begin{array}{c}\text { Turbidez } \\
(\mathrm{uT})\end{array}\end{array}$} \\
\hline & $\begin{array}{c}\text { Cloreto Férrico } \\
\qquad(\mathrm{mg} / \ell)\end{array}$ & $\begin{array}{c}\text { Acido } \\
\text { Clorídrico } \\
0.1 \mathrm{~N}(\mathrm{~m} \ell / \ell)\end{array}$ & $\begin{array}{c}\text { Hidróxido de } \\
\text { Sódio 0.1N } \\
(\mathrm{m} \ell / \ell)\end{array}$ & & & \\
\hline 1 & 50.0 & 1.37 & - & 6.06 & 1.33 & 1.62 \\
\hline 2 & 50.0 & - & 4.0 & 6.40 & - & 9.60 \\
\hline 3 & 70.0 & - & 6.0 & 6.16 & 1.17 & 0.63 \\
\hline 4 & 70.0 & - & 10.5 & 6.50 & 34.3 & 10.8 \\
\hline 5 & 75.0 & - & 8.0 & 6.24 & 3.74 & 1.95 \\
\hline 6 & 75.0 & - & 12.0 & 6.55 & 38.3 & 11.8 \\
\hline
\end{tabular}

\section{ESTUDO DE COAGULAÇÃO-FLOCULAÇÃO-SEDIMENTAÇÃO}

\begin{tabular}{|c|c|c|c|c|c|c|}
\hline \multirow{2}{*}{$\begin{array}{l}\text { ENSAIO } N^{\circ}: 32 \\
\text { Data : } 01 / 03 / 00\end{array}$} & \multirow{2}{*}{$\begin{array}{c}\text { COAGULANTE } \\
\text { Cloreto Férrico }\end{array}$} & \multicolumn{3}{|c|}{ MISTURA RÁPIDA } & \multicolumn{2}{|c|}{ FLOCULAÇÃO } \\
\hline & & $T m r=10 \mathrm{~s}$ & & & Tf $=20 \mathrm{~min}$ & Gf $=25 \mathrm{~s}^{-1}$ \\
\hline \multicolumn{7}{|c|}{ CARACTERÍSTICAS DA ÁGUA DE ESTUDO } \\
\hline \multirow{2}{*}{ Turbidez (uT) } & \multirow{2}{*}{$\begin{array}{l}\text { Alcalinidade Total } \\
\left(\mathrm{mg} / \ell \mathrm{CaCO}_{3}\right)\end{array}$} & \multicolumn{2}{|c|}{ pH } & \multirow{2}{*}{\multicolumn{2}{|c|}{$\begin{array}{c}\text { Temperatura } \\
{ }^{\circ} \mathrm{C}\end{array}$}} & \multirow{2}{*}{$\begin{array}{l}\text { Potencial } \\
\text { Zeta }(\mathrm{mV})\end{array}$} \\
\hline & & $\mathrm{S} /$ agit. & $\mathrm{C} /$ agit. & & & \\
\hline 102 & 28.5 & 7.79 & 7.62 & & 25 & - \\
\hline
\end{tabular}

\begin{tabular}{|c|c|c|c|c|c|c|}
\hline \multirow{2}{*}{ FRASCO } & \multicolumn{3}{|c|}{ DOSAGEM DE PRODUTO QUÍMICO } & \multirow{2}{*}{$\begin{array}{c}\text { pH } \\
\text { de } \\
\text { Coagulação }\end{array}$} & \multirow{2}{*}{$\begin{array}{c}\begin{array}{c}\mathrm{T}_{\mathrm{s} 1}=1,75 \mathrm{~min} \\
\mathrm{~V}_{\mathrm{s} 1}=4.0 \mathrm{~cm} / \mathrm{min}\end{array} \\
\begin{array}{c}\text { Turbidez } \\
(\mathrm{uT})\end{array}\end{array}$} & \multirow{2}{*}{$\begin{array}{c}\mathrm{T}_{\mathrm{s} 2}=3.50 \mathrm{~min} \\
\mathrm{~V}_{\mathrm{s} 2}=2.0 \mathrm{~cm} / \mathrm{min} \\
\begin{array}{c}\text { Turbidez } \\
(\mathrm{uT})\end{array}\end{array}$} \\
\hline & $\begin{array}{c}\text { Cloreto Férrico } \\
(\mathrm{mg} / \mathfrak{\ell})\end{array}$ & $\begin{array}{c}\text { Ácido } \\
\text { Clorídrico } \\
0.1 \mathrm{~N}(\mathrm{~m} \ell / \ell)\end{array}$ & $\begin{array}{l}\text { Hidróxido de } \\
\text { Sódio 0.1N } \\
(\mathrm{m} \ell / \ell)\end{array}$ & & & \\
\hline 1 & 30.0 & - & 7.0 & 7.28 & 25.1 & 23.4 \\
\hline 2 & 45.0 & - & 8.0 & 7.00 & 14.3 & 8.09 \\
\hline 3 & 55.0 & - & 4.5 & 6.49 & 4.95 & 1.86 \\
\hline 4 & 55.0 & - & 10.0 & 6.85 & 10.0 & 5.49 \\
\hline 5 & 65.0 & - & 8.0 & 6.54 & 1.92 & 1.11 \\
\hline 6 & 65.0 & - & 10.0 & 6.63 & 4.93 & 3.33 \\
\hline
\end{tabular}


ESTUDO DE COAGULAÇÃO-FLOCULAÇÃO-SEDIMENTAÇÃO

\begin{tabular}{|c|c|c|c|c|c|c|}
\hline \multirow{2}{*}{$\begin{array}{l}\text { ENSAIO N: } 33 \\
\text { Data : } 01 / 03 / 00\end{array}$} & \multirow{2}{*}{$\begin{array}{l}\text { COAGULANTE } \\
\text { Cloreto Férrico }\end{array}$} & \multicolumn{3}{|c|}{ MISTURA RÁPIDA } & \multicolumn{2}{|c|}{ FLOCULAÇÃO } \\
\hline & & $\mathrm{Tmr}=10 \mathrm{~s}$ & \multicolumn{2}{|c|}{$\mathrm{Gmr}=1000 \mathrm{~s}^{-1}$} & $T f=20 \mathrm{~min}$ & $G f=25 s^{-1}$ \\
\hline \multicolumn{7}{|c|}{ CARACTERÍSTICAS DA ÁGUA DE ESTUDO } \\
\hline \multirow{2}{*}{ Turbidez (uT) } & \multirow{2}{*}{$\begin{array}{c}\text { Alcalinidade Total } \\
\left(\mathrm{mg} / \ell \mathrm{CaCO}_{3}\right)\end{array}$} & \multicolumn{2}{|c|}{ pH } & \multirow{2}{*}{\multicolumn{2}{|c|}{$\begin{array}{c}\text { Temperatura } \\
{ }^{\circ} \mathrm{C} \\
\end{array}$}} & \multirow{2}{*}{$\begin{array}{l}\text { Potencial } \\
\text { Zeta }(\mathrm{mV}) \\
\end{array}$} \\
\hline & & S/ agit. & $\mathrm{C} /$ agit. & & & \\
\hline 102 & 28.5 & 7.79 & 7.62 & & 25 & - \\
\hline
\end{tabular}

\begin{tabular}{|c|c|c|c|c|c|c|}
\hline \multirow{2}{*}{ FRASCO } & \multicolumn{3}{|c|}{ DOSAGEM DE PRODUTO QUÍMICO } & \multirow{2}{*}{$\begin{array}{c}\text { pH } \\
\text { de } \\
\text { Coagulação }\end{array}$} & \multirow{2}{*}{$\begin{array}{c}T_{\mathrm{s} 1}=1,75 \mathrm{~min} \\
\mathrm{~V}_{\mathrm{s} 1}=4.0 \mathrm{~cm} / \mathrm{min} \\
\begin{array}{c}\text { Turbidez } \\
\text { (uT) }\end{array}\end{array}$} & \multirow{2}{*}{$\begin{array}{c}T_{\mathrm{s} 2}=3.50 \mathrm{~min} \\
\mathrm{~V}_{\mathrm{s} 2}=\mathbf{2 . 0 \mathrm { cm } / \mathrm { min }} \\
\\
\begin{array}{c}\text { Turbidez } \\
(\mathrm{uT})\end{array}\end{array}$} \\
\hline & $\begin{array}{l}\text { Cloreto Férrico } \\
\qquad(\mathrm{mg} / \ell)\end{array}$ & $\begin{array}{c}\text { Ácido } \\
\text { Clorídrico } \\
0.1 \mathrm{~N}(\mathrm{~m} \ell / \ell)\end{array}$ & $\begin{array}{c}\text { Hidróxido de } \\
\text { Sódio 0.1N } \\
(\mathrm{m} \ell / \ell)\end{array}$ & & & \\
\hline 1 & 60.0 & - & 2.0 & 5.95 & 3.29 & 2.79 \\
\hline 2 & 60.0 & - & 3.0 & 6.07 & 1.23 & 1.08 \\
\hline 3 & 60.0 & - & 9.0 & 6.60 & 12.5 & 2.48 \\
\hline 4 & 60.0 & - & 15.0 & 7.13 & 6.25 & 4.80 \\
\hline 5 & 75.0 & - & 7.0 & 6.11 & 2.69 & 0.48 \\
\hline 6 & 75.0 & - & 14.0 & 6.70 & 12.7 & 4.90 \\
\hline
\end{tabular}

\section{ESTUDO DE COAGULAÇÃO-FLOCULAÇÃO-SEDIMENTAÇÃO}

\begin{tabular}{|c|c|c|c|c|c|c|}
\hline \multirow{2}{*}{$\begin{array}{l}\text { ENSAIO } N^{\circ}: 34 \\
\text { Data : } 01 / 03 / 00\end{array}$} & \multirow{2}{*}{$\begin{array}{c}\text { COAGULANTE } \\
\text { Cloreto Férrico }\end{array}$} & \multicolumn{3}{|c|}{ MISTURA RÁPIDA } & \multicolumn{2}{|c|}{ FLOCULAÇÃO } \\
\hline & & $T m r=10 \mathrm{~s}$ & & & Tf $=20 \mathrm{~min}$ & Gf $=25 \mathrm{~s}^{-1}$ \\
\hline \multicolumn{7}{|c|}{ CARACTERÍSTICAS DA ÁGUA DE ESTUDO } \\
\hline \multirow{2}{*}{ Turbidez (uT) } & \multirow{2}{*}{$\begin{array}{l}\text { Alcalinidade Total } \\
\left(\mathrm{mg} / \ell \mathrm{CaCO}_{3}\right)\end{array}$} & \multicolumn{2}{|c|}{ pH } & \multirow{2}{*}{\multicolumn{2}{|c|}{$\begin{array}{c}\text { Temperatura } \\
{ }^{\circ} \mathrm{C}\end{array}$}} & \multirow{2}{*}{$\begin{array}{l}\text { Potencial } \\
\text { Zeta }(\mathrm{mV})\end{array}$} \\
\hline & & $\mathrm{S} /$ agit. & $\mathrm{C} /$ agit. & & & \\
\hline 102 & 28.5 & 7.79 & 7.62 & & 25 & - \\
\hline
\end{tabular}

\begin{tabular}{|c|c|c|c|c|c|c|}
\hline \multirow{2}{*}{ FRASCO } & \multicolumn{3}{|c|}{ DOSAGEM DE PRODUTO QUÍMICO } & \multirow{2}{*}{$\begin{array}{c}\text { pH } \\
\text { de } \\
\text { Coagulação }\end{array}$} & \multirow{2}{*}{$\begin{array}{c}\begin{array}{c}T_{\mathrm{s}}=1,75 \mathrm{~min} \\
\mathrm{~V}_{\mathrm{s} 1}=4.0 \mathrm{~cm} / \mathrm{min}\end{array} \\
\begin{array}{c}\text { Turbidez } \\
(\mathrm{uT})\end{array}\end{array}$} & \multirow{2}{*}{$\begin{array}{c}\begin{array}{c}T_{\mathrm{s} 2}=3.50 \mathrm{~min} \\
\mathrm{~V}_{\mathrm{s} 2}=2.0 \mathrm{~cm} / \mathrm{min}\end{array} \\
\begin{array}{c}\text { Turbidez } \\
(\mathrm{uT})\end{array}\end{array}$} \\
\hline & $\begin{array}{c}\text { Cloreto Férrico } \\
(\mathrm{mg} / \mathfrak{\ell})\end{array}$ & $\begin{array}{c}\text { Ácido } \\
\text { Clorídrico } \\
0.1 \mathrm{~N}(\mathrm{~m} \ell / \ell)\end{array}$ & $\begin{array}{l}\text { Hidróxido de } \\
\text { Sódio 0.1N } \\
(\mathrm{ml} / \mathfrak{\ell})\end{array}$ & & & \\
\hline 1 & 50.0 & 1.50 & - & 5.81 & 89.4 & 85.0 \\
\hline 2 & 55.0 & - & 3.5 & 6.12 & 1.69 & 0.75 \\
\hline 3 & 55.0 & - & 4.0 & 6.24 & 3.14 & 0.68 \\
\hline 4 & 75.0 & - & 6.0 & 5.87 & 88.9 & 89.0 \\
\hline 5 & 75.0 & - & 15.0 & 6.64 & 15.2 & 1.86 \\
\hline 6 & 15.0 & - & - & 6.69 & 4.38 & 1.95 \\
\hline
\end{tabular}


ANEXO - C

ENSAIOS DO REATOR ESTÁTICO - ÁGUA I

PARA O COAGULANTE

HIDROXICLORETO DE ALUMÍNIO 
ESTUDO DE COAGULAÇÃO-FLOCULAÇÃO-SEDIMENTAÇÃO

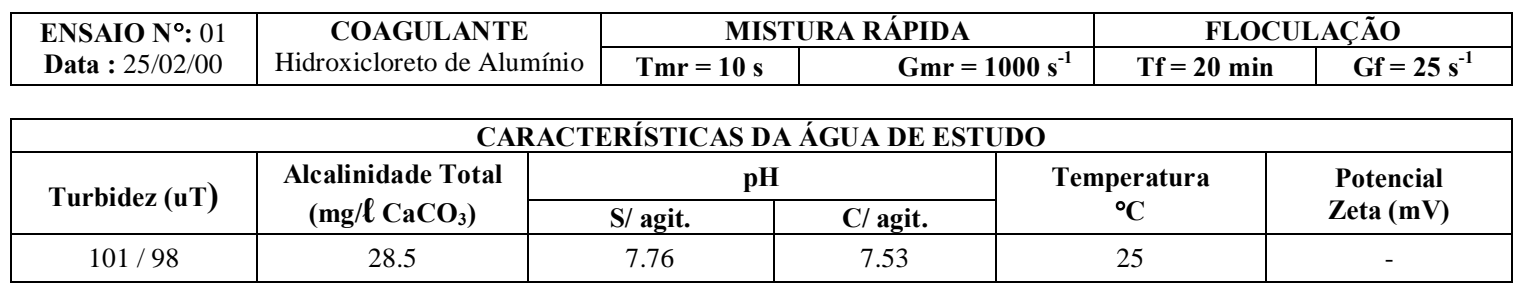

\begin{tabular}{|c|c|c|c|c|c|c|}
\hline \multirow{2}{*}{ FRASCO } & \multicolumn{3}{|c|}{ DOSAGEM DE PRODUTO QUÍMICO } & \multirow{2}{*}{$\begin{array}{c}\text { pH } \\
\text { de } \\
\text { Coagulação }\end{array}$} & \multirow{2}{*}{$\begin{array}{c}T_{\mathrm{s} 1}=1,75 \mathrm{~min} \\
\mathrm{~V}_{\mathrm{s} 1}=4.0 \mathrm{~cm} / \mathrm{min} \\
\text { Turbidez } \\
(\mathrm{uT})\end{array}$} & \multirow{2}{*}{$\begin{array}{c}T_{\mathrm{s} 2}=3.50 \mathrm{~min} \\
V_{\mathrm{s} 2}=2.0 \mathrm{~cm} / \mathrm{min} \\
\\
\text { Turbidez } \\
(u T)\end{array}$} \\
\hline & $\begin{array}{c}\text { Hidroxicloreto } \\
\text { de Alumínio } \\
(\mathrm{mg} / \mathrm{l})\end{array}$ & $\begin{array}{c}\text { Ácido } \\
\text { Clorídrico } \\
\mathbf{0 . 1 \mathrm { N }}(\mathrm{m} \ell / \ell)\end{array}$ & $\begin{array}{l}\text { Hidróxido de } \\
\text { Sódio 0.1N } \\
(\mathrm{m} \ell / \ell)\end{array}$ & & & \\
\hline 1 & 10.0 & 3.65 & - & 7.05 & 16.2 & 12.8 \\
\hline 2 & 10.0 & 1.82 & - & 7.16 & 24.6 & 8.0 \\
\hline 3 & 10.0 & - & - & 7.29 & 15.2 & 11.1 \\
\hline 4 & 10.0 & - & 1.0 & 7.47 & 24.9 & 9.37 \\
\hline 5 & 10.0 & - & 3.0 & 7.60 & 16.6 & 10.1 \\
\hline 6 & 10.0 & - & 5.0 & 8.18 & 15.3 & 12.0 \\
\hline
\end{tabular}

\section{ESTUDO DE COAGULAÇÃO-FLOCULAÇÃO-SEDIMENTAÇÃO}

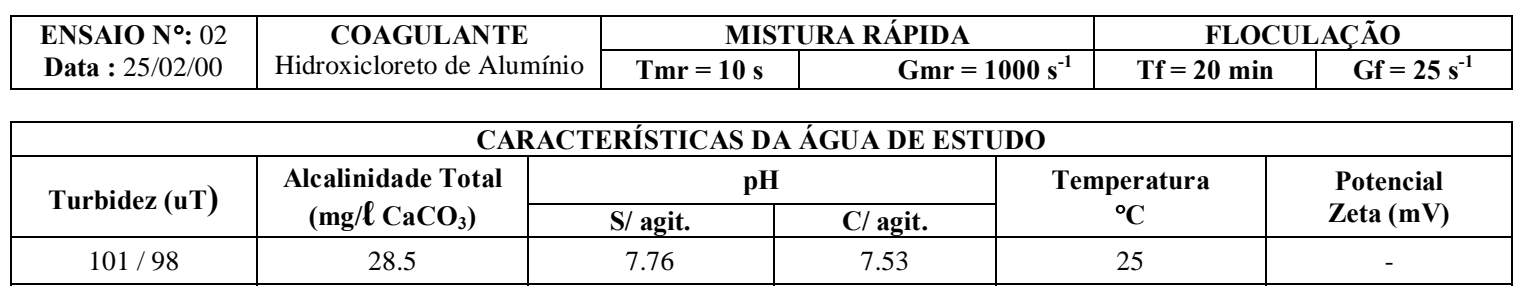

\begin{tabular}{|c|c|c|c|c|c|c|}
\hline \multirow{2}{*}{ FRASCO } & \multicolumn{3}{|c|}{ DOSAGEM DE PRODUTO QUÍMICO } & \multirow{2}{*}{$\begin{array}{c}\text { pH } \\
\text { de } \\
\text { Coagulação }\end{array}$} & \multirow{2}{*}{$\begin{array}{c}\mathrm{T}_{\mathrm{s} 1}=1,75 \mathrm{~min} \\
\mathrm{~V}_{\mathrm{s} 1}=4.0 \mathrm{~cm} / \mathrm{min} \\
\text { Turbidez } \\
(\mathrm{uT})\end{array}$} & \multirow{2}{*}{$\begin{array}{c}T_{\mathrm{s} 2}=3.50 \mathrm{~min} \\
\mathrm{~V}_{\mathrm{s} 2}=2.0 \mathrm{~cm} / \mathrm{min} \\
\\
\begin{array}{c}\text { Turbidez } \\
\text { (uT) }\end{array}\end{array}$} \\
\hline & $\begin{array}{c}\text { Hidroxicloreto } \\
\text { de Alumínio } \\
(\mathrm{mg} / \ell)\end{array}$ & 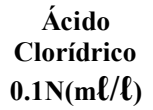 & $\begin{array}{c}\text { Hidróxido de } \\
\text { Sódio 0.1N } \\
(\mathrm{m} \ell / \ell)\end{array}$ & & & \\
\hline 1 & 15.0 & 5.47 & - & 6.90 & 10.6 & 5.66 \\
\hline 2 & 15.0 & 1.82 & - & 6.98 & 7.20 & 4.33 \\
\hline 3 & 15.0 & - & - & 7.17 & 5.80 & 3.21 \\
\hline 4 & 15.0 & - & 2.0 & 7.40 & 8.90 & 3.62 \\
\hline 5 & 15.0 & - & 4.0 & 7.73 & 13.6 & 4.99 \\
\hline 6 & 15.0 & - & 6.0 & 8.20 & 8.71 & 7.56 \\
\hline
\end{tabular}


ESTUDO DE COAGULAÇÃO-FLOCULAÇÃO-SEDIMENTAÇÃO

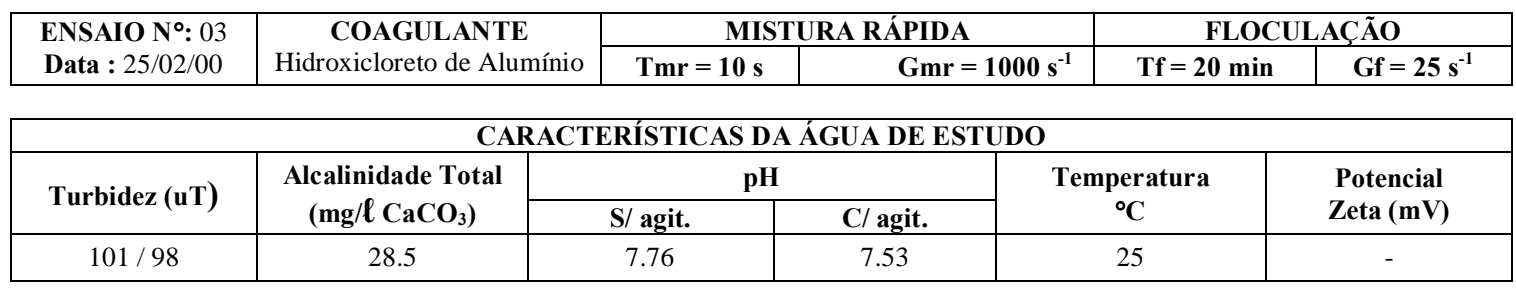

\begin{tabular}{|c|c|c|c|c|c|c|}
\hline \multirow{2}{*}{ FRASCO } & \multicolumn{3}{|c|}{ DOSAGEM DE PRODUTO QUÍMICO } & \multirow{2}{*}{$\begin{array}{c}\text { pH } \\
\text { de } \\
\text { Coagulação }\end{array}$} & \multirow{2}{*}{ 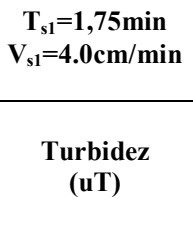 } & \multirow{2}{*}{$\begin{array}{c}T_{\mathrm{s} 2}=3.50 \mathrm{~min} \\
\mathbf{V}_{\mathrm{s} 2}=\mathbf{2 . 0 \mathrm { cm }} / \mathrm{min} \\
\begin{array}{c}\text { Turbidez } \\
\text { (uT) }\end{array}\end{array}$} \\
\hline & $\begin{array}{c}\text { Hidroxicloreto } \\
\text { de Alumínio } \\
(\mathrm{mg} / \mathfrak{l})\end{array}$ & $\begin{array}{c}\text { Ácido } \\
\text { Clorídrico } \\
0.1 \mathrm{~N}(\mathrm{~m} \ell / \ell)\end{array}$ & $\begin{array}{l}\text { Hidróxido de } \\
\text { Sódio 0.1N } \\
(\mathrm{ml} / \mathfrak{\ell})\end{array}$ & & & \\
\hline 1 & 20.0 & 7.29 & - & 6.65 & 99.8 & 97.4 \\
\hline 2 & 20.0 & 3.65 & - & 6.74 & 7.33 & 4.57 \\
\hline 3 & 20.0 & - & - & 6.93 & 3.97 & 2.17 \\
\hline 4 & 20.0 & - & 4.0 & 7.39 & 13.2 & 4.23 \\
\hline 5 & 20.0 & - & 8.0 & 8.34 & 10.1 & 3.48 \\
\hline 6 & 20.0 & - & 12.0 & 8.89 & 10.8 & 7.28 \\
\hline
\end{tabular}

\section{ESTUDO DE COAGULAÇÃO-FLOCULAÇÃO-SEDIMENTAÇÃO}

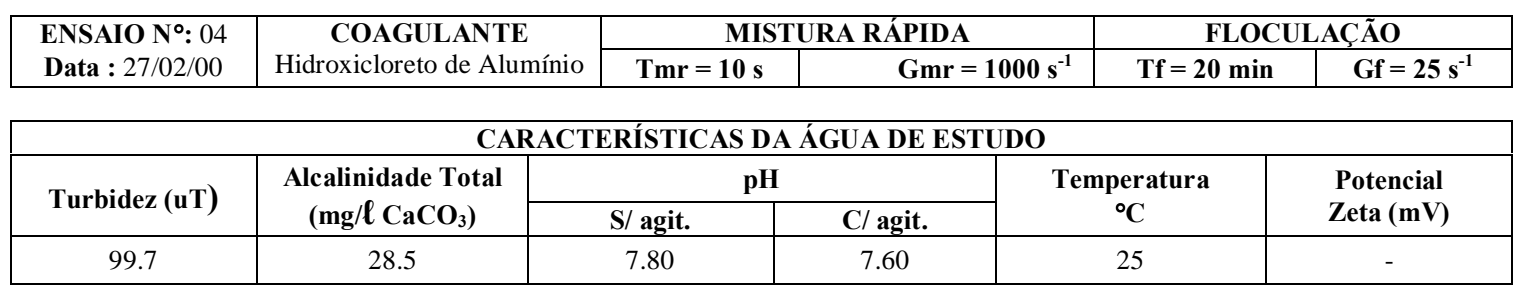

\begin{tabular}{|c|c|c|c|c|c|c|}
\hline \multirow{2}{*}{ FRASCO } & \multicolumn{3}{|c|}{ DOSAGEM DE PRODUTO QUÍMICO } & \multirow{2}{*}{$\begin{array}{c}\text { pH } \\
\text { de } \\
\text { Coagulação }\end{array}$} & \multirow{2}{*}{$\begin{array}{c}\begin{array}{c}T_{\mathrm{s} 1}=1,75 \mathrm{~min} \\
\mathrm{~V}_{\mathrm{s} 1}=4.0 \mathrm{~cm} / \mathrm{min}\end{array} \\
\begin{array}{c}\text { Turbidez } \\
\text { (uT) }\end{array}\end{array}$} & \multirow{2}{*}{$\begin{array}{c}\begin{array}{c}T_{\mathrm{s} 2}=3.50 \mathrm{~min} \\
\mathrm{~V}_{\mathrm{s} 2}=2.0 \mathrm{~cm} / \mathrm{min}\end{array} \\
\begin{array}{c}\text { Turbidez } \\
(\mathrm{uT})\end{array}\end{array}$} \\
\hline & $\begin{array}{c}\text { Hidroxicloreto } \\
\text { de Alumínio } \\
(\mathrm{mg} / \mathfrak{l})\end{array}$ & $\begin{array}{c}\text { Ácido } \\
\text { Clorídrico } \\
0.1 \mathrm{~N}(\mathrm{~m} \ell / \ell)\end{array}$ & $\begin{array}{l}\text { Hidróxido de } \\
\text { Sódio 0.1N } \\
(\mathrm{ml} / \mathfrak{\ell})\end{array}$ & & & \\
\hline 1 & 25.0 & 3.65 & - & 6.76 & 100.0 & 97.8 \\
\hline 2 & 25.0 & 1.82 & - & 6.84 & 9.43 & 6.16 \\
\hline 3 & 25.0 & - & - & 6.94 & 4.44 & 2.45 \\
\hline 4 & 25.0 & - & 6.0 & 7.67 & 14.3 & 3.94 \\
\hline 5 & 25.0 & - & 10.0 & 8.55 & 8.87 & 4.24 \\
\hline 6 & 25.0 & - & 16.0 & 9.17 & 14.2 & 9.29 \\
\hline
\end{tabular}


ESTUDO DE COAGULAÇÃO-FLOCULAÇÃO-SEDIMENTAÇÃO

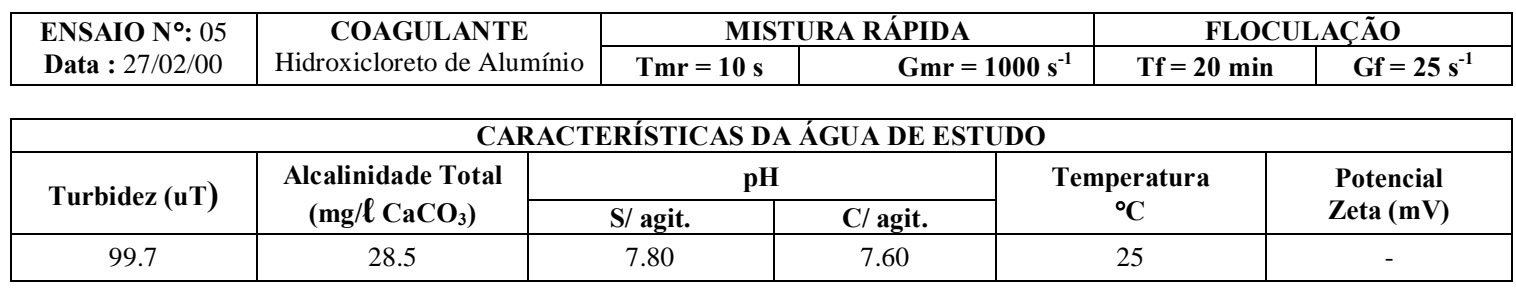

\begin{tabular}{|c|c|c|c|c|c|c|}
\hline \multirow{2}{*}{ FRASCO } & \multicolumn{3}{|c|}{ DOSAGEM DE PRODUTO QUÍMICO } & \multirow{2}{*}{$\begin{array}{c}\text { pH } \\
\text { de } \\
\text { Coagulação }\end{array}$} & \multirow{2}{*}{ 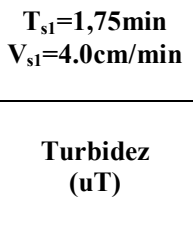 } & \multirow{2}{*}{$\begin{array}{c}\mathrm{T}_{\mathrm{s} 2}=3.50 \mathrm{~min} \\
\mathrm{~V}_{\mathrm{s} 2}=\mathbf{2 . 0 \mathrm { cm } / \mathrm { min }} \\
\begin{array}{c}\text { Turbidez } \\
(\mathrm{uT})\end{array}\end{array}$} \\
\hline & $\begin{array}{c}\text { Hidroxicloreto } \\
\text { de Alumínio } \\
(\mathrm{mg} / \mathfrak{l})\end{array}$ & $\begin{array}{c}\text { Ácido } \\
\text { Clorídrico } \\
0.1 \mathrm{~N}(\mathrm{~m} \ell / \ell)\end{array}$ & $\begin{array}{l}\text { Hidróxido de } \\
\text { Sódio 0.1N } \\
(\mathrm{ml} / \mathfrak{\ell})\end{array}$ & & & \\
\hline 1 & 30.0 & 1.82 & - & 6.90 & 101.0 & 97.6 \\
\hline 2 & 30.0 & - & - & 6.91 & 12.3 & 7.74 \\
\hline 3 & 30.0 & - & 12.0 & 8.51 & 6.77 & 4.24 \\
\hline 4 & 30.0 & - & 18.0 & 9.23 & 15.0 & 7.07 \\
\hline 5 & 30.0 & - & 24.0 & 9.56 & 10.3 & 5.86 \\
\hline 6 & 30.0 & - & 28.0 & 9.71 & 14.7 & 7.37 \\
\hline
\end{tabular}

\section{ESTUDO DE COAGULAÇÃO-FLOCULAÇÃO-SEDIMENTAÇÃO}

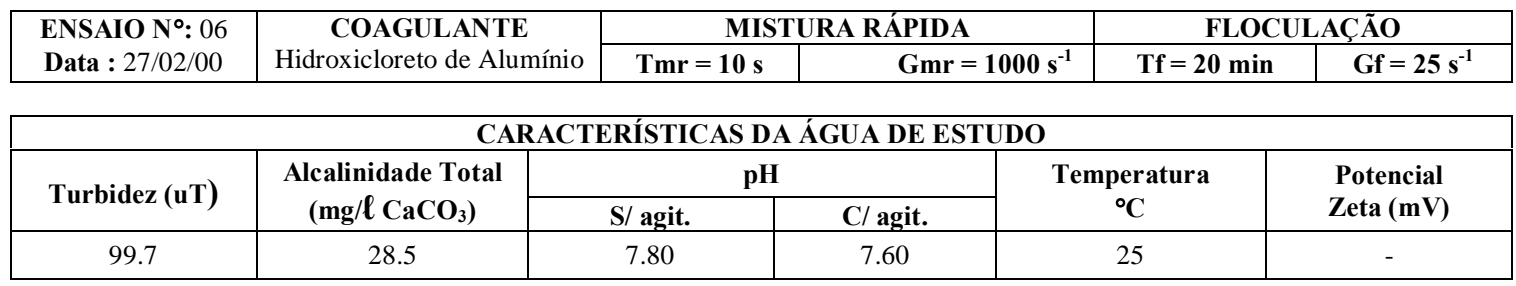

\begin{tabular}{|c|c|c|c|c|c|c|}
\hline \multirow{2}{*}{ FRASCO } & \multicolumn{3}{|c|}{ DOSAGEM DE PRODUTO QUÍMICO } & \multirow{2}{*}{$\begin{array}{c}\text { pH } \\
\text { de } \\
\text { Coagulação }\end{array}$} & \multirow{2}{*}{$\begin{array}{c}\begin{array}{c}T_{\mathrm{s} 1}=1,75 \mathrm{~min} \\
\mathrm{~V}_{\mathrm{s} 1}=4.0 \mathrm{~cm} / \mathrm{min}\end{array} \\
\begin{array}{c}\text { Turbidez } \\
\text { (uT) }\end{array}\end{array}$} & \multirow{2}{*}{$\begin{array}{c}T_{\mathrm{s} 2}=3.50 \mathrm{~min} \\
\mathrm{~V}_{\mathrm{s} 2}=2.0 \mathrm{~cm} / \mathrm{min} \\
\begin{array}{c}\text { Turbidez } \\
\text { (uT) }\end{array}\end{array}$} \\
\hline & $\begin{array}{c}\text { Hidroxicloreto } \\
\text { de Alumínio } \\
(\mathrm{mg} / \mathfrak{l})\end{array}$ & $\begin{array}{c}\text { Ácido } \\
\text { Clorídrico } \\
0.1 \mathrm{~N}(\mathrm{~m} \ell / \ell)\end{array}$ & $\begin{array}{l}\text { Hidróxido de } \\
\text { Sódio 0.1N } \\
(\mathrm{ml} / \mathfrak{l})\end{array}$ & & & \\
\hline 1 & 35.0 & - & - & 7.06 & - & - \\
\hline 2 & 35.0 & - & 18.0 & 8.96 & 16.3 & 6.66 \\
\hline 3 & 35.0 & - & 24.0 & 9.45 & 19.1 & 8.88 \\
\hline 4 & 35.0 & - & 30.0 & 9.71 & 29.0 & 10.5 \\
\hline 5 & 35.0 & - & 36.0 & 9.90 & 23.1 & 5.55 \\
\hline 6 & 35.0 & - & 42.0 & 10.07 & 25.1 & 9.84 \\
\hline
\end{tabular}


ESTUDO DE COAGULAÇÃO-FLOCULAÇÃO-SEDIMENTAÇÃO

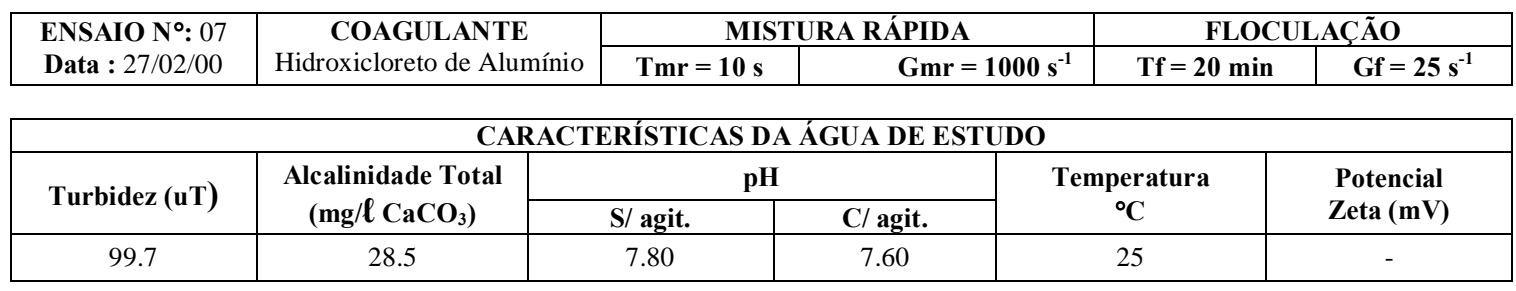

\begin{tabular}{|c|c|c|c|c|c|c|}
\hline \multirow{2}{*}{ FRASCO } & \multicolumn{3}{|c|}{ DOSAGEM DE PRODUTO QUÍMICO } & \multirow{2}{*}{$\begin{array}{c}\text { pH } \\
\text { de } \\
\text { Coagulação }\end{array}$} & \multirow{2}{*}{ 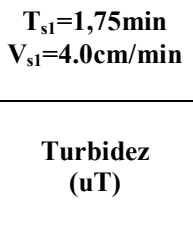 } & \multirow{2}{*}{$\begin{array}{c}\mathrm{T}_{\mathrm{s} 2}=3.50 \mathrm{~min} \\
\mathrm{~V}_{\mathrm{s} 2}=\mathbf{2 . 0 \mathrm { cm } / \mathrm { min }} \\
\begin{array}{c}\text { Turbidez } \\
(\mathrm{uT})\end{array}\end{array}$} \\
\hline & $\begin{array}{c}\text { Hidroxicloreto } \\
\text { de Alumínio } \\
(\mathrm{mg} / \mathfrak{l})\end{array}$ & $\begin{array}{c}\text { Ácido } \\
\text { Clorídrico } \\
0.1 \mathrm{~N}(\mathrm{~m} \ell / \ell)\end{array}$ & $\begin{array}{l}\text { Hidróxido de } \\
\text { Sódio 0.1N } \\
(\mathrm{ml} / \mathfrak{\ell})\end{array}$ & & & \\
\hline 1 & 40.0 & - & - & 6.84 & 96.7 & 94.3 \\
\hline 2 & 40.0 & - & 2.0 & 6.89 & 9.53 & 7.30 \\
\hline 3 & 40.0 & - & 4.0 & 6.97 & 2.68 & 0.73 \\
\hline 4 & 40.0 & - & 8.0 & 7.40 & 8.15 & 3.90 \\
\hline 5 & 40.0 & - & 12.0 & 8.07 & 10.5 & 2.08 \\
\hline 6 & 40.0 & - & 16.0 & 8.80 & 11.3 & 7.24 \\
\hline
\end{tabular}

\section{ESTUDO DE COAGULAÇÃO-FLOCULAÇÃO-SEDIMENTAÇÃO}

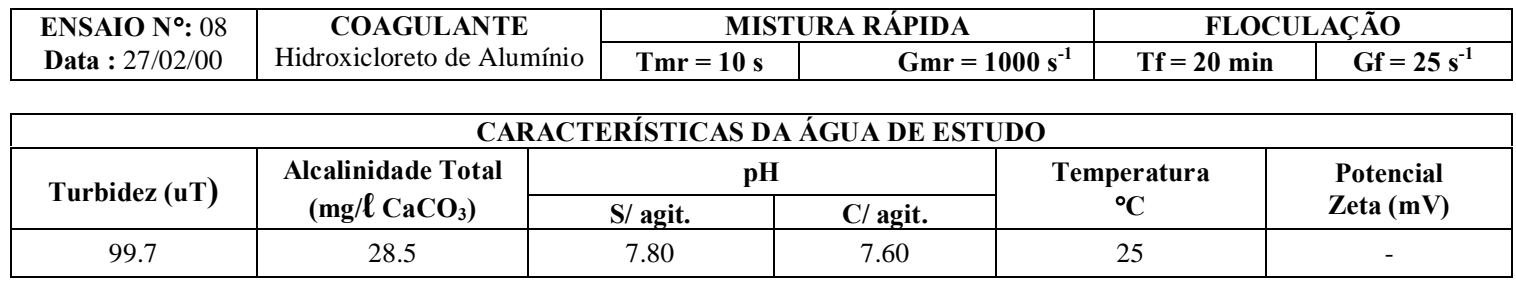

\begin{tabular}{|c|c|c|c|c|c|c|}
\hline \multirow{2}{*}{ FRASCO } & \multicolumn{3}{|c|}{ DOSAGEM DE PRODUTO QUÍMICO } & \multirow{2}{*}{$\begin{array}{c}\text { pH } \\
\text { de } \\
\text { Coagulação }\end{array}$} & \multirow{2}{*}{$\begin{array}{c}\begin{array}{c}T_{\mathrm{s1}}=1,75 \mathrm{~min} \\
\mathrm{~V}_{\mathrm{s} 1}=4.0 \mathrm{~cm} / \mathrm{min}\end{array} \\
\begin{array}{c}\text { Turbidez } \\
(\mathrm{uT})\end{array}\end{array}$} & \multirow{2}{*}{$\begin{array}{c}T_{\mathrm{s} 2}=3.50 \mathrm{~min} \\
\mathrm{~V}_{\mathrm{s} 2}=2.0 \mathrm{~cm} / \mathrm{min}\end{array}$} \\
\hline & $\begin{array}{c}\text { Hidroxicloreto } \\
\text { de Alumínio } \\
(\mathrm{mg} / \mathfrak{l})\end{array}$ & $\begin{array}{c}\text { Ácido } \\
\text { Clorídrico } \\
0.1 \mathrm{~N}(\mathrm{~m} \ell / \ell)\end{array}$ & $\begin{array}{l}\text { Hidróxido de } \\
\text { Sódio 0.1N } \\
(\mathrm{ml} / \mathfrak{l})\end{array}$ & & & \\
\hline 1 & 45.0 & - & - & 6.75 & 98.2 & 99.9 \\
\hline 2 & 45.0 & - & 2.0 & 6.78 & 97.0 & 96.1 \\
\hline 3 & 45.0 & - & 3.0 & 6.82 & 42.3 & 25.3 \\
\hline 4 & 45.0 & - & 4.0 & 6.88 & 2.27 & 1.74 \\
\hline 5 & 45.0 & - & 10.0 & 7.42 & 14.8 & 5.42 \\
\hline 6 & 45.0 & - & 16.0 & 8.49 & 21.1 & 7.00 \\
\hline
\end{tabular}


ESTUDO DE COAGULAÇÃO-FLOCULAÇÃO-SEDIMENTAÇÃO

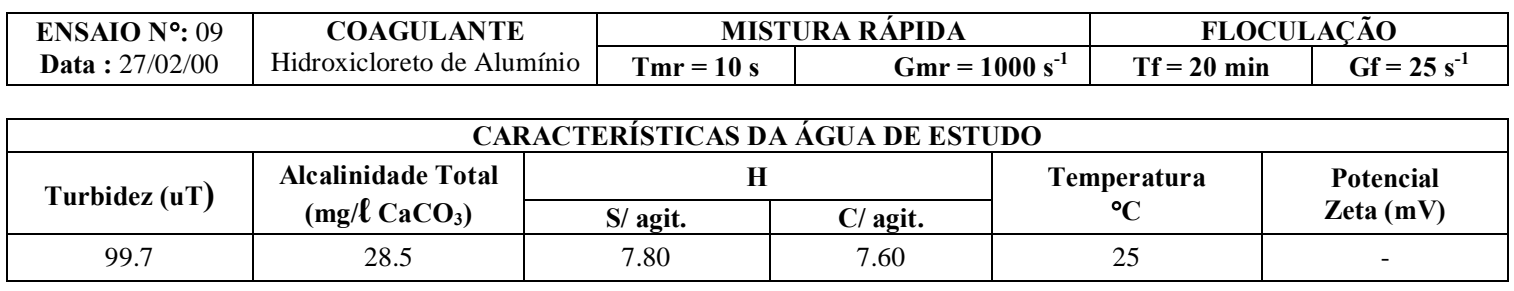

\begin{tabular}{|c|c|c|c|c|c|c|}
\hline \multirow{2}{*}{ FRASCO } & \multicolumn{3}{|c|}{ DOSAGEM DE PRODUTO QUÍMICO } & \multirow{2}{*}{$\begin{array}{c}\text { pH } \\
\text { de } \\
\text { Coagulação }\end{array}$} & \multirow{2}{*}{$\begin{array}{c}\begin{array}{c}T_{\mathrm{s1}}=1,75 \mathrm{~min} \\
\mathrm{~V}_{\mathrm{s} 1}=4.0 \mathrm{~cm} / \mathrm{min}\end{array} \\
\begin{array}{c}\text { Turbidez } \\
(\mathrm{uT})\end{array}\end{array}$} & \multirow{2}{*}{$\begin{array}{c}T_{\mathrm{s} 2}=3.50 \mathrm{~min} \\
\mathrm{~V}_{\mathrm{s} 2}=2.0 \mathrm{~cm} / \mathrm{min}\end{array}$} \\
\hline & $\begin{array}{c}\text { Hidroxicloreto } \\
\text { de Alumínio } \\
(\mathrm{mg} / \mathfrak{l})\end{array}$ & $\begin{array}{c}\text { Ácido } \\
\text { Clorídrico } \\
0.1 \mathrm{~N}(\mathrm{~m} \ell / \ell)\end{array}$ & $\begin{array}{l}\text { Hidróxido de } \\
\text { Sódio 0.1N } \\
(\mathrm{ml} / \mathfrak{l})\end{array}$ & & & \\
\hline 1 & 50.0 & - & 3.0 & 6.83 & 96.0 & 96.6 \\
\hline 2 & 50.0 & - & 5.0 & 6.86 & 3.18 & 1.46 \\
\hline 3 & 50.0 & - & 7.0 & 6.99 & 2.58 & 1.97 \\
\hline 4 & 50.0 & - & 9.0 & 7.14 & 4.70 & 1.69 \\
\hline 5 & 50.0 & - & 15.0 & 8.20 & 13.3 & 5.57 \\
\hline 6 & $50 . .0$ & - & 20.0 & 8.95 & 20.7 & 9.58 \\
\hline
\end{tabular}

\section{ESTUDO DE COAGULAÇÃO-FLOCULAÇÃO-SEDIMENTAÇÃO}

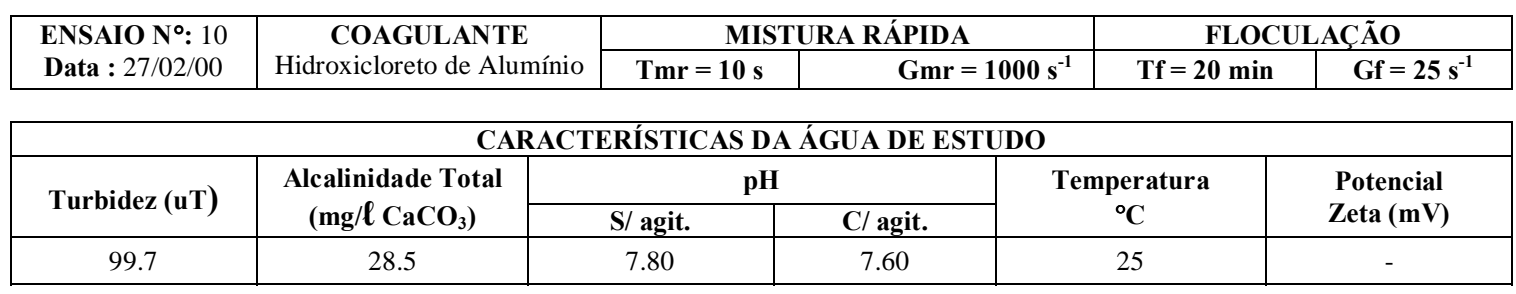

\begin{tabular}{|c|c|c|c|c|c|c|}
\hline \multirow{2}{*}{ FRASCO } & \multicolumn{3}{|c|}{ DOSAGEM DE PRODUTO QUÍMICO } & \multirow{2}{*}{$\begin{array}{c}\text { pH } \\
\text { de } \\
\text { Coagulação }\end{array}$} & \multirow{2}{*}{$\begin{array}{c}\begin{array}{c}T_{\mathrm{s} 1}=1,75 \mathrm{~min} \\
\mathrm{~V}_{\mathrm{s} 1}=4.0 \mathrm{~cm} / \mathrm{min}\end{array} \\
\begin{array}{c}\text { Turbidez } \\
\text { (uT) }\end{array}\end{array}$} & \multirow{2}{*}{$\begin{array}{c}T_{\mathrm{s} 2}=3.50 \mathrm{~min} \\
\mathrm{~V}_{\mathrm{s} 2}=2.0 \mathrm{~cm} / \mathrm{min}\end{array}$} \\
\hline & $\begin{array}{c}\text { Hidroxicloreto } \\
\text { de Alumínio } \\
(\mathrm{mg} / \mathfrak{l})\end{array}$ & $\begin{array}{c}\text { Ácido } \\
\text { Clorídrico } \\
0.1 \mathrm{~N}(\mathrm{~m} \ell / \ell)\end{array}$ & $\begin{array}{l}\text { Hidróxido de } \\
\text { Sódio 0.1N } \\
(\mathrm{ml} / \mathfrak{\ell})\end{array}$ & & & \\
\hline 1 & 55.0 & - & 4.0 & 6.83 & 95.5 & 98.9 \\
\hline 2 & 55.0 & - & 6.0 & 6.88 & 3.62 & 1.57 \\
\hline 3 & 55.0 & - & 8.0 & 7.00 & 2.85 & 1.54 \\
\hline 4 & 55.0 & - & 10.0 & 7.20 & 6.52 & 2.86 \\
\hline 5 & 55.0 & - & 16.0 & 8.10 & 20.4 & 6.42 \\
\hline 6 & 55.0 & - & 22.0 & 8.96 & 15.6 & 11.3 \\
\hline
\end{tabular}


ESTUDO DE COAGULAÇÃO-FLOCULAÇÃO-SEDIMENTAÇÃO

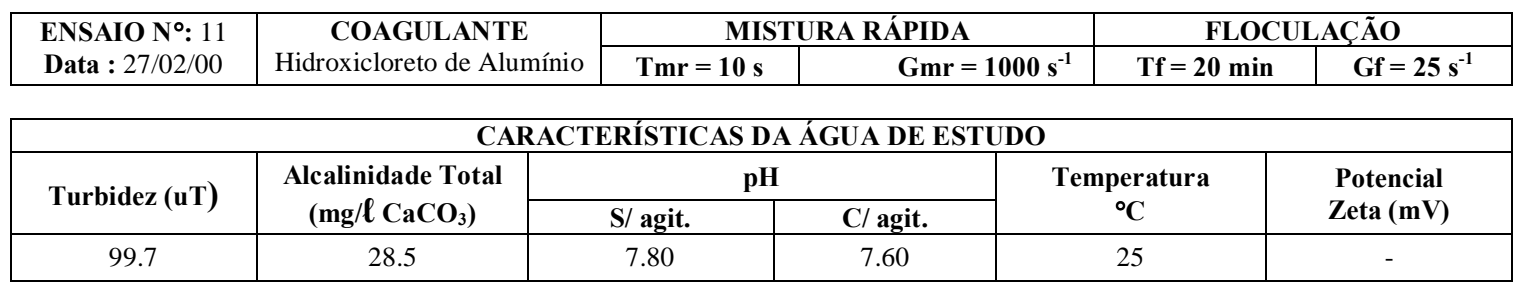

\begin{tabular}{|c|c|c|c|c|c|c|}
\hline \multirow{2}{*}{ FRASCO } & \multicolumn{3}{|c|}{ DOSAGEM DE PRODUTO QUÍMICO } & \multirow{2}{*}{$\begin{array}{c}\text { pH } \\
\text { de } \\
\text { Coagulação }\end{array}$} & \multirow{2}{*}{ 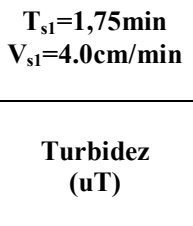 } & \multirow{2}{*}{$\begin{array}{c}T_{\mathrm{s} 2}=3.50 \mathrm{~min} \\
\mathrm{~V}_{\mathrm{s} 2}=2.0 \mathrm{~cm} / \mathrm{min} \\
\begin{array}{c}\text { Turbidez } \\
(\mathrm{uT})\end{array}\end{array}$} \\
\hline & $\begin{array}{c}\text { Hidroxicloreto } \\
\text { de Alumínio } \\
(\mathrm{mg} / \mathfrak{l})\end{array}$ & $\begin{array}{c}\text { Ácido } \\
\text { Clorídrico } \\
0.1 \mathrm{~N}(\mathrm{~m} \ell / \ell)\end{array}$ & $\begin{array}{l}\text { Hidróxido de } \\
\text { Sódio 0.1N } \\
(\mathrm{ml} / \mathfrak{l})\end{array}$ & & & \\
\hline 1 & 60.0 & - & 5.0 & 6.82 & 96.7 & 96.8 \\
\hline 2 & 60.0 & - & 7.0 & 6.88 & 2.42 & 1.79 \\
\hline 3 & 60.0 & - & 9.0 & 6.98 & 3.85 & 1.04 \\
\hline 4 & 60.0 & - & 11.0 & 7.10 & 5.12 & 1.87 \\
\hline 5 & 60.0 & - & 16.0 & 7.80 & 19.6 & 3.16 \\
\hline 6 & 60.0 & - & 22.0 & 8.78 & 22.4 & 5.35 \\
\hline
\end{tabular}

\section{ESTUDO DE COAGULAÇÃO-FLOCULAÇÃO-SEDIMENTAÇÃO}

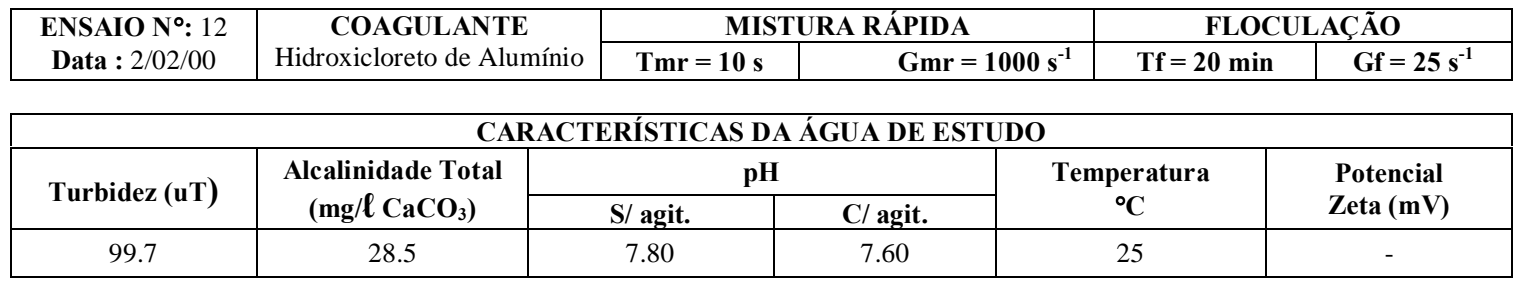

\begin{tabular}{|c|c|c|c|c|c|c|}
\hline \multirow{2}{*}{ FRASCO } & \multicolumn{3}{|c|}{ DOSAGEM DE PRODUTO QUÍMICO } & \multirow{2}{*}{$\begin{array}{c}\text { pH } \\
\text { de } \\
\text { Coagulação }\end{array}$} & \multirow{2}{*}{$\begin{array}{c}\begin{array}{c}T_{\mathrm{s1}}=1,75 \mathrm{~min} \\
\mathrm{~V}_{\mathrm{s} 1}=4.0 \mathrm{~cm} / \mathrm{min}\end{array} \\
\begin{array}{c}\text { Turbidez } \\
(\mathrm{uT})\end{array}\end{array}$} & \multirow{2}{*}{$\begin{array}{c}T_{\mathrm{s} 2}=3.50 \mathrm{~min} \\
\mathrm{~V}_{\mathrm{s} 2}=2.0 \mathrm{~cm} / \mathrm{min} \\
\begin{array}{c}\text { Turbidez } \\
\text { (uT) }\end{array}\end{array}$} \\
\hline & $\begin{array}{c}\text { Hidroxicloreto } \\
\text { de Alumínio } \\
(\mathrm{mg} / \mathfrak{l})\end{array}$ & $\begin{array}{c}\text { Ácido } \\
\text { Clorídrico } \\
0.1 \mathrm{~N}(\mathrm{~m} \ell / \ell)\end{array}$ & $\begin{array}{l}\text { Hidróxido de } \\
\text { Sódio 0.1N } \\
(\mathrm{ml} / \mathfrak{l})\end{array}$ & & & \\
\hline 1 & 65.0 & - & 6.0 & 6.84 & 97.1 & 95.5 \\
\hline 2 & 65.0 & - & 8.0 & 6.88 & 1.72 & 1.12 \\
\hline 3 & 65.0 & - & 10.0 & 6.94 & 5.63 & 2.02 \\
\hline 4 & 65.0 & - & 12.0 & 7.08 & 5.69 & 0.73 \\
\hline 5 & 65.0 & - & 18.0 & 7.86 & 27.7 & 4.89 \\
\hline 6 & 65.0 & - & 24.0 & 8.84 & 28.3 & 7.60 \\
\hline
\end{tabular}


ESTUDO DE COAGULAÇÃO-FLOCULAÇÃO-SEDIMENTAÇÃO

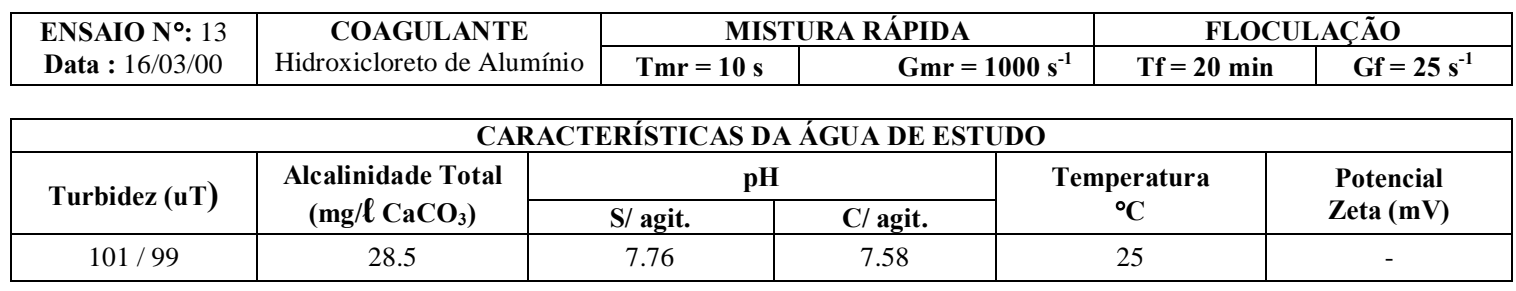

\begin{tabular}{|c|c|c|c|c|c|c|}
\hline \multirow{2}{*}{ FRASCO } & \multicolumn{3}{|c|}{ DOSAGEM DE PRODUTO QUÍMICO } & \multirow{2}{*}{$\begin{array}{c}\text { pH } \\
\text { de } \\
\text { Coagulação }\end{array}$} & \multirow{2}{*}{$\begin{array}{c}T_{\mathrm{s} 1}=1,75 \mathrm{~min} \\
\mathrm{~V}_{\mathrm{s} 1}=4.0 \mathrm{~cm} / \mathrm{min}\end{array}$} & \multirow{2}{*}{$\begin{array}{c}\begin{array}{c}T_{\mathrm{s} 2}=3.50 \mathrm{~min} \\
\mathbf{V}_{\mathrm{s} 2}=2.0 \mathrm{~cm} / \mathrm{min}\end{array} \\
\qquad \begin{array}{c}\text { Turbidez } \\
\text { (uT) }\end{array}\end{array}$} \\
\hline & $\begin{array}{c}\text { Hidroxicloreto } \\
\text { de Alumínio } \\
(\mathrm{mg} / \mathfrak{l})\end{array}$ & $\begin{array}{c}\text { Ácido } \\
\text { Clorídrico } \\
0.1 \mathrm{~N}(\mathrm{~m} \ell / \ell)\end{array}$ & $\begin{array}{l}\text { Hidróxido de } \\
\text { Sódio 0.1N } \\
(\mathrm{ml} / \mathfrak{l})\end{array}$ & & & \\
\hline 1 & 20.0 & 1.82 & - & 6.88 & 4.62 & 4.43 \\
\hline 2 & 15.0 & 0.91 & - & 7.02 & 6.74 & 4.88 \\
\hline 3 & 15.0 & - & 1.0 & 7.18 & 8.32 & 7.25 \\
\hline 4 & 25.0 & - & 1.5 & 7.11 & 3.65 & 2.06 \\
\hline 5 & 20.0 & - & 1.5 & 7.20 & 4.64 & 3.97 \\
\hline 6 & 20.0 & - & 3.0 & 7.34 & 5.36 & 3.27 \\
\hline
\end{tabular}

\section{ESTUDO DE COAGULAÇÃO-FLOCULAÇÃO-SEDIMENTAÇÃO}

\begin{tabular}{|c|c|c|c|c|c|c|}
\hline \multirow{2}{*}{$\begin{array}{l}\text { ENSAIO } N^{\circ}: 14 \\
\text { Data }: 16 / 03 / 00\end{array}$} & \multirow{2}{*}{$\begin{array}{c}\text { COAGULANTE } \\
\text { Hidroxicloreto de Alumínio } \\
\end{array}$} & \multicolumn{3}{|c|}{ MISTURA RÁPIDA } & \multicolumn{2}{|c|}{ FLOCULAÇÃO } \\
\hline & & $\mathrm{Tmr}=10 \mathrm{~s}$ & & & Tf $=20 \mathrm{~min}$ & $G f=25 \mathrm{~s}^{-1}$ \\
\hline \multicolumn{7}{|c|}{ CARACTERÍSTICAS DA ÁGUA DE ESTUDO } \\
\hline \multirow{2}{*}{ Turbidez (uT) } & \multirow{2}{*}{$\begin{array}{c}\text { Alcalinidade Total } \\
\left(\mathrm{mg} / \mathrm{\ell} \mathrm{CaCO}_{3}\right) \\
\end{array}$} & \multicolumn{2}{|c|}{ pH } & \multirow{2}{*}{\multicolumn{2}{|c|}{$\begin{array}{c}\text { Temperatura } \\
{ }^{\circ} \mathrm{C}\end{array}$}} & \multirow{2}{*}{$\begin{array}{l}\text { Potencial } \\
\text { Zeta }(m V)\end{array}$} \\
\hline & & S/ agit. & $\mathrm{C} /$ agit. & & & \\
\hline $101 / 99$ & 28.5 & 7.76 & 7.58 & & 25 & - \\
\hline
\end{tabular}

\begin{tabular}{|c|c|c|c|c|c|c|}
\hline \multirow{2}{*}{ FRASCO } & \multicolumn{3}{|c|}{ DOSAGEM DE PRODUTO QUÍMICO } & \multirow{2}{*}{$\begin{array}{c}\text { pH } \\
\text { de } \\
\text { Coagulação }\end{array}$} & \multirow{2}{*}{$\begin{array}{c}\begin{array}{c}T_{\mathrm{s1}}=1,75 \mathrm{~min} \\
\mathrm{~V}_{\mathrm{s} 1}=4.0 \mathrm{~cm} / \mathrm{min}\end{array} \\
\begin{array}{c}\text { Turbidez } \\
(\mathrm{uT})\end{array}\end{array}$} & \multirow{2}{*}{$\begin{array}{c}T_{\mathrm{s} 2}=3.50 \mathrm{~min} \\
\mathrm{~V}_{\mathrm{s} 2}=2.0 \mathrm{~cm} / \mathrm{min} \\
\begin{array}{c}\text { Turbidez } \\
\text { (uT) }\end{array}\end{array}$} \\
\hline & $\begin{array}{c}\text { Hidroxicloreto } \\
\text { de Alumínio } \\
(\mathrm{mg} / \mathfrak{l})\end{array}$ & $\begin{array}{c}\text { Ácido } \\
\text { Clorídrico } \\
0.1 \mathrm{~N}(\mathrm{~m} \ell / \ell)\end{array}$ & $\begin{array}{l}\text { Hidróxido de } \\
\text { Sódio 0.1N } \\
(\mathrm{ml} / \mathfrak{l})\end{array}$ & & & \\
\hline 1 & 30.0 & - & 2.0 & 6.97 & 2.82 & 1.98 \\
\hline 2 & 25.0 & - & 3.0 & 6.93 & 3.15 & 1.06 \\
\hline 3 & 25.0 & - & 4.5 & 7.04 & 3.20 & 0.83 \\
\hline 4 & 30.0 & - & 4.0 & 7.19 & 4.78 & 3.02 \\
\hline 5 & 35.0 & - & 4.0 & 7.16 & 3.35 & 0.91 \\
\hline 6 & 35.0 & - & 6.0 & 7.27 & 3.85 & 1.47 \\
\hline
\end{tabular}


ESTUDO DE COAGULAÇÃO-FLOCULAÇÃO-SEDIMENTAÇÃO

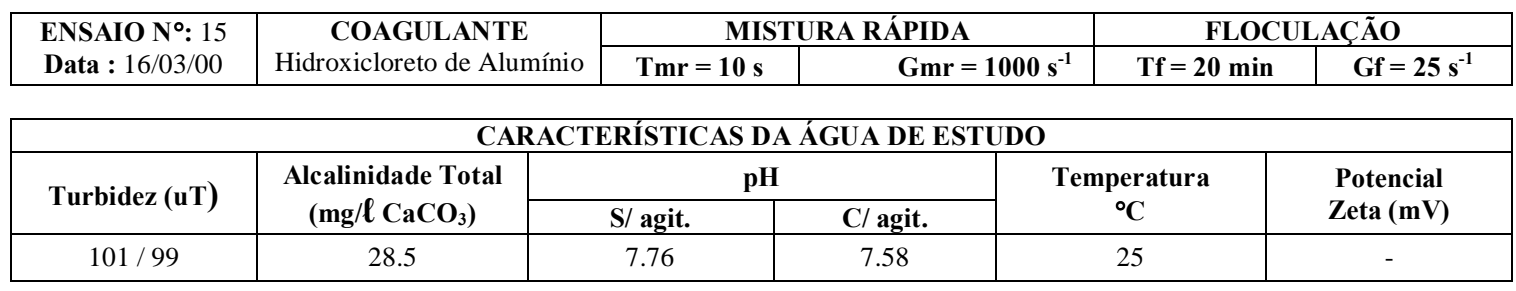

\begin{tabular}{|c|c|c|c|c|c|c|}
\hline \multirow{2}{*}{ FRASCO } & \multicolumn{3}{|c|}{ DOSAGEM DE PRODUTO QUÍMICO } & \multirow{2}{*}{$\begin{array}{c}\text { pH } \\
\text { de } \\
\text { Coagulação }\end{array}$} & \multirow{2}{*}{ 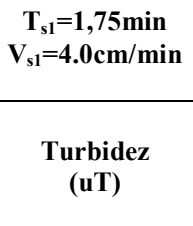 } & \multirow{2}{*}{$\begin{array}{c}\mathrm{T}_{\mathrm{s} 2}=3.50 \mathrm{~min} \\
\mathrm{~V}_{\mathrm{s} 2}=\mathbf{2 . 0 \mathrm { cm } / \mathrm { min }} \\
\begin{array}{c}\text { Turbidez } \\
(\mathrm{uT})\end{array}\end{array}$} \\
\hline & $\begin{array}{c}\text { Hidroxicloreto } \\
\text { de Alumínio } \\
(\mathrm{mg} / \mathfrak{l})\end{array}$ & $\begin{array}{c}\text { Ácido } \\
\text { Clorídrico } \\
0.1 \mathrm{~N}(\mathrm{~m} \ell / \ell)\end{array}$ & $\begin{array}{l}\text { Hidróxido de } \\
\text { Sódio 0.1N } \\
(\mathrm{ml} / \mathfrak{\ell})\end{array}$ & & & \\
\hline 1 & 20.0 & - & - & 7.59 & 6.16 & 3.20 \\
\hline 2 & 20.0 & - & 5.0 & 7.68 & 8.20 & 3.29 \\
\hline 3 & 15.0 & - & 5.0 & 8.32 & 9.16 & 5.50 \\
\hline 4 & 20.0 & - & 7.0 & 8.25 & 6.83 & 3.94 \\
\hline 5 & 25.0 & - & 7.0 & 7.97 & 13.5 & 3.34 \\
\hline 6 & 25.0 & - & 9.0 & 8.02 & 9.87 & 5.32 \\
\hline
\end{tabular}

\section{ESTUDO DE COAGULAÇÃO-FLOCULAÇÃO-SEDIMENTAÇÃO}

\begin{tabular}{|c|c|c|c|c|c|c|}
\hline \multirow{2}{*}{$\begin{array}{l}\text { ENSAIO } N^{\circ}: 16 \\
\text { Data }: 16 / 03 / 00\end{array}$} & \multirow{2}{*}{$\begin{array}{c}\text { COAGULANTE } \\
\text { Hidroxicloreto de Alumínio } \\
\end{array}$} & \multicolumn{3}{|c|}{ MISTURA RÁPIDA } & \multicolumn{2}{|c|}{ FLOCULAÇÃO } \\
\hline & & $\mathrm{Tmr}=10 \mathrm{~s}$ & & & Tf $=20 \mathrm{~min}$ & $G f=25 \mathrm{~s}^{-1}$ \\
\hline \multicolumn{7}{|c|}{ CARACTERÍSTICAS DA ÁGUA DE ESTUDO } \\
\hline \multirow{2}{*}{ Turbidez (uT) } & \multirow{2}{*}{$\begin{array}{c}\text { Alcalinidade Total } \\
\left(\mathrm{mg} / \mathrm{\ell} \mathrm{CaCO}_{3}\right) \\
\end{array}$} & \multicolumn{2}{|c|}{ pH } & \multirow{2}{*}{\multicolumn{2}{|c|}{$\begin{array}{c}\text { Temperatura } \\
{ }^{\circ} \mathrm{C}\end{array}$}} & \multirow{2}{*}{$\begin{array}{l}\text { Potencial } \\
\text { Zeta }(m V)\end{array}$} \\
\hline & & S/ agit. & $\mathrm{C} /$ agit. & & & \\
\hline $101 / 99$ & 28.5 & 7.76 & 7.58 & & 25 & - \\
\hline
\end{tabular}

\begin{tabular}{|c|c|c|c|c|c|c|}
\hline \multirow{2}{*}{ FRASCO } & \multicolumn{3}{|c|}{ DOSAGEM DE PRODUTO QUÍMICO } & \multirow{2}{*}{$\begin{array}{c}\text { pH } \\
\text { de } \\
\text { Coagulação }\end{array}$} & \multirow{2}{*}{$\begin{array}{c}\begin{array}{c}T_{\mathrm{s1}}=1,75 \mathrm{~min} \\
\mathrm{~V}_{\mathrm{s} 1}=4.0 \mathrm{~cm} / \mathrm{min}\end{array} \\
\begin{array}{c}\text { Turbidez } \\
(\mathrm{uT})\end{array}\end{array}$} & \multirow{2}{*}{$\begin{array}{c}T_{\mathrm{s} 2}=3.50 \mathrm{~min} \\
\mathrm{~V}_{\mathrm{s} 2}=2.0 \mathrm{~cm} / \mathrm{min} \\
\begin{array}{c}\text { Turbidez } \\
\text { (uT) }\end{array}\end{array}$} \\
\hline & $\begin{array}{c}\text { Hidroxicloreto } \\
\text { de Alumínio } \\
(\mathrm{mg} / \mathfrak{l})\end{array}$ & $\begin{array}{c}\text { Ácido } \\
\text { Clorídrico } \\
0.1 \mathrm{~N}(\mathrm{~m} \ell / \ell)\end{array}$ & $\begin{array}{l}\text { Hidróxido de } \\
\text { Sódio 0.1N } \\
(\mathrm{ml} / \mathfrak{l})\end{array}$ & & & \\
\hline 1 & 20.0 & - & 4.0 & 7.14 & 4.74 & 3.34 \\
\hline 2 & 30.0 & - & 6.0 & 7.09 & 2.02 & 1.15 \\
\hline 3 & 25.0 & - & 6.0 & 7.23 & 7.83 & 1.90 \\
\hline 4 & 30.0 & - & 8.0 & 7.72 & 10.4 & 2.29 \\
\hline 5 & 35.0 & - & 8.0 & 7.54 & 13.6 & 2.94 \\
\hline 6 & 35.0 & - & 10.0 & 7.73 & 12.0 & 5.91 \\
\hline
\end{tabular}


ESTUDO DE COAGULAÇÃO-FLOCULAÇÃO-SEDIMENTAÇÃO

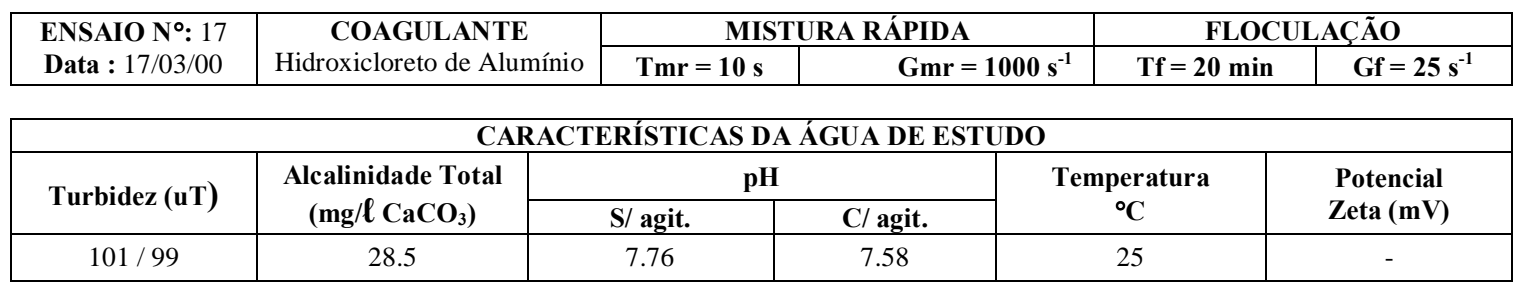

\begin{tabular}{|c|c|c|c|c|c|c|}
\hline \multirow{2}{*}{ FRASCO } & \multicolumn{3}{|c|}{ DOSAGEM DE PRODUTO QUÍMICO } & \multirow{2}{*}{$\begin{array}{c}\text { pH } \\
\text { de } \\
\text { Coagulação }\end{array}$} & \multirow{2}{*}{$\begin{array}{c}T_{\mathrm{s} 1}=1,75 \mathrm{~min} \\
\mathrm{~V}_{\mathrm{s} 1}=4.0 \mathrm{~cm} / \mathrm{min}\end{array}$} & \multirow{2}{*}{$\begin{array}{c}\begin{array}{c}T_{\mathrm{s} 2}=3.50 \mathrm{~min} \\
\mathbf{V}_{\mathrm{s} 2}=2.0 \mathrm{~cm} / \mathrm{min}\end{array} \\
\qquad \begin{array}{c}\text { Turbidez } \\
\text { (uT) }\end{array}\end{array}$} \\
\hline & $\begin{array}{c}\text { Hidroxicloreto } \\
\text { de Alumínio } \\
(\mathrm{mg} / \mathfrak{l})\end{array}$ & $\begin{array}{c}\text { Ácido } \\
\text { Clorídrico } \\
0.1 \mathrm{~N}(\mathrm{~m} \ell / \ell)\end{array}$ & $\begin{array}{l}\text { Hidróxido de } \\
\text { Sódio 0.1N } \\
(\mathrm{ml} / \mathfrak{l})\end{array}$ & & & \\
\hline 1 & 40.0 & - & 1.0 & 6.60 & 94.8 & 93.6 \\
\hline 2 & 40.0 & - & 6.0 & 7.09 & 3.52 & 2.36 \\
\hline 3 & 45.0 & - & 6.0 & 7.00 & 5.07 & 2.27 \\
\hline 4 & 45.0 & - & 8.0 & 7.21 & 8.44 & 1.77 \\
\hline 5 & 50.0 & - & 6.0 & 6.91 & 3.29 & 1.47 \\
\hline 6 & 50.0 & - & 11.0 & 7.39 & 10.0 & 5.96 \\
\hline
\end{tabular}

\section{ESTUDO DE COAGULAÇÃO-FLOCULAÇÃO-SEDIMENTAÇÃO}

\begin{tabular}{|c|c|c|c|c|c|c|}
\hline \multirow{2}{*}{$\begin{array}{l}\text { ENSAIO N }^{\circ}: 18 \\
\text { Data : } 17 / 03 / 00\end{array}$} & \multirow{2}{*}{$\begin{array}{c}\text { COAGULANTE } \\
\text { Hidroxicloreto de Alumínio } \\
\end{array}$} & \multicolumn{3}{|c|}{ MISTURA RÁPIDA } & \multicolumn{2}{|c|}{ FLOCULAÇÃO } \\
\hline & & $\mathrm{Tmr}=10 \mathrm{~s}$ & & & Tf $=20 \mathrm{~min}$ & $G f=25 \mathrm{~s}^{-1}$ \\
\hline \multicolumn{7}{|c|}{ CARACTERÍSTICAS DA ÁGUA DE ESTUDO } \\
\hline \multirow{2}{*}{ Turbidez (uT) } & \multirow{2}{*}{$\begin{array}{c}\text { Alcalinidade Total } \\
\left(\mathrm{mg} / \mathrm{\ell} \mathrm{CaCO}_{3}\right) \\
\end{array}$} & \multicolumn{2}{|c|}{ pH } & \multirow{2}{*}{\multicolumn{2}{|c|}{$\begin{array}{c}\text { Temperatura } \\
{ }^{\circ} \mathrm{C}\end{array}$}} & \multirow{2}{*}{$\begin{array}{l}\text { Potencial } \\
\text { Zeta }(m V)\end{array}$} \\
\hline & & S/ agit. & $\mathrm{C} /$ agit. & & & \\
\hline $101 / 99$ & 28.5 & 7.76 & 7.58 & & 25 & - \\
\hline
\end{tabular}

\begin{tabular}{|c|c|c|c|c|c|c|}
\hline \multirow{2}{*}{ FRASCO } & \multicolumn{3}{|c|}{ DOSAGEM DE PRODUTO QUÍMICO } & \multirow{2}{*}{$\begin{array}{c}\text { pH } \\
\text { de } \\
\text { Coagulação }\end{array}$} & \multirow{2}{*}{$\begin{array}{c}\begin{array}{c}T_{\mathrm{s} 1}=1,75 \mathrm{~min} \\
\mathrm{~V}_{\mathrm{s} 1}=4.0 \mathrm{~cm} / \mathrm{min}\end{array} \\
\begin{array}{c}\text { Turbidez } \\
\text { (uT) }\end{array}\end{array}$} & \multirow{2}{*}{$\begin{array}{c}\begin{array}{c}\mathrm{T}_{\mathrm{s} 2}=3.50 \mathrm{~min} \\
\mathrm{~V}_{\mathrm{s} 2}=2.0 \mathrm{~cm} / \mathrm{min}\end{array} \\
\begin{array}{c}\text { Turbidez } \\
(\mathrm{uT})\end{array}\end{array}$} \\
\hline & $\begin{array}{c}\text { Hidroxicloreto } \\
\text { de Alumínio } \\
\text { (mg/l) }\end{array}$ & $\begin{array}{c}\text { Ácido } \\
\text { Clorídrico } \\
0.1 \mathrm{~N}(\mathrm{~m} \ell / \ell)\end{array}$ & $\begin{array}{l}\text { Hidróxido de } \\
\text { Sódio 0.1N } \\
(\mathrm{m} \ell / \ell)\end{array}$ & & & \\
\hline 1 & 20.0 & - & - & 6.89 & 5.11 & - \\
\hline 2 & 20.0 & - & 4.5 & 7.53 & 9.30 & - \\
\hline 3 & 25.0 & - & 6.0 & 7.61 & 12.1 & - \\
\hline 4 & 30.0 & - & 5.0 & 7.32 & 3.04 & - \\
\hline 5 & 30.0 & - & 6.0 & 7.43 & 7.55 & - \\
\hline 6 & 35.0 & - & 7.0 & 7.40 & 5.75 & - \\
\hline
\end{tabular}


ESTUDO DE COAGULAÇÃO-FLOCULAÇÃO-SEDIMENTAÇÃO

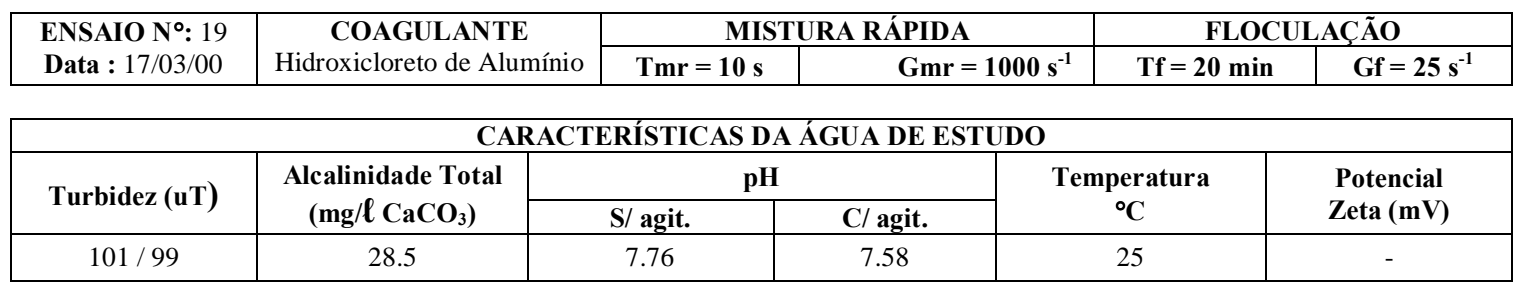

\begin{tabular}{|c|c|c|c|c|c|c|}
\hline \multirow{2}{*}{ FRASCO } & \multicolumn{3}{|c|}{ DOSAGEM DE PRODUTO QUÍMICO } & \multirow{2}{*}{$\begin{array}{c}\text { pH } \\
\text { de } \\
\text { Coagulação }\end{array}$} & \multirow{2}{*}{ 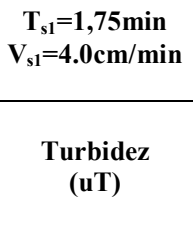 } & \multirow{2}{*}{$\begin{array}{c}T_{\mathrm{s} 2}=3.50 \mathrm{~min} \\
\mathbf{V}_{\mathrm{s} 2}=\mathbf{2 . 0 \mathrm { cm }} / \mathrm{min} \\
\begin{array}{c}\text { Turbidez } \\
\text { (uT) }\end{array}\end{array}$} \\
\hline & $\begin{array}{c}\text { Hidroxicloreto } \\
\text { de Alumínio } \\
(\mathrm{mg} / \mathfrak{l})\end{array}$ & $\begin{array}{c}\text { Ácido } \\
\text { Clorídrico } \\
0.1 \mathrm{~N}(\mathrm{~m} \ell / \ell)\end{array}$ & $\begin{array}{l}\text { Hidróxido de } \\
\text { Sódio 0.1N } \\
(\mathrm{ml} / \mathfrak{\ell})\end{array}$ & & & \\
\hline 1 & 35.0 & - & 7.0 & 7.27 & 4.37 & 3.09 \\
\hline 2 & 50.0 & - & 4.0 & 6.79 & 74.8 & 59.4 \\
\hline 3 & 45.0 & - & 9.0 & 7.51 & 12.5 & 4.01 \\
\hline 4 & 40.0 & - & 9.0 & 7.40 & 5.55 & 3.01 \\
\hline 5 & 50.0 & - & 7.5 & 7.09 & 3.87 & 1.69 \\
\hline 6 & 50.0 & - & 9.0 & 7.21 & 2.61 & 3.50 \\
\hline
\end{tabular}

\section{ESTUDO DE COAGULAÇÃO-FLOCULAÇÃO-SEDIMENTAÇÃO}

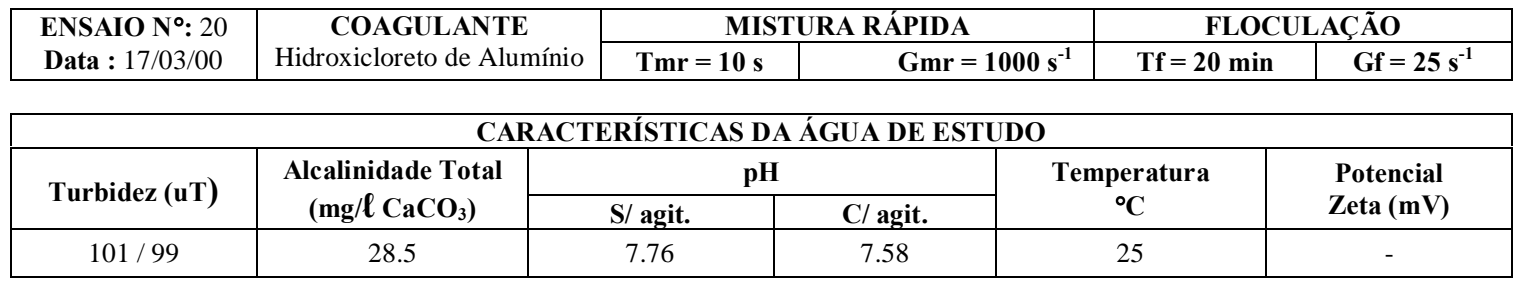

\begin{tabular}{|c|c|c|c|c|c|c|}
\hline \multirow{2}{*}{ FRASCO } & \multicolumn{3}{|c|}{ DOSAGEM DE PRODUTO QUÍMICO } & \multirow{2}{*}{$\begin{array}{c}\text { pH } \\
\text { de } \\
\text { Coagulação }\end{array}$} & \multirow{2}{*}{$\begin{array}{c}\begin{array}{c}T_{\mathrm{s1}}=1,75 \mathrm{~min} \\
\mathrm{~V}_{\mathrm{s} 1}=4.0 \mathrm{~cm} / \mathrm{min}\end{array} \\
\begin{array}{c}\text { Turbidez } \\
(\mathrm{uT})\end{array}\end{array}$} & \multirow{2}{*}{$\begin{array}{c}T_{\mathrm{s} 2}=3.50 \mathrm{~min} \\
\mathrm{~V}_{\mathrm{s} 2}=2.0 \mathrm{~cm} / \mathrm{min}\end{array}$} \\
\hline & $\begin{array}{c}\text { Hidroxicloreto } \\
\text { de Alumínio } \\
(\mathrm{mg} / \mathfrak{l})\end{array}$ & $\begin{array}{c}\text { Ácido } \\
\text { Clorídrico } \\
0.1 \mathrm{~N}(\mathrm{~m} \ell / \ell)\end{array}$ & $\begin{array}{l}\text { Hidróxido de } \\
\text { Sódio 0.1N } \\
(\mathrm{ml} / \mathfrak{l})\end{array}$ & & & \\
\hline 1 & 35.0 & - & - & 6.66 & 104 & 96.8 \\
\hline 2 & 35.0 & - & 2.0 & 6.87 & 4.47 & 1.59 \\
\hline 3 & 40.0 & - & 7.5 & 7.37 & 6.28 & 1.09 \\
\hline 4 & 30.0 & - & 7.0 & 7.68 & 8.00 & 1.82 \\
\hline 5 & 25.0 & - & 8.0 & 8.11 & 8.41 & 3.19 \\
\hline 6 & 55.0 & - & 12.0 & 7.52 & 8.50 & 1.42 \\
\hline
\end{tabular}


ESTUDO DE COAGULAÇÃO-FLOCULAÇÃO-SEDIMENTAÇÃO

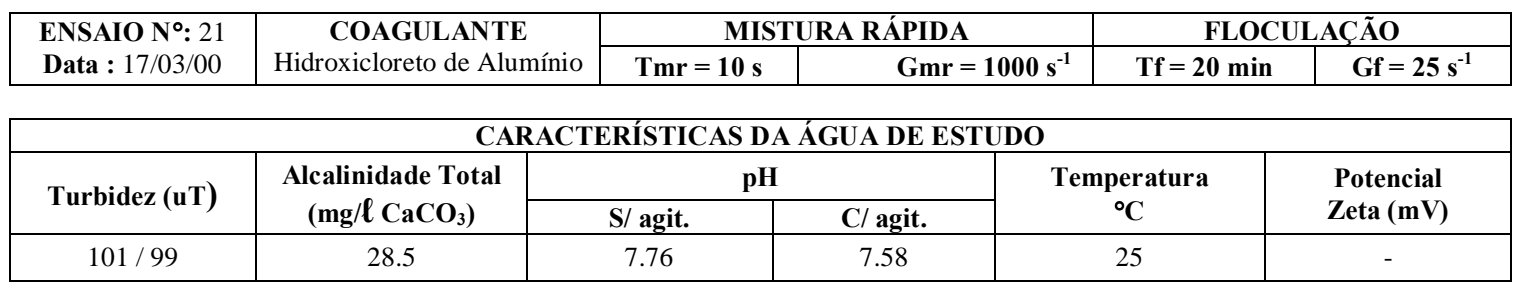

\begin{tabular}{|c|c|c|c|c|c|c|}
\hline \multirow{2}{*}{ FRASCO } & \multicolumn{3}{|c|}{ DOSAGEM DE PRODUTO QUÍMICO } & \multirow{2}{*}{$\begin{array}{c}\text { pH } \\
\text { de } \\
\text { Coagulação }\end{array}$} & \multirow{2}{*}{$\begin{array}{c}T_{\mathrm{s} 1}=1,75 \mathrm{~min} \\
\mathrm{~V}_{\mathrm{s} 1}=4.0 \mathrm{~cm} / \mathrm{min} \\
\\
\begin{array}{c}\text { Turbidez } \\
(\mathrm{uT})\end{array}\end{array}$} & \multirow{2}{*}{$\begin{array}{c}T_{\mathrm{s} 2}=3.50 \mathrm{~min} \\
\mathrm{~V}_{\mathrm{s} 2}=2.0 \mathrm{~cm} / \mathrm{min} \\
\text { Turbidez } \\
(\mathrm{uT})\end{array}$} \\
\hline & $\begin{array}{c}\text { Hidroxicloreto } \\
\text { de Alumínio } \\
(\mathrm{mg} / \boldsymbol{\ell})\end{array}$ & $\begin{array}{c}\text { Ácido } \\
\text { Clorídrico } \\
0.1 \mathrm{~N}(\mathrm{~m} \ell / \ell)\end{array}$ & $\begin{array}{l}\text { Hidróxido de } \\
\text { Sódio 0.1N } \\
(\mathrm{m} \ell / \ell)\end{array}$ & & & \\
\hline 1 & 65.0 & - & 7.0 & 6.66 & 93.3 & 88.2 \\
\hline 2 & 55.0 & - & 7.0 & 6.93 & 3.06 & 0.83 \\
\hline 3 & 55.0 & - & 9.0 & 7.13 & 6.03 & 1.08 \\
\hline 4 & 60.0 & - & 10.0 & 7.16 & 7.60 & 1.94 \\
\hline 5 & 60.0 & - & 13.0 & 7.51 & 18.2 & 2.35 \\
\hline 6 & 60.0 & - & 14.5 & 7.73 & 22.1 & 2.78 \\
\hline
\end{tabular}


ANEXO - D

ENSAIOS DO REATOR ESTÁTICO - ÁGUA I

PARA O COAGULANTE

SULFATO FÉRRICO 
ESTUDO DE COAGULAÇÃO-FLOCULAÇÃO-SEDIMENTAÇÃO

\begin{tabular}{|c|c|c|c|c|c|c|}
\hline \multirow{2}{*}{$\begin{array}{l}\text { ENSAIO N: } 01 \\
\text { Data : } 13 / 03 / 00\end{array}$} & \multirow{2}{*}{$\begin{array}{l}\text { COAGULANTE } \\
\text { Sulfato Férrico }\end{array}$} & \multicolumn{3}{|c|}{ MISTURA RÁPIDA } & \multicolumn{2}{|c|}{ FLOCULAÇÃO } \\
\hline & & $\mathrm{Tmr}=10 \mathrm{~s}$ & \multicolumn{2}{|c|}{$\mathrm{Gmr}=1000 \mathrm{~s}^{-1}$} & $T f=20 \mathrm{~min}$ & Gf $=25 \mathrm{~s}^{-1}$ \\
\hline \multicolumn{7}{|c|}{ CARACTERÍSTICAS DA ÁGUA DE ESTUDO } \\
\hline \multirow{2}{*}{ Turbidez (uT) } & \multirow{2}{*}{$\begin{array}{c}\text { Alcalinidade Total } \\
\left(\mathrm{mg} / \ell \mathrm{CaCO}_{3}\right)\end{array}$} & \multicolumn{2}{|c|}{ pH } & \multirow{2}{*}{\multicolumn{2}{|c|}{$\begin{array}{c}\text { Temperatura } \\
{ }^{\circ} \mathrm{C}\end{array}$}} & \multirow{2}{*}{$\begin{array}{l}\text { Potencial } \\
\text { Zeta }(\mathrm{mV}) \\
\end{array}$} \\
\hline & & S/ agit. & C/ agit. & & & \\
\hline 99 & 29.1 & 7.79 & 7.58 & & 25 & - \\
\hline
\end{tabular}

\begin{tabular}{|c|c|c|c|c|c|c|}
\hline \multirow{2}{*}{ FRASCO } & \multicolumn{3}{|c|}{ DOSAGEM DE PRODUTO QUÍMICO } & \multirow{2}{*}{$\begin{array}{c}\text { pH } \\
\text { de } \\
\text { Coagulação }\end{array}$} & \multirow{2}{*}{$\begin{array}{c}T_{\mathrm{s} 1}=1,75 \mathrm{~min} \\
\mathrm{~V}_{\mathrm{s} 1}=4.0 \mathrm{~cm} / \mathrm{min} \\
\text { Turbidez } \\
(u T)\end{array}$} & \multirow{2}{*}{$\begin{array}{c}T_{\mathrm{s} 2}=3.50 \mathrm{~min} \\
\mathrm{~V}_{\mathrm{s} 2}=2.0 \mathrm{~cm} / \mathrm{min} \\
\\
\text { Turbidez } \\
(u T)\end{array}$} \\
\hline & $\begin{array}{c}\text { Sulfato Férrico } \\
(\mathrm{mg} / \ell)\end{array}$ & $\begin{array}{c}\text { Ácido } \\
\text { Clorídrico } \\
0.1 \mathrm{~N}(\mathrm{~m} \ell / \ell)\end{array}$ & $\begin{array}{c}\text { Hidróxido de } \\
\text { Sódio } 0.1 \mathrm{~N} \\
(\mathrm{~m} \ell / \ell)\end{array}$ & & & \\
\hline 1 & 10.0 & 1.82 & - & 6.90 & 10.6 & 6.66 \\
\hline 2 & 10.0 & 0.91 & - & 7.02 & 10.7 & 12.7 \\
\hline 3 & 10.0 & - & - & 7.06 & 21.2 & 14.9 \\
\hline 4 & 10.0 & - & 1.0 & 7.18 & 88.9 & 81.8 \\
\hline 5 & 10.0 & - & 2.0 & 7.29 & 97.1 & 92.0 \\
\hline 6 & 10.0 & - & 3.0 & 7.48 & 96.0 & 95.8 \\
\hline
\end{tabular}

\section{ESTUDO DE COAGULAÇÃO-FLOCULAÇÃO-SEDIMENTAÇÃO}

\begin{tabular}{|c|c|c|c|c|c|c|}
\hline \multirow{2}{*}{$\begin{array}{l}\text { ENSAIO No: } 02 \\
\text { Data : } 13 / 03 / 00\end{array}$} & \multirow{2}{*}{$\begin{array}{c}\text { COAGULANTE } \\
\text { Sulfato Férrico }\end{array}$} & \multicolumn{3}{|c|}{ MISTURA RÁPIDA } & \multicolumn{2}{|c|}{ FLOCULAÇÃO } \\
\hline & & $\mathrm{Tmr}=10 \mathrm{~s}$ & Gm & $\mathrm{s}^{-1}$ & $\mathbf{T f}=\mathbf{2 0} \mathrm{min}$ & Gf $=25 \mathrm{~s}^{-1}$ \\
\hline \multicolumn{7}{|c|}{ CARACTERÍSTICAS DA ÁGUA DE ESTUDO } \\
\hline \multirow{2}{*}{ Turbidez (uT) } & \multirow{2}{*}{$\begin{array}{c}\text { Alcalinidade Total } \\
\left(\mathrm{mg} / \ell \mathrm{C} \mathrm{CaCO}_{3}\right)\end{array}$} & \multicolumn{2}{|c|}{ pH } & \multirow{2}{*}{\multicolumn{2}{|c|}{$\begin{array}{c}\text { Temperatura } \\
{ }^{\circ} \mathrm{C} \\
\end{array}$}} & \multirow{2}{*}{$\begin{array}{l}\text { Potencial } \\
\text { Zeta }(\mathrm{mV}) \\
\end{array}$} \\
\hline & & S/ agit. & $\mathrm{C} /$ agit. & & & \\
\hline 99 & 29.1 & 7.79 & 7.58 & & 25 & - \\
\hline
\end{tabular}

\begin{tabular}{|c|c|c|c|c|c|c|}
\hline \multirow{2}{*}{ FRASCO } & \multicolumn{3}{|c|}{ DOSAGEM DE PRODUTO QUÍMICO } & \multirow{2}{*}{$\begin{array}{c}\text { pH } \\
\text { de } \\
\text { Coagulação }\end{array}$} & \multirow{2}{*}{$\begin{array}{c}T_{\mathrm{s} 1}=1,75 \mathrm{~min} \\
\mathrm{~V}_{\mathrm{s} 1}=4.0 \mathrm{~cm} / \mathrm{min} \\
\begin{array}{c}\text { Turbidez } \\
\text { (uT) }\end{array}\end{array}$} & \multirow{2}{*}{$\begin{array}{c}T_{\mathrm{s} 2}=3.50 \mathrm{~min} \\
\mathrm{~V}_{\mathrm{s} 2}=2.0 \mathrm{~cm} / \mathrm{min}\end{array}$} \\
\hline & $\begin{array}{l}\text { Sulfato Férrico } \\
\qquad(\mathrm{mg} / \mathfrak{l})\end{array}$ & $\begin{array}{c}\text { Ácido } \\
\text { Clorídrico } \\
0.1 \mathrm{~N}(\mathrm{~m} \ell / \ell)\end{array}$ & $\begin{array}{l}\text { Hidróxido de } \\
\text { Sódio 0.1N } \\
(\mathrm{m} \ell / \ell)\end{array}$ & & & \\
\hline 1 & 10.0 & 7.29 & - & 6.52 & 8.29 & - \\
\hline 2 & 10.0 & 6.38 & - & 6.59 & 8.47 & - \\
\hline 3 & 10.0 & 5.47 & - & 6.67 & 11.2 & - \\
\hline 4 & 10.0 & 4.56 & - & 6.74 & 9.56 & - \\
\hline 5 & 20.0 & 2.73 & - & 6.50 & 1.97 & - \\
\hline 6 & 20.0 & 1.82 & - & 6.55 & 2.18 & - \\
\hline
\end{tabular}


ESTUDO DE COAGULAÇÃO-FLOCULAÇÃO-SEDIMENTAÇÃO

\begin{tabular}{|c|c|c|c|c|c|c|}
\hline \multirow{2}{*}{$\begin{array}{l}\text { ENSAIO N }{ }^{\circ}: 03 \\
\text { Data : } 13 / 03 / 00\end{array}$} & \multirow{2}{*}{$\begin{array}{c}\text { COAGULANTE } \\
\text { Sulfato Férrico }\end{array}$} & \multicolumn{3}{|c|}{ MISTURA RÁPIDA } & \multicolumn{2}{|c|}{ FLOCULAÇÃO } \\
\hline & & $\mathrm{Tmr}=10 \mathrm{~s}$ & $\mathbf{G m}$ & & $T f=20 \mathrm{~min}$ & Gf $=25 \mathrm{~s}^{-1}$ \\
\hline \multicolumn{7}{|c|}{ CARACTERÍSTICAS DA ÁGUA DE ESTUDO } \\
\hline \multirow{2}{*}{ Turbidez (uT) } & \multirow{2}{*}{$\begin{array}{l}\text { Alcalinidade Total } \\
\left(\mathrm{mg} / \ell \mathrm{CaCO}_{3}\right)\end{array}$} & \multicolumn{2}{|c|}{ pH } & \multirow{2}{*}{\multicolumn{2}{|c|}{$\begin{array}{c}\text { Temperatura } \\
{ }^{\circ} \mathrm{C} \\
\end{array}$}} & \multirow{2}{*}{$\begin{array}{l}\text { Potencial } \\
\text { Zeta }(\mathrm{mV})\end{array}$} \\
\hline & & S/ agit. & $\mathrm{C} /$ agit. & & & \\
\hline 99 & 29.1 & 7.79 & 7.58 & & 25 & - \\
\hline
\end{tabular}

\begin{tabular}{|c|c|c|c|c|c|c|}
\hline \multirow{2}{*}{ FRASCO } & \multicolumn{3}{|c|}{ DOSAGEM DE PRODUTO QUÍMICO } & \multirow{2}{*}{$\begin{array}{c}\text { pH } \\
\text { de } \\
\text { Coagulação }\end{array}$} & \multirow{2}{*}{$\begin{array}{c}\begin{array}{c}T_{\mathrm{s} 1}=1,75 \mathrm{~min} \\
\mathrm{~V}_{\mathrm{s} 1}=4.0 \mathrm{~cm} / \mathrm{min}\end{array} \\
\begin{array}{c}\text { Turbidez } \\
(\mathrm{uT})\end{array}\end{array}$} & \multirow{2}{*}{$\begin{array}{c}\mathrm{T}_{\mathrm{s} 2}=3.50 \mathrm{~min} \\
\mathrm{~V}_{\mathrm{s} 2}=2.0 \mathrm{~cm} / \mathrm{min} \\
\begin{array}{c}\text { Turbidez } \\
\text { (uT) }\end{array}\end{array}$} \\
\hline & $\begin{array}{c}\text { Sulfato Férrico } \\
(\mathrm{mg} / \mathfrak{\ell})\end{array}$ & $\begin{array}{c}\text { Ácido } \\
\text { Clorídrico } \\
0.1 \mathrm{~N}(\mathrm{~m} \ell / \ell)\end{array}$ & $\begin{array}{l}\text { Hidróxido de } \\
\text { Sódio 0.1N } \\
(\mathrm{m} \ell / \ell)\end{array}$ & & & \\
\hline 1 & 10.0 & 9.11 & - & 6.29 & 6.99 & 6.08 \\
\hline 2 & 10.0 & 6.38 & - & 6.56 & 8.44 & 5.19 \\
\hline 3 & 20.0 & 7.29 & - & 6.07 & 3.75 & 2.71 \\
\hline 4 & 20.0 & 3.65 & - & 6.40 & 3.48 & 2.28 \\
\hline 5 & 20.0 & 1.82 & - & 6.57 & - & 3.49 \\
\hline 6 & 20.0 & - & - & 6.76 & 10.7 & 7.70 \\
\hline
\end{tabular}

\section{ESTUDO DE COAGULAÇÃO-FLOCULAÇÃO-SEDIMENTAÇÃO}

\begin{tabular}{|c|c|c|c|c|c|c|}
\hline \multirow{2}{*}{$\begin{array}{l}\text { ENSAIO No: } 04 \\
\text { Data }: 13 / 03 / 00\end{array}$} & \multirow{2}{*}{$\begin{array}{c}\text { COAGULANTE } \\
\text { Sulfato Férrico }\end{array}$} & \multicolumn{3}{|c|}{ MISTURA RÁPIDA } & \multicolumn{2}{|c|}{ FLOCULAÇÃO } \\
\hline & & $T m r=10 s$ & Gm & & $T f=20 \mathrm{~min}$ & Gf $=25 \mathrm{~s}^{-1}$ \\
\hline \multicolumn{7}{|c|}{ CARACTERÍSTICAS DA ÁGUA DE ESTUDO } \\
\hline \multirow{2}{*}{ Turbidez (uT) } & \multirow{2}{*}{$\begin{array}{c}\text { Alcalinidade Total } \\
\left(\mathrm{mg} / \ell \mathrm{CaCO}_{3}\right)\end{array}$} & \multicolumn{2}{|c|}{ pH } & \multirow{2}{*}{\multicolumn{2}{|c|}{$\begin{array}{c}\text { Temperatura } \\
{ }^{\circ} \mathrm{C} \\
\end{array}$}} & \multirow{2}{*}{$\begin{array}{r}\text { Potencial } \\
\text { Zeta }(\mathrm{mV}) \\
\end{array}$} \\
\hline & & S/ agit. & $\mathrm{C} /$ agit. & & & \\
\hline 99 & 29.1 & 7.79 & 7.58 & & 25 & - \\
\hline
\end{tabular}

\begin{tabular}{|c|c|c|c|c|c|c|}
\hline \multirow{2}{*}{ FRASCO } & \multicolumn{3}{|c|}{ DOSAGEM DE PRODUTO QUÍMICO } & \multirow{2}{*}{$\begin{array}{c}\text { pH } \\
\text { de } \\
\text { Coagulação }\end{array}$} & \multirow{2}{*}{$\begin{array}{c}\begin{array}{c}\mathrm{T}_{\mathrm{s} 1}=1,75 \mathrm{~min} \\
\mathrm{~V}_{\mathrm{s} 1}=4.0 \mathrm{~cm} / \mathrm{min}\end{array} \\
\begin{array}{c}\text { Turbidez } \\
\text { (uT) }\end{array}\end{array}$} & \multirow{2}{*}{$\begin{array}{c}\begin{array}{c}T_{\mathrm{s} 2}=3.50 \mathrm{~min} \\
\mathbf{V}_{\mathrm{s} 2}=2.0 \mathrm{~cm} / \mathrm{min}\end{array} \\
\begin{array}{c}\text { Turbidez } \\
(\mathrm{uT})\end{array}\end{array}$} \\
\hline & $\begin{array}{l}\text { Sulfato Férrico } \\
\qquad(\mathrm{mg} / \mathfrak{l})\end{array}$ & $\begin{array}{c}\text { Ácido } \\
\text { Clorídrico } \\
0.1 \mathrm{~N}(\mathrm{~m} \ell / \ell)\end{array}$ & $\begin{array}{l}\text { Hidróxido de } \\
\text { Sódio 0.1N } \\
(\mathrm{m} \ell / \mathfrak{l})\end{array}$ & & & \\
\hline 1 & 15.0 & 9.11 & - & 6.18 & 6.91 & 3.88 \\
\hline 2 & 15.0 & 7.29 & - & 6.33 & 5.50 & 2.45 \\
\hline 3 & 15.0 & 5.47 & - & 6.39 & 6.56 & 2.81 \\
\hline 4 & 15.0 & 3.65 & - & 6.61 & 5.92 & 2.40 \\
\hline 5 & 15.0 & 1.82 & - & 6.72 & 7.03 & 2.79 \\
\hline 6 & 15.0 & - & - & 6.91 & 7.35 & 4.10 \\
\hline
\end{tabular}


ESTUDO DE COAGULAÇÃO-FLOCULAÇÃO-SEDIMENTAÇÃO

\begin{tabular}{|c|c|c|c|c|c|c|}
\hline \multirow{2}{*}{$\begin{array}{l}\text { ENSAIO No: } 05 \\
\text { Data : } 13 / 03 / 00\end{array}$} & \multirow{2}{*}{$\begin{array}{l}\text { COAGULANTE } \\
\text { Sulfato Férrico }\end{array}$} & \multicolumn{3}{|c|}{ MISTURA RÁPIDA } & \multicolumn{2}{|c|}{ FLOCULAÇÃO } \\
\hline & & $\mathrm{Tmr}=10 \mathrm{~s}$ & \multicolumn{2}{|c|}{$\mathrm{Gmr}=1000 \mathrm{~s}^{-1}$} & $\mathbf{T f}=20 \mathrm{~min}$ & Gf $=25 \mathrm{~s}^{-1}$ \\
\hline \multicolumn{7}{|c|}{ CARACTERÍSTICAS DA ÁGUA DE ESTUDO } \\
\hline \multirow{2}{*}{ Turbidez (uT) } & \multirow{2}{*}{$\begin{array}{c}\text { Alcalinidade Total } \\
\left(\mathrm{mg} / \ell \mathrm{CaCO}_{3}\right) \\
\end{array}$} & \multicolumn{2}{|c|}{ pH } & \multirow{2}{*}{\multicolumn{2}{|c|}{$\begin{array}{c}\text { Temperatura } \\
{ }^{\circ} \mathrm{C} \\
\end{array}$}} & \multirow{2}{*}{$\begin{array}{l}\text { Potencial } \\
\text { Zeta }(\mathrm{mV})\end{array}$} \\
\hline & & S/ agit. & $\mathrm{C} /$ agit. & & & \\
\hline 99 & 29.1 & 7.79 & 7.58 & & 25 & - \\
\hline
\end{tabular}

\begin{tabular}{|c|c|c|c|c|c|c|}
\hline \multirow{2}{*}{ FRASCO } & \multicolumn{3}{|c|}{ DOSAGEM DE PRODUTO QUÍMICO } & \multirow{2}{*}{$\begin{array}{c}\text { pH } \\
\text { de } \\
\text { Coagulação }\end{array}$} & \multirow{2}{*}{$\begin{array}{c}\mathrm{T}_{\mathrm{s} 1}=1,75 \mathrm{~min} \\
\mathrm{~V}_{\mathrm{s} 1}=4.0 \mathrm{~cm} / \mathrm{min} \\
\\
\text { Turbidez } \\
(\mathrm{uT})\end{array}$} & \multirow{2}{*}{$\begin{array}{c}T_{\mathrm{s} 2}=3.50 \mathrm{~min} \\
\mathbf{V}_{\mathrm{s} 2}=\mathbf{2 . 0 \mathrm { cm } / \mathrm { min }} \\
\\
\begin{array}{c}\text { Turbidez } \\
(\mathrm{uT})\end{array}\end{array}$} \\
\hline & $\begin{array}{c}\text { Sulfato Férrico } \\
(\mathrm{mg} / \ell)\end{array}$ & $\begin{array}{c}\text { Ácido } \\
\text { Clorídrico } \\
0.1 \mathrm{~N}(\mathrm{~m} \ell / \ell)\end{array}$ & $\begin{array}{c}\text { Hidróxido de } \\
\text { Sódio 0.1N } \\
(\mathrm{m} \ell / \ell)\end{array}$ & & & \\
\hline 1 & 10.0 & 10.93 & - & 6.19 & 9.45 & 5.51 \\
\hline 2 & 10.0 & 5.47 & - & 6.61 & 8.48 & 4.89 \\
\hline 3 & 15.0 & 10.93 & - & 5.91 & 7.21 & 4.11 \\
\hline 4 & 15.0 & - & 1.00 & 6.88 & 8.96 & 3.77 \\
\hline 5 & 20.0 & 9.11 & - & 5.98 & 3.39 & 2.73 \\
\hline 6 & 20.0 & - & 1.00 & 6.75 & 6.24 & 2.28 \\
\hline
\end{tabular}

\section{ESTUDO DE COAGULAÇÃO-FLOCULAÇÃO-SEDIMENTAÇÃO}

\begin{tabular}{|c|c|c|c|c|c|c|}
\hline \multirow{2}{*}{$\begin{array}{l}\text { ENSAIO N: } 06 \\
\text { Data : } 14 / 03 / 00\end{array}$} & \multirow{2}{*}{$\begin{array}{l}\text { COAGULANTE } \\
\text { Sulfato Férrico }\end{array}$} & \multicolumn{3}{|c|}{ MISTURA RÁPIDA } & \multicolumn{2}{|c|}{ FLOCULAÇÃO } \\
\hline & & $\mathrm{Tmr}=10 \mathrm{~s}$ & \multicolumn{2}{|c|}{$\mathrm{Gmr}=1000 \mathrm{~s}^{-1}$} & $\mathbf{T f}=20 \mathrm{~min}$ & $G f=25 \mathrm{~s}^{-1}$ \\
\hline \multicolumn{7}{|c|}{ CARACTERÍSTICAS DA ÁGUA DE ESTUDO } \\
\hline \multirow{2}{*}{ Turbidez (uT) } & \multirow{2}{*}{$\begin{array}{c}\text { Alcalinidade Total } \\
\left(\mathrm{mg} / \ell \mathrm{CaCO}_{3}\right)\end{array}$} & \multicolumn{2}{|c|}{ pH } & \multirow{2}{*}{\multicolumn{2}{|c|}{$\begin{array}{c}\text { Temperatura } \\
{ }^{\circ} \mathrm{C} \\
\end{array}$}} & \multirow{2}{*}{$\begin{array}{c}\text { Potencial } \\
\text { Zeta }(\mathrm{mV})\end{array}$} \\
\hline & & S/ agit. & C/ agit. & & & \\
\hline 98.5 & 28.5 & 7.77 & 7.60 & & 25 & - \\
\hline
\end{tabular}

\begin{tabular}{|c|c|c|c|c|c|c|}
\hline \multirow{2}{*}{ FRASCO } & \multicolumn{3}{|c|}{ DOSAGEM DE PRODUTO QUÍMICO } & \multirow{2}{*}{$\begin{array}{c}\text { pH } \\
\text { de } \\
\text { Coagulação }\end{array}$} & \multirow{2}{*}{$\begin{array}{c}T_{\mathrm{s} 1}=1,75 \mathrm{~min} \\
\mathrm{~V}_{\mathrm{s} 1}=4.0 \mathrm{~cm} / \mathrm{min} \\
\begin{array}{c}\text { Turbidez } \\
(\mathrm{uT})\end{array}\end{array}$} & \multirow{2}{*}{$\begin{array}{c}T_{\mathrm{s} 2}=3.50 \mathrm{~min} \\
\mathrm{~V}_{\mathrm{s} 2}=2.0 \mathrm{~cm} / \mathrm{min} \\
\text { Turbidez } \\
(\mathbf{u T})\end{array}$} \\
\hline & $\begin{array}{c}\text { Sulfato Férrico } \\
(\mathrm{mg} / \ell)\end{array}$ & $\begin{array}{c}\text { Ácido } \\
\text { Clorídrico } \\
0.1 \mathrm{~N}(\mathrm{~m} \ell / \ell)\end{array}$ & $\begin{array}{c}\text { Hidróxido de } \\
\text { Sódio 0.1N } \\
(\mathrm{m} \ell / \ell)\end{array}$ & & & \\
\hline 1 & 10.0 & 12.76 & - & 5.94 & 13.0 & 9.23 \\
\hline 2 & 25.0 & 9.11 & - & 5.42 & 61.0 & 49.3 \\
\hline 3 & 20.0 & 5.47 & - & 6.15 & 5.31 & 2.87 \\
\hline 4 & 15.0 & - & 2.0 & 6.96 & 12.7 & 8.88 \\
\hline 5 & 20.0 & - & 2.0 & 6.67 & 6.85 & 5.49 \\
\hline 6 & 25.0 & - & 1.0 & 6.63 & 5.06 & 4.89 \\
\hline
\end{tabular}


ESTUDO DE COAGULAÇÃO-FLOCULAÇÃO-SEDIMENTAÇÃO

\begin{tabular}{|c|c|c|c|c|c|c|}
\hline \multirow{2}{*}{$\begin{array}{l}\text { ENSAIO N }{ }^{\circ}: 07 \\
\text { Data : } 14 / 03 / 00\end{array}$} & \multirow{2}{*}{$\begin{array}{c}\text { COAGULANTE } \\
\text { Sulfato Férrico }\end{array}$} & \multicolumn{3}{|c|}{ MISTURA RÁPIDA } & \multicolumn{2}{|c|}{ FLOCULAÇÃO } \\
\hline & & $\mathrm{Tmr}=10 \mathrm{~s}$ & $\mathbf{G m}$ & & $T f=20 \mathrm{~min}$ & Gf $=25 \mathrm{~s}^{-1}$ \\
\hline \multicolumn{7}{|c|}{ CARACTERÍSTICAS DA ÁGUA DE ESTUDO } \\
\hline \multirow{2}{*}{ Turbidez (uT) } & \multirow{2}{*}{$\begin{array}{l}\text { Alcalinidade Total } \\
\left(\mathrm{mg} / \ell \mathrm{CaCO}_{3}\right)\end{array}$} & \multicolumn{2}{|c|}{ pH } & \multirow{2}{*}{\multicolumn{2}{|c|}{$\begin{array}{c}\text { Temperatura } \\
{ }^{\circ} \mathrm{C} \\
\end{array}$}} & \multirow{2}{*}{$\begin{array}{l}\text { Potencial } \\
\text { Zeta }(\mathrm{mV})\end{array}$} \\
\hline & & S/ agit. & $\mathrm{C} /$ agit. & & & \\
\hline 98.5 & 28.5 & 7.77 & 7.60 & & 25 & - \\
\hline
\end{tabular}

\begin{tabular}{|c|c|c|c|c|c|c|}
\hline \multirow{2}{*}{ FRASCO } & \multicolumn{3}{|c|}{ DOSAGEM DE PRODUTO QUÍMICO } & \multirow{2}{*}{$\begin{array}{c}\text { pH } \\
\text { de } \\
\text { Coagulação }\end{array}$} & \multirow{2}{*}{$\begin{array}{c}T_{\mathrm{s} 1}=1,75 \mathrm{~min} \\
\mathrm{~V}_{\mathrm{s} 1}=4.0 \mathrm{~cm} / \mathrm{min}\end{array}$} & \multirow{2}{*}{$\begin{array}{c}\begin{array}{c}T_{\mathrm{s} 2}=3.50 \mathrm{~min} \\
\mathbf{V}_{\mathrm{s} 2}=2.0 \mathrm{~cm} / \mathrm{min}\end{array} \\
\qquad \begin{array}{c}\text { Turbidez } \\
\text { (uT) }\end{array}\end{array}$} \\
\hline & $\begin{array}{c}\text { Sulfato Férrico } \\
(\mathrm{mg} / \mathfrak{l})\end{array}$ & $\begin{array}{c}\text { Ácido } \\
\text { Clorídrico } \\
0.1 \mathrm{~N}(\mathrm{~m} \ell / \ell)\end{array}$ & $\begin{array}{l}\text { Hidróxido de } \\
\text { Sódio 0.1N } \\
(\mathrm{ml} / \mathfrak{l})\end{array}$ & & & \\
\hline 1 & 25.0 & 7.29 & - & 5.78 & 3.05 & 2.59 \\
\hline 2 & 25.0 & 5.47 & - & 5.97 & 1.64 & 1.61 \\
\hline 3 & 25.0 & 3.65 & - & 6.10 & 3.20 & 1.17 \\
\hline 4 & 25.0 & 1.82 & - & 6.34 & 2.48 & 2.32 \\
\hline 5 & 25.0 & - & - & 6.48 & 6.18 & 2.01 \\
\hline 6 & 30.0 & - & - & 6.34 & 2.67 & 2.15 \\
\hline
\end{tabular}

\section{ESTUDO DE COAGULAÇÃO-FLOCULAÇÃO-SEDIMENTAÇÃO}

\begin{tabular}{|c|c|c|c|c|c|c|}
\hline \multirow{2}{*}{$\begin{array}{l}\text { ENSAIO N }^{\circ}: 08 \\
\text { Data : } 14 / 03 / 00\end{array}$} & \multirow{2}{*}{$\begin{array}{c}\text { COAGULANTE } \\
\text { Sulfato Férrico }\end{array}$} & \multicolumn{3}{|c|}{ MISTURA RÁPIDA } & \multicolumn{2}{|c|}{ FLOCULAÇÃO } \\
\hline & & $\mathrm{Tmr}=10 \mathrm{~s}$ & Gm & $\mathrm{s}^{-1}$ & $\mathbf{T f}=\mathbf{2 0} \mathrm{min}$ & Gf $=25 \mathrm{~s}^{-1}$ \\
\hline \multicolumn{7}{|c|}{ CARACTERÍSTICAS DA ÁGUA DE ESTUDO } \\
\hline \multirow{2}{*}{ Turbidez (uT) } & \multirow{2}{*}{$\begin{array}{c}\text { Alcalinidade Total } \\
\left(\mathrm{mg} / \mathrm{l} \mathrm{CaCO}_{3}\right)\end{array}$} & \multicolumn{2}{|c|}{ pH } & \multirow{2}{*}{\multicolumn{2}{|c|}{$\begin{array}{c}\text { Temperatura } \\
{ }^{\circ} \mathrm{C} \\
\end{array}$}} & \multirow{2}{*}{$\begin{array}{l}\text { Potencial } \\
\text { Zeta }(\mathrm{mV}) \\
\end{array}$} \\
\hline & & S/ agit. & $\mathrm{C} /$ agit. & & & \\
\hline 98.5 & 28.5 & 7.77 & 7.60 & & 25 & - \\
\hline
\end{tabular}

\begin{tabular}{|c|c|c|c|c|c|c|}
\hline \multirow{2}{*}{ FRASCO } & \multicolumn{3}{|c|}{ DOSAGEM DE PRODUTO QUÍMICO } & \multirow{2}{*}{$\begin{array}{c}\mathrm{pH} \\
\text { de } \\
\text { Coagulação }\end{array}$} & \multirow{2}{*}{$\begin{array}{c}\begin{array}{c}T_{\mathrm{s} 1}=1,75 \mathrm{~min} \\
\mathrm{~V}_{\mathrm{s} 1}=4.0 \mathrm{~cm} / \mathrm{min}\end{array} \\
\begin{array}{c}\text { Turbidez } \\
\text { (uT) }\end{array}\end{array}$} & \multirow{2}{*}{$\begin{array}{c}\mathrm{T}_{\mathrm{s} 2}=3.50 \mathrm{~min} \\
\mathrm{~V}_{\mathrm{s} 2}=2.0 \mathrm{~cm} / \mathrm{min} \\
\\
\begin{array}{c}\text { Turbidez } \\
\text { (uT) }\end{array}\end{array}$} \\
\hline & $\begin{array}{l}\text { Sulfato Férrico } \\
(\mathrm{mg} / \mathfrak{l})\end{array}$ & $\begin{array}{c}\text { Ácido } \\
\text { Clorídrico } \\
0.1 \mathrm{~N}(\mathrm{~m} \ell / \ell)\end{array}$ & $\begin{array}{l}\text { Hidróxido de } \\
\text { Sódio 0.1N } \\
(\mathrm{m} \ell / \mathfrak{l})\end{array}$ & & & \\
\hline 1 & 30.0 & 5.47 & - & 5.92 & 4.56 & 2.18 \\
\hline 2 & 30.0 & 3.65 & - & 5.97 & 4.19 & 1.49 \\
\hline 3 & 30.0 & 1.82 & - & 6.14 & 6.31 & 1.80 \\
\hline 4 & 30.0 & - & - & 6.35 & 5.05 & 3.87 \\
\hline 5 & 30.0 & - & 1.0 & 6.43 & 10.4 & 1.37 \\
\hline 6 & 30.0 & - & 2.0 & 6.51 & 7.83 & 5.27 \\
\hline
\end{tabular}


ESTUDO DE COAGULAÇÃO-FLOCULAÇÃO-SEDIMENTAÇÃO

\begin{tabular}{|c|c|c|c|c|c|c|}
\hline \multirow{2}{*}{$\begin{array}{l}\text { ENSAIO N } \mathbf{N}^{\circ}: 09 \\
\text { Data : } 14 / 03 / 00\end{array}$} & \multirow{2}{*}{$\begin{array}{c}\text { COAGULANTE } \\
\text { Sulfato Férrico }\end{array}$} & \multicolumn{3}{|c|}{ MISTURA RÁPIDA } & \multicolumn{2}{|c|}{ FLOCULAÇÃO } \\
\hline & & $\mathrm{Tmr}=10 \mathrm{~s}$ & Gm & & $\mathbf{T f}=\mathbf{2 0} \mathrm{min}$ & $\mathbf{G f}=25 \mathrm{~s}^{-1}$ \\
\hline \multicolumn{7}{|c|}{ CARACTERÍSTICAS DA ÁGUA DE ESTUDO } \\
\hline \multirow{2}{*}{ Turbidez (uT) } & \multirow{2}{*}{$\begin{array}{l}\text { Alcalinidade Total } \\
\left(\mathrm{mg} / \ell \mathrm{CaCO}_{3}\right)\end{array}$} & \multicolumn{2}{|c|}{ pH } & \multirow{2}{*}{\multicolumn{2}{|c|}{$\begin{array}{c}\text { Temperatura } \\
{ }^{\circ} \mathrm{C} \\
\end{array}$}} & \multirow{2}{*}{$\begin{array}{r}\text { Potencial } \\
\text { Zeta }(\mathrm{mV})\end{array}$} \\
\hline & & S/ agit. & $\mathrm{C} /$ agit. & & & \\
\hline 98.5 & 28.5 & 7.77 & 7.60 & & 25 & - \\
\hline
\end{tabular}

\begin{tabular}{|c|c|c|c|c|c|c|}
\hline \multirow{2}{*}{ FRASCO } & \multicolumn{3}{|c|}{ DOSAGEM DE PRODUTO QUÍMICO } & \multirow{2}{*}{$\begin{array}{c}\text { pH } \\
\text { de } \\
\text { Coagulação }\end{array}$} & \multirow{2}{*}{$\begin{array}{c}\begin{array}{c}T_{\mathrm{s} 1}=1,75 \mathrm{~min} \\
\mathrm{~V}_{\mathrm{s1} 1}=4.0 \mathrm{~cm} / \mathrm{min}\end{array} \\
\begin{array}{c}\text { Turbidez } \\
\text { (uT) }\end{array}\end{array}$} & \multirow{2}{*}{$\begin{array}{c}\mathrm{T}_{\mathrm{s} 2}=3.50 \mathrm{~min} \\
\mathrm{~V}_{\mathrm{s} 2}=2.0 \mathrm{~cm} / \mathrm{min}\end{array}$} \\
\hline & $\begin{array}{l}\text { Sulfato Férrico } \\
(\mathrm{mg} / \mathfrak{l})\end{array}$ & $\begin{array}{c}\text { Ácido } \\
\text { Clorídrico } \\
0.1 \mathrm{~N}(\mathrm{m \ell} / \mathrm{\ell})\end{array}$ & $\begin{array}{l}\text { Hidróxido de } \\
\text { Sódio } 0.1 \mathrm{~N} \\
(\mathrm{~m} \ell / \ell)\end{array}$ & & & \\
\hline 1 & 10.0 & 13.67 & - & 5.82 & 28.0 & 20.8 \\
\hline 2 & 10.0 & 11.84 & - & 6.02 & 10.6 & 8.10 \\
\hline 3 & 15.0 & 11.84 & - & 5.51 & 25.9 & 23.9 \\
\hline 4 & 20.0 & 10.93 & - & 5.69 & 80.8 & 17.3 \\
\hline 5 & 25.0 & 8.20 & - & 5.60 & 9.35 & 4.46 \\
\hline 6 & 15.0 & - & 3.0 & 7.01 & 13.5 & 8.61 \\
\hline
\end{tabular}

\section{ESTUDO DE COAGULAÇÃO-FLOCULAÇÃO-SEDIMENTAÇÃO}

\begin{tabular}{|c|c|c|c|c|c|c|}
\hline \multirow{2}{*}{$\begin{array}{l}\text { ENSAIO N }{ }^{\circ}: 10 \\
\text { Data }: 14 / 03 / 00\end{array}$} & \multirow{2}{*}{$\begin{array}{c}\text { COAGULANTE } \\
\text { Sulfato Férrico }\end{array}$} & \multicolumn{3}{|c|}{ MISTURA RÁPIDA } & \multicolumn{2}{|c|}{ FLOCULAÇÃO } \\
\hline & & $\mathrm{Tmr}=10 \mathrm{~s}$ & $\mathbf{G m}$ & & $T f=20 \mathrm{~min}$ & $G f=25 s^{-1}$ \\
\hline \multicolumn{7}{|c|}{ CARACTERÍSTICAS DA ÁGUA DE ESTUDO } \\
\hline \multirow{2}{*}{ Turbidez (uT) } & \multirow{2}{*}{$\begin{array}{l}\text { Alcalinidade Total } \\
\left(\mathrm{mg} / \ell \mathrm{CaCO}_{3}\right)\end{array}$} & \multicolumn{2}{|c|}{ pH } & \multirow{2}{*}{\multicolumn{2}{|c|}{$\begin{array}{c}\text { Temperatura } \\
{ }^{\circ} \mathrm{C} \\
\end{array}$}} & \multirow{2}{*}{$\begin{array}{r}\text { Potencial } \\
\text { Zeta }(\mathrm{mV}) \\
\end{array}$} \\
\hline & & S/ agit. & $\mathrm{C} /$ agit. & & & \\
\hline 98.5 & 28.5 & 7.77 & 7.60 & & 25 & 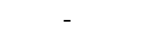 \\
\hline
\end{tabular}

\begin{tabular}{|c|c|c|c|c|c|c|}
\hline \multirow{2}{*}{ FRASCO } & \multicolumn{3}{|c|}{ DOSAGEM DE PRODUTO QUÍMICO } & \multirow{2}{*}{$\begin{array}{c}\text { pH } \\
\text { de } \\
\text { Coagulação }\end{array}$} & \multirow{2}{*}{$\begin{array}{c}\begin{array}{c}\mathrm{T}_{\mathrm{s} 1}=1,75 \mathrm{~min} \\
\mathrm{~V}_{\mathrm{s} 1}=4.0 \mathrm{~cm} / \mathrm{min}\end{array} \\
\begin{array}{c}\text { Turbidez } \\
\text { (uT) }\end{array}\end{array}$} & \multirow{2}{*}{$\begin{array}{c}\begin{array}{c}T_{\mathrm{s} 2}=3.50 \mathrm{~min} \\
\mathbf{V}_{\mathrm{s} 2}=2.0 \mathrm{~cm} / \mathrm{min}\end{array} \\
\begin{array}{c}\text { Turbidez } \\
(\mathrm{uT})\end{array}\end{array}$} \\
\hline & $\begin{array}{l}\text { Sulfato Férrico } \\
\qquad(\mathrm{mg} / \mathfrak{l})\end{array}$ & $\begin{array}{c}\text { Ácido } \\
\text { Clorídrico } \\
0.1 \mathrm{~N}(\mathrm{~m} \ell / \ell)\end{array}$ & $\begin{array}{l}\text { Hidróxido de } \\
\text { Sódio 0.1N } \\
(\mathrm{m} \ell / \mathfrak{l})\end{array}$ & & & \\
\hline 1 & 30.0 & 7.29 & - & 5.28 & 43.0 & 34.2 \\
\hline 2 & 35.0 & 1.82 & - & 5.79 & 3.64 & 2.71 \\
\hline 3 & 35.0 & - & - & 6.05 & 3.74 & 2.06 \\
\hline 4 & 35.0 & - & 1.0 & 6.26 & 5.78 & 3.79 \\
\hline 5 & 35.0 & - & 3.0 & 6.34 & 7.58 & 3.56 \\
\hline 6 & 30.0 & - & 3.0 & 6.57 & 5.78 & 6.85 \\
\hline
\end{tabular}


ESTUDO DE COAGULAÇÃO-FLOCULAÇÃO-SEDIMENTAÇÃO

\begin{tabular}{|c|c|c|c|c|c|c|}
\hline \multirow{2}{*}{$\begin{array}{l}\text { ENSAIO No: } 11 \\
\text { Data : } 14 / 03 / 00\end{array}$} & \multirow{2}{*}{$\begin{array}{l}\text { COAGULANTE } \\
\text { Sulfato Férrico }\end{array}$} & \multicolumn{3}{|c|}{ MISTURA RÁPIDA } & \multicolumn{2}{|c|}{ FLOCULAÇÃO } \\
\hline & & $\mathrm{Tmr}=10 \mathrm{~s}$ & \multicolumn{2}{|c|}{$\mathrm{Gmr}=1000 \mathrm{~s}^{-1}$} & $T f=20 \mathrm{~min}$ & $G f=25 s^{-1}$ \\
\hline \multicolumn{7}{|c|}{ CARACTERÍSTICAS DA ÁGUA DE ESTUDO } \\
\hline \multirow{2}{*}{ Turbidez (uT) } & \multirow{2}{*}{$\begin{array}{c}\text { Alcalinidade Total } \\
\left(\mathrm{mg} / \ell \mathrm{CaCO}_{3}\right)\end{array}$} & \multicolumn{2}{|c|}{$\mathrm{pH}$} & \multirow{2}{*}{\multicolumn{2}{|c|}{$\begin{array}{c}\text { Temperatura } \\
{ }^{\circ} \mathrm{C} \\
\end{array}$}} & \multirow{2}{*}{$\begin{array}{l}\text { Potencial } \\
\text { Zeta }(\mathrm{mV}) \\
\end{array}$} \\
\hline & & S/ agit. & $\mathrm{C} /$ agit. & & & \\
\hline 98.5 & 28.5 & 7.77 & 7.60 & & 25 & - \\
\hline
\end{tabular}

\begin{tabular}{|c|c|c|c|c|c|c|}
\hline \multirow{2}{*}{ FRASCO } & \multicolumn{3}{|c|}{ DOSAGEM DE PRODUTO QUÍMICO } & \multirow{2}{*}{$\begin{array}{c}\text { pH } \\
\text { de } \\
\text { Coagulação }\end{array}$} & \multirow{2}{*}{$\begin{array}{c}T_{\mathrm{s} 1}=1,75 \mathrm{~min} \\
\mathrm{~V}_{\mathrm{s} 1}=4.0 \mathrm{~cm} / \mathrm{min} \\
\begin{array}{c}\text { Turbidez } \\
(\mathrm{uT})\end{array}\end{array}$} & \multirow{2}{*}{$\begin{array}{c}T_{\mathrm{s} 2}=3.50 \mathrm{~min} \\
\mathrm{~V}_{\mathrm{s} 2}=2.0 \mathrm{~cm} / \mathrm{min} \\
\\
\text { Turbidez } \\
(\mathrm{uT})\end{array}$} \\
\hline & $\begin{array}{l}\text { Sulfato Férrico } \\
(\mathrm{mg} / \ell)\end{array}$ & $\begin{array}{c}\text { Ácido } \\
\text { Clorídrico } \\
0.1 \mathrm{~N}(\mathrm{~m} \ell / \ell)\end{array}$ & $\begin{array}{c}\text { Hidróxido de } \\
\text { Sódio } 0.1 \mathrm{~N} \\
(\mathrm{~m} \ell / \ell)\end{array}$ & & & \\
\hline 1 & 10.0 & 14.58 & - & 5.56 & 76.3 & 65.5 \\
\hline 2 & 10.0 & 7.29 & - & 6.41 & 6.27 & 6.27 \\
\hline 3 & 10.0 & 3.65 & - & 6.57 & - & 5.65 \\
\hline 4 & 15.0 & 11.39 & - & 5.90 & 5.21 & 4.47 \\
\hline 5 & 15.0 & - & 4.0 & 7.11 & 42.1 & 34.3 \\
\hline 6 & 20.0 & - & 3.0 & 6.96 & 6.46 & 3.32 \\
\hline
\end{tabular}

\section{ESTUDO DE COAGULAÇÃO-FLOCULAÇÃO-SEDIMENTAÇÃO}

\begin{tabular}{|c|c|c|c|c|c|c|}
\hline \multirow{2}{*}{$\begin{array}{l}\text { ENSAIO N: } 12 \\
\text { Data : } 14 / 03 / 00\end{array}$} & \multirow{2}{*}{$\begin{array}{l}\text { COAGULANTE } \\
\text { Sulfato Férrico }\end{array}$} & \multicolumn{3}{|c|}{ MISTURA RÁPIDA } & \multicolumn{2}{|c|}{ FLOCULAÇÃO } \\
\hline & & $\mathrm{Tmr}=10 \mathrm{~s}$ & \multicolumn{2}{|c|}{$\mathrm{Gmr}=1000 \mathrm{~s}^{-1}$} & $T f=20 \mathrm{~min}$ & Gf $=25 \mathrm{~s}^{-1}$ \\
\hline \multicolumn{7}{|c|}{ CARACTERÍSTICAS DA ÁGUA DE ESTUDO } \\
\hline \multirow{2}{*}{ Turbidez (uT) } & \multirow{2}{*}{$\begin{array}{c}\text { Alcalinidade Total } \\
\left(\mathrm{mg} / \ell \mathrm{CaCO}_{3}\right) \\
\end{array}$} & \multicolumn{2}{|c|}{ pH } & \multirow{2}{*}{\multicolumn{2}{|c|}{$\begin{array}{c}\text { Temperatura } \\
{ }^{\circ} \mathrm{C} \\
\end{array}$}} & \multirow{2}{*}{$\begin{array}{r}\text { Potencial } \\
\text { Zeta }(\mathrm{mV})\end{array}$} \\
\hline & & S/ agit. & C/ agit. & & & \\
\hline 98.5 & 28.5 & 7.77 & 7.60 & & 25 & - \\
\hline
\end{tabular}

\begin{tabular}{|c|c|c|c|c|c|c|}
\hline \multirow{2}{*}{ FRASCO } & \multicolumn{3}{|c|}{ DOSAGEM DE PRODUTO QUÍMICO } & \multirow{2}{*}{$\begin{array}{c}\text { pH } \\
\text { de } \\
\text { Coagulação }\end{array}$} & \multirow{2}{*}{$\begin{array}{c}T_{\mathrm{s} 1}=1,75 \mathrm{~min} \\
\mathrm{~V}_{\mathrm{s} 1}=4.0 \mathrm{~cm} / \mathrm{min} \\
\\
\text { Turbidez } \\
(\mathrm{uT})\end{array}$} & \multirow{2}{*}{$\begin{array}{c}T_{\mathrm{s} 2}=3.50 \mathrm{~min} \\
\mathbf{V}_{\mathrm{s} 2}=2.0 \mathrm{~cm} / \mathrm{min} \\
\\
\text { Turbidez } \\
(\mathbf{u T})\end{array}$} \\
\hline & $\begin{array}{c}\text { Sulfato Férrico } \\
(\mathrm{mg} / \ell)\end{array}$ & $\begin{array}{c}\text { Ácido } \\
\text { Clorídrico } \\
0.1 \mathrm{~N}(\mathrm{~m} \ell / \ell)\end{array}$ & $\begin{array}{c}\text { Hidróxido de } \\
\text { Sódio 0.1N } \\
(\mathrm{m} \ell / \ell)\end{array}$ & & & \\
\hline 1 & 35.0 & 3.65 & - & 5.57 & 3.64 & 2.75 \\
\hline 2 & 40.0 & 1.82 & - & 5.57 & 3.24 & 2.58 \\
\hline 3 & 40.0 & - & - & 5.81 & 2.53 & 1.98 \\
\hline 4 & 35.0 & - & 4.0 & 6.28 & 6.73 & 3.98 \\
\hline 5 & 40.0 & - & 2.0 & 6.34 & 8.84 & 2.92 \\
\hline 6 & 40.0 & - & 4.0 & 6.40 & 9.03 & 7.36 \\
\hline
\end{tabular}


ESTUDO DE COAGULAÇÃO-FLOCULAÇÃO-SEDIMENTAÇÃO

\begin{tabular}{|c|c|c|c|c|c|c|}
\hline \multirow{2}{*}{$\begin{array}{l}\text { ENSAIO No: } 13 \\
\text { Data : } 14 / 03 / 00\end{array}$} & \multirow{2}{*}{$\begin{array}{l}\text { COAGULANTE } \\
\text { Sulfato Férrico }\end{array}$} & \multicolumn{3}{|c|}{ MISTURA RÁPIDA } & \multicolumn{2}{|c|}{ FLOCULAÇÃO } \\
\hline & & $\mathrm{Tmr}=10 \mathrm{~s}$ & \multicolumn{2}{|c|}{$\mathrm{Gmr}=1000 \mathrm{~s}^{-1}$} & $T f=20 \mathrm{~min}$ & $G f=25 s^{-1}$ \\
\hline \multicolumn{7}{|c|}{ CARACTERÍSTICAS DA ÁGUA DE ESTUDO } \\
\hline \multirow{2}{*}{ Turbidez (uT) } & \multirow{2}{*}{$\begin{array}{c}\text { Alcalinidade Total } \\
\left(\mathrm{mg} / \ell \mathrm{CaCO}_{3}\right)\end{array}$} & \multicolumn{2}{|c|}{$\mathrm{pH}$} & \multirow{2}{*}{\multicolumn{2}{|c|}{$\begin{array}{c}\text { Temperatura } \\
{ }^{\circ} \mathrm{C} \\
\end{array}$}} & \multirow{2}{*}{$\begin{array}{l}\text { Potencial } \\
\text { Zeta }(\mathrm{mV}) \\
\end{array}$} \\
\hline & & S/ agit. & $\mathrm{C} /$ agit. & & & \\
\hline 98.5 & 28.5 & 7.77 & 7.60 & & 25 & - \\
\hline
\end{tabular}

\begin{tabular}{|c|c|c|c|c|c|c|}
\hline \multirow{2}{*}{ FRASCO } & \multicolumn{3}{|c|}{ DOSAGEM DE PRODUTO QUÍMICO } & \multirow{2}{*}{$\begin{array}{c}\text { pH } \\
\text { de } \\
\text { Coagulação }\end{array}$} & \multirow{2}{*}{$\begin{array}{c}\mathrm{T}_{\mathrm{s} 1}=1,75 \mathrm{~min} \\
\mathrm{~V}_{\mathrm{s} 1}=4.0 \mathrm{~cm} / \mathrm{min} \\
\\
\text { Turbidez } \\
(\mathrm{uT})\end{array}$} & \multirow{2}{*}{$\begin{array}{c}T_{\mathrm{s} 2}=3.50 \mathrm{~min} \\
\mathbf{V}_{\mathrm{s} 2}=\mathbf{2 . 0 \mathrm { cm } / \mathrm { min }} \\
\\
\begin{array}{c}\text { Turbidez } \\
(\mathrm{uT})\end{array}\end{array}$} \\
\hline & $\begin{array}{c}\text { Sulfato Férrico } \\
(\mathrm{mg} / \ell)\end{array}$ & $\begin{array}{c}\text { Ácido } \\
\text { Clorídrico } \\
0.1 \mathrm{~N}(\mathrm{~m} \ell / \ell)\end{array}$ & $\begin{array}{c}\text { Hidróxido de } \\
\text { Sódio 0.1N } \\
(\mathrm{m} \ell / \ell)\end{array}$ & & & \\
\hline 1 & 15.0 & 11.84 & - & 5.71 & 28.4 & 21.5 \\
\hline 2 & 2.0 & 10.02 & - & 5.66 & 19.0 & 13.1 \\
\hline 3 & 30.0 & 5.47 & - & 5.66 & 3.08 & 2.75 \\
\hline 4 & 30.0 & 3.65 & - & 5.99 & 2.61 & 2.71 \\
\hline 5 & 25.0 & - & 2.0 & 6.67 & 8.55 & 5.99 \\
\hline 6 & 20.0 & - & 4.0 & 6.99 & 9.08 & 4.52 \\
\hline
\end{tabular}

\section{ESTUDO DE COAGULAÇÃO-FLOCULAÇÃO-SEDIMENTAÇÃO}

\begin{tabular}{|c|c|c|c|c|c|c|}
\hline \multirow{2}{*}{$\begin{array}{l}\text { ENSAIO No: } 14 \\
\text { Data : } 14 / 03 / 00\end{array}$} & \multirow{2}{*}{$\begin{array}{l}\text { COAGULANTE } \\
\text { Sulfato Férrico }\end{array}$} & \multicolumn{3}{|c|}{ MISTURA RÁPIDA } & \multicolumn{2}{|c|}{ FLOCULAÇÃO } \\
\hline & & $\mathrm{Tmr}=10 \mathrm{~s}$ & \multicolumn{2}{|c|}{$\mathrm{Gmr}=1000 \mathrm{~s}^{-1}$} & $T f=20 \mathrm{~min}$ & $G f=25 \mathrm{~s}^{-1}$ \\
\hline \multicolumn{7}{|c|}{ CARACTERÍSTICAS DA ÁGUA DE ESTUDO } \\
\hline \multirow{2}{*}{ Turbidez (uT) } & \multirow{2}{*}{$\begin{array}{c}\text { Alcalinidade Total } \\
\left(\mathrm{mg} / \ell \mathrm{CaCO}_{3}\right)\end{array}$} & \multicolumn{2}{|c|}{ pH } & \multirow{2}{*}{\multicolumn{2}{|c|}{$\begin{array}{c}\text { Temperatura } \\
{ }^{\circ} \mathrm{C} \\
\end{array}$}} & \multirow{2}{*}{$\begin{array}{c}\text { Potencial } \\
\text { Zeta }(\mathrm{mV})\end{array}$} \\
\hline & & S/ agit. & C/ agit. & & & \\
\hline 98.5 & 28.5 & 7.77 & 7.60 & & 25 & - \\
\hline
\end{tabular}

\begin{tabular}{|c|c|c|c|c|c|c|}
\hline \multirow{2}{*}{ FRASCO } & \multicolumn{3}{|c|}{ DOSAGEM DE PRODUTO QUÍMICO } & \multirow{2}{*}{$\begin{array}{c}\text { pH } \\
\text { de } \\
\text { Coagulação }\end{array}$} & \multirow{2}{*}{$\begin{array}{c}T_{\mathrm{s} 1}=1,75 \mathrm{~min} \\
\mathrm{~V}_{\mathrm{s} 1}=4.0 \mathrm{~cm} / \mathrm{min} \\
\\
\text { Turbidez } \\
(\mathrm{uT})\end{array}$} & \multirow{2}{*}{$\begin{array}{c}T_{\mathrm{s} 2}=3.50 \mathrm{~min} \\
\mathrm{~V}_{\mathrm{s} 2}=2.0 \mathrm{~cm} / \mathrm{min} \\
\\
\begin{array}{c}\text { Turbidez } \\
(\mathbf{u T})\end{array}\end{array}$} \\
\hline & $\begin{array}{c}\text { Sulfato Férrico } \\
(\mathrm{mg} / \ell)\end{array}$ & $\begin{array}{c}\text { Ácido } \\
\text { Clorídrico } \\
0.1 \mathrm{~N}(\mathrm{~m} \ell / \ell)\end{array}$ & $\begin{array}{c}\text { Hidróxido de } \\
\text { Sódio 0.1N } \\
(\mathrm{m} \ell / \ell)\end{array}$ & & & \\
\hline 1 & 35.0 & 5.47 & - & 4.99 & - & 7.41 \\
\hline 2 & 30.0 & - & 4.0 & 6.52 & 8.76 & 4.79 \\
\hline 3 & 35.0 & - & 5.0 & 6.55 & 11.2 & 3.45 \\
\hline 4 & 40.0 & - & 1.0 & 6.08 & 2.97 & 1.35 \\
\hline 5 & 40.0 & - & 5.0 & 6.72 & 14.3 & 3.75 \\
\hline 6 & 40.0 & - & 6.0 & 6.89 & 14.2 & 5.08 \\
\hline
\end{tabular}


ESTUDO DE COAGULAÇÃO-FLOCULAÇÃO-SEDIMENTAÇÃO

\begin{tabular}{|c|c|c|c|c|c|c|}
\hline \multirow{2}{*}{$\begin{array}{l}\text { ENSAIO No: } 15 \\
\text { Data : } 15 / 03 / 00\end{array}$} & \multirow{2}{*}{$\begin{array}{l}\text { COAGULANTE } \\
\text { Sulfato Férrico }\end{array}$} & \multicolumn{3}{|c|}{ MISTURA RÁPIDA } & \multicolumn{2}{|c|}{ FLOCULAÇÃO } \\
\hline & & $\mathrm{Tmr}=10 \mathrm{~s}$ & \multicolumn{2}{|c|}{$\mathrm{Gmr}=1000 \mathrm{~s}^{-1}$} & $T f=20 \mathrm{~min}$ & $G f=25 s^{-1}$ \\
\hline \multicolumn{7}{|c|}{ CARACTERÍSTICAS DA ÁGUA DE ESTUDO } \\
\hline \multirow{2}{*}{ Turbidez (uT) } & \multirow{2}{*}{$\begin{array}{c}\text { Alcalinidade Total } \\
\left(\mathrm{mg} / \ell \mathrm{CaCO}_{3}\right)\end{array}$} & \multicolumn{2}{|c|}{$\mathrm{pH}$} & \multirow{2}{*}{\multicolumn{2}{|c|}{$\begin{array}{c}\text { Temperatura } \\
{ }^{\circ} \mathrm{C} \\
\end{array}$}} & \multirow{2}{*}{$\begin{array}{l}\text { Potencial } \\
\text { Zeta }(\mathrm{mV}) \\
\end{array}$} \\
\hline & & S/ agit. & $\mathrm{C} /$ agit. & & & \\
\hline $101 / 99$ & 28.5 & 7.76 & 7.58 & & 25 & - \\
\hline
\end{tabular}

\begin{tabular}{|c|c|c|c|c|c|c|}
\hline \multirow{2}{*}{ FRASCO } & \multicolumn{3}{|c|}{ DOSAGEM DE PRODUTO QUÍMICO } & \multirow{2}{*}{$\begin{array}{c}\text { pH } \\
\text { de } \\
\text { Coagulação }\end{array}$} & \multirow{2}{*}{$\begin{array}{c}\mathrm{T}_{\mathrm{s} 1}=1,75 \mathrm{~min} \\
\mathrm{~V}_{\mathrm{s} 1}=4.0 \mathrm{~cm} / \mathrm{min} \\
\\
\text { Turbidez } \\
(\mathrm{uT})\end{array}$} & \multirow{2}{*}{$\begin{array}{c}T_{\mathrm{s} 2}=3.50 \mathrm{~min} \\
\mathbf{V}_{\mathrm{s} 2}=\mathbf{2 . 0 \mathrm { cm } / \mathrm { min }} \\
\\
\begin{array}{c}\text { Turbidez } \\
(\mathrm{uT})\end{array}\end{array}$} \\
\hline & $\begin{array}{c}\text { Sulfato Férrico } \\
(\mathrm{mg} / \ell)\end{array}$ & $\begin{array}{c}\text { Ácido } \\
\text { Clorídrico } \\
0.1 \mathrm{~N}(\mathrm{~m} \ell / \ell)\end{array}$ & $\begin{array}{c}\text { Hidróxido de } \\
\text { Sódio 0.1N } \\
(\mathrm{m} \ell / \ell)\end{array}$ & & & \\
\hline 1 & 35.0 & 6.38 & - & 4.95 & 22.8 & 18.4 \\
\hline 2 & 30.0 & 6.38 & - & 5.36 & 6.49 & 4.22 \\
\hline 3 & 25.0 & - & 3.5 & 6.71 & 11.8 & 5.80 \\
\hline 4 & 20.0 & - & 5.5 & 7.12 & 15.9 & 10.3 \\
\hline 5 & 35.0 & - & 6.0 & 6.72 & 16.5 & 10.1 \\
\hline 6 & 30.0 & - & 6.0 & 6.89 & 16.5 & 12.6 \\
\hline
\end{tabular}

\section{ESTUDO DE COAGULAÇÃO-FLOCULAÇÃO-SEDIMENTAÇÃO}

\begin{tabular}{|c|c|c|c|c|c|c|}
\hline \multirow{2}{*}{$\begin{array}{l}\text { ENSAIO No: } 16 \\
\text { Data : } 15 / 03 / 00\end{array}$} & \multirow{2}{*}{$\begin{array}{l}\text { COAGULANTE } \\
\text { Sulfato Férrico }\end{array}$} & \multicolumn{3}{|c|}{ MISTURA RÁPIDA } & \multicolumn{2}{|c|}{ FLOCULAÇÃO } \\
\hline & & $\mathrm{Tmr}=10 \mathrm{~s}$ & \multicolumn{2}{|c|}{$\mathrm{Gmr}=1000 \mathrm{~s}^{-1}$} & $\mathbf{T f}=20 \mathrm{~min}$ & $G f=25 \mathrm{~s}^{-1}$ \\
\hline \multicolumn{7}{|c|}{ CARACTERÍSTICAS DA ÁGUA DE ESTUDO } \\
\hline \multirow{2}{*}{ Turbidez (uT) } & \multirow{2}{*}{$\begin{array}{c}\text { Alcalinidade Total } \\
\left(\mathrm{mg} / \ell \mathrm{CaCO}_{3}\right)\end{array}$} & \multicolumn{2}{|c|}{ pH } & \multirow{2}{*}{\multicolumn{2}{|c|}{$\begin{array}{c}\text { Temperatura } \\
{ }^{\circ} \mathrm{C} \\
\end{array}$}} & \multirow{2}{*}{$\begin{array}{c}\text { Potencial } \\
\text { Zeta }(\mathrm{mV})\end{array}$} \\
\hline & & S/ agit. & C/ agit. & & & \\
\hline $101 / 99$ & 28.5 & 7.76 & 7.58 & & 25 & - \\
\hline
\end{tabular}

\begin{tabular}{|c|c|c|c|c|c|c|}
\hline \multirow{2}{*}{ FRASCO } & \multicolumn{3}{|c|}{ DOSAGEM DE PRODUTO QUÍMICO } & \multirow{2}{*}{$\begin{array}{c}\text { pH } \\
\text { de } \\
\text { Coagulação }\end{array}$} & \multirow{2}{*}{$\begin{array}{c}T_{\mathrm{s} 1}=1,75 \mathrm{~min} \\
\mathrm{~V}_{\mathrm{s} 1}=4.0 \mathrm{~cm} / \mathrm{min} \\
\\
\text { Turbidez } \\
(\mathrm{uT})\end{array}$} & \multirow{2}{*}{$\begin{array}{c}T_{\mathrm{s} 2}=3.50 \mathrm{~min} \\
\mathbf{V}_{\mathrm{s} 2}=2.0 \mathrm{~cm} / \mathrm{min} \\
\\
\text { Turbidez } \\
(\mathbf{u T})\end{array}$} \\
\hline & $\begin{array}{c}\text { Sulfato Férrico } \\
(\mathrm{mg} / \ell)\end{array}$ & $\begin{array}{c}\text { Ácido } \\
\text { Clorídrico } \\
0.1 \mathrm{~N}(\mathrm{~m} \ell / \ell)\end{array}$ & $\begin{array}{c}\text { Hidróxido de } \\
\text { Sódio 0.1N } \\
(\mathrm{m} \ell / \ell)\end{array}$ & & & \\
\hline 1 & 40.0 & 3.65 & - & 5.38 & 4.38 & 3.20 \\
\hline 2 & 45.0 & 1.82 & - & 5.28 & 4.22 & 2.81 \\
\hline 3 & 45.0 & - & 2.0 & 5.81 & 5.54 & 1.63 \\
\hline 4 & 45.0 & - & 4.0 & 6.15 & 7.31 & 5.91 \\
\hline 5 & 45.0 & - & 6.0 & 6.32 & 16.0 & 7.29 \\
\hline 6 & 40.0 & - & 8.0 & 6.64 & 12.2 & 6.10 \\
\hline
\end{tabular}


ESTUDO DE COAGULAÇÃO-FLOCULAÇÃO-SEDIMENTAÇÃO

\begin{tabular}{|c|c|c|c|c|c|c|}
\hline \multirow{2}{*}{$\begin{array}{l}\text { ENSAIO No: } 17 \\
\text { Data : } 15 / 03 / 00\end{array}$} & \multirow{2}{*}{$\begin{array}{l}\text { COAGULANTE } \\
\text { Sulfato Férrico }\end{array}$} & \multicolumn{3}{|c|}{ MISTURA RÁPIDA } & \multicolumn{2}{|c|}{ FLOCULAÇÃO } \\
\hline & & $\mathrm{Tmr}=10 \mathrm{~s}$ & \multicolumn{2}{|c|}{$\mathrm{Gmr}=1000 \mathrm{~s}^{-1}$} & $\mathbf{T f}=20 \mathrm{~min}$ & $G f=25 \mathrm{~s}^{-1}$ \\
\hline \multicolumn{7}{|c|}{ CARACTERÍSTICAS DA ÁGUA DE ESTUDO } \\
\hline \multirow{2}{*}{ Turbidez (uT) } & \multirow{2}{*}{$\begin{array}{c}\text { Alcalinidade Total } \\
\left(\mathrm{mg} / \ell \mathrm{CaCO}_{3}\right) \\
\end{array}$} & \multicolumn{2}{|c|}{ pH } & \multirow{2}{*}{\multicolumn{2}{|c|}{$\begin{array}{c}\text { Temperatura } \\
{ }^{\circ} \mathrm{C} \\
\end{array}$}} & \multirow{2}{*}{$\begin{array}{l}\text { Potencial } \\
\text { Zeta }(\mathrm{mV})\end{array}$} \\
\hline & & S/ agit. & $\mathrm{C} /$ agit. & & & \\
\hline $101 / 99$ & 28.5 & 7.76 & 7.58 & & 25 & - \\
\hline
\end{tabular}

\begin{tabular}{|c|c|c|c|c|c|c|}
\hline \multirow{2}{*}{ FRASCO } & \multicolumn{3}{|c|}{ DOSAGEM DE PRODUTO QUÍMICO } & \multirow{2}{*}{$\begin{array}{c}\text { pH } \\
\text { de } \\
\text { Coagulação }\end{array}$} & \multirow{2}{*}{$\begin{array}{c}\mathrm{T}_{\mathrm{s} 1}=1,75 \mathrm{~min} \\
\mathrm{~V}_{\mathrm{s} 1}=4.0 \mathrm{~cm} / \mathrm{min} \\
\\
\text { Turbidez } \\
(\mathrm{uT})\end{array}$} & \multirow{2}{*}{$\begin{array}{c}T_{\mathrm{s} 2}=3.50 \mathrm{~min} \\
\mathbf{V}_{\mathrm{s} 2}=\mathbf{2 . 0 \mathrm { cm } / \mathrm { min }} \\
\\
\begin{array}{c}\text { Turbidez } \\
(\mathrm{uT})\end{array}\end{array}$} \\
\hline & $\begin{array}{c}\text { Sulfato Férrico } \\
(\mathrm{mg} / \ell)\end{array}$ & $\begin{array}{c}\text { Ácido } \\
\text { Clorídrico } \\
0.1 \mathrm{~N}(\mathrm{~m} \ell / \ell)\end{array}$ & $\begin{array}{c}\text { Hidróxido de } \\
\text { Sódio 0.1N } \\
(\mathrm{m} \ell / \ell)\end{array}$ & & & \\
\hline 1 & 25.0 & - & 5.0 & 6.94 & 9.82 & 3.82 \\
\hline 2 & 20.0 & - & 7.0 & 7.30 & 97.6 & 95.3 \\
\hline 3 & 30.0 & - & 7.5 & 7.03 & 9.67 & 4.42 \\
\hline 4 & 35.0 & - & 7.5 & 6.88 & 28.6 & 5.28 \\
\hline 5 & 40.0 & - & 4.5 & 6.50 & 7.32 & 1.75 \\
\hline 6 & 40.0 & - & 8.0 & 6.71 & 13.3 & 7.37 \\
\hline
\end{tabular}

\section{ESTUDO DE COAGULAÇÃO-FLOCULAÇÃO-SEDIMENTAÇÃO}

\begin{tabular}{|c|c|c|c|c|c|c|}
\hline \multirow{2}{*}{$\begin{array}{l}\text { ENSAIO No: } 18 \\
\text { Data : } 15 / 03 / 00\end{array}$} & \multirow{2}{*}{$\begin{array}{l}\text { COAGULANTE } \\
\text { Sulfato Férrico }\end{array}$} & \multicolumn{3}{|c|}{ MISTURA RÁPIDA } & \multicolumn{2}{|c|}{ FLOCULAÇÃO } \\
\hline & & $\mathrm{Tmr}=10 \mathrm{~s}$ & \multicolumn{2}{|c|}{$\mathrm{Gmr}=1000 \mathrm{~s}^{-1}$} & $T f=20 \mathrm{~min}$ & $G f=25 \mathrm{~s}^{-1}$ \\
\hline \multicolumn{7}{|c|}{ CARACTERÍSTICAS DA ÁGUA DE ESTUDO } \\
\hline \multirow{2}{*}{ Turbidez (uT) } & \multirow{2}{*}{$\begin{array}{c}\text { Alcalinidade Total } \\
\left(\mathrm{mg} / \ell \mathrm{CaCO}_{3}\right)\end{array}$} & \multicolumn{2}{|c|}{ pH } & \multirow{2}{*}{\multicolumn{2}{|c|}{$\begin{array}{c}\text { Temperatura } \\
{ }^{\circ} \mathrm{C} \\
\end{array}$}} & \multirow{2}{*}{$\begin{array}{c}\text { Potencial } \\
\text { Zeta }(\mathrm{mV})\end{array}$} \\
\hline & & S/ agit. & C/ agit. & & & \\
\hline $101 / 99$ & 28.5 & 7.76 & 7.58 & & 25 & - \\
\hline
\end{tabular}

\begin{tabular}{|c|c|c|c|c|c|c|}
\hline \multirow{2}{*}{ FRASCO } & \multicolumn{3}{|c|}{ DOSAGEM DE PRODUTO QUÍMICO } & \multirow{2}{*}{$\begin{array}{c}\text { pH } \\
\text { de } \\
\text { Coagulação }\end{array}$} & \multirow{2}{*}{$\begin{array}{c}T_{\mathrm{s} 1}=1,75 \mathrm{~min} \\
\mathrm{~V}_{\mathrm{s} 1}=4.0 \mathrm{~cm} / \mathrm{min} \\
\\
\text { Turbidez } \\
(\mathrm{uT})\end{array}$} & \multirow{2}{*}{$\begin{array}{c}T_{\mathrm{s} 2}=3.50 \mathrm{~min} \\
\mathbf{V}_{\mathrm{s} 2}=\mathbf{2 . 0 \mathrm { cm } / \mathrm { min }} \\
\\
\text { Turbidez } \\
\text { (uT) }\end{array}$} \\
\hline & $\begin{array}{l}\text { Sulfato Férrico } \\
(\mathrm{mg} / \ell)\end{array}$ & $\begin{array}{c}\text { Ácido } \\
\text { Clorídrico } \\
\mathbf{0 . 1 N}(\mathrm{m} \ell / \ell)\end{array}$ & $\begin{array}{c}\text { Hidróxido de } \\
\text { Sódio 0.1N } \\
(\mathrm{m} \ell / \ell)\end{array}$ & & & \\
\hline 1 & 20.0 & 12.76 & - & 4.79 & 99.8 & 97.1 \\
\hline 2 & 40.0 & 5.47 & - & 4.71 & 8.50 & 5.43 \\
\hline 3 & 25.0 & - & 6.5 & 6.93 & 9.57 & 7.34 \\
\hline 4 & 35.0 & - & 8.5 & 6.88 & 21.9 & - \\
\hline 5 & 30.0 & - & 9.0 & 7.02 & 11.5 & 3.75 \\
\hline 6 & 40.0 & - & 10.0 & 6.80 & 19.0 & 8.25 \\
\hline
\end{tabular}


ESTUDO DE COAGULAÇÃO-FLOCULAÇÃO-SEDIMENTAÇÃO

\begin{tabular}{|c|c|c|c|c|c|c|}
\hline \multirow{2}{*}{$\begin{array}{l}\text { ENSAIO N }{ }^{\circ}: 19 \\
\text { Data : } 15 / 03 / 00\end{array}$} & \multirow{2}{*}{$\begin{array}{c}\text { COAGULANTE } \\
\text { Sulfato Férrico }\end{array}$} & \multicolumn{3}{|c|}{ MISTURA RÁPIDA } & \multicolumn{2}{|c|}{ FLOCULAÇÃO } \\
\hline & & $\mathrm{Tmr}=10 \mathrm{~s}$ & Gm & & $\mathbf{T f}=\mathbf{2 0} \mathrm{min}$ & Gf $=25 \mathrm{~s}^{-1}$ \\
\hline \multicolumn{7}{|c|}{ CARACTERÍSTICAS DA ÁGUA DE ESTUDO } \\
\hline \multirow{2}{*}{ Turbidez (uT) } & \multirow{2}{*}{$\begin{array}{l}\text { Alcalinidade Total } \\
\left(\mathrm{mg} / \ell \mathrm{CaCO}_{3}\right)\end{array}$} & \multicolumn{2}{|c|}{ pH } & \multirow{2}{*}{\multicolumn{2}{|c|}{$\begin{array}{c}\text { Temperatura } \\
{ }^{\circ} \mathrm{C} \\
\end{array}$}} & \multirow{2}{*}{$\begin{array}{r}\text { Potencial } \\
\text { Zeta }(\mathrm{mV})\end{array}$} \\
\hline & & S/ agit. & $\mathrm{C} /$ agit. & & & \\
\hline $101 / 99$ & 28.5 & 7.76 & 7.58 & & 25 & - \\
\hline
\end{tabular}

\begin{tabular}{|c|c|c|c|c|c|c|}
\hline \multirow{2}{*}{ FRASCO } & \multicolumn{3}{|c|}{ DOSAGEM DE PRODUTO QUÍMICO } & \multirow{2}{*}{$\begin{array}{c}\text { pH } \\
\text { de } \\
\text { Coagulação }\end{array}$} & \multirow{2}{*}{$\begin{array}{c}T_{\mathrm{s} 1}=1,75 \mathrm{~min} \\
\mathrm{~V}_{\mathrm{s} 1}=4.0 \mathrm{~cm} / \mathrm{min}\end{array}$} & \multirow{2}{*}{$\begin{array}{c}\begin{array}{c}T_{\mathrm{s} 2}=3.50 \mathrm{~min} \\
\mathbf{V}_{\mathrm{s} 2}=2.0 \mathrm{~cm} / \mathrm{min}\end{array} \\
\qquad \begin{array}{c}\text { Turbidez } \\
\text { (uT) }\end{array}\end{array}$} \\
\hline & $\begin{array}{c}\text { Sulfato Férrico } \\
(\mathrm{mg} / \mathfrak{l})\end{array}$ & $\begin{array}{c}\text { Ácido } \\
\text { Clorídrico } \\
0.1 \mathrm{~N}(\mathrm{~m} \ell / \ell)\end{array}$ & $\begin{array}{l}\text { Hidróxido de } \\
\text { Sódio 0.1N } \\
(\mathrm{ml} / \mathfrak{l})\end{array}$ & & & \\
\hline 1 & 40.0 & 7.29 & - & 4.24 & 34.4 & 23.3 \\
\hline 2 & 45.0 & 3.65 & - & 4.65 & 6.17 & 4.90 \\
\hline 3 & 45.0 & - & - & 5.47 & 3.79 & 2.01 \\
\hline 4 & 30.0 & - & 11.0 & 7.12 & 77.4 & 69.5 \\
\hline 5 & 40.0 & - & 12.0 & 7.03 & 8.22 & 3.42 \\
\hline 6 & 45.0 & - & 10.0 & 6.71 & 17.1 & 6.72 \\
\hline
\end{tabular}

\section{ESTUDO DE COAGULAÇÃO-FLOCULAÇÃO-SEDIMENTAÇÃO}

\begin{tabular}{|c|c|c|c|c|c|c|}
\hline \multirow{2}{*}{$\begin{array}{l}\text { ENSAIO N }{ }^{\circ}: 20 \\
\text { Data }: 15 / 03 / 00\end{array}$} & \multirow{2}{*}{$\begin{array}{c}\text { COAGULANTE } \\
\text { Sulfato Férrico }\end{array}$} & \multicolumn{3}{|c|}{ MISTURA RÁPIDA } & \multicolumn{2}{|c|}{ FLOCULAÇÃO } \\
\hline & & $\mathrm{Tmr}=10 \mathrm{~s}$ & $\mathbf{G m}$ & & $T f=20 \mathrm{~min}$ & $G f=25 s^{-1}$ \\
\hline \multicolumn{7}{|c|}{ CARACTERÍSTICAS DA ÁGUA DE ESTUDO } \\
\hline \multirow{2}{*}{ Turbidez (uT) } & \multirow{2}{*}{$\begin{array}{l}\text { Alcalinidade Total } \\
\left(\mathrm{mg} / \ell \mathrm{CaCO}_{3}\right)\end{array}$} & \multicolumn{2}{|c|}{ pH } & \multirow{2}{*}{\multicolumn{2}{|c|}{$\begin{array}{c}\text { Temperatura } \\
{ }^{\circ} \mathrm{C} \\
\end{array}$}} & \multirow{2}{*}{$\begin{array}{r}\text { Potencial } \\
\text { Zeta }(\mathrm{mV}) \\
\end{array}$} \\
\hline & & S/ agit. & $\mathrm{C} /$ agit. & & & \\
\hline $101 / 99$ & 28.5 & 7.76 & 7.58 & & 25 & - \\
\hline
\end{tabular}

\begin{tabular}{|c|c|c|c|c|c|c|}
\hline \multirow{2}{*}{ FRASCO } & \multicolumn{3}{|c|}{ DOSAGEM DE PRODUTO QUÍMICO } & \multirow{2}{*}{$\begin{array}{c}\text { pH } \\
\text { de } \\
\text { Coagulação }\end{array}$} & \multirow{2}{*}{$\begin{array}{c}\begin{array}{c}T_{\mathrm{s} 1}=1,75 \mathrm{~min} \\
\mathbf{V}_{\mathrm{s1}}=4.0 \mathrm{~cm} / \mathrm{min}\end{array} \\
\begin{array}{c}\text { Turbidez } \\
(\mathrm{uT})\end{array}\end{array}$} & \multirow{2}{*}{$\begin{array}{c}T_{\mathrm{s} 2}=3.50 \mathrm{~min} \\
\mathrm{~V}_{\mathrm{s} 2}=2.0 \mathrm{~cm} / \mathrm{min} \\
\begin{array}{c}\text { Turbidez } \\
\text { (uT) }\end{array}\end{array}$} \\
\hline & $\begin{array}{c}\text { Sulfato Férrico } \\
(\mathrm{mg} / \mathfrak{l})\end{array}$ & $\begin{array}{c}\text { Ácido } \\
\text { Clorídrico } \\
0.1 \mathrm{~N}(\mathrm{~m} \ell / \ell)\end{array}$ & $\begin{array}{l}\text { Hidróxido de } \\
\text { Sódio 0.1N } \\
(\mathrm{m} \ell / \ell)\end{array}$ & & & \\
\hline 1 & 30.0 & 6.38 & - & 5.54 & 3.54 & 2.69 \\
\hline 2 & 35.0 & 7.29 & - & 4.83 & 48.7 & 34.2 \\
\hline 3 & 25.0 & - & 8.0 & 7.09 & 95.5 & 90.8 \\
\hline 4 & 35.0 & - & 10.0 & 6.97 & 11.5 & 5.84 \\
\hline 5 & 40.0 & - & 14.0 & 7.12 & 12.5 & 8.01 \\
\hline 6 & 45.0 & - & 12.0 & 6.78 & 23.6 & 8.07 \\
\hline
\end{tabular}


ESTUDO DE COAGULAÇÃO-FLOCULAÇÃO-SEDIMENTAÇÃO

\begin{tabular}{|c|c|c|c|c|c|c|}
\hline \multirow{2}{*}{$\begin{array}{l}\text { ENSAIO No: } 21 \\
\text { Data : } 15 / 03 / 00\end{array}$} & \multirow{2}{*}{$\begin{array}{l}\text { COAGULANTE } \\
\text { Sulfato Férrico }\end{array}$} & \multicolumn{3}{|c|}{ MISTURA RÁPIDA } & \multicolumn{2}{|c|}{ FLOCULAÇÃO } \\
\hline & & $\mathrm{Tmr}=10 \mathrm{~s}$ & \multicolumn{2}{|c|}{$\mathrm{Gmr}=1000 \mathrm{~s}^{-1}$} & $T f=20 \mathrm{~min}$ & $G f=25 s^{-1}$ \\
\hline \multicolumn{7}{|c|}{ CARACTERÍSTICAS DA ÁGUA DE ESTUDO } \\
\hline \multirow{2}{*}{ Turbidez (uT) } & \multirow{2}{*}{$\begin{array}{c}\text { Alcalinidade Total } \\
\left(\mathrm{mg} / \mathrm{l} \mathrm{CaCO}_{3}\right)\end{array}$} & \multicolumn{2}{|c|}{$\mathrm{pH}$} & \multirow{2}{*}{\multicolumn{2}{|c|}{$\begin{array}{c}\text { Temperatura } \\
{ }^{\circ} \mathrm{C} \\
\end{array}$}} & \multirow{2}{*}{$\begin{array}{l}\text { Potencial } \\
\text { Zeta }(\mathrm{mV}) \\
\end{array}$} \\
\hline & & S/ agit. & $\mathrm{C} /$ agit. & & & \\
\hline $101 / 99$ & 28.5 & 7.76 & 7.58 & & 25 & - \\
\hline
\end{tabular}

\begin{tabular}{|c|c|c|c|c|c|c|}
\hline \multirow{2}{*}{ FRASCO } & \multicolumn{3}{|c|}{ DOSAGEM DE PRODUTO QUÍMICO } & \multirow{2}{*}{$\begin{array}{c}\text { pH } \\
\text { de } \\
\text { Coagulação }\end{array}$} & \multirow{2}{*}{$\begin{array}{c}\mathrm{T}_{\mathrm{s} 1}=1,75 \mathrm{~min} \\
\mathrm{~V}_{\mathrm{s} 1}=4.0 \mathrm{~cm} / \mathrm{min} \\
\\
\text { Turbidez } \\
(\mathrm{uT})\end{array}$} & \multirow{2}{*}{$\begin{array}{c}T_{\mathrm{s} 2}=3.50 \mathrm{~min} \\
\mathbf{V}_{\mathrm{s} 2}=\mathbf{2 . 0 \mathrm { cm } / \mathrm { min }} \\
\\
\begin{array}{c}\text { Turbidez } \\
(\mathrm{uT})\end{array}\end{array}$} \\
\hline & $\begin{array}{c}\text { Sulfato Férrico } \\
(\mathrm{mg} / \ell)\end{array}$ & $\begin{array}{c}\text { Ácido } \\
\text { Clorídrico } \\
0.1 \mathrm{~N}(\mathrm{~m} \ell / \ell)\end{array}$ & $\begin{array}{c}\text { Hidróxido de } \\
\text { Sódio 0.1N } \\
(\mathrm{m} \ell / \ell)\end{array}$ & & & \\
\hline 1 & 50.0 & - & - & 5.22 & 3.08 & 2.68 \\
\hline 2 & 50.0 & - & 4.0 & 5.83 & 5.67 & 3.20 \\
\hline 3 & 50.0 & - & 8.0 & 6.26 & 13.5 & 2.51 \\
\hline 4 & 45.0 & - & 14.0 & 6.90 & 9.47 & 3.21 \\
\hline 5 & 35.0 & - & 12.0 & 7.17 & 21.9 & 14.0 \\
\hline 6 & 40.0 & - & 16.0 & 7.42 & 98.9 & 92.2 \\
\hline
\end{tabular}

\section{ESTUDO DE COAGULAÇÃO-FLOCULAÇÃO-SEDIMENTAÇÃO}

\begin{tabular}{|c|c|c|c|c|c|c|}
\hline \multirow{2}{*}{$\begin{array}{l}\text { ENSAIO No: } 22 \\
\text { Data : } 15 / 03 / 00\end{array}$} & \multirow{2}{*}{$\begin{array}{c}\text { COAGULANTE } \\
\text { Sulfato Férrico }\end{array}$} & \multicolumn{3}{|c|}{ MISTURA RÁPIDA } & \multicolumn{2}{|c|}{ FLOCULAÇÃO } \\
\hline & & $\mathrm{Tmr}=10 \mathrm{~s}$ & \multicolumn{2}{|c|}{$\mathrm{Gmr}=1000 \mathrm{~s}^{-1}$} & $T f=20 \mathrm{~min}$ & $G f=25 \mathrm{~s}^{-1}$ \\
\hline \multicolumn{7}{|c|}{ CARACTERÍSTICAS DA ÁGUA DE ESTUDO } \\
\hline \multirow{2}{*}{ Turbidez (uT) } & \multirow{2}{*}{$\begin{array}{c}\text { Alcalinidade Total } \\
\left(\mathrm{mg} / \ell \mathrm{CaCO}_{3}\right)\end{array}$} & \multicolumn{2}{|c|}{ pH } & \multirow{2}{*}{\multicolumn{2}{|c|}{$\begin{array}{c}\text { Temperatura } \\
{ }^{\circ} \mathrm{C} \\
\end{array}$}} & \multirow{2}{*}{$\begin{array}{c}\text { Potencial } \\
\text { Zeta }(\mathrm{mV})\end{array}$} \\
\hline & & S/ agit. & C/ agit. & & & \\
\hline $101 / 99$ & 28.5 & 7.76 & 7.58 & & 25 & - \\
\hline
\end{tabular}

\begin{tabular}{|c|c|c|c|c|c|c|}
\hline \multirow{2}{*}{ FRASCO } & \multicolumn{3}{|c|}{ DOSAGEM DE PRODUTO QUÍMICO } & \multirow{2}{*}{$\begin{array}{c}\text { pH } \\
\text { de } \\
\text { Coagulação }\end{array}$} & \multirow{2}{*}{$\begin{array}{c}T_{\mathrm{s} 1}=1,75 \mathrm{~min} \\
\mathrm{~V}_{\mathrm{s} 1}=4.0 \mathrm{~cm} / \mathrm{min} \\
\begin{array}{c}\text { Turbidez } \\
(\mathrm{uT})\end{array}\end{array}$} & \multirow{2}{*}{$\begin{array}{c}T_{\mathrm{s} 2}=3.50 \mathrm{~min} \\
\mathrm{~V}_{\mathrm{s} 2}=2.0 \mathrm{~cm} / \mathrm{min} \\
\text { Turbidez } \\
(\mathbf{u T})\end{array}$} \\
\hline & $\begin{array}{c}\text { Sulfato Férrico } \\
(\mathrm{mg} / \ell)\end{array}$ & $\begin{array}{c}\text { Ácido } \\
\text { Clorídrico } \\
0.1 \mathrm{~N}(\mathrm{~m} \ell / \ell)\end{array}$ & $\begin{array}{c}\text { Hidróxido de } \\
\text { Sódio 0.1N } \\
(\mathrm{m} \ell / \ell)\end{array}$ & & & \\
\hline 1 & 50.0 & 5.47 & - & 4.03 & 30.4 & 17.0 \\
\hline 2 & 50.0 & 3.65 & - & 4.30 & 12.3 & 4.72 \\
\hline 3 & 50.0 & - & 2.0 & 5.48 & 6.89 & 1.25 \\
\hline 4 & 50.0 & - & 6.0 & 6.05 & 21.3 & 1.67 \\
\hline 5 & 50.0 & - & 10.0 & 6.47 & 21.5 & 2.88 \\
\hline 6 & 45.0 & - & 16.0 & 7.07 & 14.0 & 9.85 \\
\hline
\end{tabular}


ESTUDO DE COAGULAÇÃO-FLOCULAÇÃO-SEDIMENTAÇÃO

\begin{tabular}{|c|c|c|c|c|c|c|}
\hline \multirow{2}{*}{$\begin{array}{l}\text { ENSAIO N }{ }^{\circ}: 23 \\
\text { Data }: 15 / 03 / 00\end{array}$} & \multirow{2}{*}{$\begin{array}{c}\text { COAGULANTE } \\
\text { Sulfato Férrico }\end{array}$} & \multicolumn{3}{|c|}{ MISTURA RÁPIDA } & \multicolumn{2}{|c|}{ FLOCULAÇÃO } \\
\hline & & $\mathrm{Tmr}=10 \mathrm{~s}$ & Gm & & $\mathbf{T f}=\mathbf{2 0} \mathrm{min}$ & Gf $=25 \mathrm{~s}^{-1}$ \\
\hline \multicolumn{7}{|c|}{ CARACTERÍSTICAS DA ÁGUA DE ESTUDO } \\
\hline \multirow{2}{*}{ Turbidez (uT) } & \multirow{2}{*}{$\begin{array}{l}\text { Alcalinidade Total } \\
\left(\mathrm{mg} / \ell \mathrm{CaCO}_{3}\right)\end{array}$} & \multicolumn{2}{|c|}{ pH } & \multirow{2}{*}{\multicolumn{2}{|c|}{$\begin{array}{c}\text { Temperatura } \\
{ }^{\circ} \mathrm{C} \\
\end{array}$}} & \multirow{2}{*}{$\begin{array}{r}\text { Potencial } \\
\text { Zeta }(\mathrm{mV})\end{array}$} \\
\hline & & S/ agit. & $\mathrm{C} /$ agit. & & & \\
\hline $101 / 99$ & 28.5 & 7.76 & 7.58 & & 25 & - \\
\hline
\end{tabular}

\begin{tabular}{|c|c|c|c|c|c|c|}
\hline \multirow{2}{*}{ FRASCO } & \multicolumn{3}{|c|}{ DOSAGEM DE PRODUTO QUÍMICO } & \multirow{2}{*}{$\begin{array}{c}\text { pH } \\
\text { de } \\
\text { Coagulação }\end{array}$} & \multirow{2}{*}{$\begin{array}{c}T_{\mathrm{s} 1}=1,75 \mathrm{~min} \\
\mathrm{~V}_{\mathrm{s} 1}=4.0 \mathrm{~cm} / \mathrm{min}\end{array}$} & \multirow{2}{*}{$\begin{array}{c}\begin{array}{c}T_{\mathrm{s} 2}=3.50 \mathrm{~min} \\
\mathbf{V}_{\mathrm{s} 2}=2.0 \mathrm{~cm} / \mathrm{min}\end{array} \\
\qquad \begin{array}{c}\text { Turbidez } \\
\text { (uT) }\end{array}\end{array}$} \\
\hline & $\begin{array}{c}\text { Sulfato Férrico } \\
(\mathrm{mg} / \mathfrak{l})\end{array}$ & $\begin{array}{c}\text { Ácido } \\
\text { Clorídrico } \\
0.1 \mathrm{~N}(\mathrm{~m} \ell / \ell)\end{array}$ & $\begin{array}{l}\text { Hidróxido de } \\
\text { Sódio 0.1N } \\
(\mathrm{ml} / \mathfrak{l})\end{array}$ & & & \\
\hline 1 & 45.0 & 5.47 & - & 4.28 & 16.8 & 6.77 \\
\hline 2 & 45.0 & 2.73 & - & 4.81 & 4.16 & 2.01 \\
\hline 3 & 50.0 & 1.82 & - & 4.67 & 6.98 & 2.09 \\
\hline 4 & 40.0 & - & 15.0 & 7.16 & 19.8 & 10.2 \\
\hline 5 & 50.0 & - & 12.0 & 6.64 & 18.9 & 5.35 \\
\hline 6 & 45.0 & - & 18.0 & 7.23 & 30.2 & 24.0 \\
\hline
\end{tabular}

\section{ESTUDO DE COAGULAÇÃO-FLOCULAÇÃO-SEDIMENTAÇÃO}

\begin{tabular}{|c|c|c|c|c|c|c|}
\hline \multirow{2}{*}{$\begin{array}{l}\text { ENSAIO N }{ }^{\circ}: 24 \\
\text { Data }: 15 / 03 / 00\end{array}$} & \multirow{2}{*}{$\begin{array}{c}\text { COAGULANTE } \\
\text { Sulfato Férrico }\end{array}$} & \multicolumn{3}{|c|}{ MISTURA RÁPIDA } & \multicolumn{2}{|c|}{ FLOCULAÇÃO } \\
\hline & & $\mathrm{Tmr}=10 \mathrm{~s}$ & $\mathbf{G m}$ & & $T f=20 \mathrm{~min}$ & $G f=25 s^{-1}$ \\
\hline \multicolumn{7}{|c|}{ CARACTERÍSTICAS DA ÁGUA DE ESTUDO } \\
\hline \multirow{2}{*}{ Turbidez (uT) } & \multirow{2}{*}{$\begin{array}{l}\text { Alcalinidade Total } \\
\left(\mathrm{mg} / \ell \mathrm{CaCO}_{3}\right)\end{array}$} & \multicolumn{2}{|c|}{ pH } & \multirow{2}{*}{\multicolumn{2}{|c|}{$\begin{array}{c}\text { Temperatura } \\
{ }^{\circ} \mathrm{C} \\
\end{array}$}} & \multirow{2}{*}{$\begin{array}{r}\text { Potencial } \\
\text { Zeta }(\mathrm{mV}) \\
\end{array}$} \\
\hline & & S/ agit. & $\mathrm{C} /$ agit. & & & \\
\hline $101 / 99$ & 28.5 & 7.76 & 7.58 & & 25 & - \\
\hline
\end{tabular}

\begin{tabular}{|c|c|c|c|c|c|c|}
\hline \multirow{2}{*}{ FRASCO } & \multicolumn{3}{|c|}{ DOSAGEM DE PRODUTO QUÍMICO } & \multirow{2}{*}{$\begin{array}{c}\text { pH } \\
\text { de } \\
\text { Coagulação }\end{array}$} & \multirow{2}{*}{$\begin{array}{c}\begin{array}{c}\mathrm{T}_{\mathrm{s} 1}=1,75 \mathrm{~min} \\
\mathrm{~V}_{\mathrm{s} 1}=4.0 \mathrm{~cm} / \mathrm{min}\end{array} \\
\begin{array}{c}\text { Turbidez } \\
\text { (uT) }\end{array}\end{array}$} & \multirow{2}{*}{$\begin{array}{c}\begin{array}{c}T_{\mathrm{s} 2}=3.50 \mathrm{~min} \\
\mathbf{V}_{\mathrm{s} 2}=2.0 \mathrm{~cm} / \mathrm{min}\end{array} \\
\begin{array}{c}\text { Turbidez } \\
(\mathrm{uT})\end{array}\end{array}$} \\
\hline & $\begin{array}{l}\text { Sulfato Férrico } \\
\qquad(\mathrm{mg} / \mathfrak{l})\end{array}$ & $\begin{array}{c}\text { Ácido } \\
\text { Clorídrico } \\
0.1 \mathrm{~N}(\mathrm{~m} \ell / \ell)\end{array}$ & $\begin{array}{l}\text { Hidróxido de } \\
\text { Sódio 0.1N } \\
(\mathrm{m} \ell / \mathfrak{l})\end{array}$ & & & \\
\hline 1 & 55.0 & 3.65 & - & 4.01 & 19.8 & 11.0 \\
\hline 2 & 55.0 & 1.82 & - & 4.21 & 16.0 & 5.10 \\
\hline 3 & 55.0 & - & - & 4.45 & 8.04 & 2.27 \\
\hline 4 & 55.0 & - & 6.0 & 5.72 & 9.22 & 3.98 \\
\hline 5 & 55.0 & - & 10.0 & 6.22 & 20.3 & 2.00 \\
\hline 6 & 55.0 & - & 12.0 & 6.40 & 25.1 & 7.17 \\
\hline
\end{tabular}


ESTUDO DE COAGULAÇÃO-FLOCULAÇÃO-SEDIMENTAÇÃO

\begin{tabular}{|c|c|c|c|c|c|c|}
\hline \multirow{2}{*}{$\begin{array}{l}\text { ENSAIO N } \mathbf{N}^{\circ}: 25 \\
\text { Data : } 17 / 03 / 00\end{array}$} & \multirow{2}{*}{$\begin{array}{l}\text { COAGULANTE } \\
\text { Sulfato Férrico }\end{array}$} & \multicolumn{3}{|c|}{ MISTURA RÁPIDA } & \multicolumn{2}{|c|}{ FLOCULAÇÃO } \\
\hline & & $\mathrm{Tmr}=10 \mathrm{~s}$ & \multicolumn{2}{|c|}{$\mathrm{Gmr}=1000 \mathrm{~s}^{-1}$} & $T f=20 \mathrm{~min}$ & $G f=25 s^{-1}$ \\
\hline \multicolumn{7}{|c|}{ CARACTERÍSTICAS DA ÁGUA DE ESTUDO } \\
\hline \multirow{2}{*}{ Turbidez (uT) } & \multirow{2}{*}{$\begin{array}{c}\text { Alcalinidade Total } \\
\left(\mathrm{mg} / \mathrm{l} \mathrm{CaCO}_{3}\right)\end{array}$} & \multicolumn{2}{|c|}{$\mathrm{pH}$} & \multirow{2}{*}{\multicolumn{2}{|c|}{$\begin{array}{c}\text { Temperatura } \\
{ }^{\circ} \mathrm{C} \\
\end{array}$}} & \multirow{2}{*}{$\begin{array}{l}\text { Potencial } \\
\text { Zeta }(\mathrm{mV}) \\
\end{array}$} \\
\hline & & S/ agit. & $\mathrm{C} /$ agit. & & & \\
\hline $101 / 99$ & 28.5 & 7.76 & 7.58 & & 25 & - \\
\hline
\end{tabular}

\begin{tabular}{|c|c|c|c|c|c|c|}
\hline \multirow{2}{*}{ FRASCO } & \multicolumn{3}{|c|}{ DOSAGEM DE PRODUTO QUÍMICO } & \multirow{2}{*}{$\begin{array}{c}\text { pH } \\
\text { de } \\
\text { Coagulação }\end{array}$} & \multirow{2}{*}{$\begin{array}{c}T_{\mathrm{s} 1}=1,75 \mathrm{~min} \\
\mathrm{~V}_{\mathrm{s} 1}=4.0 \mathrm{~cm} / \mathrm{min} \\
\begin{array}{c}\text { Turbidez } \\
\text { (uT) }\end{array}\end{array}$} & \multirow{2}{*}{$\begin{array}{c}T_{\mathrm{s} 2}=3.50 \mathrm{~min} \\
\mathrm{~V}_{\mathrm{s} 2}=\mathbf{2 . 0 \mathrm { cm } / \mathrm { min }} \\
\\
\begin{array}{c}\text { Turbidez } \\
(\mathrm{uT})\end{array}\end{array}$} \\
\hline & $\begin{array}{c}\text { Sulfato Férrico } \\
(\mathrm{mg} / \ell)\end{array}$ & $\begin{array}{c}\text { Ácido } \\
\text { Clorídrico } \\
0.1 \mathrm{~N}(\mathrm{~m} \ell / \ell)\end{array}$ & $\begin{array}{c}\text { Hidróxido de } \\
\text { Sódio 0.1N } \\
(\mathrm{m} \ell / \ell)\end{array}$ & & & \\
\hline 1 & 60.0 & 3.65 & - & 3.98 & 39.9 & 12.5 \\
\hline 2 & 60.0 & 1.82 & - & 4.20 & 22.3 & 3.67 \\
\hline 3 & 60.0 & - & 2.0 & 4.74 & 12.4 & 1.57 \\
\hline 4 & 60.0 & - & 6.0 & 5.61 & 11.1 & 1.42 \\
\hline 5 & 60.0 & - & 8.0 & 5.97 & 10.2 & 3.16 \\
\hline 6 & 60.0 & - & 10.0 & 6.15 & 11.7 & 3.41 \\
\hline
\end{tabular}

\section{ESTUDO DE COAGULAÇÃO-FLOCULAÇÃO-SEDIMENTAÇÃO}

\begin{tabular}{|c|c|c|c|c|c|c|}
\hline \multirow{2}{*}{$\begin{array}{l}\text { ENSAIO N: } 26 \\
\text { Data : } 19 / 03 / 00\end{array}$} & \multirow{2}{*}{$\begin{array}{l}\text { COAGULANTE } \\
\text { Sulfato Férrico }\end{array}$} & \multicolumn{3}{|c|}{ MISTURA RÁPIDA } & \multicolumn{2}{|c|}{ FLOCULAÇÃO } \\
\hline & & $\mathrm{Tmr}=10 \mathrm{~s}$ & \multicolumn{2}{|c|}{$\mathrm{Gmr}=1000 \mathrm{~s}^{-1}$} & $\mathbf{T f}=20 \mathrm{~min}$ & $G f=25 \mathrm{~s}^{-1}$ \\
\hline \multicolumn{7}{|c|}{ CARACTERÍSTICAS DA ÁGUA DE ESTUDO } \\
\hline \multirow{2}{*}{ Turbidez (uT) } & \multirow{2}{*}{$\begin{array}{c}\text { Alcalinidade Total } \\
\left(\mathrm{mg} / \ell \mathrm{CaCO}_{3}\right)\end{array}$} & \multicolumn{2}{|c|}{ pH } & \multirow{2}{*}{\multicolumn{2}{|c|}{$\begin{array}{c}\text { Temperatura } \\
{ }^{\circ} \mathrm{C} \\
\end{array}$}} & \multirow{2}{*}{$\begin{array}{r}\text { Potencial } \\
\text { Zeta }(\mathrm{mV})\end{array}$} \\
\hline & & S/ agit. & C/ agit. & & & \\
\hline $101 / 99$ & 28.5 & 7.76 & 7.58 & & 25 & - \\
\hline
\end{tabular}

\begin{tabular}{|c|c|c|c|c|c|c|}
\hline \multirow{2}{*}{ FRASCO } & \multicolumn{3}{|c|}{ DOSAGEM DE PRODUTO QUÍMICO } & \multirow{2}{*}{$\begin{array}{c}\text { pH } \\
\text { de } \\
\text { Coagulação }\end{array}$} & \multirow{2}{*}{$\begin{array}{c}T_{\mathrm{s} 1}=1,75 \mathrm{~min} \\
\mathrm{~V}_{\mathrm{s} 1}=4.0 \mathrm{~cm} / \mathrm{min} \\
\\
\text { Turbidez } \\
(\mathrm{uT})\end{array}$} & \multirow{2}{*}{$\begin{array}{c}T_{\mathrm{s} 2}=3.50 \mathrm{~min} \\
\mathbf{V}_{\mathrm{s} 2}=2.0 \mathrm{~cm} / \mathrm{min} \\
\\
\text { Turbidez } \\
(\mathbf{u T})\end{array}$} \\
\hline & $\begin{array}{c}\text { Sulfato Férrico } \\
(\mathrm{mg} / \ell)\end{array}$ & $\begin{array}{c}\text { Ácido } \\
\text { Clorídrico } \\
0.1 \mathrm{~N}(\mathrm{~m} \ell / \ell)\end{array}$ & $\begin{array}{c}\text { Hidróxido de } \\
\text { Sódio } 0.1 \mathrm{~N} \\
(\mathrm{~m} \ell / \ell)\end{array}$ & & & \\
\hline 1 & 50.0 & 0.91 & - & 5.05 & 5.47 & 2.31 \\
\hline 2 & 55.0 & - & 1.0 & 5.05 & 8.47 & 2.22 \\
\hline 3 & 50.0 & - & 1.0 & 5.55 & 7.38 & 1.90 \\
\hline 4 & 60.0 & - & 3.0 & 5.00 & 10.6 & 4.35 \\
\hline 5 & 60.0 & - & 4.0 & 5.20 & 9.56 & 2.89 \\
\hline 6 & 60.0 & - & 5.0 & 5.46 & 9.66 & 3.89 \\
\hline
\end{tabular}


ANEXO - E

ENSAIOS DO REATOR ESTÁTICO - ÁGUA II PARA O COAGULANTE

SULFATO DE ALUMÍNIO 
ESTUDO DE COAGULAÇÄO-FLOCULAÇÄO-SEDIMENTAÇÄO

\begin{tabular}{|c|c|c|c|c|c|}
\hline \multirow{2}{*}{$\begin{array}{c}\text { ENSAIO No } \\
\text { Data:09/04/00 }\end{array}$} & $\begin{array}{c}\text { COAGULANTE: } \\
\text { Sulfato de Alumínio }\end{array}$ & \multicolumn{2}{|c|}{ MISTURA RÁPIDA } & \multicolumn{2}{|c|}{ FLOCULAC̈O } \\
\cline { 3 - 5 } & & Tmr=5s & Gmr=1000s & Tf=30min & ${\text { Gf }=15 \mathbf{s}^{-1}}^{-1}$ \\
\hline
\end{tabular}

\begin{tabular}{|c|c|c|c|c|c|c|c|}
\hline \multicolumn{8}{|c|}{ CARACTERÍSTICAS DA ÁGUA DE ESTUDO } \\
\hline \multirow[b]{2}{*}{ Turbidez (uT) } & \multirow[b]{2}{*}{$\begin{array}{c}\text { Cor Aparente } \\
\text { (uC) }\end{array}$} & \multirow{2}{*}{$\begin{array}{c}\text { Cor Verdadeira } \\
\text { (uC) }\end{array}$} & \multirow[b]{2}{*}{$\begin{array}{l}\text { Alcalinidade Total } \\
\left(\mathrm{mg} / \mathrm{\ell} \mathrm{CaCO}_{3}\right)\end{array}$} & \multicolumn{2}{|c|}{ pH } & \multirow[b]{2}{*}{$\begin{array}{c}\text { Temperatura } \\
{ }^{\circ} \mathrm{C}\end{array}$} & \multirow[b]{2}{*}{$\begin{array}{l}\text { Potencial } \\
\text { Zeta (mV) }\end{array}$} \\
\hline & & & & S/Agit. & C/Agit. & & \\
\hline 6.22 & 147 & 102 & 30 & 7.92 & 7.58 & 25 & - \\
\hline
\end{tabular}

\begin{tabular}{|c|c|c|c|c|c|c|}
\hline \multirow[b]{2}{*}{ FRASCO } & \multicolumn{3}{|c|}{ DOSAGEM DE PRODUTO QUÍMICO } & \multirow{2}{*}{$\begin{array}{c}\text { pH de } \\
\text { Coagulação }\end{array}$} & \multirow{2}{*}{$\begin{array}{c}\mathrm{T}_{\mathrm{s} 2}=7,00 \mathrm{~min} \\
\mathrm{~V}_{\mathrm{s} 2}=1.0 \mathrm{~cm} / \mathrm{min} \\
\begin{array}{c}\mathrm{Cor} \\
(\mathrm{uC})\end{array}\end{array}$} & \multirow{2}{*}{$\begin{array}{c}\mathrm{T}_{\mathrm{s} 1}=3,50 \mathrm{~min} \\
\mathrm{~V}_{\mathrm{s} 1}=2.0 \mathrm{~cm} / \mathrm{min} \\
\begin{array}{c}\mathrm{Cor} \\
(\mathrm{uC})\end{array}\end{array}$} \\
\hline & $\begin{array}{c}\text { Sulfato de } \\
\text { Alumínio }(\mathrm{mg} / \mathfrak{l})\end{array}$ & $\begin{array}{c}\text { Ácido } \\
\text { Clorídrico } \\
0.1 \mathrm{~N}(\mathrm{~m} \ell / \ell)\end{array}$ & $\begin{array}{c}\text { Hidróxido de } \\
\text { Sódio 0,1N } \\
(\mathrm{ml} / \mathrm{l})\end{array}$ & & & \\
\hline 1 & 80 & 1.82 & - & 6.03 & 140 & 140 \\
\hline 2 & 80 & - & - & 6.22 & 59 & 98 \\
\hline 3 & 80 & - & 2.0 & 6.38 & 47 & 71 \\
\hline 4 & 80 & - & 4.0 & 6.59 & 57 & 97 \\
\hline 5 & 80 & - & 6.0 & 6.74 & 51 & 118 \\
\hline 6 & 80 & - & 8.0 & 6.91 & 57 & 83 \\
\hline
\end{tabular}

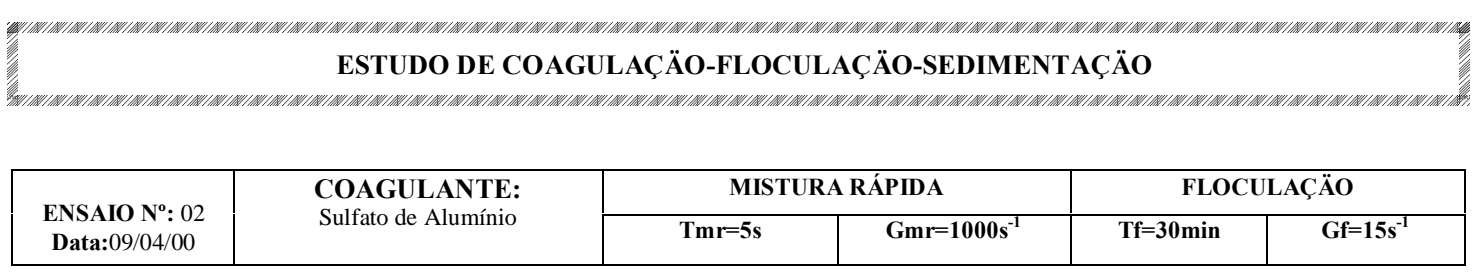

\begin{tabular}{|c|c|c|c|c|c|c|c|}
\hline \multicolumn{8}{|c|}{ CARACTERÍSTICAS DA ÁGUA DE ESTUDO } \\
\hline \multirow[b]{2}{*}{ Turbidez (uT) } & \multirow[b]{2}{*}{$\begin{array}{c}\text { Cor Aparente } \\
\text { (uC) }\end{array}$} & \multirow[b]{2}{*}{$\begin{array}{c}\text { Cor Verdadeira } \\
\text { (uC) }\end{array}$} & \multirow[b]{2}{*}{$\begin{array}{l}\text { Alcalinidade Total } \\
\left(\mathrm{mg} / / \mathrm{CaCO}_{3}\right)\end{array}$} & \multicolumn{2}{|c|}{ pH } & \multirow[b]{2}{*}{$\begin{array}{c}\text { Temperatura } \\
{ }^{\circ} \mathbf{C}\end{array}$} & \multirow[b]{2}{*}{$\begin{array}{r}\text { Potencial } \\
\text { Zeta }(m \mathrm{~V})\end{array}$} \\
\hline & & & & S/Agit. & \begin{tabular}{|l} 
C/Agit. \\
.
\end{tabular} & & \\
\hline 6.22 & 147 & 102 & 30 & 7.92 & 7.58 & 25 & - \\
\hline
\end{tabular}

\begin{tabular}{|c|c|c|c|c|c|c|}
\hline \multirow[b]{2}{*}{ FRASCO } & \multicolumn{3}{|c|}{ DOSAGEM DE PRODUTO QUÍMICO } & \multirow{2}{*}{$\begin{array}{c}\text { pH de } \\
\text { Coagulação }\end{array}$} & \multirow{2}{*}{$\begin{array}{c}T_{\mathrm{s} 2}=7,00 \mathrm{~min} \\
V_{\mathrm{s} 2}=1.0 \mathrm{~cm} / \mathrm{min} \\
\begin{array}{c}\mathrm{Cor} \\
(\mathrm{uC})\end{array}\end{array}$} & \multirow{2}{*}{$\begin{array}{c}T_{\mathrm{s} 1}=3,50 \mathrm{~min} \\
V_{\mathrm{s} 1}=2.0 \mathrm{~cm} / \mathrm{min} \\
\begin{array}{c}\mathrm{Cor} \\
(\mathrm{uC})\end{array}\end{array}$} \\
\hline & $\begin{array}{c}\text { Sulfato de } \\
\text { Alumínio }(\mathrm{mg} / \mathfrak{l})\end{array}$ & $\begin{array}{c}\text { Ácido } \\
\text { Clorídrico } \\
0.1 \mathrm{~N}(\mathrm{~m} \ell / \ell)\end{array}$ & $\begin{array}{c}\text { Hidróxido de } \\
\text { Sódio 0,1N } \\
(\mathrm{ml} / \mathbf{l})\end{array}$ & & & \\
\hline 1 & 80 & - & 10.0 & 7.05 & 23 & 54 \\
\hline 2 & 80 & - & 12.0 & 7.14 & 67 & 110 \\
\hline 3 & 80 & - & 14.0 & 7.50 & 140 & 140 \\
\hline 4 & 80 & - & 16.0 & 7.66 & 139 & 144 \\
\hline 5 & 80 & - & 18.0 & 7.96 & 143 & 142 \\
\hline 6 & 80 & - & 20.0 & 8.25 & 144 & 143 \\
\hline
\end{tabular}


ESTUDO DE COAGULAÇÄO-FLOCULAÇÄO-SEDIMENTAÇÄO

\begin{tabular}{|c|c|c|c|c|c|}
\hline \multirow{2}{*}{$\begin{array}{c}\text { ENSAIO No } \\
\text { Data: } 09 / 04 / 00\end{array}$} & $\begin{array}{c}\text { COAGULANTE: } \\
\text { Sulfato de Alumínio }\end{array}$ & \multicolumn{2}{|c|}{ MISTURA RÁPIDA } & \multicolumn{2}{|c|}{ FLOCULAC̆̈O } \\
\cline { 3 - 5 } & & Tmr=5s & Gmr=1000s & Tf=30min & ${\text { Gf }=\mathbf{1 5} \mathbf{s}^{-1}}^{-1}$ \\
\hline
\end{tabular}

\begin{tabular}{|c|c|c|c|c|c|c|c|}
\hline \multicolumn{8}{|c|}{ CARACTERÍSTICAS DA ÁGUA DE ESTUDO } \\
\hline \multirow[b]{2}{*}{ Turbidez (uT) } & \multirow[b]{2}{*}{$\begin{array}{l}\text { Cor Aparente } \\
\text { (uC) }\end{array}$} & \multirow[b]{2}{*}{$\begin{array}{l}\text { Cor Verdadeira } \\
\text { (uC) }\end{array}$} & \multirow[b]{2}{*}{$\begin{array}{l}\text { Alcalinidade Total } \\
\left(\mathrm{mg} / \mathrm{l} \mathrm{CaCO}_{3}\right)\end{array}$} & \multicolumn{2}{|c|}{ pH } & \multirow[b]{2}{*}{$\begin{array}{c}\text { Temperatura } \\
{ }^{\circ} \mathrm{C}\end{array}$} & \multirow[b]{2}{*}{$\begin{array}{l}\text { Potencial } \\
\text { Zeta (mV) }\end{array}$} \\
\hline & & & & S/Agit. & C/Agit. & & \\
\hline 6.22 & 147 & 102 & 30 & 7.92 & 7.58 & 25 & - \\
\hline
\end{tabular}

\begin{tabular}{|c|c|c|c|c|c|c|}
\hline \multirow[b]{2}{*}{ FRASCO } & \multicolumn{3}{|c|}{ DOSAGEM DE PRODUTO QUÍMICO } & \multirow{2}{*}{$\begin{array}{c}\text { pH de } \\
\text { Coagulação }\end{array}$} & \multirow{2}{*}{$\begin{array}{c}T_{\mathrm{s} 2}=7,00 \mathrm{~min} \\
V_{\mathrm{s} 2}=1.0 \mathrm{~cm} / \mathrm{min} \\
\begin{array}{c}\text { Cor } \\
(\mathrm{uC})\end{array}\end{array}$} & \multirow{2}{*}{$\begin{array}{c}T_{\mathrm{s} 1}=3,50 \mathrm{~min} \\
\mathrm{~V}_{\mathrm{s} 1}=2.0 \mathrm{~cm} / \mathrm{min} \\
\begin{array}{c}\mathrm{Cor} \\
(\mathrm{uC})\end{array}\end{array}$} \\
\hline & $\begin{array}{c}\text { Sulfato de } \\
\text { Alumínio (mg/l) }\end{array}$ & $\begin{array}{c}\text { Ácido } \\
\text { Clorídrico } \\
0.1 \mathrm{~N}(\mathrm{~m} \ell / \ell)\end{array}$ & $\begin{array}{c}\text { Hidróxido de } \\
\text { Sódio 0,1N } \\
(\mathrm{ml} / \mathbf{l})\end{array}$ & & & \\
\hline 1 & 120 & 3.64 & - & 4.84 & - & - \\
\hline 2 & 120 & 1.82 & - & 5.02 & - & - \\
\hline 3 & 120 & - & - & 5.28 & - & - \\
\hline 4 & 120 & - & 2.0 & 5.60 & - & - \\
\hline 5 & 120 & - & 4.0 & 5.82 & - & - \\
\hline 6 & 120 & - & 6.0 & 6.05 & 119 & 130 \\
\hline
\end{tabular}

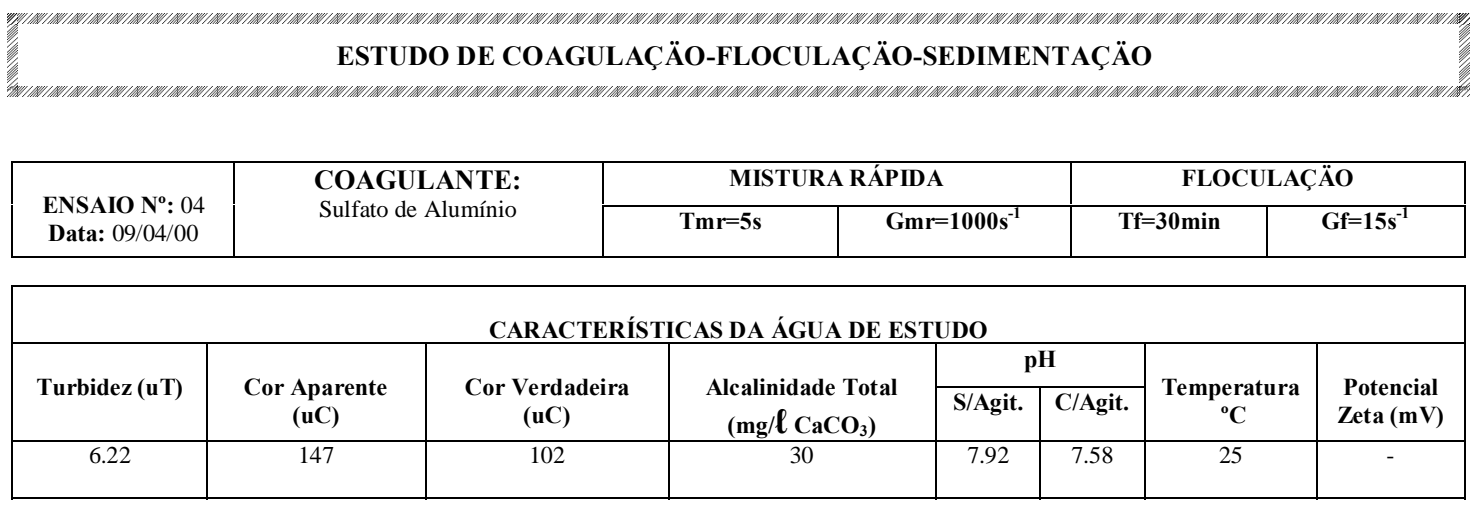

\begin{tabular}{|c|c|c|c|c|c|c|}
\hline \multirow[b]{2}{*}{ FRASCO } & \multicolumn{3}{|c|}{ DOSAGEM DE PRODUTO QUÍMICO } & \multirow{2}{*}{$\begin{array}{c}\mathrm{pH} \mathrm{de} \\
\text { Coagulação }\end{array}$} & \multirow{2}{*}{$\begin{array}{c}\mathrm{T}_{\mathrm{s} 2}=7,00 \mathrm{~min} \\
\mathrm{~V}_{\mathrm{s} 2}=1.0 \mathrm{~cm} / \mathrm{min} \\
\begin{array}{c}\mathrm{Cor} \\
(\mathrm{uC})\end{array}\end{array}$} & \multirow{2}{*}{$\begin{array}{c}\mathrm{T}_{\mathrm{s} 1}=3,50 \mathrm{~min} \\
\mathrm{~V}_{\mathrm{s} 1}=2.0 \mathrm{~cm} / \mathrm{min} \\
\begin{array}{c}\mathrm{Cor} \\
(\mathrm{uC})\end{array}\end{array}$} \\
\hline & $\begin{array}{c}\text { Sulfato de } \\
\text { Alumínio }(\mathrm{mg} / \mathfrak{l})\end{array}$ & $\begin{array}{c}\text { Ácido } \\
\text { Clorídrico } \\
0.1 \mathrm{~N}(\mathrm{~m} \ell / \ell)\end{array}$ & $\begin{array}{l}\text { Hidróxido de } \\
\text { Sódio 0,1N } \\
(\mathrm{m} \ell / \ell)\end{array}$ & & & \\
\hline 1 & 120 & - & 8.0 & 6.16 & 65 & 118 \\
\hline 2 & 120 & - & 10.0 & 6.33 & 75 & 118 \\
\hline 3 & 120 & - & 11.0 & 6.42 & 49 & 103 \\
\hline 4 & 120 & - & 10.0 & 6.50 & 71 & 119 \\
\hline 5 & 120 & - & 14.0 & 6.67 & 20 & 51 \\
\hline 6 & 120 & - & 16.0 & 6.79 & 40 & 72 \\
\hline
\end{tabular}




\section{ESTUDO DE COAGULAÇÄO-FLOCULAÇÄO-SEDIMENTAÇÄO}

\begin{tabular}{|c|c|c|c|c|c|}
\hline \multirow{2}{*}{$\begin{array}{c}\text { ENSAIO No } \\
\text { Data: } 05 / 04 / 00\end{array}$} & $\begin{array}{c}\text { COAGULANTE: } \\
\text { Sulfato de Alumínio }\end{array}$ & \multicolumn{2}{|c|}{ MISTURA RÁPIDA } & \multicolumn{2}{|c|}{ FLOCULAÇO } \\
\cline { 3 - 5 } & & Tmr=5s & Gmr=1000s & Tf=30min & Gf $=\mathbf{1 5 5}^{-1}$ \\
\hline
\end{tabular}

\begin{tabular}{|c|c|c|c|c|c|c|c|}
\hline \multicolumn{8}{|c|}{ CARACTERÍSTICAS DA ÁGUA DE ESTUDO } \\
\hline \multirow[b]{2}{*}{ Turbidez (uT) } & \multirow[b]{2}{*}{$\begin{array}{l}\text { Cor Aparente } \\
\text { (uC) }\end{array}$} & \multirow[b]{2}{*}{$\begin{array}{l}\text { Cor Verdadeira } \\
\text { (uC) }\end{array}$} & \multirow[b]{2}{*}{$\begin{array}{l}\text { Alcalinidade Total } \\
\left(\mathrm{mg} / \mathrm{l} \mathrm{CaCO}_{3}\right)\end{array}$} & \multicolumn{2}{|c|}{ pH } & \multirow[b]{2}{*}{$\begin{array}{c}\text { Temperatura } \\
{ }^{\circ} \mathrm{C}\end{array}$} & \multirow[b]{2}{*}{$\begin{array}{l}\text { Potencial } \\
\text { Zeta (mV) }\end{array}$} \\
\hline & & & & S/Agit. & C/Agit. & & \\
\hline 6.22 & 147 & 102 & 30 & 7.92 & 7.58 & 25 & - \\
\hline
\end{tabular}

\begin{tabular}{|c|c|c|c|c|c|c|}
\hline \multirow[b]{2}{*}{ FRASCO } & \multicolumn{3}{|c|}{ DOSAGEM DE PRODUTO QUÍMICO } & \multirow{2}{*}{$\begin{array}{c}\text { pH de } \\
\text { Coagulação }\end{array}$} & \multirow{2}{*}{$\begin{array}{c}\mathrm{T}_{\mathrm{s} 2}=7,00 \mathrm{~min} \\
\mathrm{~V}_{\mathrm{s} 2}=1.0 \mathrm{~cm} / \mathrm{min} \\
\begin{array}{c}\mathrm{Cor} \\
(\mathrm{uC})\end{array}\end{array}$} & \multirow{2}{*}{$\begin{array}{c}\mathrm{T}_{\mathrm{s} 1}=3,50 \mathrm{~min} \\
\mathrm{~V}_{\mathrm{s} 1}=2.0 \mathrm{~cm} / \mathrm{min} \\
\begin{array}{c}\mathrm{Cor} \\
(\mathrm{uC})\end{array}\end{array}$} \\
\hline & $\begin{array}{c}\text { Sulfato de } \\
\text { Alumínio }(\mathrm{mg} / \mathfrak{l})\end{array}$ & $\begin{array}{c}\text { Ácido } \\
\text { Clorídrico } \\
0.1 \mathrm{~N}(\mathrm{~m} \ell / \ell)\end{array}$ & $\begin{array}{c}\text { Hidróxido de } \\
\text { Sódio 0,1N } \\
(\mathrm{ml} / \mathbf{l})\end{array}$ & & & \\
\hline 1 & 160 & - & - & 4.59 & - & - \\
\hline 2 & 160 & - & 2.0 & 4.73 & - & - \\
\hline 3 & 160 & - & 4.0 & 4.87 & - & - \\
\hline 4 & 160 & - & 6.0 & 5.16 & - & - \\
\hline 5 & 160 & - & 18.0 & 6.86 & 22 & 50 \\
\hline 6 & 160 & - & 20.0 & 7.09 & 79 & 95 \\
\hline
\end{tabular}

\begin{tabular}{|c|c|c|c|c|c|c|c|c|}
\hline \multirow{2}{*}{$\begin{array}{l}\text { ENSAIO No: } 06 \\
\text { Data: } 09 / 04 / 00\end{array}$} & \multirow{2}{*}{\multicolumn{2}{|c|}{$\begin{array}{l}\text { COAGULANTE: } \\
\text { Sulfato de Alumínio }\end{array}$}} & \multicolumn{3}{|c|}{ MISTURA RÁPIDA } & \multicolumn{3}{|c|}{ FLOCULAÇÄO } \\
\hline & & & Tmr $=5 \mathrm{~s}$ & \multicolumn{2}{|c|}{ Gmr $=1000 s^{-1}$} & \multicolumn{2}{|c|}{ Tf=30min } & Gf $=15 s^{-1}$ \\
\hline \multicolumn{9}{|c|}{ CARACTERÍSTICAS DA ÁGUA DE ESTUDO } \\
\hline \multirow{2}{*}{ Turbidez (uT) } & \multirow[b]{2}{*}{$\begin{array}{l}\text { Cor Aparente } \\
\text { (uC) }\end{array}$} & \multirow{2}{*}{$\begin{array}{c}\text { Cor Verdadeira } \\
(\mathrm{uC})\end{array}$} & \multirow{2}{*}{\multicolumn{2}{|c|}{$\begin{array}{c}\text { Alcalinidade Total } \\
\left(\mathrm{mg} / \ell \mathrm{CaCO}_{3}\right) \\
\end{array}$}} & \multicolumn{2}{|c|}{ pH } & \multirow[b]{2}{*}{$\mid \begin{array}{c}\text { Temperatura } \\
{ }^{\circ} \mathbf{C}\end{array}$} & \multirow[b]{2}{*}{$\begin{array}{l}\text { Potencial } \\
\text { Zeta (mV) }\end{array}$} \\
\hline & & & & & S/Agit. & \begin{tabular}{|l} 
C/Agit. \\
\end{tabular} & & \\
\hline 6.22 & 147 & 102 & \multicolumn{2}{|c|}{30} & 7.92 & 7.58 & 25 & - \\
\hline
\end{tabular}

\begin{tabular}{|c|c|c|c|c|c|c|}
\hline \multirow[b]{2}{*}{ FRASCO } & \multicolumn{3}{|c|}{ DOSAGEM DE PRODUTO QUÍMICO } & \multirow{2}{*}{$\begin{array}{c}\text { pH de } \\
\text { Coagulação }\end{array}$} & \multirow{2}{*}{$\begin{array}{c}\mathrm{T}_{\mathrm{s} 2}=7,00 \mathrm{~min} \\
\mathrm{~V}_{\mathrm{s} 2}=1.0 \mathrm{~cm} / \mathrm{min} \\
\begin{array}{c}\mathrm{Cor} \\
(\mathrm{uC})\end{array}\end{array}$} & \multirow{2}{*}{$\begin{array}{c}\mathrm{T}_{\mathrm{s} 1}=3,50 \mathrm{~min} \\
\mathrm{~V}_{\mathrm{s} 1}=2.0 \mathrm{~cm} / \mathrm{min} \\
\begin{array}{c}\mathrm{Cor} \\
(\mathrm{uC})\end{array}\end{array}$} \\
\hline & $\begin{array}{c}\text { Sulfato de } \\
\text { Alumínio }(\mathrm{mg} / \mathfrak{l})\end{array}$ & $\begin{array}{c}\text { Ácido } \\
\text { Clorídrico } \\
0.1 \mathrm{~N}(\mathrm{~m} \ell / \ell)\end{array}$ & $\begin{array}{l}\text { Hidróxido de } \\
\text { Sódio 0,1N } \\
(\mathrm{m} \ell / \ell)\end{array}$ & & & \\
\hline 1 & 160 & - & 10.0 & 5.70 & - & - \\
\hline 2 & 160 & - & 12.0 & 5.91 & - & - \\
\hline 3 & 160 & - & 14.0 & 6.09 & 94 & 121 \\
\hline 4 & 160 & - & 13.0 & 6.49 & 68 & 90 \\
\hline 5 & 160 & - & 15.0 & 6.67 & 38 & 60 \\
\hline 6 & 160 & & 17.0 & 6.89 & 26 & 65 \\
\hline
\end{tabular}




\section{ESTUDO DE COAGULAÇÄO-FLOCULAÇÄO-SEDIMENTAÇÄO}

\begin{tabular}{|c|c|c|c|c|c|}
\hline \multirow{2}{*}{$\begin{array}{c}\text { ENSAIO No } \\
\text { Data: }: 12 / 04 / 00\end{array}$} & $\begin{array}{c}\text { COAGULANTE: } \\
\text { Sulfato de Alumínio }\end{array}$ & \multicolumn{2}{|c|}{ MISTURA RÁPIDA } & \multicolumn{2}{|c|}{ FLOCULAÇO } \\
\cline { 3 - 5 } & & Tmr=5s & Gmr=1000s & Tf=30min & Gf $=\mathbf{1 5 5}^{-1}$ \\
\hline
\end{tabular}

\begin{tabular}{|c|c|c|c|c|c|c|c|}
\hline \multicolumn{8}{|c|}{ CARACTERÍSTICAS DA ÁGUA DE ESTUDO } \\
\hline \multirow[b]{2}{*}{ Turbidez (uT) } & \multirow[b]{2}{*}{$\begin{array}{l}\text { Cor Aparente } \\
\text { (uC) }\end{array}$} & \multirow[b]{2}{*}{$\begin{array}{l}\text { Cor Verdadeira } \\
\text { (uC) }\end{array}$} & \multirow[b]{2}{*}{$\begin{array}{l}\text { Alcalinidade Total } \\
\left(\mathrm{mg} / \mathrm{l} \mathrm{CaCO}_{3}\right)\end{array}$} & \multicolumn{2}{|c|}{ pH } & \multirow[b]{2}{*}{$\begin{array}{c}\text { Temperatura } \\
{ }^{\circ} \mathrm{C}\end{array}$} & \multirow[b]{2}{*}{$\begin{array}{l}\text { Potencial } \\
\text { Zeta (mV) }\end{array}$} \\
\hline & & & & S/Agit. & C/Agit. & & \\
\hline 6.03 & 140 & 104 & 30 & 7.85 & 7.47 & 25 & - \\
\hline
\end{tabular}

\begin{tabular}{|c|c|c|c|c|c|c|}
\hline \multirow[b]{2}{*}{ FRASCO } & \multicolumn{3}{|c|}{ DOSAGEM DE PRODUTO QUÍMICO } & \multirow{2}{*}{$\begin{array}{c}\text { pH de } \\
\text { Coagulação }\end{array}$} & \multirow{2}{*}{$\begin{array}{c}\mathrm{T}_{\mathrm{s} 2}=7,00 \mathrm{~min} \\
\mathrm{~V}_{\mathrm{s} 2}=1.0 \mathrm{~cm} / \mathrm{min} \\
\begin{array}{c}\mathrm{Cor} \\
(\mathrm{uC})\end{array}\end{array}$} & \multirow{2}{*}{$\begin{array}{c}\mathrm{T}_{\mathrm{s} 1}=3,50 \mathrm{~min} \\
\mathrm{~V}_{\mathrm{s} 1}=2.0 \mathrm{~cm} / \mathrm{min} \\
\begin{array}{c}\mathrm{Cor} \\
(\mathrm{uC})\end{array}\end{array}$} \\
\hline & $\begin{array}{c}\text { Sulfato de } \\
\text { Alumínio }(\mathrm{mg} / \mathfrak{l})\end{array}$ & $\begin{array}{c}\text { Ácido } \\
\text { Clorídrico } \\
0.1 \mathrm{~N}(\mathrm{~m} \ell / \ell)\end{array}$ & $\begin{array}{c}\text { Hidróxido de } \\
\text { Sódio 0,1N } \\
(\mathrm{ml} / \mathbf{l})\end{array}$ & & & \\
\hline 1 & 160 & - & 16.0 & 6.22 & 61 & 118 \\
\hline 2 & 160 & - & 18.0 & 6.36 & 34 & 98 \\
\hline 3 & 160 & - & 20.0 & 6.53 & 33 & 95 \\
\hline 4 & 160 & - & 22.0 & 6.70 & 24 & 99 \\
\hline 5 & 160 & - & 28.0 & 7.61 & 143 & 144 \\
\hline 6 & 120 & - & 22.0 & 7.52 & 146 & 147 \\
\hline
\end{tabular}

\begin{tabular}{|c|c|c|c|c|c|c|c|c|}
\hline \multirow{2}{*}{$\begin{array}{l}\text { ENSAIO No: } 08 \\
\text { Data: } 12 / 04 / 00\end{array}$} & \multirow{2}{*}{\multicolumn{2}{|c|}{$\begin{array}{l}\text { COAGULANTE: } \\
\text { Sulfato de Alumínio }\end{array}$}} & \multicolumn{3}{|c|}{ MISTURA RÁPIDA } & \multicolumn{3}{|c|}{ FLOCULAÇÄO } \\
\hline & & & Tmr $=5 \mathrm{~s}$ & \multicolumn{2}{|c|}{ Gmr $=1000 s^{-1}$} & \multicolumn{2}{|c|}{$\mathrm{Tf}=\mathbf{3 0} \mathrm{min}$} & Gf $=15 s^{-1}$ \\
\hline \multicolumn{9}{|c|}{ CARACTERÍSTICAS DA ÁGUA DE ESTUDO } \\
\hline \multirow{2}{*}{ Turbidez (uT) } & \multirow[b]{2}{*}{$\begin{array}{l}\text { Cor Aparente } \\
\text { (uC) }\end{array}$} & \multirow{2}{*}{$\begin{array}{c}\text { Cor Verdadeira } \\
\text { (uC) }\end{array}$} & \multirow{2}{*}{\multicolumn{2}{|c|}{$\begin{array}{c}\text { Alcalinidade Total } \\
\left(\mathrm{mg} / \ell \mathrm{CaCO}_{3}\right) \\
\end{array}$}} & \multicolumn{2}{|c|}{ pH } & \multirow[b]{2}{*}{$\underset{{ }^{\circ} \mathrm{C}}{\text { Temperatura }}$} & \multirow[b]{2}{*}{$\begin{array}{l}\text { Potencial } \\
\text { Zeta (mV) }\end{array}$} \\
\hline & & & & & S/Agit. & \begin{tabular}{|l|} 
C/Agit. \\
\end{tabular} & & \\
\hline 6.03 & 140 & 104 & \multicolumn{2}{|c|}{30} & 7.85 & 7.47 & 25 & - \\
\hline
\end{tabular}

\begin{tabular}{|c|c|c|c|c|c|c|}
\hline \multirow[b]{2}{*}{ FRASCO } & \multicolumn{3}{|c|}{ DOSAGEM DE PRODUTO QUÍMICO } & \multirow{2}{*}{$\begin{array}{c}\text { pH de } \\
\text { Coagulação }\end{array}$} & \multirow{2}{*}{$\begin{array}{c}\mathrm{T}_{\mathrm{s} 2}=7,00 \mathrm{~min} \\
\mathrm{~V}_{\mathrm{s} 2}=1.0 \mathrm{~cm} / \mathrm{min} \\
\begin{array}{c}\mathrm{Cor} \\
(\mathrm{uC})\end{array}\end{array}$} & \multirow{2}{*}{$\begin{array}{c}\mathrm{T}_{\mathrm{s} 1}=3,50 \mathrm{~min} \\
\mathrm{~V}_{\mathrm{s} 1}=2.0 \mathrm{~cm} / \mathrm{min} \\
\begin{array}{c}\mathrm{Cor} \\
(\mathrm{uC})\end{array}\end{array}$} \\
\hline & $\begin{array}{c}\text { Sulfato de } \\
\text { Alumínio }(\mathrm{mg} / \mathfrak{l})\end{array}$ & $\begin{array}{c}\text { Ácido } \\
\text { Clorídrico } \\
0.1 \mathrm{~N}(\mathrm{~m} \ell / \ell)\end{array}$ & $\begin{array}{l}\text { Hidróxido de } \\
\text { Sódio 0,1N } \\
(\mathrm{m} \ell / \ell)\end{array}$ & & & \\
\hline 1 & 320 & - & 48.0 & 6.63 & 22 & 78 \\
\hline 2 & 280 & - & 42.0 & 6.80 & 17 & 44 \\
\hline 3 & 240 & - & 36.0 & 6.92 & 27 & 70 \\
\hline 4 & 200 & - & 30.0 & 7.03 & 38 & 59 \\
\hline 5 & 160 & - & 24.0 & 7.15 & 41 & 63 \\
\hline 6 & 160 & & 26.0 & 7.39 & 98 & 117 \\
\hline
\end{tabular}


ESTUDO DE COAGULAÇÄO-FLOCULAÇÄO-SEDIMENTAÇÄO

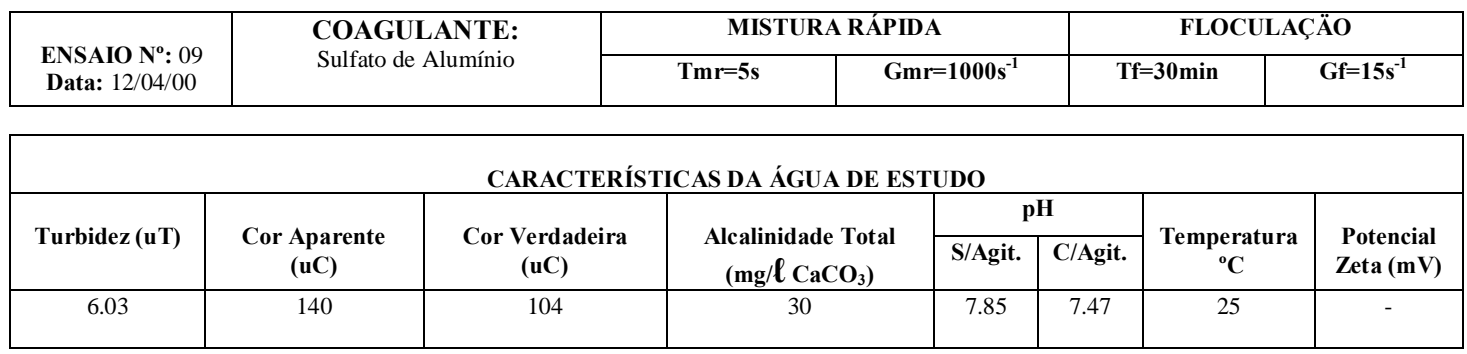

\begin{tabular}{|c|c|c|c|c|c|c|}
\hline \multirow[b]{2}{*}{ FRASCO } & \multicolumn{3}{|c|}{ DOSAGEM DE PRODUTO QUÍMICO } & \multirow{2}{*}{$\begin{array}{c}\text { pH de } \\
\text { Coagulação }\end{array}$} & \multirow{2}{*}{$\begin{array}{c}T_{\mathrm{s} 2}=7,00 \mathrm{~min} \\
V_{\mathrm{s} 2}=1.0 \mathrm{~cm} / \mathrm{min} \\
\begin{array}{c}\mathrm{Cor} \\
(\mathrm{uC})\end{array}\end{array}$} & \multirow{2}{*}{$\begin{aligned} & T_{\mathrm{s} 1}= 3,50 \mathrm{~min} \\
& V_{\mathrm{s} 1}= 2.0 \mathrm{~cm} / \mathrm{min} \\
& \begin{array}{c}\text { Cor } \\
(\mathrm{uC})\end{array}\end{aligned}$} \\
\hline & $\begin{array}{c}\text { Sulfato de } \\
\text { Alumínio }(\mathrm{mg} / \mathfrak{l})\end{array}$ & $\begin{array}{c}\text { Ácido } \\
\text { Clorídrico } \\
0.1 \mathrm{~N}(\mathrm{~m} \ell / \ell)\end{array}$ & $\begin{array}{c}\text { Hidróxido de } \\
\text { Sódio 0,1N } \\
(\mathrm{ml} / \mathrm{l})\end{array}$ & & & \\
\hline 1 & 200 & - & 24.0 & 6.49 & 44 & 99 \\
\hline 2 & 200 & - & 26.0 & 6.57 & 36 & 66 \\
\hline 3 & 200 & - & 28.0 & 6.75 & 38 & 62 \\
\hline 4 & 200 & - & 32.0 & 7.16 & 34 & 55 \\
\hline 5 & 200 & - & 34.0 & 7.54 & - & - \\
\hline 6 & 200 & - & 36.0 & 7.63 & - & - \\
\hline
\end{tabular}

\begin{tabular}{|c|c|c|c|c|c|c|c|c|}
\hline \multirow{2}{*}{$\begin{array}{c}\text { ENSAIO No: } 10 \\
\text { Data: } 12 / 04 / 00\end{array}$} & \multirow{2}{*}{\multicolumn{2}{|c|}{$\begin{array}{l}\text { COAGULANTE: } \\
\text { Sulfato de Alumínio }\end{array}$}} & \multicolumn{3}{|c|}{ MISTURA RÁPIDA } & \multicolumn{3}{|c|}{ FLOCULAÇÄO } \\
\hline & & & Tmr $=5 \mathrm{~s}$ & \multicolumn{2}{|c|}{ Gmr $=1000 s^{-1}$} & \multicolumn{2}{|c|}{$\mathbf{T f}=\mathbf{3 0} \min$} & $\mathbf{G f}=15 \mathrm{~s}^{-1}$ \\
\hline \multicolumn{9}{|c|}{ CARACTERÍSTICAS DA ÁGUA DE ESTUDO } \\
\hline \multirow{2}{*}{ Turbidez (uT) } & \multirow{2}{*}{$\begin{array}{c}\text { Cor Aparente } \\
\text { (uC) }\end{array}$} & \multirow{2}{*}{$\begin{array}{c}\text { Cor Verdadeira } \\
(\mathrm{uC})\end{array}$} & \multirow{2}{*}{\multicolumn{2}{|c|}{$\begin{array}{l}\text { Alcalinidade Total } \\
\left(\mathrm{mg} / \ell / \mathrm{CaCO}_{3}\right)\end{array}$}} & \multicolumn{2}{|c|}{ pH } & \multirow{2}{*}{$\underset{{ }^{\circ} \mathrm{C}}{\text { Temperatur: }}$} & \multirow{2}{*}{$\begin{array}{r}\text { Potencial } \\
\text { Zeta }(\mathrm{mV})\end{array}$} \\
\hline & & & & & S/Agit. & C/Agit. & & \\
\hline 6.03 & 140 & 104 & & & 7.85 & 7.47 & 25 & - \\
\hline
\end{tabular}

\begin{tabular}{|c|c|c|c|c|c|c|}
\hline \multirow[b]{2}{*}{ FRASCO } & \multicolumn{3}{|c|}{ DOSAGEM DE PRODUTO QUÍMICO } & \multirow{2}{*}{$\begin{array}{c}\text { pH de } \\
\text { Coagulação }\end{array}$} & \multirow{2}{*}{$\begin{array}{c}\mathrm{T}_{\mathrm{s} 2}=7,00 \mathrm{~min} \\
\mathrm{~V}_{\mathrm{s} 2}=1.0 \mathrm{~cm} / \mathrm{min} \\
\begin{array}{c}\text { Cor } \\
(\mathrm{uC})\end{array}\end{array}$} & \multirow{2}{*}{$\begin{array}{c}\mathrm{T}_{\mathrm{s} 1}=3,50 \mathrm{~min} \\
\mathrm{~V}_{\mathrm{s} 1}=2.0 \mathrm{~cm} / \mathrm{min} \\
\begin{array}{c}\mathrm{Cor} \\
(\mathrm{uC})\end{array}\end{array}$} \\
\hline & $\begin{array}{c}\text { Sulfato de } \\
\text { Alumínio }(\mathrm{mg} / \mathfrak{l})\end{array}$ & $\begin{array}{c}\text { Ácido } \\
\text { Clorídrico } \\
0.1 \mathrm{~N}(\mathrm{~m} \ell / \ell)\end{array}$ & $\begin{array}{l}\text { Hidróxido de } \\
\text { Sódio 0,1N } \\
(\mathrm{m} \ell / \ell)\end{array}$ & & & \\
\hline 1 & 200 & - & 22.0 & 6.27 & 48 & 96 \\
\hline 2 & 240 & - & 28.0 & 6.20 & 49 & 77 \\
\hline 3 & 240 & - & 30.0 & 6.33 & 28 & 78 \\
\hline 4 & 240 & - & 32.0 & 6.48 & 33 & 49 \\
\hline 5 & 240 & - & 34.0 & 6.62 & 22 & 57 \\
\hline 6 & 240 & - & 38.0 & 6.92 & 26 & 50 \\
\hline
\end{tabular}


ESTUDO DE COAGULAÇÄO-FLOCULAÇÄO-SEDIMENTAÇÄO

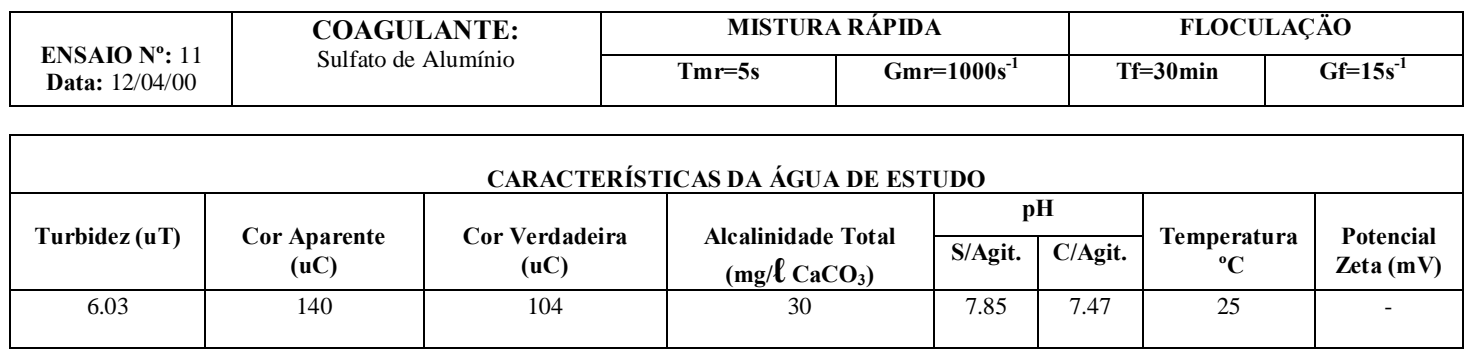

\begin{tabular}{|c|c|c|c|c|c|c|}
\hline \multirow[b]{2}{*}{ FRASCO } & \multicolumn{3}{|c|}{ DOSAGEM DE PRODUTO QUÍMICO } & \multirow{2}{*}{$\begin{array}{c}\text { pH de } \\
\text { Coagulação }\end{array}$} & \multirow{2}{*}{$\begin{array}{c}T_{\mathrm{s} 2}=7,00 \mathrm{~min} \\
V_{\mathrm{s} 2}=1.0 \mathrm{~cm} / \mathrm{min} \\
\begin{array}{c}\mathrm{Cor} \\
(\mathrm{uC})\end{array}\end{array}$} & \multirow{2}{*}{$\begin{aligned} & T_{\mathrm{s} 1}= 3,50 \mathrm{~min} \\
& V_{\mathrm{s} 1}= 2.0 \mathrm{~cm} / \mathrm{min} \\
& \begin{array}{c}\text { Cor } \\
(\mathrm{uC})\end{array}\end{aligned}$} \\
\hline & $\begin{array}{c}\text { Sulfato de } \\
\text { Alumínio }(\mathrm{mg} / \mathfrak{l})\end{array}$ & $\begin{array}{c}\text { Ácido } \\
\text { Clorídrico } \\
0.1 \mathrm{~N}(\mathrm{~m} \ell / \ell)\end{array}$ & $\begin{array}{c}\text { Hidróxido de } \\
\text { Sódio 0,1N } \\
(\mathrm{ml} / \mathrm{l})\end{array}$ & & & \\
\hline 1 & 200 & - & 20.0 & 6.06 & 57 & 117 \\
\hline 2 & 240 & - & 26.0 & 6.04 & 53 & 143 \\
\hline 3 & 280 & - & 38.0 & 6.41 & 33 & 41 \\
\hline 4 & 280 & - & 40.0 & 6.57 & 28 & 43 \\
\hline 5 & 280 & - & 44.0 & 6.79 & 22 & 49 \\
\hline 6 & 240 & - & 40.0 & 7.12 & 22 & 44 \\
\hline
\end{tabular}

\begin{tabular}{|c|c|c|c|c|c|c|c|c|}
\hline \multirow{2}{*}{$\begin{array}{c}\text { ENSAIO No: } 12 \\
\text { Data: } 12 / 04 / 00\end{array}$} & \multirow{2}{*}{\multicolumn{2}{|c|}{$\begin{array}{l}\text { COAGULANTE: } \\
\text { Sulfato de Alumínio }\end{array}$}} & \multicolumn{3}{|c|}{ MISTURA RÁPIDA } & \multicolumn{3}{|c|}{ FLOCULAÇÄO } \\
\hline & & & Tmr $=5 \mathrm{~s}$ & \multicolumn{2}{|c|}{ Gmr $=1000 s^{-1}$} & \multicolumn{2}{|c|}{$\mathbf{T f}=\mathbf{3 0} \min$} & Gf $=15 \mathrm{~s}^{-1}$ \\
\hline \multicolumn{9}{|c|}{ CARACTERÍSTICAS DA ÁGUA DE ESTUDO } \\
\hline \multirow{2}{*}{ Turbidez (uT) } & \multirow{2}{*}{$\begin{array}{c}\text { Cor Aparente } \\
\text { (uC) }\end{array}$} & \multirow{2}{*}{$\begin{array}{c}\text { Cor Verdadeira } \\
\text { (uC) }\end{array}$} & \multirow{2}{*}{\multicolumn{2}{|c|}{$\begin{array}{l}\text { Alcalinidade Total } \\
\left(\mathrm{mg} / \ell / \mathrm{CaCO}_{3}\right)\end{array}$}} & \multicolumn{2}{|c|}{ pH } & \multirow{2}{*}{$\underset{{ }^{\circ} \mathrm{C}}{\text { Temperatur }}$} & \multirow{2}{*}{$\begin{array}{r}\text { Potencial } \\
\text { Zeta }(\mathrm{mV})\end{array}$} \\
\hline & & & & & S/Agit. & C/Agit. & & \\
\hline 6.03 & 140 & 104 & & & 7.85 & 7.47 & 25 & - \\
\hline
\end{tabular}

\begin{tabular}{|c|c|c|c|c|c|c|}
\hline \multirow[b]{2}{*}{ FRASCO } & \multicolumn{3}{|c|}{ DOSAGEM DE PRODUTO QUÍMICO } & \multirow{2}{*}{$\begin{array}{c}\text { pH de } \\
\text { Coagulação }\end{array}$} & \multirow{2}{*}{$\begin{array}{c}\mathrm{T}_{\mathrm{s} 2}=7,00 \mathrm{~min} \\
\mathrm{~V}_{\mathrm{s} 2}=1.0 \mathrm{~cm} / \mathrm{min} \\
\begin{array}{c}\mathrm{Cor} \\
(\mathrm{uC})\end{array}\end{array}$} & \multirow{2}{*}{$\begin{array}{c}\mathrm{T}_{\mathrm{s} 1}=3,50 \mathrm{~min} \\
\mathrm{~V}_{\mathrm{s} 1}=2.0 \mathrm{~cm} / \mathrm{min} \\
\begin{array}{c}\mathrm{Cor} \\
(\mathrm{uC})\end{array}\end{array}$} \\
\hline & $\begin{array}{c}\text { Sulfato de } \\
\text { Alumínio }(\mathrm{mg} / \mathfrak{l})\end{array}$ & $\begin{array}{c}\text { Ácido } \\
\text { Clorídrico } \\
0.1 \mathrm{~N}(\mathrm{~m} \ell / \ell)\end{array}$ & $\begin{array}{c}\text { Hidróxido de } \\
\text { Sódio 0,1N } \\
(\mathrm{m} \ell / \ell)\end{array}$ & & & \\
\hline 1 & 240 & - & 24.0 & 5.81 & 69 & 118 \\
\hline 2 & 200 & - & 18.0 & 5.95 & 83 & 127 \\
\hline 3 & 280 & - & 34.0 & 6.12 & 40 & 65 \\
\hline 4 & 280 & - & 36.0 & 6.26 & 18 & 54 \\
\hline 5 & 280 & - & 46.0 & 6.96 & 18 & 33 \\
\hline 6 & 240 & - & 42.0 & 7.28 & - & - \\
\hline
\end{tabular}


ESTUDO DE COAGULAÇÄO-FLOCULAÇÄO-SEDIMENTAÇÄO

\begin{tabular}{|c|c|c|c|c|c|}
\hline \multirow{2}{*}{$\begin{array}{c}\text { ENSAIO No } \\
\text { Data: }: 12 / 04 / 00\end{array}$} & $\begin{array}{c}\text { COAGULANTE: } \\
\text { Sulfato de Alumínio }\end{array}$ & \multicolumn{2}{|c|}{ MISTURA RÁPIDA } & \multicolumn{2}{|c|}{ FLOCULAÇÖO } \\
\cline { 3 - 5 } & & Tmr=5s & Gmr=1000s & Tf=30min & ${\text { Gf }=\mathbf{1 5} \mathbf{s}^{-1}}^{-1}$ \\
\hline
\end{tabular}

\begin{tabular}{|c|c|c|c|c|c|c|c|}
\hline \multicolumn{8}{|c|}{ CARACTERÍSTICAS DA ÁGUA DE ESTUDO } \\
\hline \multirow[b]{2}{*}{ Turbidez (uT) } & \multirow[b]{2}{*}{$\begin{array}{l}\text { Cor Aparente } \\
\text { (uC) }\end{array}$} & \multirow[b]{2}{*}{$\begin{array}{c}\text { Cor Verdadeira } \\
(\mathrm{uC})\end{array}$} & \multirow[b]{2}{*}{$\begin{array}{l}\text { Alcalinidade Total } \\
\left(\mathrm{mg} / \mathrm{l} \mathrm{CaCO}_{3}\right)\end{array}$} & \multicolumn{2}{|c|}{ pH } & \multirow[b]{2}{*}{$\begin{array}{c}\text { Temperatura } \\
{ }^{\circ} \mathrm{C}\end{array}$} & \multirow[b]{2}{*}{$\begin{array}{l}\text { Potencial } \\
\text { Zeta }(\mathrm{mV})\end{array}$} \\
\hline & & & & S/Agit. & C/Agit. & & \\
\hline 6.03 & 140 & 104 & 30 & 7.85 & 7.47 & 25 & - \\
\hline
\end{tabular}

\begin{tabular}{|c|c|c|c|c|c|c|}
\hline \multirow[b]{2}{*}{ FRASCO } & \multicolumn{3}{|c|}{ DOSAGEM DE PRODUTO QUÍMICO } & \multirow{2}{*}{$\begin{array}{c}\text { pH de } \\
\text { Coagulação }\end{array}$} & \multirow{2}{*}{$\begin{array}{c}\mathrm{T}_{\mathrm{s} 2}=7,00 \mathrm{~min} \\
\mathrm{~V}_{\mathrm{s} 2}=1.0 \mathrm{~cm} / \mathrm{min} \\
\begin{array}{c}\mathrm{Cor} \\
(\mathrm{uC})\end{array}\end{array}$} & \multirow{2}{*}{$\begin{array}{c}\mathrm{T}_{\mathrm{s} 1}=3,50 \mathrm{~min} \\
\mathrm{~V}_{\mathrm{s} 1}=2.0 \mathrm{~cm} / \mathrm{min} \\
\begin{array}{c}\mathrm{Cor} \\
(\mathrm{uC})\end{array}\end{array}$} \\
\hline & $\begin{array}{c}\text { Sulfato de } \\
\text { Alumínio }(\mathrm{mg} / \mathfrak{l})\end{array}$ & $\begin{array}{c}\text { Ácido } \\
\text { Clorídrico } \\
0.1 \mathrm{~N}(\mathrm{~m} \ell / \ell)\end{array}$ & $\begin{array}{c}\text { Hidróxido de } \\
\text { Sódio 0,1N } \\
(\mathrm{ml} / \mathbf{l})\end{array}$ & & & \\
\hline 1 & 280 & - & 32.0 & 5.90 & 39 & 120 \\
\hline 2 & 320 & - & 46.0 & 6.40 & 19 & 49 \\
\hline 3 & 320 & - & 48.0 & 6.54 & 17 & 40 \\
\hline 4 & 320 & - & 50.0 & 6.73 & 12 & 16 \\
\hline 5 & 320 & - & 52.0 & 6.88 & 13 & 35 \\
\hline 6 & 320 & - & 48.0 & 7.15 & 17 & 37 \\
\hline
\end{tabular}

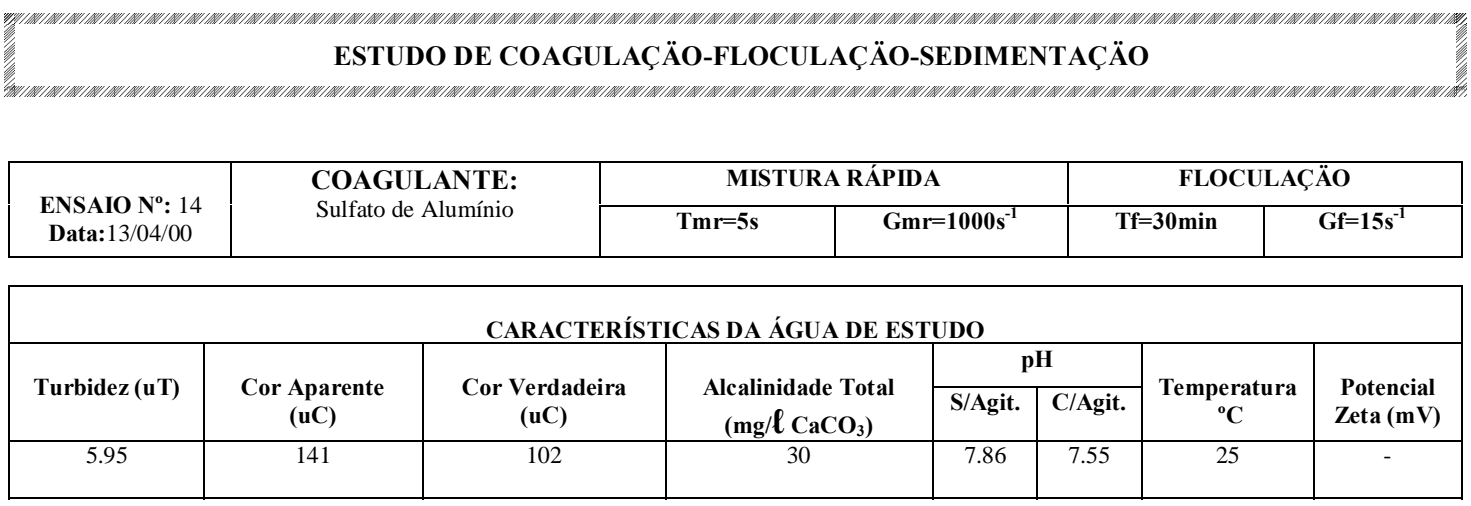

\begin{tabular}{|c|c|c|c|c|c|c|}
\hline \multirow[b]{2}{*}{ FRASCO } & \multicolumn{3}{|c|}{ DOSAGEM DE PRODUTO QUÍMICO } & \multirow{2}{*}{$\begin{array}{c}\text { pH de } \\
\text { Coagulação }\end{array}$} & \multirow{2}{*}{$\begin{array}{c}T_{\mathrm{s} 2}=7,00 \mathrm{~min} \\
V_{\mathrm{s} 2}=1.0 \mathrm{~cm} / \mathrm{min} \\
\begin{array}{c}\text { Cor } \\
(\mathrm{uC})\end{array}\end{array}$} & \multirow{2}{*}{$\begin{array}{c}\mathrm{T}_{\mathrm{s} 1}=3,50 \mathrm{~min} \\
\mathrm{~V}_{\mathrm{s} 1}=2.0 \mathrm{~cm} / \mathrm{min} \\
\begin{array}{c}\mathrm{Cor} \\
(\mathrm{uC})\end{array}\end{array}$} \\
\hline & $\begin{array}{c}\text { Sulfato de } \\
\text { Alumínio }(\mathrm{mg} / \mathfrak{l})\end{array}$ & $\begin{array}{c}\text { Ácido } \\
\text { Clorídrico } \\
0.1 \mathrm{~N}(\mathrm{~m} \ell / \ell)\end{array}$ & $\begin{array}{l}\text { Hidróxido de } \\
\text { Sódio 0,1N } \\
(\mathrm{m} \ell / \ell)\end{array}$ & & & \\
\hline 1 & 100 & - & 4.0 & 6.26 & 32 & 87 \\
\hline 2 & 100 & - & 6.0 & 6.40 & 52 & 65 \\
\hline 3 & 100 & - & 8.0 & 6.60 & 46 & 97 \\
\hline 4 & 100 & - & 10.0 & 6.77 & 50 & 75 \\
\hline 5 & 100 & - & 12.0 & 6.90 & 18 & 48 \\
\hline 6 & 100 & - & 14.0 & 7.10 & 32 & 47 \\
\hline
\end{tabular}




\section{ESTUDO DE COAGULAÇÄO-FLOCULAÇÄO-SEDIMENTAÇÄO}

\begin{tabular}{|c|c|c|c|c|c|}
\hline \multirow{2}{*}{$\begin{array}{c}\text { ENSAIO No } \\
\text { Data: } 13 / 04 / 00\end{array}$} & $\begin{array}{c}\text { COAGULANTE: } \\
\text { Sulfato de Alumínio }\end{array}$ & \multicolumn{2}{|c|}{ MISTURA RÁPIDA } & \multicolumn{2}{|c|}{ FLOCULAC̆O } \\
\cline { 3 - 5 } & & Tmr=5s & Gmr=1000s & Tf=30min & Gf $=\mathbf{1 5 5}^{-1}$ \\
\hline
\end{tabular}

\begin{tabular}{|c|c|c|c|c|c|c|c|}
\hline \multicolumn{8}{|c|}{ CARACTERÍSTICAS DA ÁGUA DE ESTUDO } \\
\hline \multirow[b]{2}{*}{ Turbidez (uT) } & \multirow[b]{2}{*}{$\begin{array}{l}\text { Cor Aparente } \\
\text { (uC) }\end{array}$} & \multirow[b]{2}{*}{$\begin{array}{l}\text { Cor Verdadeira } \\
\text { (uC) }\end{array}$} & \multirow[b]{2}{*}{$\begin{array}{l}\text { Alcalinidade Total } \\
\left(\mathrm{mg} / \mathrm{l} \mathrm{CaCO}_{3}\right)\end{array}$} & \multicolumn{2}{|c|}{ pH } & \multirow[b]{2}{*}{$\begin{array}{c}\text { Temperatura } \\
{ }^{\circ} \mathrm{C}\end{array}$} & \multirow[b]{2}{*}{$\begin{array}{l}\text { Potencial } \\
\text { Zeta (mV) }\end{array}$} \\
\hline & & & & S/Agit. & C/Agit. & & \\
\hline 5.95 & 141 & 102 & 30 & 7.86 & 7.55 & 25 & - \\
\hline
\end{tabular}

\begin{tabular}{|c|c|c|c|c|c|c|}
\hline \multirow[b]{2}{*}{ FRASCO } & \multicolumn{3}{|c|}{ DOSAGEM DE PRODUTO QUÍMICO } & \multirow{2}{*}{$\begin{array}{c}\text { pH de } \\
\text { Coagulação }\end{array}$} & \multirow{2}{*}{$\begin{array}{c}T_{\mathrm{s} 2}=7,00 \mathrm{~min} \\
V_{\mathrm{s} 2}=1.0 \mathrm{~cm} / \mathrm{min} \\
\begin{array}{c}\mathrm{Cor} \\
(\mathrm{uC})\end{array}\end{array}$} & \multirow{2}{*}{$\begin{array}{c}T_{\mathrm{s} 1}=3,50 \mathrm{~min} \\
\mathrm{~V}_{\mathrm{s} 1}=2.0 \mathrm{~cm} / \mathrm{mir} \\
\begin{array}{c}\mathrm{Cor} \\
(\mathrm{uC})\end{array}\end{array}$} \\
\hline & $\begin{array}{c}\text { Sulfato de } \\
\text { Alumínio }(\mathrm{mg} / \mathfrak{l})\end{array}$ & $\begin{array}{c}\text { Ácido } \\
\text { Clorídrico } \\
0.1 \mathrm{~N}(\mathrm{~m} \ell / \ell)\end{array}$ & $\begin{array}{l}\text { Hidróxido de } \\
\text { Sódio 0,1N } \\
(\mathrm{ml} / \mathbf{l})\end{array}$ & & & \\
\hline 1 & 140 & - & 10.0 & 6.09 & 100 & 127 \\
\hline 2 & 140 & - & 12.0 & 6.28 & 74 & 133 \\
\hline 3 & 140 & - & 14.0 & 6.49 & 63 & 68 \\
\hline 4 & 140 & - & 16.0 & 6.66 & 44 & 55 \\
\hline 5 & 140 & - & 18.0 & 6.84 & 20 & 37 \\
\hline 6 & 140 & - & 20.0 & 7.00 & 28 & 33 \\
\hline
\end{tabular}

\begin{tabular}{|c|c|c|c|c|c|c|c|c|}
\hline \multirow{2}{*}{$\begin{array}{l}\text { ENSAIO No }: 16 \\
\text { Data: } 13 / 04 / 00\end{array}$} & \multirow{2}{*}{\multicolumn{2}{|c|}{$\begin{array}{l}\text { COAGULANTE: } \\
\text { Sulfato de Alumínio }\end{array}$}} & \multicolumn{3}{|c|}{ MISTURA RÁPIDA } & \multicolumn{3}{|c|}{ FLOCULAÇÄO } \\
\hline & & & Tmr $=5 \mathrm{~s}$ & \multicolumn{2}{|c|}{ Gmr $=1000 s^{-1}$} & \multicolumn{2}{|c|}{$\mathbf{T f}=\mathbf{3 0} \min$} & Gf $=15 \mathrm{~s}^{-1}$ \\
\hline \multicolumn{9}{|c|}{ CARACTERÍSTICAS DA ÁGUA DE ESTUDO } \\
\hline \multirow{2}{*}{ Turbidez (uT) } & \multirow{2}{*}{$\begin{array}{c}\text { Cor Aparente } \\
\text { (uC) }\end{array}$} & \multirow{2}{*}{$\begin{array}{c}\text { Cor Verdadeira } \\
\text { (uC) }\end{array}$} & \multirow{2}{*}{\multicolumn{2}{|c|}{$\begin{array}{l}\text { Alcalinidade Total } \\
\left(\mathrm{mg} / \ell / \mathrm{CaCO}_{3}\right)\end{array}$}} & \multicolumn{2}{|c|}{ pH } & \multirow{2}{*}{$\underset{{ }^{\circ} \mathrm{C}}{\text { Temperatur: }}$} & \multirow{2}{*}{$\begin{array}{r}\text { Potencial } \\
\text { Zeta }(\mathrm{mV})\end{array}$} \\
\hline & & & & & S/Agit. & C/Agit. & & \\
\hline 5.95 & 141 & 102 & & & 7.86 & 7.55 & 25 & - \\
\hline
\end{tabular}

\begin{tabular}{|c|c|c|c|c|c|c|}
\hline \multirow[b]{2}{*}{ FRASCO } & \multicolumn{3}{|c|}{ DOSAGEM DE PRODUTO QUÍMICO } & \multirow{2}{*}{$\begin{array}{c}\text { pH de } \\
\text { Coagulação }\end{array}$} & \multirow{2}{*}{$\begin{array}{c}\mathrm{T}_{\mathrm{s} 2}=7,00 \mathrm{~min} \\
\mathrm{~V}_{\mathrm{s} 2}=1.0 \mathrm{~cm} / \mathrm{min} \\
\begin{array}{c}\mathrm{Cor} \\
(\mathrm{uC})\end{array}\end{array}$} & \multirow{2}{*}{$\begin{array}{c}\mathrm{T}_{\mathrm{s} 1}=3,50 \mathrm{~min} \\
\mathrm{~V}_{\mathrm{s} 1}=2.0 \mathrm{~cm} / \mathrm{min} \\
\begin{array}{c}\mathrm{Cor} \\
(\mathrm{uC})\end{array}\end{array}$} \\
\hline & $\begin{array}{c}\text { Sulfato de } \\
\text { Alumínio }(\mathrm{mg} / \mathfrak{l})\end{array}$ & $\begin{array}{c}\text { Ácido } \\
\text { Clorídrico } \\
0.1 \mathrm{~N}(\mathrm{~m} \ell / \ell)\end{array}$ & $\begin{array}{c}\text { Hidróxido de } \\
\text { Sódio 0,1N } \\
(\mathrm{ml} / \mathbf{l})\end{array}$ & & & \\
\hline 1 & 100 & - & 2.0 & 6.17 & - & - \\
\hline 2 & 180 & - & 20.0 & 6.52 & 50 & 107 \\
\hline 3 & 180 & - & 26.0 & 7.00 & 25 & 61 \\
\hline 4 & 180 & - & 28.0 & 7.16 & 31 & 59 \\
\hline 5 & 180 & - & 30.0 & 7.35 & 37 & 77 \\
\hline 6 & 100 & - & 16.0 & 7.40 & 99 & 122 \\
\hline
\end{tabular}


ESTUDO DE COAGULAÇÄO-FLOCULAÇÄO-SEDIMENTAÇÄO

\begin{tabular}{|c|c|c|c|c|c|}
\hline \multirow{2}{*}{$\begin{array}{c}\text { ENSAIO No } \\
\text { Data: } 13 / 04 / 00\end{array}$} & $\begin{array}{c}\text { COAGULANTE: } \\
\text { Sulfato de Alumínio }\end{array}$ & \multicolumn{2}{|c|}{ MISTURA RÁPIDA } & \multicolumn{2}{|c|}{ FLOCULAC̆̈O } \\
\cline { 3 - 5 } & & Tmr=5s & Gmr=1000s & Tf=30min & ${\text { Gf }=\mathbf{1 5} \mathbf{s}^{-1}}^{-1}$ \\
\hline
\end{tabular}

\begin{tabular}{|c|c|c|c|c|c|c|c|}
\hline \multicolumn{8}{|c|}{ CARACTERÍSTICAS DA ÁGUA DE ESTUDO } \\
\hline \multirow[b]{2}{*}{ Turbidez (uT) } & \multirow[b]{2}{*}{$\begin{array}{l}\text { Cor Aparente } \\
\text { (uC) }\end{array}$} & \multirow[b]{2}{*}{$\begin{array}{l}\text { Cor Verdadeira } \\
\text { (uC) }\end{array}$} & \multirow[b]{2}{*}{$\begin{array}{l}\text { Alcalinidade Total } \\
\left(\mathrm{mg} / \mathrm{l} \mathrm{CaCO}_{3}\right)\end{array}$} & \multicolumn{2}{|c|}{ pH } & \multirow[b]{2}{*}{$\begin{array}{c}\text { Temperatura } \\
{ }^{\circ} \mathrm{C}\end{array}$} & \multirow[b]{2}{*}{$\begin{array}{l}\text { Potencial } \\
\text { Zeta (mV) }\end{array}$} \\
\hline & & & & S/Agit. & C/Agit. & & \\
\hline 5.95 & 141 & 102 & 30 & 7.86 & 7.55 & 25 & - \\
\hline
\end{tabular}

\begin{tabular}{|c|c|c|c|c|c|c|}
\hline \multirow[b]{2}{*}{ FRASCO } & \multicolumn{3}{|c|}{ DOSAGEM DE PRODUTO QUÍMICO } & \multirow{2}{*}{$\begin{array}{c}\text { pH de } \\
\text { Coagulação }\end{array}$} & \multirow{2}{*}{$\begin{array}{c}\mathrm{T}_{\mathrm{s} 2}=7,00 \mathrm{~min} \\
\mathrm{~V}_{\mathrm{s} 2}=1.0 \mathrm{~cm} / \mathrm{min} \\
\begin{array}{c}\mathrm{Cor} \\
(\mathrm{uC})\end{array}\end{array}$} & \multirow{2}{*}{$\begin{array}{c}T_{\mathrm{s} 1}=3,50 \mathrm{~min} \\
V_{\mathrm{s} 1}=2.0 \mathrm{~cm} / \mathrm{min} \\
\begin{array}{c}\mathrm{Cor} \\
(\mathrm{uC})\end{array}\end{array}$} \\
\hline & $\begin{array}{c}\text { Sulfato de } \\
\text { Alumínio }(\mathrm{mg} / \mathfrak{l})\end{array}$ & $\begin{array}{c}\text { Ácido } \\
\text { Clorídrico } \\
0.1 \mathrm{~N}(\mathrm{~m} \ell / \ell)\end{array}$ & $\begin{array}{c}\text { Hidróxido de } \\
\text { Sódio 0,1N } \\
(\mathrm{ml} / \mathbf{l})\end{array}$ & & & \\
\hline 1 & 180 & - & 18.0 & 6.24 & 70 & 127 \\
\hline 2 & 160 & - & 23.0 & 6.95 & 25 & 38 \\
\hline 3 & 180 & - & 32.0 & 7.48 & - & - \\
\hline 4 & 140 & - & 22.0 & 7.24 & 36 & 52 \\
\hline 5 & 120 & - & 21.0 & 7.48 & - & - \\
\hline 6 & 200 & - & 33.0 & 7.29 & 43 & 79 \\
\hline
\end{tabular}

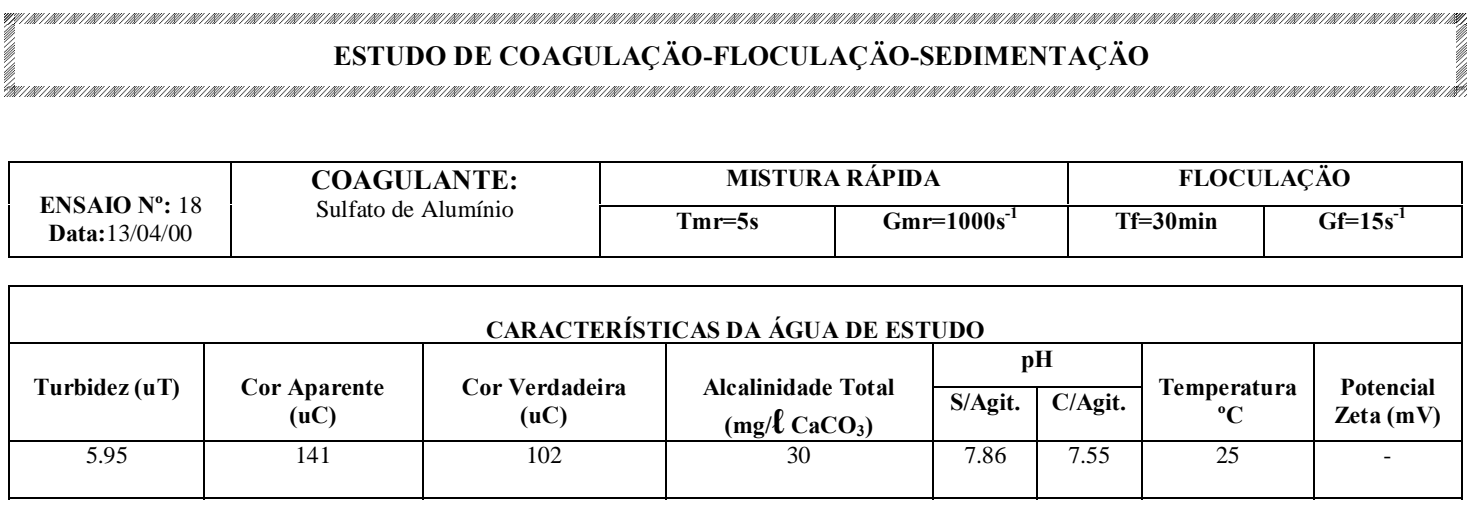

\begin{tabular}{|c|c|c|c|c|c|c|}
\hline \multirow[b]{2}{*}{ FRASCO } & \multicolumn{3}{|c|}{ DOSAGEM DE PRODUTO QUÍMICO } & \multirow{2}{*}{$\begin{array}{c}\text { pH de } \\
\text { Coagulação }\end{array}$} & \multirow{2}{*}{$\begin{array}{c}\mathrm{T}_{\mathrm{s} 2}=7,00 \mathrm{~min} \\
\mathrm{~V}_{\mathrm{s} 2}=1.0 \mathrm{~cm} / \mathrm{min} \\
\begin{array}{c}\mathrm{Cor} \\
(\mathrm{uC})\end{array}\end{array}$} & \multirow{2}{*}{$\begin{array}{c}T_{\mathrm{s} 1}=3,50 \mathrm{~min} \\
\mathrm{~V}_{\mathrm{s} 1}=2.0 \mathrm{~cm} / \mathrm{min} \\
\begin{array}{c}\mathrm{Cor} \\
(\mathrm{uC})\end{array}\end{array}$} \\
\hline & $\begin{array}{c}\text { Sulfato de } \\
\text { Alumínio }(\mathrm{mg} / \mathfrak{l})\end{array}$ & $\begin{array}{c}\text { Ácido } \\
\text { Clorídrico } \\
0.1 \mathrm{~N}(\mathrm{~m} \ell / \ell)\end{array}$ & $\begin{array}{c}\text { Hidróxido de } \\
\text { Sódio 0,1N } \\
(\mathrm{m} \ell / \ell)\end{array}$ & & & \\
\hline 1 & 220 & - & 22.0 & 5.95 & 69 & 137 \\
\hline 2 & 220 & - & 24.0 & 6.07 & 45 & 137 \\
\hline 3 & 220 & - & 26.0 & 6.25 & 38 & 97 \\
\hline 4 & 220 & - & 28.0 & 6.40 & 24 & 87 \\
\hline 5 & 120 & - & 20.5 & 7.32 & - & - \\
\hline 6 & 180 & - & 31.0 & 7.33 & - & - \\
\hline
\end{tabular}


ESTUDO DE COAGULAÇÄO-FLOCULAÇÄO-SEDIMENTAÇÄO

\begin{tabular}{|c|c|c|c|c|c|}
\hline \multirow{2}{*}{$\begin{array}{c}\text { ENSAIO No } \\
\text { Data: } 13 / 04 / 00\end{array}$} & $\begin{array}{c}\text { COAGULANTE: } \\
\text { Sulfato de Alumínio }\end{array}$ & \multicolumn{2}{|c|}{ MISTURA RÁPIDA } & \multicolumn{2}{|c|}{ FLOCULAÇÖO } \\
\cline { 3 - 5 } & & Tmr=5s & Gmr=1000s & Tf=30min & ${\text { Gf }=\mathbf{1 5} \mathbf{s}^{-1}}^{-1}$ \\
\hline
\end{tabular}

\begin{tabular}{|c|c|c|c|c|c|c|c|}
\hline \multicolumn{8}{|c|}{ CARACTERÍSTICAS DA ÁGUA DE ESTUDO } \\
\hline \multirow[b]{2}{*}{ Turbidez (uT) } & \multirow[b]{2}{*}{$\begin{array}{l}\text { Cor Aparente } \\
\text { (uC) }\end{array}$} & \multirow[b]{2}{*}{$\begin{array}{l}\text { Cor Verdadeira } \\
\text { (uC) }\end{array}$} & \multirow[b]{2}{*}{$\begin{array}{l}\text { Alcalinidade Total } \\
\left(\mathrm{mg} / \mathrm{l} \mathrm{CaCO}_{3}\right)\end{array}$} & \multicolumn{2}{|c|}{ pH } & \multirow[b]{2}{*}{$\begin{array}{c}\text { Temperatura } \\
{ }^{\circ} \mathrm{C}\end{array}$} & \multirow[b]{2}{*}{$\begin{array}{l}\text { Potencial } \\
\text { Zeta (mV) }\end{array}$} \\
\hline & & & & S/Agit. & C/Agit. & & \\
\hline 5.95 & 141 & 102 & 30 & 7.86 & 7.55 & 25 & - \\
\hline
\end{tabular}

\begin{tabular}{|c|c|c|c|c|c|c|}
\hline \multirow[b]{2}{*}{ FRASCO } & \multicolumn{3}{|c|}{ DOSAGEM DE PRODUTO QUÍMICO } & \multirow{2}{*}{$\begin{array}{c}\text { pH de } \\
\text { Coagulação }\end{array}$} & \multirow{2}{*}{$\begin{array}{c}\mathrm{T}_{\mathrm{s} 2}=7,00 \mathrm{~min} \\
\mathrm{~V}_{\mathrm{s} 2}=1.0 \mathrm{~cm} / \mathrm{min} \\
\begin{array}{c}\mathrm{Cor} \\
(\mathrm{uC})\end{array}\end{array}$} & \multirow{2}{*}{$\begin{array}{c}T_{\mathrm{s} 1}=3,50 \mathrm{~min} \\
V_{\mathrm{s} 1}=2.0 \mathrm{~cm} / \mathrm{min} \\
\begin{array}{c}\mathrm{Cor} \\
(\mathrm{uC})\end{array}\end{array}$} \\
\hline & $\begin{array}{c}\text { Sulfato de } \\
\text { Alumínio }(\mathrm{mg} / \mathfrak{l})\end{array}$ & $\begin{array}{c}\text { Ácido } \\
\text { Clorídrico } \\
0.1 \mathrm{~N}(\mathrm{~m} \ell / \ell)\end{array}$ & $\begin{array}{c}\text { Hidróxido de } \\
\text { Sódio 0,1N } \\
(\mathrm{ml} / \mathbf{l})\end{array}$ & & & \\
\hline 1 & 260 & - & 32.0 & 6.15 & 32 & 62 \\
\hline 2 & 220 & - & 30.0 & 6.52 & 28 & 51 \\
\hline 3 & 220 & - & 32.0 & 6.73 & 11 & 33 \\
\hline 4 & 220 & - & 34.0 & 6.91 & 27 & 46 \\
\hline 5 & 220 & - & 36.0 & 7.07 & 15 & 42 \\
\hline 6 & 220 & - & 38.0 & 7.28 & 72 & 95 \\
\hline
\end{tabular}

\begin{tabular}{|c|c|c|c|c|c|c|c|c|}
\hline \multirow{2}{*}{$\begin{array}{c}\text { ENSAIO No: } 20 \\
\text { Data: } 13 / 04 / 00\end{array}$} & \multirow{2}{*}{\multicolumn{2}{|c|}{$\begin{array}{l}\text { COAGULANTE: } \\
\text { Sulfato de Alumínio }\end{array}$}} & \multicolumn{3}{|c|}{ MISTURA RÁPIDA } & \multicolumn{3}{|c|}{ FLOCULAÇÄO } \\
\hline & & & $\mathrm{Tmr}=5 \mathrm{~s}$ & \multicolumn{2}{|c|}{ Gmr $=1000 s^{-1}$} & \multicolumn{2}{|c|}{$\mathrm{Tf}=30 \mathrm{~min}$} & $\mathbf{G} \mathbf{G}=15 \mathrm{~s}^{-1}$ \\
\hline \multicolumn{9}{|c|}{ CARACTERÍSTICAS DA ÁGUA DE ESTUDO } \\
\hline \multirow{2}{*}{ Turbidez (uT) } & \multirow[b]{2}{*}{$\begin{array}{l}\text { Cor Aparente } \\
\text { (uC) }\end{array}$} & \multirow[b]{2}{*}{$\begin{array}{c}\text { Cor Verdadeira } \\
(\mathrm{uC})\end{array}$} & \multirow{2}{*}{\multicolumn{2}{|c|}{$\begin{array}{c}\text { Alcalinidade Total } \\
\left(\mathrm{mg} / \mathrm{l}_{\left.\mathrm{CaCO}_{3}\right)}\right.\end{array}$}} & \multicolumn{2}{|c|}{ pH } & \multirow[b]{2}{*}{$\underset{{ }^{\circ} \mathrm{C}}{\text { Temperatura }}$} & \multirow[b]{2}{*}{$\begin{array}{l}\text { Potencial } \\
\text { Zeta (mV) }\end{array}$} \\
\hline & & & & & S/Agit. & C/Agit. & & \\
\hline 5.95 & 141 & 102 & \multicolumn{2}{|c|}{30} & 7.86 & 7.55 & 25 & - \\
\hline
\end{tabular}

\begin{tabular}{|c|c|c|c|c|c|c|}
\hline \multirow[b]{2}{*}{ FRASCO } & \multicolumn{3}{|c|}{ DOSAGEM DE PRODUTO QUÍMICO } & \multirow{2}{*}{$\begin{array}{c}\text { pH de } \\
\text { Coagulação }\end{array}$} & \multirow{2}{*}{$\begin{array}{c}\mathrm{T}_{\mathrm{s} 2}=7,00 \mathrm{~min} \\
\mathrm{~V}_{\mathrm{s} 2}=1.0 \mathrm{~cm} / \mathrm{min} \\
\begin{array}{c}\text { Cor } \\
(\mathrm{uC})\end{array}\end{array}$} & \multirow{2}{*}{$\begin{array}{c}\mathrm{T}_{\mathrm{s} 1}=3,50 \mathrm{~min} \\
\mathrm{~V}_{\mathrm{s} 1}=2.0 \mathrm{~cm} / \mathrm{min} \\
\begin{array}{c}\mathrm{Cor} \\
(\mathrm{uC})\end{array}\end{array}$} \\
\hline & $\begin{array}{c}\text { Sulfato de } \\
\text { Alumínio }(\mathrm{mg} / \mathfrak{l})\end{array}$ & $\begin{array}{c}\text { Ácido } \\
\text { Clorídrico } \\
0.1 \mathrm{~N}(\mathrm{~m} \ell / \ell)\end{array}$ & $\begin{array}{l}\text { Hidróxido de } \\
\text { Sódio 0,1N } \\
(\mathrm{m} \ell / \ell)\end{array}$ & & & \\
\hline 1 & 260 & - & 34.0 & 6.28 & 34 & 70 \\
\hline 2 & 260 & - & 36.0 & 6.46 & 33 & 26 \\
\hline 3 & 260 & - & 38.0 & 6.64 & 32 & 29 \\
\hline 4 & 260 & - & 40.0 & 6.78 & 31 & 41 \\
\hline 5 & 260 & - & 42.0 & 6.98 & 19 & 62 \\
\hline 6 & 260 & - & 44.0 & 7.14 & 29 & 46 \\
\hline
\end{tabular}


ESTUDO DE COAGULAÇÄO-FLOCULAÇÄO-SEDIMENTAÇÄO

\begin{tabular}{|c|c|c|c|c|c|}
\hline \multirow{2}{*}{$\begin{array}{l}\text { ENSAIO N } \mathbf{N}^{\mathbf{0}}: 21 \\
\text { Data: } 13 / 04 / 00\end{array}$} & \multirow{2}{*}{$\begin{array}{l}\text { COAGULANTE: } \\
\text { Sulfato de Alumínio }\end{array}$} & \multicolumn{2}{|c|}{ MISTURA RÁPIDA } & \multicolumn{2}{|c|}{ FLOCULAÇÄO } \\
\hline & & Tmr $=5 \mathrm{~s}$ & Gmr $=1000 \mathrm{~s}^{-1}$ & $\mathrm{Tf}=\mathbf{3 0} \mathrm{min}$ & $G f=15 s^{-1}$ \\
\hline
\end{tabular}

\begin{tabular}{|c|c|c|c|c|c|c|c|}
\hline \multicolumn{8}{|c|}{ CARACTERÍSTICAS DA ÁGUA DE ESTUDO } \\
\hline \multirow[b]{2}{*}{ Turbidez (uT) } & \multirow[b]{2}{*}{$\begin{array}{l}\text { Cor Aparente } \\
\text { (uC) }\end{array}$} & \multirow[b]{2}{*}{$\begin{array}{l}\text { Cor Verdadeira } \\
\text { (uC) }\end{array}$} & \multirow[b]{2}{*}{$\begin{array}{l}\text { Alcalinidade Total } \\
\left(\mathrm{mg} / \mathrm{l} \mathrm{CaCO}_{3}\right)\end{array}$} & \multicolumn{2}{|c|}{ pH } & \multirow[b]{2}{*}{$\begin{array}{c}\text { Temperatura } \\
{ }^{\circ} \mathrm{C}\end{array}$} & \multirow[b]{2}{*}{$\begin{array}{l}\text { Potencial } \\
\text { Zeta }(\mathrm{mV})\end{array}$} \\
\hline & & & & S/Agit. & C/Agit. & & \\
\hline 5.95 & 141 & 102 & 30 & 7.86 & 7.55 & 25 & - \\
\hline
\end{tabular}

\begin{tabular}{|c|c|c|c|c|c|c|}
\hline \multirow[b]{2}{*}{ FRASCO } & \multicolumn{3}{|c|}{ DOSAGEM DE PRODUTO QUÍMICO } & \multirow{2}{*}{$\begin{array}{c}\text { pH de } \\
\text { Coagulação }\end{array}$} & \multirow{2}{*}{$\begin{array}{c}T_{\mathrm{s} 2}=7,00 \mathrm{~min} \\
V_{\mathrm{s} 2}=1.0 \mathrm{~cm} / \mathrm{min} \\
\begin{array}{c}\text { Cor } \\
(\mathrm{uC})\end{array}\end{array}$} & \multirow{2}{*}{$\begin{array}{c}T_{\mathrm{s} 1}=3,50 \mathrm{~min} \\
\mathrm{~V}_{\mathrm{s} 1}=2.0 \mathrm{~cm} / \mathrm{min} \\
\begin{array}{c}\mathrm{Cor} \\
(\mathrm{uC})\end{array}\end{array}$} \\
\hline & $\begin{array}{c}\text { Sulfato de } \\
\text { Alumínio (mg/l) }\end{array}$ & $\begin{array}{c}\text { Ácido } \\
\text { Clorídrico } \\
0.1 \mathrm{~N}(\mathrm{~m} \ell / \ell)\end{array}$ & $\begin{array}{c}\text { Hidróxido de } \\
\text { Sódio 0,1N } \\
(\mathrm{ml} / \mathbf{l})\end{array}$ & & & \\
\hline 1 & 300 & - & 38.0 & 6.08 & 31 & 34 \\
\hline 2 & 300 & - & 40.0 & 6.25 & 19 & 44 \\
\hline 3 & 300 & - & 42.0 & 6.43 & 11 & 38 \\
\hline 4 & 300 & - & 44.0 & 6.57 & 21 & 30 \\
\hline 5 & 300 & - & 46.0 & 6.70 & 10 & 39 \\
\hline 6 & 300 & - & 48.0 & 6.87 & 06 & 48 \\
\hline
\end{tabular}

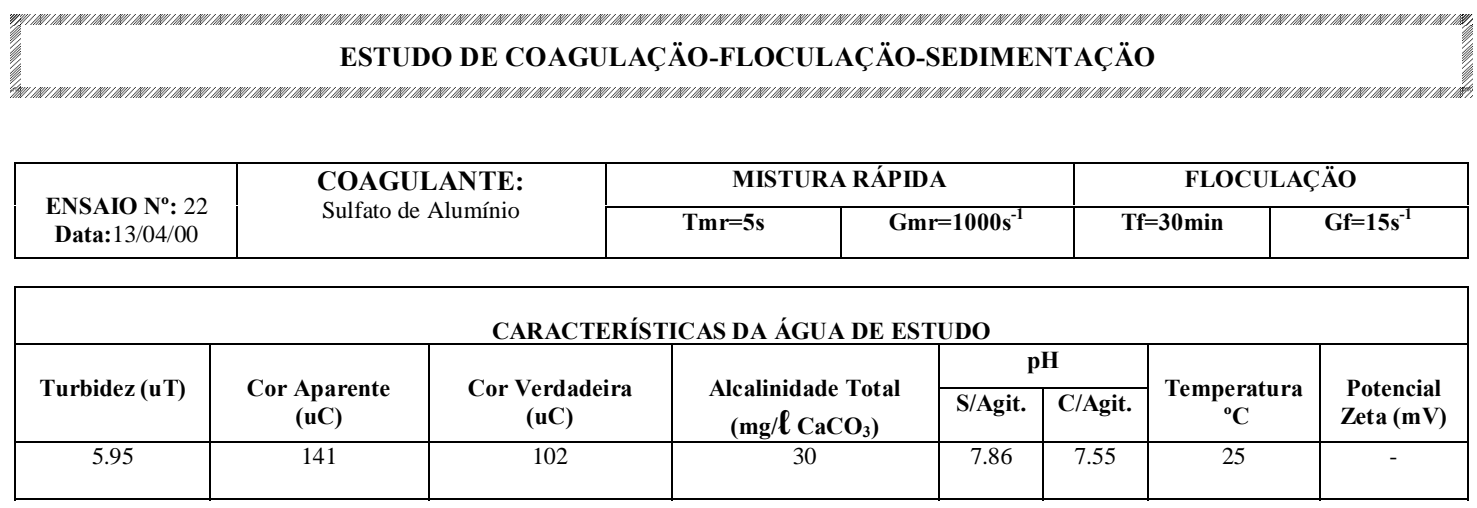

\begin{tabular}{|c|c|c|c|c|c|c|}
\hline \multirow[b]{2}{*}{ FRASCO } & \multicolumn{3}{|c|}{ DOSAGEM DE PRODUTO QUÍMICO } & \multirow{2}{*}{$\begin{array}{c}\text { pH de } \\
\text { Coagulação }\end{array}$} & \multirow{2}{*}{$\begin{array}{c}\mathrm{T}_{\mathrm{s} 2}=7,00 \mathrm{~min} \\
\mathrm{~V}_{\mathrm{s} 2}=1.0 \mathrm{~cm} / \mathrm{min} \\
\begin{array}{c}\text { Cor } \\
(\mathrm{uC})\end{array}\end{array}$} & \multirow{2}{*}{$\begin{array}{c}T_{\mathrm{s} 1}=3,50 \mathrm{~min} \\
\mathrm{~V}_{\mathrm{s} 1}=2.0 \mathrm{~cm} / \mathrm{min} \\
\begin{array}{c}\mathrm{Cor} \\
(\mathrm{uC})\end{array}\end{array}$} \\
\hline & $\begin{array}{c}\text { Sulfato de } \\
\text { Alumínio }(\mathrm{mg} / \ell)\end{array}$ & $\begin{array}{c}\text { Ácido } \\
\text { Clorídrico } \\
0.1 \mathrm{~N}(\mathrm{~m} \ell / \ell)\end{array}$ & $\begin{array}{c}\text { Hidróxido de } \\
\text { Sódio 0,1N } \\
(\mathrm{ml} / \mathrm{l})\end{array}$ & & & \\
\hline 1 & 280 & - & 31.0 & 5.87 & 63 & 126 \\
\hline 2 & 260 & - & 30.0 & 6.05 & 47 & 77 \\
\hline 3 & 180 & - & 23.0 & 6.59 & 12 & 48 \\
\hline 4 & 280 & - & 50.0 & 7.33 & 142 & 146 \\
\hline 5 & 260 & - & 46.0 & 7.35 & - & - \\
\hline 6 & 140 & - & 24.0 & 7.42 & - & - \\
\hline
\end{tabular}




\section{ESTUDO DE COAGULAÇÄO-FLOCULAÇÄO-SEDIMENTAÇÄO}

\begin{tabular}{|c|c|c|c|c|c|}
\hline \multirow{2}{*}{$\begin{array}{c}\text { ENSAIO No }: 23 \\
\text { Data: } 13 / 04 / 00\end{array}$} & \multirow{2}{*}{$\begin{array}{l}\text { COAGULANTE: } \\
\text { Sulfato de Alumínio }\end{array}$} & \multicolumn{2}{|c|}{ MISTURA RÁPIDA } & \multicolumn{2}{|c|}{ FLOCULAÇÄO } \\
\hline & & Tmr $=5 \mathrm{~s}$ & Gmr $=1000 \mathrm{~s}^{-1}$ & $\mathrm{Tf}=\mathbf{3 0} \mathrm{min}$ & $G f=15 s^{-1}$ \\
\hline
\end{tabular}

\begin{tabular}{|c|c|c|c|c|c|c|c|}
\hline \multicolumn{8}{|c|}{ CARACTERÍSTICAS DA ÁGUA DE ESTUDO } \\
\hline \multirow[b]{2}{*}{ Turbidez (uT) } & \multirow[b]{2}{*}{$\begin{array}{l}\text { Cor Aparente } \\
\text { (uC) }\end{array}$} & \multirow[b]{2}{*}{$\begin{array}{l}\text { Cor Verdadeira } \\
\text { (uC) }\end{array}$} & \multirow[b]{2}{*}{$\begin{array}{l}\text { Alcalinidade Total } \\
\left(\mathrm{mg} / \mathrm{l} \mathrm{CaCO}_{3}\right)\end{array}$} & \multicolumn{2}{|c|}{ pH } & \multirow[b]{2}{*}{$\begin{array}{c}\text { Temperatura } \\
{ }^{\circ} \mathrm{C}\end{array}$} & \multirow[b]{2}{*}{$\begin{array}{l}\text { Potencial } \\
\text { Zeta (mV) }\end{array}$} \\
\hline & & & & S/Agit. & C/Agit. & & \\
\hline 5.95 & 141 & 102 & 30 & 7.86 & 7.55 & 25 & - \\
\hline
\end{tabular}

\begin{tabular}{|c|c|c|c|c|c|c|}
\hline \multirow[b]{2}{*}{ FRASCO } & \multicolumn{3}{|c|}{ DOSAGEM DE PRODUTO QUÍMICO } & \multirow{2}{*}{$\begin{array}{c}\text { pH de } \\
\text { Coagulação }\end{array}$} & \multirow{2}{*}{$\begin{array}{c}T_{\mathrm{s} 2}=7,00 \mathrm{~min} \\
V_{\mathrm{s} 2}=1.0 \mathrm{~cm} / \mathrm{min} \\
\begin{array}{c}\text { Cor } \\
(\mathrm{uC})\end{array}\end{array}$} & \multirow{2}{*}{$\begin{array}{c}T_{\mathrm{s} 1}=3,50 \mathrm{~min} \\
\mathrm{~V}_{\mathrm{s} 1}=2.0 \mathrm{~cm} / \mathrm{min} \\
\begin{array}{c}\mathrm{Cor} \\
(\mathrm{uC})\end{array}\end{array}$} \\
\hline & $\begin{array}{c}\text { Sulfato de } \\
\text { Alumínio (mg/l) }\end{array}$ & $\begin{array}{c}\text { Ácido } \\
\text { Clorídrico } \\
0.1 \mathrm{~N}(\mathrm{~m} \ell / \ell)\end{array}$ & $\begin{array}{c}\text { Hidróxido de } \\
\text { Sódio 0,1N } \\
(\mathrm{ml} / \mathbf{l})\end{array}$ & & & \\
\hline 1 & 300 & - & 36.0 & 5.95 & 36 & 70 \\
\hline 2 & 320 & - & 40.0 & 5.98 & 30 & 52 \\
\hline 3 & 320 & - & 42.0 & 6.14 & 37 & 53 \\
\hline 4 & 320 & - & 44.0 & 6.29 & 18 & 48 \\
\hline 5 & 320 & - & 54.0 & 7.05 & 19 & 36 \\
\hline 6 & 300 & - & 50.0 & 7.03 & 15 & 34 \\
\hline
\end{tabular}

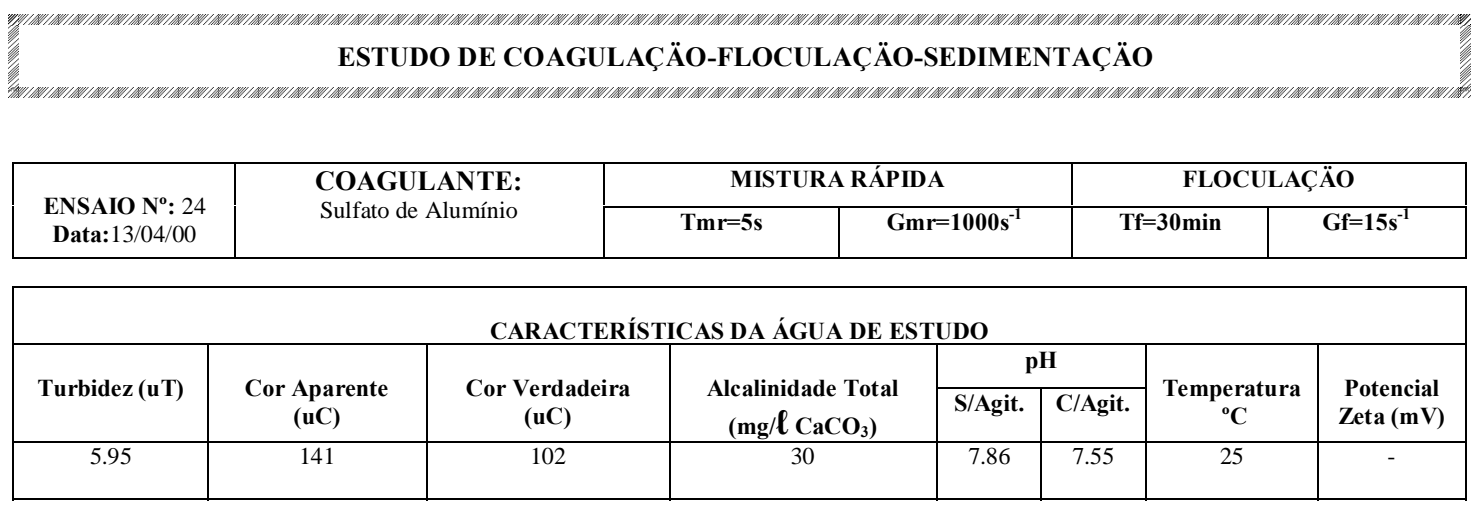

\begin{tabular}{|c|c|c|c|c|c|c|}
\hline \multirow[b]{2}{*}{ FRASCO } & \multicolumn{3}{|c|}{ DOSAGEM DE PRODUTO QUÍMICO } & \multirow{2}{*}{$\begin{array}{c}\text { pH de } \\
\text { Coagulação }\end{array}$} & \multirow{2}{*}{$\begin{array}{c}T_{\mathrm{s} 2}=7,00 \mathrm{~min} \\
V_{\mathrm{s} 2}=1.0 \mathrm{~cm} / \mathrm{min} \\
\begin{array}{c}\text { Cor } \\
(\mathrm{uC})\end{array}\end{array}$} & \multirow{2}{*}{$\begin{array}{c}T_{\mathrm{s} 1}=3,50 \mathrm{~min} \\
V_{\mathrm{s} 1}=2.0 \mathrm{~cm} / \mathrm{min} \\
\begin{array}{c}\mathrm{Cor} \\
(\mathrm{uC})\end{array}\end{array}$} \\
\hline & $\begin{array}{c}\text { Sulfato de } \\
\text { Alumínio }(\mathrm{mg} / \ell)\end{array}$ & $\begin{array}{c}\text { Ácido } \\
\text { Clorídrico } \\
\mathbf{0 . 1 N}(\mathrm{m} \ell / \ell)\end{array}$ & $\begin{array}{c}\text { Hidróxido de } \\
\text { Sódio } 0,1 \mathrm{~N} \\
(\mathrm{~m} \ell / \ell)\end{array}$ & & & \\
\hline 1 & 340 & - & 48.0 & 6.25 & 18 & 44 \\
\hline 2 & 340 & - & 50.0 & 6.44 & 12 & 45 \\
\hline 3 & 340 & - & 52.0 & 6.55 & 25 & 50 \\
\hline 4 & 340 & - & 54.0 & 6.68 & 13 & 50 \\
\hline 5 & 340 & - & 56.0 & 6.87 & 15 & 56 \\
\hline 6 & 300 & - & 52.0 & 7.20 & 20 & 35 \\
\hline
\end{tabular}




\section{ESTUDO DE COAGULAÇÄO-FLOCULAÇÄO-SEDIMENTAÇÄO}

\begin{tabular}{|c|c|c|c|c|c|c|c|c|}
\hline \multirow[b]{2}{*}{$\begin{array}{c}\text { ENSAIO No: } 2 \\
\text { Data: } 14 / 04 / 00\end{array}$} & \multirow{2}{*}{\multicolumn{2}{|c|}{$\begin{array}{l}\text { COAGULANTE: } \\
\text { Sulfato de Alumínio }\end{array}$}} & \multicolumn{3}{|c|}{ MISTURA RÁPIDA } & \multicolumn{3}{|c|}{ FLOCULAÇÄO } \\
\hline & & & Tmr $=5 \mathrm{~s}$ & \multicolumn{2}{|c|}{ Gmr $=1000 s^{-1}$} & \multicolumn{2}{|c|}{$\mathrm{Tf}=30 \mathrm{~min}$} & Gf $=15 \mathrm{~s}^{-1}$ \\
\hline \multicolumn{9}{|c|}{ CARACTERÍSTICAS DA ÁGUA DE ESTUDO } \\
\hline \multirow[b]{2}{*}{ Turbidez (uT) } & \multirow[b]{2}{*}{$\begin{array}{c}\text { Cor Aparente } \\
\text { (uC) }\end{array}$} & \multirow[b]{2}{*}{$\begin{array}{c}\text { Cor Verdadeira } \\
(\mathrm{uC})\end{array}$} & \multirow{2}{*}{\multicolumn{2}{|c|}{$\begin{array}{l}\text { Alcalinidade Total } \\
\left(\mathrm{mg} / \mathrm{\ell} \mathrm{CaCO}_{3}\right)\end{array}$}} & \multicolumn{2}{|c|}{$\mathrm{pH}$} & \multirow[b]{2}{*}{$\begin{array}{c}\text { Temperatura } \\
{ }^{\circ} \mathbf{C}\end{array}$} & \multirow[b]{2}{*}{$\begin{array}{l}\text { Potencial } \\
\text { Zeta (mV) }\end{array}$} \\
\hline & & & & & S/Agit. & C/Agit. & & \\
\hline 5.75 & 140 & & & & 7.94 & 7.49 & 25 & - \\
\hline
\end{tabular}

\begin{tabular}{|c|c|c|c|c|c|c|}
\hline \multirow[b]{2}{*}{ FRASCO } & \multicolumn{3}{|c|}{ DOSAGEM DE PRODUTO QUÍMICO } & \multirow{2}{*}{$\begin{array}{c}\text { pH de } \\
\text { Coagulação }\end{array}$} & \multirow{2}{*}{$\begin{array}{c}T_{\mathrm{s} 2}=7,00 \mathrm{~min} \\
V_{\mathrm{s} 2}=1.0 \mathrm{~cm} / \mathrm{min} \\
\begin{array}{c}\mathrm{Cor} \\
(\mathrm{uC})\end{array}\end{array}$} & \multirow{2}{*}{$\begin{aligned} & T_{\mathrm{s} 1}= 3,50 \mathrm{~min} \\
& V_{\mathrm{s} 1}= 2.0 \mathrm{~cm} / \mathrm{min} \\
& \begin{array}{c}\text { Cor } \\
(\mathrm{uC})\end{array}\end{aligned}$} \\
\hline & $\begin{array}{c}\text { Sulfato de } \\
\text { Alumínio }(\mathrm{mg} / \mathfrak{l})\end{array}$ & $\begin{array}{c}\text { Ácido } \\
\text { Clorídrico } \\
0.1 \mathrm{~N}(\mathrm{~m} \ell / \ell)\end{array}$ & $\begin{array}{c}\text { Hidróxido de } \\
\text { Sódio 0,1N } \\
(\mathrm{ml} / \mathrm{l})\end{array}$ & & & \\
\hline 1 & 300 & - & 34.0 & 5.83 & 70 & 132 \\
\hline 2 & 320 & - & 38.0 & 5.95 & 44 & 71 \\
\hline 3 & 180 & - & 24.0 & 6.73 & 32 & 27 \\
\hline 4 & 320 & - & 54.0 & 7.16 & 27 & 34 \\
\hline 5 & 320 & - & 56.0 & 7.38 & 48 & 62 \\
\hline 6 & 300 & - & 54.0 & 7.46 & 150 & 155 \\
\hline
\end{tabular}

\section{ESTUDO DE COAGULAÇÄO-FLOCULAÇÄO-SEDIMENTAÇÄO}

\begin{tabular}{|c|c|c|c|c|}
\hline \multirow{2}{*}{$\begin{array}{c}\text { ENSAIO N } \\
\text { Data: }: 26 / 04 / 00\end{array}$} & $\begin{array}{c}\text { COAGULANTE: } \\
\text { Sulfato de Alumínio }\end{array}$ & & MISTURA RÁPIDA & \multicolumn{2}{|c|}{ FLOCULAÇÄO } \\
\cline { 3 - 5 } & & Tmr $=\mathbf{5 s}$ & $\mathbf{G m r}=\mathbf{1 0 0 0 \mathbf { s } ^ { - 1 }}$ & Tf $=\mathbf{3 0 m i n}^{\mathbf{G f}=15 \mathbf{s}^{-1}}$ \\
\hline
\end{tabular}

\begin{tabular}{|c|c|c|c|c|c|c|c|}
\hline \multicolumn{8}{|c|}{ CARACTERÍSTICAS DA ÁGUA DE ESTUDO } \\
\hline \multirow[b]{2}{*}{ Turbidez (uT) } & \multirow[b]{2}{*}{$\begin{array}{c}\text { Cor Aparente } \\
\text { (uC) }\end{array}$} & \multirow[b]{2}{*}{$\begin{array}{c}\text { Cor Verdadeira } \\
\text { (uC) }\end{array}$} & \multirow[b]{2}{*}{$\begin{array}{c}\text { Alcalinidade Total } \\
\left(\mathrm{mg} / \boldsymbol{\ell}_{\mathrm{CaCO}}\right)\end{array}$} & \multicolumn{2}{|c|}{$\mathrm{pH}$} & \multirow[b]{2}{*}{$\begin{array}{c}\text { Temperatura } \\
{ }^{\circ} \mathrm{C}\end{array}$} & \multirow[b]{2}{*}{$\begin{array}{r}\text { Potencial } \\
\text { Zeta }(\mathrm{mV})\end{array}$} \\
\hline & & & & S/Agit. & C/Agit. & & \\
\hline 5.75 & 140 & 104 & 29.1 & 7.94 & 7.49 & 25 & - \\
\hline
\end{tabular}

\begin{tabular}{|c|c|c|c|c|c|c|}
\hline \multirow[b]{2}{*}{ FRASCO } & \multicolumn{3}{|c|}{ DOSAGEM DE PRODUTO QUÍMICO } & \multirow{2}{*}{$\begin{array}{c}\text { pH de } \\
\text { Coagulação }\end{array}$} & \multirow{2}{*}{$\begin{array}{c}\mathrm{T}_{\mathrm{s} 2}=7,00 \mathrm{~min} \\
\mathrm{~V}_{\mathrm{s} 2}=1.0 \mathrm{~cm} / \mathrm{min} \\
\begin{array}{c}\text { Cor } \\
(\mathrm{uC})\end{array}\end{array}$} & \multirow{2}{*}{$\begin{array}{c}T_{\mathrm{s} 1}=3,50 \mathrm{~min} \\
\mathrm{~V}_{\mathrm{s} 1}=2.0 \mathrm{~cm} / \mathrm{min} \\
\begin{array}{c}\mathrm{Cor} \\
(\mathrm{uC})\end{array}\end{array}$} \\
\hline & $\begin{array}{c}\text { Sulfato de } \\
\text { Alumínio }(\mathrm{mg} / \boldsymbol{\ell})\end{array}$ & $\begin{array}{c}\text { Ácido } \\
\text { Clorídrico } \\
\mathbf{0 . 1 \mathrm { N }}(\mathrm{m} \ell / \ell)\end{array}$ & $\begin{array}{c}\text { Hidróxido de } \\
\text { Sódio } 0,1 \mathrm{~N} \\
(\mathrm{~m} \ell / \ell)\end{array}$ & & & \\
\hline 1 & 360 & - & 52.0 & 6.35 & 17 & 50 \\
\hline 2 & 360 & - & 54.0 & 6.49 & 17 & 46 \\
\hline 3 & 360 & - & 56.0 & 6.63 & 31 & 46 \\
\hline 4 & 360 & - & 58.0 & 6.81 & 24 & 47 \\
\hline 5 & 360 & - & 60.0 & 6.96 & 23 & 50 \\
\hline 6 & 360 & - & 62.0 & 7.15 & 30 & 43 \\
\hline
\end{tabular}


ESTUDO DE COAGULAÇÄO-FLOCULAÇÄO-SEDIMENTAÇÄO

\begin{tabular}{|c|c|c|c|c|c|}
\hline \multirow{2}{*}{$\begin{array}{c}\text { ENSAIO No } \\
\text { Data: }: 14 / 04 / 00\end{array}$} & $\begin{array}{c}\text { COAGULANTE: } \\
\text { Sulfato de Alumínio }\end{array}$ & \multicolumn{2}{|c|}{ MISTURA RÁPIDA } & \multicolumn{2}{|c|}{ FLOCULAC̈O } \\
\cline { 3 - 5 } & & Tmr=5s & Gmr=1000s & Tf $=\mathbf{3 0 m i n}$ & ${\text { Gf }=15 \mathbf{s}^{-1}}^{-1}$ \\
\hline
\end{tabular}

\begin{tabular}{|c|c|c|c|c|c|c|c|}
\hline \multicolumn{8}{|c|}{ CARACTERÍSTICAS DA ÁGUA DE ESTUDO } \\
\hline \multirow[b]{2}{*}{ Turbidez (uT) } & \multirow[b]{2}{*}{$\begin{array}{l}\text { Cor Aparente } \\
\text { (uC) }\end{array}$} & \multirow[b]{2}{*}{$\begin{array}{c}\text { Cor Verdadeira } \\
\text { (uC) }\end{array}$} & \multirow[b]{2}{*}{$\begin{array}{l}\text { Alcalinidade Total } \\
\left(\mathrm{mg} / \boldsymbol{\ell} \mathrm{CaCO}_{3}\right)\end{array}$} & \multicolumn{2}{|c|}{ pH } & \multirow[b]{2}{*}{$\underset{{ }^{\circ} \mathrm{C}}{\text { Temperatura }}$} & \multirow[b]{2}{*}{$\begin{array}{l}\text { Potencial } \\
\text { Zeta }(\mathrm{mV})\end{array}$} \\
\hline & & & & S/Agit. & C/Agit. & & \\
\hline 5.75 & 140 & 104 & 29.1 & 7.94 & 7.49 & 25 & - \\
\hline
\end{tabular}

\begin{tabular}{|c|c|c|c|c|c|c|}
\hline \multirow[b]{2}{*}{ FRASCO } & \multicolumn{3}{|c|}{ DOSAGEM DE PRODUTO QUÍMICO } & \multirow{2}{*}{$\begin{array}{c}\text { pH de } \\
\text { Coagulação }\end{array}$} & \multirow{2}{*}{$\begin{array}{c}T_{\mathrm{s} 2}=7,00 \mathrm{~min} \\
V_{\mathrm{s} 2}=1.0 \mathrm{~cm} / \mathrm{min} \\
\begin{array}{c}\mathrm{Cor} \\
(\mathrm{uC})\end{array}\end{array}$} & \multirow{2}{*}{$\begin{aligned} & T_{\mathrm{s} 1}=3,50 \mathrm{~min} \\
& V_{\mathrm{s} 1}= 2.0 \mathrm{~cm} / \mathrm{min} \\
& \begin{array}{c}\text { Cor } \\
(\mathrm{uC})\end{array}\end{aligned}$} \\
\hline & $\begin{array}{c}\text { Sulfato de } \\
\text { Alumínio }(\mathrm{mg} / \mathfrak{l})\end{array}$ & $\begin{array}{c}\text { Ácido } \\
\text { Clorídrico } \\
0.1 \mathrm{~N}(\mathrm{~m} \ell / \ell)\end{array}$ & $\begin{array}{c}\text { Hidróxido de } \\
\text { Sódio 0,1N } \\
(\mathrm{m \ell} / \mathbf{l})\end{array}$ & & & \\
\hline 1 & 360 & - & 44.0 & 5.81 & 49 & 89 \\
\hline 2 & 360 & - & 46.0 & 5.93 & 45 & 87 \\
\hline 3 & 360 & - & 48.0 & 6.05 & 33 & 77 \\
\hline 4 & 360 & - & 50.0 & 6.23 & 38 & 63 \\
\hline 5 & 360 & - & 64.0 & 7.29 & 32 & 41 \\
\hline 6 & 360 & - & 66.0 & 7.43 & 151 & 155 \\
\hline
\end{tabular}

\begin{tabular}{|c|c|c|c|c|c|c|c|c|}
\hline \multirow{2}{*}{$\begin{array}{c}\text { ENSAIO No: } 28 \\
\text { Data: } 14 / 04 / 00\end{array}$} & \multirow{2}{*}{\multicolumn{2}{|c|}{$\begin{array}{l}\text { COAGULANTE: } \\
\text { Sulfato de Alumínio }\end{array}$}} & \multicolumn{3}{|c|}{ MISTURA RÁPIDA } & \multicolumn{3}{|c|}{ FLOCULAÇÄO } \\
\hline & & & Tmr $=5 \mathrm{~s}$ & \multicolumn{2}{|c|}{ Gmr $=1000 \mathrm{~s}^{-1}$} & \multicolumn{2}{|c|}{$\mathrm{Tf}=30 \mathrm{~min}$} & $G f=15 s^{-1}$ \\
\hline \multicolumn{9}{|c|}{ CARACTERÍSTICAS DA ÁGUA DE ESTUdO } \\
\hline \multirow[b]{2}{*}{ Turbidez (uT) } & \multirow[b]{2}{*}{$\begin{array}{l}\text { Cor Aparente } \\
\text { (uC) }\end{array}$} & \multirow[b]{2}{*}{$\begin{array}{c}\text { Cor Verdadeira } \\
\text { (uC) }\end{array}$} & \multirow{2}{*}{\multicolumn{2}{|c|}{$\begin{array}{l}\text { Alcalinidade Total } \\
\left(\mathrm{mg} / \ell \mathrm{CaCO}_{3}\right)\end{array}$}} & \multicolumn{2}{|c|}{ pH } & \multirow[b]{2}{*}{$\begin{array}{c}\text { Temperatura } \\
{ }^{\circ} \mathrm{C}\end{array}$} & \multirow[b]{2}{*}{$\begin{array}{l}\text { Potencial } \\
\text { Zeta (mV) }\end{array}$} \\
\hline & & & & & S/Agit. & C/Agit. & & \\
\hline 5.75 & 140 & 104 & & & 7.94 & 7.49 & 25 & - \\
\hline
\end{tabular}

\begin{tabular}{|c|c|c|c|c|c|c|}
\hline \multirow[b]{2}{*}{ FRASCO } & \multicolumn{3}{|c|}{ DOSAGEM DE PRODUTO QUÍMICO } & \multirow{2}{*}{$\begin{array}{c}\text { pH de } \\
\text { Coagulação }\end{array}$} & \multirow{2}{*}{$\begin{array}{c}\mathrm{T}_{\mathrm{s} 2}=7,00 \mathrm{~min} \\
\mathrm{~V}_{\mathrm{s} 2}=1.0 \mathrm{~cm} / \mathrm{min} \\
\begin{array}{c}\mathrm{Cor} \\
(\mathrm{uC})\end{array}\end{array}$} & \multirow{2}{*}{$\begin{array}{c}\mathrm{T}_{\mathrm{s} 1}=3,50 \mathrm{~min} \\
\mathrm{~V}_{\mathrm{s} 1}=2.0 \mathrm{~cm} / \mathrm{min} \\
\begin{array}{c}\mathrm{Cor} \\
(\mathrm{uC})\end{array}\end{array}$} \\
\hline & $\begin{array}{c}\text { Sulfato de } \\
\text { Alumínio (mg/l) }\end{array}$ & $\begin{array}{c}\text { Ácido } \\
\text { Clorídrico } \\
0.1 \mathrm{~N}(\mathrm{~m} \ell / \ell)\end{array}$ & $\begin{array}{c}\text { Hidróxido de } \\
\text { Sódio 0,1N } \\
(\mathrm{m} \ell / \ell)\end{array}$ & & & \\
\hline 1 & 340 & - & 36.0 & 5.38 & 77 & 149 \\
\hline 2 & 340 & - & 38.0 & 5.56 & 71 & 156 \\
\hline 3 & 340 & - & 40.0 & 5.71 & 58 & 160 \\
\hline 4 & 340 & - & 42.0 & 5.87 & 58 & 108 \\
\hline 5 & 340 & - & 58.0 & 7.00 & 21 & 41 \\
\hline 6 & 340 & - & 60.0 & 7.20 & 19 & 45 \\
\hline
\end{tabular}


ANEXO - F

ENSAIOS DO REATOR ESTÁTICO - ÁGUA II PARA O COAGULANTE CLORETO FÉRRICO 


\section{ESTUDO DE COAGULAÇÃO-FLOCULAÇÃO-SEDIMENTAÇÃO}

\begin{tabular}{|c|c|c|c|c|c|c|c|}
\hline \multirow{2}{*}{$\begin{array}{l}\text { ENSAIO No: } 0 \\
\text { Data : } 14 / 04 / 0\end{array}$} & \multirow{2}{*}{\multicolumn{2}{|c|}{$\begin{array}{l}\text { COAGULANTE } \\
\text { Cloreto Férrico }\end{array}$}} & \multicolumn{3}{|c|}{ MISTURA RÁPIDA } & \multicolumn{2}{|c|}{ FLOCULAÇÃO } \\
\hline & & & $T m r=5 s$ & \multicolumn{2}{|c|}{ Gmr $=1000 \mathrm{~s}^{-1}$} & Tf $=30 \mathrm{~min}$ & $G f=15 s^{-1}$ \\
\hline \multicolumn{8}{|c|}{ CARACTERÍSTICAS DA ÁGUA DE ESTUDO } \\
\hline \multirow{2}{*}{ Turbidez (uT) } & \multirow{2}{*}{$\begin{array}{l}\text { Cor Aparente } \\
\text { (uC) }\end{array}$} & \multirow{2}{*}{$\begin{array}{c}\text { Cor Verdadeira } \\
\text { (uC) }\end{array}$} & \multirow{2}{*}{$\begin{array}{l}\text { Alcalinidade Total } \\
\left(\mathrm{mg} / \ell \mathrm{CaCO}_{3}\right)\end{array}$} & \multicolumn{2}{|c|}{ pH } & \multirow{2}{*}{$\begin{array}{c}\text { Temperatura } \\
{ }^{\circ} \mathrm{C}\end{array}$} & \multirow{2}{*}{$\begin{array}{r}\text { Potencial } \\
\text { Zeta }(\mathrm{mV})\end{array}$} \\
\hline & & & & S/ agit. & C/ agit. & & \\
\hline 5.75 & 140 & 104 & 29.1 & 7.94 & 7.49 & 25 & - \\
\hline
\end{tabular}

\begin{tabular}{|c|c|c|c|c|c|c|}
\hline \multirow{2}{*}{ FRASCO } & \multicolumn{3}{|c|}{ DOSAGEM DE PRODUTO QUÍMICO } & \multirow{2}{*}{$\begin{array}{c}\text { pH } \\
\text { de } \\
\text { Coagulação }\end{array}$} & \multirow{2}{*}{$\begin{array}{c}T_{\mathrm{s} 2}=7,00 \mathrm{~min} \\
\mathrm{~V}_{\mathrm{s} 2}=1.0 \mathrm{~cm} / \mathrm{min} \\
\begin{array}{c}\mathrm{Cor} \\
(\mathrm{uC})\end{array} \\
\end{array}$} & \multirow{2}{*}{$\begin{array}{c}T_{\mathrm{s} 1}=3,50 \mathrm{~min} \\
V_{\mathrm{s} 1}=2.0 \mathrm{~cm} / \mathrm{min} \\
\begin{array}{c}\mathrm{Cor} \\
(\mathrm{uC})\end{array} \\
\end{array}$} \\
\hline & $\begin{array}{l}\text { Cloreto Férrico } \\
(\mathrm{mg} / \mathfrak{\ell})\end{array}$ & $\begin{array}{c}\text { Ácido } \\
\text { Clorídrico } \\
0.1 \mathrm{~N}(\mathrm{~m} \ell / \ell) \\
\end{array}$ & $\begin{array}{c}\text { Hidróxido de } \\
\text { Sódio } 0.1 \mathrm{~N}(\mathrm{~m} \ell / \ell)\end{array}$ & & & \\
\hline 1 & - & - & - & 5.28 & - & - \\
\hline 2 & 60 & - & - & 5.86 & 16 & 24 \\
\hline 3 & 60 & - & 2.0 & 5.99 & 16 & 30 \\
\hline 4 & 40 & 1.82 & - & 6.32 & 25 & 49 \\
\hline 5 & 40 & - & - & 6.47 & 25 & 49 \\
\hline 6 & 40 & - & 2.0 & 6.60 & 28 & 41 \\
\hline
\end{tabular}

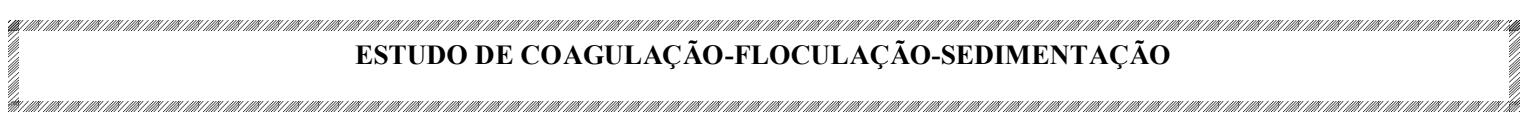

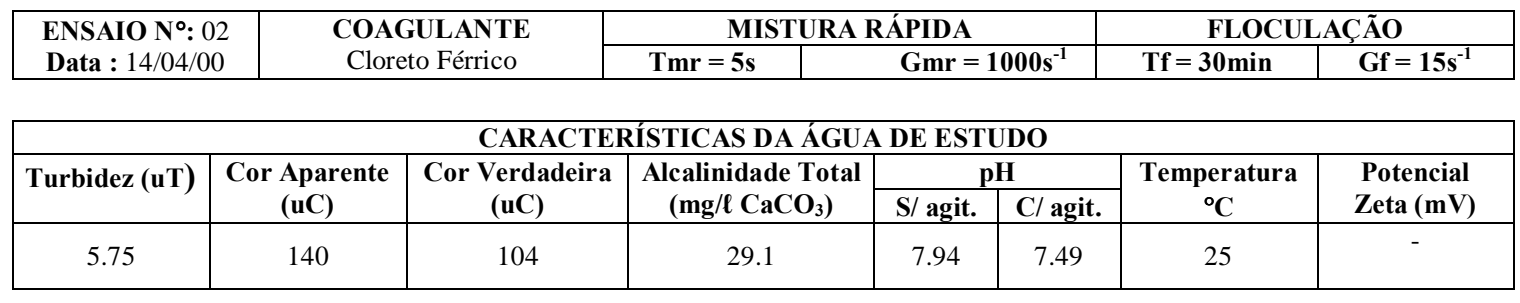

\begin{tabular}{|c|c|c|c|c|c|c|}
\hline \multirow{2}{*}{ FRASCO } & \multicolumn{3}{|c|}{ DOSAGEM DE PRODUTO QUÍMICO } & \multirow{2}{*}{$\begin{array}{c}\text { pH } \\
\text { de } \\
\text { Coagulação }\end{array}$} & \multirow{2}{*}{$\begin{array}{c}T_{\mathrm{s} 2}=7,00 \mathrm{~min} \\
V_{\mathrm{s} 2}=1.0 \mathrm{~cm} / \mathrm{min} \\
\begin{array}{c}\text { Cor } \\
(\mathrm{uC})\end{array}\end{array}$} & \multirow{2}{*}{$\begin{array}{c}T_{\mathrm{s} 1}=3,50 \mathrm{~min} \\
V_{\mathrm{s} 1}=2.0 \mathrm{~cm} / \mathrm{min} \\
\begin{array}{c}\mathrm{Cor} \\
(\mathrm{uC})\end{array}\end{array}$} \\
\hline & $\begin{array}{l}\text { Cloreto Férrico } \\
(\mathrm{mg} / \ell)\end{array}$ & $\begin{array}{c}\text { Ácido } \\
\text { Clorídrico } \\
0.1 \mathrm{~N}(\mathrm{~m} \ell / \ell) \\
\end{array}$ & 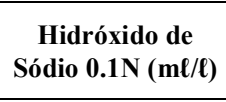 & & & \\
\hline 1 & 60 & - & 4.0 & 6.14 & 21 & 48 \\
\hline 2 & 40 & 3.64 & - & 6.04 & 19 & 44 \\
\hline 3 & 60 & - & 6.0 & 6.32 & 16 & 49 \\
\hline 4 & 60 & - & 8.0 & 6.53 & 24 & 51 \\
\hline 5 & 40 & - & 4.0 & 6.70 & 37 & 84 \\
\hline 6 & 40 & - & 6.0 & 6.89 & 160 & 168 \\
\hline
\end{tabular}




\section{ESTUDO DE COAGULAÇÃO-FLOCULAÇÃO-SEDIMENTAÇÃO}

\begin{tabular}{|c|c|c|c|c|c|c|c|}
\hline \multirow{2}{*}{$\begin{array}{l}\text { ENSAIO N }{ }^{\circ}: 0 \\
\text { Data }: 14 / 04 / 0\end{array}$} & \multirow{2}{*}{\multicolumn{2}{|c|}{$\begin{array}{c}\text { COAGULANTE } \\
\text { Cloreto Férrico }\end{array}$}} & \multicolumn{3}{|c|}{ MISTURA RÁPIDA } & \multicolumn{2}{|c|}{ FLOCULACC̃̃O } \\
\hline & & & $T m r=5 s$ & \multicolumn{2}{|c|}{ Gmr $=1000 \mathrm{~s}^{-1}$} & Tf $=30 \mathrm{~min}$ & $G f=15 s^{-1}$ \\
\hline \multicolumn{8}{|c|}{ CARACTERÍSTICAS DA ÁGUA DE ESTUDO } \\
\hline \multirow{2}{*}{ Turbidez (uT) } & \multirow{2}{*}{$\begin{array}{l}\text { Cor Aparente } \\
\text { (uC) }\end{array}$} & \multirow{2}{*}{$\begin{array}{c}\text { Cor Verdadeira } \\
\text { (uC) }\end{array}$} & \multirow{2}{*}{$\begin{array}{l}\text { Alcalinidade Total } \\
\left(\mathrm{mg} / \ell \mathrm{CaCO}_{3}\right)\end{array}$} & \multicolumn{2}{|c|}{ pH } & \multirow{2}{*}{$\begin{array}{c}\text { Temperatura } \\
{ }^{\circ} \mathrm{C}\end{array}$} & \multirow{2}{*}{$\begin{array}{r}\text { Potencial } \\
\text { Zeta }(\mathrm{mV})\end{array}$} \\
\hline & & & & S/ agit. & C/ agit. & & \\
\hline 5.75 & 140 & 104 & 29.1 & 7.94 & 7.49 & 25 & - \\
\hline
\end{tabular}

\begin{tabular}{|c|c|c|c|c|c|c|}
\hline \multirow{2}{*}{ FRASCO } & \multicolumn{3}{|c|}{ DOSAGEM DE PRODUTO QUÍMICO } & \multirow{2}{*}{$\begin{array}{c}\text { pH } \\
\text { de } \\
\text { Coagulação }\end{array}$} & \multirow{2}{*}{$\begin{array}{c}T_{\mathrm{s} 2}=7,00 \mathrm{~min} \\
V_{\mathrm{s} 2}=1.0 \mathrm{~cm} / \mathrm{min} \\
\begin{array}{c}\mathrm{Cor} \\
(\mathrm{uC})\end{array} \\
\end{array}$} & \multirow{2}{*}{$\begin{array}{c}T_{\mathrm{s} 1}=3,50 \mathrm{~min} \\
V_{\mathrm{s} 1}=2.0 \mathrm{~cm} / \mathrm{min} \\
\begin{array}{c}\mathrm{Cor} \\
(\mathrm{uC})\end{array}\end{array}$} \\
\hline & $\begin{array}{l}\text { Cloreto Férrico } \\
(\mathrm{mg} / \mathfrak{\ell})\end{array}$ & $\begin{array}{c}\text { Ácido } \\
\text { Clorídrico } \\
\mathbf{0 . 1 N}(\mathrm{m} \ell / \ell) \\
\end{array}$ & $\begin{array}{c}\text { Hidróxido de } \\
\text { Sódio } 0.1 \mathrm{~N}(\mathrm{~m} \ell / \ell)\end{array}$ & & & \\
\hline 1 & 40 & 5.47 & - & 5.83 & 19 & 27 \\
\hline 2 & 80 & - & 6.0 & 5.64 & 32 & 40 \\
\hline 3 & 80 & - & 8.0 & 5.96 & 11 & 18 \\
\hline 4 & 80 & - & 10.0 & 6.18 & 16 & 26 \\
\hline 5 & 80 & - & 12.0 & 6.35 & 14 & 40 \\
\hline 6 & 80 & - & 14.0 & 6.55 & 19 & 41 \\
\hline
\end{tabular}

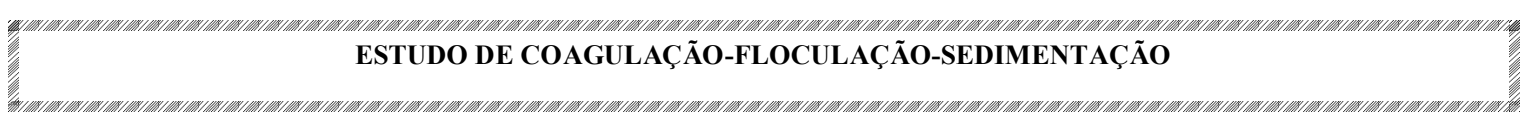

\begin{tabular}{|c|c|c|c|c|c|}
\hline ENSAIO $\mathbf{N}^{\circ}: 04$ & COAGULANTE & \multicolumn{2}{|c|}{ MISTURA RÁPIDA } & \multicolumn{2}{|c|}{ FLOCULAÇÃO } \\
\cline { 3 - 6 } Data $: 14 / 04 / 00$ & Cloreto Férrico & Tmr $=\mathbf{5 s}$ & $\mathbf{G m r}=\mathbf{1 0 0 0 s}^{-1}$ & $\mathbf{T f}=\mathbf{3 0 m i n}$ & $\mathbf{G f}^{-1} \mathbf{1 5 s}^{-1}$ \\
\hline
\end{tabular}

\begin{tabular}{|c|c|c|c|c|c|c|c|}
\hline \multicolumn{8}{|c|}{ CARACTERÍSTICAS DA ÁGUA DE ESTUDO } \\
\hline \multirow[t]{2}{*}{ Turbidez (uT) } & \multirow{2}{*}{$\begin{array}{c}\begin{array}{l}\text { Cor Aparente } \\
\text { (uC) }\end{array} \\
\end{array}$} & \multirow{2}{*}{$\begin{array}{c}\text { Cor Verdadeira } \\
(\mathrm{uC})\end{array}$} & \multirow{2}{*}{$\begin{array}{c}\text { Alcalinidade Total } \\
\left(\mathrm{mg} / \ell \mathrm{CaCO}_{3}\right)\end{array}$} & \multicolumn{2}{|c|}{ pH } & \multirow{2}{*}{$\begin{array}{c}\text { Temperatura } \\
{ }^{\circ} \mathrm{C} \\
\end{array}$} & \multirow{2}{*}{$\begin{array}{l}\text { Potencial } \\
\text { Zeta }(\mathrm{mV}) \\
\end{array}$} \\
\hline & & & & S/ agit. & C/ agit. & & \\
\hline 5.75 & 140 & 104 & 29.1 & 7.94 & 7.49 & 25 & - \\
\hline
\end{tabular}

\begin{tabular}{|c|c|c|c|c|c|c|}
\hline \multirow{2}{*}{ FRASCO } & \multicolumn{3}{|c|}{ DOSAGEM DE PRODUTO QUÍMICO } & \multirow{2}{*}{$\begin{array}{c}\text { pH } \\
\text { de } \\
\text { Coagulação }\end{array}$} & \multirow{2}{*}{$\begin{array}{c}T_{\mathrm{s} 2}=7,00 \mathrm{~min} \\
V_{\mathrm{s} 2}=1.0 \mathrm{~cm} / \mathrm{min} \\
\begin{array}{c}\text { Cor } \\
(\mathrm{uC})\end{array}\end{array}$} & \multirow{2}{*}{$\begin{array}{c}T_{\mathrm{s} 1}=3,50 \mathrm{~min} \\
V_{\mathrm{s} 1}=2.0 \mathrm{~cm} / \mathrm{min} \\
\begin{array}{c}\mathrm{Cor} \\
(\mathrm{uC})\end{array}\end{array}$} \\
\hline & $\begin{array}{l}\text { Cloreto Férrico } \\
(\mathrm{mg} / \mathrm{\ell})\end{array}$ & $\begin{array}{c}\text { Ácido } \\
\text { Clorídrico } \\
0.1 \mathrm{~N}(\mathrm{~m} \ell / \ell) \\
\end{array}$ & $\begin{array}{c}\text { Hidróxido de } \\
\text { Sódio } 0.1 \mathrm{~N}(\mathrm{~m} \ell / \mathfrak{l})\end{array}$ & & & \\
\hline 1 & 40 & 7.29 & - & 5.51 & 43 & 53 \\
\hline 2 & 60 & 1.82 & - & 5.24 & - & - \\
\hline 3 & 80 & - & 4.0 & 5.25 & - & - \\
\hline 4 & 100 & - & 14.0 & 5.98 & 13 & 19 \\
\hline 5 & 60 & - & 10.0 & 6.76 & 42 & 65 \\
\hline 6 & 80 & - & 16.0 & 6.7 & 26 & 44 \\
\hline
\end{tabular}


ESTUDO DE COAGULAÇÃO-FLOCULAÇÃO-SEDIMENTAÇÃO

\begin{tabular}{|c|c|c|c|c|c|c|c|}
\hline \multirow{2}{*}{$\begin{array}{l}\text { ENSAIO N }{ }^{\circ}: 05 \\
\text { Data }: 15 / 04 / 00\end{array}$} & \multirow{2}{*}{\multicolumn{2}{|c|}{$\begin{array}{l}\text { COAGULANTE } \\
\text { Cloreto Férico }\end{array}$}} & \multicolumn{3}{|c|}{ MISTURA RÁPIDA } & \multicolumn{2}{|c|}{ FLOCULAÇÃO } \\
\hline & & & $T m r=5 s$ & \multicolumn{2}{|c|}{ Gmr $=1000 \mathrm{~s}^{-1}$} & Tf $=30 \mathrm{~min}$ & $G f=15 s^{-1}$ \\
\hline \multicolumn{8}{|c|}{ CARACTERÍSTICAS DA ÁGUA DE ESTUDO } \\
\hline \multirow{2}{*}{ Turbidez (uT) } & \multirow{2}{*}{$\begin{array}{c}\text { Cor Aparente } \\
\text { (uC) }\end{array}$} & \multirow{2}{*}{$\begin{array}{c}\text { Cor Verdadeira } \\
\text { (uC) }\end{array}$} & \multirow{2}{*}{$\begin{array}{c}\text { Alcalinidade Total } \\
\left(\mathrm{mg} / \ell \mathrm{CaCO}_{3}\right)\end{array}$} & \multicolumn{2}{|c|}{ pH } & \multirow{2}{*}{$\begin{array}{c}\text { Temperatura } \\
{ }^{\circ} \mathrm{C} \\
\end{array}$} & \multirow{2}{*}{$\begin{array}{r}\text { Potencial } \\
\text { Zeta }(\mathrm{mV})\end{array}$} \\
\hline & & & & S/ agit. & C/ agit. & & \\
\hline 5.75 & 140 & 104 & 29.1 & 7.94 & 7.49 & 25 & - \\
\hline
\end{tabular}

\begin{tabular}{|c|c|c|c|c|c|c|}
\hline \multirow{2}{*}{ FRASCO } & \multicolumn{3}{|c|}{ DOSAGEM DE PRODUTO QUÍMICO } & \multirow{2}{*}{$\begin{array}{c}\text { pH } \\
\text { de } \\
\text { Coagulação }\end{array}$} & \multirow{2}{*}{$\begin{array}{c}T_{\mathrm{s} 2}=7,00 \mathrm{~min} \\
V_{\mathrm{s} 2}=1.0 \mathrm{~cm} / \mathrm{min} \\
\begin{array}{c}\mathrm{Cor} \\
(\mathrm{uC})\end{array}\end{array}$} & \multirow{2}{*}{$\begin{array}{c}T_{\mathrm{s} 1}=3,50 \mathrm{~min} \\
V_{\mathrm{s} 1}=2.0 \mathrm{~cm} / \mathrm{min} \\
\begin{array}{c}\mathrm{Cor} \\
(\mathrm{uC})\end{array}\end{array}$} \\
\hline & $\begin{array}{c}\text { Cloreto Férrico } \\
(\mathrm{mg} / \mathfrak{\ell})\end{array}$ & $\begin{array}{c}\text { Ácido } \\
\text { Clorídrico } \\
\text { 0.1N(m/ } / \ell) \\
\end{array}$ & $\begin{array}{c}\text { Hidróxido de } \\
\text { Sódio } 0.1 \mathrm{~N}(\mathrm{~m} \ell / \ell)\end{array}$ & & & \\
\hline 1 & 60 & 0.91 & - & 5.77 & - & - \\
\hline 2 & 80 & - & 5.0 & 5.66 & - & - \\
\hline 3 & 80 & - & 7.0 & 5.91 & 11 & 11 \\
\hline 4 & 100 & - & 12.0 & 5.77 & 26 & 34 \\
\hline 5 & 100 & - & 16.0 & 6.26 & 10 & 10 \\
\hline 6 & 80 & - & 17.0 & 6.81 & 17 & 20 \\
\hline
\end{tabular}

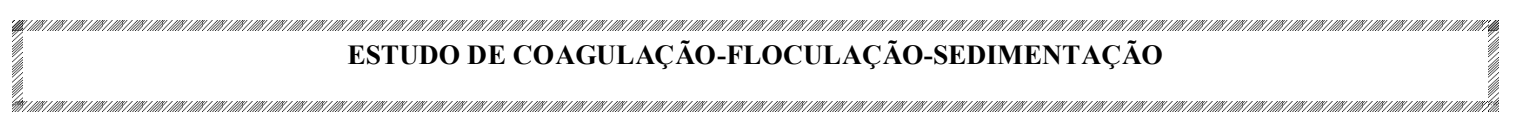

\begin{tabular}{|c|c|c|c|c|c|}
\hline ENSAIO $\mathbf{N}^{\circ}: 06$ & COAGULANTE & \multicolumn{2}{|c|}{ MISTURA RÁPIDA } & \multicolumn{2}{|c|}{ FLOCULAÇÃO } \\
\cline { 3 - 6 } Data $: 15 / 04 / 00$ & Cloreto Férrico & Tmr $=\mathbf{5 s}$ & $\mathbf{G m r}=\mathbf{1 0 0 0 s}^{-1}$ & $\mathbf{T f}=\mathbf{3 0 m i n}$ & $\mathbf{G f}^{-1} \mathbf{1 5 s}^{-1}$ \\
\hline
\end{tabular}

\begin{tabular}{|c|c|c|c|c|c|c|c|}
\hline \multicolumn{8}{|c|}{ CARACTERÍSTICAS DA ÁGUA DE ESTUDO } \\
\hline \multirow[t]{2}{*}{ Turbidez (uT) } & \multirow{2}{*}{$\begin{array}{c}\text { Cor Aparente } \\
\text { (uC) }\end{array}$} & \multirow{2}{*}{$\begin{array}{c}\text { Cor Verdadeira } \\
(\mathrm{uC})\end{array}$} & \multirow{2}{*}{$\begin{array}{c}\text { Alcalinidade Total } \\
\left(\mathrm{mg} / \ell \mathrm{CaCO}_{3}\right)\end{array}$} & \multicolumn{2}{|c|}{ pH } & \multirow{2}{*}{$\begin{array}{c}\text { Temperatura } \\
{ }^{\circ} \mathrm{C}\end{array}$} & \multirow{2}{*}{$\begin{array}{r}\text { Potencial } \\
\text { Zeta }(\mathrm{mV})\end{array}$} \\
\hline & & & & S/ agit. & $\mathrm{C} /$ agit. & & \\
\hline 5.75 & 140 & 104 & 29.1 & 7.94 & 7.49 & 25 & - \\
\hline
\end{tabular}

\begin{tabular}{|c|c|c|c|c|c|c|}
\hline \multirow{2}{*}{ FRASCO } & \multicolumn{3}{|c|}{ DOSAGEM DE PRODUTO QUÍMICO } & \multirow{2}{*}{$\begin{array}{c}\text { pH } \\
\text { de } \\
\text { Coagulação }\end{array}$} & \multirow{2}{*}{$\begin{array}{c}T_{\mathrm{s} 2}=7,00 \mathrm{~min} \\
V_{\mathrm{s} 2}=1.0 \mathrm{~cm} / \mathrm{min} \\
\begin{array}{c}\mathrm{Cor} \\
(\mathrm{uC})\end{array}\end{array}$} & \multirow{2}{*}{$\begin{array}{c}T_{\mathrm{s} 1}=3,50 \mathrm{~min} \\
V_{\mathrm{s} 1}=2.0 \mathrm{~cm} / \mathrm{min} \\
\begin{array}{c}\mathrm{Cor} \\
(\mathrm{uC})\end{array}\end{array}$} \\
\hline & $\begin{array}{c}\text { Cloreto Férrico } \\
(\mathrm{mg} / \mathrm{\ell})\end{array}$ & $\begin{array}{c}\text { Ácido } \\
\text { Clorídrico } \\
0.1 \mathrm{~N}(\mathrm{~m} \ell / \ell)\end{array}$ & $\begin{array}{c}\text { Hidróxido de } \\
\text { Sódio } 0.1 \mathrm{~N}(\mathrm{m \ell} / \mathfrak{l})\end{array}$ & & & \\
\hline 1 & 120 & - & 18.0 & 5.60 & 121 & 136 \\
\hline 2 & 120 & - & 20.0 & 5.89 & 12 & 15 \\
\hline 3 & 120 & - & 22.0 & 6.18 & 13 & 17 \\
\hline 4 & 100 & - & 18.0 & 6.40 & 16 & 20 \\
\hline 5 & 100 & - & 20.0 & 6.55 & 23 & 20 \\
\hline 6 & 100 & - & 22.0 & 6.72 & 24 & 21 \\
\hline
\end{tabular}




\section{ESTUDO DE COAGULAÇÃO-FLOCULAÇÃO-SEDIMENTAÇÃO}

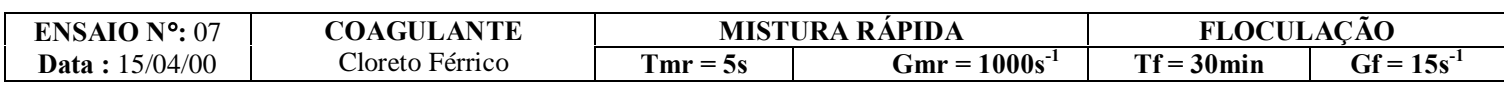

\begin{tabular}{|c|c|c|c|c|c|c|c|}
\hline \multicolumn{8}{|c|}{ CARACTERÍSTICAS DA ÁGUA DE ESTUDO } \\
\hline \multirow{2}{*}{ Turbidez (uT) } & \multirow{2}{*}{$\begin{array}{c}\text { Cor Aparente } \\
\text { (uC) }\end{array}$} & \multirow{2}{*}{$\begin{array}{c}\text { Cor Verdadeira } \\
\text { (uC) }\end{array}$} & \multirow{2}{*}{$\begin{array}{l}\text { Alcalinidade Total } \\
\left(\mathrm{mg} / \ell \mathrm{CaCO}_{3}\right)\end{array}$} & \multicolumn{2}{|c|}{ pH } & \multirow{2}{*}{$\begin{array}{c}\text { Temperatura } \\
{ }^{\circ} \mathrm{C} \\
\end{array}$} & \multirow{2}{*}{$\begin{array}{l}\text { Potencial } \\
\text { Zeta }(\mathrm{mV})\end{array}$} \\
\hline & & & & S/ agit. & $\mathrm{C} /$ agit. & & \\
\hline 5.75 & 140 & 104 & 29.1 & 7.94 & 7.49 & 25 & - \\
\hline
\end{tabular}

\begin{tabular}{|c|c|c|c|c|c|c|}
\hline \multirow{2}{*}{ FRASCO } & \multicolumn{3}{|c|}{ DOSAGEM DE PRODUTO QUÍMICO } & \multirow{2}{*}{$\begin{array}{c}\text { pH } \\
\text { de } \\
\text { Coagulação }\end{array}$} & \multirow{2}{*}{$\begin{array}{c}T_{\mathrm{s} 2}=7,00 \mathrm{~min} \\
V_{\mathrm{s} 2}=1.0 \mathrm{~cm} / \mathrm{min} \\
\begin{array}{c}\mathrm{Cor} \\
(\mathrm{uC})\end{array}\end{array}$} & \multirow{2}{*}{$\begin{array}{c}T_{\mathrm{s} 1}=3,50 \mathrm{~min} \\
V_{\mathrm{s} 1}=2.0 \mathrm{~cm} / \mathrm{min} \\
\begin{array}{l}\mathrm{Cor} \\
(\mathrm{uC})\end{array}\end{array}$} \\
\hline & $\begin{array}{c}\text { Cloreto Férrico } \\
(\mathrm{mg} / \mathrm{l})\end{array}$ & $\begin{array}{c}\text { Ácido } \\
\text { Clorídrico } \\
0.1 \mathrm{~N}(\mathrm{~m} \ell / \ell) \\
\end{array}$ & $\begin{array}{c}\text { Hidróxido de } \\
\text { Sódio 0.1N }(\mathrm{m} \ell / \ell)\end{array}$ & & & \\
\hline 1 & 140 & - & 24.0 & 5.66 & 52 & 53 \\
\hline 2 & 140 & - & 26.0 & 5.93 & 15 & 13 \\
\hline 3 & 140 & - & 28.0 & 6.20 & 9 & 8 \\
\hline 4 & 120 & - & 24.0 & 6.40 & 12 & 20 \\
\hline 5 & 120 & - & 26.0 & 6.57 & 9 & 24 \\
\hline 6 & 100 & - & 24.0 & 6.92 & 11 & 13 \\
\hline
\end{tabular}

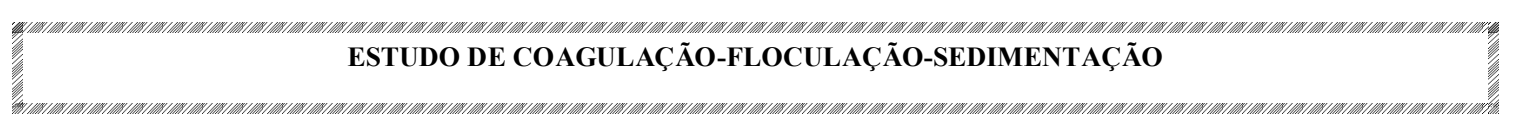

\begin{tabular}{|c|c|c|c|c|c|c|c|}
\hline \multirow{2}{*}{$\begin{array}{l}\text { ENSAIO No: } 8 \\
\text { Data }: 15 / 04 / 00\end{array}$} & \multirow{2}{*}{\multicolumn{2}{|c|}{$\begin{array}{l}\text { COAGULANTE } \\
\text { Cloreto Férrico }\end{array}$}} & \multicolumn{3}{|c|}{ MISTURA RÁPIDA } & \multicolumn{2}{|c|}{ FLOCULAÇÃO } \\
\hline & & & $T m r=5 s$ & \multicolumn{2}{|c|}{$\mathrm{Gmr}=1000 \mathrm{~s}^{-1}$} & $T f=30 \mathrm{~min}$ & $G f=15 s^{-1}$ \\
\hline \multicolumn{8}{|c|}{ CARACTERÍSTICAS DA ÁGUA DE ESTUDO } \\
\hline \multirow[t]{2}{*}{ Turbidez (uT) } & \multirow{2}{*}{$\begin{array}{c}\text { Cor Aparente } \\
\text { (uC) }\end{array}$} & \multirow{2}{*}{$\begin{array}{c}\text { Cor Verdadeira } \\
(\mathrm{uC})\end{array}$} & \multirow{2}{*}{$\begin{array}{c}\text { Alcalinidade Total } \\
\left(\mathrm{mg} / \ell \mathrm{CaCO}_{3}\right)\end{array}$} & \multicolumn{2}{|c|}{ pH } & \multirow{2}{*}{$\begin{array}{c}\text { Temperatura } \\
{ }^{\circ} \mathrm{C} \\
\end{array}$} & \multirow{2}{*}{$\begin{array}{r}\text { Potencial } \\
\text { Zeta }(\mathrm{mV}) \\
\end{array}$} \\
\hline & & & & S/ agit. & $\mathrm{C} /$ agit. & & \\
\hline 5.75 & 140 & 104 & 29.1 & 7.94 & 7.49 & 25 & 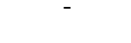 \\
\hline
\end{tabular}

\begin{tabular}{|c|c|c|c|c|c|c|}
\hline \multirow{2}{*}{ FRASCO } & \multicolumn{3}{|c|}{ DOSAGEM DE PRODUTO QUÍMICO } & \multirow{2}{*}{$\begin{array}{c}\text { pH } \\
\text { de } \\
\text { Coagulação }\end{array}$} & \multirow{2}{*}{$\begin{array}{c}T_{\mathrm{s} 2}=7,00 \mathrm{~min} \\
V_{\mathrm{s} 2}=1.0 \mathrm{~cm} / \mathrm{min} \\
\begin{array}{c}\mathrm{Cor} \\
(\mathrm{uC})\end{array}\end{array}$} & \multirow{2}{*}{$\begin{array}{c}T_{\mathrm{s} 1}=3,50 \mathrm{~min} \\
V_{\mathrm{s} 1}=2.0 \mathrm{~cm} / \mathrm{min} \\
\begin{array}{c}\mathrm{Cor} \\
(\mathrm{uC})\end{array}\end{array}$} \\
\hline & $\begin{array}{c}\text { Cloreto Férrico } \\
(\mathrm{mg} / \mathrm{l})\end{array}$ & $\begin{array}{c}\text { Ácido } \\
\text { Clorídrico } \\
\text { 0.1N }(\mathrm{m} \ell / \ell)\end{array}$ & 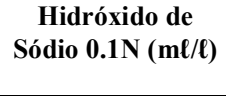 & & & \\
\hline 1 & 140 & - & 30.0 & 6.30 & 6 & 16 \\
\hline 2 & 140 & - & 32.0 & 6.51 & 9 & 13 \\
\hline 3 & 120 & - & 28.0 & 6.68 & 14 & 21 \\
\hline 4 & 120 & - & 30.0 & 6.89 & 9 & 12 \\
\hline 5 & 100 & - & 26.0 & 7.06 & 18 & 31 \\
\hline 6 & 80 & - & 18.0 & 6.87 & 11 & 16 \\
\hline
\end{tabular}




\section{ESTUDO DE COAGULAÇÃO-FLOCULAÇÃO-SEDIMENTAÇÃO}

\begin{tabular}{|l|c|c|c|c|c|}
\hline ENSAIO No: & COAGULANTE & \multicolumn{2}{|c|}{ MISTURA RÁPIDA } & \multicolumn{2}{c|}{ FLOCULAČ̃̃ } \\
\cline { 3 - 5 } Data $: 15 / 04 / 00$ & Cloreto Férrico & Tmr $=\mathbf{5 s}$ & $\mathbf{G m r}=\mathbf{1 0 0 0 s}^{-1}$ & $\mathbf{T f}=\mathbf{3 0 m i n}$ & $\mathbf{G f}^{-1}=\mathbf{1 5 s}^{-1}$ \\
\hline
\end{tabular}

\begin{tabular}{|c|c|c|c|c|c|c|c|}
\hline \multicolumn{8}{|c|}{ CARACTERÍSTICAS DA ÁGUA DE ESTUDO } \\
\hline \multirow{2}{*}{ Turbidez (uT) } & \multirow{2}{*}{$\begin{array}{c}\text { Cor Aparente } \\
\text { (uC) }\end{array}$} & \multirow{2}{*}{$\begin{array}{c}\text { Cor Verdadeira } \\
\text { (uC) }\end{array}$} & \multirow{2}{*}{$\begin{array}{l}\text { Alcalinidade Total } \\
\left(\mathrm{mg} / \ell \mathrm{CaCO}_{3}\right)\end{array}$} & \multicolumn{2}{|c|}{ pH } & \multirow{2}{*}{$\begin{array}{c}\text { Temperatura } \\
{ }^{\circ} \mathrm{C} \\
\end{array}$} & \multirow{2}{*}{$\begin{array}{l}\text { Potencial } \\
\text { Zeta }(\mathrm{mV})\end{array}$} \\
\hline & & & & S/ agit. & $\mathrm{C} /$ agit. & & \\
\hline 5.75 & 140 & 104 & 29.1 & 7.94 & 7.49 & 25 & - \\
\hline
\end{tabular}

\begin{tabular}{|c|c|c|c|c|c|c|}
\hline \multirow{2}{*}{ FRASCO } & \multicolumn{3}{|c|}{ DOSAGEM DE PRODUTO QUÍMICO } & \multirow{2}{*}{$\begin{array}{c}\text { pH } \\
\text { de } \\
\text { Coagulação }\end{array}$} & \multirow{2}{*}{$\begin{array}{c}T_{\mathrm{s} 2}=7,00 \mathrm{~min} \\
V_{\mathrm{s} 2}=1.0 \mathrm{~cm} / \mathrm{min} \\
\begin{array}{c}\mathrm{Cor} \\
(\mathrm{uC})\end{array}\end{array}$} & \multirow{2}{*}{$\begin{array}{c}T_{\mathrm{s} 1}=3,50 \mathrm{~min} \\
V_{\mathrm{s} 1}=2.0 \mathrm{~cm} / \mathrm{min} \\
\begin{array}{l}\mathrm{Cor} \\
(\mathrm{uC})\end{array}\end{array}$} \\
\hline & $\begin{array}{c}\text { Cloreto Férrico } \\
(\mathrm{mg} / \mathrm{L})\end{array}$ & $\begin{array}{c}\text { Ácido } \\
\text { Clorídrico } \\
0.1 \mathrm{~N}(\mathrm{~m} \ell / \ell) \\
\end{array}$ & $\begin{array}{c}\text { Hidróxido de } \\
\text { Sódio 0.1N }(\mathrm{m} \ell / \ell)\end{array}$ & & & \\
\hline 1 & 160 & - & 30.0 & 5.61 & 157 & 162 \\
\hline 2 & 160 & - & 32.0 & 5.88 & 6 & 10 \\
\hline 3 & 140 & - & 34.0 & 6.65 & 10 & 38 \\
\hline 4 & 120 & - & 32.0 & 7.00 & 10 & 13 \\
\hline 5 & 100 & - & 28.0 & 7.27 & 170 & 205 \\
\hline 6 & 80 & - & 20.0 & 7.08 & 40 & 44 \\
\hline
\end{tabular}

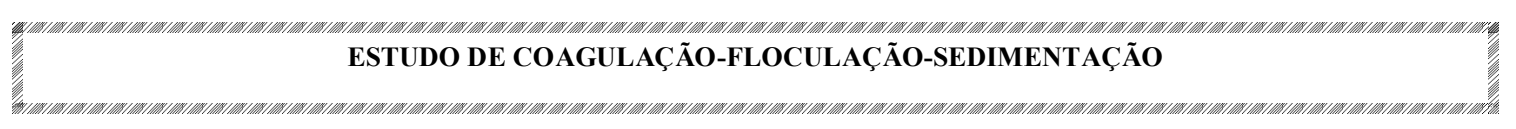

\begin{tabular}{|c|c|c|c|c|c|c|c|}
\hline \multirow{2}{*}{$\begin{array}{l}\text { ENSAIO No: } 1 \\
\text { Data : } 16 / 04 / 0\end{array}$} & \multirow{2}{*}{\multicolumn{2}{|c|}{$\begin{array}{l}\text { COAGULANTE } \\
\text { Cloreto Férrico }\end{array}$}} & \multicolumn{3}{|c|}{ MISTURA RÁPIDA } & \multicolumn{2}{|c|}{ FLOCULAÇÃO } \\
\hline & & & Tmr $=5 \mathrm{~s}$ & \multicolumn{2}{|c|}{$\mathrm{Gmr}=1000 \mathrm{~s}^{-1}$} & $T f=30 \mathrm{~min}$ & $G f=15 s^{-1}$ \\
\hline \multicolumn{8}{|c|}{ CARACTERÍSTICAS DA ÁGUA DE ESTUDO } \\
\hline \multirow[t]{2}{*}{ Turbidez (uT) } & \multirow{2}{*}{$\begin{array}{c}\text { Cor Aparente } \\
\text { (uC) }\end{array}$} & \multirow{2}{*}{$\begin{array}{c}\text { Cor Verdadeira } \\
(\mathrm{uC})\end{array}$} & \multirow{2}{*}{$\begin{array}{l}\text { Alcalinidade Total } \\
\left(\mathrm{mg} / \ell \mathrm{CaCO}_{3}\right)\end{array}$} & \multicolumn{2}{|c|}{ pH } & \multirow{2}{*}{$\begin{array}{c}\text { Temperatura } \\
{ }^{\circ} \mathrm{C} \\
\end{array}$} & \multirow{2}{*}{$\begin{array}{r}\text { Potencial } \\
\text { Zeta }(\mathrm{mV}) \\
\end{array}$} \\
\hline & & & & S/agit. & $\mathrm{C} /$ agit. & & \\
\hline 5.75 & 137 & 100 & 29.1 & 7.94 & 7.49 & 25 & 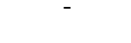 \\
\hline
\end{tabular}

\begin{tabular}{|c|c|c|c|c|c|c|}
\hline \multirow{2}{*}{ FRASCO } & \multicolumn{3}{|c|}{ DOSAGEM DE PRODUTO QUÍMICO } & \multirow{2}{*}{$\begin{array}{c}\text { pH } \\
\text { de } \\
\text { Coagulação }\end{array}$} & \multirow{2}{*}{$\begin{array}{c}T_{\mathrm{s} 2}=7,00 \mathrm{~min} \\
\mathrm{~V}_{\mathrm{s} 2}=1.0 \mathrm{~cm} / \mathrm{min} \\
\begin{array}{c}\text { Cor } \\
(\mathrm{uC})\end{array}\end{array}$} & \multirow{2}{*}{$\begin{array}{c}T_{\mathrm{s} 1}=3,50 \mathrm{~min} \\
V_{\mathrm{s} 1}=2.0 \mathrm{~cm} / \mathrm{min} \\
\begin{array}{c}\mathrm{Cor} \\
(\mathrm{uC})\end{array}\end{array}$} \\
\hline & $\begin{array}{c}\text { Cloreto Férrico } \\
(\mathrm{mg} / \mathrm{\ell})\end{array}$ & $\begin{array}{c}\text { Ácido } \\
\text { Clorídrico } \\
\mathbf{0 . 1 N}(\mathrm{m} \ell / \ell) \\
\end{array}$ & $\begin{array}{c}\text { Hidróxido de } \\
\text { Sódio } 0.1 \mathrm{~N}(\mathrm{~m} \ell / \mathfrak{l})\end{array}$ & & & \\
\hline 1 & 160 & - & 34.0 & 6.33 & 6 & 19 \\
\hline 2 & 160 & - & 36.0 & 6.52 & 9 & 11 \\
\hline 3 & 160 & - & 38.0 & 6.64 & 9 & 36 \\
\hline 4 & 140 & - & 36.0 & 7.05 & 5 & 11 \\
\hline 5 & 140 & - & 38.0 & 7.28 & 6 & 31 \\
\hline 6 & 120 & - & 34.0 & 7.48 & 227 & 239 \\
\hline
\end{tabular}




\section{ESTUDO DE COAGULAÇÃO-FLOCULAÇÃO-SEDIMENTAÇÃO}

\begin{tabular}{|l|c|c|c|c|c|}
\hline ENSAIO $\mathbf{N}^{\circ}: 11$ & COAGULANTE & \multicolumn{2}{|c|}{ MISTURA RÁPIDA } & \multicolumn{2}{c|}{ FLOCULAČ̃̃ } \\
\cline { 3 - 5 } Data $: 16 / 04 / 00$ & Cloreto Férrico & Tmr $=\mathbf{5 s}$ & $\mathbf{G m r}=\mathbf{1 0 0 0 s}^{-1}$ & $\mathbf{T f}=\mathbf{3 0 m i n}$ & $\mathbf{G f}^{-1}=\mathbf{1 5 s}^{-1}$ \\
\hline
\end{tabular}

\begin{tabular}{|c|c|c|c|c|c|c|c|}
\hline \multicolumn{8}{|c|}{ CARACTERÍSTICAS DA ÁGUA DE ESTUDO } \\
\hline \multirow{2}{*}{ Turbidez (uT) } & \multirow{2}{*}{$\begin{array}{c}\text { Cor Aparente } \\
\text { (uC) }\end{array}$} & \multirow{2}{*}{$\begin{array}{c}\text { Cor Verdadeira } \\
\text { (uC) }\end{array}$} & \multirow{2}{*}{$\begin{array}{c}\text { Alcalinidade Total } \\
\left(\mathrm{mg} / \ell \mathrm{CaCO}_{3}\right)\end{array}$} & \multicolumn{2}{|c|}{ pH } & \multirow{2}{*}{$\begin{array}{c}\text { Temperatura } \\
{ }^{\circ} \mathrm{C} \\
\end{array}$} & \multirow{2}{*}{$\begin{array}{l}\text { Potencial } \\
\text { Zeta }(\mathrm{mV})\end{array}$} \\
\hline & & & & S/ agit. & $\mathrm{C} /$ agit. & & \\
\hline 5.75 & 137 & 100 & 29.1 & 7.94 & 7.49 & 25 & - \\
\hline
\end{tabular}

\begin{tabular}{|c|c|c|c|c|c|c|}
\hline \multirow{2}{*}{ FRASCO } & \multicolumn{3}{|c|}{ DOSAGEM DE PRODUTO QUÍMICO } & \multirow{2}{*}{$\begin{array}{c}\text { pH } \\
\text { de } \\
\text { Coagulação }\end{array}$} & \multirow{2}{*}{$\begin{array}{c}T_{\mathrm{s} 2}=7,00 \mathrm{~min} \\
V_{\mathrm{s} 2}=1.0 \mathrm{~cm} / \mathrm{min} \\
\begin{array}{c}\mathrm{Cor} \\
(\mathrm{uC})\end{array}\end{array}$} & \multirow{2}{*}{$\begin{array}{c}T_{\mathrm{s} 1}=3,50 \mathrm{~min} \\
V_{\mathrm{s} 1}=2.0 \mathrm{~cm} / \mathrm{min} \\
\begin{array}{c}\mathrm{Cor} \\
(\mathrm{uC})\end{array}\end{array}$} \\
\hline & $\begin{array}{c}\text { Cloreto Férrico } \\
(\mathrm{mg} / \mathfrak{\ell})\end{array}$ & $\begin{array}{c}\text { Ácido } \\
\text { Clorídrico } \\
\text { 0.1N(m/ } / \ell) \\
\end{array}$ & $\begin{array}{c}\text { Hidróxido de } \\
\text { Sódio } 0.1 \mathrm{~N}(\mathrm{~m} \ell / \ell)\end{array}$ & & & \\
\hline 1 & 180 & - & 36.0 & 5.62 & 184 & 181 \\
\hline 2 & 180 & - & 38.0 & 5.94 & 9 & 16 \\
\hline 3 & 180 & - & 40.0 & 6.14 & 10 & 22 \\
\hline 4 & 160 & - & 40.0 & 6.75 & 8 & 36 \\
\hline 5 & 160 & - & 42.0 & 6.90 & 12 & 24 \\
\hline 6 & 140 & - & 40.0 & 7.42 & 70 & 72 \\
\hline
\end{tabular}

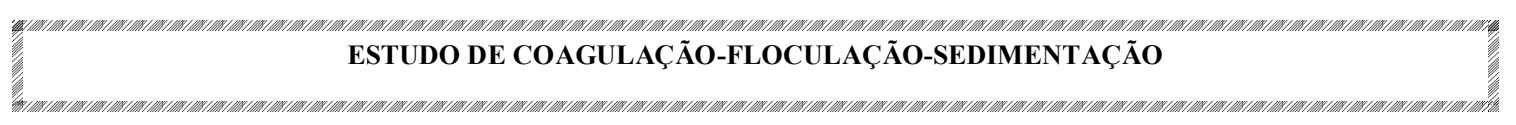

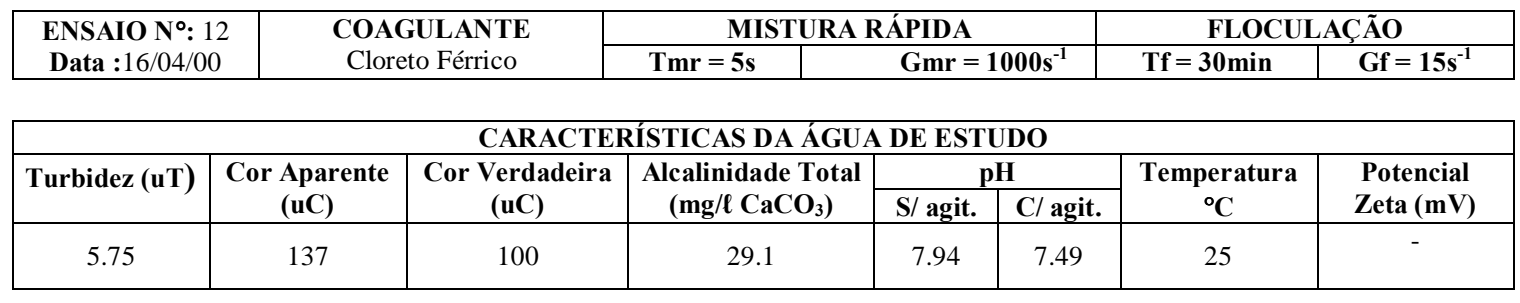

\begin{tabular}{|c|c|c|c|c|c|c|}
\hline \multirow{2}{*}{ FRASCO } & \multicolumn{3}{|c|}{ DOSAGEM DE PRODUTO QUÍMICO } & \multirow{2}{*}{$\begin{array}{c}\text { pH } \\
\text { de } \\
\text { Coagulação }\end{array}$} & \multirow{2}{*}{$\begin{array}{c}T_{\mathrm{s} 2}=7,00 \mathrm{~min} \\
V_{\mathrm{s} 2}=1.0 \mathrm{~cm} / \mathrm{min} \\
\begin{array}{c}\mathrm{Cor} \\
(\mathrm{uC})\end{array}\end{array}$} & \multirow{2}{*}{$\begin{array}{c}T_{\mathrm{s} 1}=3,50 \mathrm{~min} \\
V_{\mathrm{s} 1}=2.0 \mathrm{~cm} / \mathrm{min} \\
\begin{array}{c}\mathrm{Cor} \\
(\mathrm{uC})\end{array} \\
\end{array}$} \\
\hline & $\begin{array}{c}\text { Cloreto Férrico } \\
(\mathrm{mg} / \mathrm{\ell})\end{array}$ & $\begin{array}{c}\text { Ácido } \\
\text { Clorídrico } \\
0.1 \mathrm{~N}(\mathrm{~m} \ell / \ell) \\
\end{array}$ & $\begin{array}{c}\text { Hidróxido de } \\
\text { Sódio 0.1N }(\mathrm{m} \ell / \ell)\end{array}$ & & & \\
\hline 1 & 160 & - & 33.0 & 5.78 & 12 & 18 \\
\hline 2 & 180 & - & 42.0 & 6.30 & 10 & 34 \\
\hline 3 & 180 & - & 44.0 & 6.58 & 13 & 18 \\
\hline 4 & 140 & - & 35.0 & 6.84 & 11 & 27 \\
\hline 5 & 120 & - & 33.0 & 7.18 & 17 & 23 \\
\hline 6 & 140 & - & 41.0 & 7.47 & - & - \\
\hline
\end{tabular}




\section{ESTUDO DE COAGULAÇÃO-FLOCULAÇÃO-SEDIMENTAÇÃO}

\begin{tabular}{|c|c|c|c|c|c|c|c|}
\hline \multirow{2}{*}{$\begin{array}{l}\text { ENSAIO } N^{\circ}: 13 \\
\text { Data : } 16 / 04 / 00\end{array}$} & \multirow{2}{*}{\multicolumn{2}{|c|}{$\begin{array}{l}\text { COAGULANTE } \\
\text { Cloreto Férrico }\end{array}$}} & \multicolumn{3}{|c|}{ MISTURA RÁPIDA } & \multicolumn{2}{|c|}{ FLOCULAÇÃO } \\
\hline & & & $T m r=5 s$ & \multicolumn{2}{|c|}{ Gmr $=1000 \mathrm{~s}^{-1}$} & $T f=30 \mathrm{~min}$ & $G f=15 s^{-1}$ \\
\hline \multicolumn{8}{|c|}{ CARACTERÍSTICAS DA ÁGUA DE ESTUDO } \\
\hline \multirow{2}{*}{ Turbidez (uT) } & \multirow{2}{*}{$\begin{array}{c}\text { Cor Aparente } \\
\text { (uC) }\end{array}$} & \multirow{2}{*}{$\begin{array}{c}\text { Cor Verdadeira } \\
\text { (uC) }\end{array}$} & \multirow{2}{*}{$\begin{array}{l}\text { Alcalinidade Total } \\
\left(\mathrm{mg} / \ell \mathrm{CaCO}_{3}\right)\end{array}$} & \multicolumn{2}{|c|}{ pH } & \multirow{2}{*}{$\begin{array}{c}\text { Temperatura } \\
{ }^{\circ} \mathrm{C} \\
\end{array}$} & \multirow{2}{*}{$\begin{array}{r}\text { Potencial } \\
\text { Zeta }(m V)\end{array}$} \\
\hline & & & & S/ agit. & $\mathrm{C} /$ agit. & & \\
\hline 5.75 & 137 & 100 & 29.1 & 7.94 & 7.49 & 25 & - \\
\hline
\end{tabular}

\begin{tabular}{|c|c|c|c|c|c|c|}
\hline \multirow{2}{*}{ FRASCO } & \multicolumn{3}{|c|}{ DOSAGEM DE PRODUTO QUÍMICO } & \multirow{2}{*}{$\begin{array}{c}\text { pH } \\
\text { de } \\
\text { Coagulação }\end{array}$} & \multirow{2}{*}{$\begin{array}{c}T_{\mathrm{s} 2}=7,00 \mathrm{~min} \\
\mathrm{~V}_{\mathrm{s} 2}=1.0 \mathrm{~cm} / \mathrm{min} \\
\begin{array}{c}\mathrm{Cor} \\
(\mathrm{uC})\end{array}\end{array}$} & \multirow{2}{*}{$\begin{array}{c}T_{\mathrm{s} 1}=3,50 \mathrm{~min} \\
V_{\mathrm{s} 1}=2.0 \mathrm{~cm} / \mathrm{min} \\
\begin{array}{c}\mathrm{Cor} \\
(\mathrm{uC})\end{array}\end{array}$} \\
\hline & $\begin{array}{c}\text { Cloreto Férrico } \\
(\mathrm{mg} / \mathrm{l})\end{array}$ & $\begin{array}{c}\text { Ácido } \\
\text { Clorídrico } \\
\mathbf{0 . 1 N}(\mathrm{m} \ell / \ell) \\
\end{array}$ & $\begin{array}{c}\text { Hidróxido de } \\
\text { Sódio } 0.1 \mathrm{~N}(\mathrm{~m} \ell / \ell)\end{array}$ & & & \\
\hline 1 & 200 & - & 42.0 & 5.61 & 113 & 115 \\
\hline 2 & 200 & - & 44.0 & 5.94 & 9 & 12 \\
\hline 3 & 200 & - & 46.0 & 6.13 & 8 & 7 \\
\hline 4 & 180 & - & 46.0 & 6.72 & 14 & 23 \\
\hline 5 & 160 & - & 44.0 & 7.10 & 16 & 13 \\
\hline 6 & 160 & - & 46.0 & 7.32 & 34 & 36 \\
\hline
\end{tabular}

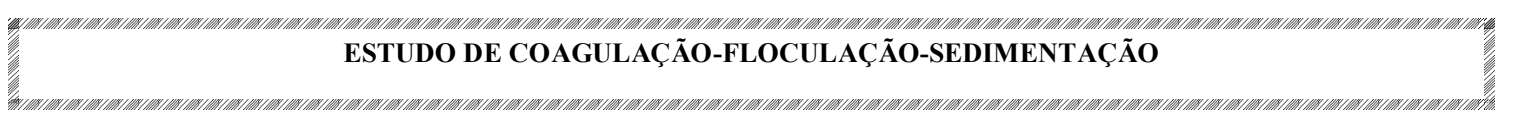

\begin{tabular}{|c|c|c|c|c|c|}
\hline ENSAIO $\mathbf{N}^{\circ}: 14$ & COAGULANTE & \multicolumn{2}{|c|}{ MISTURA RÁPIDA } & \multicolumn{2}{|c|}{ FLOCULAÇÃO } \\
\cline { 3 - 6 } Data $: 16 / 04 / 00$ & Cloreto Férrico & Tmr $=\mathbf{5 s}$ & $\mathbf{G m r}=\mathbf{1 0 0 0 s}^{-1}$ & $\mathbf{T f}=\mathbf{3 0 m i n}$ & $\mathbf{G f}^{-1} \mathbf{1 5 s}^{-1}$ \\
\hline
\end{tabular}

\begin{tabular}{|c|c|c|c|c|c|c|c|}
\hline \multicolumn{8}{|c|}{ CARACTERÍSTICAS DA ÁGUA DE ESTUDO } \\
\hline \multirow[t]{2}{*}{ Turbidez (uT) } & \multirow{2}{*}{$\begin{array}{c}\text { Cor Aparente } \\
\text { (uC) }\end{array}$} & \multirow{2}{*}{$\begin{array}{c}\text { Cor Verdadeira } \\
(\mathrm{uC})\end{array}$} & \multirow{2}{*}{$\begin{array}{l}\text { Alcalinidade Total } \\
\left(\mathrm{mg} / \ell \mathrm{CaCO}_{3}\right)\end{array}$} & \multicolumn{2}{|c|}{ pH } & \multirow{2}{*}{$\begin{array}{c}\text { Temperatura } \\
{ }^{\circ} \mathrm{C} \\
\end{array}$} & \multirow{2}{*}{$\begin{array}{r}\text { Potencial } \\
\text { Zeta }(\mathrm{mV}) \\
\end{array}$} \\
\hline & & & & S/ agit. & $\mathrm{C} /$ agit. & & \\
\hline 5.75 & 137 & 100 & 29.1 & 7.94 & 7.49 & 25 & 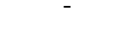 \\
\hline
\end{tabular}

\begin{tabular}{|c|c|c|c|c|c|c|}
\hline \multirow{2}{*}{ FRASCO } & \multicolumn{3}{|c|}{ DOSAGEM DE PRODUTO QUÍMICO } & \multirow{2}{*}{$\begin{array}{c}\text { pH } \\
\text { de } \\
\text { Coagulação }\end{array}$} & \multirow{2}{*}{$\begin{array}{c}T_{\mathrm{s} 2}=7,00 \mathrm{~min} \\
\mathrm{~V}_{\mathrm{s} 2}=1.0 \mathrm{~cm} / \mathrm{min} \\
\begin{array}{c}\mathrm{Cor} \\
(\mathrm{uC})\end{array}\end{array}$} & \multirow{2}{*}{$\begin{array}{c}T_{\mathrm{s} 1}=3,50 \mathrm{~min} \\
V_{\mathrm{s} 1}=2.0 \mathrm{~cm} / \mathrm{min} \\
\begin{array}{c}\mathrm{Cor} \\
(\mathrm{uC})\end{array}\end{array}$} \\
\hline & $\begin{array}{c}\text { Cloreto Férrico } \\
(\mathrm{mg} / \mathrm{\ell})\end{array}$ & $\begin{array}{c}\text { Ácido } \\
\text { Clorídrico } \\
\mathbf{0 . 1 N}(\mathrm{m} \ell / \ell) \\
\end{array}$ & $\begin{array}{c}\text { Hidróxido de } \\
\text { Sódio } 0.1 \mathrm{~N}(\mathrm{~m} \ell / \ell)\end{array}$ & & & \\
\hline 1 & 160 & - & 33.5 & 6.06 & 12 & 5 \\
\hline 2 & 200 & - & 48.0 & 6.29 & 9 & 17 \\
\hline 3 & 200 & - & 50.0 & 6.48 & 14 & 23 \\
\hline 4 & 180 & - & 48.0 & 6.88 & 5 & 12 \\
\hline 5 & 180 & - & 50.0 & 7.13 & 7 & 12 \\
\hline 6 & 160 & - & 48.0 & 7.62 & - & - \\
\hline
\end{tabular}




\section{ESTUDO DE COAGULAÇÃO-FLOCULAÇÃO-SEDIMENTAÇÃO}

\begin{tabular}{|c|c|c|c|c|c|}
\hline ENSAIO $\mathbf{N}^{\circ}: 15$ & COAGULANTE & \multicolumn{2}{|c|}{ MISTURA RÁPIDA } & \multicolumn{2}{c|}{ FLOCULAČ̃̃ } \\
\cline { 3 - 5 } Data $: 16 / 04 / 00$ & Cloreto Férrico & Tmr $=\mathbf{5 s}$ & $\mathbf{G m r}=\mathbf{1 0 0 0 s}^{-1}$ & $\mathbf{T f}=\mathbf{3 0 m i n}$ & $\mathbf{G f}^{-1}=\mathbf{1 5 s}^{-1}$ \\
\hline
\end{tabular}

\begin{tabular}{|c|c|c|c|c|c|c|c|}
\hline \multicolumn{8}{|c|}{ CARACTERÍSTICAS DA ÁGUA DE ESTUDO } \\
\hline \multirow{2}{*}{ Turbidez (uT) } & \multirow{2}{*}{$\begin{array}{c}\text { Cor Aparente } \\
\text { (uC) }\end{array}$} & \multirow{2}{*}{$\begin{array}{c}\text { Cor Verdadeira } \\
\text { (uC) }\end{array}$} & \multirow{2}{*}{$\begin{array}{c}\text { Alcalinidade Total } \\
\left(\mathrm{mg} / \ell \mathrm{CaCO}_{3}\right)\end{array}$} & \multicolumn{2}{|c|}{ pH } & \multirow{2}{*}{$\begin{array}{c}\text { Temperatura } \\
{ }^{\circ} \mathrm{C} \\
\end{array}$} & \multirow{2}{*}{$\begin{array}{l}\text { Potencial } \\
\text { Zeta }(\mathrm{mV})\end{array}$} \\
\hline & & & & S/ agit. & $\mathrm{C} /$ agit. & & \\
\hline 5.75 & 137 & 100 & 29.1 & 7.94 & 7.49 & 25 & - \\
\hline
\end{tabular}

\begin{tabular}{|c|c|c|c|c|c|c|}
\hline \multirow{2}{*}{ FRASCO } & \multicolumn{3}{|c|}{ DOSAGEM DE PRODUTO QUÍMICO } & \multirow{2}{*}{$\begin{array}{c}\text { pH } \\
\text { de } \\
\text { Coagulação }\end{array}$} & \multirow{2}{*}{$\begin{array}{c}T_{\mathrm{s} 2}=7,00 \mathrm{~min} \\
V_{\mathrm{s} 2}=1.0 \mathrm{~cm} / \mathrm{min} \\
\begin{array}{c}\mathrm{Cor} \\
(\mathrm{uC})\end{array}\end{array}$} & \multirow{2}{*}{$\begin{array}{c}T_{\mathrm{s} 1}=3,50 \mathrm{~min} \\
V_{\mathrm{s} 1}=2.0 \mathrm{~cm} / \mathrm{min} \\
\begin{array}{c}\mathrm{Cor} \\
(\mathrm{uC})\end{array}\end{array}$} \\
\hline & $\begin{array}{c}\text { Cloreto Férrico } \\
(\mathrm{mg} / \mathfrak{\ell})\end{array}$ & $\begin{array}{c}\text { Ácido } \\
\text { Clorídrico } \\
\text { 0.1N(m/ } / \ell) \\
\end{array}$ & $\begin{array}{c}\text { Hidróxido de } \\
\text { Sódio } 0.1 \mathrm{~N}(\mathrm{~m} \ell / \ell)\end{array}$ & & & \\
\hline 1 & 220 & - & 47.0 & 5.36 & - & - \\
\hline 2 & 220 & - & 48.0 & 5.60 & 80 & 90 \\
\hline 3 & 220 & - & $50 . .0$ & 5.80 & 11 & 19 \\
\hline 4 & 200 & - & 52.0 & 6.57 & 27 & 20 \\
\hline 5 & 200 & - & 54.0 & 6.84 & 7 & 12 \\
\hline 6 & 180 & - & 52.0 & 7.33 & 18 & 32 \\
\hline
\end{tabular}

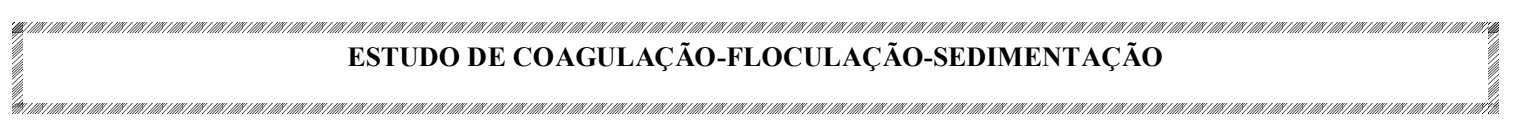

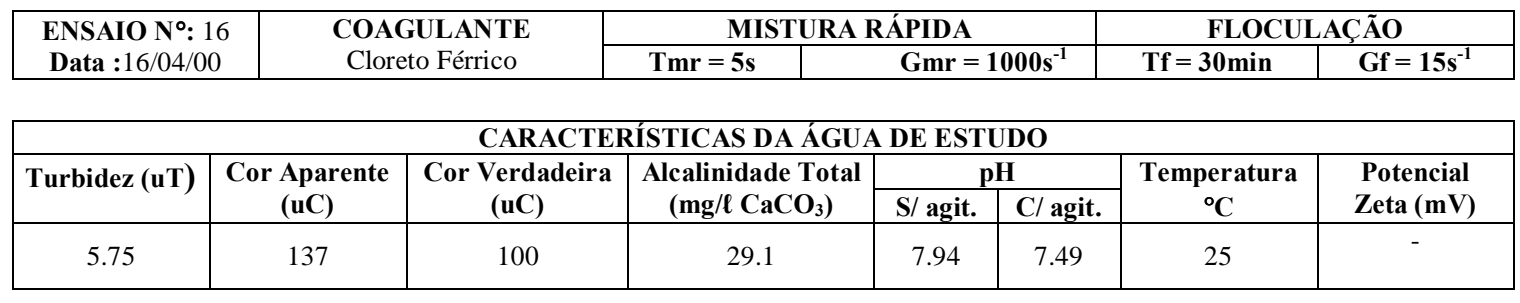

\begin{tabular}{|c|c|c|c|c|c|c|}
\hline \multirow{2}{*}{ FRASCO } & \multicolumn{3}{|c|}{ DOSAGEM DE PRODUTO QUÍMICO } & \multirow{2}{*}{$\begin{array}{c}\text { pH } \\
\text { de } \\
\text { Coagulação }\end{array}$} & \multirow{2}{*}{$\begin{array}{c}T_{\mathrm{s} 2}=7,00 \mathrm{~min} \\
V_{\mathrm{s} 2}=1.0 \mathrm{~cm} / \mathrm{min} \\
\begin{array}{c}\mathrm{Cor} \\
(\mathrm{uC})\end{array}\end{array}$} & \multirow{2}{*}{$\begin{array}{c}T_{\mathrm{s} 1}=3,50 \mathrm{~min} \\
V_{\mathrm{s} 1}=2.0 \mathrm{~cm} / \mathrm{min} \\
\begin{array}{c}\mathrm{Cor} \\
(\mathrm{uC})\end{array}\end{array}$} \\
\hline & $\begin{array}{c}\text { Cloreto Férrico } \\
(\mathrm{mg} / \mathrm{\ell})\end{array}$ & $\begin{array}{c}\text { Ácido } \\
\text { Clorídrico } \\
0.1 \mathrm{~N}(\mathrm{~m} \ell / \ell) \\
\end{array}$ & 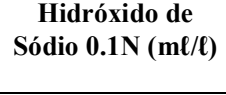 & & & \\
\hline 1 & 220 & - & 52.0 & 6.08 & 9 & 10 \\
\hline 2 & 220 & - & 54.0 & 6.30 & 18 & 29 \\
\hline 3 & 220 & - & 56.0 & 6.48 & 21 & 35 \\
\hline 4 & 200 & - & 56.0 & 7.09 & 10 & 9 \\
\hline 5 & 200 & - & 58.0 & 7.37 & 20 & 36 \\
\hline 6 & 180 & - & 54.0 & 7.60 & - & - \\
\hline
\end{tabular}




\section{ESTUDO DE COAGULAÇÃO-FLOCULAÇÃO-SEDIMENTAÇÃO}

\begin{tabular}{|c|c|c|c|c|c|}
\hline ENSAIO $\mathbf{N}^{\circ}: 17$ & COAGULANTE & \multicolumn{2}{|c|}{ MISTURA RÁPIDA } & \multicolumn{2}{c|}{ FLOCULAČ̃̃ } \\
\cline { 3 - 5 } Data $: 16 / 04 / 00$ & Cloreto Férrico & Tmr $=\mathbf{5 s}$ & $\mathbf{G m r}=\mathbf{1 0 0 0 s}^{-1}$ & $\mathbf{T f}=\mathbf{3 0 m i n}$ & $\mathbf{G f}^{-1}=\mathbf{1 5 s}^{-1}$ \\
\hline
\end{tabular}

\begin{tabular}{|c|c|c|c|c|c|c|c|}
\hline \multicolumn{8}{|c|}{ CARACTERÍSTICAS DA ÁGUA DE ESTUDO } \\
\hline \multirow{2}{*}{ Turbidez (uT) } & \multirow{2}{*}{$\begin{array}{c}\text { Cor Aparente } \\
\text { (uC) }\end{array}$} & \multirow{2}{*}{$\begin{array}{c}\text { Cor Verdadeira } \\
\text { (uC) }\end{array}$} & \multirow{2}{*}{$\begin{array}{c}\text { Alcalinidade Total } \\
\left(\mathrm{mg} / \ell \mathrm{CaCO}_{3}\right)\end{array}$} & \multicolumn{2}{|c|}{ pH } & \multirow{2}{*}{$\begin{array}{c}\text { Temperatura } \\
{ }^{\circ} \mathrm{C} \\
\end{array}$} & \multirow{2}{*}{$\begin{array}{l}\text { Potencial } \\
\text { Zeta }(\mathrm{mV})\end{array}$} \\
\hline & & & & S/ agit. & $\mathrm{C} /$ agit. & & \\
\hline 5.75 & 137 & 100 & 29.1 & 7.94 & 7.49 & 25 & - \\
\hline
\end{tabular}

\begin{tabular}{|c|c|c|c|c|c|c|}
\hline \multirow{2}{*}{ FRASCO } & \multicolumn{3}{|c|}{ DOSAGEM DE PRODUTO QUÍMICO } & \multirow{2}{*}{$\begin{array}{c}\text { pH } \\
\text { de } \\
\text { Coagulação }\end{array}$} & \multirow{2}{*}{$\begin{array}{c}T_{\mathrm{s} 2}=7,00 \mathrm{~min} \\
V_{\mathrm{s} 2}=1.0 \mathrm{~cm} / \mathrm{min} \\
\begin{array}{c}\mathrm{Cor} \\
(\mathrm{uC})\end{array}\end{array}$} & \multirow{2}{*}{$\begin{array}{c}T_{\mathrm{s} 1}=3,50 \mathrm{~min} \\
\frac{V_{\mathrm{s} 1}=2.0 \mathrm{~cm} / \mathrm{min}}{\mathrm{Cor}} \\
(\mathrm{uC})\end{array}$} \\
\hline & $\begin{array}{c}\text { Cloreto Férrico } \\
(\mathrm{mg} / \mathfrak{\ell})\end{array}$ & 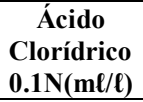 & $\begin{array}{c}\text { Hidróxido de } \\
\text { Sódio } 0.1 \mathrm{~N}(\mathrm{~m} \ell / \ell)\end{array}$ & & & \\
\hline 1 & 200 & - & 43.0 & 5.84 & 8 & 19 \\
\hline 2 & 180 & - & 37.0 & 5.79 & 11 & 20 \\
\hline 3 & 220 & - & 58.0 & 6.58 & 11 & 46 \\
\hline 4 & 200 & - & 53.0 & 6.68 & 25 & 42 \\
\hline 5 & 220 & - & 60.0 & 6.76 & 6 & 44 \\
\hline 6 & 200 & - & 60.0 & 7.26 & 11 & 22 \\
\hline
\end{tabular}

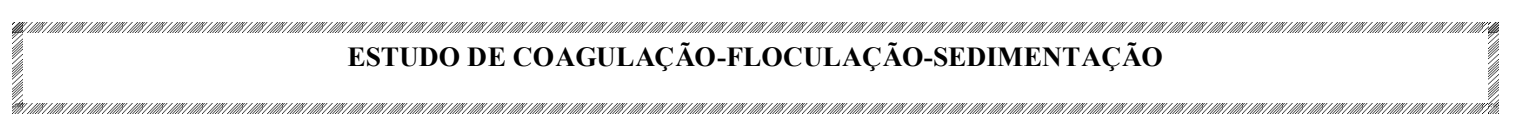

\begin{tabular}{|c|c|c|c|c|c|c|c|}
\hline \multirow{2}{*}{$\begin{array}{l}\text { ENSAIO No: } 1 \\
\text { Data : } 16 / 04 / 0\end{array}$} & \multirow{2}{*}{\multicolumn{2}{|c|}{$\begin{array}{l}\text { COAGULANTE } \\
\text { Cloreto Férrico }\end{array}$}} & \multicolumn{3}{|c|}{ MISTURA RÁPIDA } & \multicolumn{2}{|c|}{ FLOCULAÇÃO } \\
\hline & & & Tmr $=5 \mathrm{~s}$ & \multicolumn{2}{|c|}{$\mathrm{Gmr}=1000 \mathrm{~s}^{-1}$} & $T f=30 \mathrm{~min}$ & $G f=15 s^{-1}$ \\
\hline \multicolumn{8}{|c|}{ CARACTERÍSTICAS DA ÁGUA DE ESTUDO } \\
\hline \multirow[t]{2}{*}{ Turbidez (uT) } & \multirow{2}{*}{$\begin{array}{c}\text { Cor Aparente } \\
\text { (uC) }\end{array}$} & \multirow{2}{*}{$\begin{array}{c}\text { Cor Verdadeira } \\
(\mathrm{uC})\end{array}$} & \multirow{2}{*}{$\begin{array}{l}\text { Alcalinidade Total } \\
\left(\mathrm{mg} / \ell \mathrm{CaCO}_{3}\right)\end{array}$} & \multicolumn{2}{|c|}{ pH } & \multirow{2}{*}{$\begin{array}{c}\text { Temperatura } \\
{ }^{\circ} \mathrm{C} \\
\end{array}$} & \multirow{2}{*}{$\begin{array}{r}\text { Potencial } \\
\text { Zeta }(\mathrm{mV}) \\
\end{array}$} \\
\hline & & & & S/agit. & $\mathrm{C} /$ agit. & & \\
\hline 5.75 & 137 & 100 & 29.1 & 7.94 & 7.49 & 25 & 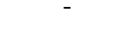 \\
\hline
\end{tabular}

\begin{tabular}{|c|c|c|c|c|c|c|}
\hline \multirow{2}{*}{ FRASCO } & \multicolumn{3}{|c|}{ DOSAGEM DE PRODUTO QUÍMICO } & \multirow{2}{*}{$\begin{array}{c}\text { pH } \\
\text { de } \\
\text { Coagulação }\end{array}$} & \multirow{2}{*}{$\begin{array}{c}T_{\mathrm{s} 2}=7,00 \mathrm{~min} \\
V_{\mathrm{s} 2}=1.0 \mathrm{~cm} / \mathrm{min} \\
\begin{array}{c}\mathrm{Cor} \\
(\mathrm{uC})\end{array}\end{array}$} & \multirow{2}{*}{$\begin{array}{c}T_{\mathrm{s} 1}=3,50 \mathrm{~min} \\
V_{\mathrm{s} 1}=2.0 \mathrm{~cm} / \mathrm{min} \\
\begin{array}{c}\mathrm{Cor} \\
(\mathrm{uC})\end{array}\end{array}$} \\
\hline & $\begin{array}{c}\text { Cloreto Férrico } \\
(\mathrm{mg} / \ell)\end{array}$ & $\begin{array}{c}\text { Ácido } \\
\text { Clorídrico } \\
\text { 0.1N }(m \ell / \ell)\end{array}$ & $\begin{array}{c}\text { Hidróxido de } \\
\text { Sódio } 0.1 \mathrm{~N}(\mathrm{~m} \ell / \ell)\end{array}$ & & & \\
\hline 1 & 240 & - & 54.0 & 5.43 & - & - \\
\hline 2 & 240 & - & 55.0 & 5.77 & 12 & 21 \\
\hline 3 & 240 & - & 56.0 & 5.97 & 8 & 17 \\
\hline 4 & 240 & - & 58.0 & 6.22 & 11 & 17 \\
\hline 5 & 240 & - & 60.0 & 5.43 & 19 & 31 \\
\hline 6 & 240 & - & 62.0 & 6.57 & 18 & 38 \\
\hline
\end{tabular}




\section{ESTUDO DE COAGULAÇÃO-FLOCULAÇÃO-SEDIMENTAÇÃO}

\begin{tabular}{|l|c|c|c|c|c|}
\hline ENSAIO $\mathbf{N}^{\circ}: 19$ & COAGULANTE & \multicolumn{2}{|c|}{ MISTURA RÁPIDA } & \multicolumn{2}{c|}{ FLOCULAČ̃̃ } \\
\cline { 3 - 5 } Data $: 16 / 04 / 00$ & Cloreto Férrico & Tmr $=\mathbf{5 s}$ & $\mathbf{G m r}=\mathbf{1 0 0 0 s}^{-1}$ & $\mathbf{T f}=\mathbf{3 0 m i n}$ & $\mathbf{G f}^{-1}=\mathbf{1 5 s}^{-1}$ \\
\hline
\end{tabular}

\begin{tabular}{|c|c|c|c|c|c|c|c|}
\hline \multicolumn{8}{|c|}{ CARACTERÍSTICAS DA ÁGUA DE ESTUDO } \\
\hline \multirow{2}{*}{ Turbidez (uT) } & \multirow{2}{*}{$\begin{array}{c}\text { Cor Aparente } \\
\text { (uC) }\end{array}$} & \multirow{2}{*}{$\begin{array}{c}\text { Cor Verdadeira } \\
\text { (uC) }\end{array}$} & \multirow{2}{*}{$\begin{array}{l}\text { Alcalinidade Total } \\
\left(\mathrm{mg} / \ell \mathrm{CaCO}_{3}\right)\end{array}$} & \multicolumn{2}{|c|}{ pH } & \multirow{2}{*}{$\begin{array}{c}\text { Temperatura } \\
{ }^{\circ} \mathrm{C}\end{array}$} & \multirow{2}{*}{$\begin{array}{l}\text { Potencial } \\
\text { Zeta }(\mathrm{mV})\end{array}$} \\
\hline & & & & S/ agit. & $\mathrm{C} /$ agit. & & \\
\hline 5.75 & 137 & 100 & 29.1 & 7.94 & 7.49 & 25 & - \\
\hline
\end{tabular}

\begin{tabular}{|c|c|c|c|c|c|c|}
\hline \multirow{2}{*}{ FRASCO } & \multicolumn{3}{|c|}{ DOSAGEM DE PRODUTO QUÍMICO } & \multirow{2}{*}{$\begin{array}{c}\text { pH } \\
\text { de } \\
\text { Coagulação }\end{array}$} & \multirow{2}{*}{$\begin{array}{c}T_{\mathrm{s} 2}=7,00 \mathrm{~min} \\
V_{\mathrm{s} 2}=1.0 \mathrm{~cm} / \mathrm{min} \\
\begin{array}{c}\mathrm{Cor} \\
(\mathrm{uC})\end{array}\end{array}$} & \multirow{2}{*}{$\begin{array}{c}T_{\mathrm{s} 1}=3,50 \mathrm{~min} \\
V_{\mathrm{s} 1}=2.0 \mathrm{~cm} / \mathrm{min} \\
\begin{array}{c}\mathrm{Cor} \\
(\mathrm{uC})\end{array}\end{array}$} \\
\hline & $\begin{array}{c}\text { Cloreto Férrico } \\
(\mathrm{mg} / \mathfrak{\ell})\end{array}$ & $\begin{array}{c}\text { Ácido } \\
\text { Clorídrico } \\
\text { 0.1N(m/ } / \ell) \\
\end{array}$ & $\begin{array}{c}\text { Hidróxido de } \\
\text { Sódio } 0.1 \mathrm{~N}(\mathrm{~m} \ell / \ell)\end{array}$ & & & \\
\hline 1 & 240 & - & 64.0 & 6.65 & 11 & 44 \\
\hline 2 & 240 & - & 66.0 & 6.87 & 4 & 17 \\
\hline 3 & 220 & - & 62.0 & 7.13 & 5 & 12 \\
\hline 4 & 220 & - & 64.0 & 7.45 & 19 & 22 \\
\hline 5 & 220 & - & 66.0 & 7.69 & - & - \\
\hline 6 & 200 & - & 62.0 & 7.84 & - & - \\
\hline
\end{tabular}

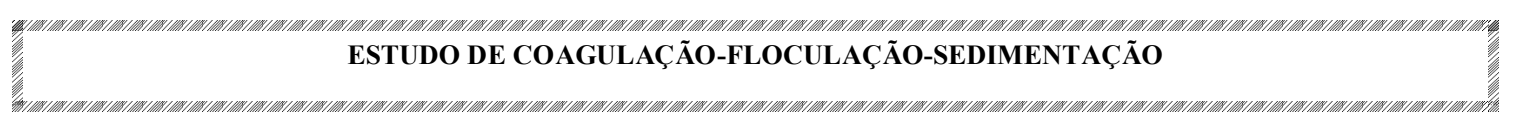

\begin{tabular}{|c|c|c|c|c|c|c|c|}
\hline \multirow{2}{*}{$\begin{array}{l}\text { ENSAIO } \mathbf{N}^{\circ}: 20 \\
\text { Data }: 16 / 04 / 00\end{array}$} & \multirow{2}{*}{\multicolumn{2}{|c|}{$\begin{array}{l}\text { COAGULANTE } \\
\text { Cloreto Férrico }\end{array}$}} & \multicolumn{3}{|c|}{ MISTURA RÁPIDA } & \multicolumn{2}{|c|}{ FLOCULAÇÃO } \\
\hline & & & Tmr $=5 \mathrm{~s}$ & \multicolumn{2}{|c|}{$\mathrm{Gmr}=1000 \mathrm{~s}^{-1}$} & $\mathbf{T f}=30 \mathrm{~min}$ & $\mathbf{G f}=15 \mathrm{~s}^{-1}$ \\
\hline \multicolumn{8}{|c|}{ CARACTERÍSTICAS DA ÁGUA DE ESTUDO } \\
\hline \multirow[t]{2}{*}{ Turbidez (uT) } & \multirow{2}{*}{$\begin{array}{c}\text { Cor Aparente } \\
\text { (uC) }\end{array}$} & \multirow{2}{*}{$\begin{array}{c}\text { Cor Verdadeira } \\
(\mathrm{uC})\end{array}$} & \multirow{2}{*}{$\begin{array}{l}\text { Alcalinidade Total } \\
\left(\mathrm{mg} / \ell \mathrm{CaCO}_{3}\right)\end{array}$} & \multicolumn{2}{|c|}{ pH } & \multirow{2}{*}{$\begin{array}{c}\text { Temperatura } \\
{ }^{\circ} \mathrm{C} \\
\end{array}$} & \multirow{2}{*}{$\begin{array}{r}\text { Potencial } \\
\text { Zeta }(\mathrm{mV}) \\
\end{array}$} \\
\hline & & & & S/ agit. & $\mathrm{C} /$ agit. & & \\
\hline 5.75 & 137 & 100 & 29.1 & 7.94 & 7.49 & 25 & 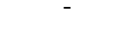 \\
\hline
\end{tabular}

\begin{tabular}{|c|c|c|c|c|c|c|}
\hline \multirow{2}{*}{ FRASCO } & \multicolumn{3}{|c|}{ DOSAGEM DE PRODUTO QUÍMICO } & \multirow{2}{*}{$\begin{array}{c}\text { pH } \\
\text { de } \\
\text { Coagulação }\end{array}$} & \multirow{2}{*}{$\begin{array}{c}T_{\mathrm{s} 2}=7,00 \mathrm{~min} \\
V_{\mathrm{s} 2}=1.0 \mathrm{~cm} / \mathrm{min} \\
\begin{array}{c}\text { Cor } \\
(\mathrm{uC})\end{array}\end{array}$} & \multirow{2}{*}{$\begin{array}{c}T_{\mathrm{s} 1}=3,50 \mathrm{~min} \\
V_{\mathrm{s} 1}=2.0 \mathrm{~cm} / \mathrm{min} \\
\begin{array}{c}\mathrm{Cor} \\
(\mathrm{uC})\end{array}\end{array}$} \\
\hline & $\begin{array}{c}\text { Cloreto Férrico } \\
(\mathrm{mg} / \ell)\end{array}$ & $\begin{array}{c}\text { Ácido } \\
\text { Clorídrico } \\
\mathbf{0 . 1}(\mathrm{m} / / \mathrm{l}) \\
\end{array}$ & $\begin{array}{c}\text { Hidróxido de } \\
\text { Sódio } 0.1 \mathrm{~N}(\mathrm{~m} \ell / \ell)\end{array}$ & & & \\
\hline 1 & 260 & - & 60.0 & 5.48 & - & - \\
\hline 2 & 260 & - & 61.0 & 5.86 & 7 & 10 \\
\hline 3 & 260 & - & 62.0 & 5.85 & 10 & 12 \\
\hline 4 & 260 & - & 63.0 & 6.03 & 10 & 13 \\
\hline 5 & 260 & - & 65.0 & 6.20 & 16 & 37 \\
\hline 6 & 240 & - & 68.0 & 7.03 & 5 & 24 \\
\hline
\end{tabular}




\section{ESTUDO DE COAGULAÇÃO-FLOCULAÇÃO-SEDIMENTAÇÃO}

\begin{tabular}{|l|c|c|c|c|c|}
\hline ENSAIO $\mathbf{N}^{\circ}: 21$ & COAGULANTE & \multicolumn{2}{|c|}{ MISTURA RÁPIDA } & \multicolumn{2}{c|}{ FLOCULAČ̃̃ } \\
\cline { 3 - 5 } Data $: 16 / 04 / 00$ & Cloreto Férrico & Tmr $=\mathbf{5 s}$ & $\mathbf{G m r}=\mathbf{1 0 0 0 s}^{-1}$ & $\mathbf{T f}=\mathbf{3 0 m i n}$ & $\mathbf{G f}^{-1}=\mathbf{1 5 s}^{-1}$ \\
\hline
\end{tabular}

\begin{tabular}{|c|c|c|c|c|c|c|c|}
\hline \multicolumn{8}{|c|}{ CARACTERÍSTICAS DA ÁGUA DE ESTUDO } \\
\hline \multirow{2}{*}{ Turbidez (uT) } & \multirow{2}{*}{$\begin{array}{c}\text { Cor Aparente } \\
\text { (uC) }\end{array}$} & \multirow{2}{*}{$\begin{array}{c}\text { Cor Verdadeira } \\
\text { (uC) }\end{array}$} & \multirow{2}{*}{$\begin{array}{l}\text { Alcalinidade Total } \\
\left(\mathrm{mg} / \ell \mathrm{CaCO}_{3}\right)\end{array}$} & \multicolumn{2}{|c|}{ pH } & \multirow{2}{*}{$\begin{array}{c}\text { Temperatura } \\
{ }^{\circ} \mathrm{C}\end{array}$} & \multirow{2}{*}{$\begin{array}{l}\text { Potencial } \\
\text { Zeta }(\mathrm{mV})\end{array}$} \\
\hline & & & & S/ agit. & $\mathrm{C} /$ agit. & & \\
\hline 5.75 & 137 & 100 & 29.1 & 7.94 & 7.49 & 25 & - \\
\hline
\end{tabular}

\begin{tabular}{|c|c|c|c|c|c|c|}
\hline \multirow{2}{*}{ FRASCO } & \multicolumn{3}{|c|}{ DOSAGEM DE PRODUTO QUÍMICO } & \multirow{2}{*}{$\begin{array}{c}\text { pH } \\
\text { de } \\
\text { Coagulação }\end{array}$} & \multirow{2}{*}{$\begin{array}{c}T_{\mathrm{s} 2}=7,00 \mathrm{~min} \\
V_{\mathrm{s} 2}=1.0 \mathrm{~cm} / \mathrm{min} \\
\begin{array}{c}\mathrm{Cor} \\
(\mathrm{uC})\end{array}\end{array}$} & \multirow{2}{*}{$\begin{array}{c}T_{\mathrm{s} 1}=3,50 \mathrm{~min} \\
V_{\mathrm{s} 1}=2.0 \mathrm{~cm} / \mathrm{min} \\
\begin{array}{c}\mathrm{Cor} \\
(\mathrm{uC})\end{array}\end{array}$} \\
\hline & $\begin{array}{c}\text { Cloreto Férrico } \\
(\mathrm{mg} / \mathfrak{\ell})\end{array}$ & $\begin{array}{c}\text { Ácido } \\
\text { Clorídrico } \\
\text { 0.1N(m/ } / \ell) \\
\end{array}$ & $\begin{array}{c}\text { Hidróxido de } \\
\text { Sódio } 0.1 \mathrm{~N}(\mathrm{~m} \ell / \ell)\end{array}$ & & & \\
\hline 1 & 260 & - & 67.0 & 6.57 & 32 & 19 \\
\hline 2 & 260 & - & 69.0 & 6.76 & 18 & 25 \\
\hline 3 & 220 & - & 61.0 & 7.06 & 11 & 32 \\
\hline 4 & 220 & - & 63.0 & 7.29 & 13 & 35 \\
\hline 5 & 240 & - & 70.0 & 7.42 & 16 & 20 \\
\hline 6 & 200 & - & 61.0 & 7.79 & - & - \\
\hline
\end{tabular}

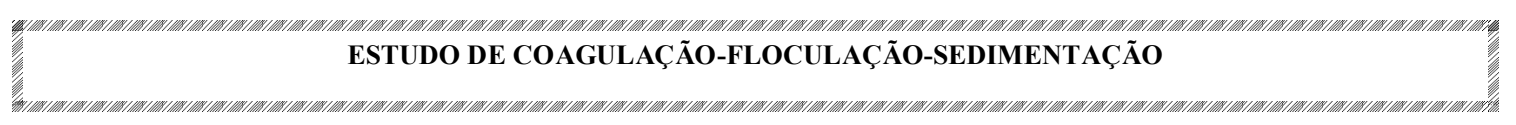

\begin{tabular}{|c|c|c|c|c|c|c|c|}
\hline \multirow{2}{*}{$\begin{array}{l}\text { ENSAIO N}^{\circ}: 22 \\
\text { Data : } 16 / 04 / 00\end{array}$} & \multirow{2}{*}{\multicolumn{2}{|c|}{$\begin{array}{l}\text { COAGULANTE } \\
\text { Cloreto Férrico }\end{array}$}} & \multicolumn{3}{|c|}{ MISTURA RÁPIDA } & \multicolumn{2}{|c|}{ FLOCULAÇÃO } \\
\hline & & & Tmr $=5 \mathrm{~s}$ & \multicolumn{2}{|c|}{ Gmr $=1000 s^{-1}$} & $T f=30 \mathrm{~min}$ & $G f=15 s^{-1}$ \\
\hline \multicolumn{8}{|c|}{ CARACTERÍSTICAS DA ÁGUA DE ESTUDO } \\
\hline \multirow[t]{2}{*}{ Turbidez (uT) } & \multirow{2}{*}{$\begin{array}{c}\text { Cor Aparente } \\
\text { (uC) }\end{array}$} & \multirow{2}{*}{$\begin{array}{c}\text { Cor Verdadeira } \\
(\mathrm{uC})\end{array}$} & \multirow{2}{*}{$\begin{array}{l}\text { Alcalinidade Total } \\
\left(\mathrm{mg} / \ell \mathrm{CaCO}_{3}\right)\end{array}$} & \multicolumn{2}{|c|}{ pH } & \multirow{2}{*}{$\begin{array}{c}\text { Temperatura } \\
{ }^{\circ} \mathrm{C} \\
\end{array}$} & \multirow{2}{*}{$\begin{array}{r}\text { Potencial } \\
\text { Zeta }(\mathrm{mV}) \\
\end{array}$} \\
\hline & & & & S/agit. & $\mathrm{C} /$ agit. & & \\
\hline 5.75 & 137 & 100 & 29.1 & 7.94 & 7.49 & 25 & 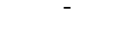 \\
\hline
\end{tabular}

\begin{tabular}{|c|c|c|c|c|c|c|}
\hline \multirow{2}{*}{ FRASCO } & \multicolumn{3}{|c|}{ DOSAGEM DE PRODUTO QUÍMICO } & \multirow{2}{*}{$\begin{array}{c}\text { pH } \\
\text { de } \\
\text { Coagulação }\end{array}$} & \multirow{2}{*}{$\begin{array}{c}T_{\mathrm{s} 2}=7,00 \mathrm{~min} \\
V_{\mathrm{s} 2}=1.0 \mathrm{~cm} / \mathrm{min} \\
\begin{array}{c}\mathrm{Cor} \\
(\mathrm{uC})\end{array}\end{array}$} & \multirow{2}{*}{$\begin{array}{c}T_{\mathrm{s} 1}=3,50 \mathrm{~min} \\
V_{\mathrm{s} 1}=2.0 \mathrm{~cm} / \mathrm{min} \\
\begin{array}{c}\mathrm{Cor} \\
(\mathrm{uC})\end{array}\end{array}$} \\
\hline & $\begin{array}{c}\text { Cloreto Férrico } \\
(\mathrm{mg} / \mathrm{l})\end{array}$ & $\begin{array}{c}\text { Ácido } \\
\text { Clorídrico } \\
\mathbf{0 . 1 N}(\mathrm{m} \ell / \ell) \\
\end{array}$ & 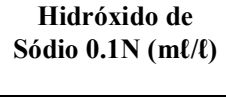 & & & \\
\hline 1 & 280 & - & 67.0 & 5.90 & 11 & 15 \\
\hline 2 & 280 & - & 68.0 & 6.15 & 15 & 18 \\
\hline 3 & - & - & - & - & - & - \\
\hline 4 & 260 & - & 71.0 & 6.10 & 7 & 25 \\
\hline 5 & 260 & - & 73.0 & 6.75 & 15 & 30 \\
\hline 6 & 240 & - & 72.0 & 6.60 & 16 & 47 \\
\hline
\end{tabular}




\section{ESTUDO DE COAGULAÇÃO-FLOCULAÇÃO-SEDIMENTAÇÃO}

\begin{tabular}{|l|c|c|c|c|c|}
\hline ENSAIO $\mathbf{N}^{\circ}: 23$ & COAGULANTE & \multicolumn{2}{|c|}{ MISTURA RÁPIDA } & \multicolumn{2}{c|}{ FLOCULAČ̃̃ } \\
\cline { 3 - 5 } Data $: 16 / 04 / 00$ & Cloreto Férrico & Tmr $=\mathbf{5 s}$ & $\mathbf{G m r}=\mathbf{1 0 0 0 s}^{-1}$ & $\mathbf{T f}=\mathbf{3 0 m i n}$ & $\mathbf{G f}^{-1}=\mathbf{1 5 s}^{-1}$ \\
\hline
\end{tabular}

\begin{tabular}{|c|c|c|c|c|c|c|c|}
\hline \multicolumn{8}{|c|}{ CARACTERÍSTICAS DA ÁGUA DE ESTUDO } \\
\hline \multirow{2}{*}{ Turbidez (uT) } & \multirow{2}{*}{$\begin{array}{c}\text { Cor Aparente } \\
\text { (uC) }\end{array}$} & \multirow{2}{*}{$\begin{array}{c}\text { Cor Verdadeira } \\
\text { (uC) }\end{array}$} & \multirow{2}{*}{$\begin{array}{l}\text { Alcalinidade Total } \\
\left(\mathrm{mg} / \ell \mathrm{CaCO}_{3}\right)\end{array}$} & \multicolumn{2}{|c|}{ pH } & \multirow{2}{*}{$\begin{array}{c}\text { Temperatura } \\
{ }^{\circ} \mathrm{C}\end{array}$} & \multirow{2}{*}{$\begin{array}{l}\text { Potencial } \\
\text { Zeta }(\mathrm{mV})\end{array}$} \\
\hline & & & & S/ agit. & $\mathrm{C} /$ agit. & & \\
\hline 5.75 & 137 & 100 & 29.1 & 7.94 & 7.49 & 25 & - \\
\hline
\end{tabular}

\begin{tabular}{|c|c|c|c|c|c|c|}
\hline \multirow{2}{*}{ FRASCO } & \multicolumn{3}{|c|}{ DOSAGEM DE PRODUTO QUÍMICO } & \multirow{2}{*}{$\begin{array}{c}\text { pH } \\
\text { de } \\
\text { Coagulação }\end{array}$} & \multirow{2}{*}{$\begin{array}{c}T_{\mathrm{s} 2}=7,00 \mathrm{~min} \\
V_{\mathrm{s} 2}=1.0 \mathrm{~cm} / \mathrm{min} \\
\begin{array}{c}\mathrm{Cor} \\
(\mathrm{uC})\end{array}\end{array}$} & \multirow{2}{*}{$\begin{array}{c}T_{\mathrm{s} 1}=3,50 \mathrm{~min} \\
V_{\mathrm{s} 1}=2.0 \mathrm{~cm} / \mathrm{min} \\
\begin{array}{c}\mathrm{Cor} \\
(\mathrm{uC})\end{array}\end{array}$} \\
\hline & $\begin{array}{c}\text { Cloreto Férrico } \\
(\mathrm{mg} / \mathfrak{\ell})\end{array}$ & $\begin{array}{c}\text { Ácido } \\
\text { Clorídrico } \\
\text { 0.1N(m/ } / \ell) \\
\end{array}$ & $\begin{array}{c}\text { Hidróxido de } \\
\text { Sódio } 0.1 \mathrm{~N}(\mathrm{~m} \ell / \ell)\end{array}$ & & & \\
\hline 1 & 240 & - & 54.5 & 5.90 & 8 & 12 \\
\hline 2 & 260 & - & 60.5 & 5.79 & 15 & 16 \\
\hline 3 & 260 & - & 66.0 & 6.31 & 10 & 29 \\
\hline 4 & 220 & - & 60.5 & 6.91 & 5 & 13 \\
\hline 5 & 240 & - & 69.0 & 7.29 & 12 & 23 \\
\hline 6 & 240 & - & 74.0 & 7.78 & - & - \\
\hline
\end{tabular}

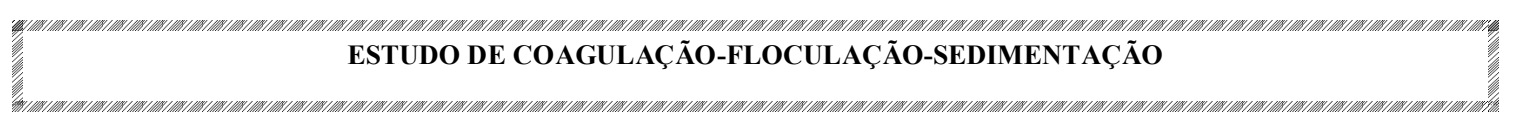

\begin{tabular}{|c|c|c|c|c|c|c|c|}
\hline \multirow{2}{*}{$\begin{array}{l}\text { ENSAIO No: } 24 \\
\text { Data : } 16 / 04 / 00\end{array}$} & \multirow{2}{*}{\multicolumn{2}{|c|}{$\begin{array}{l}\text { COAGULANTE } \\
\text { Cloreto Férrico }\end{array}$}} & \multicolumn{3}{|c|}{ MISTURA RÁPIDA } & \multicolumn{2}{|c|}{ FLOCULAÇÃO } \\
\hline & & & Tmr $=5 \mathrm{~s}$ & \multicolumn{2}{|c|}{$\mathrm{Gmr}=1000 \mathrm{~s}^{-1}$} & $\mathbf{T f}=30 \mathrm{~min}$ & $\mathbf{G f}=15 \mathrm{~s}^{-1}$ \\
\hline \multicolumn{8}{|c|}{ CARACTERÍSTICAS DA ÁGUA DE ESTUDO } \\
\hline \multirow[t]{2}{*}{ Turbidez (uT) } & \multirow{2}{*}{$\begin{array}{c}\text { Cor Aparente } \\
\text { (uC) }\end{array}$} & \multirow{2}{*}{$\begin{array}{c}\text { Cor Verdadeira } \\
(\mathrm{uC})\end{array}$} & \multirow{2}{*}{$\begin{array}{l}\text { Alcalinidade Total } \\
\left(\mathrm{mg} / \ell \mathrm{CaCO}_{3}\right)\end{array}$} & \multicolumn{2}{|c|}{ pH } & \multirow{2}{*}{$\begin{array}{c}\text { Temperatura } \\
{ }^{\circ} \mathrm{C} \\
\end{array}$} & \multirow{2}{*}{$\begin{array}{r}\text { Potencial } \\
\text { Zeta }(\mathrm{mV}) \\
\end{array}$} \\
\hline & & & & S/ agit. & $\mathrm{C} /$ agit. & & \\
\hline 5.75 & 137 & 100 & 29.1 & 7.94 & 7.49 & 25 & 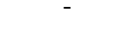 \\
\hline
\end{tabular}

\begin{tabular}{|c|c|c|c|c|c|c|}
\hline \multirow{2}{*}{ FRASCO } & \multicolumn{3}{|c|}{ DOSAGEM DE PRODUTO QUÍMICO } & \multirow{2}{*}{$\begin{array}{c}\text { pH } \\
\text { de } \\
\text { Coagulação }\end{array}$} & \multirow{2}{*}{$\begin{array}{c}T_{\mathrm{s} 2}=7,00 \mathrm{~min} \\
V_{\mathrm{s} 2}=1.0 \mathrm{~cm} / \mathrm{min} \\
\begin{array}{c}\mathrm{Cor} \\
(\mathrm{uC})\end{array}\end{array}$} & \multirow{2}{*}{$\begin{array}{c}T_{\mathrm{s} 1}=3,50 \mathrm{~min} \\
V_{\mathrm{s} 1}=2.0 \mathrm{~cm} / \mathrm{min} \\
\begin{array}{c}\mathrm{Cor} \\
(\mathrm{uC})\end{array} \\
\end{array}$} \\
\hline & $\begin{array}{c}\text { Cloreto Férrico } \\
\text { (mg/ })\end{array}$ & $\begin{array}{c}\text { Ácido } \\
\text { Clorídrico } \\
\text { 0.1N }(\mathrm{m} \ell / \ell) \\
\end{array}$ & 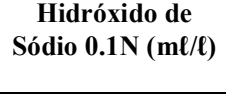 & & & \\
\hline 1 & 280 & - & 66.5 & 5.73 & 26 & 35 \\
\hline 2 & 280 & - & 69.0 & 6.02 & 10 & 18 \\
\hline 3 & 280 & - & 71.0 & 6.31 & 11 & 35 \\
\hline 4 & 280 & - & 73.0 & 6.46 & 10 & 53 \\
\hline 5 & 280 & - & 75.0 & 6.65 & 11 & 24 \\
\hline 6 & 280 & - & 77.0 & 6.78 & 11 & 17 \\
\hline
\end{tabular}


ESTUDO DE COAGULAÇÃ̃O-FLOCULAÇÃO-SEDIMENTAÇÃO

\begin{tabular}{|c|c|c|c|c|c|c|c|}
\hline \multirow{2}{*}{$\begin{array}{l}\text { ENSAIO N}^{\circ}: 25 \\
\text { Data : } 17 / 04 / 00\end{array}$} & \multirow{2}{*}{\multicolumn{2}{|c|}{$\begin{array}{l}\text { COAGULANTE } \\
\text { Cloreto Férrico }\end{array}$}} & \multicolumn{3}{|c|}{ MISTURA RÁPIDA } & \multicolumn{2}{|c|}{ FLOCULAÇÃO } \\
\hline & & & Tmr $=5 \mathrm{~s}$ & \multicolumn{2}{|c|}{$\mathrm{Gmr}=1000 \mathrm{~s}^{-1}$} & Tf $=30 \mathrm{~min}$ & $\mathbf{G f}=15 \mathrm{~s}^{-1}$ \\
\hline \multicolumn{8}{|c|}{ CARACTERÍSTICAS DA ÁGUA DE ESTUDO } \\
\hline \multirow{2}{*}{ Turbidez (uT) } & \multirow{2}{*}{$\begin{array}{c}\text { Cor Aparente } \\
\text { (uC) }\end{array}$} & \multirow{2}{*}{$\begin{array}{c}\text { Cor Verdadeira } \\
\text { (uC) }\end{array}$} & \multirow{2}{*}{$\begin{array}{c}\text { Alcalinidade Total } \\
\left(\mathrm{mg} / \ell \mathrm{CaCO}_{3}\right)\end{array}$} & \multicolumn{2}{|c|}{ pH } & \multirow{2}{*}{$\begin{array}{c}\text { Temperatura } \\
{ }^{\circ} \mathrm{C} \\
\end{array}$} & \multirow{2}{*}{$\begin{array}{r}\text { Potencial } \\
\text { Zeta }(\mathrm{mV})\end{array}$} \\
\hline & & & & S/ agit. & C/ agit. & & \\
\hline 6.31 & 139 & 100 & 30 & 7.98 & 7.62 & 25 & \\
\hline
\end{tabular}

\begin{tabular}{|c|c|c|c|c|c|c|}
\hline \multirow{2}{*}{ FRASCO } & \multicolumn{3}{|c|}{ DOSAGEM DE PRODUTO QUÍMICO } & \multirow{2}{*}{$\begin{array}{c}\text { pH } \\
\text { de } \\
\text { Coagulação }\end{array}$} & \multirow{2}{*}{$\begin{array}{c}T_{\mathrm{s} 2}=7,00 \mathrm{~min} \\
V_{\mathrm{s} 2}=1.0 \mathrm{~cm} / \mathrm{min} \\
\begin{array}{c}\mathrm{Cor} \\
(\mathrm{uC})\end{array}\end{array}$} & \multirow{2}{*}{$\begin{array}{c}T_{\mathrm{s} 1}=3,50 \mathrm{~min} \\
V_{\mathrm{s} 1}=2.0 \mathrm{~cm} / \mathrm{min} \\
\begin{array}{l}\mathrm{Cor} \\
(\mathrm{uC})\end{array}\end{array}$} \\
\hline & $\begin{array}{c}\text { Cloreto Férrico } \\
(\mathrm{mg} / \mathrm{l})\end{array}$ & $\begin{array}{c}\text { Ácido } \\
\text { Clorídrico } \\
0.1 \mathrm{~N}(\mathrm{~m} \ell / \ell) \\
\end{array}$ & $\begin{array}{c}\text { Hidróxido de } \\
\text { Sódio 0.1N }(\mathrm{m} \ell / \ell)\end{array}$ & & & \\
\hline 1 & 240 & - & 54.0 & 6.02 & 14 & 32 \\
\hline 2 & 260 & - & 60.0 & 5.98 & 12 & 31 \\
\hline 3 & 260 & - & 72.0 & 7.01 & 8 & 39 \\
\hline 4 & 280 & - & 80.0 & 7.17 & 10 & 15 \\
\hline 5 & 260 & - & 74.0 & 7.14 & 8 & 14 \\
\hline 6 & 240 & - & 73.0 & 7.70 & - & - \\
\hline
\end{tabular}

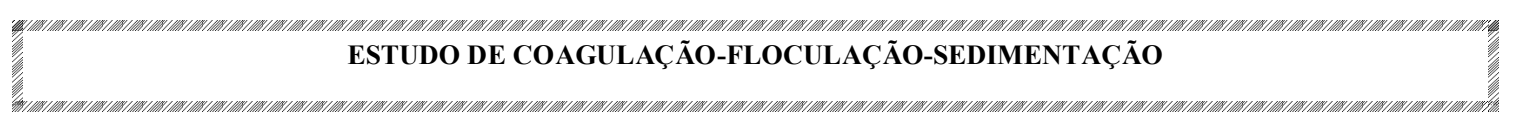

\begin{tabular}{|c|c|c|c|c|c|c|c|}
\hline \multirow{2}{*}{$\begin{array}{l}\text { ENSAIO No: } \\
\text { Data : } 17 / 04 / 0\end{array}$} & \multirow{2}{*}{\multicolumn{2}{|c|}{$\begin{array}{l}\text { COAGULANTE } \\
\text { Cloreto Férrico }\end{array}$}} & \multicolumn{3}{|c|}{ MISTURA RÁPIDA } & \multicolumn{2}{|c|}{ FLOCULAÇÃO } \\
\hline & & & Tmr $=5 \mathrm{~s}$ & \multicolumn{2}{|c|}{$\mathrm{Gmr}=1000 \mathrm{~s}^{-1}$} & $T f=30 \mathrm{~min}$ & $G f=15 s^{-1}$ \\
\hline \multicolumn{8}{|c|}{ CARACTERÍSTICAS DA ÁGUA DE ESTUDO } \\
\hline \multirow[t]{2}{*}{ Turbidez (uT) } & \multirow{2}{*}{$\begin{array}{c}\text { Cor Aparente } \\
\text { (uC) }\end{array}$} & \multirow{2}{*}{$\begin{array}{c}\text { Cor Verdadeira } \\
(\mathrm{uC})\end{array}$} & \multirow{2}{*}{$\begin{array}{l}\text { Alcalinidade Total } \\
\left(\mathrm{mg} / \ell \mathrm{CaCO}_{3}\right)\end{array}$} & \multicolumn{2}{|c|}{ pH } & \multirow{2}{*}{$\begin{array}{c}\text { Temperatura } \\
{ }^{\circ} \mathrm{C} \\
\end{array}$} & \multirow{2}{*}{$\begin{array}{r}\text { Potencial } \\
\text { Zeta }(\mathrm{mV}) \\
\end{array}$} \\
\hline & & & & S/agit. & $\mathrm{C} /$ agit. & & \\
\hline 6.31 & 139 & 100 & 30 & 7.98 & 7.62 & 25 & 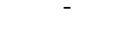 \\
\hline
\end{tabular}

\begin{tabular}{|c|c|c|c|c|c|c|}
\hline \multirow{2}{*}{ FRASCO } & \multicolumn{3}{|c|}{ DOSAGEM DE PRODUTO QUÍMICO } & \multirow{2}{*}{$\begin{array}{c}\text { pH } \\
\text { de } \\
\text { Coagulação }\end{array}$} & \multirow{2}{*}{$\begin{array}{c}T_{\mathrm{s} 2}=7,00 \mathrm{~min} \\
\mathrm{~V}_{\mathrm{s} 2}=1.0 \mathrm{~cm} / \mathrm{min} \\
\begin{array}{c}\mathrm{Cor} \\
(\mathrm{uC})\end{array}\end{array}$} & \multirow{2}{*}{$\begin{array}{c}T_{\mathrm{s} 1}=3,50 \mathrm{~min} \\
V_{\mathrm{s} 1}=2.0 \mathrm{~cm} / \mathrm{min} \\
\begin{array}{c}\mathrm{Cor} \\
(\mathrm{uC})\end{array}\end{array}$} \\
\hline & $\begin{array}{c}\text { Cloreto Férrico } \\
(\mathrm{mg} / \ell)\end{array}$ & $\begin{array}{c}\text { Ácido } \\
\text { Clorídrico } \\
0.1 \mathrm{~N}(\mathrm{~m} / / \ell) \\
\end{array}$ & $\begin{array}{c}\text { Hidróxido de } \\
\text { Sódio } 0.1 \mathrm{~N}(\mathrm{~m} / \mathrm{l})\end{array}$ & & & \\
\hline 1 & 300 & - & 72.0 & 5.66 & 111 & 117 \\
\hline 2 & 300 & - & 73.0 & 5.77 & 24 & 33 \\
\hline 3 & 300 & - & 74.0 & 5.91 & 14 & 19 \\
\hline 4 & 300 & - & 76.0 & 6.15 & 13 & 24 \\
\hline 5 & 300 & - & 78.0 & 6.42 & 18 & 24 \\
\hline 6 & 300 & - & 80.0 & 6.59 & 16 & 54 \\
\hline
\end{tabular}




\section{ESTUDO DE COAGULAÇÃO-FLOCULAÇÃO-SEDIMENTAÇÃO}

\begin{tabular}{|c|c|c|c|c|c|c|c|}
\hline \multirow{2}{*}{$\begin{array}{l}\text { ENSAIO N }{ }^{\circ}: 2 \\
\text { Data }: 17 / 04 / 00\end{array}$} & \multirow{2}{*}{\multicolumn{2}{|c|}{$\begin{array}{l}\text { COAGULANTE } \\
\text { Cloreto Férrico }\end{array}$}} & \multicolumn{3}{|c|}{ MISTURA RÁPIDA } & \multicolumn{2}{|c|}{ FLOCULACÃO } \\
\hline & & & $\mathrm{Tmr}=\mathbf{5 s}$ & \multicolumn{2}{|c|}{$\mathrm{Gmr}=1000 \mathrm{~s}^{-1}$} & Tf $=30 \mathrm{~min}$ & $G f=15 s^{-1}$ \\
\hline \multicolumn{8}{|c|}{ CARACTERÍSTICAS DA ÁGUA DE ESTUDO } \\
\hline \multirow{2}{*}{ Turbidez (uT) } & \multirow{2}{*}{$\begin{array}{l}\text { Cor Aparente } \\
\text { (uC) }\end{array}$} & \multirow{2}{*}{$\begin{array}{c}\text { Cor Verdadeira } \\
\text { (uC) }\end{array}$} & \multirow{2}{*}{$\begin{array}{c}\text { Alcalinidade Total } \\
\left(\mathrm{mg} / \ell \mathrm{CaCO}_{3}\right)\end{array}$} & \multicolumn{2}{|c|}{ pH } & \multirow{2}{*}{$\begin{array}{c}\text { Temperatura } \\
{ }^{\circ} \mathrm{C}\end{array}$} & \multirow{2}{*}{$\begin{array}{r}\text { Potencial } \\
\text { Zeta }(\mathrm{mV})\end{array}$} \\
\hline & & & & S/ agit. & C/ agit. & & \\
\hline 6.31 & 139 & 100 & 30 & 7.98 & 7.62 & 25 & - \\
\hline
\end{tabular}

\begin{tabular}{|c|c|c|c|c|c|c|}
\hline \multirow{2}{*}{ FRASCO } & \multicolumn{3}{|c|}{ DOSAGEM DE PRODUTO QUÍMICO } & \multirow{2}{*}{$\begin{array}{c}\text { pH } \\
\text { de } \\
\text { Coagulação }\end{array}$} & \multirow{2}{*}{$\begin{array}{c}T_{\mathrm{s} 2}=7,00 \mathrm{~min} \\
V_{\mathrm{s} 2}=1.0 \mathrm{~cm} / \mathrm{min} \\
\begin{array}{c}\mathrm{Cor} \\
(\mathrm{uC})\end{array}\end{array}$} & \multirow{2}{*}{$\begin{array}{c}T_{\mathrm{s} 1}=3,50 \mathrm{~min} \\
V_{\mathrm{s} 1}=2.0 \mathrm{~cm} / \mathrm{min} \\
\begin{array}{c}\mathrm{Cor} \\
(\mathrm{uC})\end{array}\end{array}$} \\
\hline & $\begin{array}{c}\text { Cloreto Férrico } \\
(\mathrm{mg} / \mathfrak{\ell})\end{array}$ & $\begin{array}{c}\text { Ácido } \\
\text { Clorídrico } \\
\text { 0.1N(m/ } / \ell) \\
\end{array}$ & $\begin{array}{c}\text { Hidróxido de } \\
\text { Sódio } 0.1 \mathrm{~N}(\mathrm{~m} \ell / \ell)\end{array}$ & & & \\
\hline 1 & 280 & - & 78.5 & 6.94 & 11 & 18 \\
\hline 2 & 260 & - & 76.0 & 7.36 & 11 & 17 \\
\hline 3 & 280 & - & 82.0 & 7.64 & 12 & 19 \\
\hline 4 & 260 & - & 78.0 & 7.43 & 45 & 53 \\
\hline 5 & 280 & - & 84.0 & 6.59 & 21 & 30 \\
\hline 6 & 260 & - & 80.0 & 7.72 & - & - \\
\hline
\end{tabular}

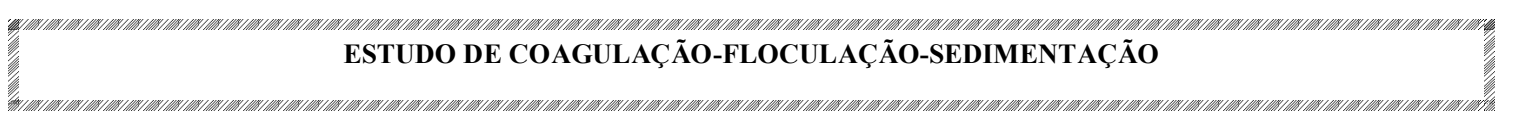

\begin{tabular}{|c|c|c|c|c|c|}
\hline ENSAIO $\mathbf{N}^{\circ}: 28$ & COAGULANTE & \multicolumn{2}{|c|}{ MISTURA RÁPIDA } & \multicolumn{2}{|c|}{ FLOCULAÇÃO } \\
\cline { 3 - 6 } Data $: 17 / 04 / 00$ & Cloreto Férrico & Tmr $=\mathbf{5 s}$ & $\mathbf{G m r}=\mathbf{1 0 0 0 s}^{-1}$ & $\mathbf{T f}=\mathbf{3 0 m i n}$ & $\mathbf{G f}^{-1} \mathbf{1 5} \mathbf{s}^{-1}$ \\
\hline
\end{tabular}

\begin{tabular}{|c|c|c|c|c|c|c|c|}
\hline \multicolumn{8}{|c|}{ CARACTERÍSTICAS DA ÁGUA DE ESTUDO } \\
\hline \multirow[t]{2}{*}{ Turbidez (uT) } & \multirow{2}{*}{$\begin{array}{c}\text { Cor Aparente } \\
\text { (uC) }\end{array}$} & \multirow{2}{*}{$\begin{array}{c}\text { Cor Verdadeira } \\
(\mathrm{uC})\end{array}$} & \multirow{2}{*}{$\begin{array}{c}\text { Alcalinidade Total } \\
\left(\mathrm{mg} / \ell \mathrm{CaCO}_{3}\right)\end{array}$} & \multicolumn{2}{|c|}{ pH } & \multirow{2}{*}{$\begin{array}{c}\text { Temperatura } \\
{ }^{\circ} \mathrm{C} \\
\end{array}$} & \multirow{2}{*}{$\begin{array}{r}\text { Potencial } \\
\text { Zeta }(\mathrm{mV}) \\
\end{array}$} \\
\hline & & & & S/ agit. & $\mathrm{C} /$ agit. & & \\
\hline 6.31 & 139 & 100 & 30 & 7.98 & 7.62 & 25 & 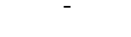 \\
\hline
\end{tabular}

\begin{tabular}{|c|c|c|c|c|c|c|}
\hline \multirow{2}{*}{ FRASCO } & \multicolumn{3}{|c|}{ DOSAGEM DE PRODUTO QUÍMICO } & \multirow{2}{*}{$\begin{array}{c}\text { pH } \\
\text { de } \\
\text { Coagulação }\end{array}$} & \multirow{2}{*}{$\begin{array}{c}T_{\mathrm{s} 2}=7,00 \mathrm{~min} \\
V_{\mathrm{s} 2}=1.0 \mathrm{~cm} / \mathrm{min} \\
\begin{array}{c}\mathrm{Cor} \\
(\mathrm{uC})\end{array}\end{array}$} & \multirow{2}{*}{$\begin{array}{c}T_{\mathrm{s} 1}=3,50 \mathrm{~min} \\
V_{\mathrm{s} 1}=2.0 \mathrm{~cm} / \mathrm{min} \\
\begin{array}{c}\mathrm{Cor} \\
(\mathrm{uC})\end{array} \\
\end{array}$} \\
\hline & $\begin{array}{c}\text { Cloreto Férrico } \\
\text { (mg/L) }\end{array}$ & $\begin{array}{c}\text { Ácido } \\
\text { Clorídrico } \\
\text { 0.1N }(\mathrm{m} \ell / \ell) \\
\end{array}$ & 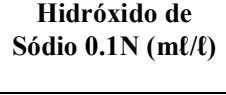 & & & \\
\hline 1 & 300 & - & 82.0 & 6.75 & 18 & 50 \\
\hline 2 & 300 & - & 84.0 & 6.93 & 13 & 22 \\
\hline 3 & 300 & - & 86.0 & 7.15 & 11 & 17 \\
\hline 4 & 300 & - & 88.0 & 7.39 & 13 & 18 \\
\hline 5 & 280 & - & 81.0 & 7.35 & 11 & 18 \\
\hline 6 & 300 & - & 90.0 & 7.78 & 73 & 81 \\
\hline
\end{tabular}




\section{ESTUDO DE COAGULAÇÃO-FLOCULAÇÃO-SEDIMENTAÇÃO}

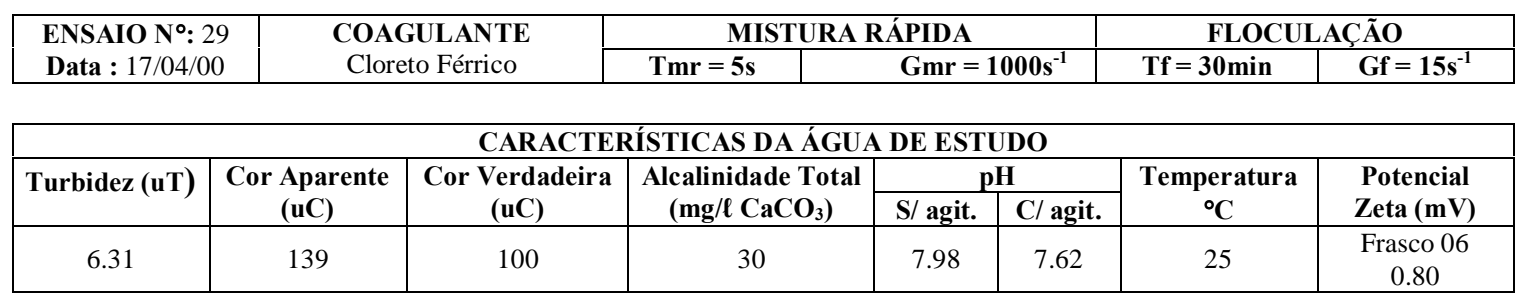

\begin{tabular}{|c|c|c|c|c|c|c|}
\hline \multirow{2}{*}{ FRASCO } & \multicolumn{3}{|c|}{ DOSAGEM DE PRODUTO QUÍMICO } & \multirow{2}{*}{$\begin{array}{c}\text { pH } \\
\text { de } \\
\text { Coagulação }\end{array}$} & \multirow{2}{*}{$\begin{array}{c}T_{\mathrm{s} 2}=7,00 \mathrm{~min} \\
V_{\mathrm{s} 2}=1.0 \mathrm{~cm} / \mathrm{min} \\
\begin{array}{c}\mathrm{Cor} \\
(\mathrm{uC})\end{array}\end{array}$} & \multirow{2}{*}{$\begin{array}{c}T_{\mathrm{s} 1}=3,50 \mathrm{~min} \\
V_{\mathrm{s} 1}=2.0 \mathrm{~cm} / \mathrm{min} \\
\begin{array}{c}\mathrm{Cor} \\
(\mathrm{uC})\end{array}\end{array}$} \\
\hline & $\begin{array}{c}\text { Cloreto Férrico } \\
(\mathrm{mg} / \mathfrak{l})\end{array}$ & $\begin{array}{c}\text { Ácido } \\
\text { Clorídrico } \\
0.1 \mathrm{~N}(\mathrm{~m} / / \ell)\end{array}$ & $\begin{array}{c}\text { Hidróxido de } \\
\text { Sódio } 0.1 \mathrm{~N}(\mathrm{~m} \ell / \ell)\end{array}$ & & & \\
\hline 1 & 240 & - & 66.5 & 6.94 & 17 & 25 \\
\hline 2 & 240 & - & 67.0 & 7.00 & 15 & 24 \\
\hline 3 & 180 & - & 48.5 & 7.01 & 17 & 25 \\
\hline 4 & 180 & - & 49.0 & 7.04 & 19 & 23 \\
\hline 5 & 140 & - & 36.5 & 7.09 & 16 & 29 \\
\hline 6 & 140 & - & 37.0 & 7.06 & 13 & 21 \\
\hline
\end{tabular}

\section{ESTUDO DE COAGULAÇÃO-FLOCULAÇÃO-SEDIMENTAÇÃO}

\begin{tabular}{|c|c|c|c|c|c|}
\hline \multirow{2}{*}{$\begin{array}{l}\text { ENSAIO N }^{\circ}: 30 \\
\text { Data }: 17 / 04 / 00\end{array}$} & \multirow{2}{*}{$\begin{array}{c}\text { COAGULANTE } \\
\text { Cloreto Férrico }\end{array}$} & \multirow{2}{*}{\multicolumn{2}{|c|}{ MISTURA RÁPIDA }} & \multicolumn{2}{|c|}{ FLOCULAÇÃO } \\
\hline & & & & $\mathbf{T f}=30 \mathrm{~min}$ & $G f=15 s^{-1}$ \\
\hline
\end{tabular}

\begin{tabular}{|c|c|c|c|c|c|c|c|}
\hline \multicolumn{8}{|c|}{ CARACTERÍSTICAS DA ÁGUA DE ESTUDO } \\
\hline \multirow[t]{2}{*}{ Turbidez (uT) } & \multirow{2}{*}{$\begin{array}{c}\text { Cor Aparente } \\
\text { (uC) }\end{array}$} & \multirow{2}{*}{$\begin{array}{c}\text { Cor Verdadeira } \\
(\mathrm{uC})\end{array}$} & \multirow{2}{*}{$\begin{array}{c}\text { Alcalinidade Total } \\
\left(\mathrm{mg} / \mathrm{l} \mathrm{CaCO}_{3}\right)\end{array}$} & \multicolumn{2}{|c|}{ pH } & \multirow{2}{*}{$\begin{array}{c}\text { Temperatura } \\
{ }^{\circ} \mathrm{C} \\
\end{array}$} & \multirow{2}{*}{$\begin{array}{r}\text { Potencial } \\
\text { Zeta }(\mathrm{mV})\end{array}$} \\
\hline & & & & S/ agit. & $\mathrm{C} /$ agit. & & \\
\hline 6.31 & 139 & 100 & 30 & 7.98 & 7.62 & 25 & $\begin{array}{c}\text { Frasco } 02 \\
0.40\end{array}$ \\
\hline
\end{tabular}

\begin{tabular}{|c|c|c|c|c|c|c|}
\hline \multirow{2}{*}{ FRASCO } & \multicolumn{3}{|c|}{ DOSAGEM DE PRODUTO QUÍMICO } & \multirow{2}{*}{$\begin{array}{c}\text { pH } \\
\text { de } \\
\text { Coagulação }\end{array}$} & \multirow{2}{*}{$\begin{array}{c}T_{\mathrm{s} 2}=7,00 \mathrm{~min} \\
V_{\mathrm{s} 2}=1.0 \mathrm{~cm} / \mathrm{min} \\
\begin{array}{c}\mathrm{Cor} \\
(\mathrm{uC})\end{array}\end{array}$} & \multirow{2}{*}{$\begin{array}{c}T_{\mathrm{s} 1}=3,50 \mathrm{~min} \\
V_{\mathrm{s} 1}=2.0 \mathrm{~cm} / \mathrm{min} \\
\begin{array}{l}\mathrm{Cor} \\
(\mathrm{uC})\end{array}\end{array}$} \\
\hline & $\begin{array}{c}\text { Cloreto Férrico } \\
(\mathrm{mg} / \mathfrak{\ell})\end{array}$ & $\begin{array}{c}\text { Ácido } \\
\text { Clorídrico } \\
\text { 0.1N(m } / \mathrm{l} / \mathrm{t})\end{array}$ & $\begin{array}{c}\text { Hidróxido de } \\
\text { Sódio } 0.1 \mathrm{~N}(\mathrm{~m} \ell / \ell)\end{array}$ & & & \\
\hline 1 & 200 & - & 44.0 & 6.20 & 17 & 19 \\
\hline 2 & 200 & - & 45.0 & 6.20 & 12 & 8 \\
\hline 3 & 200 & - & 46.0 & 6.27 & 8 & 12 \\
\hline 4 & 140 & - & 29.0 & 6.41 & 11 & 14 \\
\hline 5 & 140 & - & 30.0 & 6.48 & 13 & 18 \\
\hline 6 & 140 & - & 31.0 & 6.59 & 13 & 32 \\
\hline
\end{tabular}


ANEXO - G

ENSAIOS DO REATOR ESTÁTICO - ÁGUA II PARA O COAGULANTE

HIDROXICLORETO DE ALUMÍNIO 


\section{ESTUDO DE COAGULAÇÃO-FLOCULAÇÃO-SEDIMENTAÇÃO}

\begin{tabular}{|c|c|c|c|c|c|c|c|}
\hline \multirow{2}{*}{$\begin{array}{l}\text { ENSAIO No: } 01 \\
\text { Data : } 18 / 04 / 00 \\
\end{array}$} & \multirow{2}{*}{\multicolumn{2}{|c|}{$\begin{array}{c}\text { COAGULANTE } \\
\text { Hidroxicloreto de Alumínio }\end{array}$}} & \multicolumn{3}{|c|}{ MISTURA RÁPIDA } & \multicolumn{2}{|c|}{ FLOCULAÇÃO } \\
\hline & & & Tmr $=5 \mathrm{~s}$ & \multicolumn{2}{|c|}{$\mathrm{Gmr}=1000 \mathrm{~s}^{-1}$} & $T f=30 \mathrm{~min}$ & $G f=15 s^{-1}$ \\
\hline \multicolumn{8}{|c|}{ CARACTERÍSTICAS DA ÁGUA DE ESTUDO } \\
\hline \multirow{2}{*}{ Turbidez (uT) } & \multirow{2}{*}{$\begin{array}{c}\text { Cor Aparente } \\
\text { (uC) }\end{array}$} & \multirow{2}{*}{$\begin{array}{c}\text { Cor Verdadeira } \\
\text { (uC) }\end{array}$} & \multirow{2}{*}{$\begin{array}{l}\text { Alcalinidade Total } \\
\left(\mathrm{mg} / \ell \mathrm{CaCO}_{3}\right)\end{array}$} & \multicolumn{2}{|c|}{ pH } & \multirow{2}{*}{$\begin{array}{c}\text { Temperatura } \\
{ }^{\circ} \mathrm{C}\end{array}$} & \multirow{2}{*}{$\begin{array}{r}\text { Potencial } \\
\text { Zeta }(\mathrm{mV})\end{array}$} \\
\hline & & & & S/ agit. & $\mathrm{C} /$ agit. & & \\
\hline 6.58 & 143 & 102 & 30 & 8.00 & 7.59 & 25 & - \\
\hline
\end{tabular}

\begin{tabular}{|c|c|c|c|c|c|c|}
\hline \multirow{2}{*}{ FRASCO } & \multicolumn{3}{|c|}{ DOSAGEM DE PRODUTO QUÍMICO } & \multirow{2}{*}{$\begin{array}{c}\text { pH } \\
\text { de } \\
\text { Coagulação }\end{array}$} & \multirow{2}{*}{$\begin{array}{c}T_{\mathrm{s} 2}=7,00 \mathrm{~min} \\
\mathrm{~V}_{\mathrm{s} 2}=1.0 \mathrm{~cm} / \mathrm{min} \\
\begin{array}{c}\mathrm{Cor} \\
(\mathrm{uC})\end{array} \\
\end{array}$} & \multirow{2}{*}{$\begin{array}{c}T_{\mathrm{s} 1}=3,50 \mathrm{~min} \\
V_{\mathrm{s} 1}=2.0 \mathrm{~cm} / \mathrm{min} \\
\begin{array}{c}\mathrm{Cor} \\
(\mathrm{uC})\end{array}\end{array}$} \\
\hline & $\begin{array}{c}\text { Hidroxicloreto } \\
\text { de Alumínio } \\
\text { (mg/l) }\end{array}$ & $\begin{array}{c}\text { Ácido } \\
\text { Clorídrico } \\
\text { 0.1N(m } / \text { / }) \\
\end{array}$ & $\begin{array}{c}\text { Hidróxido de } \\
\text { Sódio } 0.1 \mathrm{~N}(\mathrm{~m} \ell / \ell)\end{array}$ & & & \\
\hline 1 & 40 & - & - & 6.76 & 22 & 41 \\
\hline 2 & 40 & - & 2.0 & 6.94 & 24 & 34 \\
\hline 3 & 40 & - & 4.0 & 7.10 & 34 & 50 \\
\hline 4 & 40 & - & 6.0 & 7.37 & 34 & 64 \\
\hline 5 & 40 & - & 8.0 & 7.57 & 36 & 75 \\
\hline 6 & 40 & - & 10.0 & 7.92 & 138 & 139 \\
\hline
\end{tabular}

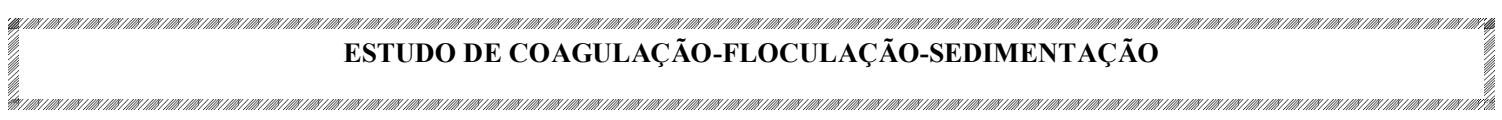

\begin{tabular}{|c|c|c|c|c|c|}
\hline ENSAIO No: 02 & COAGULANTE & \multicolumn{2}{|c|}{ MISTURA RÁPIDA } & \multicolumn{2}{|c|}{ FLOCULAÇÃO } \\
\cline { 3 - 6 } Data $: 18 / 04 / 00$ & Hidroxicloreto de Alumínio & $\mathbf{T m r}=\mathbf{5 s}$ & $\mathbf{G m r}=\mathbf{1 0 0 0 s}^{-1}$ & $\mathbf{T f}=\mathbf{3 0 m i n}$ & $\mathbf{G f}^{-1} \mathbf{1 5 s}^{-1}$ \\
\hline
\end{tabular}

\begin{tabular}{|c|c|c|c|c|c|c|c|}
\hline \multicolumn{8}{|c|}{ CARACTERÍSTICAS DA ÁGUA DE ESTUDO } \\
\hline \multirow[t]{2}{*}{ Turbidez (uT) } & \multirow{2}{*}{$\begin{array}{c}\begin{array}{c}\text { Cor Aparente } \\
\text { (uC) }\end{array} \\
\end{array}$} & \multirow{2}{*}{$\begin{array}{c}\begin{array}{c}\text { Cor Verdadeira } \\
(\mathrm{uC})\end{array} \\
\end{array}$} & \multirow{2}{*}{$\begin{array}{c}\text { Alcalinidade Total } \\
\left(\mathrm{mg} / \ell \mathrm{CaCO}_{3}\right)\end{array}$} & \multicolumn{2}{|c|}{$\mathrm{pH}$} & \multirow{2}{*}{$\begin{array}{c}\text { Temperatura } \\
{ }^{\circ} \mathrm{C} \\
\end{array}$} & \multirow{2}{*}{$\begin{array}{r}\text { Potencial } \\
\text { Zeta }(\mathrm{mV}) \\
\end{array}$} \\
\hline & & & & S/ agit. & $\mathrm{C} /$ agit. & & \\
\hline 6.58 & 143 & 102 & 30 & 8.00 & 7.59 & 25 & - \\
\hline
\end{tabular}

\begin{tabular}{|c|c|c|c|c|c|c|}
\hline \multirow{2}{*}{ FRASCO } & \multicolumn{3}{|c|}{ DOSAGEM DE PRODUTO QUÍMICO } & \multirow{2}{*}{$\begin{array}{c}\text { pH } \\
\text { de } \\
\text { Coagulação }\end{array}$} & \multirow{2}{*}{$\begin{array}{c}T_{\mathrm{s} 2}=7,00 \mathrm{~min} \\
V_{\mathrm{s} 2}=1.0 \mathrm{~cm} / \mathrm{min} \\
\begin{array}{c}\mathrm{Cor} \\
(\mathrm{uC})\end{array}\end{array}$} & \multirow{2}{*}{$\begin{array}{c}T_{\mathrm{s} 1}=3,50 \mathrm{~min} \\
V_{\mathrm{s} 1}=2.0 \mathrm{~cm} / \mathrm{min} \\
\begin{array}{c}\mathrm{Cor} \\
(\mathrm{uC})\end{array}\end{array}$} \\
\hline & $\begin{array}{c}\text { Hidroxicloreto } \\
\text { de Alumínio } \\
(\mathrm{mg} / \ell)\end{array}$ & $\begin{array}{c}\text { Ácido } \\
\text { Clorídrico } \\
0.1 \mathrm{~N}(\mathrm{~m} \ell / \ell) \\
\end{array}$ & $\begin{array}{c}\text { Hidróxido de } \\
\text { Sódio } 0.1 \mathrm{~N}(\mathrm{~m} \ell / \ell)\end{array}$ & & & \\
\hline 1 & 60 & - & - & 6.21 & - & - \\
\hline 2 & 60 & - & 2.0 & 6.40 & - & - \\
\hline 3 & 60 & - & 4.0 & 6.59 & 51 & 112 \\
\hline 4 & 60 & - & 6.0 & 6.76 & 10 & 45 \\
\hline 5 & 60 & - & 8.0 & 6.94 & 21 & 38 \\
\hline 6 & 60 & - & 10.0 & 7.15 & 15 & 36 \\
\hline
\end{tabular}




\section{ESTUDO DE COAGULAÇÃO-FLOCULAÇÃO-SEDIMENTAÇÃO}

\begin{tabular}{|c|c|c|c|c|c|c|c|}
\hline \multirow{2}{*}{$\begin{array}{l}\text { ENSAIO N }{ }^{\circ}: 03 \\
\text { Data : } 18 / 04 / 00 \\
\end{array}$} & \multirow{2}{*}{\multicolumn{2}{|c|}{$\begin{array}{c}\text { COAGULANTE } \\
\text { Hidroxicloreto de Alumínio } \\
\end{array}$}} & \multicolumn{3}{|c|}{ MISTURA RÁPIDA } & \multicolumn{2}{|c|}{ FLOCULAÇÃO } \\
\hline & & & $\mathrm{Tmr}=\mathbf{5 s}$ & \multicolumn{2}{|c|}{$\mathrm{Gmr}=1000 \mathrm{~s}^{-1}$} & $T f=30 \mathrm{~min}$ & $\mathbf{G f}=15 \mathrm{~s}^{-1}$ \\
\hline \multicolumn{8}{|c|}{ CARACTERÍSTICAS DA ÁGUA DE ESTUDO } \\
\hline \multirow{2}{*}{ Turbidez (uT) } & \multirow{2}{*}{$\begin{array}{c}\text { Cor Aparente } \\
\text { (uC) }\end{array}$} & \multirow{2}{*}{$\begin{array}{c}\text { Cor Verdadeira } \\
(\mathrm{uC})\end{array}$} & \multirow{2}{*}{$\begin{array}{l}\text { Alcalinidade Total } \\
\left(\mathrm{mg} / \mathrm{\ell} \mathrm{CaCO}_{3}\right)\end{array}$} & \multicolumn{2}{|c|}{ pH } & \multirow{2}{*}{$\begin{array}{l}\text { Temperatura } \\
{ }^{\circ} \mathrm{C}\end{array}$} & \multirow{2}{*}{$\begin{array}{r}\text { Potencial } \\
\text { Zeta }(\mathrm{mV})\end{array}$} \\
\hline & & & & S/ agit. & $\mathrm{C} /$ agit. & & \\
\hline 6.58 & 143 & 102 & 30 & 8.00 & 7.59 & 25 & - \\
\hline
\end{tabular}

\begin{tabular}{|c|c|c|c|c|c|c|}
\hline \multirow{2}{*}{ FRASCO } & \multicolumn{3}{|c|}{ DOSAGEM DE PRODUTO QUÍMICO } & \multirow{2}{*}{$\begin{array}{c}\text { pH } \\
\text { de } \\
\text { Coagulação }\end{array}$} & \multirow{2}{*}{$\begin{array}{c}T_{\mathrm{s} 2}=7,00 \mathrm{~min} \\
\mathrm{~V}_{\mathrm{s} 2}=1.0 \mathrm{~cm} / \mathrm{min} \\
\begin{array}{c}\mathrm{Cor} \\
(\mathrm{uC})\end{array} \\
\end{array}$} & \multirow{2}{*}{$\begin{array}{c}T_{\mathrm{s} 1}=3,50 \mathrm{~min} \\
V_{\mathrm{s} 1}=2.0 \mathrm{~cm} / \mathrm{min} \\
\begin{array}{c}\mathrm{Cor} \\
(\mathrm{uC})\end{array}\end{array}$} \\
\hline & $\begin{array}{c}\text { Hidroxicloreto } \\
\text { de Alumínio } \\
\text { (mg/l) }\end{array}$ & $\begin{array}{c}\text { Ácido } \\
\text { Clorídrico } \\
\text { 0.1N(m } / \text { / }) \\
\end{array}$ & $\begin{array}{c}\text { Hidróxido de } \\
\text { Sódio } 0.1 \mathrm{~N}(\mathrm{~m} \ell / \ell)\end{array}$ & & & \\
\hline 1 & 40 & .091 & - & 6.46 & 32 & 55 \\
\hline 2 & 80 & - & 12.0 & 6.80 & 13 & 22 \\
\hline 3 & 80 & - & 14.0 & 6.99 & 18 & 27 \\
\hline 4 & 100 & - & 18.0 & 6.97 & 13 & 15 \\
\hline 5 & 100 & - & 20.0 & 7.18 & 12 & 19 \\
\hline 6 & 60 & - & 12.0 & 7.39 & 27 & 44 \\
\hline
\end{tabular}

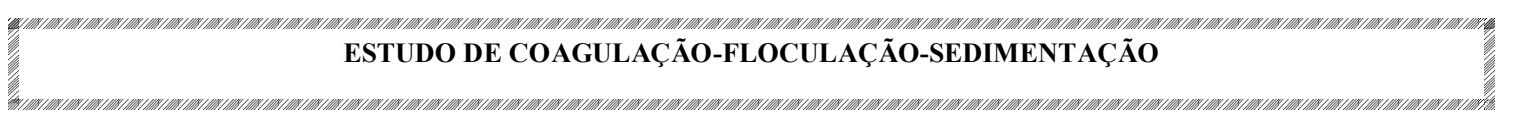

\begin{tabular}{|c|c|c|c|c|c|}
\hline ENSAIO No: 04 & COAGULANTE & \multicolumn{2}{|c|}{ MISTURA RÁPIDA } & \multicolumn{2}{|c|}{ FLOCULAÇÃO } \\
\cline { 3 - 6 } Data $: 18 / 04 / 00$ & Hidroxicloreto de Alumínio & $\mathbf{T m r}=\mathbf{5 s}$ & $\mathbf{G m r}=\mathbf{1 0 0 0 s}^{-1}$ & $\mathbf{T f}=\mathbf{3 0 m i n}$ & $\mathbf{G f}^{-1} \mathbf{1 5 s}^{-1}$ \\
\hline
\end{tabular}

\begin{tabular}{|c|c|c|c|c|c|c|c|}
\hline \multicolumn{8}{|c|}{ CARACTERÍSTICAS DA ÁGUA DE ESTUDO } \\
\hline \multirow[t]{2}{*}{ Turbidez (uT) } & \multirow{2}{*}{$\begin{array}{c}\begin{array}{c}\text { Cor Aparente } \\
\text { (uC) }\end{array} \\
\end{array}$} & \multirow{2}{*}{$\begin{array}{c}\begin{array}{c}\text { Cor Verdadeira } \\
(\mathrm{uC})\end{array} \\
\end{array}$} & \multirow{2}{*}{$\begin{array}{c}\text { Alcalinidade Total } \\
\left(\mathrm{mg} / \ell \mathrm{CaCO}_{3}\right)\end{array}$} & \multicolumn{2}{|c|}{$\mathrm{pH}$} & \multirow{2}{*}{$\begin{array}{c}\text { Temperatura } \\
{ }^{\circ} \mathrm{C} \\
\end{array}$} & \multirow{2}{*}{$\begin{array}{r}\text { Potencial } \\
\text { Zeta }(\mathrm{mV}) \\
\end{array}$} \\
\hline & & & & S/ agit. & $\mathrm{C} /$ agit. & & \\
\hline 6.58 & 143 & 102 & 30 & 8.00 & 7.59 & 25 & - \\
\hline
\end{tabular}

\begin{tabular}{|c|c|c|c|c|c|c|}
\hline \multirow{2}{*}{ FRASCO } & \multicolumn{3}{|c|}{ DOSAGEM DE PRODUTO QUÍMICO } & \multirow{2}{*}{$\begin{array}{c}\text { pH } \\
\text { de } \\
\text { Coagulação }\end{array}$} & \multirow{2}{*}{$\begin{array}{c}T_{\mathrm{s} 2}=7,00 \mathrm{~min} \\
V_{\mathrm{s} 2}=1.0 \mathrm{~cm} / \mathrm{min} \\
\begin{array}{c}\mathrm{Cor} \\
(\mathrm{uC})\end{array}\end{array}$} & \multirow{2}{*}{$\begin{array}{c}T_{\mathrm{s} 1}=3,50 \mathrm{~min} \\
V_{\mathrm{s} 1}=2.0 \mathrm{~cm} / \mathrm{min} \\
\begin{array}{c}\mathrm{Cor} \\
(\mathrm{uC})\end{array}\end{array}$} \\
\hline & $\begin{array}{c}\text { Hidroxicloreto } \\
\text { de Alumínio } \\
(\mathrm{mg} / \ell)\end{array}$ & $\begin{array}{c}\text { Ácido } \\
\text { Clorídrico } \\
0.1 \mathrm{~N}(\mathrm{~m} \ell / \ell) \\
\end{array}$ & $\begin{array}{c}\text { Hidróxido de } \\
\text { Sódio } 0.1 \mathrm{~N}(\mathrm{~m} \ell / \ell)\end{array}$ & & & \\
\hline 1 & 80 & - & 9.0 & 6.47 & 51 & 64 \\
\hline 2 & 80 & - & 10.0 & 6.58 & 19 & 25 \\
\hline 3 & 100 & - & 16.0 & 6.71 & 14 & 18 \\
\hline 4 & 80 & - & 16.0 & 7.21 & 19 & 33 \\
\hline 5 & 100 & - & 22.0 & 7.42 & 17 & 29 \\
\hline 6 & 60 & - & 14.0 & 8.92 & - & - \\
\hline
\end{tabular}




\section{ESTUDO DE COAGULAÇÃO-FLOCULAÇÃO-SEDIMENTAÇÃO}

\begin{tabular}{|c|c|c|c|c|c|c|c|}
\hline \multirow{2}{*}{$\begin{array}{l}\text { ENSAIO N }{ }^{\circ}: 05 \\
\text { Data : } 18 / 05 / 00 \\
\end{array}$} & \multirow{2}{*}{\multicolumn{2}{|c|}{$\begin{array}{c}\text { COAGULANTE } \\
\text { Hidroxicloreto de Alumínio } \\
\end{array}$}} & \multicolumn{3}{|c|}{ MISTURA RÁPIDA } & \multicolumn{2}{|c|}{ FLOCULAÇÃO } \\
\hline & & & $\mathbf{T m r}=\mathbf{5 s}$ & \multicolumn{2}{|c|}{$\mathrm{Gmr}=1000 \mathrm{~s}^{-1}$} & $T f=30 \mathrm{~min}$ & $\mathbf{G f}=15 \mathrm{~s}^{-1}$ \\
\hline \multicolumn{8}{|c|}{ CARACTERÍSTICAS DA ÁGUA DE ESTUDO } \\
\hline \multirow{2}{*}{ Turbidez (uT) } & \multirow{2}{*}{$\begin{array}{c}\text { Cor Aparente } \\
\text { (uC) }\end{array}$} & \multirow{2}{*}{$\begin{array}{c}\text { Cor Verdadeira } \\
(\mathrm{uC})\end{array}$} & \multirow{2}{*}{$\begin{array}{l}\text { Alcalinidade Total } \\
\left(\mathrm{mg} / \mathrm{\ell} \mathrm{CaCO}_{3}\right)\end{array}$} & \multicolumn{2}{|c|}{ pH } & \multirow{2}{*}{$\begin{array}{l}\text { Temperatura } \\
{ }^{\circ} \mathrm{C}\end{array}$} & \multirow{2}{*}{$\begin{array}{r}\text { Potencial } \\
\text { Zeta }(\mathrm{mV})\end{array}$} \\
\hline & & & & S/ agit. & $\mathrm{C} /$ agit. & & \\
\hline 6.58 & 143 & 102 & 30 & 8.00 & 7.59 & 25 & - \\
\hline
\end{tabular}

\begin{tabular}{|c|c|c|c|c|c|c|}
\hline \multirow{2}{*}{ FRASCO } & \multicolumn{3}{|c|}{ DOSAGEM DE PRODUTO QUÍMICO } & \multirow{2}{*}{$\begin{array}{c}\text { pH } \\
\text { de } \\
\text { Coagulação }\end{array}$} & \multirow{2}{*}{$\begin{array}{c}T_{\mathrm{s} 2}=7,00 \mathrm{~min} \\
\mathrm{~V}_{\mathrm{s} 2}=1.0 \mathrm{~cm} / \mathrm{min} \\
\begin{array}{c}\mathrm{Cor} \\
(\mathrm{uC})\end{array} \\
\end{array}$} & \multirow{2}{*}{$\begin{array}{c}T_{\mathrm{s} 1}=3,50 \mathrm{~min} \\
V_{\mathrm{s} 1}=2.0 \mathrm{~cm} / \mathrm{min} \\
\begin{array}{c}\mathrm{Cor} \\
(\mathrm{uC})\end{array}\end{array}$} \\
\hline & $\begin{array}{c}\text { Hidroxicloreto } \\
\text { de Alumínio } \\
\text { (mg/l) }\end{array}$ & $\begin{array}{c}\text { Ácido } \\
\text { Clorídrico } \\
\text { 0.1N(m } / \text { / }) \\
\end{array}$ & $\begin{array}{c}\text { Hidróxido de } \\
\text { Sódio } 0.1 \mathrm{~N}(\mathrm{~m} \ell / \ell)\end{array}$ & & & \\
\hline 1 & 100 & - & 15.0 & 6.57 & 15 & 16 \\
\hline 2 & 120 & - & 20.0 & 6.66 & 18 & 19 \\
\hline 3 & 120 & - & 22.0 & 6.88 & 16 & 27 \\
\hline 4 & 120 & - & 24.0 & 7.09 & 19 & 18 \\
\hline 5 & 80 & - & 18.0 & 7.50 & 33 & 36 \\
\hline 6 & 100 & - & 24.0 & 7.64 & 40 & 53 \\
\hline
\end{tabular}

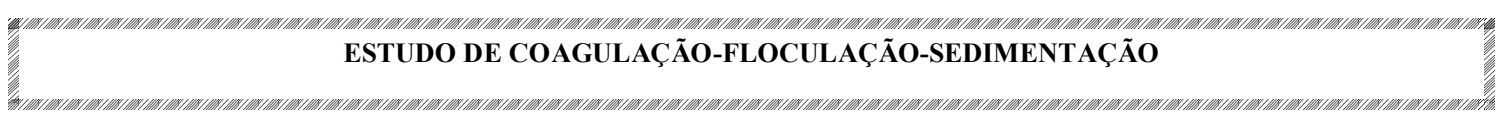

\begin{tabular}{|c|c|c|c|c|c|}
\hline ENSAIO No: 06 & COAGULANTE & \multicolumn{2}{|c|}{ MISTURA RÁPIDA } & \multicolumn{2}{|c|}{ FLOCULAÇÃO } \\
\cline { 3 - 6 } Data $: 18 / 04 / 00$ & Hidroxicloreto de Alumínio & $\mathbf{T m r}=\mathbf{5 s}$ & $\mathbf{G m r}=\mathbf{1 0 0 0 s}^{-1}$ & $\mathbf{T f}=\mathbf{3 0 m i n}$ & $\mathbf{G f}^{-1} \mathbf{1 5 s}^{-1}$ \\
\hline
\end{tabular}

\begin{tabular}{|c|c|c|c|c|c|c|c|}
\hline \multicolumn{8}{|c|}{ CARACTERÍSTICAS DA ÁGUA DE ESTUDO } \\
\hline \multirow[t]{2}{*}{ Turbidez (uT) } & \multirow{2}{*}{$\begin{array}{c}\begin{array}{c}\text { Cor Aparente } \\
\text { (uC) }\end{array} \\
\end{array}$} & \multirow{2}{*}{$\begin{array}{c}\begin{array}{c}\text { Cor Verdadeira } \\
(\mathrm{uC})\end{array} \\
\end{array}$} & \multirow{2}{*}{$\begin{array}{c}\text { Alcalinidade Total } \\
\left(\mathrm{mg} / \ell \mathrm{CaCO}_{3}\right)\end{array}$} & \multicolumn{2}{|c|}{$\mathrm{pH}$} & \multirow{2}{*}{$\begin{array}{c}\text { Temperatura } \\
{ }^{\circ} \mathrm{C} \\
\end{array}$} & \multirow{2}{*}{$\begin{array}{r}\text { Potencial } \\
\text { Zeta }(\mathrm{mV}) \\
\end{array}$} \\
\hline & & & & S/ agit. & $\mathrm{C} /$ agit. & & \\
\hline 6.58 & 143 & 102 & 30 & 8.00 & 7.59 & 25 & - \\
\hline
\end{tabular}

\begin{tabular}{|c|c|c|c|c|c|c|}
\hline \multirow{2}{*}{ FRASCO } & \multicolumn{3}{|c|}{ DOSAGEM DE PRODUTO QUÍMICO } & \multirow{2}{*}{$\begin{array}{c}\text { pH } \\
\text { de } \\
\text { Coagulação }\end{array}$} & \multirow{2}{*}{$\begin{array}{c}T_{\mathrm{s} 2}=7,00 \mathrm{~min} \\
\mathrm{~V}_{\mathrm{s} 2}=1.0 \mathrm{~cm} / \mathrm{min} \\
\begin{array}{c}\mathrm{Cor} \\
(\mathrm{uC})\end{array}\end{array}$} & \multirow{2}{*}{$\begin{array}{c}T_{\mathrm{s} 1}=3,50 \mathrm{~min} \\
\frac{V_{\mathrm{s} 1}=2.0 \mathrm{~cm} / \mathrm{min}}{\mathrm{Cor}} \\
(\mathrm{uC})\end{array}$} \\
\hline & $\begin{array}{c}\text { Hidroxicloreto } \\
\text { de Alumínio } \\
\text { (mg/t) }\end{array}$ & 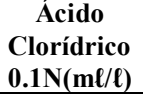 & 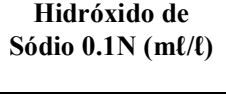 & & & \\
\hline 1 & 120 & - & 18.0 & 6.46 & 31 & 36 \\
\hline 2 & 140 & - & 26.0 & 6.77 & 21 & 17 \\
\hline 3 & 140 & - & 28.0 & 6.93 & 18 & 18 \\
\hline 4 & 120 & - & 26.0 & 7.23 & 20 & 32 \\
\hline 5 & 80 & - & 20.0 & 7.77 & 68 & 78 \\
\hline 6 & 100 & - & 26.0 & 7.96 & 62 & 81 \\
\hline
\end{tabular}




\section{ESTUDO DE COAGULAÇÃO-FLOCULAÇÃO-SEDIMENTAÇÃO}

\begin{tabular}{|c|c|c|c|c|c|c|c|}
\hline \multirow{2}{*}{$\begin{array}{l}\text { ENSAIO N }{ }^{\circ}: 07 \\
\text { Data : } 18 / 04 / 00\end{array}$} & \multirow{2}{*}{\multicolumn{2}{|c|}{$\begin{array}{c}\text { COAGULANTE } \\
\text { Hidroxicloreto de Alumínio } \\
\end{array}$}} & \multicolumn{3}{|c|}{ MISTURA RÁPIDA } & \multicolumn{2}{|c|}{ FLOCULAÇÃO } \\
\hline & & & Tmr $=5 \mathrm{~s}$ & \multicolumn{2}{|c|}{$\mathrm{Gmr}=1000 \mathrm{~s}^{-1}$} & Tf $=30 \mathrm{~min}$ & Gf $=15 \mathrm{~s}^{-1}$ \\
\hline \multicolumn{8}{|c|}{ CARACTERÍSTICAS DA ÁGUA DE ESTUDO } \\
\hline \multirow{2}{*}{ Turbidez (uT) } & \multirow{2}{*}{$\begin{array}{c}\text { Cor Aparente } \\
\text { (uC) }\end{array}$} & \multirow{2}{*}{$\begin{array}{c}\text { Cor Verdadeira } \\
(\mathrm{uC})\end{array}$} & \multirow{2}{*}{$\begin{array}{l}\text { Alcalinidade Total } \\
\left(\mathrm{mg} / \mathrm{\ell} \mathrm{CaCO}_{3}\right)\end{array}$} & \multicolumn{2}{|c|}{ pH } & \multirow{2}{*}{$\begin{array}{l}\text { Temperatura } \\
{ }^{\circ} \mathrm{C}\end{array}$} & \multirow{2}{*}{$\begin{array}{r}\text { Potencial } \\
\text { Zeta }(\mathrm{mV})\end{array}$} \\
\hline & & & & S/ agit. & $\mathrm{C} /$ agit. & & \\
\hline 6.58 & 143 & 102 & 30 & 8.00 & 7.59 & 25 & - \\
\hline
\end{tabular}

\begin{tabular}{|c|c|c|c|c|c|c|}
\hline \multirow{2}{*}{ FRASCO } & \multicolumn{3}{|c|}{ DOSAGEM DE PRODUTO QUÍMICO } & \multirow{2}{*}{$\begin{array}{c}\text { pH } \\
\text { de } \\
\text { Coagulação }\end{array}$} & \multirow{2}{*}{$\begin{array}{c}T_{\mathrm{s} 2}=7,00 \mathrm{~min} \\
\mathrm{~V}_{\mathrm{s} 2}=1.0 \mathrm{~cm} / \mathrm{min} \\
\begin{array}{c}\mathrm{Cor} \\
(\mathrm{uC})\end{array} \\
\end{array}$} & \multirow{2}{*}{$\begin{array}{c}T_{\mathrm{s} 1}=3,50 \mathrm{~min} \\
V_{\mathrm{s} 1}=2.0 \mathrm{~cm} / \mathrm{min} \\
\begin{array}{c}\mathrm{Cor} \\
(\mathrm{uC})\end{array}\end{array}$} \\
\hline & $\begin{array}{c}\text { Hidroxicloreto } \\
\text { de Alumínio } \\
\text { (mg/l) }\end{array}$ & $\begin{array}{c}\text { Ácido } \\
\text { Clorídrico } \\
\text { 0.1N(m } / \text { / }) \\
\end{array}$ & $\begin{array}{c}\text { Hidróxido de } \\
\text { Sódio } 0.1 \mathrm{~N}(\mathrm{~m} \ell / \ell)\end{array}$ & & & \\
\hline 1 & 100 & - & 14.0 & 6.09 & - & - \\
\hline 2 & 140 & - & 30.0 & 6.75 & 17 & 23 \\
\hline 3 & 140 & - & 32.0 & 6.99 & 18 & 18 \\
\hline 4 & - & - & - & 7.75 & 48 & 53 \\
\hline 5 & 120 & - & 28.0 & 8.29 & - & - \\
\hline 6 & 120 & - & 30.0 & 7.92 & 55 & 100 \\
\hline
\end{tabular}

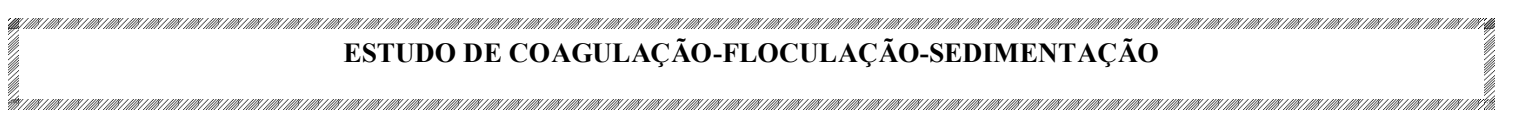

\begin{tabular}{|c|c|c|c|c|c|}
\hline ENSAIO No: 08 & COAGULANTE & \multicolumn{2}{|c|}{ MISTURA RÁPIDA } & \multicolumn{2}{|c|}{ FLOCULAÇÃO } \\
\cline { 3 - 6 } Data $: 18 / 04 / 00$ & Hidroxicloreto de Alumínio & $\mathbf{T m r}=\mathbf{5 s}$ & $\mathbf{G m r}=\mathbf{1 0 0 0 s}^{-1}$ & $\mathbf{T f}=\mathbf{3 0 m i n}$ & $\mathbf{G f}^{-1} \mathbf{1 5 s}^{-1}$ \\
\hline
\end{tabular}

\begin{tabular}{|c|c|c|c|c|c|c|c|}
\hline \multicolumn{8}{|c|}{ CARACTERÍSTICAS DA ÁGUA DE ESTUDO } \\
\hline \multirow[t]{2}{*}{ Turbidez (uT) } & \multirow{2}{*}{$\begin{array}{c}\text { Cor Aparente } \\
\text { (uC) }\end{array}$} & \multirow{2}{*}{$\begin{array}{c}\text { Cor Verdadeira } \\
(\mathrm{uC})\end{array}$} & \multirow{2}{*}{$\begin{array}{c}\text { Alcalinidade Total } \\
\left(\mathrm{mg} / \ell \mathrm{CaCO}_{3}\right)\end{array}$} & \multicolumn{2}{|c|}{ pH } & \multirow{2}{*}{$\begin{array}{c}\text { Temperatura } \\
{ }^{\circ} \mathrm{C} \\
\end{array}$} & \multirow{2}{*}{$\begin{array}{r}\text { Potencial } \\
\text { Zeta }(\mathrm{mV}) \\
\end{array}$} \\
\hline & & & & S/ agit. & $\mathrm{C} /$ agit. & & \\
\hline 6.58 & 143 & 102 & 30 & 8.00 & 7.59 & 25 & 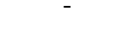 \\
\hline
\end{tabular}

\begin{tabular}{|c|c|c|c|c|c|c|}
\hline \multirow{2}{*}{ FRASCO } & \multicolumn{3}{|c|}{ DOSAGEM DE PRODUTO QUÍMICO } & \multirow{2}{*}{$\begin{array}{c}\text { pH } \\
\text { de } \\
\text { Coagulação }\end{array}$} & \multirow{2}{*}{$\begin{array}{c}T_{\mathrm{s} 2}=7,00 \mathrm{~min} \\
V_{\mathrm{s} 2}=1.0 \mathrm{~cm} / \mathrm{min} \\
\begin{array}{c}\mathrm{Cor} \\
(\mathrm{uC})\end{array}\end{array}$} & \multirow{2}{*}{$\begin{array}{c}T_{\mathrm{s} 1}=3,50 \mathrm{~min} \\
V_{\mathrm{s} 1}=2.0 \mathrm{~cm} / \mathrm{min} \\
\begin{array}{c}\mathrm{Cor} \\
(\mathrm{uC})\end{array}\end{array}$} \\
\hline & $\begin{array}{c}\text { Hidroxicloreto } \\
\text { de Alumínio } \\
(\mathrm{mg} / \ell)\end{array}$ & $\begin{array}{c}\text { Ácido } \\
\text { Clorídrico } \\
0.1 \mathrm{~N}(\mathrm{~m} \ell / \ell) \\
\end{array}$ & $\begin{array}{c}\text { Hidróxido de } \\
\text { Sódio } 0.1 \mathrm{~N}(\mathrm{~m} \ell / \ell)\end{array}$ & & & \\
\hline 1 & 140 & - & 24 & 6.50 & 11 & 20 \\
\hline 2 & 160 & - & 30 & 6.68 & 10 & 19 \\
\hline 3 & 160 & - & 32 & 6.83 & 12 & 15 \\
\hline 4 & 160 & - & 34 & 7.07 & 11 & 16 \\
\hline 5 & 160 & - & 36 & 7.36 & 14 & 39 \\
\hline 6 & 160 & - & 38 & 7.59 & 21 & 32 \\
\hline
\end{tabular}




\section{ESTUDO DE COAGULAÇÃO-FLOCULAÇÃO-SEDIMENTAÇÃO}

\begin{tabular}{|c|c|c|c|c|c|c|c|}
\hline \multirow{2}{*}{$\begin{array}{l}\text { ENSAIO N } \mathbf{N}^{\circ}: 09 \\
\text { Data : } 18 / 04 / 00\end{array}$} & \multirow{2}{*}{\multicolumn{2}{|c|}{\begin{tabular}{|c|} 
COAGULANTE \\
Hidroxicloreto de Alumínio \\
\end{tabular}}} & \multicolumn{3}{|c|}{ MISTURA RÁPIDA } & \multicolumn{2}{|c|}{ FLOCULAÇÃO } \\
\hline & & & Tmr $=5 \mathrm{~s}$ & \multicolumn{2}{|c|}{ Gmr $=1000 \mathrm{~s}^{-1}$} & $T f=30 \mathrm{~min}$ & $G f=15 s^{-1}$ \\
\hline \multicolumn{8}{|c|}{ CARACTERÍSTICAS DA ÁGUA DE ESTUDO } \\
\hline \multirow{2}{*}{ Turbidez (uT) } & \multirow{2}{*}{$\begin{array}{c}\text { Cor Aparente } \\
\text { (uC) }\end{array}$} & \multirow{2}{*}{$\begin{array}{c}\text { Cor Verdadeira } \\
\text { (uC) }\end{array}$} & \multirow{2}{*}{$\begin{array}{c}\text { Alcalinidade Total } \\
\left(\mathrm{mg} / \ell \mathrm{CaCO}_{3}\right)\end{array}$} & \multicolumn{2}{|c|}{ pH } & \multirow{2}{*}{$\begin{array}{c}\text { Temperatura } \\
{ }^{\circ} \mathrm{C} \\
\end{array}$} & \multirow{2}{*}{$\begin{array}{r}\text { Potencial } \\
\text { Zeta }(\mathrm{mV})\end{array}$} \\
\hline & & & & S/ agit. & C/ agit. & & \\
\hline 6.58 & 143 & 102 & 30 & 8.00 & 7.59 & 25 & 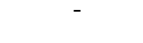 \\
\hline
\end{tabular}

\begin{tabular}{|c|c|c|c|c|c|c|}
\hline \multirow{2}{*}{ FRASCO } & \multicolumn{3}{|c|}{ DOSAGEM DE PRODUTO QUÍMICO } & \multirow{2}{*}{$\begin{array}{c}\text { pH } \\
\text { de } \\
\text { Coagulação }\end{array}$} & \multirow{2}{*}{$\begin{array}{c}T_{\mathrm{s} 2}=7,00 \mathrm{~min} \\
\mathrm{~V}_{\mathrm{s} 2}=1.0 \mathrm{~cm} / \mathrm{min} \\
\begin{array}{c}\mathrm{Cor} \\
(\mathrm{uC})\end{array} \\
\end{array}$} & \multirow{2}{*}{$\begin{array}{c}T_{\mathrm{s} 1}=3,50 \mathrm{~min} \\
V_{\mathrm{s} 1}=2.0 \mathrm{~cm} / \mathrm{min} \\
\begin{array}{c}\mathrm{Cor} \\
(\mathrm{uC})\end{array}\end{array}$} \\
\hline & $\begin{array}{c}\text { Hidroxicloreto } \\
\text { de Alumínio } \\
\text { (mg/l) }\end{array}$ & $\begin{array}{c}\text { Ácido } \\
\text { Clorídrico } \\
\text { 0.1N(m } / \text { / }) \\
\end{array}$ & $\begin{array}{c}\text { Hidróxido de } \\
\text { Sódio } 0.1 \mathrm{~N}(\mathrm{~m} \ell / \ell)\end{array}$ & & & \\
\hline 1 & 160 & - & 28.0 & 6.45 & 18 & 26 \\
\hline 2 & 180 & - & 36.0 & 6.75 & 15 & 19 \\
\hline 3 & 180 & - & 38.0 & 6.94 & 11 & 16 \\
\hline 4 & 180 & - & 40.0 & 7.24 & 14 & 27 \\
\hline 5 & 140 & - & 33.0 & 7.59 & 22 & 37 \\
\hline 6 & 120 & - & 28.0 & 7.57 & 32 & 40 \\
\hline
\end{tabular}

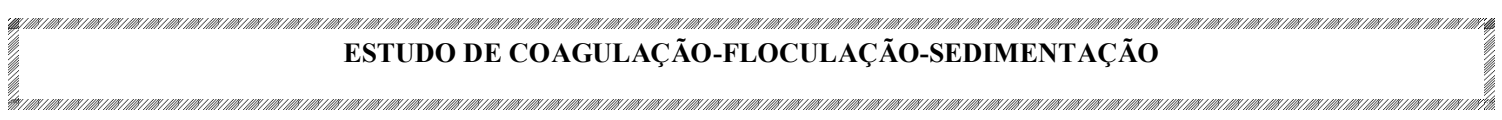

\begin{tabular}{|c|c|c|c|c|c|}
\hline ENSAIO No: 10 & COAGULANTE & \multicolumn{2}{|c|}{ MISTURA RÁPIDA } & \multicolumn{2}{|c|}{ FLOCULAÇÃO } \\
\cline { 3 - 6 } Data $: 18 / 04 / 00$ & Hidroxicloreto de Alumínio & $\mathbf{T m r}=\mathbf{5 s}$ & $\mathbf{G m r}=\mathbf{1 0 0 0 s}^{-1}$ & $\mathbf{T f}=\mathbf{3 0 m i n}$ & $\mathbf{G f}^{-1} \mathbf{1 5 s}^{-1}$ \\
\hline
\end{tabular}

\begin{tabular}{|c|c|c|c|c|c|c|c|}
\hline \multicolumn{8}{|c|}{ CARACTERÍSTICAS DA ÁGUA DE ESTUDO } \\
\hline \multirow[t]{2}{*}{ Turbidez (uT) } & \multirow{2}{*}{$\begin{array}{c}\begin{array}{c}\text { Cor Aparente } \\
\text { (uC) }\end{array} \\
\end{array}$} & \multirow{2}{*}{$\begin{array}{c}\begin{array}{c}\text { Cor Verdadeira } \\
(\mathrm{uC})\end{array} \\
\end{array}$} & \multirow{2}{*}{$\begin{array}{c}\text { Alcalinidade Total } \\
\left(\mathrm{mg} / \ell \mathrm{CaCO}_{3}\right)\end{array}$} & \multicolumn{2}{|c|}{$\mathrm{pH}$} & \multirow{2}{*}{$\begin{array}{c}\text { Temperatura } \\
{ }^{\circ} \mathrm{C} \\
\end{array}$} & \multirow{2}{*}{$\begin{array}{r}\text { Potencial } \\
\text { Zeta }(\mathrm{mV}) \\
\end{array}$} \\
\hline & & & & S/ agit. & $\mathrm{C} /$ agit. & & \\
\hline 6.58 & 143 & 102 & 30 & 8.00 & 7.59 & 25 & - \\
\hline
\end{tabular}

\begin{tabular}{|c|c|c|c|c|c|c|}
\hline \multirow{2}{*}{ FRASCO } & \multicolumn{3}{|c|}{ DOSAGEM DE PRODUTO QUÍMICO } & \multirow{2}{*}{$\begin{array}{c}\text { pH } \\
\text { de } \\
\text { Coagulação }\end{array}$} & \multirow{2}{*}{$\begin{array}{c}T_{\mathrm{s} 2}=7,00 \mathrm{~min} \\
V_{\mathrm{s} 2}=1.0 \mathrm{~cm} / \mathrm{min} \\
\begin{array}{c}\mathrm{Cor} \\
(\mathrm{uC})\end{array}\end{array}$} & \multirow{2}{*}{$\begin{array}{c}T_{\mathrm{s} 1}=3,50 \mathrm{~min} \\
V_{\mathrm{s} 1}=2.0 \mathrm{~cm} / \mathrm{min} \\
\begin{array}{c}\mathrm{Cor} \\
(\mathrm{uC})\end{array}\end{array}$} \\
\hline & $\begin{array}{c}\text { Hidroxicloreto } \\
\text { de Alumínio } \\
(\mathrm{mg} / \ell)\end{array}$ & $\begin{array}{c}\text { Ácido } \\
\text { Clorídrico } \\
0.1 \mathrm{~N}(\mathrm{~m} \ell / \ell) \\
\end{array}$ & $\begin{array}{c}\text { Hidróxido de } \\
\text { Sódio } 0.1 \mathrm{~N}(\mathrm{~m} \ell / \ell)\end{array}$ & & & \\
\hline 1 & 180 & - & 34.0 & 6.57 & 13 & 20 \\
\hline 2 & 200 & - & 42.0 & 6.90 & 10 & 16 \\
\hline 3 & 200 & - & 44.0 & 7.14 & 13 & 15 \\
\hline 4 & 200 & - & 46.0 & 7.41 & 15 & 31 \\
\hline 5 & 180 & - & 42.0 & 7.49 & 18 & 31 \\
\hline 6 & 180 & - & 44.0 & 7.76 & 30 & 40 \\
\hline
\end{tabular}




\section{ESTUDO DE COAGULAÇÃO-FLOCULAÇÃO-SEDIMENTAÇÃO}

\begin{tabular}{|c|c|c|c|c|c|c|c|}
\hline \multirow{2}{*}{$\begin{array}{l}\text { ENSAIO No: } 11 \\
\text { Data : } 18 / 04 / 00\end{array}$} & \multirow{2}{*}{\multicolumn{2}{|c|}{\begin{tabular}{c|} 
COAGULANTE \\
Hidroxicloreto de Alumínio \\
\end{tabular}}} & \multicolumn{3}{|c|}{ MISTURA RÁPIDA } & \multicolumn{2}{|c|}{ FLOCULACÃO } \\
\hline & & & $T m r=5 s$ & \multicolumn{2}{|c|}{ Gmr $=1000 \mathrm{~s}^{-1}$} & $T f=30 \mathrm{~min}$ & $G f=15 s^{-1}$ \\
\hline \multicolumn{8}{|c|}{ CARACTERÍSTICAS DA ÁGUA DE ESTUDO } \\
\hline \multirow{2}{*}{ Turbidez (uT) } & \multirow{2}{*}{$\begin{array}{c}\text { Cor Aparente } \\
\text { (uC) }\end{array}$} & \multirow{2}{*}{$\begin{array}{c}\text { Cor Verdadeira } \\
(\mathrm{uC})\end{array}$} & \multirow{2}{*}{$\begin{array}{l}\text { Alcalinidade Total } \\
\left(\mathrm{mg} / \ell \mathrm{CaCO}_{3}\right)\end{array}$} & \multicolumn{2}{|c|}{ pH } & \multirow{2}{*}{$\begin{array}{c}\text { Temperatura } \\
{ }^{\circ} \mathrm{C} \\
\end{array}$} & \multirow{2}{*}{$\begin{array}{r}\text { Potencial } \\
\text { Zeta }(m V)\end{array}$} \\
\hline & & & & S/ agit. & $\mathrm{C} /$ agit. & & \\
\hline 6.58 & 143 & 102 & 30 & 8.00 & 7.59 & 25 & - \\
\hline
\end{tabular}

\begin{tabular}{|c|c|c|c|c|c|c|}
\hline \multirow{2}{*}{ FRASCO } & \multicolumn{3}{|c|}{ DOSAGEM DE PRODUTO QUÍMICO } & \multirow{2}{*}{$\begin{array}{c}\text { pH } \\
\text { de } \\
\text { Coagulação }\end{array}$} & \multirow{2}{*}{$\begin{array}{c}T_{\mathrm{s} 2}=7,00 \mathrm{~min} \\
\mathrm{~V}_{\mathrm{s} 2}=1.0 \mathrm{~cm} / \mathrm{min} \\
\begin{array}{c}\mathrm{Cor} \\
(\mathrm{uC})\end{array} \\
\end{array}$} & \multirow{2}{*}{$\begin{array}{c}T_{\mathrm{s} 1}=3,50 \mathrm{~min} \\
V_{\mathrm{s} 1}=2.0 \mathrm{~cm} / \mathrm{min} \\
\begin{array}{c}\mathrm{Cor} \\
(\mathrm{uC})\end{array}\end{array}$} \\
\hline & $\begin{array}{c}\text { Hidroxicloreto } \\
\text { de Alumínio } \\
\text { (mg/l) }\end{array}$ & $\begin{array}{c}\text { Ácido } \\
\text { Clorídrico } \\
\text { 0.1N(m } / \text { / }) \\
\end{array}$ & $\begin{array}{c}\text { Hidróxido de } \\
\text { Sódio } 0.1 \mathrm{~N}(\mathrm{~m} \ell / \ell)\end{array}$ & & & \\
\hline 1 & 160 & - & 27.0 & 6.41 & 54 & 64 \\
\hline 2 & 140 & - & 22.0 & 6.42 & - & - \\
\hline 3 & 140 & - & 30.0 & 7.09 & 15 & 18 \\
\hline 4 & 120 & - & 27.0 & 7.36 & 27 & 44 \\
\hline 5 & 140 & - & 31.5 & 7.34 & 18 & 25 \\
\hline 6 & 160 & - & 39.0 & 7.70 & 28 & 34 \\
\hline
\end{tabular}

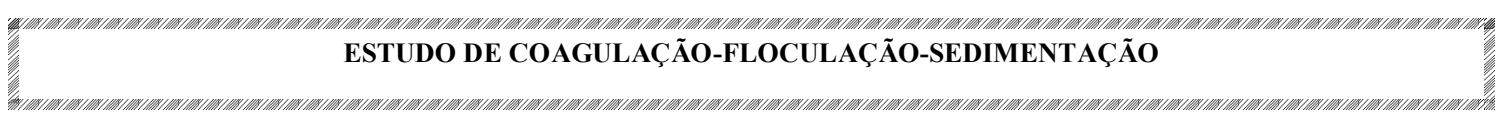

\begin{tabular}{|c|c|c|c|c|c|}
\hline ENSAIO No: 12 & COAGULANTE & \multicolumn{2}{|c|}{ MISTURA RÁPIDA } & \multicolumn{2}{|c|}{ FLOCULAÇÃO } \\
\cline { 3 - 6 } Data $: 18 / 04 / 00$ & Hidroxicloreto de Alumínio & $\mathbf{T m r}=\mathbf{5 s}$ & $\mathbf{G m r}=\mathbf{1 0 0 0 s}^{-1}$ & $\mathbf{T f}=\mathbf{3 0 m i n}$ & $\mathbf{G f}^{-1} \mathbf{1 5 s}^{-1}$ \\
\hline
\end{tabular}

\begin{tabular}{|c|c|c|c|c|c|c|c|}
\hline \multicolumn{8}{|c|}{ CARACTERÍSTICAS DA ÁGUA DE ESTUDO } \\
\hline \multirow[t]{2}{*}{ Turbidez (uT) } & \multirow{2}{*}{$\begin{array}{c}\text { Cor Aparente } \\
\text { (uC) }\end{array}$} & \multirow{2}{*}{$\begin{array}{c}\text { Cor Verdadeira } \\
(\mathrm{uC})\end{array}$} & \multirow{2}{*}{$\begin{array}{l}\text { Alcalinidade Total } \\
\left(\mathrm{mg} / \ell \mathrm{CaCO}_{3}\right)\end{array}$} & \multicolumn{2}{|c|}{ pH } & \multirow{2}{*}{$\begin{array}{c}\text { Temperatura } \\
{ }^{\circ} \mathrm{C} \\
\end{array}$} & \multirow{2}{*}{$\begin{array}{l}\text { Potencial } \\
\text { Zeta }(\mathrm{mV})\end{array}$} \\
\hline & & & & S/ agit. & $\mathrm{C} /$ agit. & & \\
\hline 6.58 & 143 & 102 & 30 & 8.00 & 7.59 & 25 & $\begin{array}{c}\text { Frasco } 04 \\
-0.1\end{array}$ \\
\hline
\end{tabular}

\begin{tabular}{|c|c|c|c|c|c|c|}
\hline \multirow{2}{*}{ FRASCO } & \multicolumn{3}{|c|}{ DOSAGEM DE PRODUTO QUÍMICO } & \multirow{2}{*}{$\begin{array}{c}\text { pH } \\
\text { de } \\
\text { Coagulação }\end{array}$} & \multirow{2}{*}{$\begin{array}{c}T_{\mathrm{s} 2}=7,00 \mathrm{~min} \\
V_{\mathrm{s} 2}=1.0 \mathrm{~cm} / \mathrm{min} \\
\begin{array}{c}\mathrm{Cor} \\
(\mathrm{uC})\end{array}\end{array}$} & \multirow{2}{*}{$\begin{array}{c}T_{\mathrm{s} 1}=3,50 \mathrm{~min} \\
V_{\mathrm{s} 1}=2.0 \mathrm{~cm} / \mathrm{min} \\
\begin{array}{c}\mathrm{Cor} \\
(\mathrm{uC})\end{array}\end{array}$} \\
\hline & $\begin{array}{c}\text { Hidroxicloreto } \\
\text { de Alumínio } \\
(\mathrm{mg} / \ell)\end{array}$ & $\begin{array}{c}\text { Ácido } \\
\text { Clorídrico } \\
0.1 \mathrm{~N}(\mathrm{~m} \ell / \ell) \\
\end{array}$ & $\begin{array}{c}\text { Hidróxido de } \\
\text { Sódio } 0.1 \mathrm{~N}(\mathrm{~m} \ell / \ell)\end{array}$ & & & \\
\hline 1 & 180 & - & 33.0 & 6.50 & 8 & 13 \\
\hline 2 & 200 & - & 38.0 & 7.11 & 11 & 20 \\
\hline 3 & 220 & - & 44.0 & 6.24 & - & - \\
\hline 4 & 220 & - & 46.0 & 6.92 & 6 & 13 \\
\hline 5 & 200 & - & 48.0 & 7.62 & 18 & 25 \\
\hline 6 & 200 & - & 49.0 & 7.88 & 27 & 34 \\
\hline
\end{tabular}




\section{ESTUDO DE COAGULAÇÃO-FLOCULAÇÃO-SEDIMENTAÇÃO}

\begin{tabular}{|c|c|c|c|c|c|c|c|}
\hline \multirow{2}{*}{$\begin{array}{l}\text { ENSAIO N }{ }^{\circ}: 13 \\
\text { Data }: 18 / 04 / 00\end{array}$} & \multirow{2}{*}{\multicolumn{2}{|c|}{\begin{tabular}{|c|} 
COAGULANTE \\
Hidroxicloreto de Alumínio \\
\end{tabular}}} & \multicolumn{3}{|c|}{ MISTURA RÁPIDA } & \multicolumn{2}{|c|}{ FLOCULAÇÃO } \\
\hline & & & Tmr $=5 \mathrm{~s}$ & \multicolumn{2}{|c|}{$\mathrm{Gmr}=1000 \mathrm{~s}^{-1}$} & Tf $=30 \mathrm{~min}$ & $\mathbf{G f}=15 \mathrm{~s}^{-1}$ \\
\hline \multicolumn{8}{|c|}{ CARACTERÍSTICAS DA ÁGUA DE ESTUDO } \\
\hline \multirow{2}{*}{ Turbidez (uT) } & \multirow{2}{*}{$\begin{array}{c}\text { Cor Aparente } \\
\text { (uC) }\end{array}$} & \multirow{2}{*}{$\begin{array}{c}\text { Cor Verdadeira } \\
\text { (uC) }\end{array}$} & \multirow{2}{*}{$\begin{array}{c}\text { Alcalinidade Total } \\
\left(\mathrm{mg} / \ell \mathrm{CaCO}_{3}\right)\end{array}$} & \multicolumn{2}{|c|}{ pH } & \multirow{2}{*}{$\begin{array}{l}\text { Temperatura } \\
{ }^{\circ} \mathrm{C}\end{array}$} & \multirow{2}{*}{$\begin{array}{l}\text { Potencial } \\
\text { Zeta }(\mathrm{mV}\end{array}$} \\
\hline & & & & S/ agit. & C/ agit. & & \\
\hline 6.58 & 143 & 102 & 30 & 8.00 & 7.59 & 25 & 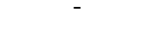 \\
\hline
\end{tabular}

\begin{tabular}{|c|c|c|c|c|c|c|}
\hline \multirow{2}{*}{ FRASCO } & \multicolumn{3}{|c|}{ DOSAGEM DE PRODUTO QUÍMICO } & \multirow{2}{*}{$\begin{array}{c}\text { pH } \\
\text { de } \\
\text { Coagulação }\end{array}$} & \multirow{2}{*}{$\begin{array}{c}T_{\mathrm{s} 2}=7,00 \mathrm{~min} \\
\mathrm{~V}_{\mathrm{s} 2}=1.0 \mathrm{~cm} / \mathrm{min} \\
\begin{array}{c}\mathrm{Cor} \\
(\mathrm{uC})\end{array} \\
\end{array}$} & \multirow{2}{*}{$\begin{array}{c}T_{\mathrm{s} 1}=3,50 \mathrm{~min} \\
V_{\mathrm{s} 1}=2.0 \mathrm{~cm} / \mathrm{min} \\
\begin{array}{c}\mathrm{Cor} \\
(\mathrm{uC})\end{array}\end{array}$} \\
\hline & $\begin{array}{c}\text { Hidroxicloreto } \\
\text { de Alumínio } \\
\text { (mg/l) }\end{array}$ & $\begin{array}{c}\text { Ácido } \\
\text { Clorídrico } \\
\text { 0.1N(m } / \text { / }) \\
\end{array}$ & $\begin{array}{c}\text { Hidróxido de } \\
\text { Sódio } 0.1 \mathrm{~N}(\mathrm{~m} \ell / \ell)\end{array}$ & & & \\
\hline 1 & 200 & - & 36.0 & 6.38 & 53 & 61 \\
\hline 2 & 240 & - & 50.0 & 6.80 & 9 & 19 \\
\hline 3 & 240 & - & 52.0 & 6.99 & 8 & 12 \\
\hline 4 & 220 & -- & 48.0 & 7.05 & 9 & 13 \\
\hline 5 & 220 & - & 50.0 & 7.38 & 11 & 18 \\
\hline 6 & 220 & - & 52.0 & 7.70 & 17 & 23 \\
\hline
\end{tabular}

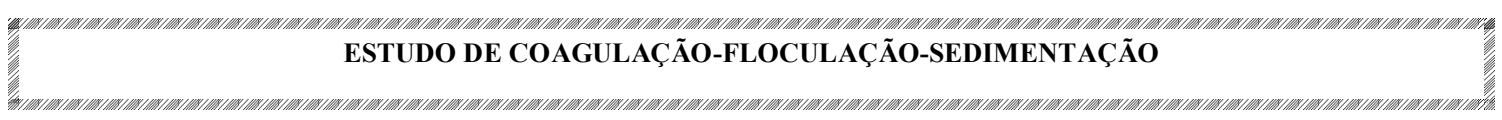

\begin{tabular}{|c|c|c|c|c|c|}
\hline ENSAIO No: $: 14$ & COAGULANTE & \multicolumn{2}{|c|}{ MISTURA RÁPIDA } & \multicolumn{2}{|c|}{ FLOCULAÇÃO } \\
\cline { 3 - 6 } Data $: 18 / 04 / 00$ & Hidroxicloreto de Alumínio & $\mathbf{T m r}=\mathbf{5 s}$ & $\mathbf{G m r}=\mathbf{1 0 0 0 s}^{-1}$ & $\mathbf{T f}=\mathbf{3 0 m i n}$ & $\mathbf{G f}^{-1} \mathbf{1 5 s}^{-1}$ \\
\hline
\end{tabular}

\begin{tabular}{|c|c|c|c|c|c|c|c|}
\hline \multicolumn{8}{|c|}{ CARACTERÍSTICAS DA ÁGUA DE ESTUDO } \\
\hline \multirow[t]{2}{*}{ Turbidez (uT) } & \multirow{2}{*}{$\begin{array}{c}\begin{array}{c}\text { Cor Aparente } \\
\text { (uC) }\end{array} \\
\end{array}$} & \multirow{2}{*}{$\begin{array}{c}\begin{array}{c}\text { Cor Verdadeira } \\
(\mathrm{uC})\end{array} \\
\end{array}$} & \multirow{2}{*}{$\begin{array}{c}\text { Alcalinidade Total } \\
\left(\mathrm{mg} / \ell \mathrm{CaCO}_{3}\right)\end{array}$} & \multicolumn{2}{|c|}{$\mathrm{pH}$} & \multirow{2}{*}{$\begin{array}{c}\text { Temperatura } \\
{ }^{\circ} \mathrm{C} \\
\end{array}$} & \multirow{2}{*}{$\begin{array}{r}\text { Potencial } \\
\text { Zeta }(\mathrm{mV}) \\
\end{array}$} \\
\hline & & & & S/ agit. & $\mathrm{C} /$ agit. & & \\
\hline 6.58 & 143 & 102 & 30 & 8.00 & 7.59 & 25 & - \\
\hline
\end{tabular}

\begin{tabular}{|c|c|c|c|c|c|c|}
\hline \multirow{2}{*}{ FRASCO } & \multicolumn{3}{|c|}{ DOSAGEM DE PRODUTO QUÍMICO } & \multirow{2}{*}{$\begin{array}{c}\text { pH } \\
\text { de } \\
\text { Coagulação }\end{array}$} & \multirow{2}{*}{$\begin{array}{c}T_{\mathrm{s} 2}=7,00 \mathrm{~min} \\
\mathrm{~V}_{\mathrm{s} 2}=1.0 \mathrm{~cm} / \mathrm{min} \\
\begin{array}{c}\mathrm{Cor} \\
(\mathrm{uC})\end{array}\end{array}$} & \multirow{2}{*}{$\begin{array}{c}T_{\mathrm{s} 1}=3,50 \mathrm{~min} \\
\frac{V_{\mathrm{s} 1}=2.0 \mathrm{~cm} / \mathrm{min}}{\mathrm{Cor}} \\
(\mathrm{uC})\end{array}$} \\
\hline & $\begin{array}{c}\text { Hidroxicloreto } \\
\text { de Alumínio } \\
\text { (mg/t) }\end{array}$ & 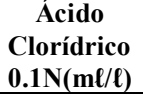 & 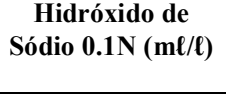 & & & \\
\hline 1 & 200 & - & 37.0 & 6.43 & 16 & 18 \\
\hline 2 & 220 & - & $45 . .0$ & 6.74 & 10 & 12 \\
\hline 3 & 200 & - & 39.0 & 6.62 & 10 & 14 \\
\hline 4 & 220 & - & 45.5 & 6.82 & 14 & 19 \\
\hline 5 & 220 & - & 49 & 7.18 & 10 & 24 \\
\hline 6 & 220 & - & 51 & 7.50 & 10 & 24 \\
\hline
\end{tabular}




\section{ESTUDO DE COAGULAÇÃO-FLOCULAÇÃO-SEDIMENTAÇÃO}

\begin{tabular}{|c|c|c|c|c|c|c|c|}
\hline \multirow{2}{*}{$\begin{array}{l}\text { ENSAIO N }{ }^{\circ}: 15 \\
\text { Data }: 18 / 04 / 00 \\
\end{array}$} & \multirow{2}{*}{\multicolumn{2}{|c|}{$\begin{array}{c}\text { COAGULANTE } \\
\text { Hidroxicloreto de Alumínio } \\
\end{array}$}} & \multicolumn{3}{|c|}{ MISTURA RÁPIDA } & \multicolumn{2}{|c|}{ FLOCULAÇÃO } \\
\hline & & & $\mathrm{Tmr}=\mathbf{5 s}$ & \multicolumn{2}{|c|}{$\mathrm{Gmr}=1000 \mathrm{~s}^{-1}$} & $T f=30 \mathrm{~min}$ & $\mathbf{G f}=15 \mathrm{~s}^{-1}$ \\
\hline \multicolumn{8}{|c|}{ CARACTERÍSTICAS DA ÁGUA DE ESTUDO } \\
\hline \multirow{2}{*}{ Turbidez (uT) } & \multirow{2}{*}{$\begin{array}{c}\text { Cor Aparente } \\
\text { (uC) }\end{array}$} & \multirow{2}{*}{$\begin{array}{c}\text { Cor Verdadeira } \\
(\mathrm{uC})\end{array}$} & \multirow{2}{*}{$\begin{array}{l}\text { Alcalinidade Total } \\
\left(\mathrm{mg} / \mathrm{\ell} \mathrm{CaCO}_{3}\right)\end{array}$} & \multicolumn{2}{|c|}{ pH } & \multirow{2}{*}{$\begin{array}{l}\text { Temperatura } \\
{ }^{\circ} \mathrm{C}\end{array}$} & \multirow{2}{*}{$\begin{array}{r}\text { Potencial } \\
\text { Zeta }(\mathrm{mV})\end{array}$} \\
\hline & & & & S/ agit. & $\mathrm{C} /$ agit. & & \\
\hline 6.58 & 143 & 102 & 30 & 8.00 & 7.59 & 25 & - \\
\hline
\end{tabular}

\begin{tabular}{|c|c|c|c|c|c|c|}
\hline \multirow{2}{*}{ FRASCO } & \multicolumn{3}{|c|}{ DOSAGEM DE PRODUTO QUÍMICO } & \multirow{2}{*}{$\begin{array}{c}\text { pH } \\
\text { de } \\
\text { Coagulação }\end{array}$} & \multirow{2}{*}{$\begin{array}{c}T_{\mathrm{s} 2}=7,00 \mathrm{~min} \\
\mathrm{~V}_{\mathrm{s} 2}=1.0 \mathrm{~cm} / \mathrm{min} \\
\begin{array}{c}\mathrm{Cor} \\
(\mathrm{uC})\end{array} \\
\end{array}$} & \multirow{2}{*}{$\begin{array}{c}T_{\mathrm{s} 1}=3,50 \mathrm{~min} \\
V_{\mathrm{s} 1}=2.0 \mathrm{~cm} / \mathrm{min} \\
\begin{array}{c}\mathrm{Cor} \\
(\mathrm{uC})\end{array}\end{array}$} \\
\hline & $\begin{array}{c}\text { Hidroxicloreto } \\
\text { de Alumínio } \\
\text { (mg/l) }\end{array}$ & $\begin{array}{c}\text { Ácido } \\
\text { Clorídrico } \\
\text { 0.1N(m } / \text { / }) \\
\end{array}$ & $\begin{array}{c}\text { Hidróxido de } \\
\text { Sódio } 0.1 \mathrm{~N}(\mathrm{~m} \ell / \ell)\end{array}$ & & & \\
\hline 1 & 240 & - & 48.0 & 6.54 & 7 & 13 \\
\hline 2 & 260 & - & 54.0 & 6.72 & 6 & 14 \\
\hline 3 & 260 & - & 56.0 & 6.95 & 9 & 16 \\
\hline 4 & 280 & - & 62.0 & 7.13 & 13 & 14 \\
\hline 5 & 280 & - & 64.0 & 7.40 & 12 & 19 \\
\hline 6 & 240 & - & 54.0 & 7.27 & 15 & 28 \\
\hline
\end{tabular}

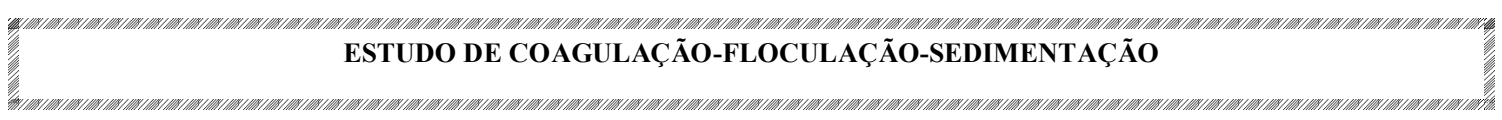

\begin{tabular}{|c|c|c|c|c|c|}
\hline ENSAIO No: $: 16$ & COAGULANTE & \multicolumn{2}{|c|}{ MISTURA RÁPIDA } & \multicolumn{2}{|c|}{ FLOCULAÇÃO } \\
\cline { 3 - 6 } Data $: 19 / 04 / 00$ & Hidroxicloreto de Alumínio & $\mathbf{T m r}=\mathbf{5 s}$ & $\mathbf{G m r}=\mathbf{1 0 0 0 s}^{-1}$ & $\mathbf{T f}=\mathbf{3 0 m i n}$ & $\mathbf{G f}^{-1} \mathbf{1 5 s}^{-1}$ \\
\hline
\end{tabular}

\begin{tabular}{|c|c|c|c|c|c|c|c|}
\hline \multicolumn{8}{|c|}{ CARACTERÍSTICAS DA ÁGUA DE ESTUDO } \\
\hline \multirow[t]{2}{*}{ Turbidez (uT) } & \multirow{2}{*}{$\begin{array}{l}\text { Cor Aparente } \\
\text { (uC) }\end{array}$} & \multirow{2}{*}{$\begin{array}{c}\text { Cor Verdadeira } \\
(\mathrm{uC})\end{array}$} & \multirow{2}{*}{$\begin{array}{l}\text { Alcalinidade Total } \\
\left(\mathrm{mg} / \ell \mathrm{CaCO}_{3}\right)\end{array}$} & \multicolumn{2}{|c|}{ pH } & \multirow{2}{*}{$\begin{array}{c}\text { Temperatura } \\
{ }^{\circ} \mathrm{C} \\
\end{array}$} & \multirow{2}{*}{$\begin{array}{r}\text { Potencial } \\
\text { Zeta }(\mathrm{mV})\end{array}$} \\
\hline & & & & S/ agit. & $\mathrm{C} /$ agit. & & \\
\hline 6.19 & 139 & 101 & 30 & 8.01 & 7.58 & 25 & $\begin{array}{c}\text { Frasco } 06 \\
0.3\end{array}$ \\
\hline
\end{tabular}

\begin{tabular}{|c|c|c|c|c|c|c|}
\hline \multirow{2}{*}{ FRASCO } & \multicolumn{3}{|c|}{ DOSAGEM DE PRODUTO QUÍMICO } & \multirow{2}{*}{$\begin{array}{c}\text { pH } \\
\text { de } \\
\text { Coagulação }\end{array}$} & \multirow{2}{*}{$\begin{array}{c}T_{\mathrm{s} 2}=7,00 \mathrm{~min} \\
\mathrm{~V}_{\mathrm{s} 2}=1.0 \mathrm{~cm} / \mathrm{min} \\
\begin{array}{c}\mathrm{Cor} \\
(\mathrm{uC})\end{array}\end{array}$} & \multirow{2}{*}{$\begin{array}{c}T_{\mathrm{s} 1}=3,50 \mathrm{~min} \\
\frac{V_{\mathrm{s} 1}=2.0 \mathrm{~cm} / \mathrm{min}}{\mathrm{Cor}} \\
(\mathrm{uC})\end{array}$} \\
\hline & $\begin{array}{c}\text { Hidroxicloreto } \\
\text { de Alumínio } \\
\text { (mg/t) }\end{array}$ & 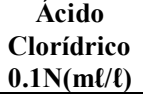 & 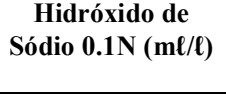 & & & \\
\hline 1 & 240 & - & 47.0 & 6.70 & 5 & 10 \\
\hline 2 & 260 & - & 54.0 & 6.95 & 1 & 13 \\
\hline 3 & 220 & - & 44.0 & 6.88 & 2 & 14 \\
\hline 4 & 260 & - & 55.0 & 6.98 & 3 & 9 \\
\hline 5 & 280 & - & 59.0 & 6.95 & 1 & 7 \\
\hline 6 & 280 & - & 60.5 & 7.11 & 5 & 5 \\
\hline
\end{tabular}




\section{ESTUDO DE COAGULAÇÃO-FLOCULAÇÃO-SEDIMENTAÇÃO}

\begin{tabular}{|c|c|c|c|c|c|c|c|}
\hline \multirow{2}{*}{$\begin{array}{l}\text { ENSAIO No: } 17 \\
\text { Data : } 19 / 04 / 00 \\
\end{array}$} & \multirow{2}{*}{\multicolumn{2}{|c|}{$\begin{array}{c}\text { COAGULANTE } \\
\text { Hidroxicloreto de Alumínio }\end{array}$}} & \multicolumn{3}{|c|}{ MISTURA RÁPIDA } & \multicolumn{2}{|c|}{ FLOCULAÇÃO } \\
\hline & & & Tmr $=5 \mathrm{~s}$ & \multicolumn{2}{|c|}{$\mathrm{Gmr}=1000 \mathrm{~s}^{-1}$} & $T f=30 \mathrm{~min}$ & $G f=15 s^{-1}$ \\
\hline \multicolumn{8}{|c|}{ CARACTERÍSTICAS DA ÁGUA DE ESTUDO } \\
\hline \multirow{2}{*}{ Turbidez (uT) } & \multirow{2}{*}{$\begin{array}{c}\text { Cor Aparente } \\
\text { (uC) }\end{array}$} & \multirow{2}{*}{$\begin{array}{c}\text { Cor Verdadeira } \\
\text { (uC) }\end{array}$} & \multirow{2}{*}{$\begin{array}{l}\text { Alcalinidade Total } \\
\left(\mathrm{mg} / \ell \mathrm{CaCO}_{3}\right)\end{array}$} & \multicolumn{2}{|c|}{ pH } & \multirow{2}{*}{$\begin{array}{c}\text { Temperatura } \\
{ }^{\circ} \mathrm{C}\end{array}$} & \multirow{2}{*}{$\begin{array}{r}\text { Potencial } \\
\text { Zeta }(\mathrm{mV})\end{array}$} \\
\hline & & & & S/ agit. & $\mathrm{C} /$ agit. & & \\
\hline 6.19 & 139 & 101 & 30 & 8.01 & 7.58 & 25 & - \\
\hline
\end{tabular}

\begin{tabular}{|c|c|c|c|c|c|c|}
\hline \multirow{2}{*}{ FRASCO } & \multicolumn{3}{|c|}{ DOSAGEM DE PRODUTO QUÍMICO } & \multirow{2}{*}{$\begin{array}{c}\text { pH } \\
\text { de } \\
\text { Coagulação }\end{array}$} & \multirow{2}{*}{$\begin{array}{c}T_{\mathrm{s} 2}=7,00 \mathrm{~min} \\
\mathrm{~V}_{\mathrm{s} 2}=1.0 \mathrm{~cm} / \mathrm{min} \\
\begin{array}{c}\mathrm{Cor} \\
(\mathrm{uC})\end{array} \\
\end{array}$} & \multirow{2}{*}{$\begin{array}{c}T_{\mathrm{s} 1}=3,50 \mathrm{~min} \\
V_{\mathrm{s} 1}=2.0 \mathrm{~cm} / \mathrm{min} \\
\begin{array}{c}\mathrm{Cor} \\
(\mathrm{uC})\end{array}\end{array}$} \\
\hline & $\begin{array}{c}\text { Hidroxicloreto } \\
\text { de Alumínio } \\
\text { (mg/l) }\end{array}$ & $\begin{array}{c}\text { Ácido } \\
\text { Clorídrico } \\
\text { 0.1N(m } / \text { / }) \\
\end{array}$ & $\begin{array}{c}\text { Hidróxido de } \\
\text { Sódio } 0.1 \mathrm{~N}(\mathrm{~m} \ell / \ell)\end{array}$ & & & \\
\hline 1 & 260 & - & 58.0 & 7.30 & 8 & 15 \\
\hline 2 & 260 & - & 60.0 & 7.52 & 7 & 14 \\
\hline 3 & 240 & - & 56.0 & 7.50 & 13 & 18 \\
\hline 4 & 280 & - & 66.0 & 7.81 & 10 & 15 \\
\hline 5 & 260 & - & 62.0 & 7.95 & 13 & 18 \\
\hline 6 & 240 & - & 58.0 & 8.05 & 17 & 28 \\
\hline
\end{tabular}

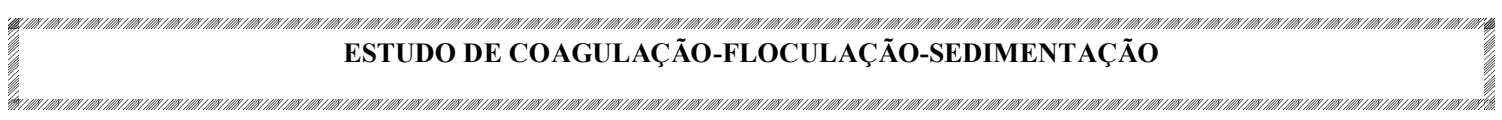

\begin{tabular}{|c|c|c|c|c|c|}
\hline ENSAIO No: 18 & COAGULANTE & \multicolumn{2}{|c|}{ MISTURA RÁPIDA } & \multicolumn{2}{|c|}{ FLOCULAÇÃO } \\
\cline { 3 - 6 } Data $: 19 / 04 / 00$ & Hidroxicloreto de Alumínio & $\mathbf{T m r}=\mathbf{5 s}$ & $\mathbf{G m r}=\mathbf{1 0 0 0 s}^{-1}$ & $\mathbf{T f}=\mathbf{3 0 m i n}$ & $\mathbf{G f}^{-1} \mathbf{1 5 s}^{-1}$ \\
\hline
\end{tabular}

\begin{tabular}{|c|c|c|c|c|c|c|c|}
\hline \multicolumn{8}{|c|}{ CARACTERÍSTICAS DA ÁGUA DE ESTUDO } \\
\hline \multirow[t]{2}{*}{ Turbidez (uT) } & \multirow{2}{*}{$\begin{array}{c}\begin{array}{c}\text { Cor Aparente } \\
\text { (uC) }\end{array} \\
\end{array}$} & \multirow{2}{*}{$\begin{array}{c}\begin{array}{c}\text { Cor Verdadeira } \\
(\mathrm{uC})\end{array} \\
\end{array}$} & \multirow{2}{*}{$\begin{array}{c}\text { Alcalinidade Total } \\
\left(\mathrm{mg} / \ell \mathrm{CaCO}_{3}\right)\end{array}$} & \multicolumn{2}{|c|}{$\mathrm{pH}$} & \multirow{2}{*}{$\begin{array}{c}\text { Temperatura } \\
{ }^{\circ} \mathrm{C} \\
\end{array}$} & \multirow{2}{*}{$\begin{array}{r}\text { Potencial } \\
\text { Zeta }(\mathrm{mV}) \\
\end{array}$} \\
\hline & & & & S/ agit. & $\mathrm{C} /$ agit. & & \\
\hline 6.19 & 139 & 101 & 30 & 8.01 & 7.58 & 25 & - \\
\hline
\end{tabular}

\begin{tabular}{|c|c|c|c|c|c|c|}
\hline \multirow{2}{*}{ FRASCO } & \multicolumn{3}{|c|}{ DOSAGEM DE PRODUTO QUÍMICO } & \multirow{2}{*}{$\begin{array}{c}\text { pH } \\
\text { de } \\
\text { Coagulação }\end{array}$} & \multirow{2}{*}{$\begin{array}{c}T_{\mathrm{s} 2}=7,00 \mathrm{~min} \\
V_{\mathrm{s} 2}=1.0 \mathrm{~cm} / \mathrm{min} \\
\begin{array}{c}\mathrm{Cor} \\
(\mathrm{uC})\end{array}\end{array}$} & \multirow{2}{*}{$\begin{array}{c}T_{\mathrm{s} 1}=3,50 \mathrm{~min} \\
V_{\mathrm{s} 1}=2.0 \mathrm{~cm} / \mathrm{min} \\
\begin{array}{c}\mathrm{Cor} \\
(\mathrm{uC})\end{array}\end{array}$} \\
\hline & $\begin{array}{c}\text { Hidroxicloreto } \\
\text { de Alumínio } \\
(\mathrm{mg} / \ell)\end{array}$ & $\begin{array}{c}\text { Ácido } \\
\text { Clorídrico } \\
0.1 \mathrm{~N}(\mathrm{~m} \ell / \ell) \\
\end{array}$ & $\begin{array}{c}\text { Hidróxido de } \\
\text { Sódio } 0.1 \mathrm{~N}(\mathrm{~m} \ell / \ell)\end{array}$ & & & \\
\hline 1 & 240 & - & 45.0 & 6.32 & - & - \\
\hline 2 & 220 & - & 42.0 & 6.56 & 9 & 12 \\
\hline 3 & 260 & - & 52.0 & 6.65 & 3 & 8 \\
\hline 4 & 280 & - & 58.0 & 6.78 & 4 & 8 \\
\hline 5 & 260 & -- & 53.0 & 6.77 & 6 & 8 \\
\hline 6 & 280 & - & 68.0 & 7.82 & 13 & 18 \\
\hline
\end{tabular}




\section{ESTUDO DE COAGULAÇÃO-FLOCULAÇÃO-SEDIMENTAÇÃO}

\begin{tabular}{|c|c|c|c|c|c|c|c|}
\hline \multirow{2}{*}{$\begin{array}{l}\text { ENSAIO No: } 19 \\
\text { Data : } 19 / 04 / 00 \\
\end{array}$} & \multirow{2}{*}{\multicolumn{2}{|c|}{$\begin{array}{c}\text { COAGULANTE } \\
\text { Hidroxicloreto de Alumínio }\end{array}$}} & \multicolumn{3}{|c|}{ MISTURA RÁPIDA } & \multicolumn{2}{|c|}{ FLOCULAÇÃO } \\
\hline & & & Tmr $=5 \mathrm{~s}$ & \multicolumn{2}{|c|}{$\mathrm{Gmr}=1000 \mathrm{~s}^{-1}$} & $T f=30 \mathrm{~min}$ & $G f=15 s^{-1}$ \\
\hline \multicolumn{8}{|c|}{ CARACTERÍSTICAS DA ÁGUA DE ESTUDO } \\
\hline \multirow{2}{*}{ Turbidez (uT) } & \multirow{2}{*}{$\begin{array}{c}\text { Cor Aparente } \\
\text { (uC) }\end{array}$} & \multirow{2}{*}{$\begin{array}{c}\text { Cor Verdadeira } \\
\text { (uC) }\end{array}$} & \multirow{2}{*}{$\begin{array}{l}\text { Alcalinidade Total } \\
\left(\mathrm{mg} / \ell \mathrm{CaCO}_{3}\right)\end{array}$} & \multicolumn{2}{|c|}{ pH } & \multirow{2}{*}{$\begin{array}{c}\text { Temperatura } \\
{ }^{\circ} \mathrm{C}\end{array}$} & \multirow{2}{*}{$\begin{array}{r}\text { Potencial } \\
\text { Zeta }(\mathrm{mV})\end{array}$} \\
\hline & & & & S/ agit. & $\mathrm{C} /$ agit. & & \\
\hline 6.19 & 139 & 101 & 30 & 8.01 & 7.58 & 25 & - \\
\hline
\end{tabular}

\begin{tabular}{|c|c|c|c|c|c|c|}
\hline \multirow{2}{*}{ FRASCO } & \multicolumn{3}{|c|}{ DOSAGEM DE PRODUTO QUÍMICO } & \multirow{2}{*}{$\begin{array}{c}\text { pH } \\
\text { de } \\
\text { Coagulação }\end{array}$} & \multirow{2}{*}{$\begin{array}{c}T_{\mathrm{s} 2}=7,00 \mathrm{~min} \\
\mathrm{~V}_{\mathrm{s} 2}=1.0 \mathrm{~cm} / \mathrm{min} \\
\begin{array}{c}\mathrm{Cor} \\
(\mathrm{uC})\end{array} \\
\end{array}$} & \multirow{2}{*}{$\begin{array}{c}T_{\mathrm{s} 1}=3,50 \mathrm{~min} \\
V_{\mathrm{s} 1}=2.0 \mathrm{~cm} / \mathrm{min} \\
\begin{array}{c}\mathrm{Cor} \\
(\mathrm{uC})\end{array}\end{array}$} \\
\hline & $\begin{array}{c}\text { Hidroxicloreto } \\
\text { de Alumínio } \\
\text { (mg/l) }\end{array}$ & $\begin{array}{c}\text { Ácido } \\
\text { Clorídrico } \\
\text { 0.1N(m } / \text { / }) \\
\end{array}$ & $\begin{array}{c}\text { Hidróxido de } \\
\text { Sódio } 0.1 \mathrm{~N}(\mathrm{~m} \ell / \ell)\end{array}$ & & & \\
\hline 1 & 260 & - & 51.0 & 6.62 & 7 & 8 \\
\hline 2 & 280 & - & 57.0 & 6.71 & 5 & 11 \\
\hline 3 & 260 & - & 56.0 & 7.10 & 5 & 11 \\
\hline 4 & 280 & - & 63.0 & 7.47 & 8 & 18 \\
\hline 5 & 280 & - & 65.0 & 7.71 & 11 & 13 \\
\hline 6 & 260 & - & 61.0 & 7.75 & 9 & 21 \\
\hline
\end{tabular}

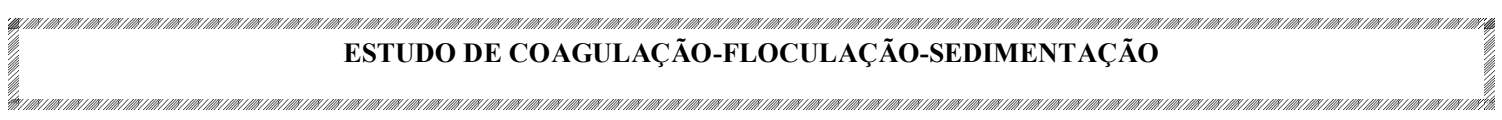

\begin{tabular}{|c|c|c|c|c|c|}
\hline ENSAIO No: 20 & COAGULANTE & \multicolumn{2}{|c|}{ MISTURA RÁPIDA } & \multicolumn{2}{|c|}{ FLOCULAÇÃO } \\
\cline { 3 - 6 } Data $: 19 / 04 / 00$ & Hidroxicloreto de Alumínio & $\mathbf{T m r}=\mathbf{5 s}$ & $\mathbf{G m r}=\mathbf{1 0 0 0 s}^{-1}$ & $\mathbf{T f}=\mathbf{3 0 m i n}$ & $\mathbf{G f}^{-1} \mathbf{1 5 s}^{-1}$ \\
\hline
\end{tabular}

\begin{tabular}{|c|c|c|c|c|c|c|c|}
\hline \multicolumn{8}{|c|}{ CARACTERÍSTICAS DA ÁGUA DE ESTUDO } \\
\hline \multirow[t]{2}{*}{ Turbidez (uT) } & \multirow{2}{*}{$\begin{array}{c}\begin{array}{c}\text { Cor Aparente } \\
\text { (uC) }\end{array} \\
\end{array}$} & \multirow{2}{*}{$\begin{array}{c}\begin{array}{c}\text { Cor Verdadeira } \\
(\mathrm{uC})\end{array} \\
\end{array}$} & \multirow{2}{*}{$\begin{array}{c}\text { Alcalinidade Total } \\
\left(\mathrm{mg} / \ell \mathrm{CaCO}_{3}\right)\end{array}$} & \multicolumn{2}{|c|}{$\mathrm{pH}$} & \multirow{2}{*}{$\begin{array}{c}\text { Temperatura } \\
{ }^{\circ} \mathrm{C} \\
\end{array}$} & \multirow{2}{*}{$\begin{array}{r}\text { Potencial } \\
\text { Zeta }(\mathrm{mV}) \\
\end{array}$} \\
\hline & & & & S/ agit. & $\mathrm{C} /$ agit. & & \\
\hline 6.19 & 139 & 101 & 30 & 8.01 & 7.58 & 25 & - \\
\hline
\end{tabular}

\begin{tabular}{|c|c|c|c|c|c|c|}
\hline \multirow{2}{*}{ FRASCO } & \multicolumn{3}{|c|}{ DOSAGEM DE PRODUTO QUÍMICO } & \multirow{2}{*}{$\begin{array}{c}\text { pH } \\
\text { de } \\
\text { Coagulação }\end{array}$} & \multirow{2}{*}{$\begin{array}{c}T_{\mathrm{s} 2}=7,00 \mathrm{~min} \\
V_{\mathrm{s} 2}=1.0 \mathrm{~cm} / \mathrm{min} \\
\begin{array}{c}\mathrm{Cor} \\
(\mathrm{uC})\end{array}\end{array}$} & \multirow{2}{*}{$\begin{array}{c}T_{\mathrm{s} 1}=3,50 \mathrm{~min} \\
V_{\mathrm{s} 1}=2.0 \mathrm{~cm} / \mathrm{min} \\
\begin{array}{c}\mathrm{Cor} \\
(\mathrm{uC})\end{array}\end{array}$} \\
\hline & $\begin{array}{c}\text { Hidroxicloreto } \\
\text { de Alumínio } \\
(\mathrm{mg} / \ell)\end{array}$ & $\begin{array}{c}\text { Ácido } \\
\text { Clorídrico } \\
0.1 \mathrm{~N}(\mathrm{~m} \ell / \ell) \\
\end{array}$ & $\begin{array}{c}\text { Hidróxido de } \\
\text { Sódio } 0.1 \mathrm{~N}(\mathrm{~m} \ell / \ell)\end{array}$ & & & \\
\hline 1 & 300 & - & 61.0 & 6.68 & 6 & 8 \\
\hline 2 & 300 & - & 62.0 & 6.79 & 6 & 8 \\
\hline 3 & 300 & - & 63.0 & 6.85 & 8 & 9 \\
\hline 4 & 300 & - & 64.0 & 6.99 & 7 & 8 \\
\hline 5 & 300 & - & 66.0 & 7.18 & 8 & 12 \\
\hline 6 & 300 & - & 68.0 & 7.49 & 7 & 15 \\
\hline
\end{tabular}




\section{ESTUDO DE COAGULAÇÃO-FLOCULAÇÃO-SEDIMENTAÇÃO}

\begin{tabular}{|c|c|c|c|c|c|c|c|}
\hline \multirow{2}{*}{$\begin{array}{l}\text { ENSAIO No: } 21 \\
\text { Data : } 19 / 04 / 00 \\
\end{array}$} & \multirow{2}{*}{\multicolumn{2}{|c|}{$\begin{array}{c}\text { COAGULANTE } \\
\text { Hidroxicloreto de Alumínio }\end{array}$}} & \multicolumn{3}{|c|}{ MISTURA RÁPIDA } & \multicolumn{2}{|c|}{ FLOCULAÇÃO } \\
\hline & & & Tmr $=5 \mathrm{~s}$ & \multicolumn{2}{|c|}{$\mathrm{Gmr}=1000 \mathrm{~s}^{-1}$} & $T f=30 \mathrm{~min}$ & Gf $=15 \mathrm{~s}^{-1}$ \\
\hline \multicolumn{8}{|c|}{ CARACTERÍSTICAS DA ÁGUA DE ESTUDO } \\
\hline \multirow{2}{*}{ Turbidez (uT) } & \multirow{2}{*}{$\begin{array}{c}\text { Cor Aparente } \\
\text { (uC) }\end{array}$} & \multirow{2}{*}{$\begin{array}{c}\text { Cor Verdadeira } \\
\text { (uC) }\end{array}$} & \multirow{2}{*}{$\begin{array}{l}\text { Alcalinidade Total } \\
\left(\mathrm{mg} / \ell \mathrm{CaCO}_{3}\right)\end{array}$} & \multicolumn{2}{|c|}{ pH } & \multirow{2}{*}{$\begin{array}{c}\text { Temperatura } \\
{ }^{\circ} \mathrm{C}\end{array}$} & \multirow{2}{*}{$\begin{array}{r}\text { Potencial } \\
\text { Zeta }(\mathrm{mV})\end{array}$} \\
\hline & & & & S/ agit. & $\mathrm{C} /$ agit. & & \\
\hline 6.19 & 139 & 101 & 30 & 8.01 & 7.58 & 25 & - \\
\hline
\end{tabular}

\begin{tabular}{|c|c|c|c|c|c|c|}
\hline \multirow{2}{*}{ FRASCO } & \multicolumn{3}{|c|}{ DOSAGEM DE PRODUTO QUÍMICO } & \multirow{2}{*}{$\begin{array}{c}\text { pH } \\
\text { de } \\
\text { Coagulação }\end{array}$} & \multirow{2}{*}{$\begin{array}{c}T_{\mathrm{s} 2}=7,00 \mathrm{~min} \\
\mathrm{~V}_{\mathrm{s} 2}=1.0 \mathrm{~cm} / \mathrm{min} \\
\begin{array}{c}\mathrm{Cor} \\
(\mathrm{uC})\end{array} \\
\end{array}$} & \multirow{2}{*}{$\begin{array}{c}T_{\mathrm{s} 1}=3,50 \mathrm{~min} \\
V_{\mathrm{s} 1}=2.0 \mathrm{~cm} / \mathrm{min} \\
\begin{array}{c}\mathrm{Cor} \\
(\mathrm{uC})\end{array}\end{array}$} \\
\hline & $\begin{array}{c}\text { Hidroxicloreto } \\
\text { de Alumínio } \\
\text { (mg/l) }\end{array}$ & $\begin{array}{c}\text { Ácido } \\
\text { Clorídrico } \\
\text { 0.1N(m } / \text { / }) \\
\end{array}$ & $\begin{array}{c}\text { Hidróxido de } \\
\text { Sódio } 0.1 \mathrm{~N}(\mathrm{~m} \ell / \ell)\end{array}$ & & & \\
\hline 1 & 260 & - & 49.0 & 6.36 & - & - \\
\hline 2 & 280 & - & 55.0 & 6.42 & - & - \\
\hline 3 & 280 & - & 63.0 & 7.07 & 10 & 12 \\
\hline 4 & 280 & - & 64.0 & 7.24 & 11 & 18 \\
\hline 5 & 240 & - & 57.0 & 7.54 & 10 & 16 \\
\hline 6 & 260 & - & 64.0 & 7.78 & 11 & 20 \\
\hline
\end{tabular}

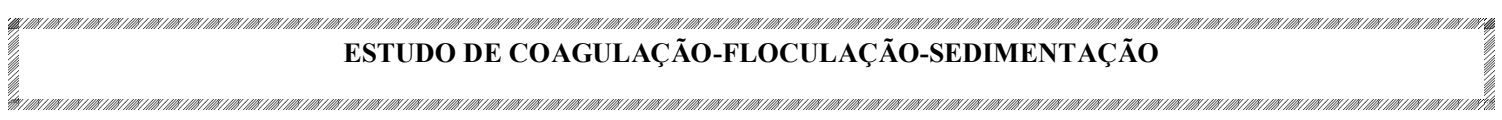

\begin{tabular}{|c|c|c|c|c|c|}
\hline ENSAIO No: 22 & COAGULANTE & \multicolumn{2}{|c|}{ MISTURA RÁPIDA } & \multicolumn{2}{|c|}{ FLOCULAÇÃO } \\
\cline { 3 - 6 } Data $: 19 / 04 / 00$ & Hidroxicloreto de Alumínio & $\mathbf{T m r}=\mathbf{5 s}$ & $\mathbf{G m r}=\mathbf{1 0 0 0 s}^{-1}$ & $\mathbf{T f}=\mathbf{3 0 m i n}$ & $\mathbf{G f}^{-1} \mathbf{1 5 s}^{-1}$ \\
\hline
\end{tabular}

\begin{tabular}{|c|c|c|c|c|c|c|c|}
\hline \multicolumn{8}{|c|}{ CARACTERÍSTICAS DA ÁGUA DE ESTUDO } \\
\hline \multirow[t]{2}{*}{ Turbidez (uT) } & \multirow{2}{*}{$\begin{array}{c}\begin{array}{c}\text { Cor Aparente } \\
\text { (uC) }\end{array} \\
\end{array}$} & \multirow{2}{*}{$\begin{array}{c}\begin{array}{c}\text { Cor Verdadeira } \\
(\mathrm{uC})\end{array} \\
\end{array}$} & \multirow{2}{*}{$\begin{array}{c}\text { Alcalinidade Total } \\
\left(\mathrm{mg} / \ell \mathrm{CaCO}_{3}\right)\end{array}$} & \multicolumn{2}{|c|}{$\mathrm{pH}$} & \multirow{2}{*}{$\begin{array}{c}\text { Temperatura } \\
{ }^{\circ} \mathrm{C} \\
\end{array}$} & \multirow{2}{*}{$\begin{array}{r}\text { Potencial } \\
\text { Zeta }(\mathrm{mV}) \\
\end{array}$} \\
\hline & & & & S/ agit. & $\mathrm{C} /$ agit. & & \\
\hline 6.19 & 139 & 101 & 30 & 8.01 & 7.58 & 25 & - \\
\hline
\end{tabular}

\begin{tabular}{|c|c|c|c|c|c|c|}
\hline \multirow{2}{*}{ FRASCO } & \multicolumn{3}{|c|}{ DOSAGEM DE PRODUTO QUÍMICO } & \multirow{2}{*}{$\begin{array}{c}\text { pH } \\
\text { de } \\
\text { Coagulação }\end{array}$} & \multirow{2}{*}{$\begin{array}{c}T_{\mathrm{s} 2}=7,00 \mathrm{~min} \\
V_{\mathrm{s} 2}=1.0 \mathrm{~cm} / \mathrm{min} \\
\begin{array}{c}\mathrm{Cor} \\
(\mathrm{uC})\end{array}\end{array}$} & \multirow{2}{*}{$\begin{array}{c}T_{\mathrm{s} 1}=3,50 \mathrm{~min} \\
V_{\mathrm{s} 1}=2.0 \mathrm{~cm} / \mathrm{min} \\
\begin{array}{c}\mathrm{Cor} \\
(\mathrm{uC})\end{array}\end{array}$} \\
\hline & $\begin{array}{c}\text { Hidroxicloreto } \\
\text { de Alumínio } \\
(\mathrm{mg} / \ell)\end{array}$ & $\begin{array}{c}\text { Ácido } \\
\text { Clorídrico } \\
0.1 \mathrm{~N}(\mathrm{~m} \ell / \ell) \\
\end{array}$ & $\begin{array}{c}\text { Hidróxido de } \\
\text { Sódio } 0.1 \mathrm{~N}(\mathrm{~m} \ell / \ell)\end{array}$ & & & \\
\hline 1 & 320 & - & 64.0 & 6.38 & - & - \\
\hline 2 & 320 & - & 66.0 & 6.50 & 7 & 10 \\
\hline 3 & 320 & - & 68.0 & 6.66 & 5 & 7 \\
\hline 4 & 320 & - & 70.0 & 6.83 & 7 & 13 \\
\hline 5 & 320 & - & 72.0 & 7.00 & 4 & 7 \\
\hline 6 & 320 & - & 74.0 & 7.20 & 9 & 14 \\
\hline
\end{tabular}




\section{ESTUDO DE COAGULAÇÃO-FLOCULAÇÃO-SEDIMENTAÇÃO}

\begin{tabular}{|c|c|c|c|c|c|c|c|}
\hline \multirow{2}{*}{$\begin{array}{l}\text { ENSAIO No: } 23 \\
\text { Data }: 19 / 04 / 00 \\
\end{array}$} & \multirow{2}{*}{\multicolumn{2}{|c|}{$\begin{array}{c}\text { COAGULANTE } \\
\text { Hidroxicloreto de Alumínio } \\
\end{array}$}} & \multicolumn{3}{|c|}{ MISTURA RÁPIDA } & \multicolumn{2}{|c|}{ FLOCULAÇÃO } \\
\hline & & & Tmr $=5 \mathrm{~s}$ & \multicolumn{2}{|c|}{$\mathrm{Gmr}=1000 \mathrm{~s}^{-1}$} & $T f=30 \mathrm{~min}$ & Gf $=15 \mathrm{~s}^{-1}$ \\
\hline \multicolumn{8}{|c|}{ CARACTERÍSTICAS DA ÁGUA DE ESTUDO } \\
\hline \multirow{2}{*}{ Turbidez (uT) } & \multirow{2}{*}{$\begin{array}{c}\text { Cor Aparente } \\
\text { (uC) }\end{array}$} & \multirow{2}{*}{$\begin{array}{c}\text { Cor Verdadeira } \\
\text { (uC) }\end{array}$} & \multirow{2}{*}{$\begin{array}{l}\text { Alcalinidade Total } \\
\left(\mathrm{mg} / \mathrm{\ell} \mathrm{CaCO}_{3}\right)\end{array}$} & \multicolumn{2}{|c|}{ pH } & \multirow{2}{*}{$\begin{array}{l}\text { Temperatura } \\
{ }^{\circ} \mathrm{C}\end{array}$} & \multirow{2}{*}{$\begin{array}{r}\text { Potencial } \\
\text { Zeta }(\mathrm{mV})\end{array}$} \\
\hline & & & & S/ agit. & $\mathrm{C} /$ agit. & & \\
\hline 6.19 & 139 & 101 & 30 & 8.01 & 7.58 & 25 & - \\
\hline
\end{tabular}

\begin{tabular}{|c|c|c|c|c|c|c|}
\hline \multirow{2}{*}{ FRASCO } & \multicolumn{3}{|c|}{ DOSAGEM DE PRODUTO QUÍMICO } & \multirow{2}{*}{$\begin{array}{c}\text { pH } \\
\text { de } \\
\text { Coagulação }\end{array}$} & \multirow{2}{*}{$\begin{array}{c}T_{\mathrm{s} 2}=7,00 \mathrm{~min} \\
\mathrm{~V}_{\mathrm{s} 2}=1.0 \mathrm{~cm} / \mathrm{min} \\
\begin{array}{c}\mathrm{Cor} \\
(\mathrm{uC})\end{array} \\
\end{array}$} & \multirow{2}{*}{$\begin{array}{c}T_{\mathrm{s} 1}=3,50 \mathrm{~min} \\
V_{\mathrm{s} 1}=2.0 \mathrm{~cm} / \mathrm{min} \\
\begin{array}{c}\mathrm{Cor} \\
(\mathrm{uC})\end{array}\end{array}$} \\
\hline & $\begin{array}{c}\text { Hidroxicloreto } \\
\text { de Alumínio } \\
\text { (mg/l) }\end{array}$ & $\begin{array}{c}\text { Ácido } \\
\text { Clorídrico } \\
\text { 0.1N(m } / \text { / }) \\
\end{array}$ & $\begin{array}{c}\text { Hidróxido de } \\
\text { Sódio } 0.1 \mathrm{~N}(\mathrm{~m} \ell / \ell)\end{array}$ & & & \\
\hline 1 & 260 & - & 50.0 & 6.51 & 8 & 7 \\
\hline 2 & 280 & - & 56.0 & 6.60 & 6 & 3 \\
\hline 3 & 300 & - & 67.0 & 7.27 & 10 & 20 \\
\hline 4 & 300 & - & 70.0 & 7.71 & 9 & 14 \\
\hline 5 & 240 & - & 58.0 & 7.88 & 16 & 28 \\
\hline 6 & 220 & - & 53.0 & 7.93 & 19 & 26 \\
\hline
\end{tabular}

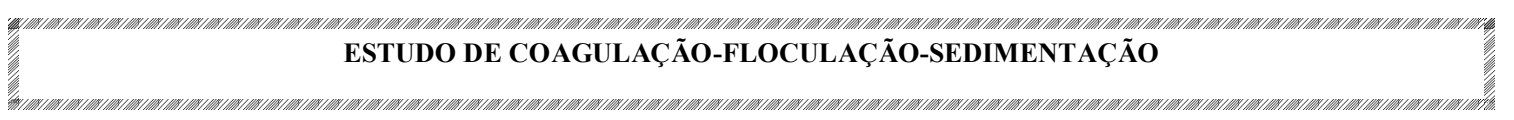

\begin{tabular}{|c|c|c|c|c|c|}
\hline ENSAIO No: 24 & COAGULANTE & \multicolumn{2}{|c|}{ MISTURA RÁPIDA } & \multicolumn{2}{|c|}{ FLOCULAÇÃO } \\
\cline { 3 - 6 } Data $: 19 / 04 / 00$ & Hidroxicloreto de Alumínio & $\mathbf{T m r}=\mathbf{5 s}$ & $\mathbf{G m r}=\mathbf{1 0 0 0 s}^{-1}$ & $\mathbf{T f}=\mathbf{3 0 m i n}$ & $\mathbf{G f}^{-1} \mathbf{1 5 s}^{-1}$ \\
\hline
\end{tabular}

\begin{tabular}{|c|c|c|c|c|c|c|c|}
\hline \multicolumn{8}{|c|}{ CARACTERÍSTICAS DA ÁGUA DE ESTUDO } \\
\hline \multirow[t]{2}{*}{ Turbidez (uT) } & \multirow{2}{*}{$\begin{array}{c}\begin{array}{c}\text { Cor Aparente } \\
\text { (uC) }\end{array} \\
\end{array}$} & \multirow{2}{*}{$\begin{array}{c}\begin{array}{c}\text { Cor Verdadeira } \\
(\mathrm{uC})\end{array} \\
\end{array}$} & \multirow{2}{*}{$\begin{array}{c}\text { Alcalinidade Total } \\
\left(\mathrm{mg} / \ell \mathrm{CaCO}_{3}\right)\end{array}$} & \multicolumn{2}{|c|}{$\mathrm{pH}$} & \multirow{2}{*}{$\begin{array}{c}\text { Temperatura } \\
{ }^{\circ} \mathrm{C} \\
\end{array}$} & \multirow{2}{*}{$\begin{array}{r}\text { Potencial } \\
\text { Zeta }(\mathrm{mV}) \\
\end{array}$} \\
\hline & & & & S/ agit. & $\mathrm{C} /$ agit. & & \\
\hline 6.19 & 139 & 101 & 30 & 8.01 & 7.58 & 25 & - \\
\hline
\end{tabular}

\begin{tabular}{|c|c|c|c|c|c|c|}
\hline \multirow{2}{*}{ FRASCO } & \multicolumn{3}{|c|}{ DOSAGEM DE PRODUTO QUÍMICO } & \multirow{2}{*}{$\begin{array}{c}\text { pH } \\
\text { de } \\
\text { Coagulação }\end{array}$} & \multirow{2}{*}{$\begin{array}{c}T_{\mathrm{s} 2}=7,00 \mathrm{~min} \\
\mathrm{~V}_{\mathrm{s} 2}=1.0 \mathrm{~cm} / \mathrm{min} \\
\begin{array}{c}\mathrm{Cor} \\
(\mathrm{uC})\end{array}\end{array}$} & \multirow{2}{*}{$\begin{array}{c}T_{\mathrm{s} 1}=3,50 \mathrm{~min} \\
\frac{V_{\mathrm{s} 1}=2.0 \mathrm{~cm} / \mathrm{min}}{\mathrm{Cor}} \\
(\mathrm{uC})\end{array}$} \\
\hline & $\begin{array}{c}\text { Hidroxicloreto } \\
\text { de Alumínio } \\
\text { (mg/t) }\end{array}$ & 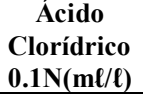 & 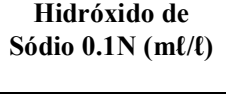 & & & \\
\hline 1 & 300 & - & 60.0 & 6.55 & 1 & 5 \\
\hline 2 & 320 & - & 76.0 & 7.79 & 6 & 11 \\
\hline 3 & 320 & - & 78.0 & 8.01 & 9 & 18 \\
\hline 4 & 300 & - & 72.0 & 7.95 & 6 & 11 \\
\hline 5 & 280 & - & 70.0 & 8.20 & 16 & 27 \\
\hline 6 & 260 & - & 64.0 & 8.20 & 18 & 28 \\
\hline
\end{tabular}




\section{ESTUDO DE COAGULAÇÃO-FLOCULAÇÃO-SEDIMENTAÇÃO}

\begin{tabular}{|c|c|c|c|c|c|}
\hline \multirow{2}{*}{$\begin{array}{l}\text { ENSAIO No: } 25 \\
\text { Data : } 19 / 04 / 00\end{array}$} & \multirow{2}{*}{$\begin{array}{c}\text { COAGULANTE } \\
\text { Hidroxicloreto de Alumínio }\end{array}$} & \multicolumn{2}{|c|}{ MISTURA RÁPIDA } & \multicolumn{2}{|c|}{ FLOCULAÇÃO } \\
\hline & & $T m r=5 s$ & $G m r=1000 s^{-1}$ & $\mathrm{Tf}=30 \mathrm{~min}$ & $G f=15 s^{-1}$ \\
\hline
\end{tabular}

\begin{tabular}{|c|c|c|c|c|c|c|c|}
\hline \multicolumn{8}{|c|}{ CARACTERÍSTICAS DA ÁGUA DE ESTUDO } \\
\hline \multirow{2}{*}{ Turbidez (uT) } & \multirow{2}{*}{$\begin{array}{c}\text { Cor Aparente } \\
\text { (uC) }\end{array}$} & \multirow{2}{*}{$\begin{array}{c}\text { Cor Verdadeira } \\
\text { (uC) }\end{array}$} & \multirow{2}{*}{$\begin{array}{c}\text { Alcalinidade Total } \\
\left(\mathrm{mg} / \ell \mathrm{CaCO}_{3}\right)\end{array}$} & \multicolumn{2}{|c|}{$\mathrm{pH}$} & \multirow{2}{*}{$\begin{array}{c}\text { Temperatura } \\
{ }^{\circ} \mathrm{C} \\
\end{array}$} & \multirow{2}{*}{$\begin{array}{r}\text { Potencial } \\
\text { Zeta }(\mathrm{mV})\end{array}$} \\
\hline & & & & S/ agit. & C/ agit. & & \\
\hline 6.19 & 139 & 101 & 30 & 8.01 & 7.58 & 25 & - \\
\hline
\end{tabular}

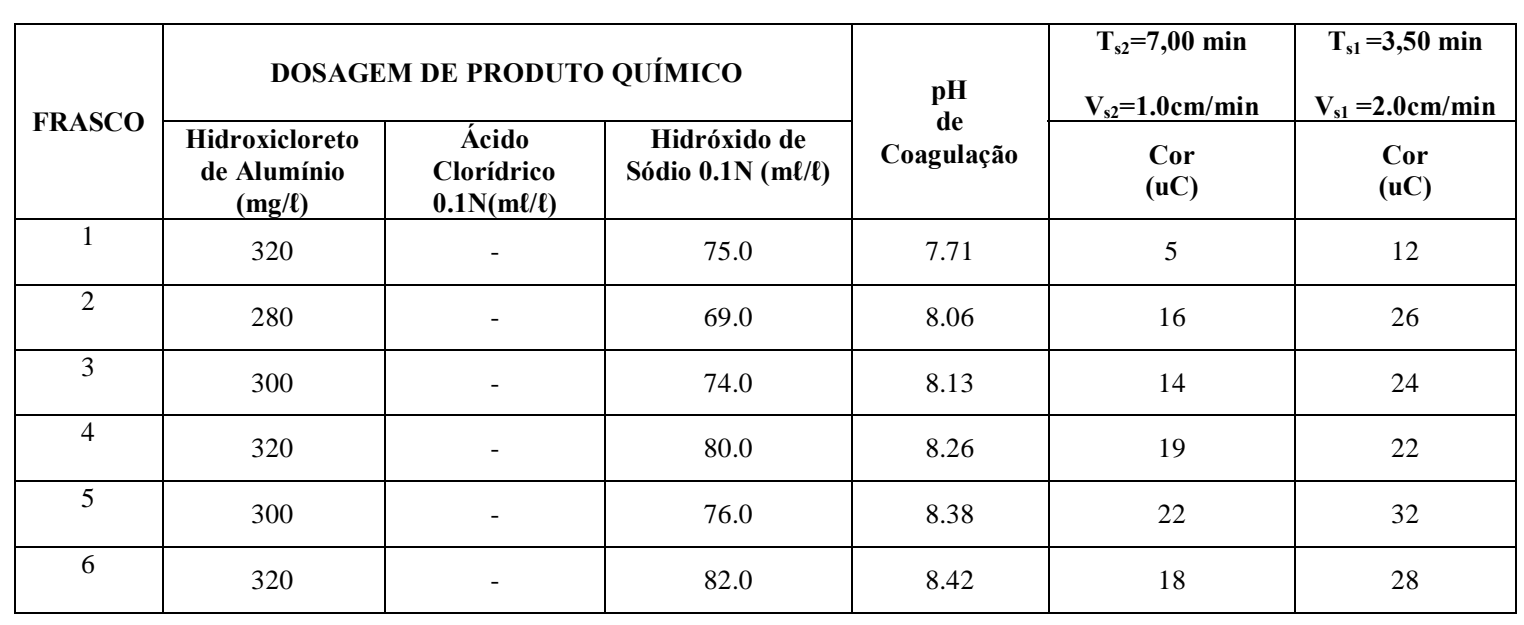


ANEXO - H

ENSAIOS DO REATOR ESTÁTICO - ÁGUA II PARA O COAGULANTE

SULFATO FÉRRICO 


\section{ESTUDO DE COAGULAÇÃO-FLOCULAÇÃO-SEDIMENTAÇÃO}

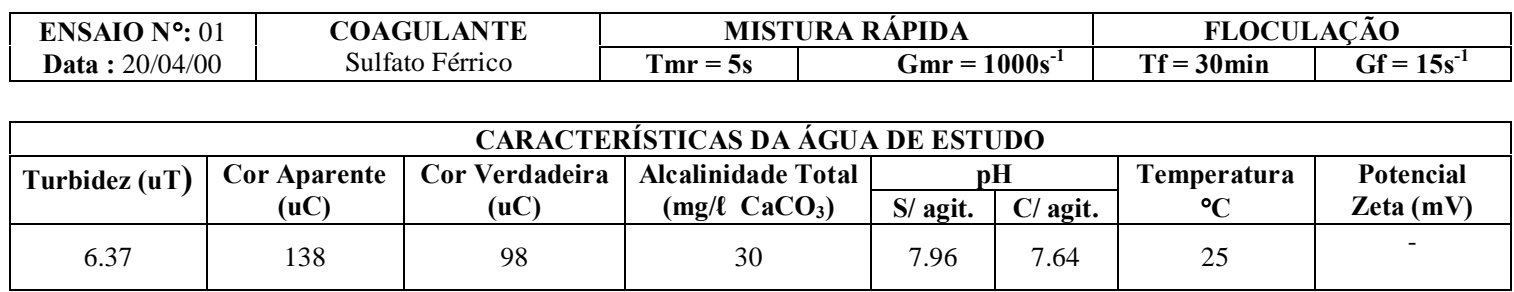

\begin{tabular}{|c|c|c|c|c|c|c|}
\hline \multirow{2}{*}{ FRASCO } & \multicolumn{3}{|c|}{ DOSAGEM DE PRODUTO QUÍMICO } & \multirow{2}{*}{$\begin{array}{c}\text { pH } \\
\text { de } \\
\text { Coagulação }\end{array}$} & \multirow{2}{*}{$\begin{array}{c}T_{\mathrm{s} 2}=7,00 \mathrm{~min} \\
V_{\mathrm{s} 2}=1.0 \mathrm{~cm} / \mathrm{min} \\
\begin{array}{c}\mathrm{Cor} \\
(\mathrm{uC})\end{array}\end{array}$} & \multirow{2}{*}{$\begin{array}{c}T_{\mathrm{s} 2}=3,50 \mathrm{~min} \\
V_{\mathrm{s} 1}=2.0 \mathrm{~cm} / \mathrm{min} \\
\begin{array}{c}\mathrm{Cor} \\
(\mathrm{uC})\end{array}\end{array}$} \\
\hline & $\begin{array}{c}\text { Sulfato férrico } \\
(\mathrm{mg} / \ell)\end{array}$ & $\begin{array}{c}\text { Ácido } \\
\text { Clorídrico } \\
0.1 \mathrm{~N}(\mathrm{~m} / / \ell)\end{array}$ & $\begin{array}{c}\text { Hidróxido de } \\
\text { Sódio } 0.1 \mathrm{~N}(\mathrm{~m} \ell / \ell)\end{array}$ & & & \\
\hline 1 & 80 & - & 8.0 & 4.79 & 35 & 49 \\
\hline 2 & 80 & - & 12.0 & 5.58 & 23 & 50 \\
\hline 3 & 60 & - & 4.0 & 5.46 & 23 & 48 \\
\hline 4 & 60 & - & 8.0 & 6.06 & 17 & 58 \\
\hline 5 & 40 & - & - & 6.10 & 14 & 50 \\
\hline 6 & 40 & - & 4.0 & $6 . .45$ & 25 & 26 \\
\hline
\end{tabular}

\section{ESTUDO DE COAGULAÇÃO-FLOCULAÇÃO-SEDIMENTAÇÃO}

\begin{tabular}{|c|c|c|c|c|c|}
\hline \multirow{2}{*}{$\begin{array}{l}\text { ENSAIO } N^{\circ}: 02 \\
\text { Data }: 20 / 04 / 00\end{array}$} & \multirow{2}{*}{$\begin{array}{c}\text { COAGULANTE } \\
\text { Sulfato Férrico }\end{array}$} & \multicolumn{2}{|c|}{ MISTURA RÁPIDA } & \multicolumn{2}{|c|}{ FLOCULAÇÃO } \\
\hline & & Tmr $=5 \mathrm{~s}$ & $\mathrm{Gmr}=1000 \mathrm{~s}^{-1}$ & Tf $=30 \mathrm{~min}$ & $G f=15 s^{-1}$ \\
\hline
\end{tabular}

\begin{tabular}{|c|c|c|c|c|c|c|c|}
\hline \multicolumn{8}{|c|}{ CARACTERÍSTICAS DA ÁGUA DE ESTUDO } \\
\hline \multirow{2}{*}{ Turbidez (uT) } & \multirow{2}{*}{$\begin{array}{c}\text { Cor Aparente } \\
\text { (uC) }\end{array}$} & \multirow{2}{*}{$\begin{array}{c}\text { Cor Verdadeira } \\
\text { (uC) }\end{array}$} & \multirow{2}{*}{$\begin{array}{c}\text { Alcalinidade Total } \\
\left(\mathrm{mg} / \ell \mathrm{CaCO}_{3}\right)\end{array}$} & \multicolumn{2}{|c|}{ pH } & \multirow{2}{*}{$\begin{array}{c}\text { Temperatura } \\
{ }^{\circ} \mathrm{C} \\
\end{array}$} & \multirow{2}{*}{$\begin{array}{l}\text { Potencial } \\
\text { Zeta }(\mathrm{mV})\end{array}$} \\
\hline & & & & S/ agit. & C/ agit. & & \\
\hline 6.37 & 138 & 98 & 30 & 7.96 & 7.64 & 25 & - \\
\hline
\end{tabular}

\begin{tabular}{|c|c|c|c|c|c|c|}
\hline \multirow{2}{*}{ FRASCO } & \multicolumn{3}{|c|}{ DOSAGEM DE PRODUTO QUÍMICO } & \multirow{2}{*}{$\begin{array}{c}\text { pH } \\
\text { de } \\
\text { Coagulação }\end{array}$} & \multirow{2}{*}{$\begin{array}{c}T_{\mathrm{s} 2}=7,00 \mathrm{~min} \\
V_{\mathrm{s} 2}=1.0 \mathrm{~cm} / \mathrm{min} \\
\begin{array}{c}\mathrm{Cor} \\
(\mathrm{uC})\end{array}\end{array}$} & \multirow{2}{*}{$\begin{array}{c}T_{\mathrm{s} 2}=3,50 \mathrm{~min} \\
V_{\mathrm{s} 1}=2.0 \mathrm{~cm} / \mathrm{min} \\
\begin{array}{c}\mathrm{Cor} \\
(\mathrm{uC})\end{array}\end{array}$} \\
\hline & $\begin{array}{c}\text { Sulfato férrico } \\
(\mathrm{mg} / \mathfrak{l})\end{array}$ & $\begin{array}{c}\text { Ácido } \\
\text { Clorídrico } \\
\mathbf{0 . 1 N}(\mathrm{m} \ell / \ell) \\
\end{array}$ & $\begin{array}{c}\text { Hidróxido de } \\
\text { Sódio } 0.1 \mathrm{~N}(\mathrm{~m} \ell / \ell)\end{array}$ & & & \\
\hline 1 & 80 & - & 8.0 & 4.23 & 41 & 61 \\
\hline 2 & 80 & - & 10.0 & 4.98 & 22 & 54 \\
\hline 3 & 60 & - & 6.0 & 5.59 & 21 & 89 \\
\hline 4 & 40 & 0.91 & - & 5.28 & 36 & 69 \\
\hline 5 & 40 & - & 8.0 & 6.63 & 33 & 69 \\
\hline 6 & 40 & - & 12.0 & 7.00 & - & - \\
\hline
\end{tabular}




\section{ESTUDO DE COAGULAÇÃO-FLOCULAÇÃO-SEDIMENTAÇÃO}

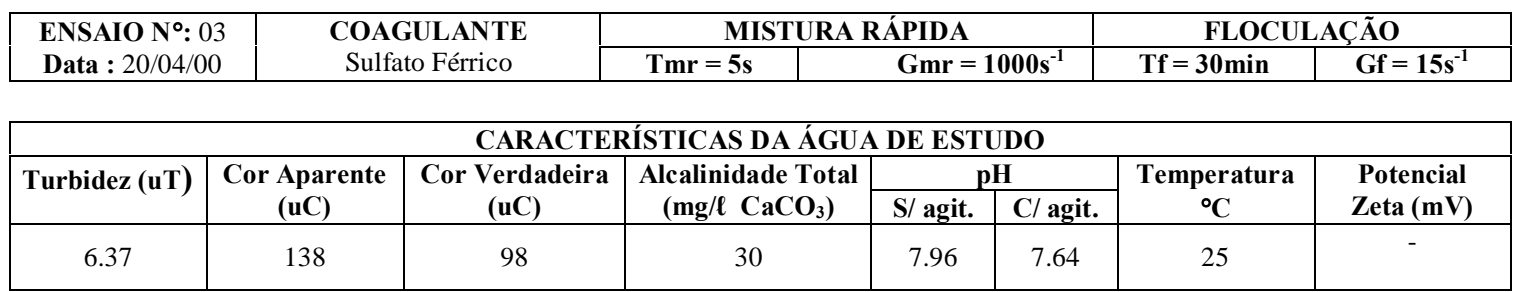

\begin{tabular}{|c|c|c|c|c|c|c|}
\hline \multirow{2}{*}{ FRASCO } & \multicolumn{3}{|c|}{ DOSAGEM DE PRODUTO QUÍMICO } & \multirow{2}{*}{$\begin{array}{c}\text { pH } \\
\text { de } \\
\text { Coagulação }\end{array}$} & \multirow{2}{*}{$\begin{array}{c}T_{\mathrm{s} 2}=7,00 \mathrm{~min} \\
V_{\mathrm{s} 2}=1.0 \mathrm{~cm} / \mathrm{min} \\
\begin{array}{c}\mathrm{Cor} \\
(\mathrm{uC})\end{array}\end{array}$} & \multirow{2}{*}{$\begin{array}{c}T_{\mathrm{s} 2}=3,50 \mathrm{~min} \\
V_{\mathrm{s} 1}=2.0 \mathrm{~cm} / \mathrm{min} \\
\begin{array}{c}\mathrm{Cor} \\
(\mathrm{uC})\end{array}\end{array}$} \\
\hline & $\begin{array}{c}\text { Sulfato férrico } \\
(\mathrm{mg} / \ell)\end{array}$ & $\begin{array}{c}\text { Ácido } \\
\text { Clorídrico } \\
0.1 \mathrm{~N}(\mathrm{~m} / / \ell)\end{array}$ & $\begin{array}{c}\text { Hidróxido de } \\
\text { Sódio } 0.1 \mathrm{~N}(\mathrm{~m} \ell / \ell)\end{array}$ & & & \\
\hline 1 & 100 & - & 16.0 & 4.73 & 19 & 47 \\
\hline 2 & 100 & - & 18.0 & 5.04 & 22 & 26 \\
\hline 3 & 100 & - & 20.0 & 5.37 & 36 & 22 \\
\hline 4 & 80 & - & 14.0 & 5.70 & 45 & 63 \\
\hline 5 & 60 & - & 12.0 & 6.27 & 48 & 78 \\
\hline 6 & 60 & - & 14.0 & 6.46 & 47 & 66 \\
\hline
\end{tabular}

\section{ESTUDO DE COAGULAÇÃO-FLOCULAÇÃO-SEDIMENTAÇÃO}

\begin{tabular}{|c|c|c|c|c|c|}
\hline \multirow{2}{*}{$\begin{array}{l}\text { ENSAIO N } \mathbf{N}^{\circ}: 04 \\
\text { Data : } 20 / 04 / 00\end{array}$} & \multirow{2}{*}{$\begin{array}{c}\text { COAGULANTE } \\
\text { Sulfato Férrico }\end{array}$} & \multicolumn{2}{|c|}{ MISTURA RÁPIDA } & \multicolumn{2}{|c|}{ FLOCULAÇÃO } \\
\hline & & Tmr $=5 \mathrm{~s}$ & $\mathrm{Gmr}=1000 \mathrm{~s}^{-1}$ & Tf $=30 \mathrm{~min}$ & $G f=15 s^{-1}$ \\
\hline
\end{tabular}

\begin{tabular}{|c|c|c|c|c|c|c|c|}
\hline \multicolumn{8}{|c|}{ CARACTERÍSTICAS DA ÁGUA DE ESTUDO } \\
\hline \multirow{2}{*}{ Turbidez (uT) } & \multirow{2}{*}{$\begin{array}{c}\text { Cor Aparente } \\
\text { (uC) }\end{array}$} & \multirow{2}{*}{$\begin{array}{c}\text { Cor Verdadeira } \\
\text { (uC) }\end{array}$} & \multirow{2}{*}{$\begin{array}{c}\text { Alcalinidade Total } \\
\left(\mathrm{mg} / \ell \mathrm{CaCO}_{3}\right)\end{array}$} & \multicolumn{2}{|c|}{ pH } & \multirow{2}{*}{$\begin{array}{c}\text { Temperatura } \\
{ }^{\circ} \mathrm{C} \\
\end{array}$} & \multirow{2}{*}{$\begin{array}{l}\text { Potencial } \\
\text { Zeta }(\mathrm{mV})\end{array}$} \\
\hline & & & & S/ agit. & C/ agit. & & \\
\hline 6.37 & 138 & 98 & 30 & 7.96 & 7.64 & 25 & - \\
\hline
\end{tabular}

\begin{tabular}{|c|c|c|c|c|c|c|}
\hline \multirow{2}{*}{ FRASCO } & \multicolumn{3}{|c|}{ DOSAGEM DE PRODUTO QUÍMICO } & \multirow{2}{*}{$\begin{array}{c}\text { pH } \\
\text { de } \\
\text { Coagulação }\end{array}$} & \multirow{2}{*}{$\begin{array}{c}T_{\mathrm{s} 2}=7,00 \mathrm{~min} \\
V_{\mathrm{s} 2}=1.0 \mathrm{~cm} / \mathrm{min} \\
\begin{array}{c}\mathrm{Cor} \\
(\mathrm{uC})\end{array}\end{array}$} & \multirow{2}{*}{$\begin{array}{c}T_{\mathrm{s} 2}=3,50 \mathrm{~min} \\
V_{\mathrm{s} 1}=2.0 \mathrm{~cm} / \mathrm{min} \\
\begin{array}{c}\mathrm{Cor} \\
(\mathrm{uC})\end{array}\end{array}$} \\
\hline & $\begin{array}{c}\text { Sulfato férrico } \\
(\mathrm{mg} / \mathfrak{l})\end{array}$ & $\begin{array}{c}\text { Ácido } \\
\text { Clorídrico } \\
\mathbf{0 . 1 N}(\mathrm{m} \ell / \ell) \\
\end{array}$ & $\begin{array}{c}\text { Hidróxido de } \\
\text { Sódio } 0.1 \mathrm{~N}(\mathrm{~m} \ell / \ell)\end{array}$ & & & \\
\hline 1 & 140 & - & 34.0 & 5.13 & 33 & 47 \\
\hline 2 & 120 & - & 24.0 & 4.68 & 30 & 55 \\
\hline 3 & 140 & - & 37.0 & 5.59 & 28 & 70 \\
\hline 4 & 120 & - & 27.0 & 5.27 & 48 & 71 \\
\hline 5 & 140 & - & 40.0 & 5.92 & 56 & 70 \\
\hline 6 & 120 & - & 30.0 & 5.70 & 37 & 25 \\
\hline
\end{tabular}




\section{ESTUDO DE COAGULAÇÃO-FLOCULAÇÃO-SEDIMENTAÇÃO}

\begin{tabular}{|c|c|c|c|c|c|c|c|}
\hline \multirow{2}{*}{$\begin{array}{l}\text { ENSAIO N }{ }^{\circ}: 05 \\
\text { Data : } 20 / 04 / 00\end{array}$} & \multirow{2}{*}{\multicolumn{2}{|c|}{$\begin{array}{l}\text { COAGULANTE } \\
\text { Sulfato Férrico }\end{array}$}} & \multicolumn{3}{|c|}{ MISTURA RÁPIDA } & \multicolumn{2}{|c|}{ FLOCULAÇÃO } \\
\hline & & & $\mathrm{Tmr}=5 \mathrm{~s}$ & \multicolumn{2}{|c|}{$\mathrm{Gmr}=1000 \mathrm{~s}^{-1}$} & $T f=30 \mathrm{~min}$ & $G f=15 s^{-1}$ \\
\hline \multicolumn{8}{|c|}{ CARACTERÍSTICAS DA ÁGUA DE ESTUDO } \\
\hline \multirow[t]{2}{*}{ Turbidez (uT) } & \multirow{2}{*}{$\begin{array}{c}\text { Cor Aparente } \\
\text { (uC) }\end{array}$} & \multirow{2}{*}{$\begin{array}{c}\text { Cor Verdadeira } \\
\text { (uC) }\end{array}$} & \multirow{2}{*}{\begin{tabular}{|c|} 
Alcalinidade Total \\
$\left(\mathrm{mg} / \ell \mathrm{CaCO}_{3}\right)$
\end{tabular}} & \multicolumn{2}{|c|}{ pH } & \multirow{2}{*}{$\begin{array}{c}\text { Temperatura } \\
{ }^{\circ} \mathrm{C} \\
\end{array}$} & \multirow{2}{*}{$\begin{array}{r}\text { Potencial } \\
\text { Zeta }(\mathrm{mV}) \\
\end{array}$} \\
\hline & & & & S/ agit. & $\mathrm{C} /$ agit. & & \\
\hline 6.37 & 138 & 98 & 30 & 7.96 & 7.64 & 25 & - \\
\hline
\end{tabular}

\begin{tabular}{|c|c|c|c|c|c|c|}
\hline \multirow{2}{*}{ FRASCO } & \multicolumn{3}{|c|}{ DOSAGEM DE PRODUTO QUÍMICO } & \multirow{2}{*}{$\begin{array}{c}\text { pH } \\
\text { de } \\
\text { Coagulação }\end{array}$} & \multirow{2}{*}{$\begin{array}{c}T_{\mathrm{s} 2}=7,00 \mathrm{~min} \\
V_{\mathrm{s} 2}=1.0 \mathrm{~cm} / \mathrm{min} \\
\begin{array}{c}\mathrm{Cor} \\
(\mathrm{uC})\end{array}\end{array}$} & \multirow{2}{*}{$\begin{array}{c}T_{\mathrm{s} 2}=3,50 \mathrm{~min} \\
V_{\mathrm{s} 1}=\mathbf{2 . 0 \mathrm { cm } / \mathrm { min }} \\
\begin{array}{c}\mathrm{Cor} \\
(\mathrm{uC})\end{array}\end{array}$} \\
\hline & $\begin{array}{c}\text { Sulfato férrico } \\
(\mathrm{mg} / \ell)\end{array}$ & $\begin{array}{c}\text { Ácido } \\
\text { Clorídrico } \\
0.1 \mathrm{~N}(\mathrm{~m} / \mathrm{\ell})\end{array}$ & $\begin{array}{c}\text { Hidróxido de } \\
\text { Sódio } 0.1 \mathrm{~N}(\mathrm{~m} \ell / \mathrm{\ell})\end{array}$ & & & \\
\hline 1 & 100 & - & 14.0 & 4.28 & 59 & 73 \\
\hline 2 & 60 & - & - & 4.35 & 53 & 50 \\
\hline 3 & 60 & - & 2.0 & 6.64 & 39 & 30 \\
\hline 4 & 40 & - & - & 5.85 & 31 & 23 \\
\hline 5 & 60 & - & 7.0 & 5.69 & 31 & 40 \\
\hline 6 & 40 & - & 2.0 & 6.06 & 20 & 38 \\
\hline
\end{tabular}

\section{ESTUDO DE COAGULAÇÃO-FLOCULAÇÃO-SEDIMENTAÇÃO}

\begin{tabular}{|l|c|c|c|c|c|}
\hline ENSAIO N & : 06 & COAGULANTE & \multicolumn{2}{|c|}{ MISTURA RÁPIDA } & \multicolumn{2}{c|}{ FLOCULAÇ̃̃O } \\
\cline { 3 - 6 } Data $: 20 / 04 / 00$ & Sulfato Férrico & $\mathbf{T m r}=\mathbf{5 s}$ & $\mathbf{G m r}=\mathbf{1 0 0 0 \mathbf { s } ^ { - 1 }}$ & $\mathbf{T f}=\mathbf{3 0 m i n}$ & $\mathbf{G f}=\mathbf{1 5 s}^{-1}$ \\
\hline
\end{tabular}

\begin{tabular}{|c|c|c|c|c|c|c|c|}
\hline \multicolumn{8}{|c|}{ CARACTERÍSTICAS DA ÁGUA DE ESTUDO } \\
\hline \multirow{2}{*}{ Turbidez (uT) } & \multirow{2}{*}{$\begin{array}{c}\text { Cor Aparente } \\
\text { (uC) }\end{array}$} & \multirow{2}{*}{$\begin{array}{c}\text { Cor Verdadeira } \\
\text { (uC) }\end{array}$} & \multirow{2}{*}{$\begin{array}{c}\text { Alcalinidade Total } \\
\left(\mathrm{mg} / \ell \mathrm{CaCO}_{3}\right)\end{array}$} & \multicolumn{2}{|c|}{ pH } & \multirow{2}{*}{$\begin{array}{c}\text { Temperatura } \\
{ }^{\circ} \mathrm{C} \\
\end{array}$} & \multirow{2}{*}{$\begin{array}{l}\text { Potencial } \\
\text { Zeta }(\mathrm{mV})\end{array}$} \\
\hline & & & & S/ agit. & C/ agit. & & \\
\hline 6.37 & 138 & 98 & 30 & 7.96 & 7.64 & 25 & - \\
\hline
\end{tabular}

\begin{tabular}{|c|c|c|c|c|c|c|}
\hline \multirow{2}{*}{ FRASCO } & \multicolumn{3}{|c|}{ DOSAGEM DE PRODUTO QUÍMICO } & \multirow{2}{*}{$\begin{array}{c}\text { pH } \\
\text { de } \\
\text { Coagulação }\end{array}$} & \multirow{2}{*}{$\begin{array}{c}T_{\mathrm{s} 2}=7,00 \mathrm{~min} \\
V_{\mathrm{s} 2}=1.0 \mathrm{~cm} / \mathrm{min} \\
\begin{array}{c}\mathrm{Cor} \\
(\mathrm{uC})\end{array}\end{array}$} & \multirow{2}{*}{$\begin{array}{c}T_{\mathrm{s} 2}=3,50 \mathrm{~min} \\
V_{\mathrm{s} 1}=2.0 \mathrm{~cm} / \mathrm{min} \\
\begin{array}{c}\mathrm{Cor} \\
(\mathrm{uC})\end{array}\end{array}$} \\
\hline & $\begin{array}{l}\text { Sulfato férrico } \\
(\mathrm{mg} / \ell)\end{array}$ & $\begin{array}{c}\text { Ácido } \\
\text { Clorídrico } \\
0.1 \mathrm{~N}(\mathrm{~m} / \mathrm{\ell})\end{array}$ & $\begin{array}{c}\text { Hidróxido de } \\
\text { Sódio } 0.1 \mathrm{~N}(\mathrm{~m} \ell / \ell)\end{array}$ & & & \\
\hline 1 & 80 & - & 7.0 & 4.27 & 68 & - \\
\hline 2 & 120 & - & 13.0 & 3.60 & - & - \\
\hline 3 & 40 & 1.82 & - & 5.54 & 28 & 39 \\
\hline 4 & 80 & - & 11.0 & 5.14 & 52 & 53 \\
\hline 5 & 140 & - & 17.5 & 3.53 & - & - \\
\hline 6 & 120 & - & 14.0 & 3.72 & - & - \\
\hline
\end{tabular}




\section{ESTUDO DE COAGULAÇÃO-FLOCULAÇÃO-SEDIMENTAÇÃO}

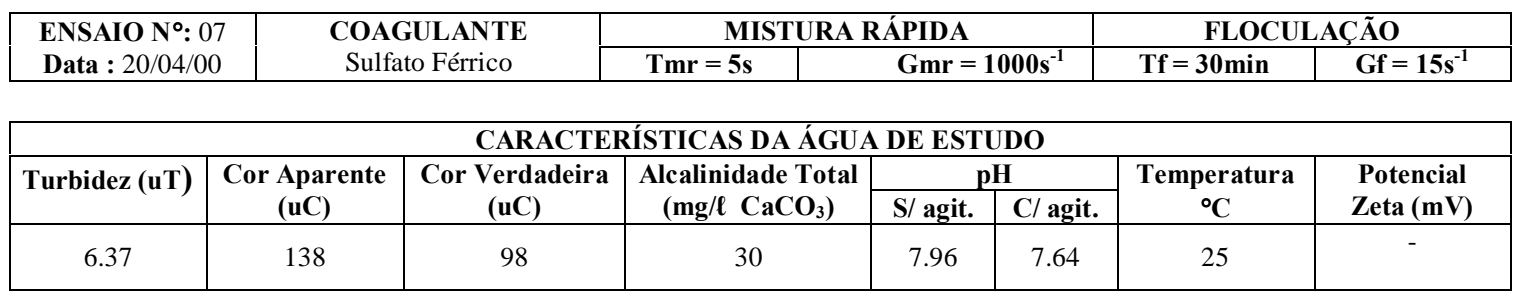

\begin{tabular}{|c|c|c|c|c|c|c|}
\hline \multirow{2}{*}{ FRASCO } & \multicolumn{3}{|c|}{ DOSAGEM DE PRODUTO QUÍMICO } & \multirow{2}{*}{$\begin{array}{c}\text { pH } \\
\text { de } \\
\text { Coagulação }\end{array}$} & \multirow{2}{*}{$\begin{array}{c}T_{\mathrm{s} 2}=7,00 \mathrm{~min} \\
V_{\mathrm{s} 2}=1.0 \mathrm{~cm} / \mathrm{min} \\
\begin{array}{c}\mathrm{Cor} \\
(\mathrm{uC})\end{array}\end{array}$} & \multirow{2}{*}{$\begin{array}{c}T_{\mathrm{s} 2}=3,50 \mathrm{~min} \\
V_{\mathrm{s} 1}=2.0 \mathrm{~cm} / \mathrm{min} \\
\begin{array}{c}\mathrm{Cor} \\
(\mathrm{uC})\end{array}\end{array}$} \\
\hline & $\begin{array}{c}\text { Sulfato férrico } \\
(\mathrm{mg} / \ell)\end{array}$ & $\begin{array}{c}\text { Ácido } \\
\text { Clorídrico } \\
0.1 \mathrm{~N}(\mathrm{~m} / / \ell)\end{array}$ & $\begin{array}{c}\text { Hidróxido de } \\
\text { Sódio } 0.1 \mathrm{~N}(\mathrm{~m} \ell / \ell)\end{array}$ & & & \\
\hline 1 & 140 & - & 30.0 & 4.50 & 55 & 71 \\
\hline 2 & 140 & - & 32.0 & 4.72 & 53 & - \\
\hline 3 & 60 & - & 3.0 & 5.01 & 31 & 50 \\
\hline 4 & 100 & - & 22.0 & 5.58 & 35 & 68 \\
\hline 5 & 80 & - & 16.0 & 5.79 & 44 & 51 \\
\hline 6 & 120 & - & 32.0 & 5.81 & 51 & 98 \\
\hline
\end{tabular}

\section{ESTUDO DE- COAGULAÇÃO-FLOCULAÇÃO-SEDIMENTAÇÃO}

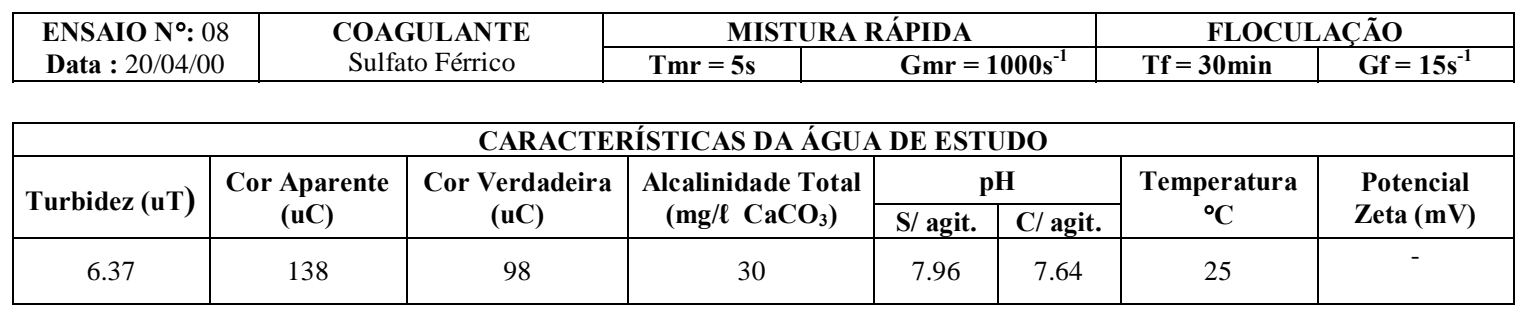

\begin{tabular}{|c|c|c|c|c|c|c|}
\hline \multirow{2}{*}{ FRASCO } & \multicolumn{3}{|c|}{ DOSAGEM DE PRODUTO QUÍMICO } & \multirow{2}{*}{$\begin{array}{c}\text { pH } \\
\text { de } \\
\text { Coagulação }\end{array}$} & \multirow{2}{*}{$\begin{array}{c}T_{\mathrm{s} 2}=7,00 \mathrm{~min} \\
V_{\mathrm{s} 2}=1.0 \mathrm{~cm} / \mathrm{min} \\
\begin{array}{c}\mathrm{Cor} \\
(\mathrm{uC})\end{array}\end{array}$} & \multirow{2}{*}{$\begin{array}{c}T_{\mathrm{s} 2}=3,50 \mathrm{~min} \\
V_{\mathrm{s} 1}=2.0 \mathrm{~cm} / \mathrm{min} \\
\begin{array}{c}\mathrm{Cor} \\
(\mathrm{uC})\end{array}\end{array}$} \\
\hline & $\begin{array}{c}\text { Sulfato férrico } \\
(\mathrm{mg} / \mathfrak{l})\end{array}$ & $\begin{array}{c}\text { Ácido } \\
\text { Clorídrico } \\
\mathbf{0 . 1 N}(\mathrm{m} \ell / \ell) \\
\end{array}$ & $\begin{array}{c}\text { Hidróxido de } \\
\text { Sódio } 0.1 \mathrm{~N}(\mathrm{~m} \ell / \ell)\end{array}$ & & & \\
\hline 1 & 120 & - & 25.5 & 5.04 & 50 & 96 \\
\hline 2 & 140 & - & 35.5 & 5.32 & 62 & - \\
\hline 3 & 120 & - & 27.5 & 5.31 & 47 & 62 \\
\hline 4 & 100 & - & 24.0 & 5.83 & 41 & - \\
\hline 5 & 80 & - & 18.0 & 6.03 & 42 & 80 \\
\hline 6 & 120 & - & 34.0 & 6.05 & 38 & 67 \\
\hline
\end{tabular}




\section{ESTUDO DE COAGULAÇÃO-FLOCULAÇÃO-SEDIMENTAÇÃO}

\begin{tabular}{|c|c|c|c|c|c|c|c|}
\hline \multirow{2}{*}{$\begin{array}{l}\text { ENSAIO } \mathbf{N}^{\circ}: 09 \\
\text { Data : } 20 / 04 / 00\end{array}$} & \multirow{2}{*}{\multicolumn{2}{|c|}{$\begin{array}{l}\text { COAGULANTE } \\
\text { Sulfato Férrico }\end{array}$}} & \multicolumn{3}{|c|}{ MISTURA RÁPIDA } & \multicolumn{2}{|c|}{ FLOCULAÇÃO } \\
\hline & & & $\mathbf{T m r}=\mathbf{5 s}$ & \multicolumn{2}{|c|}{$\mathrm{Gmr}=1000 \mathrm{~s}^{-1}$} & $\mathrm{Tf}=\mathbf{3 0 \mathrm { min }}$ & $G f=15 s^{-1}$ \\
\hline \multicolumn{8}{|c|}{ CARACTERÍSTICAS DA ÁGUA DE ESTUDO } \\
\hline \multirow[t]{2}{*}{ Turbidez (uT) } & \multirow{2}{*}{$\begin{array}{c}\text { Cor Aparente } \\
\text { (uC) }\end{array}$} & \multirow{2}{*}{$\begin{array}{c}\text { Cor Verdadeira } \\
(\mathrm{uC})\end{array}$} & \multirow{2}{*}{\begin{tabular}{|c|}
$\begin{array}{c}\text { Alcalinidade Total } \\
\left(\mathrm{mg} / \ell \mathrm{CaCO}_{3}\right)\end{array}$ \\
\end{tabular}} & \multicolumn{2}{|c|}{ pH } & \multirow{2}{*}{$\begin{array}{c}\text { Temperatura } \\
{ }^{\circ} \mathrm{C} \\
\end{array}$} & \multirow{2}{*}{$\begin{array}{r}\text { Potencial } \\
\text { Zeta }(\mathrm{mV}) \\
\end{array}$} \\
\hline & & & & S/ agit. & $\mathrm{C} /$ agit. & & \\
\hline 6.37 & 138 & 98 & 30 & 7.96 & 7.64 & 25 & - \\
\hline
\end{tabular}

\begin{tabular}{|c|c|c|c|c|c|c|}
\hline \multirow{2}{*}{ FRASCO } & \multicolumn{3}{|c|}{ DOSAGEM DE PRODUTO QUÍMICO } & \multirow{2}{*}{$\begin{array}{c}\text { pH } \\
\text { de } \\
\text { Coagulação }\end{array}$} & \multirow{2}{*}{$\begin{array}{c}T_{\mathrm{s} 2}=7,00 \mathrm{~min} \\
V_{\mathrm{s} 2}=1.0 \mathrm{~cm} / \mathrm{min} \\
\begin{array}{c}\mathrm{Cor} \\
(\mathrm{uC})\end{array}\end{array}$} & \multirow{2}{*}{$\begin{array}{c}T_{\mathrm{s} 2}=3,50 \mathrm{~min} \\
V_{\mathrm{s} 1}=2.0 \mathrm{~cm} / \mathrm{min} \\
\begin{array}{l}\text { Cor } \\
(\mathrm{uC})\end{array}\end{array}$} \\
\hline & $\begin{array}{l}\text { Sulfato férrico } \\
(\mathrm{mg} / \ell)\end{array}$ & $\begin{array}{c}\text { Ácido } \\
\text { Clorídrico } \\
0.1 \mathrm{~N}(\mathrm{~m} \ell / \ell) \\
\end{array}$ & $\begin{array}{c}\text { Hidróxido de } \\
\text { Sódio } 0.1 \mathrm{~N}(\mathrm{~m} / \ell)\end{array}$ & & & \\
\hline 1 & 200 & - & 50.0 & 4.20 & 72 & - \\
\hline 2 & 200 & - & 52.0 & 4.38 & 34 & 71 \\
\hline 3 & 180 & - & 46.0 & 4.57 & 74 & - \\
\hline 4 & 180 & - & 48.0 & 4.97 & 22 & 54 \\
\hline 5 & 160 & - & 42.0 & 5.17 & 55 & 64 \\
\hline 6 & 160 & - & 44.0 & 5.29 & 49 & - \\
\hline
\end{tabular}

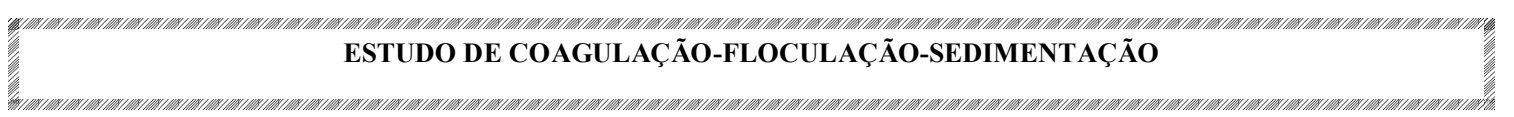

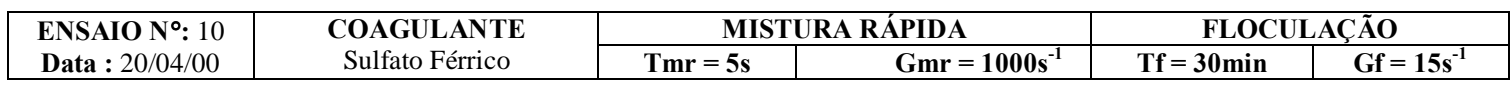

\begin{tabular}{|c|c|c|c|c|c|c|c|}
\hline \multicolumn{1}{|c|}{ CARACTERÍSTICAS DA ÁGUA DE ESTUDO } \\
\hline \multirow{2}{*}{ Turbidez (uT) } & $\begin{array}{c}\text { Cor Aparente } \\
(\mathbf{u C})\end{array}$ & $\begin{array}{c}\text { Cor Verdadeira } \\
(\mathbf{u C})\end{array}$ & $\begin{array}{c}\text { Alcalinidade Total } \\
\left(\mathbf{m g} / \mathbf{\ell} \mathbf{C a C O}_{\mathbf{3}}\right)\end{array}$ & \multicolumn{2}{|c|}{$\mathbf{p H}$} & Temperatura & $\begin{array}{c}\text { Potencial } \\
\text { Zeta }(\mathbf{m V})\end{array}$ \\
\hline 6.37 & 138 & 98 & 30 & 7.96 & 7.64 & 25 & - \\
\hline
\end{tabular}

\begin{tabular}{|c|c|c|c|c|c|c|}
\hline \multirow{2}{*}{ FRASCO } & \multicolumn{3}{|c|}{ DOSAGEM DE PRODUTO QUÍMICO } & \multirow{2}{*}{$\begin{array}{c}\text { pH } \\
\text { de } \\
\text { Coagulação }\end{array}$} & \multirow{2}{*}{$\begin{array}{c}T_{\mathrm{s} 2}=7,00 \mathrm{~min} \\
V_{\mathrm{s} 2}=1.0 \mathrm{~cm} / \mathrm{min} \\
\begin{array}{c}\text { Cor } \\
(\mathrm{uC})\end{array}\end{array}$} & \multirow{2}{*}{$\begin{array}{c}T_{\mathrm{s} 2}=3,50 \mathrm{~min} \\
V_{\mathrm{s} 1}=2.0 \mathrm{~cm} / \mathrm{min} \\
\begin{array}{c}\mathrm{Cor} \\
(\mathrm{uC})\end{array}\end{array}$} \\
\hline & $\begin{array}{l}\text { Sulfato férrico } \\
(\mathrm{mg} / \ell)\end{array}$ & $\begin{array}{c}\text { Ácido } \\
\text { Clorídrico } \\
\mathbf{0 . 1 N}(\mathrm{m} \ell / \ell) \\
\end{array}$ & $\begin{array}{c}\text { Hidróxido de } \\
\text { Sódio } 0.1 \mathrm{~N}(\mathrm{~m} \ell / \mathrm{\ell})\end{array}$ & & & \\
\hline 1 & 260 & - & 66.0 & 3.85 & 95 & 129 \\
\hline 2 & 260 & - & 68.0 & 3.90 & 53 & 89 \\
\hline 3 & 240 & - & 62.0 & 3.96 & 49 & 128 \\
\hline 4 & 240 & - & 64.0 & 4.16 & 71 & 109 \\
\hline 5 & 220 & - & 58.0 & 4.26 & 64 & 149 \\
\hline 6 & 220 & - & 60.0 & 4.59 & 41 & 124 \\
\hline
\end{tabular}


ESTUDO DE COAGULAÇÃ̃O-FLOCULAÇÃO-SEDIMENTAÇÃO

\begin{tabular}{|c|c|c|c|c|c|c|c|}
\hline \multirow{2}{*}{$\begin{array}{l}\text { ENSAIO N }{ }^{\circ}: 11 \\
\text { Data }: 20 / 04 / 00\end{array}$} & \multirow{2}{*}{\multicolumn{2}{|c|}{$\begin{array}{l}\text { COAGULANTE } \\
\text { Sulfato Férrico }\end{array}$}} & \multicolumn{3}{|c|}{ MISTURA RÁPIDA } & \multicolumn{2}{|c|}{ FLOCULAÇÃO } \\
\hline & & & $\mathrm{Tmr}=5 \mathrm{~s}$ & \multicolumn{2}{|c|}{$\mathrm{Gmr}=1000 \mathrm{~s}^{-1}$} & $T f=30 \mathrm{~min}$ & $G f=15 s^{-1}$ \\
\hline \multicolumn{8}{|c|}{ CARACTERÍSTICAS DA ÁGUA DE ESTUDO } \\
\hline \multirow[t]{2}{*}{ Turbidez (uT) } & \multirow{2}{*}{$\begin{array}{c}\text { Cor Aparente } \\
\text { (uC) }\end{array}$} & \multirow{2}{*}{$\begin{array}{c}\text { Cor Verdadeira } \\
\text { (uC) }\end{array}$} & \multirow{2}{*}{\begin{tabular}{|c|} 
Alcalinidade Total \\
$\left(\mathrm{mg} / \ell \mathrm{CaCO}_{3}\right)$
\end{tabular}} & \multicolumn{2}{|c|}{ pH } & \multirow{2}{*}{$\begin{array}{c}\text { Temperatura } \\
{ }^{\circ} \mathrm{C} \\
\end{array}$} & \multirow{2}{*}{$\begin{array}{r}\text { Potencial } \\
\text { Zeta }(\mathrm{mV}) \\
\end{array}$} \\
\hline & & & & S/ agit. & $\mathrm{C} /$ agit. & & \\
\hline 6.37 & 138 & 98 & 30 & 7.96 & 7.64 & 25 & - \\
\hline
\end{tabular}

\begin{tabular}{|c|c|c|c|c|c|c|}
\hline \multirow{2}{*}{ FRASCO } & \multicolumn{3}{|c|}{ DOSAGEM DE PRODUTO QUÍMICO } & \multirow{2}{*}{$\begin{array}{c}\text { pH } \\
\text { de } \\
\text { Coagulação }\end{array}$} & \multirow{2}{*}{$\begin{array}{c}T_{\mathrm{s} 2}=7,00 \mathrm{~min} \\
V_{\mathrm{s} 2}=1.0 \mathrm{~cm} / \mathrm{min} \\
\begin{array}{c}\mathrm{Cor} \\
(\mathrm{uC})\end{array}\end{array}$} & \multirow{2}{*}{$\begin{array}{c}T_{\mathrm{s} 2}=3,50 \mathrm{~min} \\
V_{\mathrm{s} 1}=2.0 \mathrm{~cm} / \mathrm{min} \\
\begin{array}{c}\mathrm{Cor} \\
(\mathrm{uC})\end{array}\end{array}$} \\
\hline & $\begin{array}{l}\text { Sulfato férrico } \\
(\mathrm{mg} / \mathfrak{\ell})\end{array}$ & $\begin{array}{c}\text { Ácido } \\
\text { Clorídrico } \\
\mathbf{0 . 1 N}(\mathrm{m} / \ell) \\
\end{array}$ & $\begin{array}{c}\text { Hidróxido de } \\
\text { Sódio } 0.1 \mathrm{~N}(\mathrm{~m} \ell / \mathrm{\ell})\end{array}$ & & & \\
\hline 1 & 200 & - & 54.0 & 4.86 & 61 & 92 \\
\hline 2 & 200 & - & 56.0 & 5.10 & 50 & 91 \\
\hline 3 & 180 & - & 47.0 & 4.85 & 46 & 124 \\
\hline 4 & 160 & - & 40.0 & 4.86 & 48 & 92 \\
\hline 5 & 180 & - & 50.0 & 5.16 & 39 & 103 \\
\hline 6 & 160 & - & 46.0 & 5.77 & 39 & 94 \\
\hline
\end{tabular}

\section{ESTUDO DE COAGULAÇÃOO-FLOCULAÇÃO-SEDIMENTAÇÃO}

\begin{tabular}{|c|c|c|c|c|c|}
\hline \multirow{2}{*}{$\begin{array}{l}\text { ENSAIO } N^{\circ}: 12 \\
\text { Data }: 20 / 04 / 00\end{array}$} & \multirow{2}{*}{$\begin{array}{c}\text { COAGULANTE } \\
\text { Sulfato Férrico }\end{array}$} & \multicolumn{2}{|c|}{ MISTURA RÁPIDA } & \multicolumn{2}{|c|}{ FLOCULAÇÃO } \\
\hline & & $\mathrm{Tmr}=5 \mathrm{~s}$ & Gmr $=1000 \mathrm{~s}^{-1}$ & $\mathbf{T f}=30 \mathrm{~min}$ & $G f=15 s^{-1}$ \\
\hline
\end{tabular}

\begin{tabular}{|c|c|c|c|c|c|c|c|}
\hline \multicolumn{8}{|c|}{ CARACTERÍSTICAS DA ÁGUA DE ESTUDO } \\
\hline \multirow{2}{*}{ Turbidez (uT) } & \multirow{2}{*}{$\begin{array}{c}\text { Cor Aparente } \\
\text { (uC) }\end{array}$} & \multirow{2}{*}{$\begin{array}{c}\text { Cor Verdadeira } \\
\text { (uC) }\end{array}$} & \multirow{2}{*}{$\begin{array}{c}\text { Alcalinidade Total } \\
\left(\mathrm{mg} / \ell \mathrm{CaCO}_{3}\right)\end{array}$} & \multicolumn{2}{|c|}{ pH } & \multirow{2}{*}{$\begin{array}{c}\text { Temperatura } \\
{ }^{\circ} \mathrm{C} \\
\end{array}$} & \multirow{2}{*}{$\begin{array}{l}\text { Potencial } \\
\text { Zeta }(\mathrm{mV})\end{array}$} \\
\hline & & & & S/ agit. & C/ agit. & & \\
\hline 6.37 & 138 & 98 & 30 & 7.96 & 7.64 & 25 & - \\
\hline
\end{tabular}

\begin{tabular}{|c|c|c|c|c|c|c|}
\hline \multirow{2}{*}{ FRASCO } & \multicolumn{3}{|c|}{ DOSAGEM DE PRODUTO QUÍMICO } & \multirow{2}{*}{$\begin{array}{c}\text { pH } \\
\text { de } \\
\text { Coagulação }\end{array}$} & \multirow{2}{*}{$\begin{array}{c}T_{\mathrm{s} 2}=7,00 \mathrm{~min} \\
V_{\mathrm{s} 2}=1.0 \mathrm{~cm} / \mathrm{min} \\
\begin{array}{c}\mathrm{Cor} \\
(\mathrm{uC})\end{array}\end{array}$} & \multirow{2}{*}{$\begin{array}{c}T_{\mathrm{s} 2}=3,50 \mathrm{~min} \\
\mathrm{~V}_{\mathrm{s} 1}=2.0 \mathrm{~cm} / \mathrm{min} \\
\begin{array}{c}\mathrm{Cor} \\
(\mathrm{uC})\end{array}\end{array}$} \\
\hline & $\begin{array}{l}\text { Sulfato férrico } \\
(\mathrm{mg} / \ell)\end{array}$ & $\begin{array}{c}\text { Ácido } \\
\text { Clorídrico } \\
\mathbf{0 . 1 N}(\mathrm{m} \ell / \ell) \\
\end{array}$ & $\begin{array}{c}\text { Hidróxido de } \\
\text { Sódio } 0.1 \mathrm{~N}(\mathrm{~m} \ell / \mathfrak{l})\end{array}$ & & & \\
\hline 1 & 260 & - & 72.0 & 4.37 & 42 & 97 \\
\hline 2 & 240 & - & 68.0 & 4.66 & 22 & 78 \\
\hline 3 & 220 & - & 64.0 & 5.14 & 39 & 89 \\
\hline 4 & 200 & - & 58.0 & 5.30 & 44 & 112 \\
\hline 5 & 180 & - & 52.0 & 5.64 & 22 & 75 \\
\hline 6 & 160 & - & 48.0 & 5.89 & 35 & 67 \\
\hline
\end{tabular}


ESTUDO DE COAGULAÇÃO-FLOCULAÇÃO-SEDIMENTAÇÃO

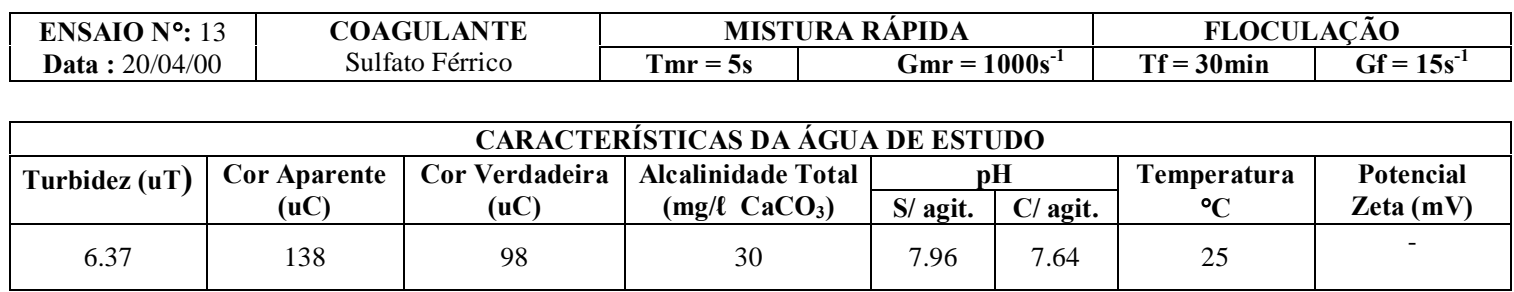

\begin{tabular}{|c|c|c|c|c|c|c|}
\hline \multirow{2}{*}{ FRASCO } & \multicolumn{3}{|c|}{ DOSAGEM DE PRODUTO QUÍMICO } & \multirow{2}{*}{$\begin{array}{c}\text { pH } \\
\text { de } \\
\text { Coagulação }\end{array}$} & \multirow{2}{*}{$\begin{array}{c}T_{\mathrm{s} 2}=7,00 \mathrm{~min} \\
V_{\mathrm{s} 2}=1.0 \mathrm{~cm} / \mathrm{min} \\
\begin{array}{c}\mathrm{Cor} \\
(\mathrm{uC})\end{array}\end{array}$} & \multirow{2}{*}{$\begin{array}{c}T_{\mathrm{s} 2}=3,50 \mathrm{~min} \\
V_{\mathrm{s} 1}=2.0 \mathrm{~cm} / \mathrm{min} \\
\begin{array}{c}\mathrm{Cor} \\
(\mathrm{uC})\end{array}\end{array}$} \\
\hline & $\begin{array}{l}\text { Sulfato férrico } \\
(\mathrm{mg} / \mathfrak{\ell})\end{array}$ & $\begin{array}{c}\text { Ácido } \\
\text { Clorídrico } \\
\mathbf{0 . 1 N}(\mathrm{m} / \ell) \\
\end{array}$ & $\begin{array}{c}\text { Hidróxido de } \\
\text { Sódio } 0.1 \mathrm{~N}(\mathrm{~m} \ell / \mathrm{\ell})\end{array}$ & & & \\
\hline 1 & 280 & - & 86.0 & 5.11 & 25 & 106 \\
\hline 2 & 280 & - & 88.0 & 8.28 & - & - \\
\hline 3 & 280 & - & 90.0 & 5.38 & 31 & 95 \\
\hline 4 & 280 & - & 92.0 & 5.60 & 33 & 88 \\
\hline 5 & 280 & - & 94.0 & 5.82 & 35 & 89 \\
\hline 6 & 280 & - & 96.0 & 5.95 & 38 & 51 \\
\hline
\end{tabular}

\section{ESTUDO DE COAGULAÇÃO-FLOCULAÇÃO-SEDIMENTAÇÃO}

\begin{tabular}{|c|c|c|c|c|c|}
\hline \multirow{2}{*}{$\begin{array}{l}\text { ENSAIO No: } 14 \\
\text { Data : } 20 / 04 / 00\end{array}$} & \multirow{2}{*}{$\begin{array}{c}\text { COAGULANTE } \\
\text { Sulfato Férrico }\end{array}$} & \multicolumn{2}{|c|}{ MISTURA RÁPIDA } & \multicolumn{2}{|c|}{ FLOCULAÇÃO } \\
\hline & & $\mathrm{Tmr}=5 \mathrm{~s}$ & Gmr $=1000 \mathrm{~s}^{-1}$ & $\mathbf{T f}=30 \mathrm{~min}$ & $G f=15 s^{-1}$ \\
\hline
\end{tabular}

\begin{tabular}{|c|c|c|c|c|c|c|c|}
\hline \multicolumn{8}{|c|}{ CARACTERÍSTICAS DA ÁGUA DE ESTUDO } \\
\hline \multirow{2}{*}{ Turbidez (uT) } & \multirow{2}{*}{$\begin{array}{c}\text { Cor Aparente } \\
\text { (uC) }\end{array}$} & \multirow{2}{*}{$\begin{array}{c}\text { Cor Verdadeira } \\
\text { (uC) }\end{array}$} & \multirow{2}{*}{$\begin{array}{c}\text { Alcalinidade Total } \\
\left(\mathrm{mg} / \ell \mathrm{CaCO}_{3}\right)\end{array}$} & \multicolumn{2}{|c|}{ pH } & \multirow{2}{*}{$\begin{array}{c}\text { Temperatura } \\
{ }^{\circ} \mathrm{C} \\
\end{array}$} & \multirow{2}{*}{$\begin{array}{l}\text { Potencial } \\
\text { Zeta }(\mathrm{mV})\end{array}$} \\
\hline & & & & S/ agit. & C/ agit. & & \\
\hline 6.37 & 138 & 98 & 30 & 7.96 & 7.64 & 25 & - \\
\hline
\end{tabular}

\begin{tabular}{|c|c|c|c|c|c|c|}
\hline \multirow{2}{*}{ FRASCO } & \multicolumn{3}{|c|}{ DOSAGEM DE PRODUTO QUÍMICO } & \multirow{2}{*}{$\begin{array}{c}\text { pH } \\
\text { de } \\
\text { Coagulação }\end{array}$} & \multirow{2}{*}{$\begin{array}{c}T_{\mathrm{s} 2}=7,00 \mathrm{~min} \\
V_{\mathrm{s} 2}=1.0 \mathrm{~cm} / \mathrm{min} \\
\begin{array}{c}\mathrm{Cor} \\
(\mathrm{uC})\end{array}\end{array}$} & \multirow{2}{*}{$\begin{array}{c}T_{\mathrm{s} 2}=3,50 \mathrm{~min} \\
\mathrm{~V}_{\mathrm{s} 1}=2.0 \mathrm{~cm} / \mathrm{min} \\
\begin{array}{c}\mathrm{Cor} \\
(\mathrm{uC})\end{array}\end{array}$} \\
\hline & $\begin{array}{l}\text { Sulfato férrico } \\
(\mathrm{mg} / \ell)\end{array}$ & $\begin{array}{c}\text { Ácido } \\
\text { Clorídrico } \\
\text { 0.1N(m }(\mathrm{m} / \ell)\end{array}$ & $\begin{array}{c}\text { Hidróxido de } \\
\text { Sódio } 0.1 \mathrm{~N}(\mathrm{~m} \ell / \mathfrak{l})\end{array}$ & & & \\
\hline 1 & 240 & - & 70.0 & 5.07 & 36 & 65 \\
\hline 2 & 240 & - & 72.0 & 5.15 & 31 & 90 \\
\hline 3 & 240 & - & 74.0 & 5.34 & 25 & 63 \\
\hline 4 & 280 & - & 98.0 & 5.99 & 19 & 95 \\
\hline 5 & 280 & - & 100.0 & 6.15 & 17 & 60 \\
\hline 6 & 280 & - & 102.0 & 6.26 & 26 & 90 \\
\hline
\end{tabular}




\section{ESTUDO DE COAGULAÇÃO-FLOCULAÇÃO-SEDIMENTAÇÃO}

\begin{tabular}{|c|c|c|c|c|c|c|c|}
\hline \multirow{2}{*}{$\begin{array}{l}\text { ENSAIO N }{ }^{\circ}: 15 \\
\text { Data }: 20 / 04 / 00\end{array}$} & \multirow{2}{*}{\multicolumn{2}{|c|}{$\begin{array}{l}\text { COAGULANTE } \\
\text { Sulfato Férrico }\end{array}$}} & \multicolumn{3}{|c|}{ MISTURA RÁPIDA } & \multicolumn{2}{|c|}{ FLOCULAÇÃO } \\
\hline & & & $\mathrm{Tmr}=5 \mathrm{~s}$ & \multicolumn{2}{|c|}{$\mathrm{Gmr}=1000 \mathrm{~s}^{-1}$} & $T f=30 \mathrm{~min}$ & $G f=15 s^{-1}$ \\
\hline \multicolumn{8}{|c|}{ CARACTERÍSTICAS DA ÁGUA DE ESTUDO } \\
\hline \multirow[t]{2}{*}{ Turbidez (uT) } & \multirow{2}{*}{$\begin{array}{c}\text { Cor Aparente } \\
\text { (uC) }\end{array}$} & \multirow{2}{*}{$\begin{array}{c}\text { Cor Verdadeira } \\
\text { (uC) }\end{array}$} & \multirow{2}{*}{\begin{tabular}{|c|} 
Alcalinidade Total \\
$\left(\mathrm{mg} / \ell \mathrm{CaCO}_{3}\right)$
\end{tabular}} & \multicolumn{2}{|c|}{ pH } & \multirow{2}{*}{$\begin{array}{c}\text { Temperatura } \\
{ }^{\circ} \mathrm{C} \\
\end{array}$} & \multirow{2}{*}{$\begin{array}{r}\text { Potencial } \\
\text { Zeta }(\mathrm{mV}) \\
\end{array}$} \\
\hline & & & & S/ agit. & $\mathrm{C} /$ agit. & & \\
\hline 6.37 & 138 & 98 & 30 & 7.96 & 7.64 & 25 & - \\
\hline
\end{tabular}

\begin{tabular}{|c|c|c|c|c|c|c|}
\hline \multirow{2}{*}{ FRASCO } & \multicolumn{3}{|c|}{ DOSAGEM DE PRODUTO QUÍMICO } & \multirow{2}{*}{$\begin{array}{c}\text { pH } \\
\text { de } \\
\text { Coagulação }\end{array}$} & \multirow{2}{*}{$\begin{array}{c}T_{\mathrm{s} 2}=7,00 \mathrm{~min} \\
V_{\mathrm{s} 2}=1.0 \mathrm{~cm} / \mathrm{min} \\
\begin{array}{c}\mathrm{Cor} \\
(\mathrm{uC})\end{array}\end{array}$} & \multirow{2}{*}{$\begin{array}{c}T_{\mathrm{s} 2}=3,50 \mathrm{~min} \\
V_{\mathrm{s} 1}=2.0 \mathrm{~cm} / \mathrm{min} \\
\begin{array}{c}\mathrm{Cor} \\
(\mathrm{uC})\end{array}\end{array}$} \\
\hline & $\begin{array}{c}\text { Sulfato férrico } \\
(\mathrm{mg} / \ell)\end{array}$ & $\begin{array}{c}\text { Ácido } \\
\text { Clorídrico } \\
0.1 \mathrm{~N}(\mathrm{~m} / / \ell)\end{array}$ & $\begin{array}{c}\text { Hidróxido de } \\
\text { Sódio } 0.1 \mathrm{~N}(\mathrm{~m} \ell / \ell)\end{array}$ & & & \\
\hline 1 & 280 & - & 82.0 & 4.56 & 35 & 90 \\
\hline 2 & 280 & - & 84.0 & 4.86 & 39 & 108 \\
\hline 3 & 240 & - & 76.0 & 5.54 & 36 & 109 \\
\hline 4 & 240 & - & 78.0 & 5.72 & 30 & 109 \\
\hline 5 & 240 & - & 80.0 & 6.02 & 28 & 112 \\
\hline 6 & 240 & - & 82.0 & 6.10 & 21 & 118 \\
\hline
\end{tabular}

\section{ESTUDO DE COAGULAÇÃO-FLOCULAÇÃO-SEDIMENTAÇÃO}

\begin{tabular}{|c|c|c|c|c|c|}
\hline \multirow{2}{*}{$\begin{array}{l}\text { ENSAIO No: } 16 \\
\text { Data }: 21 / 04 / 00\end{array}$} & \multirow{2}{*}{$\begin{array}{c}\text { COAGULANTE } \\
\text { Sulfato Férrico }\end{array}$} & \multicolumn{2}{|c|}{ MISTURA RÁPIDA } & \multicolumn{2}{|c|}{ FLOCULAÇÃO } \\
\hline & & $\mathrm{Tmr}=5 \mathrm{~s}$ & Gmr $=1000 \mathrm{~s}^{-1}$ & $\mathbf{T f}=30 \mathrm{~min}$ & $G f=15 s^{-1}$ \\
\hline
\end{tabular}

\begin{tabular}{|c|c|c|c|c|c|c|c|}
\hline \multicolumn{8}{|c|}{ CARACTERÍSTICAS DA ÁGUA DE ESTUDO } \\
\hline \multirow{2}{*}{ Turbidez (uT) } & \multirow{2}{*}{$\begin{array}{c}\text { Cor Aparente } \\
\text { (uC) }\end{array}$} & \multirow{2}{*}{$\begin{array}{c}\text { Cor Verdadeira } \\
\text { (uC) }\end{array}$} & \multirow{2}{*}{$\begin{array}{c}\text { Alcalinidade Total } \\
\left(\mathrm{mg} / \ell \mathrm{CaCO}_{3}\right)\end{array}$} & \multicolumn{2}{|c|}{ pH } & \multirow{2}{*}{$\begin{array}{c}\text { Temperatura } \\
{ }^{\circ} \mathrm{C} \\
\end{array}$} & \multirow{2}{*}{$\begin{array}{l}\text { Potencial } \\
\text { Zeta }(\mathrm{mV})\end{array}$} \\
\hline & & & & S/ agit. & C/ agit. & & \\
\hline 6.37 & 138 & 98 & 30 & 7.96 & 7.64 & 25 & - \\
\hline
\end{tabular}

\begin{tabular}{|c|c|c|c|c|c|c|}
\hline \multirow{2}{*}{ FRASCO } & \multicolumn{3}{|c|}{ DOSAGEM DE PRODUTO QUÍMICO } & \multirow{2}{*}{$\begin{array}{c}\text { pH } \\
\text { de } \\
\text { Coagulação }\end{array}$} & \multirow{2}{*}{$\begin{array}{c}T_{\mathrm{s} 2}=7,00 \mathrm{~min} \\
V_{\mathrm{s} 2}=1.0 \mathrm{~cm} / \mathrm{min} \\
\begin{array}{c}\mathrm{Cor} \\
(\mathrm{uC})\end{array}\end{array}$} & \multirow{2}{*}{$\begin{array}{c}T_{\mathrm{s} 2}=3,50 \mathrm{~min} \\
V_{\mathrm{s} 1}=2.0 \mathrm{~cm} / \mathrm{min} \\
\begin{array}{c}\mathrm{Cor} \\
(\mathrm{uC})\end{array}\end{array}$} \\
\hline & $\begin{array}{c}\text { Sulfato férrico } \\
(\mathrm{mg} / \mathfrak{l})\end{array}$ & $\begin{array}{c}\text { Ácido } \\
\text { Clorídrico } \\
\mathbf{0 . 1 N}(\mathrm{m} \ell / \ell) \\
\end{array}$ & $\begin{array}{c}\text { Hidróxido de } \\
\text { Sódio } 0.1 \mathrm{~N}(\mathrm{~m} \ell / \ell)\end{array}$ & & & \\
\hline 1 & 100 & - & 15.0 & 4.51 & 43 & 103 \\
\hline 2 & 100 & - & 17.0 & 4.85 & 33 & 94 \\
\hline 3 & 60 & - & 3.5 & 5.20 & 16 & 50 \\
\hline 4 & 80 & - & 11.5 & 5.26 & 24 & 62 \\
\hline 5 & 60 & - & 7.5 & 5.87 & 16 & 41 \\
\hline 6 & 40 & - & 3.0 & 6.25 & 17 & 38 \\
\hline
\end{tabular}


ESTUDO DE COAGULAÇÃ̃O-FLOCULAÇÃO-SEDIMENTAÇÃO

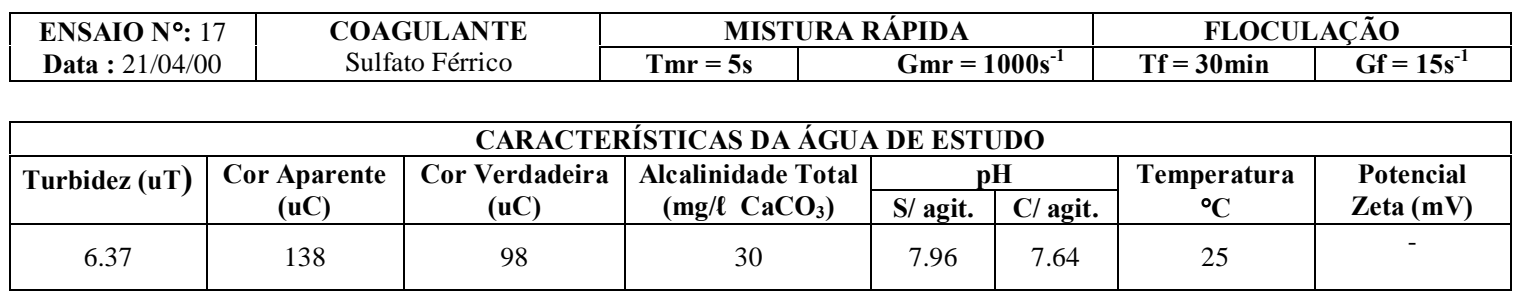

\begin{tabular}{|c|c|c|c|c|c|c|}
\hline \multirow{2}{*}{ FRASCO } & \multicolumn{3}{|c|}{ DOSAGEM DE PRODUTO QUÍMICO } & \multirow{2}{*}{$\begin{array}{c}\text { pH } \\
\text { de } \\
\text { Coagulação }\end{array}$} & \multirow{2}{*}{$\begin{array}{c}T_{\mathrm{s} 2}=7,00 \mathrm{~min} \\
V_{\mathrm{s} 2}=1.0 \mathrm{~cm} / \mathrm{min} \\
\begin{array}{c}\mathrm{Cor} \\
(\mathrm{uC})\end{array}\end{array}$} & \multirow{2}{*}{$\begin{array}{c}T_{\mathrm{s} 2}=3,50 \mathrm{~min} \\
V_{\mathrm{s} 1}=2.0 \mathrm{~cm} / \mathrm{min} \\
\begin{array}{c}\mathrm{Cor} \\
(\mathrm{uC})\end{array}\end{array}$} \\
\hline & $\begin{array}{l}\text { Sulfato férrico } \\
(\mathrm{mg} / \mathfrak{\ell})\end{array}$ & $\begin{array}{c}\text { Ácido } \\
\text { Clorídrico } \\
\mathbf{0 . 1 N}(\mathrm{m} / \ell) \\
\end{array}$ & $\begin{array}{c}\text { Hidróxido de } \\
\text { Sódio } 0.1 \mathrm{~N}(\mathrm{~m} \ell / \mathrm{\ell})\end{array}$ & & & \\
\hline 1 & 120 & - & 22.0 & 4.44 & 30 & 71 \\
\hline 2 & 120 & - & 24.75 & 4.80 & 28 & - \\
\hline 3 & 120 & - & 29.0 & 5.56 & 29 & 47 \\
\hline 4 & 120 & - & 36.0 & 6.17 & 36 & 45 \\
\hline 5 & 120 & - & 38.0 & 6.39 & 38 & 98 \\
\hline 6 & 120 & - & 40.0 & 6.52 & 40 & 73 \\
\hline
\end{tabular}

\section{ESTUDO DE COAGULAÇÃO-FLOCULAÇÃO-SEDIMENT AÇÃ̃O}

\begin{tabular}{|c|c|c|c|c|c|}
\hline \multirow{2}{*}{$\begin{array}{l}\text { ENSAIO No: } 18 \\
\text { Data }: 21 / 04 / 00\end{array}$} & \multirow{2}{*}{$\begin{array}{c}\text { COAGULANTE } \\
\text { Sulfato Férrico }\end{array}$} & \multicolumn{2}{|c|}{ MISTURA RÁPIDA } & \multicolumn{2}{|c|}{ FLOCULAÇÃO } \\
\hline & & Tmr $=5 \mathrm{~s}$ & $\mathrm{Gmr}=1000 \mathrm{~s}^{-1}$ & Tf $=30 \mathrm{~min}$ & $G f=15 s^{-1}$ \\
\hline
\end{tabular}

\begin{tabular}{|c|c|c|c|c|c|c|c|}
\hline \multicolumn{8}{|c|}{ CARACTERÍSTICAS DA ÁGUA DE ESTUDO } \\
\hline \multirow{2}{*}{ Turbidez (uT) } & \multirow{2}{*}{$\begin{array}{c}\text { Cor Aparente } \\
\text { (uC) }\end{array}$} & \multirow{2}{*}{$\begin{array}{c}\text { Cor Verdadeira } \\
\text { (uC) }\end{array}$} & \multirow{2}{*}{$\begin{array}{c}\text { Alcalinidade Total } \\
\left(\mathrm{mg} / \ell \mathrm{CaCO}_{3}\right)\end{array}$} & \multicolumn{2}{|c|}{ pH } & \multirow{2}{*}{$\begin{array}{c}\text { Temperatura } \\
{ }^{\circ} \mathrm{C} \\
\end{array}$} & \multirow{2}{*}{$\begin{array}{l}\text { Potencial } \\
\text { Zeta }(\mathrm{mV})\end{array}$} \\
\hline & & & & S/ agit. & C/ agit. & & \\
\hline 6.37 & 138 & 98 & 30 & 7.96 & 7.64 & 25 & - \\
\hline
\end{tabular}

\begin{tabular}{|c|c|c|c|c|c|c|}
\hline \multirow{2}{*}{ FRASCO } & \multicolumn{3}{|c|}{ DOSAGEM DE PRODUTO QUÍMICO } & \multirow{2}{*}{$\begin{array}{c}\text { pH } \\
\text { de } \\
\text { Coagulação }\end{array}$} & \multirow{2}{*}{$\begin{array}{c}T_{\mathrm{s} 2}=7,00 \mathrm{~min} \\
V_{\mathrm{s} 2}=1.0 \mathrm{~cm} / \mathrm{min} \\
\begin{array}{c}\mathrm{Cor} \\
(\mathrm{uC})\end{array}\end{array}$} & \multirow{2}{*}{$\begin{array}{c}T_{\mathrm{s} 2}=3,50 \mathrm{~min} \\
V_{\mathrm{s} 1}=2.0 \mathrm{~cm} / \mathrm{min} \\
\begin{array}{c}\mathrm{Cor} \\
(\mathrm{uC})\end{array}\end{array}$} \\
\hline & $\begin{array}{l}\text { Sulfato férrico } \\
(\mathrm{mg} / \mathfrak{l})\end{array}$ & 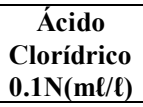 & $\begin{array}{c}\text { Hidróxido de } \\
\text { Sódio } 0.1 \mathrm{~N}(\mathrm{~m} \ell / \ell)\end{array}$ & & & \\
\hline 1 & 20 & 2.73 & - & 6.36 & 20 & 36 \\
\hline 2 & 20 & 1.82 & - & 6.49 & 21 & 78 \\
\hline 3 & 20 & 0.91 & - & 6.60 & 30 & 65 \\
\hline 4 & 20 & - & - & 6.68 & 49 & 69 \\
\hline 5 & 20 & - & 1.0 & 6.80 & - & - \\
\hline 6 & 20 & - & 2.0 & 7.10 & - & - \\
\hline
\end{tabular}




\section{ESTUDO DE COAGULAÇÃO-FLOCULAÇÃO-SEDIMENTAÇÃO}

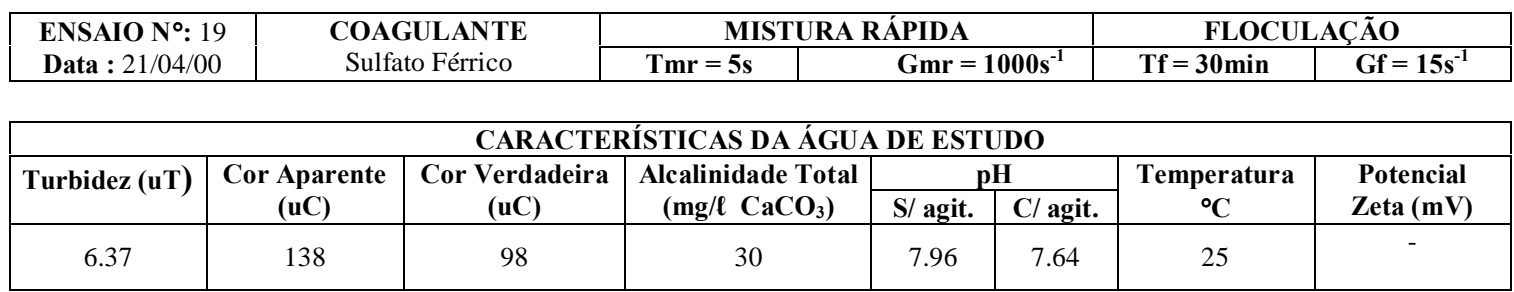

\begin{tabular}{|c|c|c|c|c|c|c|}
\hline \multirow{2}{*}{ FRASCO } & \multicolumn{3}{|c|}{ DOSAGEM DE PRODUTO QUÍMICO } & \multirow{2}{*}{$\begin{array}{c}\text { pH } \\
\text { de } \\
\text { Coagulação }\end{array}$} & \multirow{2}{*}{$\begin{array}{c}T_{\mathrm{s} 2}=7,00 \mathrm{~min} \\
V_{\mathrm{s} 2}=1.0 \mathrm{~cm} / \mathrm{min} \\
\begin{array}{c}\mathrm{Cor} \\
(\mathrm{uC})\end{array}\end{array}$} & \multirow{2}{*}{$\begin{array}{c}T_{\mathrm{s} 2}=3,50 \mathrm{~min} \\
V_{\mathrm{s} 1}=\mathbf{2 . 0 \mathrm { cm } / \mathrm { min }} \\
\begin{array}{c}\mathrm{Cor} \\
(\mathrm{uC})\end{array}\end{array}$} \\
\hline & $\begin{array}{c}\text { Sulfato férrico } \\
(\mathrm{mg} / \ell)\end{array}$ & $\begin{array}{c}\text { Ácido } \\
\text { Clorídrico } \\
0.1 \mathrm{~N}(\mathrm{~m} / \mathrm{\ell})\end{array}$ & $\begin{array}{c}\text { Hidróxido de } \\
\text { Sódio } 0.1 \mathrm{~N}(\mathrm{~m} \ell / \mathrm{\ell})\end{array}$ & & & \\
\hline 1 & 80 & - & 7.5 & 4.59 & 22 & 67 \\
\hline 2 & 160 & - & 38.0 & 4.51 & 37 & 90 \\
\hline 3 & 140 & - & 33.0 & 5.00 & 24 & 53 \\
\hline 4 & 100 & - & 19.0 & 5.22 & 10 & 67 \\
\hline 5 & 160 & - & 43.0 & 5.55 & 27 & 79 \\
\hline 6 & 140 & - & 38.5 & 5.74 & 14 & 77 \\
\hline
\end{tabular}

\section{ESTUDO DE COAGULAÇÃO-FLOCULAÇÃO-SEDIMENTAÇÃO}

\begin{tabular}{|c|c|c|c|c|c|}
\hline \multirow{2}{*}{$\begin{array}{l}\text { ENSAIO } \mathbf{N}^{\circ}: 20 \\
\text { Data }: 21 / 04 / 00\end{array}$} & \multirow{2}{*}{$\begin{array}{c}\text { COAGULANTE } \\
\text { Sulfato Férrico }\end{array}$} & \multicolumn{2}{|c|}{ MISTURA RÁPIDA } & \multicolumn{2}{|c|}{ FLOCULAÇÃO } \\
\hline & & Tmr $=5 \mathrm{~s}$ & $\mathrm{Gmr}=1000 \mathrm{~s}^{-1}$ & Tf $=30 \mathrm{~min}$ & $G f=15 s^{-1}$ \\
\hline
\end{tabular}

\begin{tabular}{|c|c|c|c|c|c|c|c|}
\hline \multicolumn{8}{|c|}{ CARACTERÍSTICAS DA ÁGUA DE ESTUDO } \\
\hline \multirow{2}{*}{ Turbidez (uT) } & \multirow{2}{*}{$\begin{array}{c}\text { Cor Aparente } \\
\text { (uC) }\end{array}$} & \multirow{2}{*}{$\begin{array}{c}\text { Cor Verdadeira } \\
\text { (uC) }\end{array}$} & \multirow{2}{*}{$\begin{array}{c}\text { Alcalinidade Total } \\
\left(\mathrm{mg} / \ell \mathrm{CaCO}_{3}\right)\end{array}$} & \multicolumn{2}{|c|}{ pH } & \multirow{2}{*}{$\begin{array}{c}\text { Temperatura } \\
{ }^{\circ} \mathrm{C} \\
\end{array}$} & \multirow{2}{*}{$\begin{array}{l}\text { Potencial } \\
\text { Zeta }(\mathrm{mV})\end{array}$} \\
\hline & & & & S/ agit. & C/ agit. & & \\
\hline 6.37 & 138 & 98 & 30 & 7.96 & 7.64 & 25 & - \\
\hline
\end{tabular}

\begin{tabular}{|c|c|c|c|c|c|c|}
\hline \multirow{2}{*}{ FRASCO } & \multicolumn{3}{|c|}{ DOSAGEM DE PRODUTO QUÍMICO } & \multirow{2}{*}{$\begin{array}{c}\text { pH } \\
\text { de } \\
\text { Coagulação }\end{array}$} & \multirow{2}{*}{$\begin{array}{c}T_{\mathrm{s} 2}=7,00 \mathrm{~min} \\
V_{\mathrm{s} 2}=1.0 \mathrm{~cm} / \mathrm{min} \\
\begin{array}{c}\mathrm{Cor} \\
(\mathrm{uC})\end{array}\end{array}$} & \multirow{2}{*}{$\begin{array}{c}T_{\mathrm{s} 2}=3,50 \mathrm{~min} \\
V_{\mathrm{s} 1}=2.0 \mathrm{~cm} / \mathrm{min} \\
\begin{array}{c}\mathrm{Cor} \\
(\mathrm{uC})\end{array}\end{array}$} \\
\hline & $\begin{array}{l}\text { Sulfato férrico } \\
\text { (mg/ } / \text { ) }\end{array}$ & $\begin{array}{c}\text { Ácido } \\
\text { Clorídrico } \\
0.1 \mathrm{~N}(\mathrm{~m} \ell / \ell) \\
\end{array}$ & 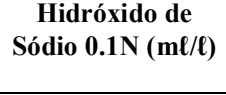 & & & \\
\hline 1 & 220 & - & 59.0 & 4.74 & 32 & 77 \\
\hline 2 & 200 & - & 53.0 & 4.69 & 28 & 76 \\
\hline 3 & 220 & - & 52.0 & 3.86 & 42 & 99 \\
\hline 4 & 180 & - & 51.0 & 5.42 & 21 & 109 \\
\hline 5 & 100 & - & 26.0 & 6.20 & 32 & 62 \\
\hline 6 & 100 & - & 28.0 & 6.36 & 15 & 31 \\
\hline
\end{tabular}




\section{ESTUDO DE COAGULAÇÃO-FLOCULAÇÃO-SEDIMENTAÇÃO}

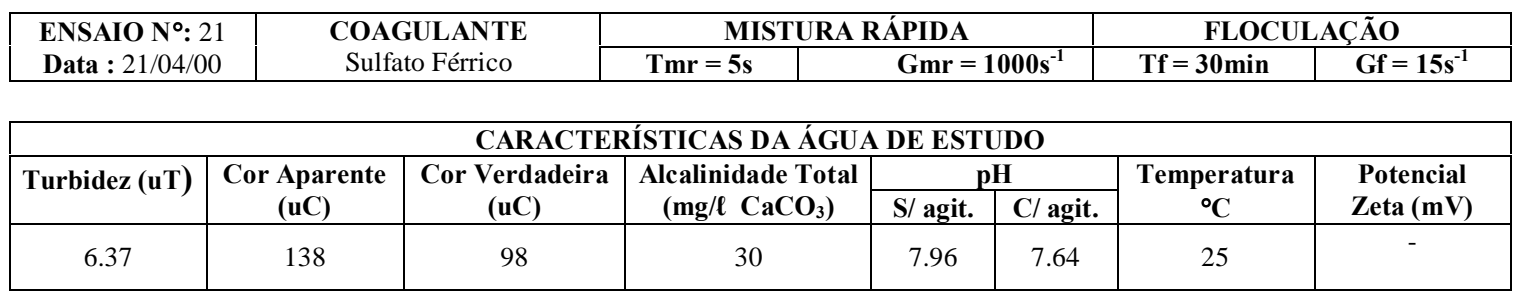

\begin{tabular}{|c|c|c|c|c|c|c|}
\hline \multirow{2}{*}{ FRASCO } & \multicolumn{3}{|c|}{ DOSAGEM DE PRODUTO QUÍMICO } & \multirow{2}{*}{$\begin{array}{c}\text { pH } \\
\text { de } \\
\text { Coagulação }\end{array}$} & \multirow{2}{*}{$\begin{array}{c}T_{\mathrm{s} 2}=7,00 \mathrm{~min} \\
V_{\mathrm{s} 2}=1.0 \mathrm{~cm} / \mathrm{min} \\
\begin{array}{c}\mathrm{Cor} \\
(\mathrm{uC})\end{array}\end{array}$} & \multirow{2}{*}{$\begin{array}{c}T_{\mathrm{s} 2}=3,50 \mathrm{~min} \\
V_{\mathrm{s} 1}=2.0 \mathrm{~cm} / \mathrm{min} \\
\begin{array}{c}\mathrm{Cor} \\
(\mathrm{uC})\end{array}\end{array}$} \\
\hline & $\begin{array}{c}\text { Sulfato férrico } \\
(\mathrm{mg} / \ell)\end{array}$ & $\begin{array}{c}\text { Ácido } \\
\text { Clorídrico } \\
0.1 \mathrm{~N}(\mathrm{~m} / / \ell)\end{array}$ & $\begin{array}{c}\text { Hidróxido de } \\
\text { Sódio } 0.1 \mathrm{~N}(\mathrm{~m} \ell / \ell)\end{array}$ & & & \\
\hline 1 & 240 & - & 66.0 & 4.50 & 24 & 116 \\
\hline 2 & 260 & - & 74.0 & 4.52 & 33 & 113 \\
\hline 3 & 240 & - & 69.0 & 4.86 & 32 & 107 \\
\hline 4 & 80 & - & 20.0 & 6.25 & 13 & 24 \\
\hline 5 & 100 & - & 30.0 & 6.52 & 26 & 72 \\
\hline 6 & 60 & - & 16.0 & 6.66 & 17 & 70 \\
\hline
\end{tabular}

\section{ESTUDO DE COAGULAÇÃO-FLOCULAÇÃO-SEDIMENTAÇÃO}

\begin{tabular}{|c|c|c|c|c|c|}
\hline \multirow{2}{*}{$\begin{array}{l}\text { ENSAIO } N^{\circ}: 22 \\
\text { Data }: 21 / 04 / 00\end{array}$} & \multirow{2}{*}{$\begin{array}{c}\text { COAGULANTE } \\
\text { Sulfato Férrico }\end{array}$} & \multicolumn{2}{|c|}{ MISTURA RÁPIDA } & \multicolumn{2}{|c|}{ FLOCULAÇÃO } \\
\hline & & Tmr $=5 \mathrm{~s}$ & $\mathrm{Gmr}=1000 \mathrm{~s}^{-1}$ & Tf $=30 \mathrm{~min}$ & $G f=15 s^{-1}$ \\
\hline
\end{tabular}

\begin{tabular}{|c|c|c|c|c|c|c|c|}
\hline \multicolumn{8}{|c|}{ CARACTERÍSTICAS DA ÁGUA DE ESTUDO } \\
\hline \multirow{2}{*}{ Turbidez (uT) } & \multirow{2}{*}{$\begin{array}{c}\text { Cor Aparente } \\
\text { (uC) }\end{array}$} & \multirow{2}{*}{$\begin{array}{c}\text { Cor Verdadeira } \\
\text { (uC) }\end{array}$} & \multirow{2}{*}{$\begin{array}{c}\text { Alcalinidade Total } \\
\left(\mathrm{mg} / \ell \mathrm{CaCO}_{3}\right)\end{array}$} & \multicolumn{2}{|c|}{ pH } & \multirow{2}{*}{$\begin{array}{c}\text { Temperatura } \\
{ }^{\circ} \mathrm{C} \\
\end{array}$} & \multirow{2}{*}{$\begin{array}{l}\text { Potencial } \\
\text { Zeta }(\mathrm{mV})\end{array}$} \\
\hline & & & & S/ agit. & C/ agit. & & \\
\hline 6.37 & 138 & 98 & 30 & 7.96 & 7.64 & 25 & - \\
\hline
\end{tabular}

\begin{tabular}{|c|c|c|c|c|c|c|}
\hline \multirow{2}{*}{ FRASCO } & \multicolumn{3}{|c|}{ DOSAGEM DE PRODUTO QUÍMICO } & \multirow{2}{*}{$\begin{array}{c}\text { pH } \\
\text { de } \\
\text { Coagulação }\end{array}$} & \multirow{2}{*}{$\begin{array}{c}T_{\mathrm{s} 2}=7,00 \mathrm{~min} \\
V_{\mathrm{s} 2}=1.0 \mathrm{~cm} / \mathrm{min} \\
\begin{array}{c}\mathrm{Cor} \\
(\mathrm{uC})\end{array}\end{array}$} & \multirow{2}{*}{$\begin{array}{c}T_{\mathrm{s} 2}=3,50 \mathrm{~min} \\
V_{\mathrm{s} 1}=2.0 \mathrm{~cm} / \mathrm{min} \\
\begin{array}{c}\mathrm{Cor} \\
(\mathrm{uC})\end{array}\end{array}$} \\
\hline & $\begin{array}{c}\text { Sulfato férrico } \\
(\mathrm{mg} / \mathfrak{l})\end{array}$ & $\begin{array}{c}\text { Ácido } \\
\text { Clorídrico } \\
\mathbf{0 . 1 N}(\mathrm{m} \ell / \ell) \\
\end{array}$ & $\begin{array}{c}\text { Hidróxido de } \\
\text { Sódio } 0.1 \mathrm{~N}(\mathrm{~m} \ell / \ell)\end{array}$ & & & \\
\hline 1 & 260 & - & 74.0 & 4.48 & 14 & 98 \\
\hline 2 & 260 & - & 76.0 & 4.58 & 27 & 133 \\
\hline 3 & 260 & - & 78.0 & 4.85 & 37 & 96 \\
\hline 4 & 260 & - & 80.0 & 5.13 & 13 & 94 \\
\hline 5 & 260 & - & 82.0 & 5.40 & 43 & 84 \\
\hline 6 & 260 & - & 84.0 & 5.55 & 22 & 47 \\
\hline
\end{tabular}




\section{ESTUDO DE COAGULAÇÃO-FLOCULAÇÃO-SEDIMENTAÇÃO}

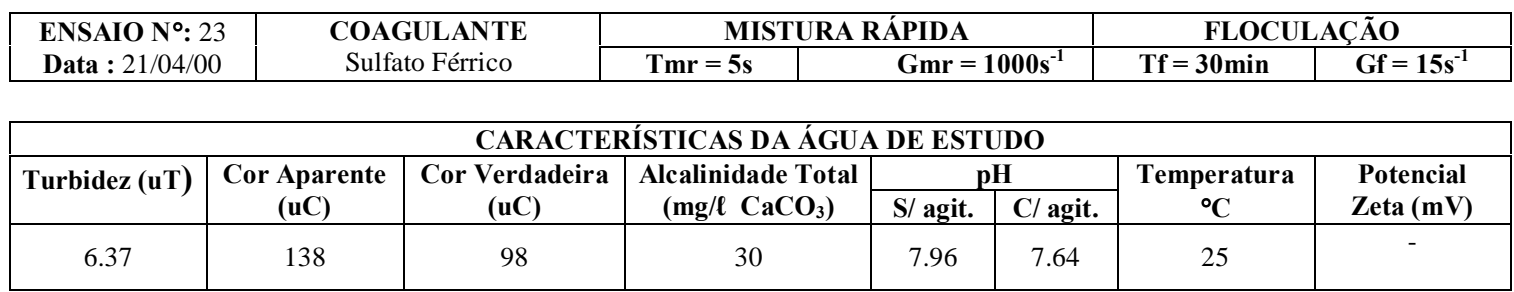

\begin{tabular}{|c|c|c|c|c|c|c|}
\hline \multirow{2}{*}{ FRASCO } & \multicolumn{3}{|c|}{ DOSAGEM DE PRODUTO QUÍMICO } & \multirow{2}{*}{$\begin{array}{c}\text { pH } \\
\text { de } \\
\text { Coagulação }\end{array}$} & \multirow{2}{*}{$\begin{array}{c}T_{\mathrm{s} 2}=7,00 \mathrm{~min} \\
V_{\mathrm{s} 2}=1.0 \mathrm{~cm} / \mathrm{min} \\
\begin{array}{c}\mathrm{Cor} \\
(\mathrm{uC})\end{array}\end{array}$} & \multirow{2}{*}{$\begin{array}{c}T_{\mathrm{s} 2}=3,50 \mathrm{~min} \\
V_{\mathrm{s} 1}=2.0 \mathrm{~cm} / \mathrm{min} \\
\begin{array}{c}\mathrm{Cor} \\
(\mathrm{uC})\end{array}\end{array}$} \\
\hline & $\begin{array}{c}\text { Sulfato férrico } \\
(\mathrm{mg} / \ell)\end{array}$ & $\begin{array}{c}\text { Ácido } \\
\text { Clorídrico } \\
0.1 \mathrm{~N}(\mathrm{~m} / / \ell)\end{array}$ & $\begin{array}{c}\text { Hidróxido de } \\
\text { Sódio } 0.1 \mathrm{~N}(\mathrm{~m} \ell / \ell)\end{array}$ & & & \\
\hline 1 & 60 & - & 2.5 & 4.84 & 18 & 59 \\
\hline 2 & 40 & 3.65 & - & 5.27 & 13 & 44 \\
\hline 3 & 40 & 2.73 & - & 5.36 & 19 & 50 \\
\hline 4 & 20 & 5.47 & - & 6.17 & 27 & 79 \\
\hline 5 & 20 & 4.53 & - & 6.22 & 24 & 70 \\
\hline 6 & 20 & 3.65 & - & 6.37 & 49 & 70 \\
\hline
\end{tabular}

\section{ESTUDO DE COAGULAÇÃO-FLOCULAÇÃO-SEDIMENTAÇÃO}

\begin{tabular}{|c|c|c|c|c|c|}
\hline \multirow{2}{*}{$\begin{array}{l}\text { ENSAIO No: } 24 \\
\text { Data }: 21 / 04 / 00\end{array}$} & \multirow{2}{*}{$\begin{array}{c}\text { COAGULANTE } \\
\text { Sulfato Férrico }\end{array}$} & \multicolumn{2}{|c|}{ MISTURA RÁPIDA } & \multicolumn{2}{|c|}{ FLOCULAÇÃO } \\
\hline & & $\mathrm{Tmr}=5 \mathrm{~s}$ & Gmr $=1000 \mathrm{~s}^{-1}$ & $\mathbf{T f}=30 \mathrm{~min}$ & $G f=15 s^{-1}$ \\
\hline
\end{tabular}

\begin{tabular}{|c|c|c|c|c|c|c|c|}
\hline \multicolumn{8}{|c|}{ CARACTERÍSTICAS DA ÁGUA DE ESTUDO } \\
\hline \multirow{2}{*}{ Turbidez (uT) } & \multirow{2}{*}{$\begin{array}{c}\text { Cor Aparente } \\
\text { (uC) }\end{array}$} & \multirow{2}{*}{$\begin{array}{c}\text { Cor Verdadeira } \\
\text { (uC) }\end{array}$} & \multirow{2}{*}{$\begin{array}{c}\text { Alcalinidade Total } \\
\left(\mathrm{mg} / \ell \mathrm{CaCO}_{3}\right)\end{array}$} & \multicolumn{2}{|c|}{ pH } & \multirow{2}{*}{$\begin{array}{c}\text { Temperatura } \\
{ }^{\circ} \mathrm{C} \\
\end{array}$} & \multirow{2}{*}{$\begin{array}{l}\text { Potencial } \\
\text { Zeta }(\mathrm{mV})\end{array}$} \\
\hline & & & & S/ agit. & C/ agit. & & \\
\hline 6.37 & 138 & 98 & 30 & 7.96 & 7.64 & 25 & - \\
\hline
\end{tabular}

\begin{tabular}{|c|c|c|c|c|c|c|}
\hline \multirow{2}{*}{ FRASCO } & \multicolumn{3}{|c|}{ DOSAGEM DE PRODUTO QUÍMICO } & \multirow{2}{*}{$\begin{array}{c}\text { pH } \\
\text { de } \\
\text { Coagulação }\end{array}$} & \multirow{2}{*}{$\begin{array}{c}T_{\mathrm{s} 2}=7,00 \mathrm{~min} \\
V_{\mathrm{s} 2}=1.0 \mathrm{~cm} / \mathrm{min} \\
\begin{array}{c}\mathrm{Cor} \\
(\mathrm{uC})\end{array}\end{array}$} & \multirow{2}{*}{$\begin{array}{c}T_{\mathrm{s} 2}=3,50 \mathrm{~min} \\
V_{\mathrm{s} 1}=2.0 \mathrm{~cm} / \mathrm{min} \\
\begin{array}{c}\mathrm{Cor} \\
(\mathrm{uC})\end{array}\end{array}$} \\
\hline & $\begin{array}{c}\text { Sulfato férrico } \\
(\mathrm{mg} / \mathfrak{l})\end{array}$ & $\begin{array}{c}\text { Ácido } \\
\text { Clorídrico } \\
\mathbf{0 . 1 N}(\mathrm{m} \ell / \ell) \\
\end{array}$ & $\begin{array}{c}\text { Hidróxido de } \\
\text { Sódio } 0.1 \mathrm{~N}(\mathrm{~m} \ell / \ell)\end{array}$ & & & \\
\hline 1 & 140 & - & 42.0 & 5.94 & 42 & 121 \\
\hline 2 & 140 & - & 44.0 & 6.15 & 47 & 115 \\
\hline 3 & 80 & - & 22.0 & 8.79 & - & - \\
\hline 4 & 80 & - & 24.0 & 6.57 & 23 & 63 \\
\hline 5 & 120 & - & 42.0 & 6.67 & 26 & 88 \\
\hline 6 & 60 & - & 18.0 & 6.73 & 19 & 19 \\
\hline
\end{tabular}


ESTUDO DE COAGULAÇÃO-FLOCULAÇÃO-SEDIMENTAÇÃ O

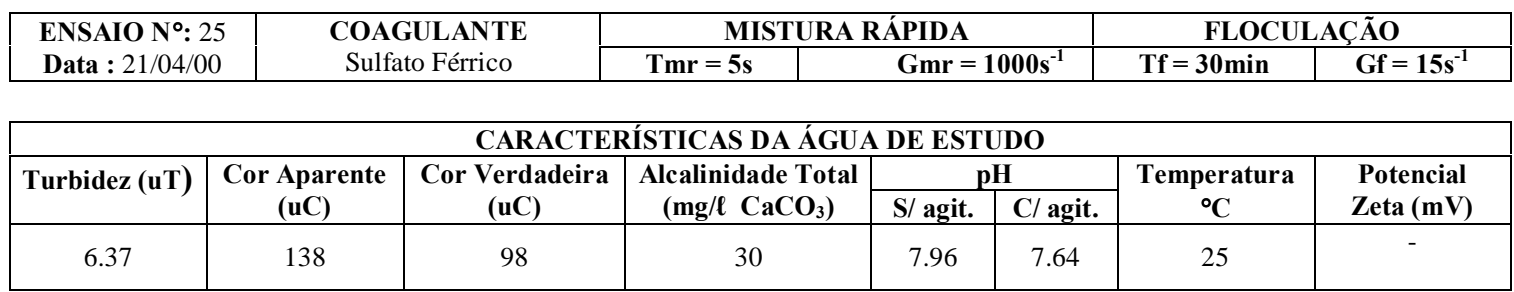

\begin{tabular}{|c|c|c|c|c|c|c|}
\hline \multirow{2}{*}{ FRASCO } & \multicolumn{3}{|c|}{ DOSAGEM DE PRODUTO QUÍMICO } & \multirow{2}{*}{$\begin{array}{c}\text { pH } \\
\text { de } \\
\text { Coagulação }\end{array}$} & \multirow{2}{*}{$\begin{array}{c}T_{\mathrm{s} 2}=7,00 \mathrm{~min} \\
V_{\mathrm{s} 2}=1.0 \mathrm{~cm} / \mathrm{min} \\
\begin{array}{c}\mathrm{Cor} \\
(\mathrm{uC})\end{array}\end{array}$} & \multirow{2}{*}{$\begin{array}{c}T_{\mathrm{s} 2}=3,50 \mathrm{~min} \\
V_{\mathrm{s} 1}=2.0 \mathrm{~cm} / \mathrm{min} \\
\begin{array}{c}\mathrm{Cor} \\
(\mathrm{uC})\end{array}\end{array}$} \\
\hline & $\begin{array}{l}\text { Sulfato férrico } \\
(\mathrm{mg} / \mathfrak{\ell})\end{array}$ & $\begin{array}{c}\text { Ácido } \\
\text { Clorídrico } \\
\mathbf{0 . 1 N}(\mathrm{m} / \ell) \\
\end{array}$ & $\begin{array}{c}\text { Hidróxido de } \\
\text { Sódio } 0.1 \mathrm{~N}(\mathrm{~m} \ell / \mathrm{\ell})\end{array}$ & & & \\
\hline 1 & 200 & - & 60.0 & 5.39 & 42 & 126 \\
\hline 2 & 200 & - & 62.0 & 5.61 & 6 & 90 \\
\hline 3 & 160 & - & 50.0 & 5.96 & 30 & 114 \\
\hline 4 & 160 & - & 52.0 & 6.16 & 26 & 82 \\
\hline 5 & 100 & - & 32.0 & 6.55 & 33 & 105 \\
\hline 6 & 100 & - & 34.0 & 6.75 & 19 & 41 \\
\hline
\end{tabular}

\section{ESTUDO DE COAGULAÇÃO-FLOCULAÇÃO-SEDIMENTAÇÃO}

\begin{tabular}{|c|c|c|c|c|c|}
\hline \multirow{2}{*}{$\begin{array}{l}\text { ENSAIO } N^{\circ}: 26 \\
\text { Data }: 21 / 04 / 00\end{array}$} & \multirow{2}{*}{$\begin{array}{c}\text { COAGULANTE } \\
\text { Sulfato Férrico }\end{array}$} & \multicolumn{2}{|c|}{ MISTURA RÁPIDA } & \multicolumn{2}{|c|}{ FLOCULAÇÃO } \\
\hline & & Tmr $=5 \mathrm{~s}$ & $\mathrm{Gmr}=1000 \mathrm{~s}^{-1}$ & Tf $=30 \mathrm{~min}$ & $G f=15 s^{-1}$ \\
\hline
\end{tabular}

\begin{tabular}{|c|c|c|c|c|c|c|c|}
\hline \multicolumn{8}{|c|}{ CARACTERÍSTICAS DA ÁGUA DE ESTUDO } \\
\hline \multirow{2}{*}{ Turbidez (uT) } & \multirow{2}{*}{$\begin{array}{c}\text { Cor Aparente } \\
\text { (uC) }\end{array}$} & \multirow{2}{*}{$\begin{array}{c}\text { Cor Verdadeira } \\
\text { (uC) }\end{array}$} & \multirow{2}{*}{$\begin{array}{c}\text { Alcalinidade Total } \\
\left(\mathrm{mg} / \ell \mathrm{CaCO}_{3}\right)\end{array}$} & \multicolumn{2}{|c|}{ pH } & \multirow{2}{*}{$\begin{array}{c}\text { Temperatura } \\
{ }^{\circ} \mathrm{C} \\
\end{array}$} & \multirow{2}{*}{$\begin{array}{l}\text { Potencial } \\
\text { Zeta }(\mathrm{mV})\end{array}$} \\
\hline & & & & S/ agit. & C/ agit. & & \\
\hline 6.37 & 138 & 98 & 30 & 7.96 & 7.64 & 25 & - \\
\hline
\end{tabular}

\begin{tabular}{|c|c|c|c|c|c|c|}
\hline \multirow{2}{*}{ FRASCO } & \multicolumn{3}{|c|}{ DOSAGEM DE PRODUTO QUÍMICO } & \multirow{2}{*}{$\begin{array}{c}\text { pH } \\
\text { de } \\
\text { Coagulação }\end{array}$} & \multirow{2}{*}{$\begin{array}{c}T_{\mathrm{s} 2}=7,00 \mathrm{~min} \\
V_{\mathrm{s} 2}=1.0 \mathrm{~cm} / \mathrm{min} \\
\begin{array}{c}\mathrm{Cor} \\
(\mathrm{uC})\end{array}\end{array}$} & \multirow{2}{*}{$\begin{array}{c}T_{\mathrm{s} 2}=3,50 \mathrm{~min} \\
V_{\mathrm{s} 1}=2.0 \mathrm{~cm} / \mathrm{min} \\
\begin{array}{c}\mathrm{Cor} \\
(\mathrm{uC})\end{array}\end{array}$} \\
\hline & $\begin{array}{l}\text { Sulfato férrico } \\
(\mathrm{mg} / \mathfrak{l})\end{array}$ & 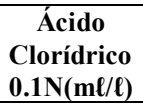 & $\begin{array}{c}\text { Hidróxido de } \\
\text { Sódio } 0.1 \mathrm{~N}(\mathrm{~m} \ell / \ell)\end{array}$ & & & \\
\hline 1 & 40 & 7.29 & - & 4.20 & 59 & 93 \\
\hline 2 & 20 & 9.11 & - & 5.77 & 16 & 60 \\
\hline 3 & 280 & - & 104.0 & 6.20 & 27 & 132 \\
\hline 4 & 280 & - & 106.0 & 6.33 & 18 & 76 \\
\hline 5 & 60 & - & 18.0 & 6.74 & 28 & 129 \\
\hline 6 & 60 & - & 20.0 & 6.90 & 44 & 78 \\
\hline
\end{tabular}




\section{ESTUDO DE COAGULAÇÃO-FLOCULAÇÃO-SEDIMENTAÇÃO}

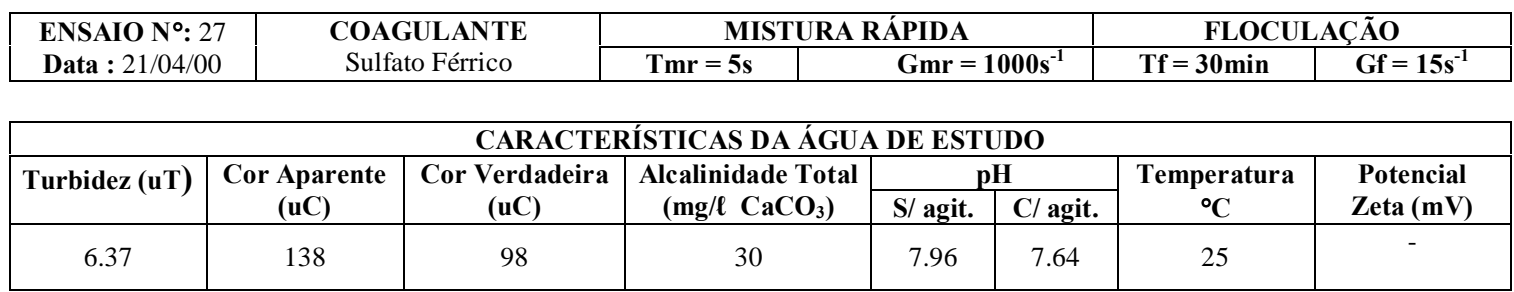

\begin{tabular}{|c|c|c|c|c|c|c|}
\hline \multirow{2}{*}{ FRASCO } & \multicolumn{3}{|c|}{ DOSAGEM DE PRODUTO QUÍMICO } & \multirow{2}{*}{$\begin{array}{c}\text { pH } \\
\text { de } \\
\text { Coagulação }\end{array}$} & \multirow{2}{*}{$\begin{array}{c}T_{\mathrm{s} 2}=7,00 \mathrm{~min} \\
V_{\mathrm{s} 2}=1.0 \mathrm{~cm} / \mathrm{min} \\
\begin{array}{c}\mathrm{Cor} \\
(\mathrm{uC})\end{array}\end{array}$} & \multirow{2}{*}{$\begin{array}{c}T_{\mathrm{s} 2}=3,50 \mathrm{~min} \\
V_{\mathrm{s} 1}=2.0 \mathrm{~cm} / \mathrm{min} \\
\begin{array}{c}\mathrm{Cor} \\
(\mathrm{uC})\end{array}\end{array}$} \\
\hline & $\begin{array}{c}\text { Sulfato férrico } \\
(\mathrm{mg} / \ell)\end{array}$ & $\begin{array}{c}\text { Ácido } \\
\text { Clorídrico } \\
0.1 \mathrm{~N}(\mathrm{~m} / / \ell)\end{array}$ & $\begin{array}{c}\text { Hidróxido de } \\
\text { Sódio } 0.1 \mathrm{~N}(\mathrm{~m} \ell / \ell)\end{array}$ & & & \\
\hline 1 & 220 & - & 62.0 & 4.84 & 46 & 101 \\
\hline 2 & 220 & - & 67.0 & 5.36 & 34 & 113 \\
\hline 3 & 220 & - & 70.0 & 5.62 & 48 & 100 \\
\hline 4 & 160 & - & 54.0 & 6.29 & 19 & 104 \\
\hline 5 & 160 & - & 57.0 & 6.59 & 43 & 99 \\
\hline 6 & 160 & - & 60.0 & 6.93 & 16 & 23 \\
\hline
\end{tabular}

\section{ESTUDO DE COAGULAÇÃO-FLOCULAÇÃO-SEDIMENTAÇÃO}

\begin{tabular}{|c|c|c|c|c|c|}
\hline \multirow{2}{*}{$\begin{array}{l}\text { ENSAIO } N^{\circ}: 28 \\
\text { Data }: 03 / 05 / 00\end{array}$} & \multirow{2}{*}{$\begin{array}{c}\text { COAGULANTE } \\
\text { Sulfato Férrico }\end{array}$} & \multicolumn{2}{|c|}{ MISTURA RÁPIDA } & \multicolumn{2}{|c|}{ FLOCULAÇÃO } \\
\hline & & Tmr $=5 \mathrm{~s}$ & $\mathrm{Gmr}=1000 \mathrm{~s}^{-1}$ & Tf $=30 \mathrm{~min}$ & $G f=15 s^{-1}$ \\
\hline
\end{tabular}

\begin{tabular}{|c|c|c|c|c|c|c|c|}
\hline \multicolumn{8}{|c|}{ CARACTERÍSTICAS DA ÁGUA DE ESTUDO } \\
\hline \multirow{2}{*}{ Turbidez (uT) } & \multirow{2}{*}{$\begin{array}{c}\text { Cor Aparente } \\
\text { (uC) }\end{array}$} & \multirow{2}{*}{$\begin{array}{c}\text { Cor Verdadeira } \\
\text { (uC) }\end{array}$} & \multirow{2}{*}{$\begin{array}{c}\text { Alcalinidade Total } \\
\left(\mathrm{mg} / \ell \mathrm{CaCO}_{3}\right)\end{array}$} & \multicolumn{2}{|c|}{ pH } & \multirow{2}{*}{$\begin{array}{c}\text { Temperatura } \\
{ }^{\circ} \mathrm{C} \\
\end{array}$} & \multirow{2}{*}{$\begin{array}{l}\text { Potencial } \\
\text { Zeta }(\mathrm{mV})\end{array}$} \\
\hline & & & & S/ agit. & C/ agit. & & \\
\hline 6.37 & 138 & 98 & 30 & 7.96 & 7.64 & 25 & - \\
\hline
\end{tabular}

\begin{tabular}{|c|c|c|c|c|c|c|}
\hline \multirow{2}{*}{ FRASCO } & \multicolumn{3}{|c|}{ DOSAGEM DE PRODUTO QUÍMICO } & \multirow{2}{*}{$\begin{array}{c}\text { pH } \\
\text { de } \\
\text { Coagulação }\end{array}$} & \multirow{2}{*}{$\begin{array}{c}T_{\mathrm{s} 2}=7,00 \mathrm{~min} \\
V_{\mathrm{s} 2}=1.0 \mathrm{~cm} / \mathrm{min} \\
\begin{array}{c}\mathrm{Cor} \\
(\mathrm{uC})\end{array}\end{array}$} & \multirow{2}{*}{$\begin{array}{c}T_{\mathrm{s} 2}=3,50 \mathrm{~min} \\
V_{\mathrm{s} 1}=2.0 \mathrm{~cm} / \mathrm{min} \\
\begin{array}{c}\mathrm{Cor} \\
(\mathrm{uC})\end{array}\end{array}$} \\
\hline & $\begin{array}{c}\text { Sulfato férrico } \\
(\mathrm{mg} / \mathfrak{l})\end{array}$ & $\begin{array}{c}\text { Ácido } \\
\text { Clorídrico } \\
\mathbf{0 . 1 N}(\mathrm{m} \ell / \ell) \\
\end{array}$ & $\begin{array}{c}\text { Hidróxido de } \\
\text { Sódio } 0.1 \mathrm{~N}(\mathrm{~m} \ell / \ell)\end{array}$ & & & \\
\hline 1 & 240 & - & 86.0 & 7.04 & 39 & 81 \\
\hline 2 & 240 & - & 90.0 & 6.76 & 44 & 93 \\
\hline 3 & 240 & - & 94.0 & 7.00 & 31 & 59 \\
\hline 4 & 200 & - & 84.0 & 7.65 & 137 & 143 \\
\hline 5 & 200 & - & 88.0 & 8.16 & - & - \\
\hline 6 & 200 & - & 92.0 & 8.57 & - & - \\
\hline
\end{tabular}


ESTUDO DE COAGULAÇÃO-FLOCULAÇÃO-SEDIMENTAÇÃO

\begin{tabular}{|c|c|c|c|c|c|c|c|}
\hline \multirow{2}{*}{$\begin{array}{l}\text { ENSAIO No: } 29 \\
\text { Data : } 03 / 05 / 00 \\
\end{array}$} & \multirow{2}{*}{\multicolumn{2}{|c|}{$\begin{array}{l}\text { COAGULANTE } \\
\text { Sulfato Férrico }\end{array}$}} & \multicolumn{3}{|c|}{ MISTURA RÁPIDA } & \multicolumn{2}{|c|}{ FLOCULAÇÃO } \\
\hline & & & \begin{tabular}{l|l}
$\mathbf{m r}=5 \mathrm{~s}$ \\
\end{tabular} & \multicolumn{2}{|c|}{ Gmr $=1000 \mathrm{~s}^{-1}$} & $\mathbf{T f}=30 \mathrm{~min}$ & Gf $=15 s^{-1}$ \\
\hline \multicolumn{8}{|c|}{ CARACTERÍSTICAS DA ÁGUA DE ESTUDO } \\
\hline \multirow[t]{2}{*}{ Turbidez (uT) } & \multirow{2}{*}{$\begin{array}{c}\begin{array}{c}\text { Cor Aparente } \\
\text { (uC) }\end{array} \\
\end{array}$} & \multirow{2}{*}{$\begin{array}{c}\text { Cor Verdadeira } \\
(\mathrm{uC})\end{array}$} & \multirow{2}{*}{\begin{tabular}{|c|}
$\begin{array}{c}\text { Alcalinidade Total } \\
\left(\mathrm{mg} / \ell \mathrm{CaCO}_{3}\right)\end{array}$ \\
\end{tabular}} & \multicolumn{2}{|c|}{ pH } & \multirow{2}{*}{$\begin{array}{c}\text { Temperatura } \\
{ }^{\circ} \mathrm{C} \\
\end{array}$} & \multirow{2}{*}{$\begin{array}{r}\text { Potencial } \\
\text { Zeta }(\mathrm{mV}) \\
\end{array}$} \\
\hline & & & & S/ agit. & $\mathrm{C} /$ agit. & & \\
\hline 6.37 & 138 & 98 & 30 & 7.96 & 7.64 & 25 & - \\
\hline
\end{tabular}

\begin{tabular}{|c|c|c|c|c|c|c|}
\hline \multirow{2}{*}{ FRASCO } & \multicolumn{3}{|c|}{ DOSAGEM DE PRODUTO QUÍMICO } & \multirow{2}{*}{$\begin{array}{c}\text { pH } \\
\text { de } \\
\text { Coagulação }\end{array}$} & \multirow{2}{*}{$\begin{array}{c}T_{\mathrm{s} 2}=7,00 \mathrm{~min} \\
V_{\mathrm{s} 2}=1.0 \mathrm{~cm} / \mathrm{min} \\
\begin{array}{c}\mathrm{Cor} \\
(\mathrm{uC})\end{array}\end{array}$} & \multirow{2}{*}{$\begin{array}{c}T_{\mathrm{s} 2}=3,50 \mathrm{~min} \\
V_{\mathrm{s} 1}=2.0 \mathrm{~cm} / \mathrm{min} \\
\begin{array}{c}\mathrm{Cor} \\
(\mathrm{uC})\end{array}\end{array}$} \\
\hline & $\begin{array}{l}\text { Sulfato férrico } \\
(\mathrm{mg} / \mathfrak{\ell})\end{array}$ & $\begin{array}{c}\text { Ácido } \\
\text { Clorídrico } \\
\mathbf{0 . 1 N}(\mathrm{m} / \ell) \\
\end{array}$ & $\begin{array}{c}\text { Hidróxido de } \\
\text { Sódio } 0.1 \mathrm{~N}(\mathrm{~m} \ell / \mathrm{\ell})\end{array}$ & & & \\
\hline 1 & 260 & - & 88.0 & 5.97 & 39 & 93 \\
\hline 2 & 260 & - & 92.0 & 6.25 & 30 & 99 \\
\hline 3 & 260 & - & 96.0 & 6.46 & 36 & 96 \\
\hline 4 & 160 & - & 63.0 & 7.39 & 37 & 58 \\
\hline 5 & 160 & - & 66.0 & 7.61 & 125 & 133 \\
\hline 6 & 160 & - & 69.0 & 8.17 & - & - \\
\hline
\end{tabular}

\section{ESTUDO DE COAGULAÇÃO-FLOCULAÇÃO-SEDIMENTAÇÃO}

\begin{tabular}{|c|c|c|c|c|c|}
\hline \multirow{2}{*}{$\begin{array}{l}\text { ENSAIO } N^{\circ}: 30 \\
\text { Data }: 03 / 05 / 00\end{array}$} & \multirow{2}{*}{$\begin{array}{c}\text { COAGULANTE } \\
\text { Sulfato Férrico }\end{array}$} & \multicolumn{2}{|c|}{ MISTURA RÁPIDA } & \multicolumn{2}{|c|}{ FLOCULAÇÃO } \\
\hline & & Tmr $=5 \mathrm{~s}$ & $\mathrm{Gmr}=1000 \mathrm{~s}^{-1}$ & Tf $=30 \mathrm{~min}$ & $G f=15 s^{-1}$ \\
\hline
\end{tabular}

\begin{tabular}{|c|c|c|c|c|c|c|c|}
\hline \multicolumn{8}{|c|}{ CARACTERÍSTICAS DA ÁGUA DE ESTUDO } \\
\hline \multirow{2}{*}{ Turbidez (uT) } & \multirow{2}{*}{$\begin{array}{c}\text { Cor Aparente } \\
\text { (uC) }\end{array}$} & \multirow{2}{*}{$\begin{array}{c}\text { Cor Verdadeira } \\
\text { (uC) }\end{array}$} & \multirow{2}{*}{$\begin{array}{c}\text { Alcalinidade Total } \\
\left(\mathrm{mg} / \ell \mathrm{CaCO}_{3}\right)\end{array}$} & \multicolumn{2}{|c|}{ pH } & \multirow{2}{*}{$\begin{array}{c}\text { Temperatura } \\
{ }^{\circ} \mathrm{C} \\
\end{array}$} & \multirow{2}{*}{$\begin{array}{l}\text { Potencial } \\
\text { Zeta }(\mathrm{mV})\end{array}$} \\
\hline & & & & S/ agit. & C/ agit. & & \\
\hline 6.37 & 138 & 98 & 30 & 7.96 & 7.64 & 25 & - \\
\hline
\end{tabular}

\begin{tabular}{|c|c|c|c|c|c|c|}
\hline \multirow{2}{*}{ FRASCO } & \multicolumn{3}{|c|}{ DOSAGEM DE PRODUTO QUÍMICO } & \multirow{2}{*}{$\begin{array}{c}\text { pH } \\
\text { de } \\
\text { Coagulação }\end{array}$} & \multirow{2}{*}{$\begin{array}{c}T_{\mathrm{s} 2}=7,00 \mathrm{~min} \\
V_{\mathrm{s} 2}=1.0 \mathrm{~cm} / \mathrm{min} \\
\begin{array}{c}\mathrm{Cor} \\
(\mathrm{uC})\end{array}\end{array}$} & \multirow{2}{*}{$\begin{array}{c}T_{\mathrm{s} 2}=3,50 \mathrm{~min} \\
V_{\mathrm{s} 1}=2.0 \mathrm{~cm} / \mathrm{min} \\
\begin{array}{c}\mathrm{Cor} \\
(\mathrm{uC})\end{array}\end{array}$} \\
\hline & $\begin{array}{c}\text { Sulfato férrico } \\
(\mathrm{mg} / \ell)\end{array}$ & 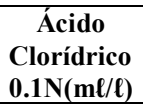 & $\begin{array}{c}\text { Hidróxido de } \\
\text { Sódio } 0.1 \mathrm{~N}(\mathrm{~m} \ell / \ell)\end{array}$ & & & \\
\hline 1 & 180 & - & 54.0 & 5.90 & 37 & 47 \\
\hline 2 & 180 & - & 56.0 & 5.99 & 55 & 73 \\
\hline 3 & 180 & - & 59.0 & 6.20 & 55 & 59 \\
\hline 4 & 180 & - & 62.0 & 6.47 & 56 & 81 \\
\hline 5 & 200 & - & 82.0 & 7.58 & 52 & 62 \\
\hline 6 & 240 & - & 98.0 & 7.48 & 35 & 36 \\
\hline
\end{tabular}


ESTUDO DE COAGULAÇÃO-FLOCULAÇÃO-SEDIMENTAÇÃO

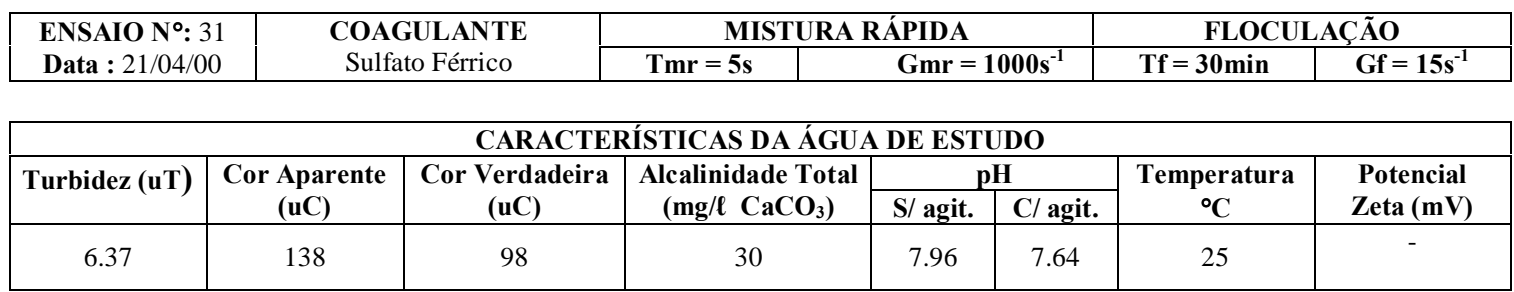

\begin{tabular}{|c|c|c|c|c|c|c|}
\hline \multirow{2}{*}{ FRASCO } & \multicolumn{3}{|c|}{ DOSAGEM DE PRODUTO QUÍMICO } & \multirow{2}{*}{$\begin{array}{c}\text { pH } \\
\text { de } \\
\text { Coagulação }\end{array}$} & \multirow{2}{*}{$\begin{array}{c}T_{\mathrm{s} 2}=7,00 \mathrm{~min} \\
V_{\mathrm{s} 2}=1.0 \mathrm{~cm} / \mathrm{min} \\
\begin{array}{c}\mathrm{Cor} \\
(\mathrm{uC})\end{array}\end{array}$} & \multirow{2}{*}{$\begin{array}{c}T_{\mathrm{s} 2}=3,50 \mathrm{~min} \\
V_{\mathrm{s} 1}=2.0 \mathrm{~cm} / \mathrm{min} \\
\begin{array}{c}\mathrm{Cor} \\
(\mathrm{uC})\end{array}\end{array}$} \\
\hline & $\begin{array}{l}\text { Sulfato férrico } \\
(\mathrm{mg} / \mathfrak{\ell})\end{array}$ & $\begin{array}{c}\text { Ácido } \\
\text { Clorídrico } \\
\mathbf{0 . 1 N}(\mathrm{m} / \ell) \\
\end{array}$ & $\begin{array}{c}\text { Hidróxido de } \\
\text { Sódio } 0.1 \mathrm{~N}(\mathrm{~m} \ell / \mathrm{\ell})\end{array}$ & & & \\
\hline 1 & 280 & - & 116.0 & 7.26 & 28 & 53 \\
\hline 2 & 260 & - & 108.0 & 7.20 & 42 & 61 \\
\hline 3 & 240 & - & 98.0 & 7.15 & 37 & 50 \\
\hline 4 & 220 & - & 88.0 & 6.96 & 38 & 49 \\
\hline 5 & 180 & - & 68.0 & 6.84 & 33 & 61 \\
\hline 6 & 200 & - & 83.0 & 7.28 & 39 & 50 \\
\hline
\end{tabular}

\section{ESTUDO DE COAGULAÇÃO-FLOCULAÇÃO-SEDIMENTAÇÃO}

\begin{tabular}{|c|c|c|c|c|c|}
\hline \multirow{2}{*}{$\begin{array}{l}\text { ENSAIO } N^{\circ}: 32 \\
\text { Data }: 21 / 04 / 00\end{array}$} & \multirow{2}{*}{$\begin{array}{c}\text { COAGULANTE } \\
\text { Sulfato Férrico }\end{array}$} & \multicolumn{2}{|c|}{ MISTURA RÁPIDA } & \multicolumn{2}{|c|}{ FLOCULAÇÃO } \\
\hline & & $\mathrm{Tmr}=5 \mathrm{~s}$ & Gmr $=1000 \mathrm{~s}^{-1}$ & $\mathbf{T f}=30 \mathrm{~min}$ & $G f=15 s^{-1}$ \\
\hline
\end{tabular}

\begin{tabular}{|c|c|c|c|c|c|c|c|}
\hline \multicolumn{8}{|c|}{ CARACTERÍSTICAS DA ÁGUA DE ESTUDO } \\
\hline \multirow{2}{*}{ Turbidez (uT) } & \multirow{2}{*}{$\begin{array}{c}\text { Cor Aparente } \\
\text { (uC) }\end{array}$} & \multirow{2}{*}{$\begin{array}{c}\text { Cor Verdadeira } \\
\text { (uC) }\end{array}$} & \multirow{2}{*}{$\begin{array}{c}\text { Alcalinidade Total } \\
\left(\mathrm{mg} / \ell \mathrm{CaCO}_{3}\right)\end{array}$} & \multicolumn{2}{|c|}{ pH } & \multirow{2}{*}{$\begin{array}{c}\text { Temperatura } \\
{ }^{\circ} \mathrm{C} \\
\end{array}$} & \multirow{2}{*}{$\begin{array}{l}\text { Potencial } \\
\text { Zeta }(\mathrm{mV})\end{array}$} \\
\hline & & & & S/ agit. & C/ agit. & & \\
\hline 6.37 & 138 & 98 & 30 & 7.96 & 7.64 & 25 & - \\
\hline
\end{tabular}

\begin{tabular}{|c|c|c|c|c|c|c|}
\hline \multirow{2}{*}{ FRASCO } & \multicolumn{3}{|c|}{ DOSAGEM DE PRODUTO QUÍMICO } & \multirow{2}{*}{$\begin{array}{c}\text { pH } \\
\text { de } \\
\text { Coagulação }\end{array}$} & \multirow{2}{*}{$\begin{array}{c}T_{\mathrm{s} 2}=7,00 \mathrm{~min} \\
V_{\mathrm{s} 2}=1.0 \mathrm{~cm} / \mathrm{min} \\
\begin{array}{c}\mathrm{Cor} \\
(\mathrm{uC})\end{array}\end{array}$} & \multirow{2}{*}{$\begin{array}{c}T_{\mathrm{s} 2}=3,50 \mathrm{~min} \\
V_{\mathrm{s} 1}=2.0 \mathrm{~cm} / \mathrm{min} \\
\begin{array}{c}\mathrm{Cor} \\
(\mathrm{uC})\end{array}\end{array}$} \\
\hline & $\begin{array}{c}\text { Sulfato férrico } \\
(\mathrm{mg} / \ell)\end{array}$ & 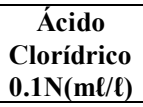 & $\begin{array}{c}\text { Hidróxido de } \\
\text { Sódio } 0.1 \mathrm{~N}(\mathrm{~m} \ell / \ell)\end{array}$ & & & \\
\hline 1 & 200 & - & 65.0 & 5.90 & 17 & 85 \\
\hline 2 & 200 & - & 68.0 & 6.11 & 20 & 120 \\
\hline 3 & 200 & - & 71.0 & 6.26 & 32 & 61 \\
\hline 4 & 200 & - & 74.0 & 6.48 & 32 & 87 \\
\hline 5 & 200 & - & 77.0 & 6.75 & 21 & 103 \\
\hline 6 & 200 & - & 80.0 & 7.02 & 8 & 22 \\
\hline
\end{tabular}




\section{ESTUDO DE COAGULAÇÃO-FLOCULAÇÃO-SEDIMENTAÇÃO}

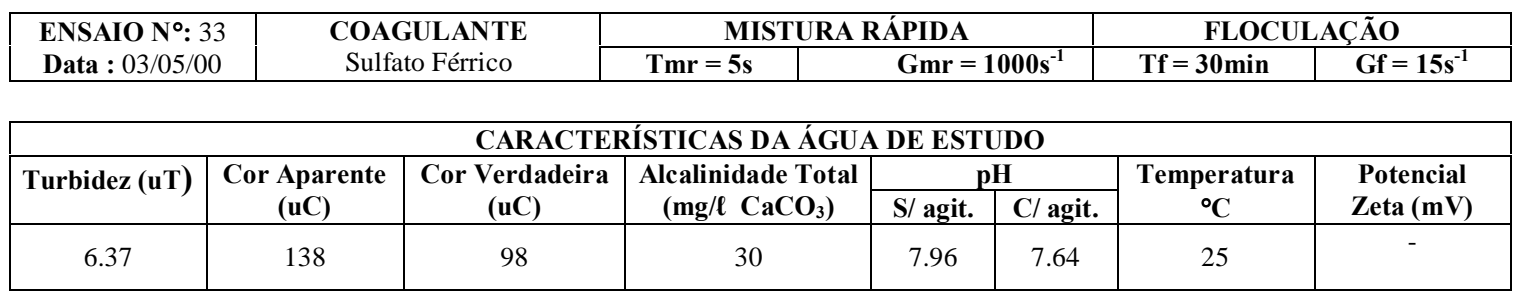

\begin{tabular}{|c|c|c|c|c|c|c|}
\hline \multirow{2}{*}{ FRASCO } & \multicolumn{3}{|c|}{ DOSAGEM DE PRODUTO QUÍMICO } & \multirow{2}{*}{$\begin{array}{c}\text { pH } \\
\text { de } \\
\text { Coagulação }\end{array}$} & \multirow{2}{*}{$\begin{array}{c}T_{\mathrm{s} 2}=7,00 \mathrm{~min} \\
V_{\mathrm{s} 2}=1.0 \mathrm{~cm} / \mathrm{min} \\
\begin{array}{c}\mathrm{Cor} \\
(\mathrm{uC})\end{array}\end{array}$} & \multirow{2}{*}{$\begin{array}{c}T_{\mathrm{s} 2}=3,50 \mathrm{~min} \\
V_{\mathrm{s} 1}=\mathbf{2 . 0 \mathrm { cm } / \mathrm { min }} \\
\begin{array}{c}\mathrm{Cor} \\
(\mathrm{uC})\end{array}\end{array}$} \\
\hline & $\begin{array}{c}\text { Sulfato férrico } \\
(\mathrm{mg} / \ell)\end{array}$ & $\begin{array}{c}\text { Ácido } \\
\text { Clorídrico } \\
0.1 \mathrm{~N}(\mathrm{~m} / \mathrm{\ell})\end{array}$ & $\begin{array}{c}\text { Hidróxido de } \\
\text { Sódio } 0.1 \mathrm{~N}(\mathrm{~m} \ell / \mathrm{\ell})\end{array}$ & & & \\
\hline 1 & 220 & - & 74.0 & 6.04 & 46 & 64 \\
\hline 2 & 220 & - & 78.0 & 6.29 & 40 & 62 \\
\hline 3 & 220 & - & 82.0 & 6.55 & 43 & 78 \\
\hline 4 & 120 & - & 44.0 & 6.95 & 31 & 33 \\
\hline 5 & 120 & - & 47.0 & 7.35 & 118 & 122 \\
\hline 6 & 120 & - & 50.0 & 7.77 & - & - \\
\hline
\end{tabular}

\section{ESTUDO DE COAGULAÇÃO-FLOCULAÇÃO-SEDIMENTAÇÃO}

\begin{tabular}{|c|c|c|c|c|c|}
\hline \multirow{2}{*}{$\begin{array}{l}\text { ENSAIO N }^{\circ}: 34 \\
\text { Data }: 03 / 05 / 00\end{array}$} & \multirow{2}{*}{$\begin{array}{c}\text { COAGULANTE } \\
\text { Sulfato Férrico }\end{array}$} & \multicolumn{2}{|c|}{ MISTURA RÁPIDA } & \multicolumn{2}{|c|}{ FLOCULAÇÃO } \\
\hline & & Tmr $=5 \mathrm{~s}$ & $\mathrm{Gmr}=1000 \mathrm{~s}^{-1}$ & Tf $=30 \mathrm{~min}$ & $G f=15 s^{-1}$ \\
\hline
\end{tabular}

\begin{tabular}{|c|c|c|c|c|c|c|c|}
\hline \multicolumn{8}{|c|}{ CARACTERÍSTICAS DA ÁGUA DE ESTUDO } \\
\hline \multirow{2}{*}{ Turbidez (uT) } & \multirow{2}{*}{$\begin{array}{c}\text { Cor Aparente } \\
\text { (uC) }\end{array}$} & \multirow{2}{*}{$\begin{array}{c}\text { Cor Verdadeira } \\
\text { (uC) }\end{array}$} & \multirow{2}{*}{$\begin{array}{c}\text { Alcalinidade Total } \\
\left(\mathrm{mg} / \ell \mathrm{CaCO}_{3}\right)\end{array}$} & \multicolumn{2}{|c|}{ pH } & \multirow{2}{*}{$\begin{array}{c}\text { Temperatura } \\
{ }^{\circ} \mathrm{C} \\
\end{array}$} & \multirow{2}{*}{$\begin{array}{l}\text { Potencial } \\
\text { Zeta }(\mathrm{mV})\end{array}$} \\
\hline & & & & S/ agit. & C/ agit. & & \\
\hline 6.37 & 138 & 98 & 30 & 7.96 & 7.64 & 25 & - \\
\hline
\end{tabular}

\begin{tabular}{|c|c|c|c|c|c|c|}
\hline \multirow{2}{*}{ FRASCO } & \multicolumn{3}{|c|}{ DOSAGEM DE PRODUTO QUÍMICO } & \multirow{2}{*}{$\begin{array}{c}\text { pH } \\
\text { de } \\
\text { Coagulação }\end{array}$} & \multirow{2}{*}{$\begin{array}{c}T_{\mathrm{s} 2}=7,00 \mathrm{~min} \\
V_{\mathrm{s} 2}=1.0 \mathrm{~cm} / \mathrm{min} \\
\begin{array}{c}\text { Cor } \\
(\mathrm{uC})\end{array}\end{array}$} & \multirow{2}{*}{$\begin{array}{c}\mathrm{T}_{\mathrm{s} 2}=3,50 \mathrm{~min} \\
\mathrm{~V}_{\mathrm{s} 1}=2.0 \mathrm{~cm} / \mathrm{min} \\
\begin{array}{c}\mathrm{Cor} \\
(\mathrm{uC})\end{array}\end{array}$} \\
\hline & $\begin{array}{l}\text { Sulfato férrico } \\
(\mathrm{mg} / \mathrm{\ell})\end{array}$ & $\begin{array}{c}\text { Ácido } \\
\text { Clorídrico } \\
\text { 0.1 }(m \ell / \ell)\end{array}$ & 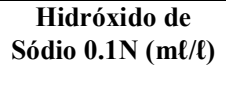 & & & \\
\hline 1 & 140 & - & 47.0 & 6.61 & 39 & 30 \\
\hline 2 & 140 & - & 50.0 & 6.77 & 14 & 35 \\
\hline 3 & 180 & - & 65.0 & 6.56 & 39 & 52 \\
\hline 4 & 140 & - & 53.0 & 7.02 & 18 & 33 \\
\hline 5 & 180 & - & 68.0 & 6.88 & 19 & 45 \\
\hline 6 & 160 & - & 61.5 & 7.06 & 38 & 28 \\
\hline
\end{tabular}




\section{ESTUDO DE COAGULAÇÃO-FLOCULAÇÃO-SEDIMENTAÇ̃̃O}

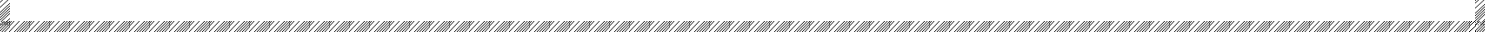

\begin{tabular}{|c|c|c|c|c|c|}
\hline \multirow{2}{*}{$\begin{array}{l}\text { ENSAIO No: } 35 \\
\text { Data : } 03 / 05 / 00\end{array}$} & \multirow{2}{*}{$\begin{array}{c}\text { COAGULANTE } \\
\text { Sulfato Férrico }\end{array}$} & \multicolumn{2}{|c|}{ MISTURA RÁPIDA } & \multicolumn{2}{|c|}{ FLOCULAÇÃO } \\
\hline & & Tmr $=5 \mathrm{~s}$ & Gmr $=1000 \mathrm{~s}^{-1}$ & Tf $=30 \mathrm{~min}$ & $G f=15 s^{-1}$ \\
\hline
\end{tabular}

\begin{tabular}{|c|c|c|c|c|c|c|c|}
\hline \multicolumn{8}{|c|}{ CARACTERÍSTICAS DA ÁGUA DE ESTUDO } \\
\hline \multirow{2}{*}{ Turbidez (uT) } & \multirow{2}{*}{$\begin{array}{c}\text { Cor Aparente } \\
(\mathrm{uC})\end{array}$} & \multirow{2}{*}{$\begin{array}{c}\text { Cor Verdadeira } \\
(\mathrm{uC})\end{array}$} & \multirow{2}{*}{$\begin{array}{c}\text { Alcalinidade Total } \\
\left(\mathrm{mg} / \ell \mathrm{CaCO}_{3}\right)\end{array}$} & \multicolumn{2}{|c|}{$\mathbf{p H}$} & \multirow{2}{*}{$\begin{array}{c}\text { Temperatura } \\
{ }^{\circ} \mathrm{C} \\
\end{array}$} & \multirow{2}{*}{$\begin{array}{r}\text { Potencial } \\
\text { Zeta }(\mathrm{mV}) \\
\end{array}$} \\
\hline & & & & S/ agit. & $\mathrm{C} /$ agit. & & \\
\hline 6.37 & 138 & 98 & 30 & 7.96 & 7.64 & 25 & \\
\hline
\end{tabular}

\begin{tabular}{|c|c|c|c|c|c|c|}
\hline \multirow{2}{*}{ FRASCO } & \multicolumn{3}{|c|}{ DOSAGEM DE PRODUTO QUÍMICO } & \multirow{2}{*}{$\begin{array}{c}\text { pH } \\
\text { de } \\
\text { Coagulação }\end{array}$} & \multirow{2}{*}{$\begin{array}{c}T_{\mathrm{s} 2}=7,00 \mathrm{~min} \\
\frac{V_{\mathrm{s} 2}=1.0 \mathrm{~cm} / \mathrm{min}}{\mathrm{Cor}} \\
(\mathrm{uC})\end{array}$} & \multirow{2}{*}{$\begin{array}{c}T_{\mathrm{s} 2}=3,50 \mathrm{~min} \\
\frac{V_{\mathrm{s} 1}=}{2.0 \mathrm{~cm} / \mathrm{min}} \\
\begin{array}{c}\mathrm{Cor} \\
(\mathrm{uC})\end{array}\end{array}$} \\
\hline & $\begin{array}{l}\text { Sulfato férrico } \\
(\mathrm{mg} / \mathrm{\ell})\end{array}$ & $\begin{array}{c}\text { Ácido } \\
\text { Clorídrico } \\
0.1 \mathrm{~N}(\mathrm{~m} \ell / \ell)\end{array}$ & $\begin{array}{c}\text { Hidróxido de } \\
\text { Sódio 0.1N }(\mathrm{m} \ell / \ell)\end{array}$ & & & \\
\hline 1 & 240 & - & 84.0 & 6.14 & 45 & 70 \\
\hline 2 & 220 & - & 86.0 & 6.87 & 32 & 49 \\
\hline 3 & 240 & - & 96.0 & 7.00 & 31 & 43 \\
\hline 4 & 220 & - & 90.0 & 7.34 & 26 & 27 \\
\hline 5 & 200 & - & 81.0 & 7.26 & 25 & 32 \\
\hline 6 & 240 & - & 100.0 & 7.45 & 31 & 32 \\
\hline
\end{tabular}




\section{REFERÊNCIAS BIBLIOGRÁFICAS}

01- AMERICAN WATER WORKS ASSOCIATION (AWWA) (1990). Water quality and treatment $-A$ handbook of community water supplies. $4^{\text {th }}$ ed. U. S. A.

02- AMIRTHARAJH, A. (1989). Tecnologias para tratamento de águas de abastecimento The mechanisms of coagulation. 20p., Jul.

03- AMIRTHARAJH, A. \& MILLS, K. M. (1982). "Rapid mix design for mechanisms of alum coagulation”. J. AWWA, V. 74 , n. 4, p. 210-216, Apr.

04- ARAUJO, R. A. (1985). Remoção de substâncias húmicas através de floculação com sulfato de alumínio, cloreto férrico e polímeros naturais e sintéticos. São Carlos. 251p. Dissertação (Mestrado) - Escola de Engenharia de São Carlos, Universidade de São Paulo.

05- AZEVEDO NETTO (1990) - Curso de treinamento à distância -Captação de Águas Subterrâneas Cap.1- Companhia de Tecnologia de Saneamento AmbientalCETESB/SP.

06- BLACK, A. P. \& CHRISTMAN, R. F. (1963) - Characteristics of colored surface waters. J. AWWA, Denver, Colorado, 55(6):753-770, Jun.

07- BRITO, S.A. (1998). Influência da velocidade de sedimentação na determinação dos coeficientes de agregação e ruptura durante a floculação. São Carlos. 64p. Dissertação (Mestrado) - Escola de Engenharia de São Carlos, Universidade do Estado de São Paulo.

08- CAMPOS (1980). Emprego do Amido de Batata como Auxiliar de Floculação de Águas para Abastecimento. São Carlos. 179p. Tese (Doutorado) - Escola de Engenharia de São Carlos, Universidade do Estado de São Paulo. 
09- CEPIS (1973). Teoria, Diseño y Control de los process de Clarificacion del Agua. p. 558.

10- CEPIS (1984). "Evaluacion de Plantas de Tratamiento de Agua", Tomo I.

11- CinTRA, O. A. F.; MALheiro, J. F.; BUENO, R. C. R.; KRAHENBUHL, S. P. (1995). Alternativas de coagulantes para tratamento de água de abastecimento público no Brasil. In: CONGRESSO BRASILEIRO DE ENGENHARIA SANITÁRIA, 15., Salvador, 1995. Anais. ABES, disquete 5.

12- CONCEIÇÃO, R. A. P. (1997). Influência da acidez do coagulante na eficiência da coagulação e decantação de água. São Carlos. 136p. Dissertação (Mestrado) - Escola de Engenharia de São Carlos, Universidade do Estado de São Paulo.

13- COSTA, C. A. C. (1992). Estudo de Adsorção e Remoção de Substâncias Húmicas por Sulfato de Alumínio em Águas de Abastecimento. São Carlos. 118p. Tese (Doutorado) Escola de Engenharia de São Carlos, Universidade do Estado de São Paulo.

14- COSTA, E. R. H. (1992). Estudo do uso de polímeros naturais como auxiliares de floculação com base no diagrama de coagulação do sulfato de alumínio. São Carlos. 123p. Dissertação (Mestrado) - Escola de Engenharia de São Carlos, Universidade do Estado de São Paulo.

15- DI BERNARDO, A. S. (2000). Influência das condições de aplicação de polímeros catiônicos na eficiência da floculação. São Carlos. 207p. Dissertação (Mestrado) - Escola de Engenharia de São Carlos, Universidade de São Paulo.

16- DI BERNARDO, L. (1993) - "Métodos e técnicas de tratamento de água" - Rio de Janeiro: ABES, V. 1.

17- DI BERNARDO, L. (1995) - "Algas s duas influências na qualidade das águas e nas tecnologias de tratamento" - Rio de Janeiro: ABES.

18- EDWARDS, G. A. \& AMIRTHARAJAH, A. (1985) - "Removing color caused by humic acids". J. AWWA, v. 77, n. 3, p. 50-57, Mar. 
19- EXALL et al. (2000). "Using coagulants to remove organic matter". J. AWWA, v. 92, n. 11, p. 93 a 102.

20- GUIMARÃES, A. F. (1987). Estudo da coagulação - floculação da água com turbidez e cor elevada. São Carlos. 145p. Dissertação (Mestrado) - Escola de Engenharia de São Carlos, Universidade do Estado de São Paulo.

21- KIRCHMER, C. J. (1992). Aspectos quimicos y fisicos de la coagulación del agua. CEPIS. Lima-Perú. p. 1 a 37.

22- K. BELL-AJY et al. (2000). "Conventional and optimizet coagulation for NOM removal”. J. AWWA, v.92, n. 10, p. 44 a 58.

23- MARINELLI, P. S. (1999). Aplicação de amidos catiônicos de milho como auxiliares de floculação no tratamento da água. São Carlos. 207p. Dissertação (Mestrado) - Escola de Engenharia de São Carlos, Universidade de São Paulo.

24- MENDES, C.G.N. (1989). Estudo da coagulação e floculação de águas sintéticas e naturais com turbidez e cor variáveis. São Carlos. 144p. Tese (Doutorado) - Escola de Engenharia de São Carlos, Universidade do Estado de São Paulo.

25- MIDWOOD, R. B. \& FELBECK (1968). Analysis of Yellow Organic Matter from Freshwater. J. AWWA, Denver, Colorado, 60(3):357, Mar.

26- PÁDUA, V. L. (1994). Metodologia para determinação dos gradientes de velocidade médios em unidades de floculação de mistura completa com câmaras em série e escoamento contínuo a partir de ensaios em reatores estáticos. São Carlos. 165p. Dissertação (Mestrado) - Escola de Engenharia de São Carlos, Universidade de São Paulo.

27- PÁDUA, V. L; DI BERNARDO, L; LIBÂNIO, M. (1998). Optimización de Gradientes de Velocidad em la Floculación. In: SEMINARIO SOBRE OPTIMIZACIÓN DE PLANTAS DE POTABILIZACIÓN. Lima, Peru. 
28- PAIXÃO, G. C. (1995). Desenvolvimento de metodologia para o uso de polímeros sintéticos como auxiliares de floculação. São Carlos. 99p. Dissertação (Mestrado) - Escola de Engenharia de São Carlos, Universidade de São Paulo.

29- STANDARD METHODS (1998). For the examination of water and wastewater $20^{\text {th }}$.

30- YOKOSAWA, M. M. (2001). Parte da tese relacionada ao potencial zeta. São Carlos. 30p. Tese (Doutorado) - Escola de Engenharia de São Carlos, Universidade de São Paulo. 